Portland State University

PDXScholar

Dissertations and Theses

Dissertations and Theses

Spring 1-1-2012

\title{
Street Art, Ideology, and Public Space
}

Tiffany Renée Conklin

Portland State University

Follow this and additional works at: https://pdxscholar.library.pdx.edu/open_access_etds

Part of the American Popular Culture Commons, Urban Studies Commons, and the Urban Studies and Planning Commons

Let us know how access to this document benefits you.

\section{Recommended Citation}

Conklin, Tiffany Renée, "Street Art, Ideology, and Public Space" (2012). Dissertations and Theses. Paper 761.

https://doi.org/10.15760/etd.761

This Thesis is brought to you for free and open access. It has been accepted for inclusion in Dissertations and Theses by an authorized administrator of PDXScholar. Please contact us if we can make this document more accessible: pdxscholar@pdx.edu. 
Street Art, Ideology, and Public Space

by

Tiffany Renée Conklin

A thesis submitted in partial fulfillment of the requirements for the degree of

\author{
Master of \\ Urban Studies
}
Thesis Committee:
Sy Adler, Chair
Carl Abbott
Hunter Shobe

Portland State University

2012 


\begin{abstract}
The concept of the city has come to play a central role in the practices of a new generation of artists for whom the city is their canvas. Street art is a complex social issue. For decades, its presence has fueled intense debate among residents of modern cities. Street art is considered by some to be a natural expression that exercises a collective right to the city, and by others, it is seen as a destructive attack upon an otherwise clean and orderly society. This research focuses on various forms of street art from the perspective of the urban audience. The general aim is to further an understanding of how people interact with and respond to street art. Qualitative and quantitative data were gathered via direct participant observations of street art installations and 139 surveys conducted with residents in Portland, Oregon.

Survey respondents distinguished between street art forms; generally preferring installations and masterpieces over tagging and stickers. More respondents considered graffiti to be a form of artistic expression, rather than an act of vandalism. Participant observations indicated that purposefully-designed street art can promote interaction between people, art, and public space. Random urban spectators became active collaborators; using art and performance to express themselves in public. These findings indicate there is a need to reconsider zero tolerance graffiti policies. Overall, these findings also contribute to a more informed discussion regarding the regulation, acceptability, and possibilities of unauthorized artistic expression in cities.
\end{abstract}




\section{Acknowledgements}

The pages of this thesis hold far more than the culmination of years of study. They also reflect the relationships with many generous and inspiring people in my life that have helped me reach this goal. I want to first thank my committee chair, Sy Adler, for his advice, supervision, patience, and crucial contributions. No matter how many times I changed directions over the years, he read my papers, provided me thoughtful feedback, and kept me on-track. I am grateful for the friendly advice and support of my second adviser, Carl Abbott. Last but not least, I thank Hunter Shobe for his guidance and friendship. His insights inspired me to follow my heart and pursue the topic of street art. I am indebted to him more than he knows.

To my colleagues at the PSU Survey Research Lab, especially Debi Elliott and Amber Johnson, thank you for your encouragement and support. Working at the lab provided me knowledge and experience that I was able to apply directly to my studies. I thank my fellow urban studies students, especially Katrina, Molly, Casey, Jen, Melissa, and Chris who have been a source of friendship, good advice, and collaboration. For my lifelong friends, Danielle, Oliver, Anton, Kyle, Jake, Adam, Christina, and Jim, thank you for your friendship and providing me much needed distractions over the years. To the street artists whose work inspires me beyond words; especially Paul, Kanye, Dr. Rasterbator, and Skam, thank you for sharing your stories, insights, opinions, and imaginations with all of us. 
Lastly, I thank my family for their love and encouragement. Thank you for instilling in me confidence and a drive to pursue my goals and dreams. I especially thank my mom for her unwavering support; I would not have made it this far without you. Most of all, I thank my loving, understanding, reassuring, and patient partner Zac whose support and assistance over the years is so appreciated. I could not have done this without you. Thank you. 


\section{Table of Contents}

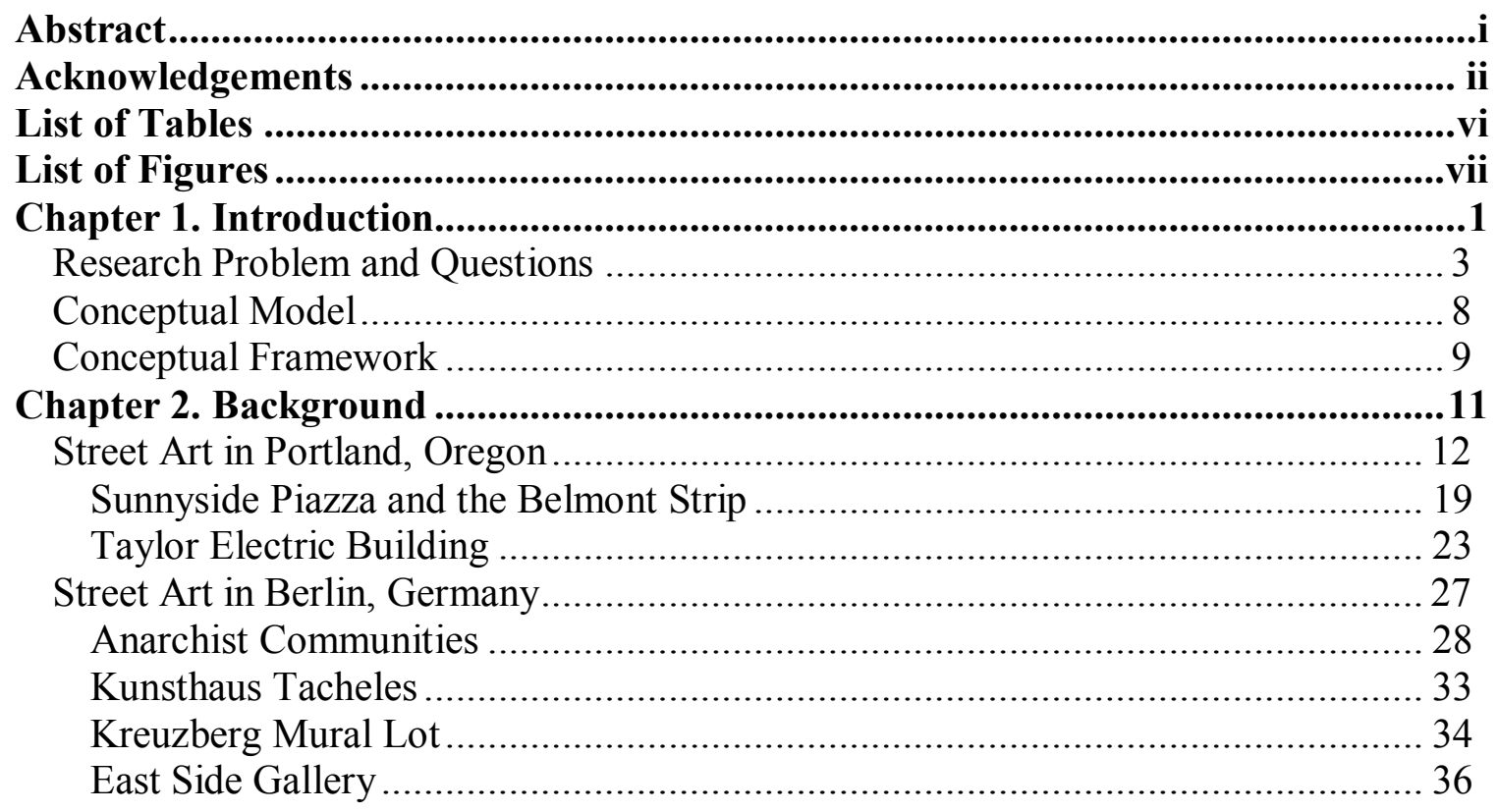

Chapter 3. Literature Review ..................................................................................40

Graffiti vs. Street Art: What is the Difference? ....................................................... 40

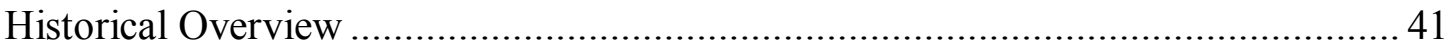

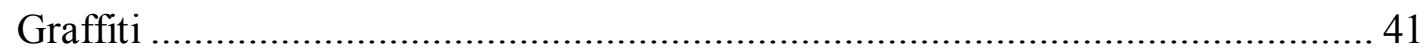

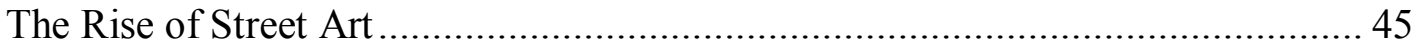

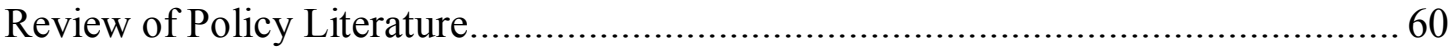

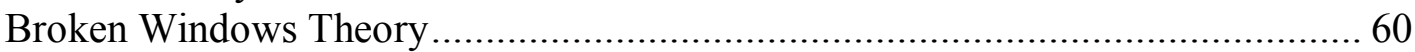

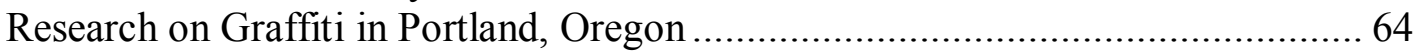

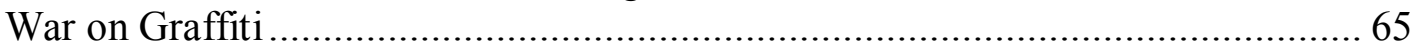

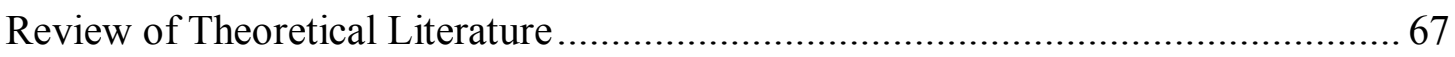

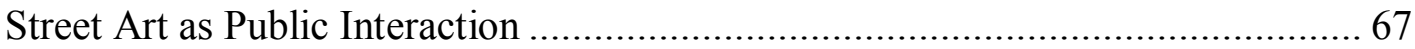

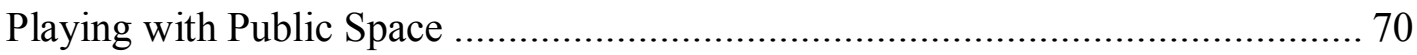

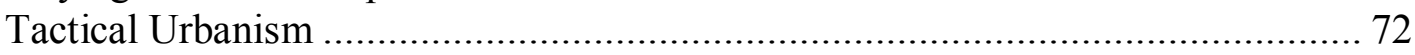

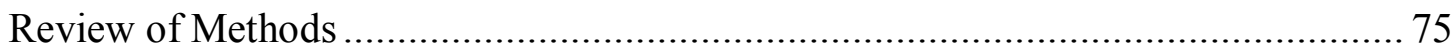

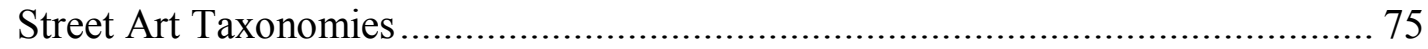

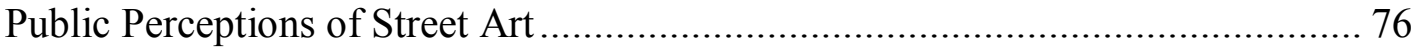

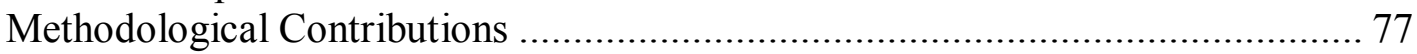

Chapter 4. Methodology ..................................................................................................79

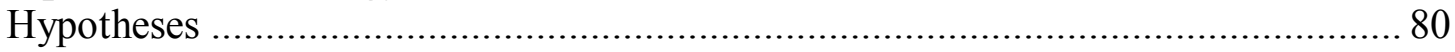

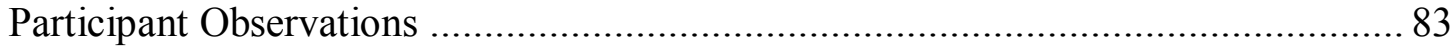

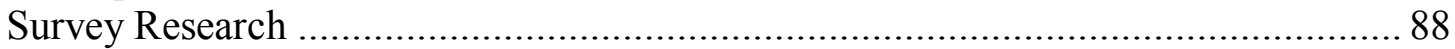

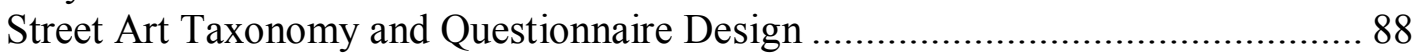

Pilot Testing and Post-Pilot Methodology Changes.............................................. 95

Web Survey Methodology and Subject Recruitment ............................................. 97 


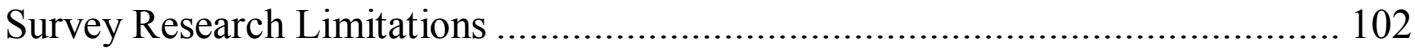

Chapter 5. Findings and Discussion.............................................................................104

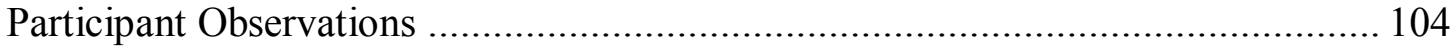

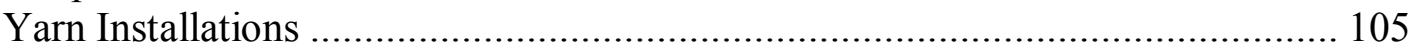

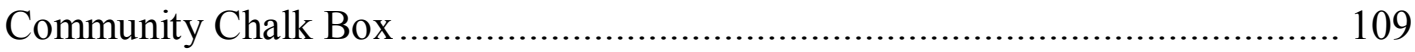

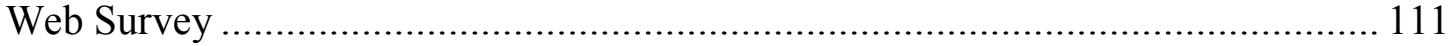

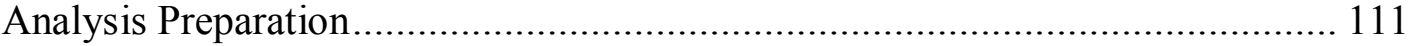

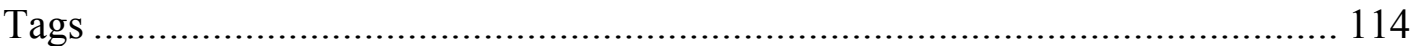

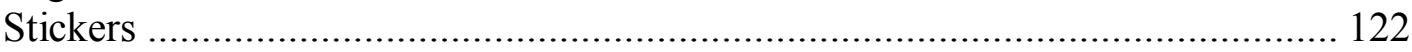

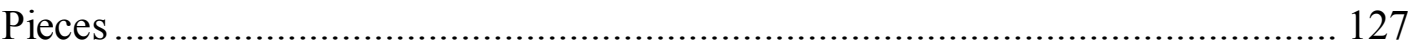

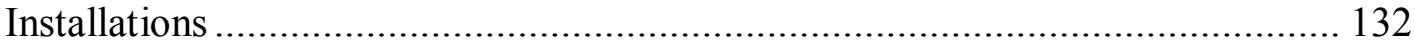

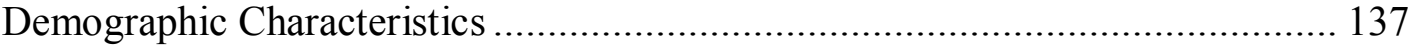

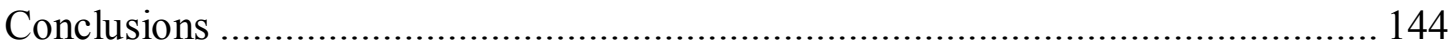

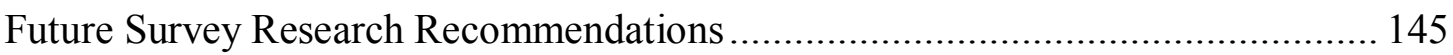

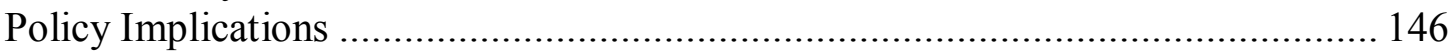

Re-evaluating the Broken Windows Theory ...................................................... 155

Chapter 6. Conclusion ................................................................................................160

Works Cited ..................................................................................................................... 162

Photograph Citations...............................................................................................................176

Appendix A. Graffiti and Street Art Evolution ...........................................................180

Appendix B. My Interventions .....................................................................................181

Appendix C. Survey Photograph Details ...........................................................................192

Appendix D. Street Art and Graffiti Survey ....................................................................196

Appendix E. Flyer Distribution Areas .......................................................................217

Appendix F. Survey Open Ends .................................................................................223

Appendix G. Bar Charts of Survey Data ....................................................................255

Appendix H. Gorilla Wallflare Press Letter, Pictures, and Newspaper Articles ....259

Appendix I. Survey Data Frequencies and Statistical Tests ......................................265 


\section{List of Tables}

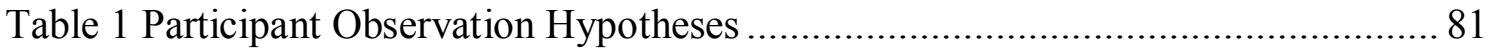

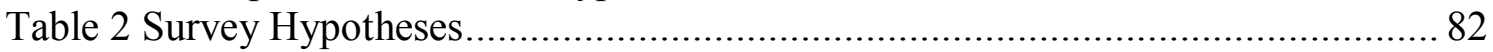

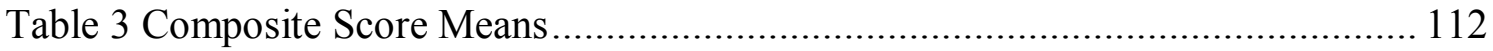

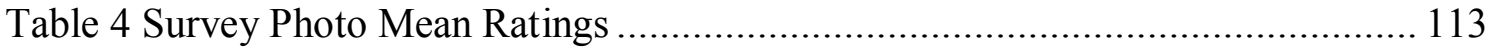

Table 5 Mean Ratings for Fever Tag................................................................... 114

Table 6 Mean Ratings for Long Live Tag ............................................................. 115

Table 7 Frequencies for 'Community Input Should be Received'............................... 118

Table 8 Mean Ratings for Stickers ................................................................... 122

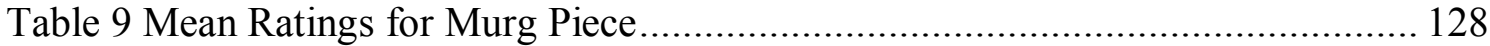

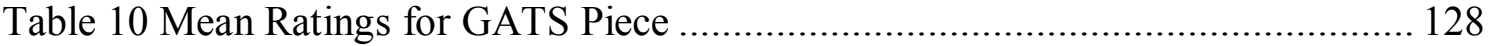

Table 11 Mean Rating for Garden Installation ...................................................... 134

Table 12 Mean Ratings for Chalk Box Installation.................................................. 135

Table 13 Mean Ratings for Yarn Installations ........................................................ 136

Table 14 Survey Respondent's Household Characteristics ........................................... 139

Table 15 Difference of Composite Scores between Renters and Owners .................... 140

Table 16 Difference of Composite Scores between Respondents Living in Neighborhood

Less than 5 Years and More than 5 Years ............................................................... 141

Table 17 Difference of Composite Scores between Respondents Earning Less than $\$ 50,000$ and More than \$50,000 per Year .......................................................... 142

Table 18 Difference of Composite Scores between Respondents Younger than 35 and 35

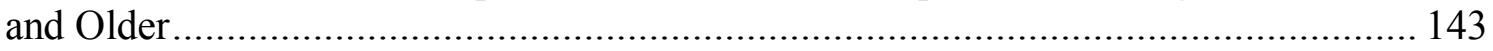




\section{List of Figures}

Figure 1 Public Variation of Horse Project 2008 ...................................................... 2

Figure 2 GrafRank Global Graffiti Concentration as of March 2012 ........................... 4

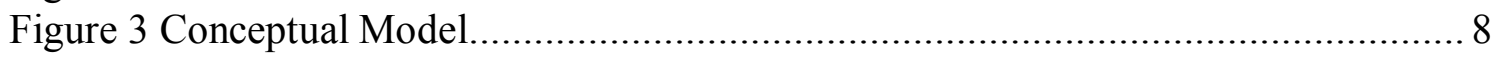

Figure 4 Lovejoy Column (Present Day)...................................................................... 13

Figure 5 Lovejoy Column (Pre-Redevelopment) ...................................................... 13

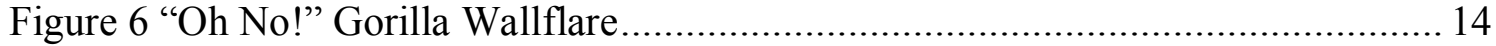

Figure 7 "Art Fills the Void," Gorilla Wallflare .......................................................... 14

Figure 8 Railyard Bathroom Sticker Installation, Curated by SKAM .......................... 17

Figure 9 Railyard Swampy Skateboard Ramp ……….............................................. 17

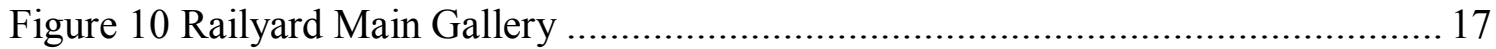

Figure 11 Reported Graffiti in Portland 2005-2006 ............................................... 19

Figure 12 Day of the Dead Installation, Belmont and 34th ......................................... 20

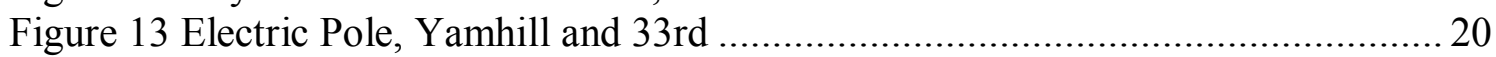

Figure 14 "I Could Use Drink," Belmont and 35th.................................................... 20

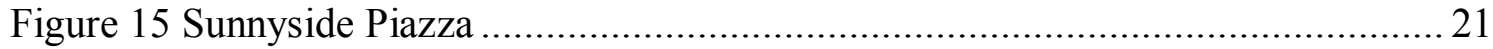

Figure 16 Sunnyside Piazza Re-Paint 2010 ………............................................... 21

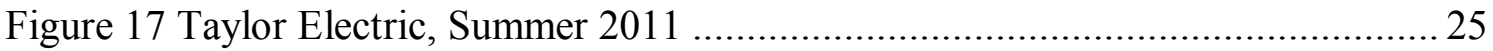

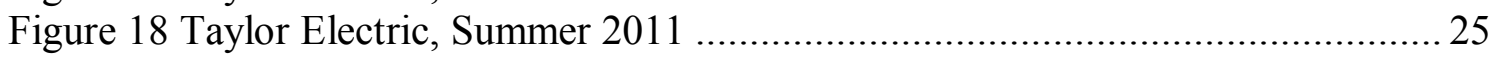

Figure 19 Taylor Electric, Winter 2012 ……………........................................... 26

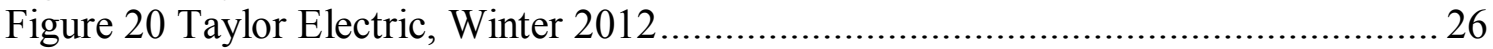

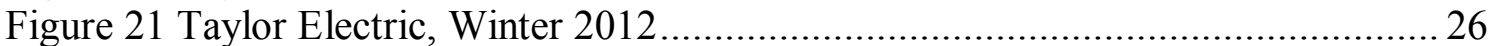

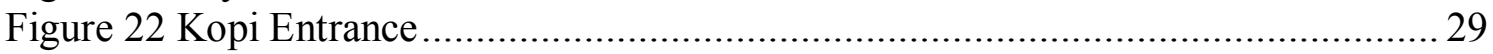

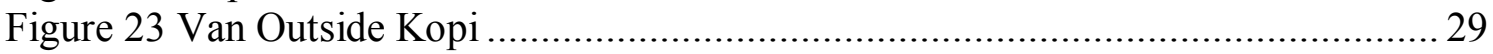

Figure 24 Unknown Collective, Free Seed-Free Life Garden ..................................... 30

Figure 25 Unknown Collective, Mean Marek............................................................... 30

Figure 26 Heil Weise "Make Vacancy Living Space Cast Out Investors" .................... 31

Figure 27 Heil Weise Community, Stencil by Czarnobyl ......................................... 31

Figure 28 Heil Weise Community, Unknown Artist................................................... 32

Figure 29 Heil Weise Community, Unknown Artist................................................. 32

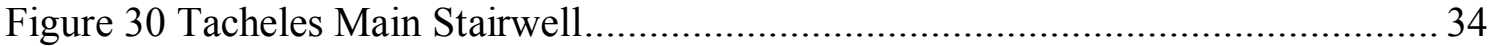

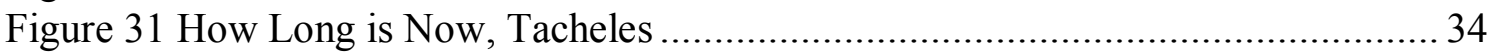

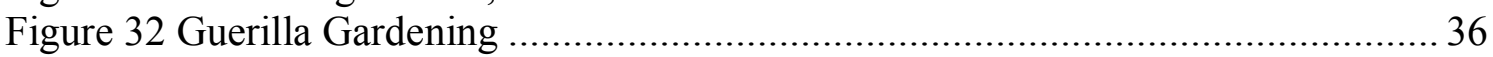

Figure 33 Miss Van, ST8MENT and Kouka, Back of Wall ........................................ 39

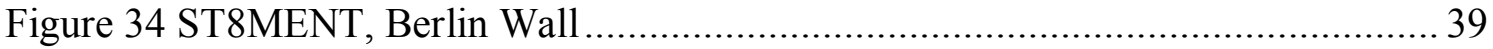

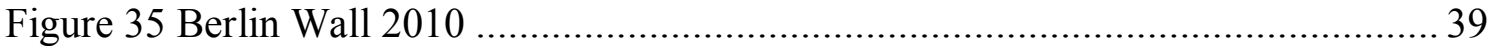

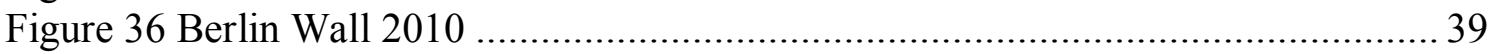

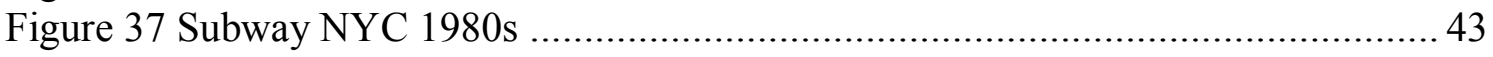

Figure 38 Lower Eastside NYC 1970s ……………….................................................. 43

Figure 39 Happy Holiday by Richie and Jason, South Bronx 1982 ………………..... 45

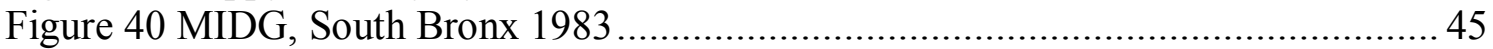

Figure 41 "Minotaur Brooklyn Bridge," Paolo Buggiani 1980 ..................................... 47 


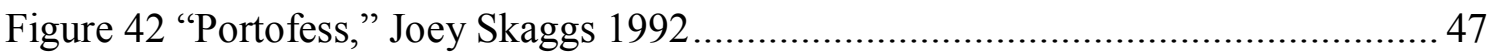

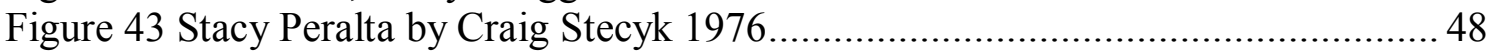

Figure 44 Blending of Graffiti and Street Art Styles .................................................5 50

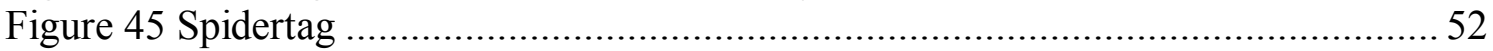

Figure 46 "The Joy of Not Being Sold Anything," Bansky, London 2005 .................... 53

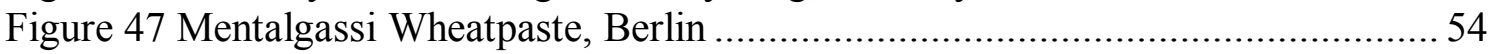

Figure 48 “Pedestrian Shuffle,” Leon Reid, Brooklyn 2011 ........................................ 54

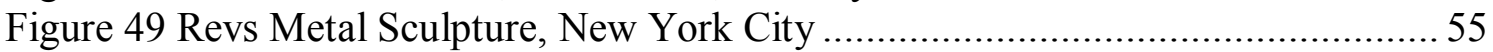

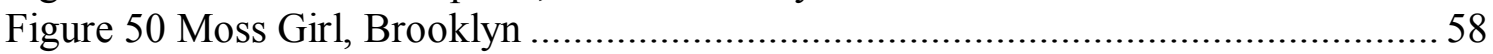

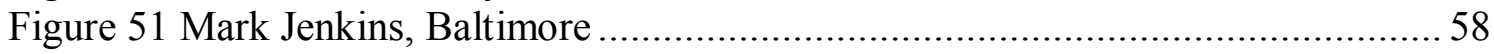

Figure 52 Haas \& Hahn, Favela Rio de Janeiro 2006 .............................................. 58

Figure 53 Yaron's Favela, Czech Republic .............................................................5 59

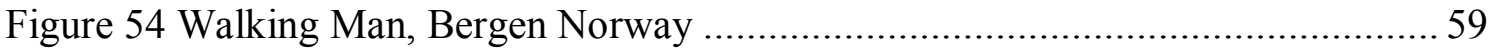

Figure 55 "Drinking Water Running through the Streets," Luzinterruptus.................... 59

Figure 56 "Protesting Potatoes in front of McDonalds," Peter Pink .............................. 59

Figure 57 "Fake Bird Twitters at Real People," NYC 2010 .......................................59

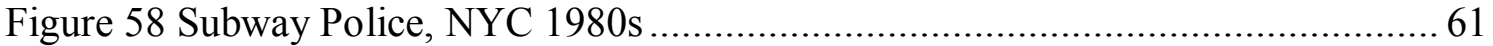

Figure 59 "The Last Graffiti Artist," Mark Jenkins, Malmo Sweden 2008 .................... 66

Figure 60 panoptICONS City Surveillance Awareness Project, Utrecht Netherlands... 66

Figure 61 Community-Contributed Shrine, Portland Oregon........................................ 68

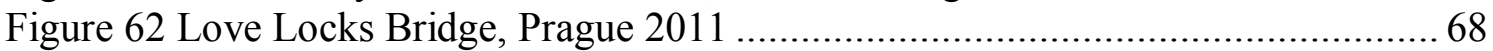

Figure 63 Don't Stop Beating Protestors, Portland Oregon 2012 …............................ 68

Figure 64 Street Artist Communication, Berlin 2011 ............................................... 70

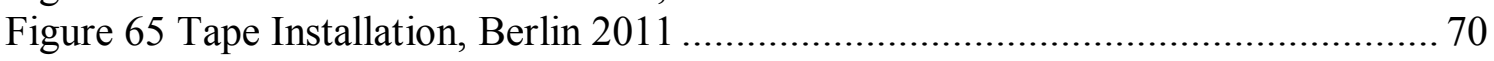

Figure 66 Faux-Front Home, Warschauer Strasse Station Berlin 2011 ........................ 72

Figure 67 Peter Pink Installation, Berlin-Bahnhof Zoo 2012 …................................ 72

Figure 68 Hung on the Cross Air Jordan, Berlin 2011 ........................................... 72

Figure 69 Skip Conversions, Oliver Bishop-Young, London 2008 ……..................... 74

Figure 70 Skip Conversions, Oliver Bishop-Young, London 2008 ……...................... 74

Figure 71 PARK(ing) Day, F.A.D., Lisa Town, and Jason King, Seattle 2009 ............. 74

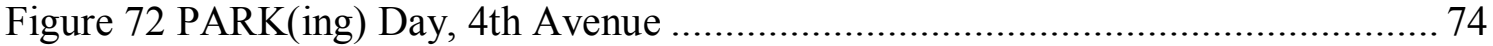

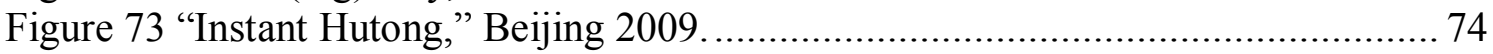

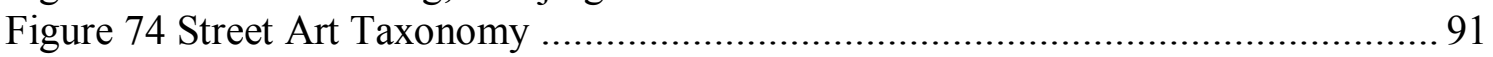

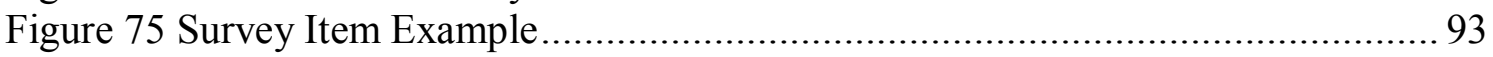

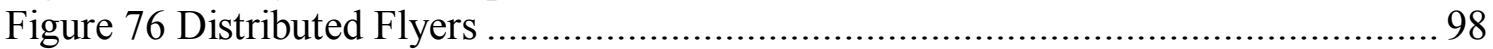

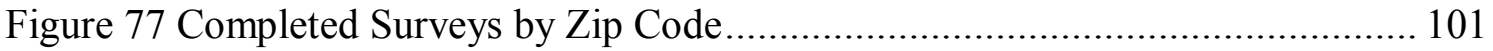

Figure 78 Counter-Intervention Plaque, Sunnyside Piazza 2001 ................................ 107

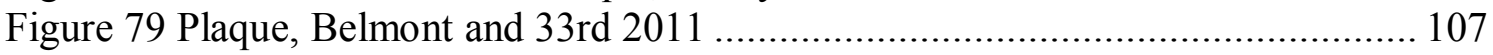

Figure 80 No Limits Stickers Printing Services, NE Alberta Portland, Oregon........... 107

Figure 81 Kanye Sticker, Portland Oregon 2012 ................................................... 107

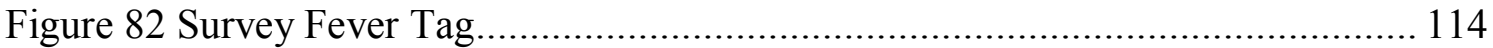

Figure 83 Survey Long Live Art in the Streets .................................................. 115

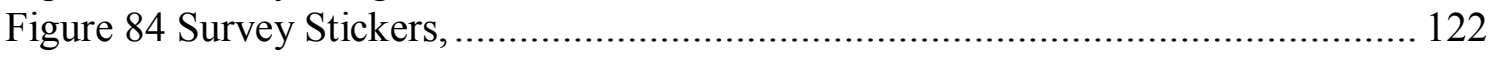

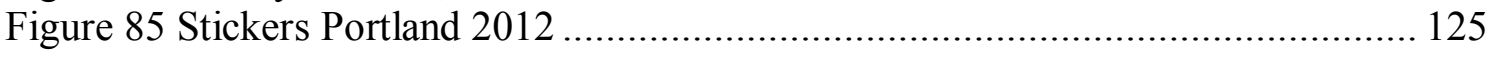

viii 
Figure 86 Hand Drawn Sticker Portland 2012 ............................................... 125

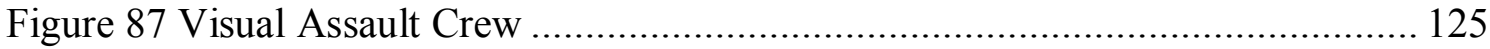

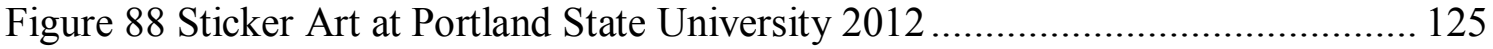

Figure 89 Survey MURG Piece, Berlin Germany................................................ 127

Figure 90 Survey GATS Piece, Portland Oregon .............................................. 127

Figure 91 Survey Community Chalk Box, Portland ........................................... 132

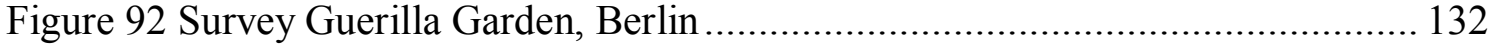

Figure 93 Survey Yarn Installation, Portland ........................................................ 132

Figure 94 Melbourne Australia ......................................................................... 150

Figure 95 Permitted Wall, Melbourne Australia ................................................ 150

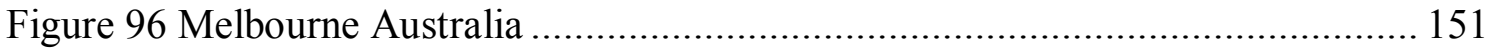

Figure 97 Shepard Fairey, Wynwood Walls Miami Florida 2011 ........................... 152

Figure 98 Ron English, Wynwood Walls Miami Florida 2011 .............................. 152

Figure 99 5Pointz, Queens NYC 2010 ................................................................ 154 


\section{Chapter 1. Introduction}

Growing up in a suburban town in Florida, I have always been fascinated with urban environments. Walking has always been my preferred method of experiencing cities. My friends and I would escape our small town and embark on adventures to cities. Not having concrete plans, we endlessly roamed the streets. The main goals: have fun and find good skateboarding spots. Drifting through the city, we searched for hidden spaces that we could temporally take over. We would allow ourselves to be drawn in random directions based on whatever way looked the most interesting or exciting. In effect, we were unknowingly participating in a psychogeographical phenomenological experience called dérive. This 'street rambling' has been described by writers such as Guy Debord, Virginia Woolf, Walter Benjamin, Michel de Certeau, Lucy Lippard, and Rebecca Solnit as a walk determined by desires that allows for close observation, soaking up ambiance, and deeply experiencing a place.

The first time I really noticed a three-dimensional piece of street art was in Portland, Oregon in 2006. The whimsical plastic giraffe was anchored to a metal sidewalk ring in front of my downtown apartment. Most people may not have even noticed this little giraffe, but I did. Every day I would glance at this somewhat insignificant piece of art. I was captivated by it. Who had made this and why? Did anyone notice it? Why is it tied to the ring? What was the ring for? I took pictures of the giraffe as the seasons changed; sometimes glistening in the rain, melting in the sun, and on rare occasions covered in snow. As time passed, it began to fade. The grime of the city streets began to collect in 
its crevices. The hot summer sun bleached-out its bright colors. And then one day it was gone.

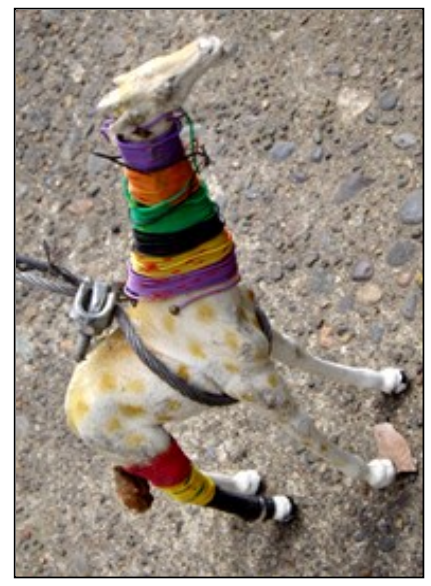

Figure 1 Public Variation of Horse Project 2008

In 2005, an artist named Scott Indiana began the Portland Horse Project. Tiny toy horses were fastened to iron sidewalk rings around the city. These rings were used in the late 1800 s to tether horses. This project drew upon Portland's collective history by helping people notice a part of the everyday landscape that they may not typically pay attention to. The horses are "quaint reminders of the horse-drawn era" (Leonard, 2006) and are meant to enhance human-environment interactions and encourage people to think about Portland's rich past and the not-so-obvious historical markers that trigger our historical imaginations. Portlanders are encouraged to make their own contributes. A website provides detailed instructions on how to make and install the horses. Portlanders have embraced the project and imaginatively adapted it as their own by adding surprising twists, like using colorful giraffes, dinosaurs, or two-headed dragons. 
Photographs of these installations can even be found in city guidebooks. They have become an example one of those quirky things that Keep Portland Weird. ${ }^{1}$

In retrospect, this insignificant event sparked my interest in street art. Gradually, I began to notice other pieces of uncommissioned art in my surroundings. I noticed more and more pieces of street art and became familiar with local artists and the various forms and styles utilized. Instead of passively experiencing the city, I began to view these everyday landscapes intertextually, reading into various symbols, making connections, and hypothesizing about their meanings. The way I looked at urban space shifted. Gazing upon the landscape, my eyes were drawn to markings and flashes of unauthorized color. Blank walls became increasingly boring. Empty spaces became alive with possibilities.

\section{Research Problem and Questions}

This research focuses on human-environment relationships by examining unauthorized artistic interventions in the city, otherwise known as street art. Street art refers to a practice of unsanctioned artistic expression found in urban public spaces and thus openly accessible for anyone to execute and observe (Jakob, 2008). Many different directions and subcultures come together to form what we think of as street art and graffiti today. ${ }^{2}$ Street art can include: spray graffiti (tags, throws, burners, and

\footnotetext{
${ }^{1}$ The Portland Horse Project was most active in 2006 and 2007, but people are still participating. Photographs of new installations can be found on Flickr and Facebook taken in 2011 and 2012. In 2011, the Oregon Cultural Trust incorporated the project into their advertising campaign showing a picture of a sidewalk horse with This is Culture printed across it. In 2011, a short film documentary about the project called It's a Ring Thing was shown at the NW Homegrown Docfest (Portland Horse Project Facebook).

${ }^{2}$ I will use the words street art and graffiti somewhat interchangeably. I discuss the similarities and differences between the two in Chapter 3.
} 
masterpieces ${ }^{3}$ ), stenciling, stickers, wheatpastes, laser projections, flash mobbing, guerilla gardening, yarn bombing, street installations, and a host of other forms. Street art can be found in every major city in the world. Cities such as New York City, Berlin, Chicago, Los Angeles, Melbourne, Oakland, Paris, San Francisco, and São Paulo are internationally known for their graffiti and street art scenes. Just like Keith Haring and Jean-Michel Basquiat in the past, names like Banksy, Shepard Fairey, Mr. Brainwash, Swoon, and Blu are increasingly recognized by mainstream culture. ${ }^{4}$ Street art is possibility the world's largest art movement since 1950s pop art (MOCA 2011). Despite this widespread cross-cultural popularity, municipalities in the United States spend billions of dollars annually on graffiti abatement and removal (M. Dennis, personal communication, March 27, 2012; Portland Police, 2012; Graffiti 911, 2008).

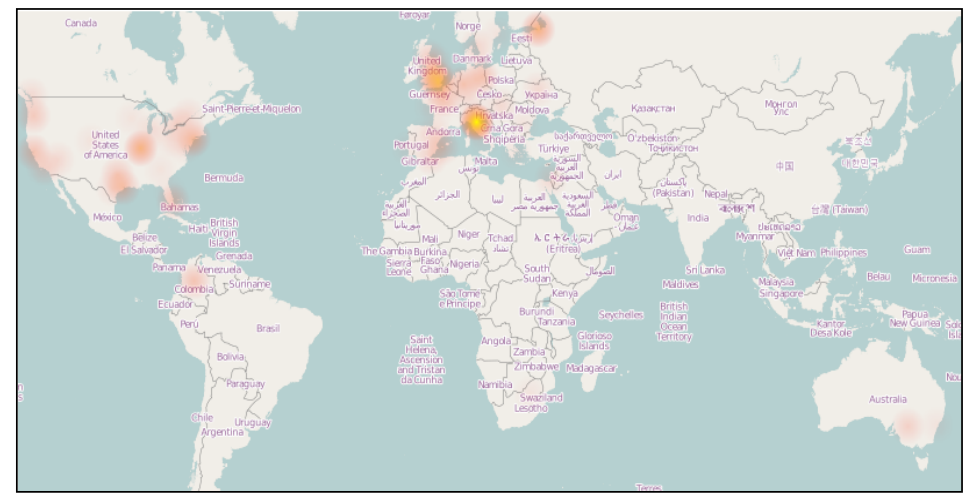

Figure 2 GrafRank Global Graffiti Concentration as of March 2012

${ }^{3}$ To apply the label of masterpiece is not a value judgment per say. Masterpiece (often abbreviated as piece) is part of a specialized vocabulary used by graffitists. Going beyond a tag, a masterpiece uses larger letters and a variety of styles. These are labor-intensive endeavors. This form of graffiti originated in NYC in the mid-1970s (Cooper \& Chalfant, 1984). Throughout this paper I use the word masterpiece when I am referring this particular form or style of graffiti. I often use the word piece to generally describe an individual object of street art or graffiti.

${ }^{4}$ The 2010 Banksy-produced film Exit through the Gift Shop was a huge success, winning at least 15 documentary film awards. The film was nominated for the Academy Award for Best Documentary Feature in 2011. Street art books are popular items on Amazon, with Banksy's Wall and Piece being the second most popular book bought in the Contemporary Art category and being \#3,535 most-sold books on the website. In April 2011, the Museum of Contemporary Art in Los Angeles, exhibited the first large-scale American museum exhibition to survey the history of graffiti and street art movements internationally. The exhibit attracted 201,352 visitors in just four months, marking the highest exhibition attendance in the museum's history (MOCA, 2011). 
Street art is not just a spatial phenomenon; it is a complex social phenomenon that produces intense emotions for different people at different times and contexts. The paradox of street art is that it is considered by some to be a natural, unmediated expression in the public realm that exercises our right to the city, and others see it as defacement, destruction, and a denunciation to a civil, clean, and orderly society. Street art plays a fluctuating role in modern consciousness. Those who see it and react to it, acting either individually or as a community, judge the meaning of street art. The audience should not be viewed as a passive receptacle for these aesthetic stimuli. The perceiver, whether reading or looking or listening, should make an active contribution to the total communicative process (Wilson, 1986).

How people interact with, experience, and are affected by, their environment can be explored by studying street art. This system of signs and symbols, taken together, are narratives that reflect, inform, and construct our collective identities and the places we inhabit. It has been said that street art is a "window into a city's soul" (Kendall, 2011). Street art can serve as a conceptual frame through which observations and interpretations of the urban cultural landscape may be developed and explored. Previous academic research on street art has tended to focus on the potential of street art to transgress and re-write normalized understandings of both art and space (Bonnett, 1992; Cresswell, 1996; Goode, 2007). Research on street art has focused on topics such as: urban identity politics and formation, masculinity, othering, presentation of self, territorial formations, gang communication, political resistance, site-specificity, subculture, spatial transgressions, and clashing images, just to name a few (Dickens, 
2008; MacDonald, 2001, 2005; Brighenti, 2010; Halsey \& Young, 2006; Hall, Clark \& Jefferson, 1976; Ferrell, 1993; Schacter, 2008; Chmielewska, 2007; Castleman, 1984; Rahn, 2001; Iveson, 2007; Austin, 2001; Sanders, 2005; Cresswell, 1992). The majority of sociological, ethnological, criminological and anthropological accounts of graffiti engage with the question of who creates it and why (Dovey, et al., 2012).

While such work has provided significant insights, it is often limited to a focus on traditional graffiti writing and the theoretical implications of the practice. To help fill this gap in scholarship, this research focuses on newer forms of street art from the perspective of the urban audience. The general aim is to further an understanding of the relationships between people and the places they live by gathering information on what people think and feel about different forms of street art. The main research questions are: How do people in Portland react to and interact with different forms of street art in the city? What do people in Portland think about different forms of street art?

This research is important for two reasons. First, the way people think about the use of space matters because the characteristics of places (e.g., design, accessibility, attractiveness, etc.) influence our understandings of the world, our identities, our attitudes toward others, and our politics (Massey, 2005). In other words, what people make of the places around them is closely connected to what they make of themselves as members of a society and inhabitants of the earth (Basso, 1996). Knowledge and perceptions of places are therefore closely linked to knowledge of self, to grasping one's position in the larger scheme of things, including one's community, and to securing a confident sense of who one is a person. Our sense of place, our sense of the past, and our 
sense of being are inseparably intertwined (Basso, 1996). In today's globalized world, we must strive towards a forward-looking 'progressive sense of place' that is open to difference, change, and global connectivity (Massey, 1994, 2005; Cresswell, 2004).

Secondly, this research is important because no other studies have gathered the general public's thoughts on street art in a systematic manner. Most accounts are anecdotal. It is essential to understand what people think about street art in order to evaluate if current policies reflect what people actually desire. The Portland Metro area spends approximately $\$ 2$ to $\$ 5$ million per year removing graffiti (Graffiti Hurts, 2011; M. Dennis, personal communication, Match 27, 2012). ${ }^{5}$ Nationwide, approximately $\$ 12$ billion to $\$ 25$ billion is spent annually on graffiti removal (Portland Police, 2012; Graffiti 911, 2008). Even the more relaxed graffiti environment of Australia spends $\$ 300$ million on graffiti removal annually (Shanti, 2012). These costs may not be entirely justified if the majority of urban residents do not want all forms street art and graffiti to be removed. There may also be better ways to deal with unwanted graffiti rather than enacting a zero-tolerance policy. The data gathered and presented in this research will contribute to a more informed discussion about the presence, acceptability, and regulation of different forms of artistic expression in cities, particularly Portland, Oregon.

The lack of existing data on what residents actually think about street art in Portland required that I collect new information to answer my research questions. Data were

\footnotetext{
${ }^{5}$ This $\$ 2$ to $\$ 5$ million estimate includes the money spent by all agencies, private property owners, public agencies (State of Oregon, ODOT, City of Portland Parks, Water, and Transportation Bureaus; PGE; PP\&L; Qwest/Century Link; Multnomah County bridges, structures, railroads; Tri-Met; and the City of Portland's Office of Neighborhood Involvement Graffiti Abatement Program) (M. Dennis, personal communication, March 27, 2012).
} 
gathered by conducting participant observations and survey interviews. These methods provided a body of techniques to acquire knowledge on the effects of street art - what happens when art is placed into public spaces without permission. Close observations also allowed me to systematically document how people reacted and interacted with street art. Finally, survey interviews provided empirical and measurable data on what people think about different forms of street art and what should be done about it.

\section{Conceptual Model}

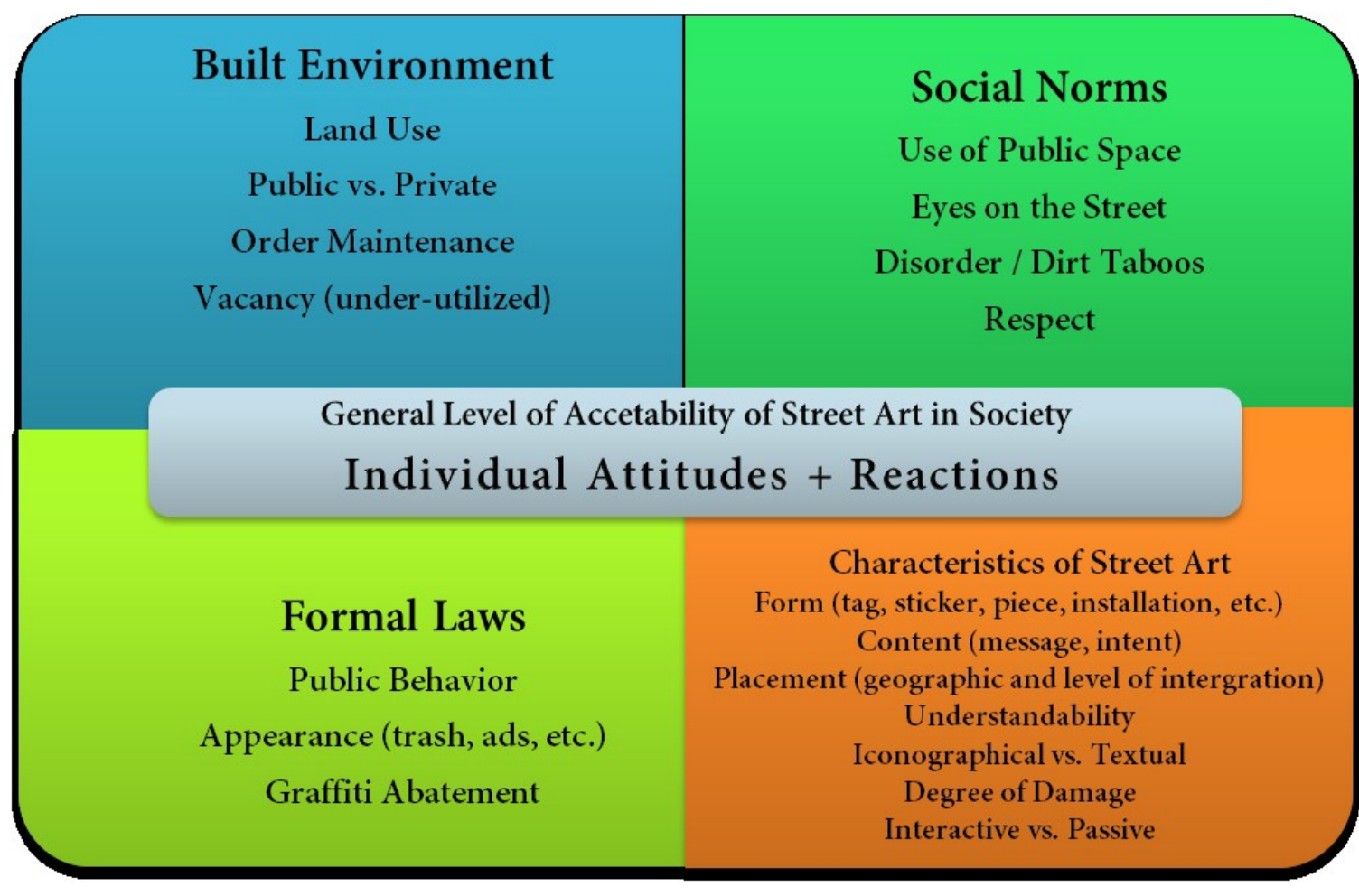

Figure 3 Conceptual Model

In order to understand what people think about a phenomenon, it is necessary to consider the factors that can influence the context of the situation in which those viewpoints are formulated. The conceptual model above was informed by empirical findings and theories. The model shows how a host of interrelated factors might 
influence what people think about street art. This model was modified throughout the research process as new findings emerged that confirmed or redirected how the issue was conceptualized. Some important factors believed to influence what people think about street art include: formal laws, social norms governing public space, the built environment, the characteristics of the piece, and the general acceptability of street art in a particular culture.

\section{Conceptual Framework}

This thesis approaches the study of street art from a few theoretical lenses, first of which is an economic and urban spatial structure framework. In this view, graffiti could be considered a practice that appropriates under-used surfaces of post-industrial urban landscapes. Depending on its form, placement, and aesthetics, graffiti can both attract and repel capital through a market desire for authenticity (Dovey, et al., 2012). Concentrations of graffiti are blamed for fostering crime and blight, but are also linked to attracting artistic talent drawn to under-utilized and affordable areas of the city. Graffiti has both positive and negative symbolic capital; it both sells and pollutes space (Dovey, et al., 2012). The sense of disorder that graffiti creates is valued by some residents and upsetting to others.

There exists a tension between the literature that approaches street art from a 'crime prevention' perspective (and thus views it as socially threatening), and the literature that approaches street art from a 'cultural' perspective (and thus views it as a phenomenon reflecting wider issues of power subversion and containment) (White, 2000). This thesis will approach the topic of street art from a cultural perspective because it is believed that 
this literature, in general, provides more compelling and well-supported arguments. Crime preventionists often focus on the superficial causes (e.g., youth gangs, rebellion, etc.) and supposed outcomes (e.g., defacement of property, fear, etc.) of street art without considering the deep human urges of free expression and the larger context of power struggle and representation, factors that I believe can more holistically explain this phenomenon. Considering the multidisciplinary nature of urban studies, the literature reviewed for this research spans several disciplines including geography, anthropology, sociology, urban planning, philosophy, architecture, and art.

This thesis also approaches the topic of street art using a Deleuzian framework (Deleuze, 1987) that focuses on assemblages produced by flows of desire (DeLanda, 2006). Graffiti is an affective process. That is, street art affects the artists' bodies, onlookers' sense of place, and the built environment (Halsey \& Young, 2006). Working from this perspective, David Massumi explains that:

Affects are basically ways of connecting, to others and other situations. They are our angle of participation in processes larger than ourselves. With intensified affect comes stronger sense of embeddedness in a larger field of life - a heightened sense of belonging, with other people and to other places. (2002, p. 214)

This view allows for questions to be asked about not just street artists, but also about those who encounter and respond to street art. This suggests that street art might be able to be used as a tool to create situations that heightens our sense of embeddedness and belonging in the city. 


\section{Chapter 2. Background}

When I began working on this thesis, I knew very little about street art or traditional graffiti. I felt the need to immerse myself in the street art scene in order to understand it from an insider's perspective. This method helped me to form a deeper understanding of the relationships between individuals, art, and public spaces. I began communicating with street artists via the Internet. I attended several local street art-inspired gallery shows. I took photographs of all the street art that I encountered. One of the most helpful aspects of this background research was informally observing areas of cities that contained concentrations of street art. I wanted to understand how these spaces were used and how they might be unique from other spaces in the city.

Informal field observations were carried out at two locations in Portland, Oregon (Sunnyside Piazza and Taylor Electric) from 2010 to 2012 and four locations in Berlin, Germany (Anarchist communities, Kunsthaus Tacheles, the Kreuzberg mural lot, and the East Side Gallery) during the summers of 2009, 2010, and 2011. Areas with street art were identified by pre-existing local knowledge, analyzing graffiti abatement maps, and literally wandering through the cities. I discovered that these locations can typically be found on the outskirts of downtowns, near or in abandoned structures, industrial areas, and in parts of town frequented by young or alternative subcultural populations. Portland was chosen out of convenience. It is where I currently live. Portland is not widelyknown for its street art scene; therefore it was more difficult to find concentrations of these activities. I included Berlin because it is one of a few cities in the world with an abundant collection of street art. Street art can be found in public playgrounds, school 
yards, parks, and pretty much everywhere else in the city. Berlin serves as an intriguing case study that illustrates what can happen when street art is no longer seen as degrading or illicit, but is instead embraced by much of the public as a unique aspect of their city and culture. The following section first provides a brief historical background of graffiti in these two cities and then the main observations that were made while conducting informal observations.

\section{Street Art in Portland, Oregon}

The best-known graffiti in Portland's history are the Lovejoy Columns, painted by Athanasios (Tom) Stefopoulos from 1948 to 1952 (West, 2012). Stefopoulos was a Greek immigrant and a watchman for the SP\&S Railroad Company (West, 2012). During idle times in the yards, he painted whimsical images of doves, owls, lions, anthropomorphic trees, and Greek mythical gods on the overpass columns. Although this was technically illegal, his art was allowed to remain for decades. ${ }^{6}$ The pillars were postcard favorites and seemed as much a part of the city's landscape as the Hawthorne Bridge (Speer, 2004). They were immortalized in Gus Van Sant's opening scene of Drugstore Cowboy and Elliott Smith's film Lucky Three, both symbols of Portland's "grimy underbelly." In 1999, when massive redevelopment swept through the area, the yard and overpass were demolished. Thanks to extensive lobbying by Rigga, a group of

\footnotetext{
${ }^{6}$ Portland's structural maintenance supervisor, Bob Koski, said that they had been requested not to paint the Lovejoy columns out (Miglavs, 1987).
} 
insurgent Portland architects and artists (Steer, 2004), ten of the painted columns ${ }^{7}$ were preserved and re-incorporated into the new 'Pearl District' urban landscape.

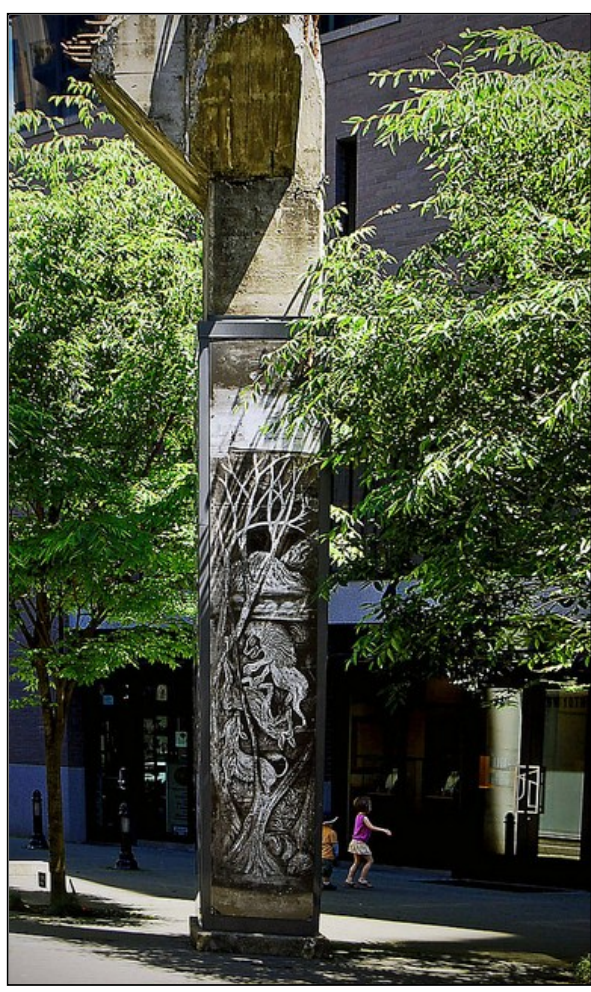

Figure 4 Lovejoy Column (Present Day)

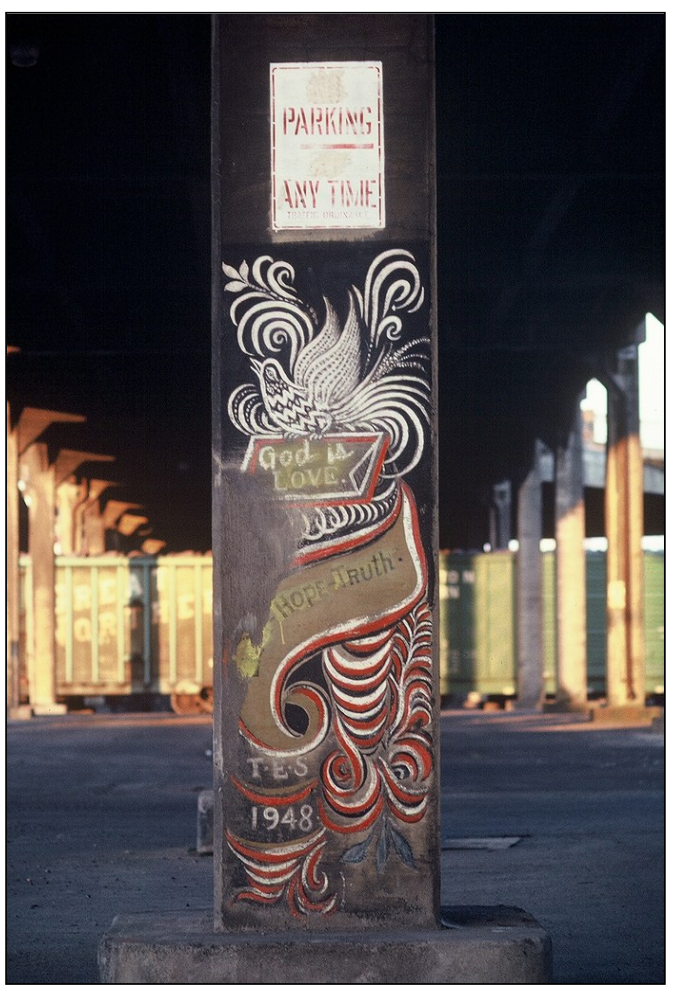

Figure 5 Lovejoy Column (Pre-Redevelopment)

With its abundant low-lying commercial buildings and ample wall space, Portland had a vibrant mural scene during the 1980s. In 1982, an anonymous group of artists formed Gorilla Wallflare (Appendix H). Their first attack was at the corner of SE $12^{\text {th }}$ and Division. Tired of seeing this dull blank wall, they took matters into their own hands and painted a large yellow banana with the slogan Art Fills the Void! on the wall (Gorilla Wallflare, 1982). Out of all the groups' guerilla murals, ${ }^{8}$ this is the only one still in existence. The owner of the building was surprised, but decided to keep the mural

\footnotetext{
${ }^{7}$ Rigga managed to convince the city to save not just the paintings, but the entire columns, arguing that if the paintings were cut free, much of their magic would be lost (Harrison, 2012).

${ }^{8}$ Gorilla Wallflare also painted a mural at the end of Hawthorne Bridge that exclaimed "Oh No!!" and a large thumbprint at $28^{\text {th }}$ and Belmont (Appendix H).
} 
(Goetze, 1982). Art Fills the Void! is Portland's oldest surviving mural today (Tracy, 2008).

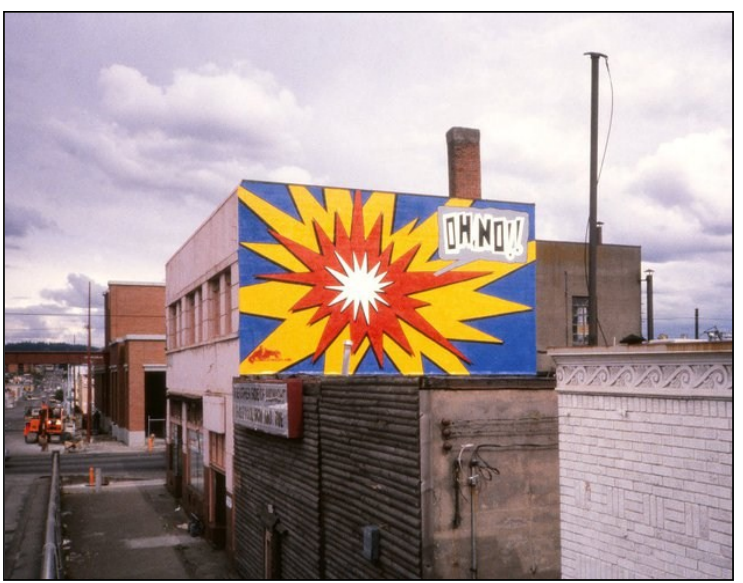

Figure 6 "Oh No!" Gorilla Wallflare

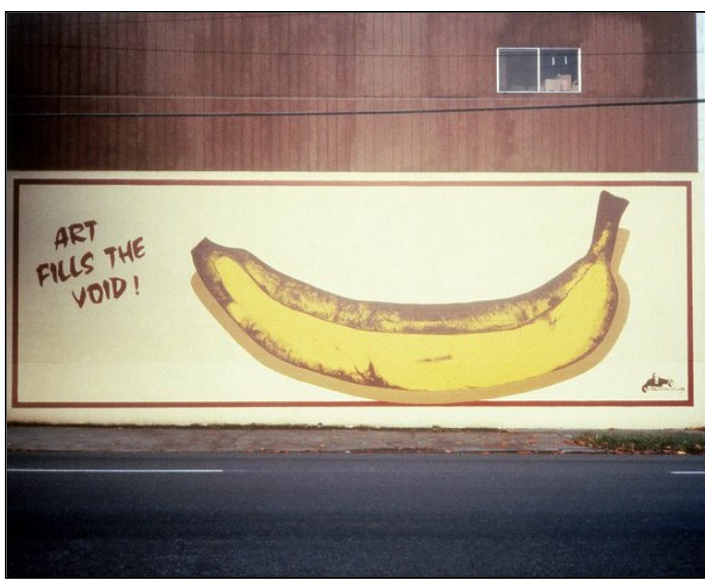

Figure 7 "Art Fills the Void," Gorilla Wallflare

The Lovejoy Columns and Art Fills the Void! are excellent examples of how a community can embrace illegal street art and shift the perception of it into something positive and valued. Portland has been informally known as a local haven for street art. People used to be able to paint on anything they had authorization from the owners to paint, without a permit or fee (B Media Collective, 2011). This openness could have been thanks to Portland's pioneer roots, general acceptance of alternative lifestyles, and support for public arts. According to the Portland Police Bureau, Hip Hop style graffiti made its way to Portland, from Southern California, in the mid-1980s (Gorsek, 2004). ${ }^{9}$ Through the 1980s and 90s, Portland had several well-known graffiti sites including the

${ }^{9}$ The first graffiti pioneers in Portland were part of the Hip Hop graffiti crew known as Criminal Minded Gangster (CMG). CMG focused their activity in inner SE, but eventually splintered into other groups (Gorsek, 2004). 
pedestrian subway ${ }^{10}$ under SW Front Avenue near the Ross Island Bridge and the tunnel ${ }^{11}$ where SW $18^{\text {th }}$ passes under Highway 26 (Miglavs, 1987). These tunnels were described as having "scrawlings so rampant and thick that digging out any meaning took meticulous archeological effort" (Miglavs, 1987). These free public art exhibits no longer exist today; both tunnels are buffed (i.e., to erase) on a regular basis.

In recent years Portland has shifted its stance and begun cracking down on graffiti. Portland is becoming tougher on graffiti, seeking restitution in more cases and going after more taggers (Barnwell, 2011). Marcia Dennis, Portland's Office of Neighborhood Involvement Graffiti Abatement Coordinator and officers Miller and Zanetti of the Portland Police Department are leading this effort. During the summer of 2011, Endless Canvas, an Oakland-based street art collective, arranged for dozens of street artists to visit Portland and participate in an art exhibit near the Brooklyn rail yards. ${ }^{12}$ Their goal was to create a Mural District that would help to change the public's perception towards street art. They sought permission to paint murals on warehouses to reduce property destruction by haphazard taggers ${ }^{13}$ and beautify neglected industrial areas (Endless Canvas, 2011). Several warehouse owners agreed to have their exterior walls painted, but at the last moment, the plans changed because the City of Portland's laws regulating

\footnotetext{
${ }^{10}$ This tunnel was nicknamed by nearby residents, the "Nazi tunnel" because of the swastika motif found on its walls (Miglavs, 1987).

${ }^{11}$ This tunnel was known for having "more academic" work due to the proximity of Portland State University (Miglavs, 1987).

${ }^{12}$ The yards span 110-acres and have been in operation since the 1860s (Waymaking, 2012).

${ }^{13}$ Neighborhood murals not only prevent graffiti, but also are good for local business. A 2008 study looked at 265 commercial corridors in the City of Philadelphia and found a positive correlation between corridor success (measured by retail sales) and the Philadelphia Mural Arts Program. Murals create neighborhood pride, build neighborhood identity and are respected by neighbors who become their unofficial stewards and protectors (Neighborhood Business Districts, 2012).
} 
signs and murals made this process too expensive and time consuming. ${ }^{14}$ The exhibit was forced to move indoors and paint the inside of a rented warehouse aptly named the Railyard. The Railyard was very popular during its short one-month existence. I had the opportunity to visit the gallery twice. I was impressed by not just the high-quality art, but also the extent to which the curator, Paul Barron, passionately spoke about the pieces themselves, the stories behind the pieces and the people who created them. Ignoring this community support, Portland's graffiti officers went into full force and allegedly resorted to intimidation tactics to persuade the warehouse's owner to evict the tenants, saying that the owner could be held responsible for the proliferation of street art around the city during this time (B Media Collective, 2011; Mirk, 2011). Within just a few days, the Railyard was closed and its murals buffed. The officially cited violations were: installation of kitchen, skate board ramp, accessory structures, and water well without permits (Portland Maps).

\footnotetext{
${ }^{14}$ In 1997, the AK Media advertising company (later bought by Clear Channel) sued the City of Portland, claiming that codes that restricted advertising intruded upon their first amendment, freedom of expression. AK Media accused the city of favoring mural art, and claimed it was also a form of advertising. The court ruled that Portland's sign code was unconstitutional, in favor of AK Media. In order to avoid losing money to a corporation, the city was forced to apply sign codes to murals. After this, in order to legally paint a mural people need to obtain a costly city permit (as high as $\$ 1,400$ ), just like advertisers. Many murals were lost or boarded up during this time. The Portland Mural Defense attended the 2006 trial to represent artists and support a more accessible mural policy. After years of struggling, Portland now allows murals only if artists go through one of two processes. A permit can be obtained from the Regional Arts \& Culture Council (RACC). Designs have to go through a panel approval process, but this permit does not require a fee. An artist can also get a permit from the City of Portland. This process does not require a design review, but does require an: application, possible structural review, a neighborhood meeting, pass inspections, and pay a fee of $\$ 250$ per mural. Although this is a better system than in the early and mid-2000s, Portland has struggled to keep its existing murals and to create new murals that reflect its growing creative population. Portland has more mural regulations than most cities. Many artists are misinformed and afraid to attempt painting a public mural (Endless Canvas, 2011). The short film, Create Abate, covers some of these issues and can be viewed on You Tube.
} 


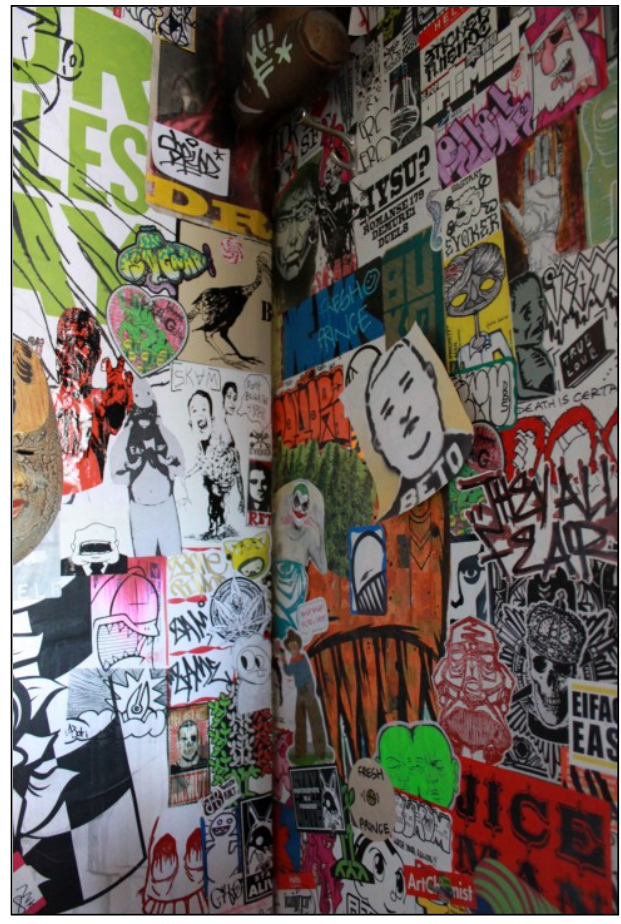

Figure 8 Railyard Bathroom Sticker Installation, Curated by SKAM

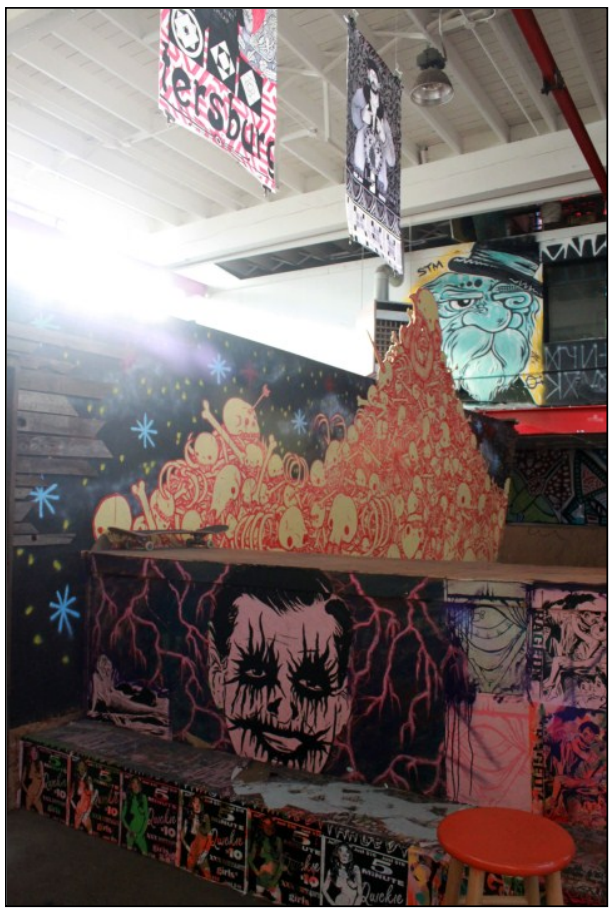

Figure 9 Railyard Swampy Skateboard Ramp

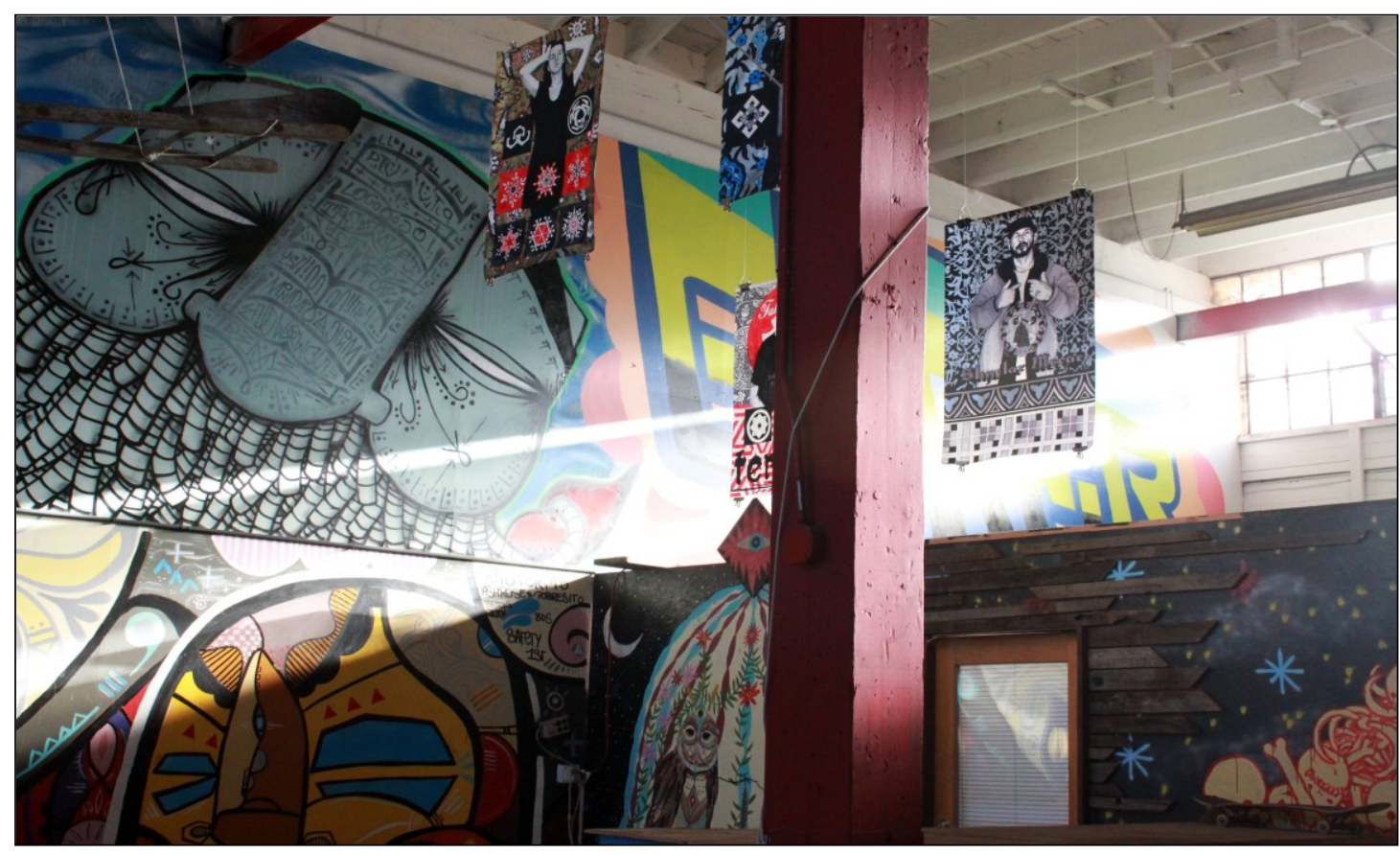

Figure 10 Railyard Main Gallery 
In March 2012, a popular hamburger joint, Hamburger Mary's in Old Town (Downtown Portland), commissioned TMK1, a group of local artists, to paint a mural of a hamburger, soft drink and fries on a their "drab and dreary" garage door (Goetze, 2012). The manager was worried that this blank door was an eyesore on a street that already had problems with drugs, loitering, and petty crime (Daisey, 2012). Unfortunately, the landlord did not agree, and thought that since the mural's lettering was done in graffiti-style that it would attract tagging along the street. The landlord forced Hamburger Mary's to paint over the mural despite protest and support from customers (Goetze, 2012).

These are just two local examples illustrating the difficulty that street artists have even when trying to work within "the system." Portland's zero-tolerance graffiti policy and prejudices towards graffiti-style art promote heavy-handed measures to be taken against these forms of expression. Graffiti removal teams typically paint over all street art and graffiti, regardless its social or artistic merit. All of this is done with little, if any community input. Additionally, Portland's strict and costly mural permitting process hinders creativity and community-based solutions to the 'graffiti problem.' Public funds are being spent fighting a never-ending battle. Neither side will back down. Both sides feel passionately about their work. 


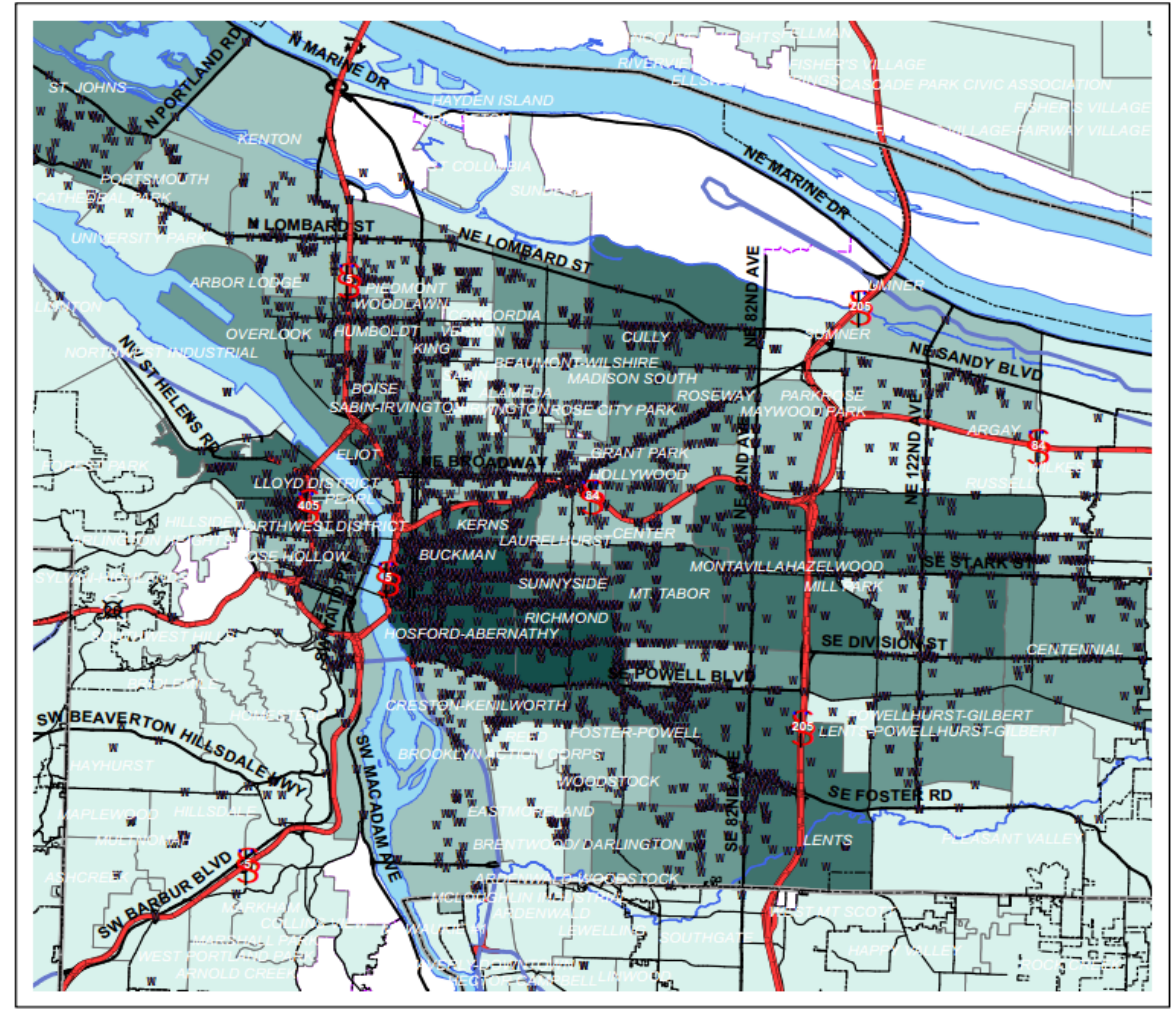

Figure 11 Reported Graffiti in Portland 2005-2006

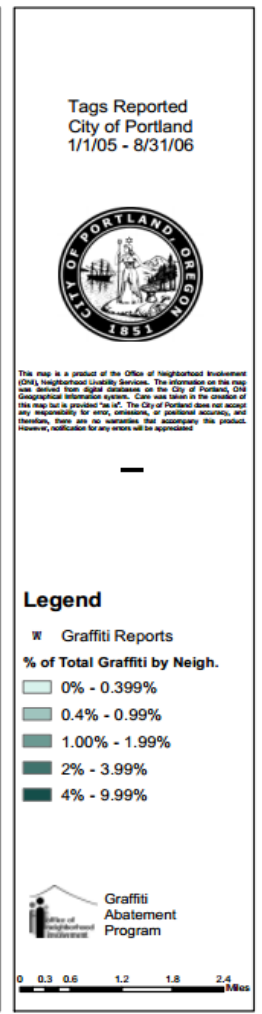

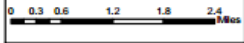

Tags Reported City of Portland

Legend

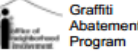

Sunnyside Piazza and the Belmont Strip

Daily observations were carried out from the summer of 2010 to the winter of 2012 in the Sunnyside neighborhood, particularly at Sunnyside Piazza and the Belmont business district. I live at $33^{\text {rd }}$ and Belmont, therefore, this proximity allowed me to notice the addition and removal of street art and graffiti fairly quickly. A long Belmont, there is a high-concentration of businesses between $33^{\text {rd }}$ and $35^{\text {th }}$ Avenues. Most of these mixed-use properties have high real-estate values due to their visibility and foot-traffic along this historic arterial roadway emanating from downtown. Through the 1980s and 90s, Sunnyside struggled with problems such as drug and alcohol abuse, crime, and vandalism (Semenza, 2006). Younger "creatives" were drawn into the neighborhood by its cheap rents, historic bungalows and Victorians, and its proximity to public transit. 
When I moved into this neighborhood in the winter of 2010, some of the businesses along Belmont were closed and boarded up. Now, all but one storefront is occupied. Businesses include a local grocery store, restaurants, hookah café, specialty boutiques, coffee shops, and multiple pool halls and bars.

Sunnyside often teems with activity. On sunny days, people fill the sidewalks, eating, drinking, taking pictures, sitting on benches, and visiting local shops. When the sun sets, the night crowd descends, frequenting the bars and pool halls on the strip. The neighborhood quiets down around $2 \mathrm{am}$ when the bars close. After a few brief hours of silence, delivery trucks come in to restock for the next day's business. Considering the amount of activity, the creative population, and the close-in location, and the main traffic corridor of Belmont, one can typically find numerous examples of street art in this area. ${ }^{15}$ Along Belmont, the most common forms of street art are stickers (on signs, poles, and newspaper stands), wheatpastes (on boarded up windows and newspaper stands), and tagging (on walls and doorways). ${ }^{16}$

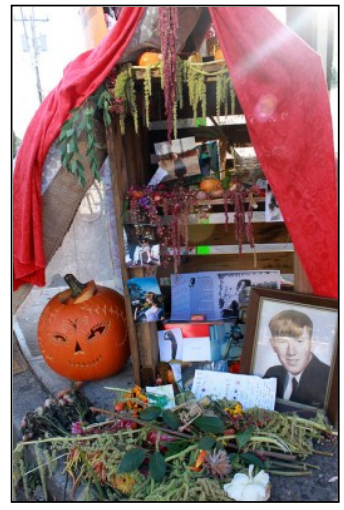

Figure 12 Day of the Dead Installation, Belmont and 34th

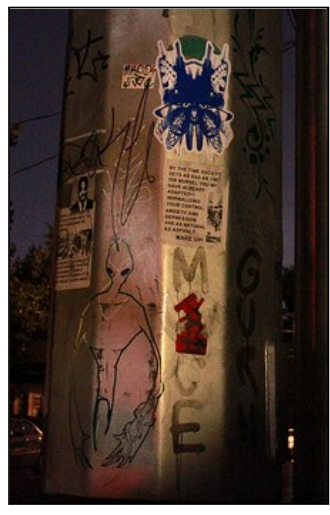

Figure 13 Electric Pole, Yamhill and 33rd

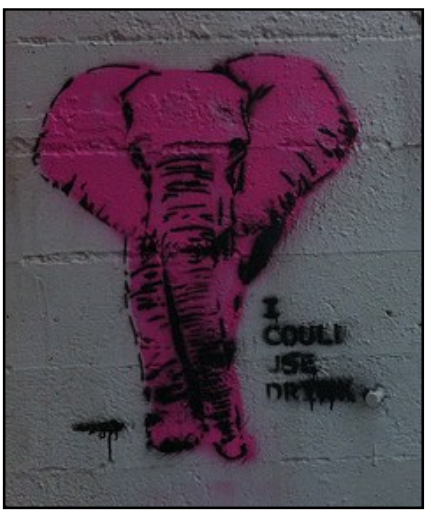

Figure 14 "I Could Use Drink," Belmont and 35th

${ }^{15}$ Chris Gorsek made this observation in 1996 as well, saying that there appeared to be a higher incidence of graffiti in the non-residential areas along Belmont near SE $35^{\text {th }}$ (2004).

${ }^{16}$ Self-adhesive stickers are used as a form of graffiti. It is a preferred medium because of its quick application. Wheatpaste is a liquid adhesive made from vegetable starch and water that is used to adhere paper to surfaces. 
The nearby Sunnyside Piazza intersection at SE $33^{\text {rd }}$ and Yamhill is an excellent example of residents coming together to create a community gathering place. This was one of Portland's City Repair's first projects that aimed to 'repair' and reclaim underutilized space. This space had been previously overtaken by traffic and crime (Semenza, 2006). In an effort to create community-oriented spaces, residents painted a huge sunflower in the middle of the intersection and installed multiple art pieces at each corner. Engaged residents have turned this intersection into a space for art, expression and community building. Residents come together annually; close the intersection to traffic to spend a weekend re-painting, talking, picnicking, and playing.

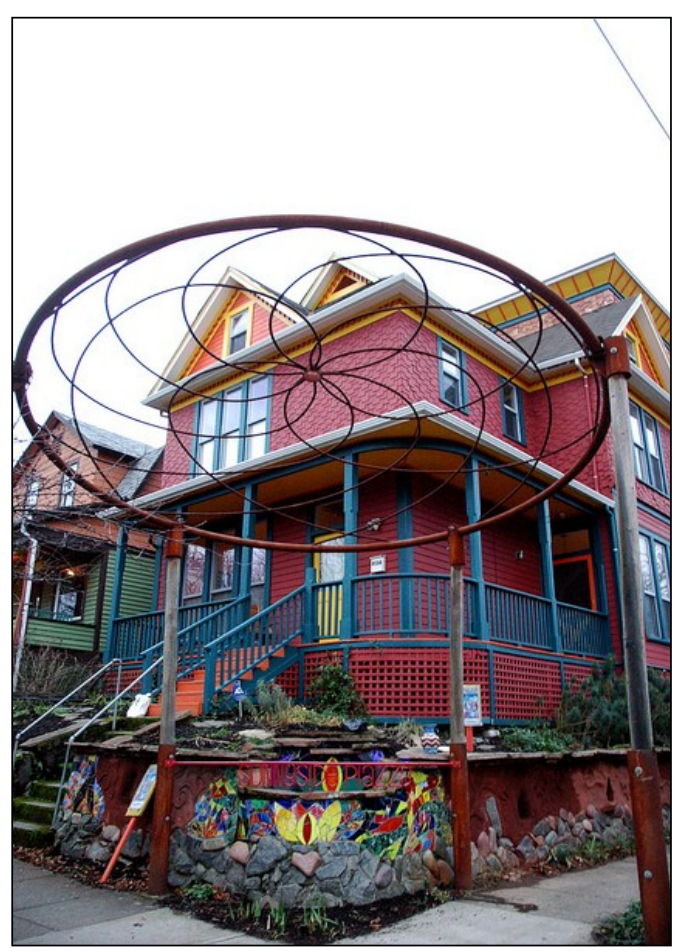

Figure 15 Sunnyside Piazza

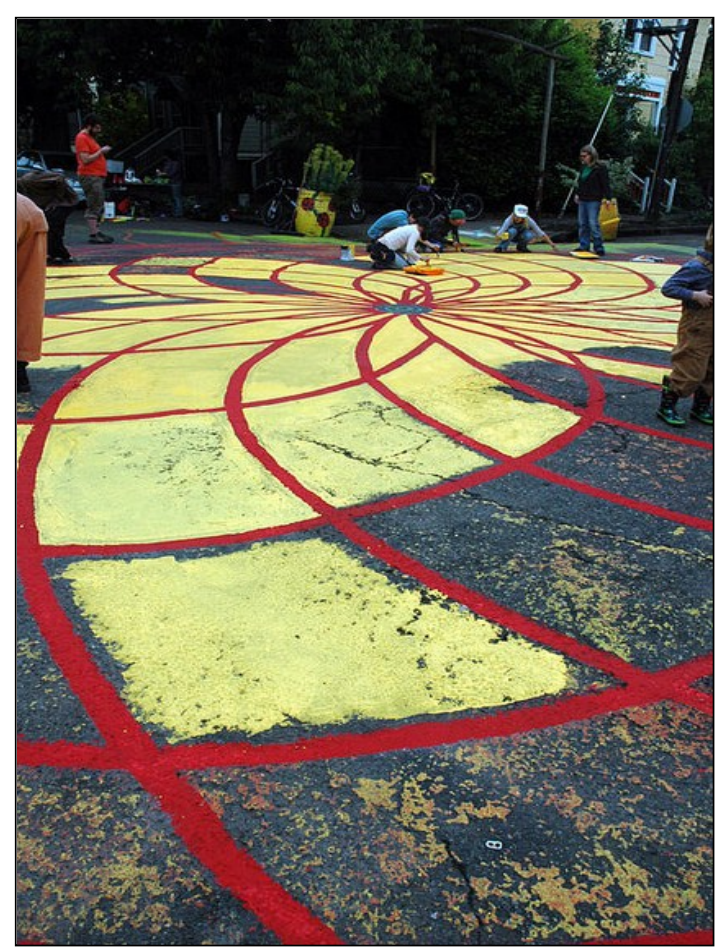

Figure 16 Sunnyside Piazza Re-Paint 2010

In addition to the commissioned and organized art at Sunnyside Piazza (i.e., the painted sunflower, cob structure information booth and bench, stained glass wall 
mosaics, three sidewalk trellises and dome, and eight planters in the parking lanes) there are several uncommissioned street art interventions in the area. These unofficial pieces include: a birdhouse, a metal flower with a bicycle spoke center, several yarn installations, and various forms of art adhered and sprayed onto stop signs and a large utility pole (including spray-painted tags, stickers, wheatpastes, and tape/marker graffiti). Passersby tend to notice the utility pole the most. They stop to read the wheatpasted posters that warn people of a 1984 Orwellian-like world. These posters were the first pieces to appear on the pole in 2010 and the pole now contains upwards of 50 different pieces, most of which appeared during the summer of 2011. People also tend to notice the yarn installations. As they pass, they touch and take pictures of them.

Sunnyside's volunteer graffiti abatement team sweeps through the neighborhood on a monthly basis. The Sunnyside newsletter asks residents to: "Help improve the livability of your neighborhood and experience the satisfaction of removing graffiti " (2011). The volunteers focus their efforts along Belmont; peeling off stickers from signs and poles, buffing out tagging at bus stops and doorways, and removing wheatpastes on the newspaper stands and boarded up windows. As soon as stickers are removed, new ones appear. Interestingly, during the two years of observations, the graffiti abatement team has left all yarn installation pieces alone. ${ }^{17}$ The medium of yarn is soft, comforting, loving, and feminized, all characteristics which contribute to its nonthreatening effect.

\footnotetext{
${ }^{17}$ I will speak more about this topic in the participant observation section in Chapter 4.
} 


\section{Taylor Electric Building}

Although Portland generally lacks a "dead zone" of derelict structures that plague many cities today, there are pockets of "gray" areas. One such area is the burnt-out Taylor Electric Supply company at SE 2nd and Clay, near the train tracks and Willamette River. In 2006, a massive fire engulfed the building. This was Portland's largest industrial fire in years (East PDX News, 2006). It was so intense that fire fighters' efforts did little to extinguish it and the fire burnt into the night. I remember watching this dramatic scene from my office downtown. The next day the fire was finally extinguished, but the entire building had collapsed, leaving a hollowed-out skeleton and ash-covered cement floor.

Six years later the building's shell stands mostly unchanged. This area could be viewed as: blighted, underutilized, ${ }^{18}$ contaminated, a potential for re-development, or even an outdoor urban art gallery. Even though a chain link fence surrounds the property, several access points along the fence allow for easy access. Hobo youth gangs sometimes sleep inside a crudely constructed shelter in the back corner. All sorts of trash litter the ground. Street art and graffiti literally covers every wall inside the structure. Some of Portland's most impressive displays of street art can be found here, in the heart of inner SE, clearly visible from the Hawthorne Bridge.

Taylor Electric's street art ranges from simple tags and stencils to huge elaborately spray-painted masterpieces. The quality of the work is better here than in other parts of

\footnotetext{
${ }^{18}$ Portland's urban growth boundary helps to decrease sprawl into the cherished countryside and increase density within the city. Due to Portland's land-use planning, vacant land such as this is rare within the urban core.
} 
the city because of the privacy, especially at night. Someone periodically buffs the visible parts of the building every few months. This is strange because not only is this an unsalvageable building, it is also located in the middle of an industrial area with no nearby households. They must believe that covering up the graffiti will deter more from being put up. Based on my informal observations, and the work of Chris Gorsek (2004) (discussed later), buffing does not to deter graffiti from reoccurring. If anything, the solid paint provides graffiti artists a fresh canvas to work on.

I believe that undeveloped landscapes such as this serve as a reminder that there is value in not having all urban space in continuous official use. These spaces 'in-between' are voids that allow for unscripted activities. Other than the constant swooshing of speeding cars from the nearby freeways, the building is peculiarly tranquil and quiet, especially on the weekends when the surrounding warehouses are closed. Although most people would think this space is far from ideal, these abandoned spaces serve as unofficial play and exploration areas. These urban wastelands are a respite from the city's watchful eyes. They are places in a state of uncertainty, caught between uses. Portland has many idyllic characteristics other cities often strive to emulate. These pleasant features are important to highlight, however, parts of Portland such as this are also fascinating because even though it is a vibrant, dense city, it has pockets of space left for unscripted activities such as graffiti. The possibility of stumbling upon the undiscovered and underused still exists. 


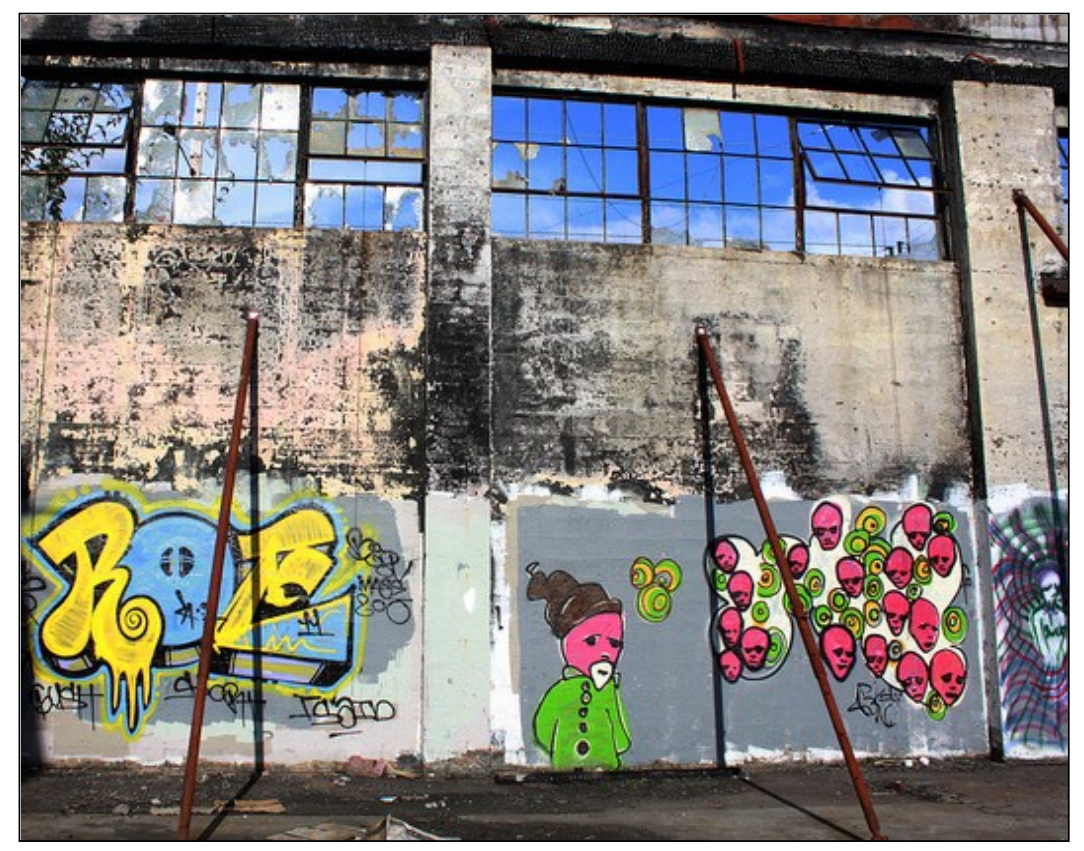

Figure 17 Taylor Electric, Summer 2011

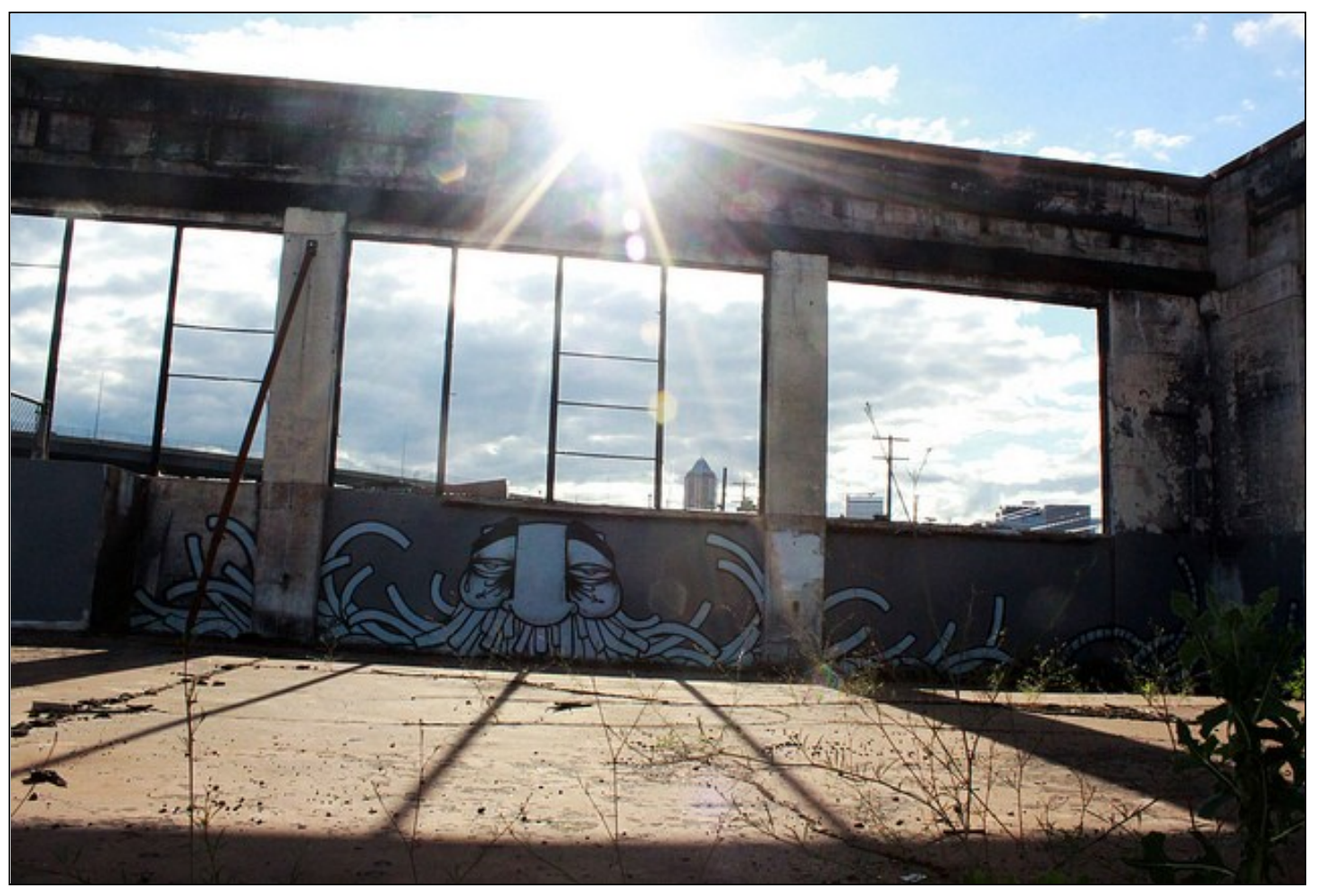

Figure 18 Taylor Electric, Summer 2011 


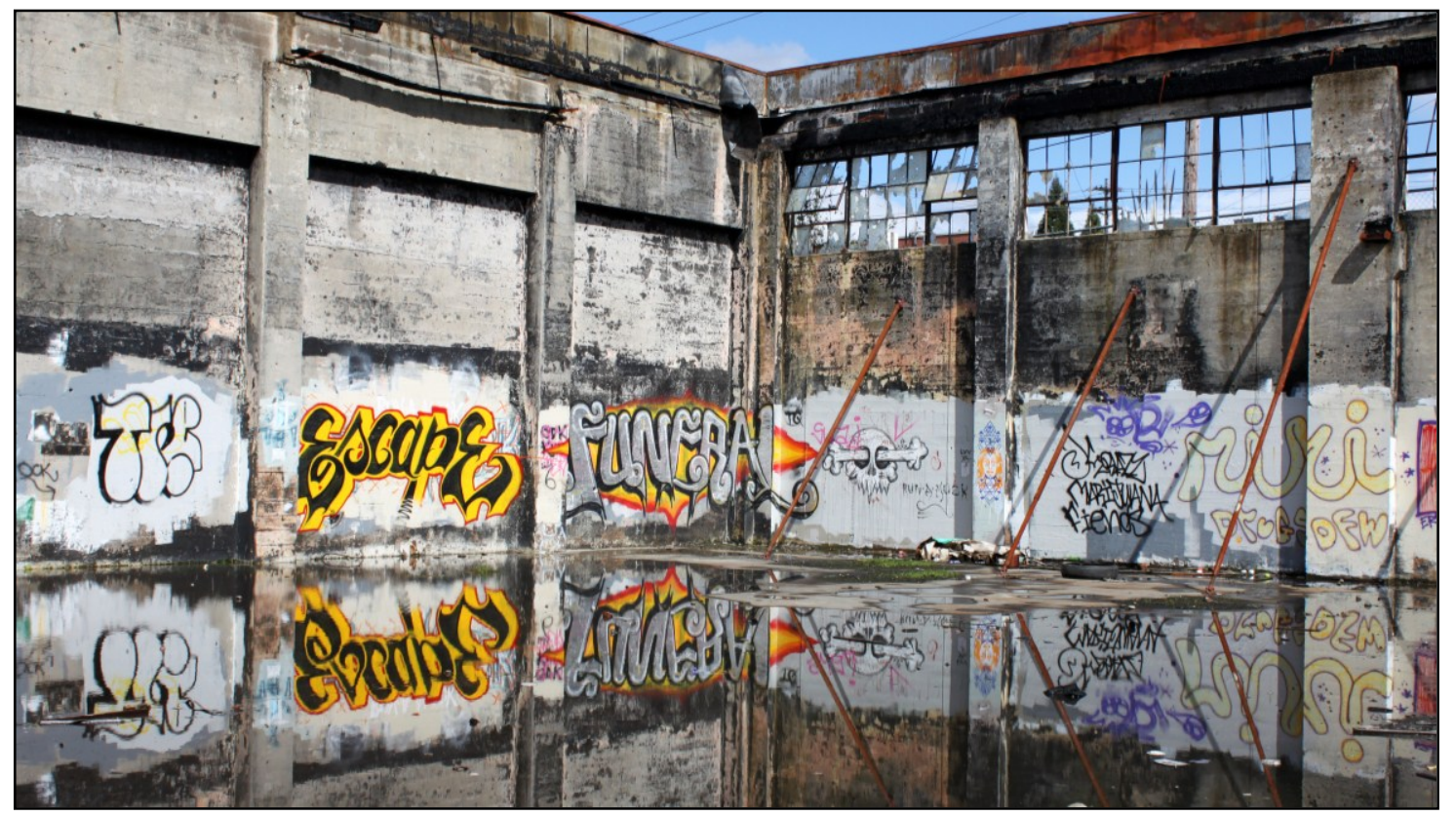

Figure 19 Taylor Electric, Winter 2012

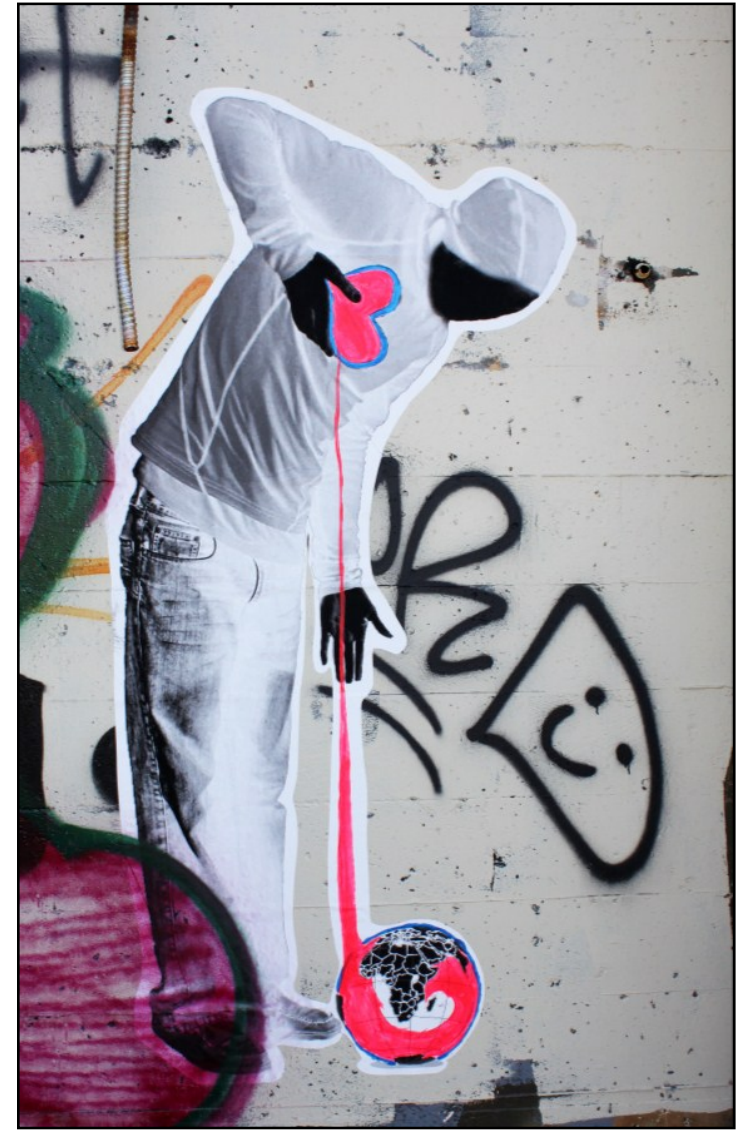

Figure 20 Taylor Electric, Winter 2012

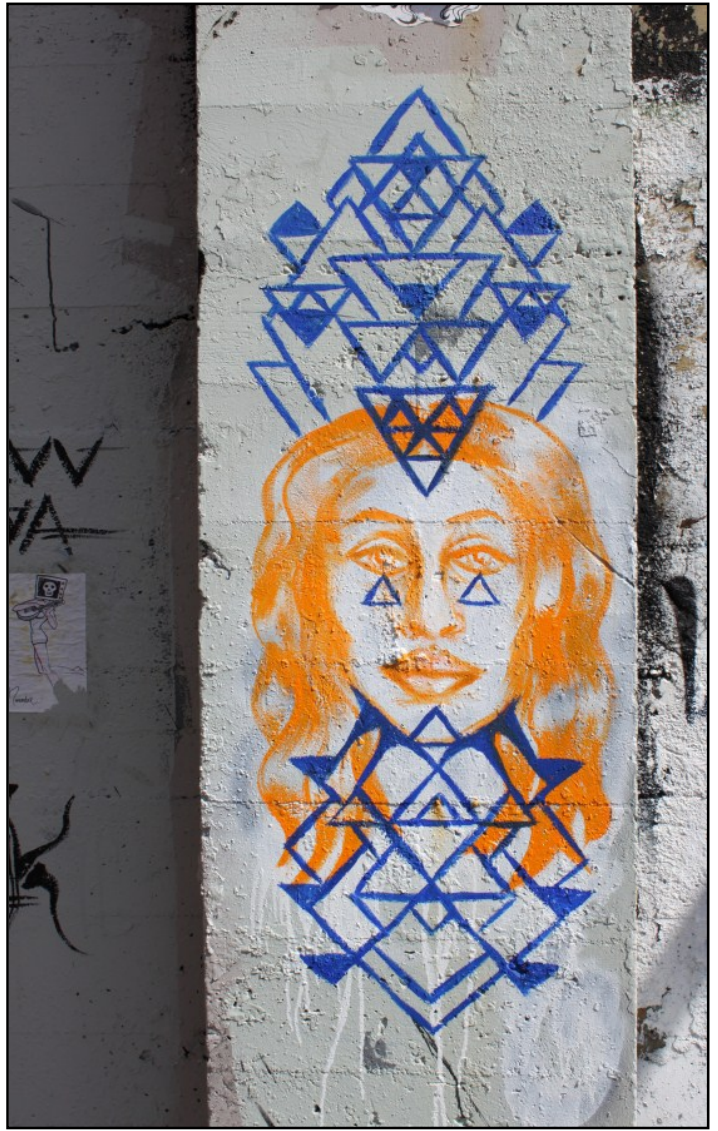

Figure 21 Taylor Electric, Winter 2012 


\section{Street Art in Berlin, Germany}

Berlin has been described as a "haunted city" because on one hand it is a metropolis characterized by separation, death, devastation, and vast vacancy but on other hand, it can also be characterized as resilient, deeply rooted in place, bold, creative, and deeply symbolic (Ladd, 1997). When the Berlin Wall was still standing, the western side boasted an impressive display of graffiti, including personal outbursts, political slogans, posters, paintings, and attachments (Ladd, 1997). The wall attracted a many creative expressions of defiance in its early years. It began flourishing as a mural site in 1976 when it was reconstructed using prefabricated concrete waterproof slabs, creating a smooth white canvas (Ladd, 1997). The wall served as an "all-purpose bulletin board" and outdoor experimental art studio, facilitating lively communication between citizens (Ladd 1997: 26). It was a 40-mile long gallery for public protest and expression.

Strangely, what was a symbol of a divided city in turmoil was also a showcase of meaningful spontaneity (Ladd, 1997). Millions of people came to see the wall during the 1980s and its art spread across the globe through stories and photographs (MacPhee, 2004). Despite resident desires to ignore this boundary, boldly colorful graffiti made the wall inescapable (Ladd, 1997). A reoccurring theme used on the wall was trompe-l'aeil (Ladd, 1997), an artistic technique that involves the creation of optical illusions that make objects appear as if they are 3D. ${ }^{19}$ Artists created faux-openings, making the wall look like it had been broken or cut through, exposing the landscape beyond. The purpose

\footnotetext{
${ }^{19}$ This technique is often used by street artists, such as Banksy, on the West Bank barrier that separates Palestine from Israel.
} 
of these depictions was to call attention to the injustice, abnormality, and artificiality of the imposed barrier (Ladd, 1997).

After the wall fell, many East Berlin neighborhoods were deserted and a sense of vacancy prevailed (Jakob, 2008). With cheap rents and available spaces, slowly these areas attracted artists, anarchists, musicians, and bohemians. The cost of living in Berlin was (and still is) relatively cheap compared to other major European cities. Galleries, independent shops, and publishers occupy many of the storefronts (Jakob, 2008). Artists gravitate to Berlin because it is always changing; a work in progress and permanently unfinished. This is especially true in neighborhoods such as Kreuzberg, Friedrichshain, and Prenzlauer Berg where multi-faceted creative lifestyles have firmly established themselves (Jakob, 2008). Residents strongly identify with their neighborhoods and communication via street art is commonplace and largely embraced (Jakob, 2008). The following observations were made while visiting Berlin during the summers of 2009 , 2010 and 2011.

\section{Anarchist Communities}

It is clear that anarchist communities ${ }^{20}$ are involved in spreading street art throughout Berlin. These communities are part of Berlin's collective housing movement that began in the 1980s. ${ }^{21}$ Citywide graffiti (particular tags and stencils) were found in

\footnotetext{
${ }^{20}$ An "anarchist community" is any society or subculture within a society that functions according to anarchist philosophy and principles.

${ }^{21}$ In the 1980 and 90s, Berlin was home to many squatting settlements. Some complexes were fought for and legalized, but many were dismantled by violent evictions during the mid-90s. At this time Berlin's Mega-Spree project was underway. This was a dramatic gentrification effort in the inner city that included major rent increases (sometimes doubling overnight) resulting in many people being pushed out of their neighborhoods. In 2009, only 30 or 50 collective houses remained in the city and 10 of those had threats of eviction in the near future (Shane, 2009).
} 
concentration in and around these anarchist complexes. Graffiti-tagged trucks were parked in front of one community. I discovered three main anarchist communities and several smaller ones. Most were repurposed apartment and school complexes. The concentration of street art and graffiti dramatically increased as I approached the communities alerting me to basically follow the art. Once at the building(s), both the outsides and insides had impressive displays of street art. The finest quality stencils I have ever seen were found in the passageways of these complexes. One of these buildings even had an anarchist community meeting space and library, that appeared open to the public, but I did not go in. Learning from experience, ${ }^{22}$ visitors are not always welcomed, especially those with cameras and who are not dressed in 'traditional' anarchist attire. ${ }^{23}$ To avoid confrontation, I was only able to photograph some of these areas while no one was around.

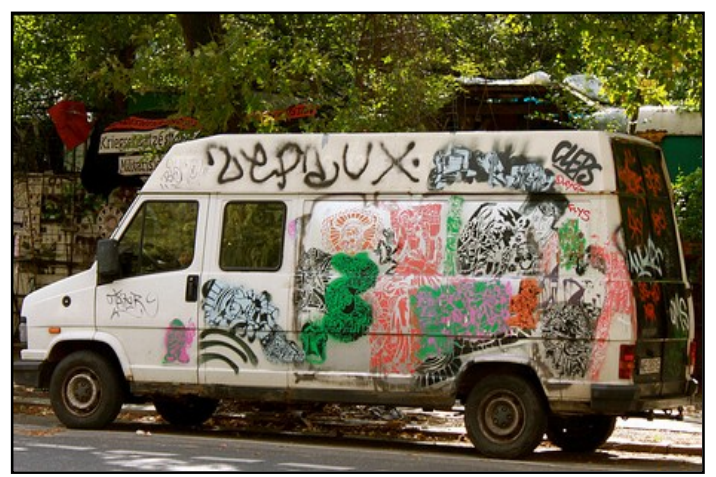

Figure 22 Van Outside Kopi

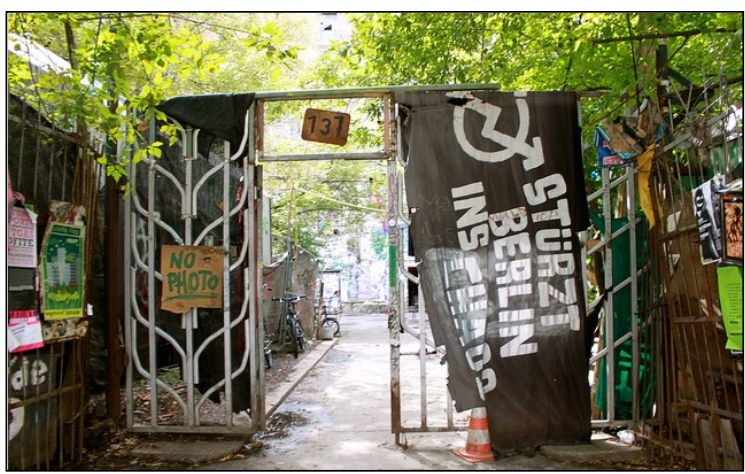

Figure 23 Kopi Entrance

\footnotetext{
${ }^{22}$ At one of the housing complexes, I was photographing the exterior, which had a "no photo" sign on the wall. A man in his late 40 s pointed at me and then at the sign. He looked quite annoyed by my presence so I quickly apologized and left the area.

${ }^{23}$ Shane, an anarchist from the Anarchist Media Group in Berlin, said that there exists a dress code, so insiders can easily identify outsiders. If a new person comes into their community and doesn't look the part, the person is assumed to be a civil cop. Shane criticized this stereotyping as being a barrier to constructive dialogs between communities (2009).
} 


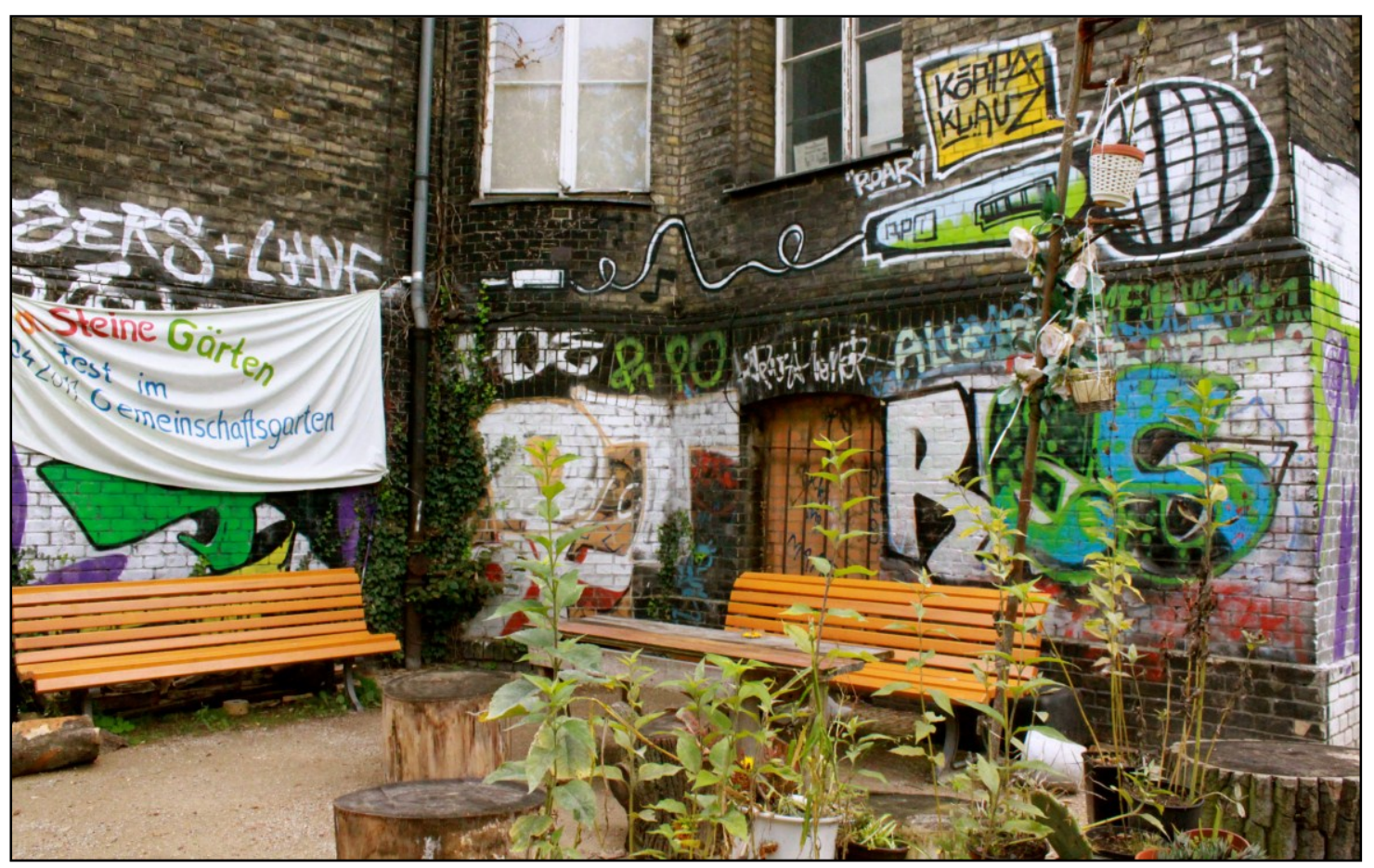

Figure 24 Unknown Collective, Free Seed-Free Life Garden

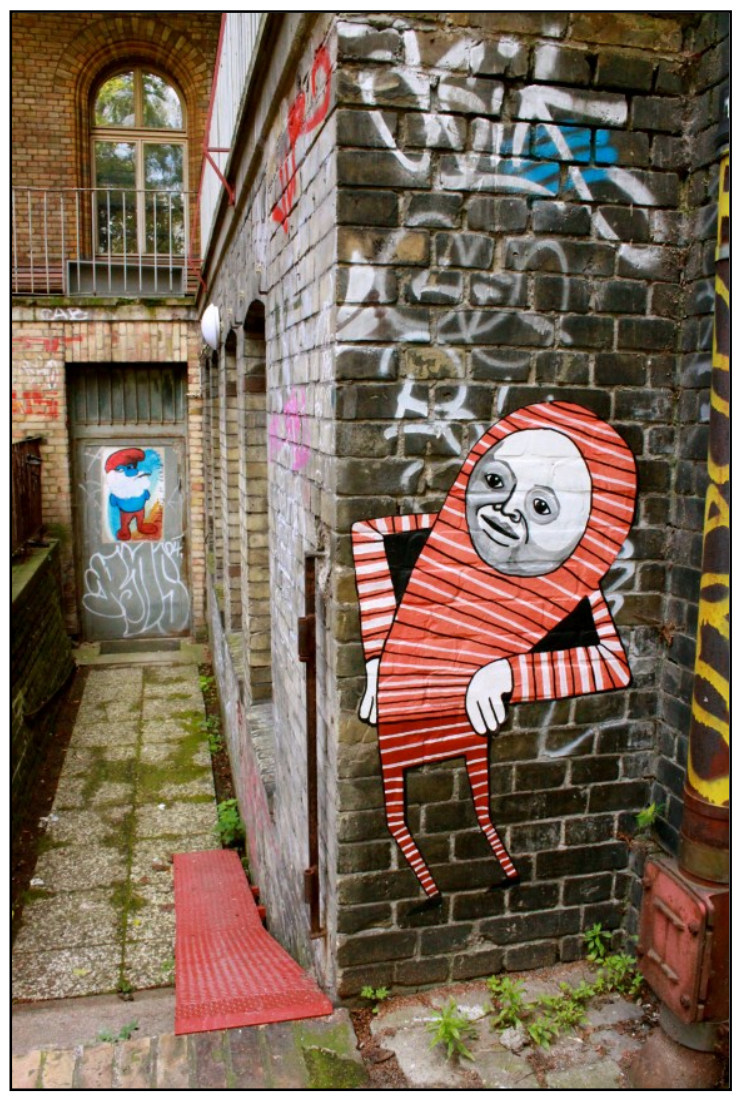

Figure 25 Unknown Collective, Mean Marek 


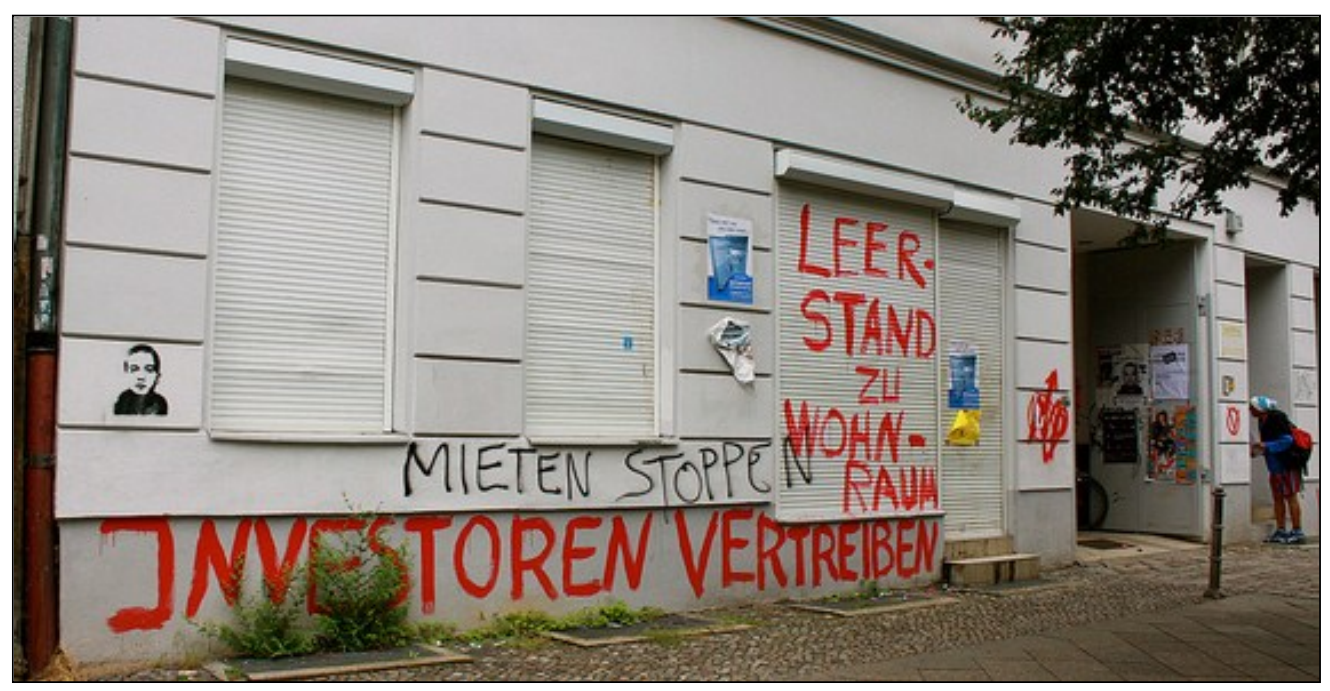

Figure 26 Heil Weise "Make Vacancy Living Space Cast Out Investors"

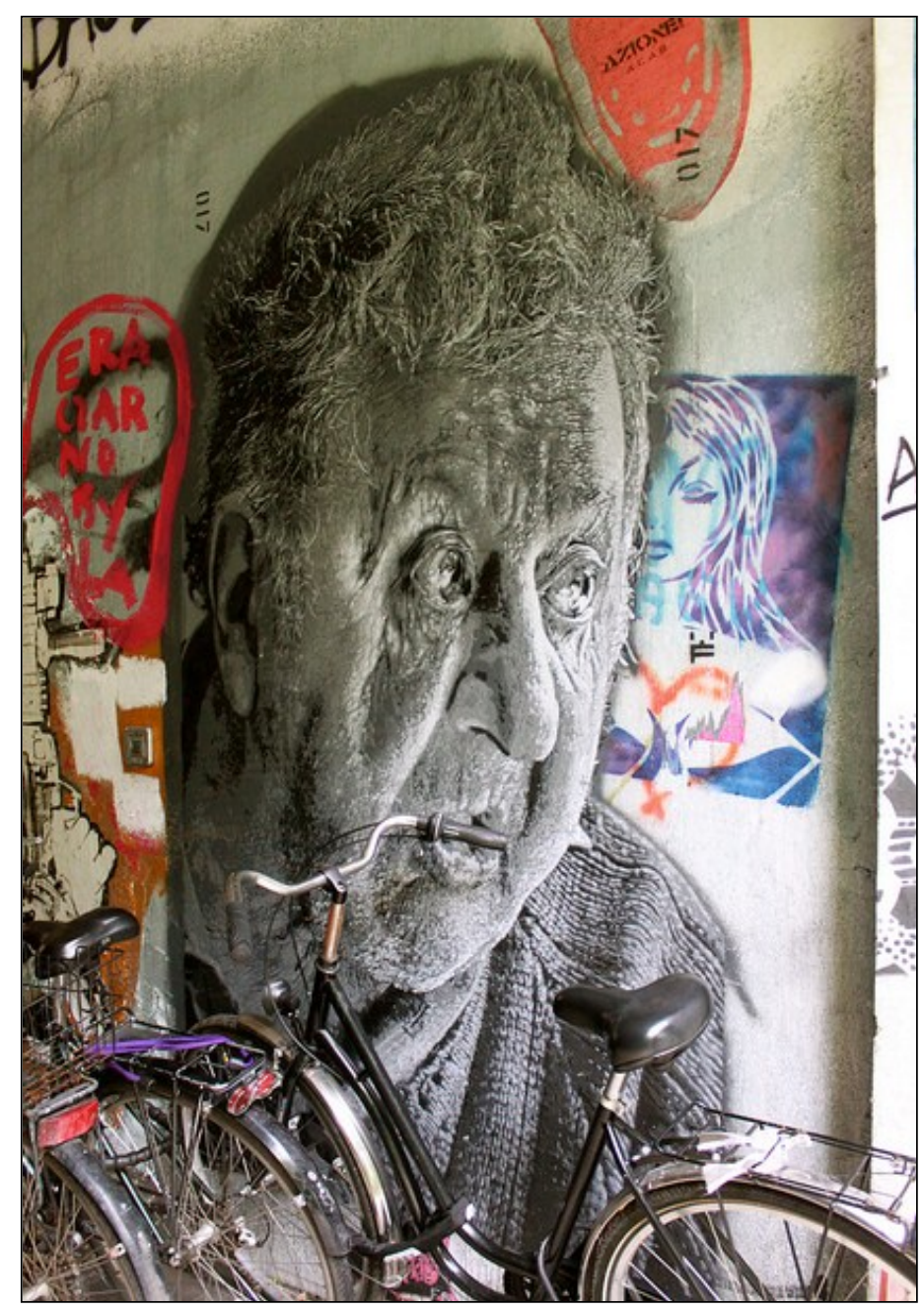

Figure 27 Heil Weise Community, Stencil by Czarnobyl 


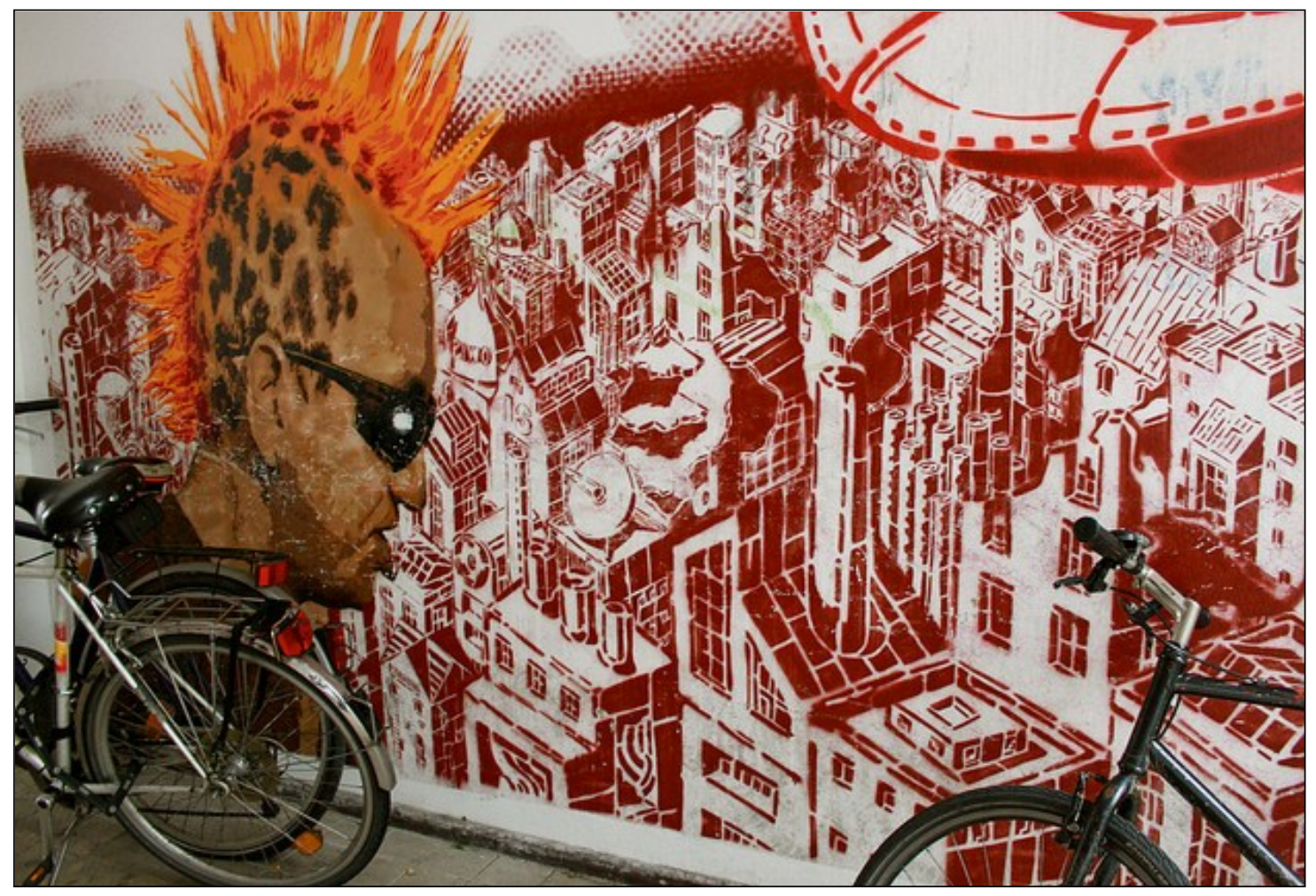

Figure 28 Heil Weise Community, Unknown Artist

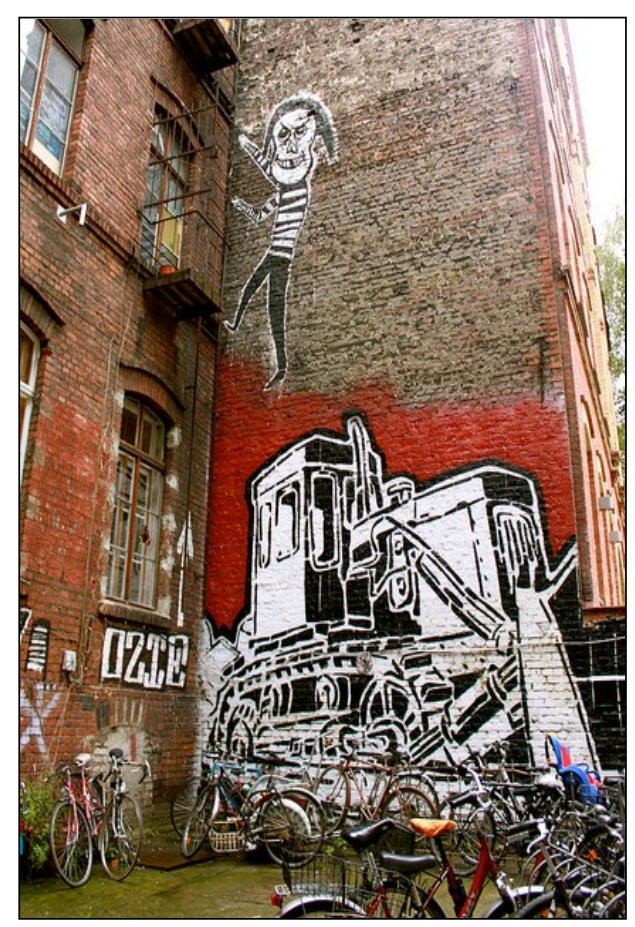

Figure 29 Heil Weise Community, Unknown Artist 


\section{Kunsthaus Tacheles}

Kunsthaus Tacheles is an art center on Oranienburger Straße in Mitte. Built in 1907, the building was originally a department store in Berlin's Jewish quarter. The attic was used by the Nazis to detain French prisoners of war at one point and then was heavily damaged during the bombing raids of WWII (Freeman, 2010). The structure sat vacant for decades. Following the fall of the Berlin Wall in 1990, a group of artists occupied the derelict building and saved it from being demolished (Freeman, 2010). Over the past two decades, about 70 artists have shared 30 studios inside the more stable parts of the structure (Freeman, 2010). Today, the art is not just in the studios, it covers the entire building. After being re-appropriated, Tacheles became a magnet for tourists. They came to clamber up its winding staircase, peer at graffiti-covered walls, chat with artists, and drink and dance in the open-air cafe and bar (Freeman, 2010). The building continues to be a popular free attraction today, having nearly 400,000 visitors annually. ${ }^{24}$

Passing through the massive complex is overwhelming; a catacomb of hallways and galleries with no directional signs or markers. To completely walk through it takes hours. The sounds of people talking and laughing echo through the structure's dimly lit stairwell. A musty smell of beer and urine fill the air. The walls, doors, stairs, rails and ceilings of the structure are entirely covered with graffiti. It appears that people can freely paint or put up anything they would like. Fresh air and beams of light filtered in

\footnotetext{
${ }^{24}$ This street art mecca is now threatened, as the artists face eviction and the building, demolition. With intense gentrification occurring around it (most likely due to its very presence); the property is estimated to be worth about 80 million euros and has caught the eye of developers who want to turn it into an upscale shopping center or a luxury hotel. This news has stunned those running the non-profit art house, as well as the supportive Berlin government, which over the years has helped fund its art projects. The battle to save Tacheles wages on. Over 85,000 signatures have been collected from people around the world in support of Tacheles (Freeman, 2010).
} 
from the busted windows. Through the broken glass, views outside reveal an overgrown courtyard with graffiti covered walls and old couches. Some artists toil away at their art ignoring your presence; other artists look for conversation. Outside, in the Sculpture Park courtyard gallery, artists weld huge iron and metal sculptures. Towering over the park is a black and white mural depicting a somber man's face that says, "How Long Is Now. ${ }^{25}$ On weekend evenings, the space roars with commotion. The pounding of music shakes the rickety structure. At the end of a hallway, a small un-marked dimly lit bar serves inexpensive beer (assuming you did not bring your own). Tacheles is a place where both locals and tourists mingle together in true Berlin-style. Those too wary of entering the intimidating structure, photograph it from the sidewalk or from one of the many upscale restaurants across the street.

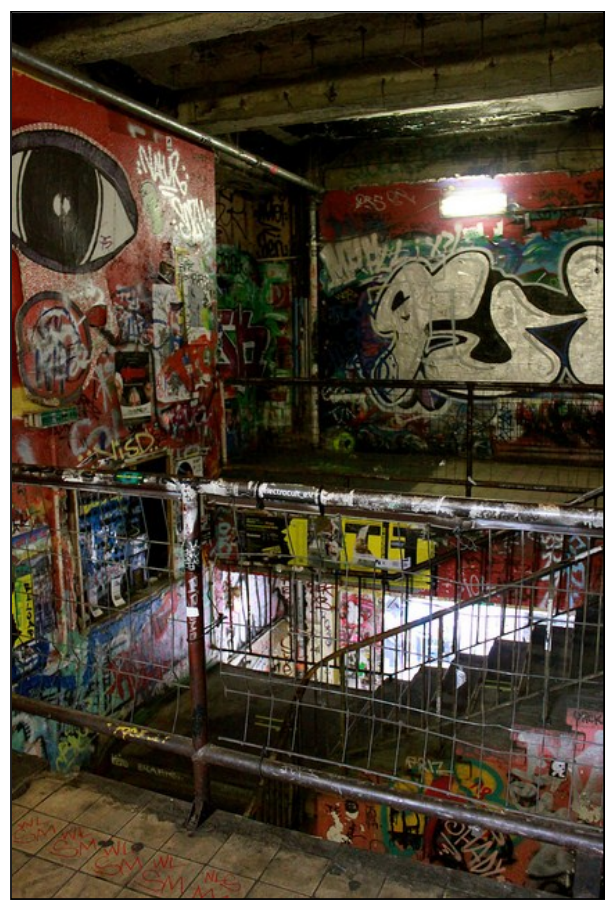

Figure 30 Tacheles Main Stairwell

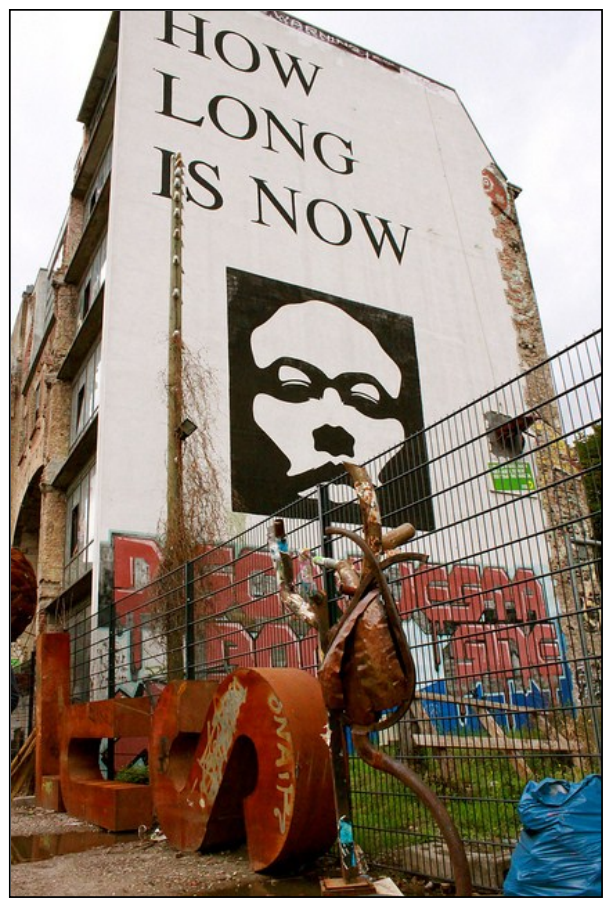

Figure 31 How Long is Now, Tacheles

\footnotetext{
${ }^{25}$ This is a philosophical question, referencing being spiritually awake in the perpetual now, while also passionately engaging with the adventure of life (Freke, 2009).
} 


\section{Kreuzberg Mural Lot}

In the Kreuzberg ${ }^{26}$ borough of Berlin sits a vacant lot along the banks of the Spree River that is world-famous for its street art. Its most well-known piece is a mural stretching across two factories. This mural was a collaboration between the Italian artist BLU (who painted the figures) and French artist JR (who wheatpasted the eyes). It was created in 2007 during a one-month street art exhibition. The image is of two masked men, one forming an ' $\mathrm{E}$ ' and the other a ' $\mathrm{W}$ ' with their hands, representing the reunification of East and West Berlin (Ferrante, 2011). To the figure's right side reads, "Reclaim Your City," a popular street art slogan. Below the mural are countless other street art pieces. In 2011, a guerilla garden appeared in the lot, compete with tomatoes, squash, herbs, and sunflowers. In the back corner there is a makeshift wooden structure with couches and an examination table inside, presumably for those in need of rest and shelter. Unfortunately, I have not witnessed anyone painting graffiti while at the lot.

Many different types of people, doing various activities, come to the lot. Most people sit along the embankment, drink beer, talk to friends, and look at the scenery. Elderly folks walk their dogs and picnic; couples play Frisbee and catch; others are there for the art, taking pictures and video. Just too the north, the landmark Oberbaum Bridge spans across the river. U-Bahn trains pass back and forth over this striking doubledecker brick bridge. This space feels calm and safe, almost like a de facto community park. One night while visiting, a "flash mob party" occurred. The group descended upon

\footnotetext{
${ }^{26}$ Historically, Kreuzberg was one of the poorest areas of Berlin, especially during the 1970s when it was in isolated West Berlin. Kreuzberg's vacancy attracted many artist and fringe-types looking for free expression and space. Kreuzberg became the epicenter of Berlin's punk rock, anarchist, squatting, queer, and other subcultural movements.
} 
the lot with candles, boom boxes, beer, wine, and snacks. This relaxed atmosphere is not taken advantage of, as there is not excessive noise, litter, or vagrancy.

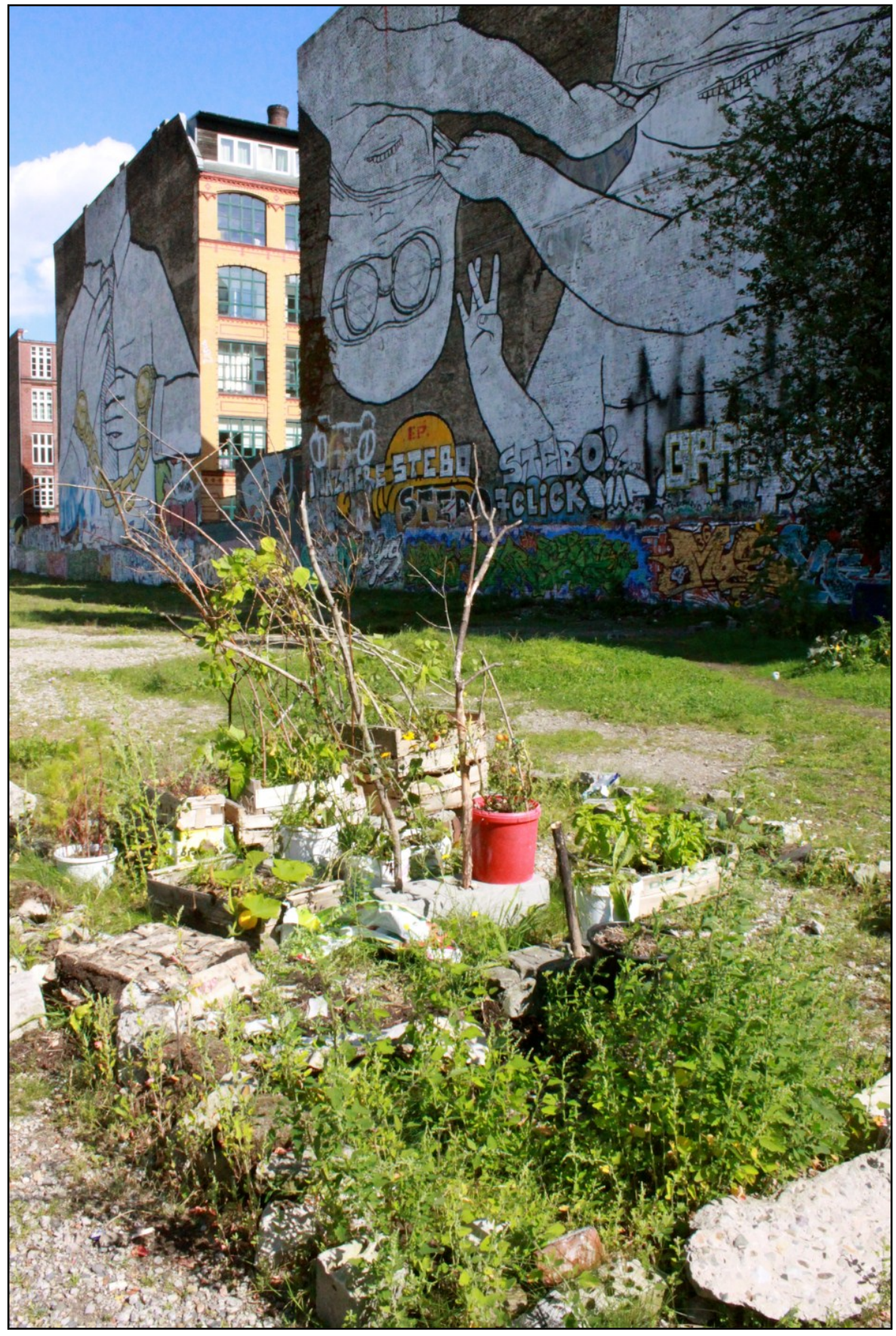

Figure 32 Guerilla Gardening 


\section{East Side Gallery}

The largest remaining section of the Berlin Wall is known as the East Side Gallery. This portion has been left standing as a poignant reminder of the city's troubled past. Over 100 sanctioned paintings by artists from around the world cover this "memorial for freedom," making it the largest open-air gallery in the world (Artists Initiative, 2002). Not surprisingly, other artists frequently use the space for uncommissioned art, which eventually covers up original murals. The Artists Initiative has been restoring the original 1989 paintings, inviting the artists to touch-up and repaint their murals. The fact that there is sustained effort to preserve the murals is both indicative of the high regard Berlin has for the street art, but is also is strangely against the ephemeral quality of street art. Preserving past images serves the important function of securing the past in a public form and constructing a cultural identity (Carlo et. al., 2010), but it is also attempts to present a static unchanging message of history that may not always translate into the present as intended and ignores new struggles and critiques from being represented on the wall.

During my first visit to Berlin in 2009, the gallery's restoration was fully underway. Artists were there busy touching up and re-painting their murals. The old murals were dull and had been covered with random markings. The newly restored murals were bright and crisp. Two years later in 2011, the murals once again began collecting uncommissioned tags and images. Uncommissioned street art can be seen on the backside of the wall facing the Spree River. Visitors and local artists, who do not want to deface the murals, use this space to showcase their work or simply mark that they 
"were here." One of the murals in 2011 had life-sized wheatpastes of two Asian tourists taking photos of the wall, an obvious effort to mock the touristy nature of this space. Groups of onlookers flood the area, posing for photos, filming, and admiring the artwork. At the end of the East Side Gallery, there is a gift shop that sells wall-related merchandise such as broken chunks of the wall covered with splashes of graffiti paint.

Berlin's many niches of spontaneous imagination show that it is possible to foster lively neighborhoods without pre-designed functionality or the feared "tragedy of the commons. ${ }^{27}$ The quality of life does not seem to be diminished; in fact, these areas seem to be thriving. Vibrant street art in Berlin is just one of the visible indications of the free creative potential of a neighborhood and shows how strongly residents wish to participate and consciously influence the design of the spaces around them (Jakob, 2008). After WWII, much of Berlin was rubble. Following this horrible event, Berliners slowly picked up the pieces, and claimed these now vacant spaces for new uses. They pushed the boundaries of expected behavior, filling their streets with colorful art, injecting war-torn spaces (purposively or not) with new functions and meanings (Hou, 2010). These differential spaces (Lefebvre, 1992) celebrate individuality, tolerate the risks of disorder, promote free interaction, and strive to exist beyond the coercion of powerful state institutions.

${ }^{27}$ The "tragedy of the commons" is the theory that multiple people, acting independently and rationally, will eventually deplete a shared resource (Hardin 1968). Researchers have argued that this logic may be flawed (Olstrom, 1990; Cresswell, 1996; Kingwell \& Turmel, 2009) because it is assuming that people will not (1) communicate with one another, (2) manage the area, (3) develop trust in one another, and (4) develop a sense of a shared future (Olstrom, 1990). There is evidence that for much of human history ecosystems were sustainably managed through the cooperation between communities of users (Steward, 1955; Barth, 1956; Rappaport, 1967; Posey, 1985; Alcorn, 1981). 


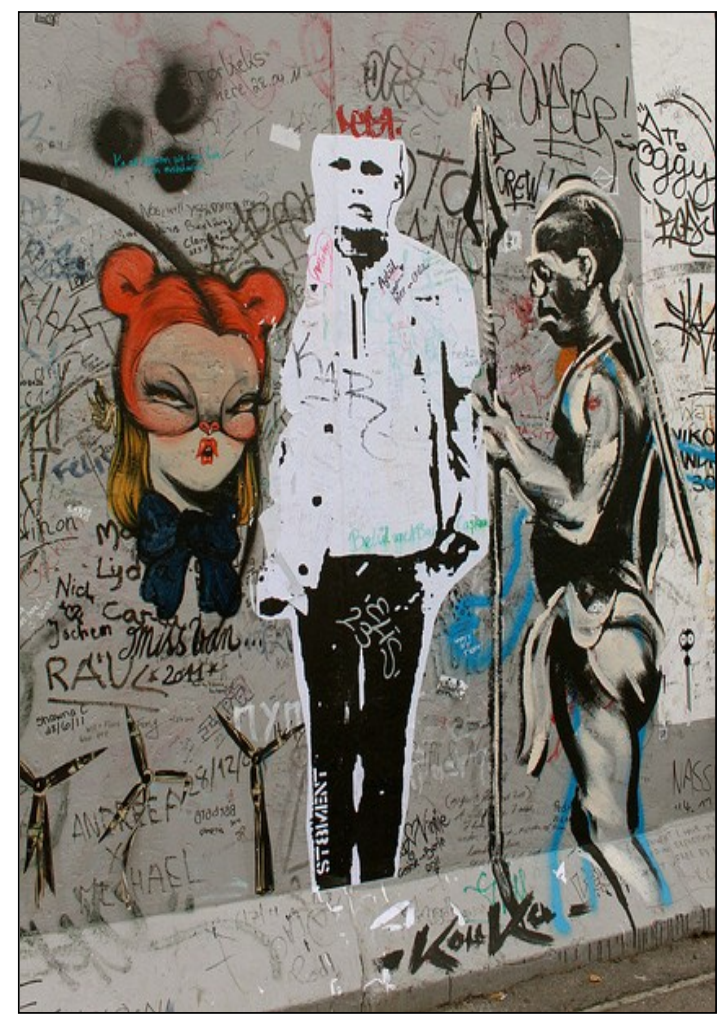

Figure 33 Miss Van, ST8MENT and Kouka, Back of Wall

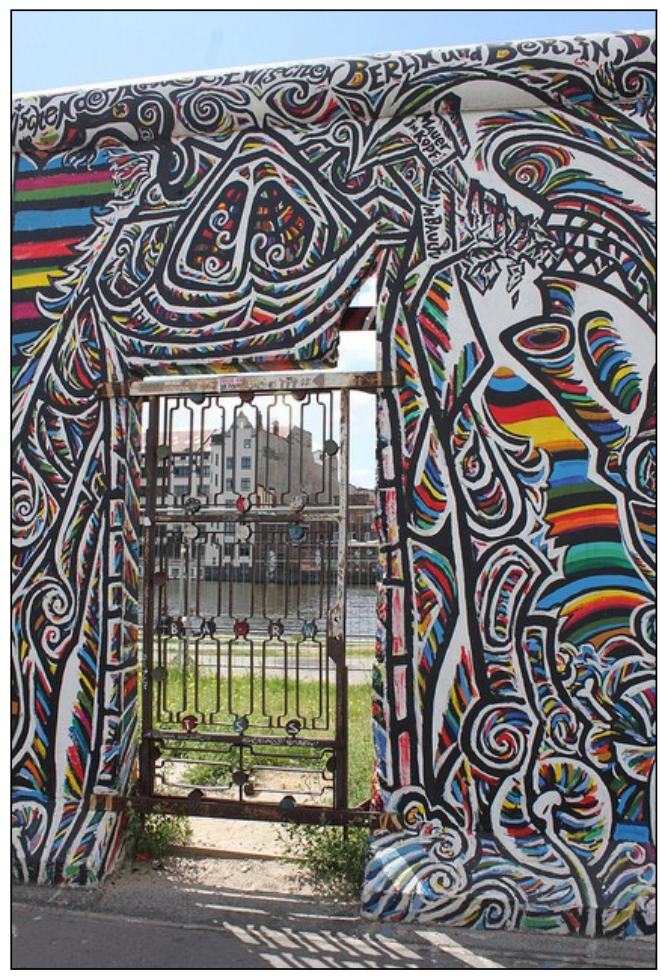

Figure 35 Berlin Wall 2010

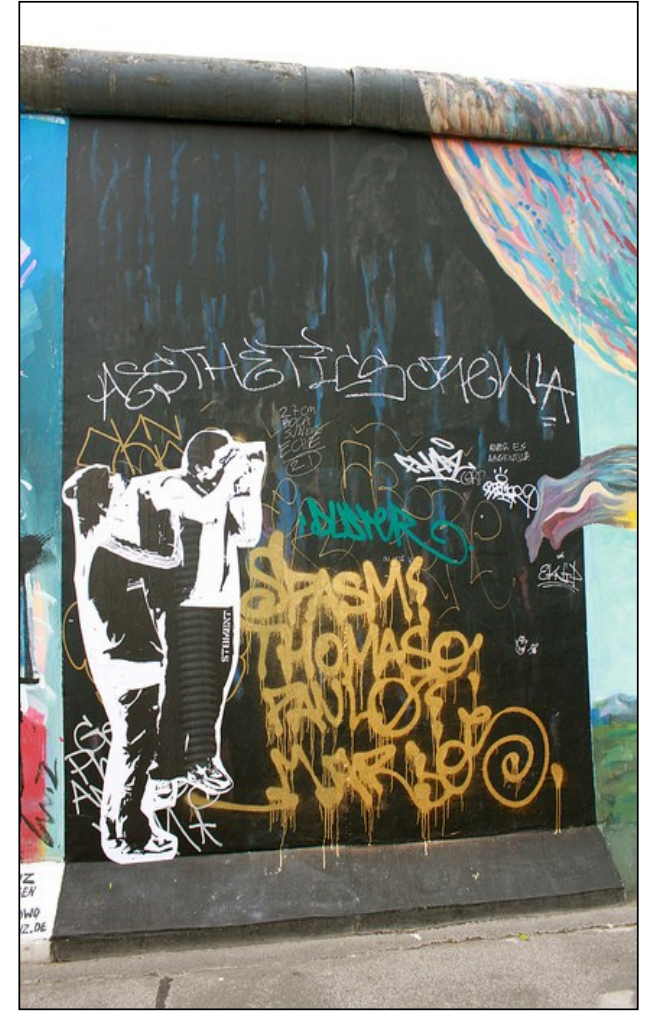

Figure 34 ST8MENT, Berlin Wall

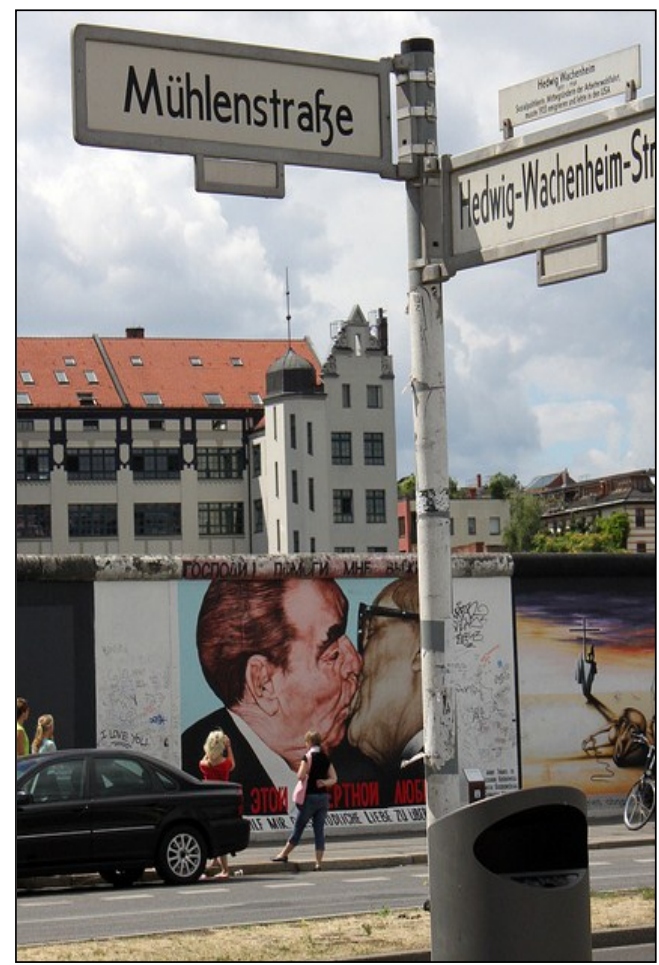

Figure 36 Berlin Wall 2010 


\section{Chapter 3. Literature Review}

For nearly 50 years researchers have investigated graffiti culture in the United States and abroad. Even with this wealth of information, the stereotyping of past transgressions is still applied to graffiti today, although the context, the practice, motivations, and society have all changed dramatically. Analyzing artistic practices is difficult because the process attempts to create order from randomness and what constitutes art is inherently subjective. Although challenging, studying patterns within a phenomenon is a powerful scientific tool that can help researchers better understand topics. The following review of the history and current state of street art will be as objective as possible and present a variety of viewpoints and observations that researchers have made about this practice. Data from other studies will be presented to provide an overview what other researchers have discovered and to position my work within this larger body of research.

\section{Graffiti vs. Street Art: What is the Difference?}

One of the first questions typically asked is: What is the difference between graffiti and street art? The differences between the two are not generalizable or easily delineated. The distinctions commonly made are based on personal taste and perceived artistic intent. When looking at a piece of unauthorized art in the street, a variety of factors can affect what people think about it. One could consider its artistic merit, its form and composition, its location, its message, and even its assumed legality. Both collective and personal ideologies influence people's opinions about the general merit of street art and its right to be in public space. The chosen label (street art or graffiti) people apply to a 
piece, conveys some information about how they feel about the piece and the larger body of work with which they associate it with. The differences and similarities between graffiti and street art are outlined in this research to provide a working definition for new forms of street art and to explore some of the reasons why people may feel so differently towards various forms of street interventions. It also explores possible reasons for the sources of variation in opinions about street art and graffiti. It is important however, to remember to not reduce this understanding to a forced graffiti/street art binary, because while these art fields represent quite different visual cultures, they also have many connections and overlapping characteristics (Dickens, 2009).

\section{Historical Overview}

\section{Graffiti}

For tens of thousands of years, humans have artistically expressed themselves in the public realm. 35,000 years ago, humans left evidence of this artistic desire with animal paintings on the walls of Chauvet-Pont-d'Arc Cave in France (MetMuseum, 2011). Early examples of textual graffiti include the mélange of political commentary, real estate advisements, lost-and-found notices, and quotations from Virgil and Ovid that were scratched ${ }^{28}$ into the walls of Pompeii (MetMuseum, 2011). It has been theorized that chaotic space only becomes cultured if it possesses signs, and thus, humans produce signs and symbols to communicate with others and to distinguish cultured space from "wild" wilderness (Wendl, 2011). In this way, anthropogenic environments become "readable," and the visual space tells a story about its past, present and future use.

${ }^{28}$ The most literal translation of the word graffiti is, "little scratchings," from the Italian verb graffiare, meaning, "to scratch" (Gottlieb, 2008). 
Like its precursors, contemporary graffiti still serves the basic need to facilitate communication among people. The word graffiti is now often used to describe the tags that began appearing in the late 1960s and 70s in New York City and Philadelphia (Ferrell, 1993). The emergence of graffiti in the 1970s occurred in a time of economic and political turmoil: the oil embargo of 1973, the stock market decline, and the Vietnam War all signaled the end of the "American dream." The unfulfilled promises of 1950s consumerism and 1960s idealism clashed with the disappointing reality of America in the 1970s, leading to angry and anti-authoritarian art forms such as graffiti and punk rock (Deitch, 2010). At that time, cities such as New York City and Philadelphia were spiraling out of control due to systemic poverty, homelessness, ongoing racism, white flight, violence, and neglected built environments, all of which led to further fragmentation of the social fabric (Günes \& Yýlmaz, 2006).

In an effort to control the deteriorating environments and express themselves, urban youth turned to writing on walls. Writers began by "getting up" their nicknames to declare "I am here!" The goal for many writers was to be "all-city," to be everywhere. ${ }^{29}$ The names that appeared most frequently became local folk heroes. As entire neighborhoods were decimated, young artists found a creative paradise of cheap rents and abandoned buildings. NYC was an open-air gallery as artists communicated with one another using art (Deitch, 2010).

${ }^{29}$ TAKI 183 was the first influential tagger. TAKI started writing his simple tag in the late 1960s. TAKI was a Greek teenager. He had a job as a messenger, so he traveled by subway across the city to make deliveries (taki183.net). While traveling, he wrote his tag everywhere he went. Competition for fame began in earnest as hundreds of youngsters, emulating TAKI 183, began to tag trains and public buildings all over the city (Cooper \& Chalfant, 1984) 


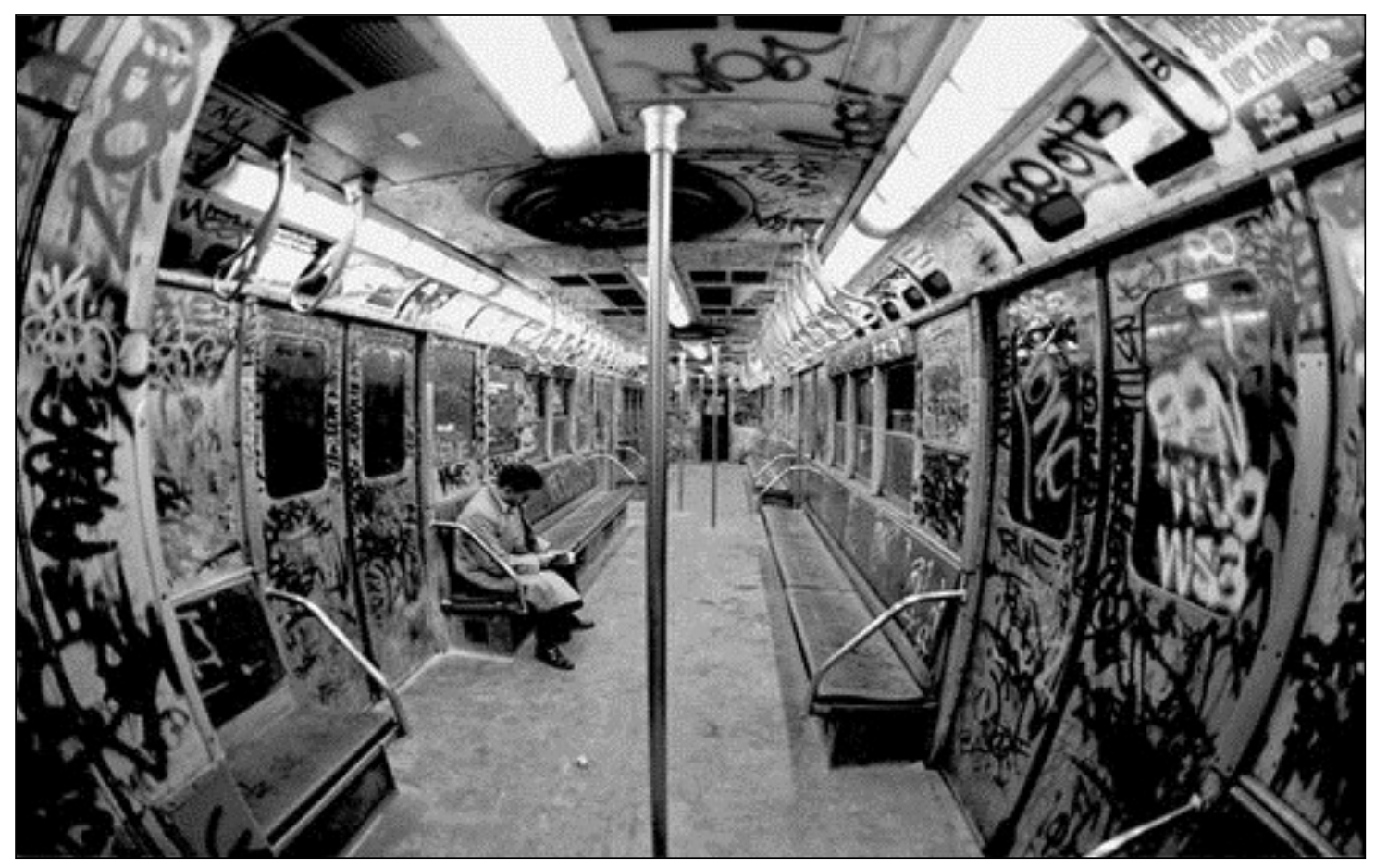

Figure 37 Subway NYC 1980s

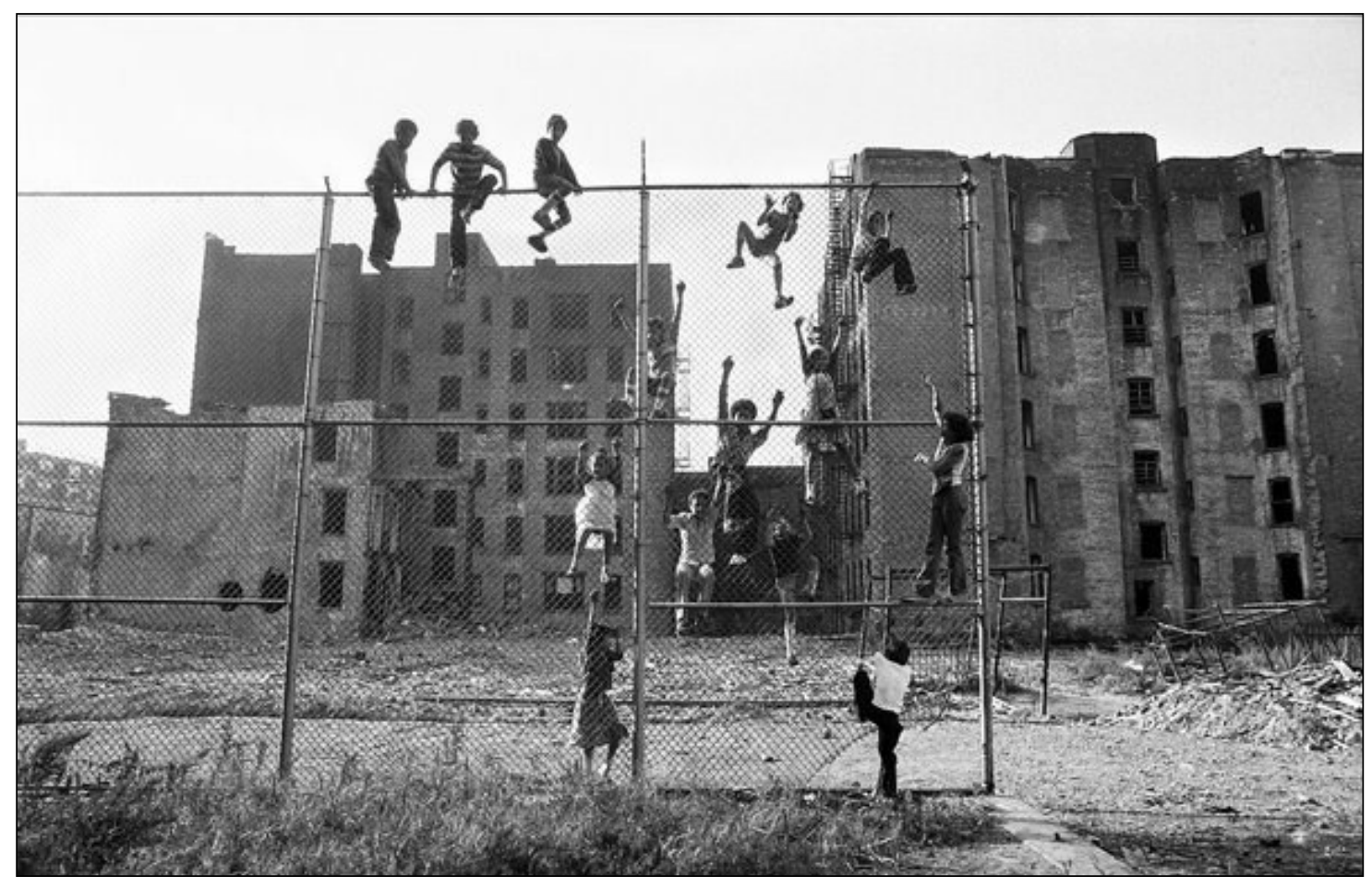

Figure 38 Lower Eastside NYC 1970s 
In the early 1970s, as available space on walls and trains filled up, it was necessary to develop a style to make a tagged name stand out from the rest (Cooper \& Chalfant, 1984). In effort to keep up with competition, some graffitists formed "crews." This teamwork allowed the scale of the paintings to grow. The first "top-to-bottom" whole subway car was painted in 1975 in NYC (Cooper \& Chalfant, 1984). In 1984, Martha Cooper and Henry Chalfant published their now historically significant photoanthropological study, Subway Art, documenting this burgeoning movement. The moving train was the perfect canvas because of its visibility throughout the city. It served as an artistic and communication link between neighborhoods.

This is also when the first chasm within the graffiti subculture formed. Some taggers moved away from easy to read monochromatic tags to executing large multi-colored "throw-ups" and "masterpieces" that involved complex compositions of "wildstyle" lettering with elaborate three-dimensional effects (Ferrell, 1993; Cooper \& Chalfant, 1984). There were now "taggers" (those who just wrote their names rather legibly) and "writers" (those who used more stylistic renditions of their name or logos). Originality and creativity in design became important (Gottlieb, 2008). Many early writers' work lacked the direct social and political content that much of modern graffiti and street art forms exhibit today. They were more interested in the way the name looked in the urban landscape, rather than gang-related motivations (such as claiming territory) or conveying socio-political messages (Gottlieb, 2008). This new artistic style was not just a change in the look of the graffiti, but more importantly, it was a shift in audience, from the general public to those within (or familiar with) the graffiti community (Gottlieb, 2008). The 
lettering in these masterpieces was often abstracted to such a degree that the name was virtually illegible to most people except those within the subculture (Gottlieb, 2008).

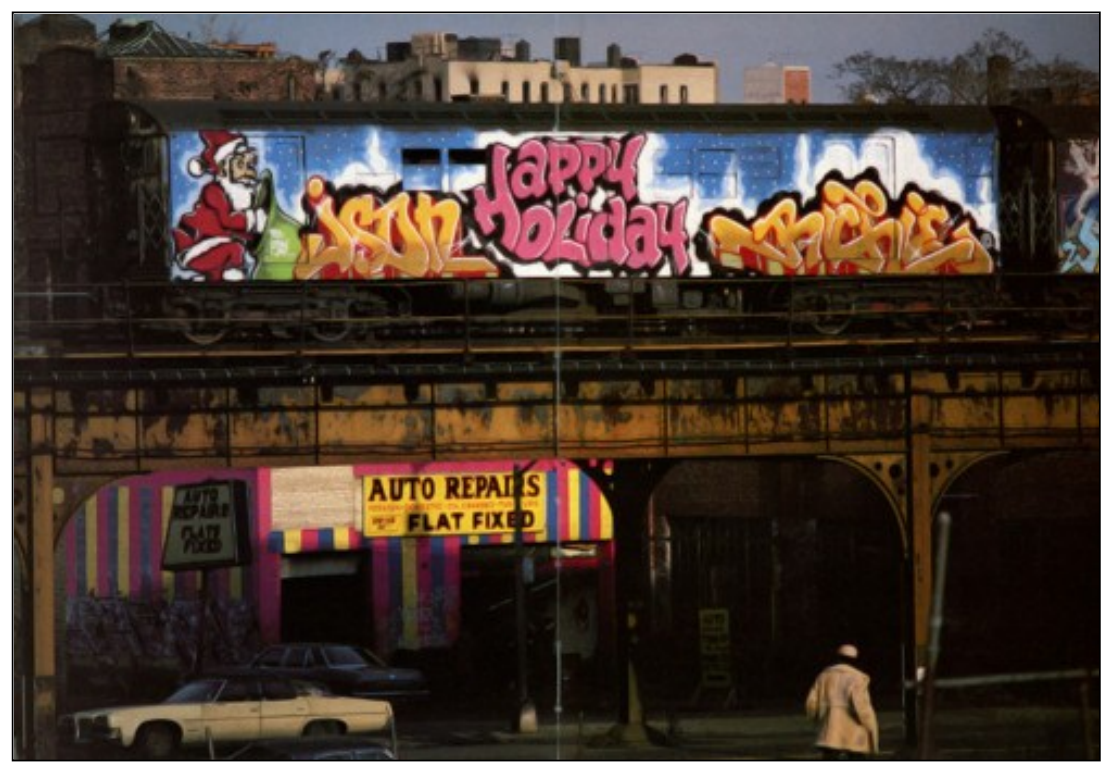

Figure 39 Happy Holiday by Richie and Jason, South Bronx 1982

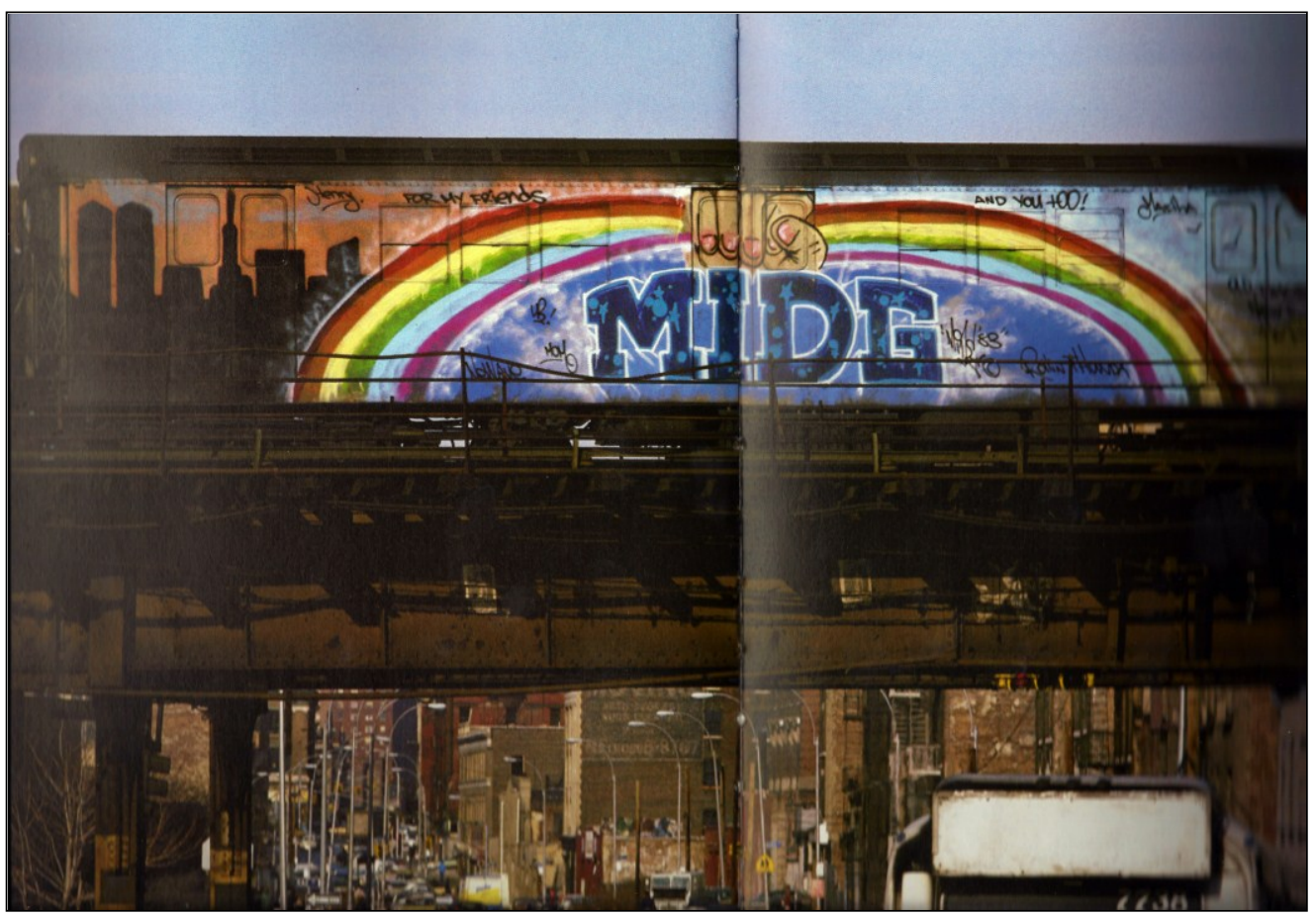

Figure 40 MIDG, South Bronx 1983 
The Rise of Street Art

Before defining street art, it is necessary to briefly review the context in which it arose. Beginning in the 1960s, and accelerating in the 1990s due to globalization, culture has been progressively commercialized, through a phenomenon called "culture industry" (Adorno \& Horkheimer, 1972). A key element to this culture industry growth was the co-opting of all forms of counter-culture (Thompson, 2004). ${ }^{30}$ While creativity and imaginativeness were being absorbed and re-packaged for mass dissemination, physical urban space underwent a parallel co-opting as gentrification re-made downtowns (displacing residents, including many artists) and public spaces were privatized (Thompson, 2004). In reaction to this changing political climate, activists and artists around the world reconceived their practices. Many took their art directly to the people and into the streets. This sequence of events triggered the rise of modern street art, evolving parallel to its counterpart, graffiti.

These politically engaged artists began using the term 'intervention' to describe their interdisciplinary approaches, which almost always took place in public spaces (MASS MoCa, 2011). Interventionist art describes the work of artists who trespass into the everyday world to critique, lampoon, disrupt, and agitate to create social awareness and sometimes advocate for social change (Pasternak, 2010). In contrast to the harsher political art of the $1980 \mathrm{~s}$, interventionist practitioners seek new paths for artistic practice, coupling serious politics with a light-handed approach, embracing the anarchist Emma Goldman's dictum that "revolutions and dancing belong together" (MASS MoCa, 2011).

\footnotetext{
${ }^{30}$ Examples include the use of symbols of political action for commercial purposes such as Che Guevara, Mao, and Bob Dylan.
} 


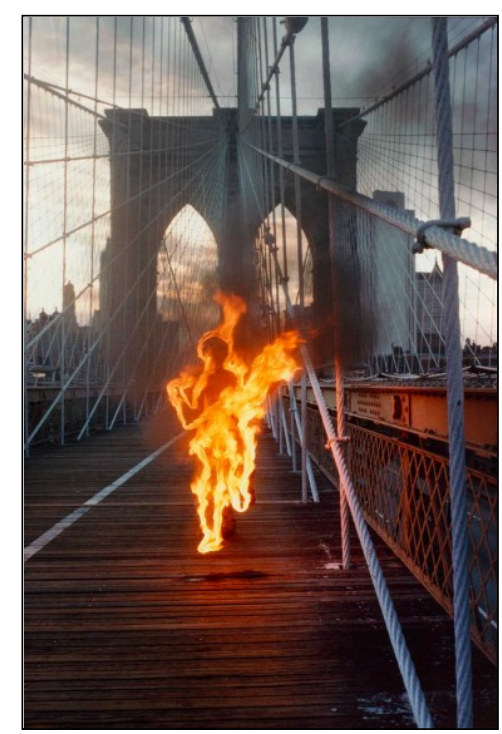

Figure 41 "Minotaur Brooklyn Bridge," Paolo Buggiani 1980

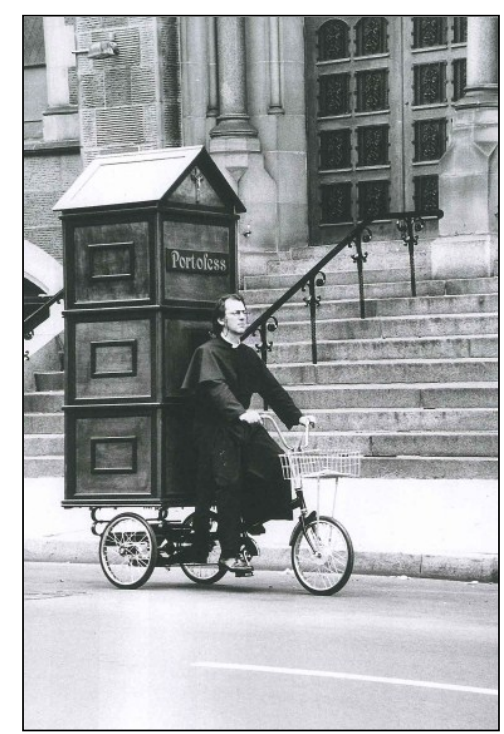

Figure 42 "Portofess," Joey Skaggs 1992

Some street art embodies similarities to activist art, culture jamming, ${ }^{31}$ and political stenciling, ${ }^{32}$ which critique society and the city's relentless barrage of logos and images (Dickens, 2008). Some graffiti installations are similar to the actions done by the Situationist International (SI) in the 1960s and agitprop art (Dickens, 2008) (Appendix A). SI also critiqued the passivity of capitalist society by implementing tactics that created absurd and playful 'situations' where people would directly interact with one another in relationships that were not mediated by commodities or money. Similarly, agitprop (agitation-propaganda) artists re-mix found objects (e.g., electronic symbols, printed slogans, visual icons, etc.) to create optical illusions or "tricks of vision" to surprise and provoke audiences (Dickens, 2008; Rose, 1999).

${ }^{31}$ Culture jamming is a tactic used by anti-consumerist social movements to disrupt and/or subvert mainstream cultural institutions, such as corporate advertising.

${ }^{32}$ A stencil is a thin sheet of material with letters or a design cut out from it. By applying spray-paint through the cut-out holes, stencils can rapidly and endlessly re-produce pieces of graffiti. The extensive lettering possible makes stencils especially attractive to political artists. Well-known graffiti artists who use stencils are: Blek le Rat, Banksy, Above, and Shepard Fairey (OBEY). 
Another important break from graffiti culture occurred in 1972 when Craig Stecyk helped to link graffiti, punk rock, and skateboard culture in Venice Beach, California, otherwise infamously known as "Dogtown." Stecyk is famous for his "rat bones" tag and his photographs of pioneering skateboarder Stacy Peralta. Peralta and the Dogtown "Z-boys" adapted surfing techniques to dry land and laid the foundations of skateboarding technique and culture. ${ }^{33}$ Like graffiti and punk, skateboarding is a creative urban performance and expression that ignores and mocks the rules of mainstream society (Deitch, 2010). This skater-graffiti dialogue that began in the 1970s and development through the 1990s, laid the foundation for the new global street art culture that we have today (Deitch, 2010).

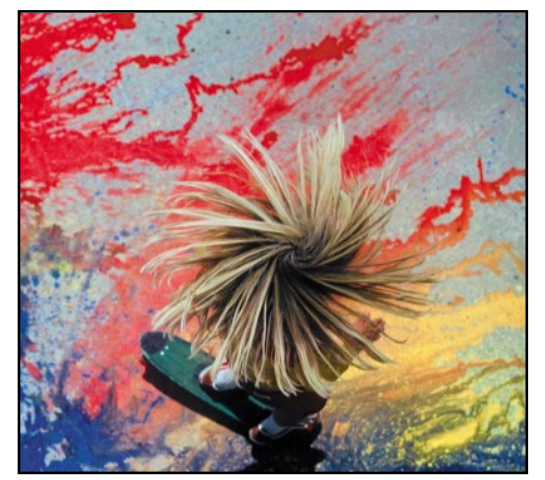

Figure 43 Stacy Peralta by Craig Stecyk 1976

Although graffiti and street art both introduce illicit pieces into urban public spaces, there are some notable differences. Graffiti is a "culture of words." The general motivations behind graffiti are to establish individual and/or group identities (White, 2000). Thus, most people outside of the group cannot decipher or understand the letters/symbols and consequently often see graffiti as a threatening unknown. Even if the

\footnotetext{
${ }^{33}$ The mid-1970s brought a serious drought to southern California. The opportunistic and innovative skateboarders used the numerous drained pools in the area to skate in.
} 
letters are decipherable, the word(s) might hold little significance for most people. Graffiti artists typically work on two-dimensional surfaces with spray paint or markers.

Street art is a 'culture of symbols.' It is more figurative, using paint, posters, stencils, stickers, or any other object imaginable to convey its message (Von Lanzenauer, 2011). The motivations behind street art are usually to communicate a message to the public or provide a unique handcrafted "gift" to a community. Another important distinction is that graffiti is sometimes more about the action of getting up, more so than the final product. Research on graffiti writers' shows that the visceral pleasure and rush that accompanies the illicit activity and the motion of the aerosol can is a significant motivator (Halsey \& Young, 2006). Spray-painting an intricate graffiti masterpiece can take hours, much longer than a street artist's wheatpaste, for example, which is made elsewhere and takes only seconds to paste-up. Even though it varies with form, the risk of getting caught actually adds to the thrill of the experience for many artists.

Rob White has described street art as a "well organized, skilled activity which has a strong aesthetic dimension, informed by techniques, learning strategies, evaluation, and group forums" (2000, p. 254). White's definition fails to adequately describe street art because many of these characteristics could also be applied to traditional graffiti. Skilled crews used handed-down paint application techniques, styles, and police evasion tactics (Halsey \& Young, 2006). Some graffiti is highly iconographical and colorful, characteristics often associated with street art. Likewise, some street art is textual and monochromatic, characteristics often associated with graffiti. Some artists practice (and are influenced by) both street art and graffiti, even within the same piece. 
In mainstream society today, the word graffiti tends to be used by outsiders who wish to represent the activity negatively, while street art is used by those who wish to represent it more positively. Generally speaking, the use of the term street art is a worldwide collective effort to re-brand this practice; an effort to differentiate newer forms of urban inscription that have arisen in the last few decades, from previous forms of graffiti.

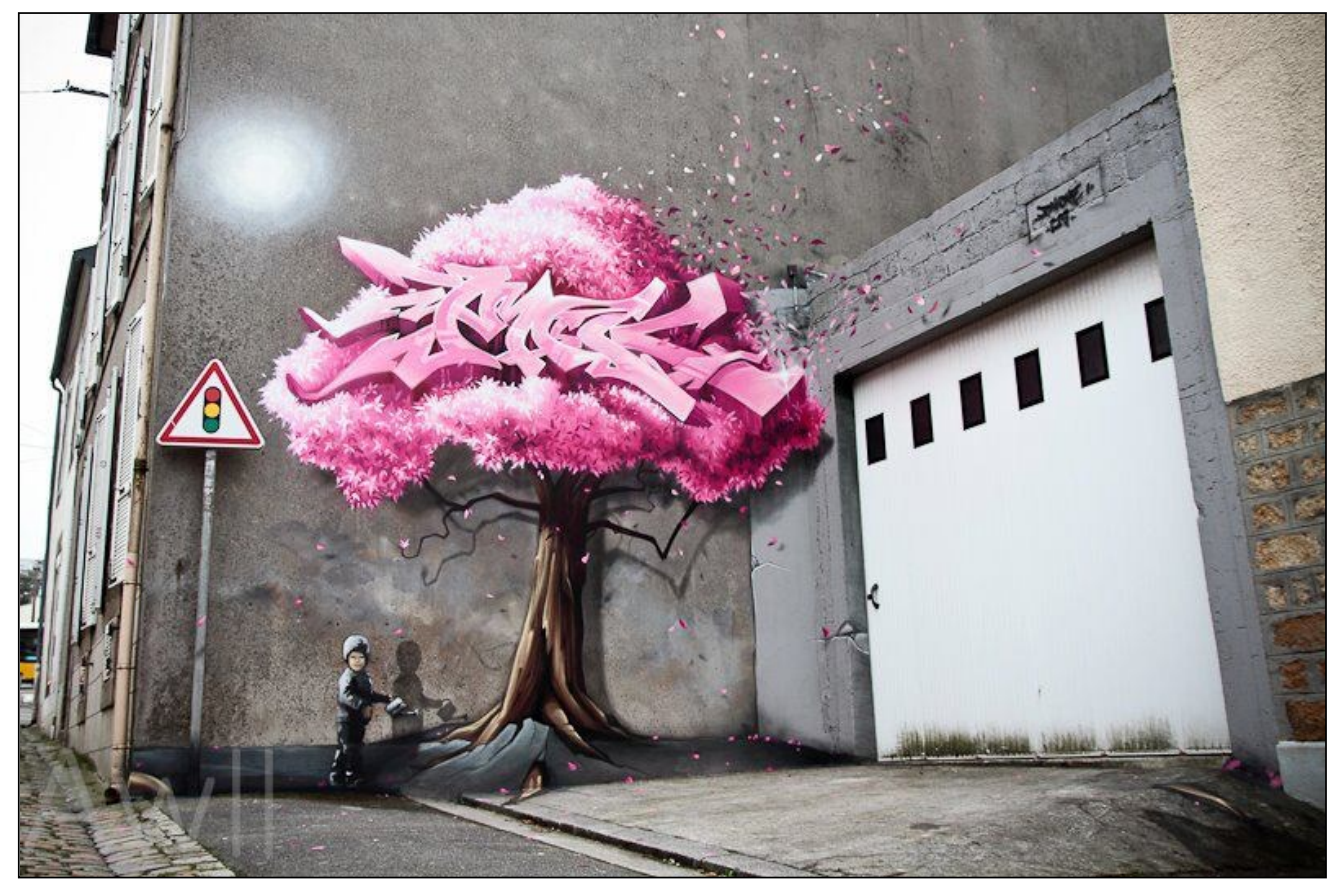

Figure 44 Blending of Graffiti and Street Art Styles

Even though the division between street art and graffiti is not straightforward, people still tend to classify pieces they see into one of the two camps. Research suggests forms of graffiti and street art are viewed differently for several reasons:

1) Damage and Permanency: Some street art is less physically damaging and can be removed easily. Posters can be peeled off or degrade quickly if exposed to the elements. Yarn installations are extremely simple to remove using a pair of scissors. With 3D installations (discussed in next section), the physical act of 
introducing an object into public space is of questionable illegality since the objects do not generally damage the surface in which they are placed and are easily removed. In many cities, acts like yarn bombing, guerrilla gardening, or leaving a piece of artwork behind, are not considered vandalism, although artists may run the risk of being cited for littering (Moore \& Prain, 2009).

2) Aesthetics: Street art may be viewed as more palatable because of its use of vibrant colors and mainstream artistic leanings, which are closer to conventional aesthetic standards than traditional graffiti (Schlecht, 1995).

3) Threating: Street art may be more "digestible" by the larger public because it is not associated with gang or other criminal activities. It is therefore seen as less threatening. For example, with yarn bombing, textiles are soft, comforting, loving, and highly feminized; all characteristics that contribute to its nonthreatening effect. Moreover, street art often embodies a degree of subtlety, humor, and playfulness (Jakob, 2008).

4) Embeddedness: Street art is generally more ingrained in its surroundings. For instance, some street artists add their own twists to everyday urban objects, such as traffic signs or lights. Sometimes the piece blends in so well that it is almost hidden and many people may not even notice it.

5) Understandability: Street art is generally easier to categorize and comprehend (because of its use of iconography and symbolism) in comparison to the more cryptic language of traditional graffiti. Iconographic street art can therefore be understood by a wider audience than traditional graffiti (especially wildstyle lettering) which is mostly understood only by those within the subculture. 
The differences between graffiti and street art can be further understood by examining what people within the groups think about each other. There is evidence of animosity between street artists and graffiti artists. Some graffiti writers feel that street artists are "art school nerds" that have a "holier-than-thou mentality" and "no respect or regard for graffiti" (EZ, 2007). This hostility may stem from the fact that street art tends to receive preferential treatment. This double-standard was part of Rafael Schacter's findings (2008) during his interviews with graffiti removal teams. They reported picking and choosing which pieces to remove based on their perceived artistic merit or the agreeability of the message. Conversely, some street artists think that graffiti writers are "obsessing on fame and their mission of getting their name out, often at the expense of quality" (EZ, 2007). Furthermore, some graffiti and street artists who use traditional methods of application, such as spray paint, view installation artists (who use yarn, plants, etc.) as being too "safe" because they do "softer," less risky actions (Endless Canvas, personal conversation, October 9, 2011). Graffiti culture has traditionally prided itself on its anarchy, edginess, and toughness. Furthermore, there are even offshoots within particular street art forms. For example, one street artist who uses the medium of yarn, but not in the typical knitted style, said, "Personally, I just prefer work that makes me think of cool stuff like Mission Impossible and not make me feel bad for not calling my grandmom" (Spidertag, 2011).

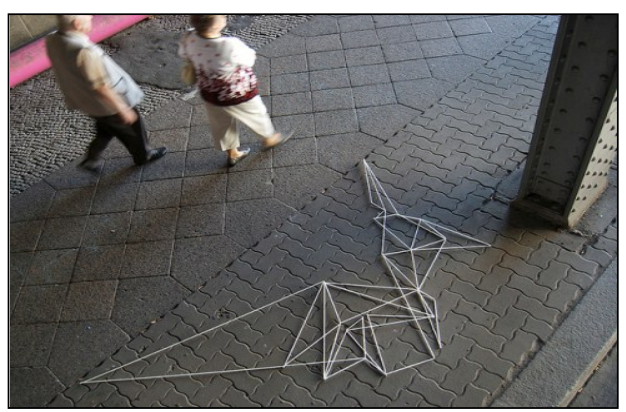

Figure 45 Spidertag 
Researchers have even gone as far as suggesting that street art generally embodies more intellect and are more purposeful, well-calculated critiques upon society (Jakob, 2008; Dickens, 2008). However, these claims seem to be based on individual observations and not well supported by empirical evidence. While, in some cases, antiestablishment critiques are more apparent in street art, both practices are acts of purposeful rebellion. Some of the simplest slogan graffiti embodies great intellect and purpose via well-calculated messages that critique society.

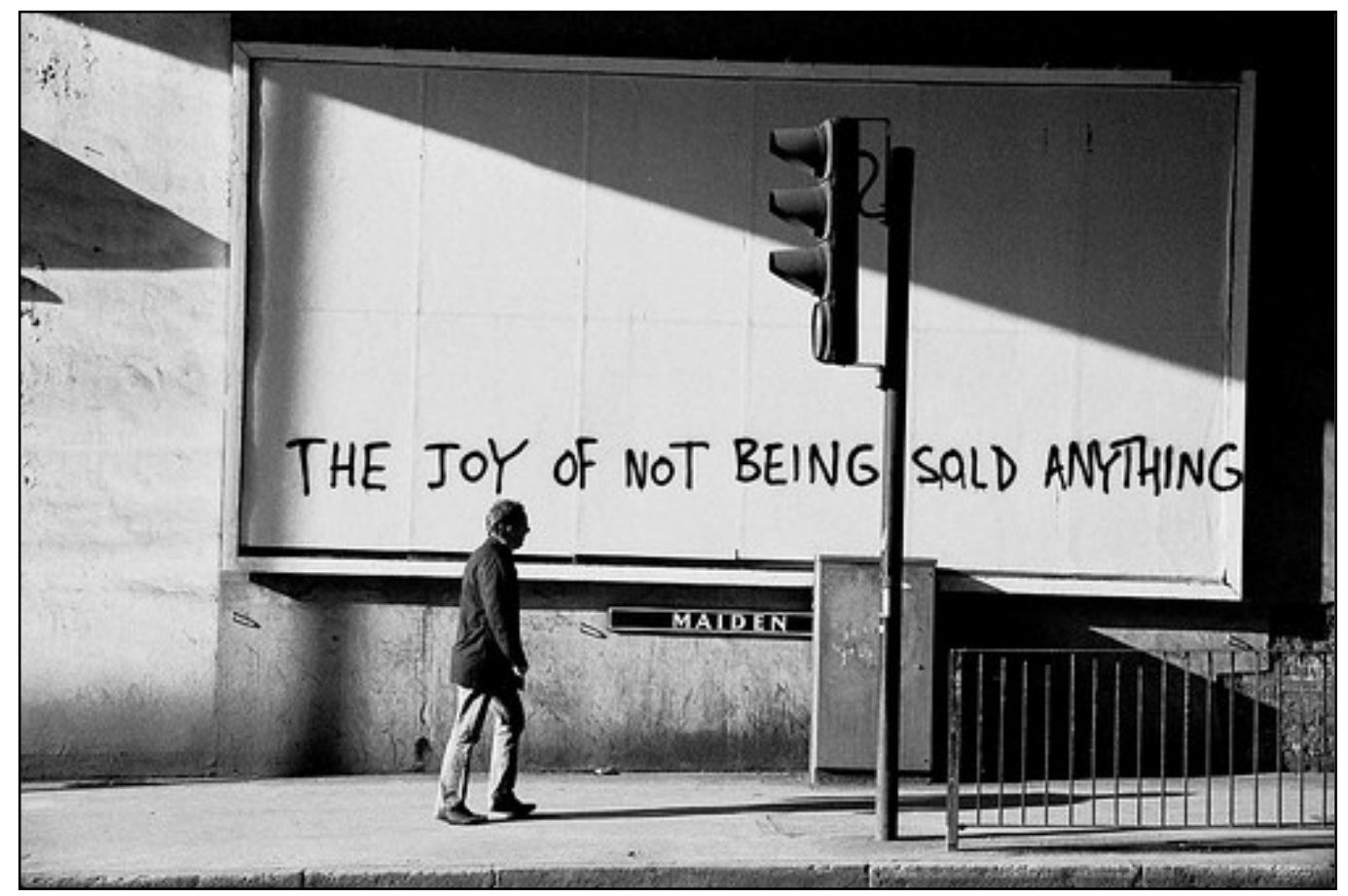

Figure 46 "The Joy of Not Being Sold Anything," Bansky, London 2005 


\section{Emergent Forms of Street Art: 3D Street Installations and Post-Graffiti}

3D street installations ${ }^{34}$ are a form of street art that involves the placement or modification of site-specific three-dimensional objects in the city. The label of $3 D$ can be applied to any street art installation that is not two-dimensional, and is either a threedimensional object itself or wrapped around a three-dimensional urban object. ${ }^{35}$
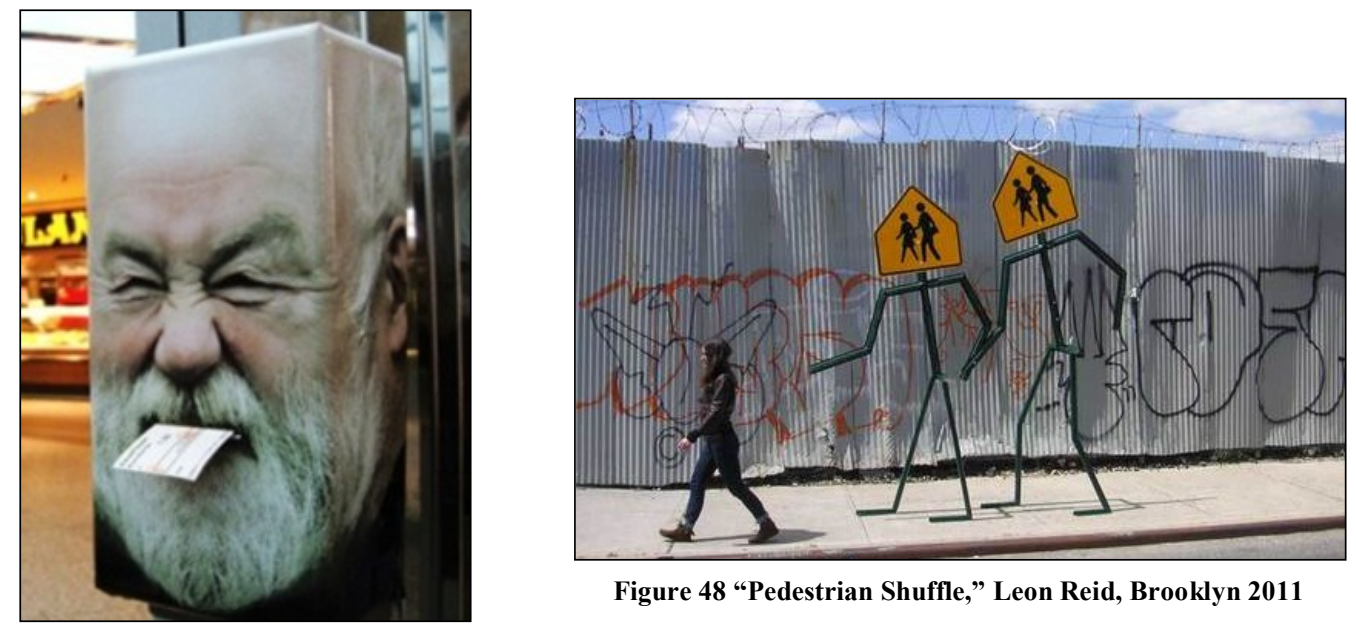

Figure 48 “Pedestrian Shuffle,” Leon Reid, Brooklyn 2011

Figure 47 Mentalgassi Wheatpaste, Berlin

Many 3D street installations could be classified as post-graffiti. The term postgraffiti was initially used in the mid-1980s to describe the use of traditional graffiti styles (found on the streets, subways, and trains) by artists displaying their work on canvases in galleries. ${ }^{36}$ This was a major shift. One day artists were in a subway tunnel

${ }^{34}$ Installation and intervention will be used interchangeably. Both words are used to describe this type of street art, although installation may be more appropriate for the type of art being discussed here since it is referring to the installation of a piece of art, rather than just an action (like flash mobbing) which is more of an urban intervention.

${ }^{35}$ The description of post-graffiti provided in this paper is an attempt to describe this developing form. The range of pieces and mediums that could be included in this category is infinite.

${ }^{36}$ These attempts to re-channel graffiti to more legitimate and commercial ends were based on the understanding of the practice, not as criminal and deviant behavior, but as a form of primitive art, whereby graffiti “writers" became "artists." In 1984, Paul Tschinkel's film Graffiti/Post-Graffiti depicted some of the big names from the 1983 Post-Graffiti gallery show (such as Jean Michel 
running from the transit authorities and the next day they were in a stylish gallery being praised by art critics and selling street art-inspired artwork.

Although 3D installation street art has existed for decades, ${ }^{37}$ it is gaining popularity and receives a disproportionate amount of attention on the Internet and in street art books. Despite its fame, there has been very little written about it academically. The research of Luke Dickens is outlined in the following section because he is the only researcher to date who specifically focuses on the post-graffiti art movement. However there is a need to support these observations with more empirical evidence, especially taking into consideration experiences from other countries and cities.

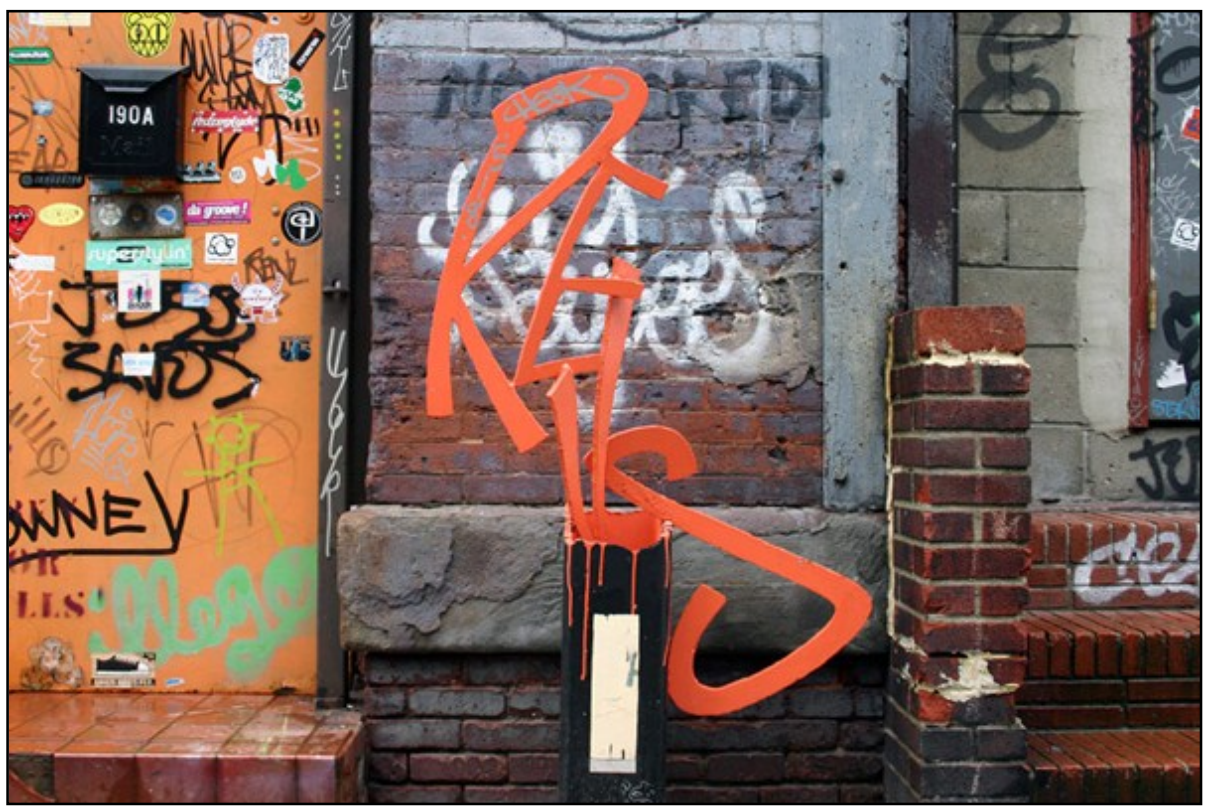

Figure 49 Revs Metal Sculpture, New York City

Basquiat, Lady Pink and Fab Five Freddy) discussing their mixed feelings about these attempts to realign their work with the art world and away from the streets (Dickens, 2009).

${ }^{37}$ Cost and Revs, a famous NYC graffiti duo who began in the 1980s, are credited as being some of the first graffiti artists to experiment with installation work. They would dress like city workers and weld metal sculptures to existing objects. 
Moving away from this original meaning, the label of post-graffiti has recently reappeared. ${ }^{38}$ Luke Dickens $(2008 ; 2009)$ is using the term as a provocation, an attempt to highlight the importance of thinking beyond historic stereotypes of graffiti and to describe the emergence of a qualitatively different contemporary style of artistic spatial interventions. Throughout the history of graffiti, the core component of graffiti writing was the tag. However, recently there has been a shift from typographic to iconographic forms of illicit street inscriptions, as "street logos" are becoming increasingly popular. ${ }^{39}$ Tristan Manco suggests this is because such logos are simultaneously inspired by and critical of, the growing visual spectacle of signage and advertising in the modern city, thus making explicit how this new form of street art is profoundly connected to larger changes in the urban landscape (Dickens, 2008). Reflecting upon this shift the popular street artist Banksy said:

Modern street art is a product of a generation tired of growing up with a relentless barrage of logos and images being thrown at their head everyday, and much of it is an attempt to pick up these visual rocks and throw them back (2006).

Post-graffiti is the work of a new generation of artists who are using all the components of the urban landscape and view the entire city as their canvas, studio, laboratory, and gallery. Post-graffiti installations move away from flat surfaces and bring art everywhere, from the small and unsuspecting, to the large and in-your-face. Dickens says that post-graffiti is different than other forms of street art and graffiti

\footnotetext{
${ }^{38}$ The term post-graffiti is also being used in popular art texts, exhibits, and conferences on the subject (Dickens, 2008).

${ }^{39}$ An early example of this approach was American artist Shepherd Fairey's cryptic and repetitive pseudo-advertising OBEY campaign.
} 
because the artists are: (1) using new aesthetic styles, materials, and techniques; (2) interested in engaging with wider audiences (art as social practice); (3) becoming increasingly professional, media savvy, and visually literate (2008). Dickens also points out that post-graffiti tends to be more iconographic (rather than textual), so it is more "readable" to audiences (2008). Therefore, unlike textual graffiti, post-graffiti are more easily transferred across cultural boundaries.

Dickens has said that a defining motto for this type of art is "the right piece, at the right time, and in the right place" (Dickens, 2008). What he means by this is if the piece were moved out of its socio-spatial context it would lose much of its intended meaning and understandability. ${ }^{40}$ The art needs the proper urban context to make sense and have the most impact. Post-graffiti artists blend the installations into the urban environment in various ways. They use existing structures in the urban environment such as paving stones, barriers, trees, lights, phone booths, benches, and fire hydrants. Sometimes they alter, replace, or add something new. Some pieces are so ingrained into their surroundings, that they can go unnoticed if passersby are not familiar with the place or paying attention. To experience these interventions to their fullest potential, you must be physically walking through the city and see them in person, in the full context of the city.

\footnotetext{
${ }^{40}$ Its site-specificity makes it difficult for post-graffiti to be displaced into galleries like other street art and graffiti forms have been.
} 


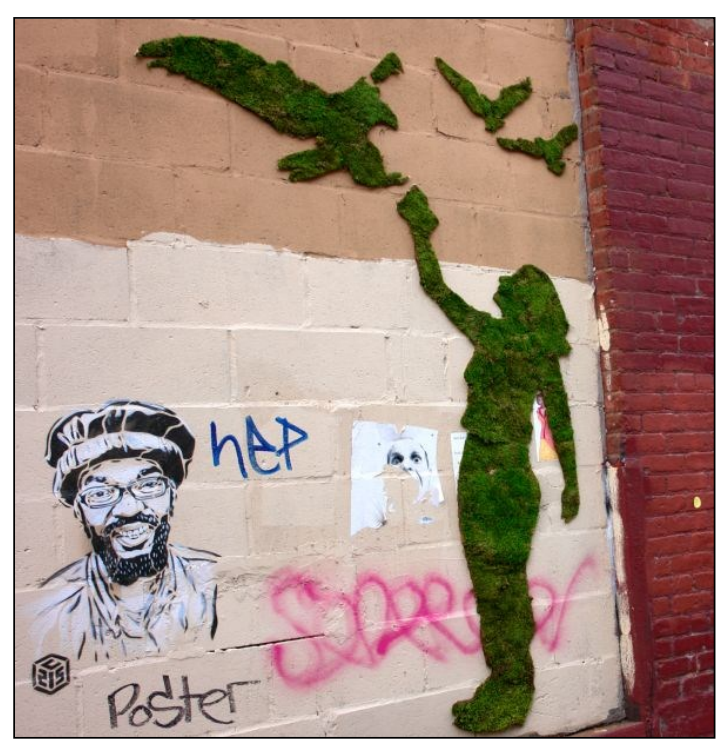

Figure 50 Moss Girl, Brooklyn

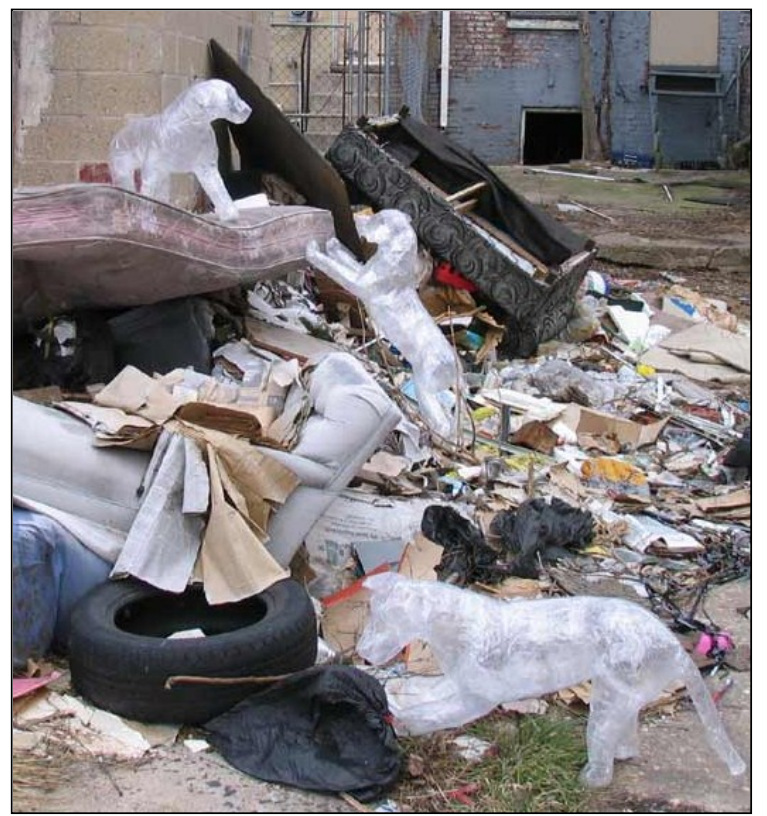

Figure 51 Mark Jenkins, Baltimore

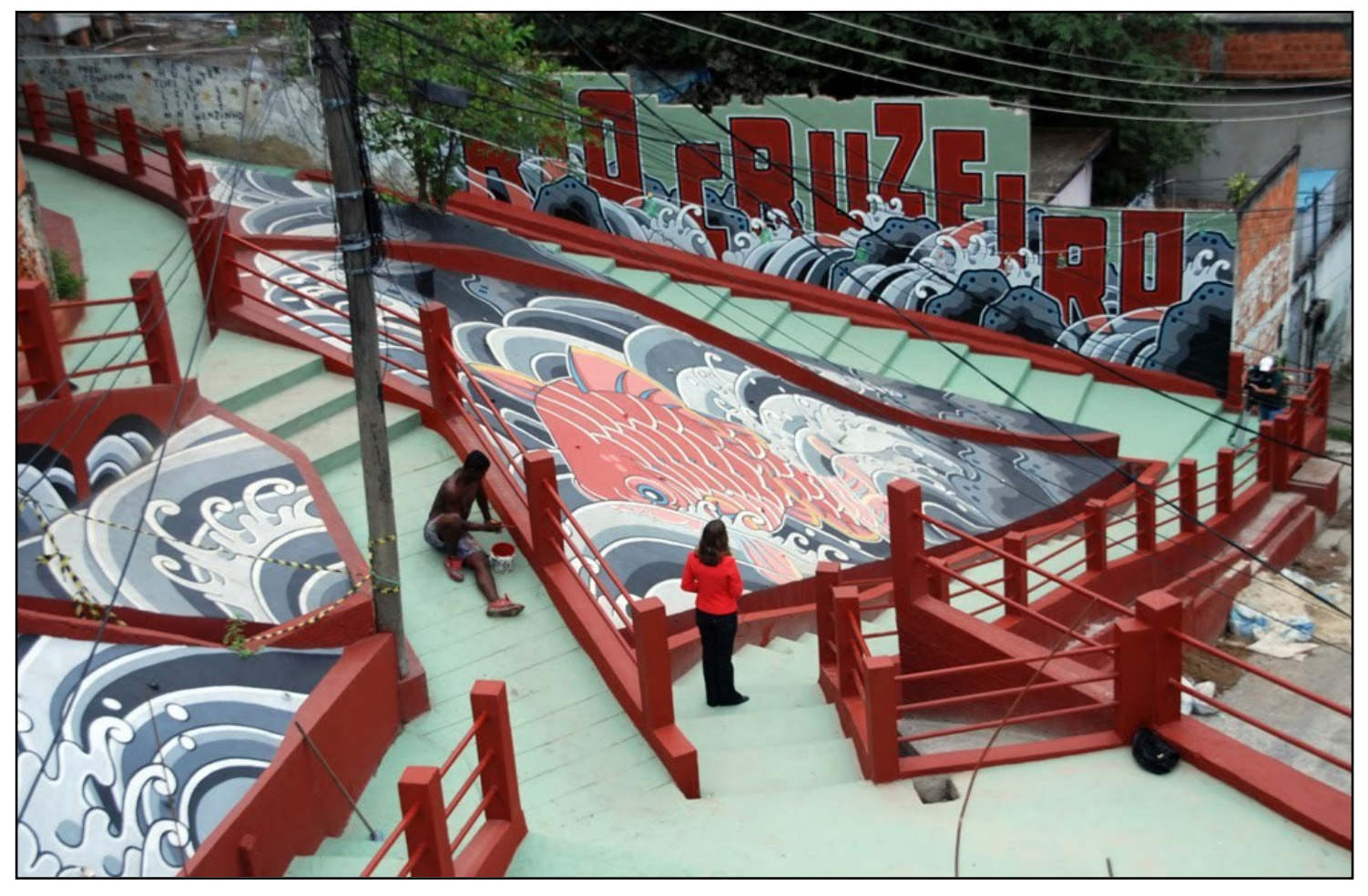

Figure 52 Haas \& Hahn, Favela Rio de Janeiro 2006 


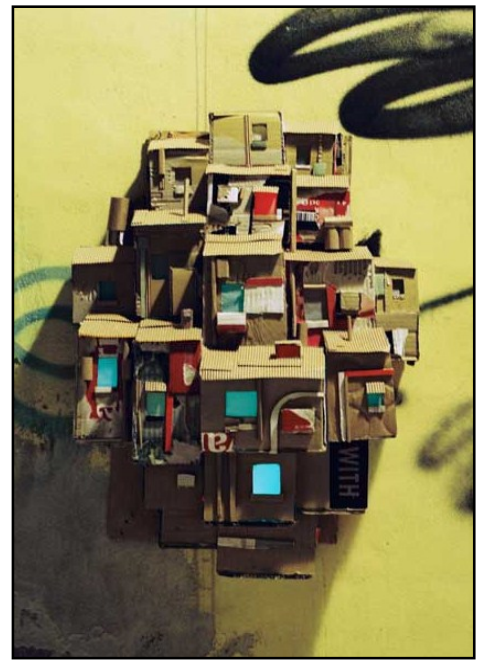

Figure 53 Yaron's Favela, Czech Republic

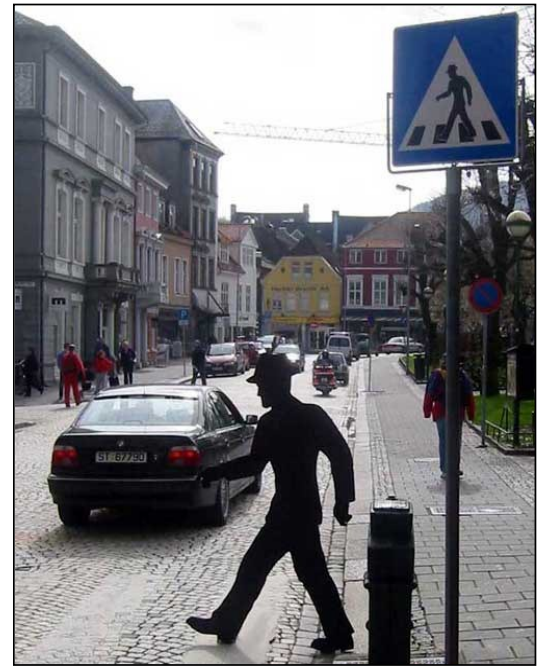

Figure 54 Walking Man, Bergen Norway

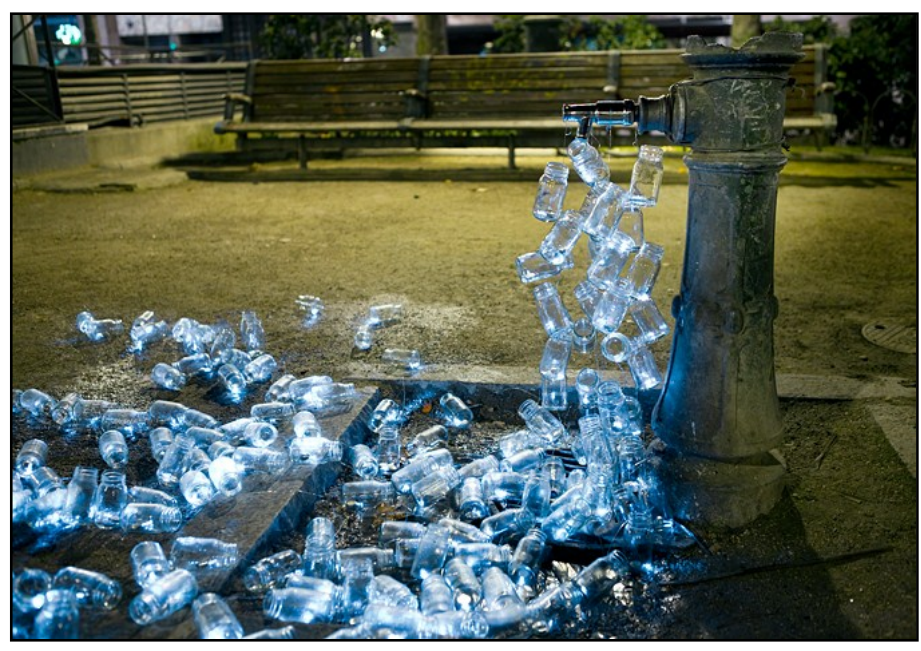

Figure 55 "Drinking Water Running through the Streets," Luzinterruptus, Madrid Spain 2012

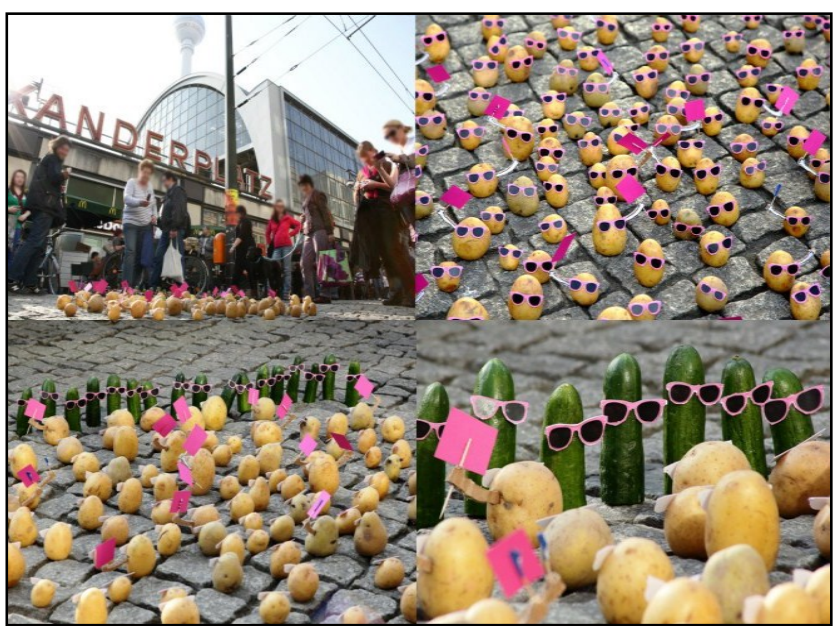

Figure 56 "Protesting Potatoes in front of McDonalds," Peter Pink, Alexanderplatz Berlin 2012

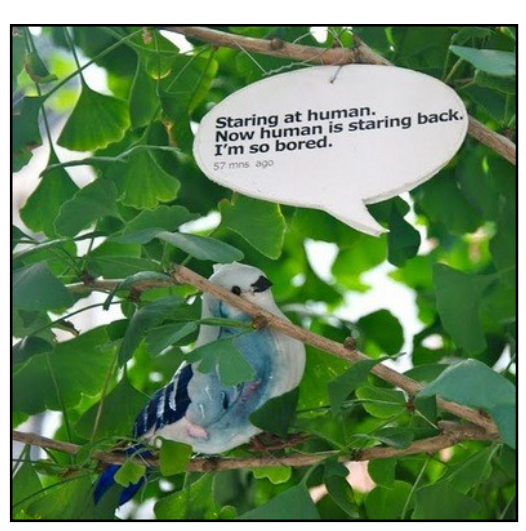

Figure 57 "Fake Bird Twitters at Real People," NYC 2010 


\section{Review of Policy Literature}

\section{Broken Windows Theory}

In the 1970s, when graffiti culture was first making its mark on modern society, some people saw it as a much needed touch of color in the dreary city; but others equated it with the urban crisis that had gripped New York at this time (Wilson \& Kelling, 1982). Amidst this political and infrastructural chaos, graffiti was deemed a visible sign of this deep disorder and was to be removed at all costs. Authorities and the media associated graffiti with dirt, decay, disease, and madness (Dickens, 2009; Cresswell, 1992). Graffiti did not belong in the city, it was out of place. Tim Cresswell $(1992,1996)$ has argued that dominant ideologies define what is and is not appropriate in public spaces. Cresswell (1996) points out that framing graffiti in this negative light acted to associate it with other places more amenable to disorder, particularly with the “third world" and ultimately racist undertones (hooks, 1995). Mary Douglas's (1996) analysis of the concepts of pollution and taboo argues something similar, but from an anthropological perspective. Douglas examines the "unclean and impure" parts of human society in order to better understand the ordering pattern that some societies strive to establish and maintain. Building upon this notion, David Sibley (1995) shows how subcultures are excluded from space by powerful groups who tend to purify space. Outsiders are viewed as polluting and dangerous and thus systematically excluded from these spaces. Kurt Iveson (2002) contextualizes these ideas and suggests that graffiti is considered a major urban problem because it challenges the rights of property owners, and by extension, the whole system through which urban space is supposed to be 
defined. Taken together, these insights can explain some of the reasons why unauthorized art in public space has been perceived as a negative force in society.

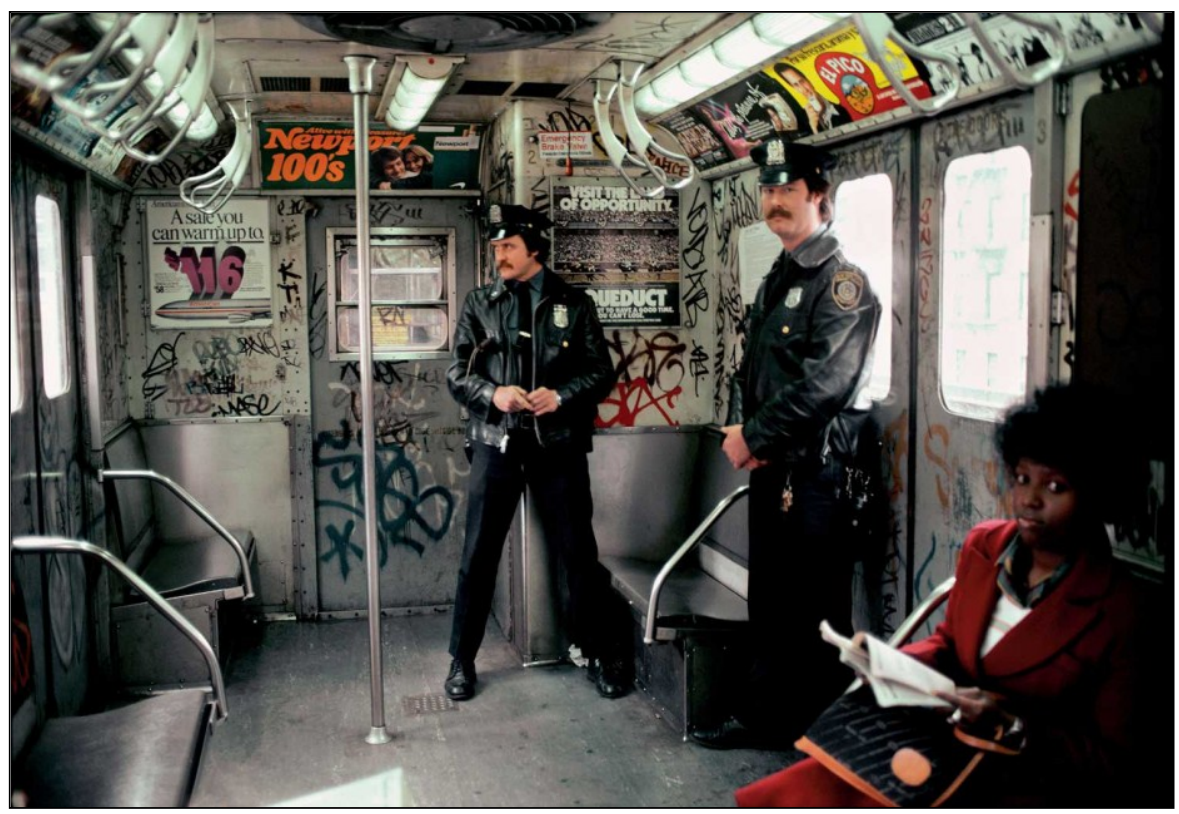

Figure 58 Subway Police, NYC 1980s

Arguments against graffiti and street art are often based on the notion that it is physically and morally harmful to society. Two things support this idea: the cost of graffiti removal to taxpayers and the putative feelings of fear that graffiti produces (Taylor, 2010). American society has been described as a "culture of fear" by Barry Glassner (1996) who has made a convincing argument that Americans simply fear being victims of crime, regardless of the probability of actually becoming victims. For example, crime rates fell throughout the 1990s, but two-thirds of Americans believed they were soaring (Glassner, 1999). Glassner proposes that the reason so many Americans harbor unrealistic fears is that immense power and money await those who tap into our moral insecurities and supply us with symbolic substitutes (Glassner, 1999). 
The proliferation of graffiti has produced "moral panics" and enforcement backlashes (particularly in the US) that have been spurred by the "fear of crime" (White, 2000). Anti-graffiti campaigns have often supported their actions by citing the broken windows theory of crime. ${ }^{41}$ This theory argues that permitting minor misdemeanors encourages more serious crime. These minor forms of public disorder not only lead to worse crimes, but also cause a downward spiral of urban decay (Wilson \& Kelling, 1982; Kelling \& Coles, 1997). The presumed reason is that visual cues of disorder (e.g., graffiti, broken windows, public intoxication, trash, abandoned cars, etc.) create an atmosphere of lawlessness that attracts criminal offenders, who assume that residents are indifferent and do not care about the neighborhood (Sampson \& Raudenbush, 2004).

Some researchers have begun to question the broken windows theory. Bernard Harcourt (2001) argues that the theory has never been empirically verified. In fact, existing data suggest that the broken windows theory may very well be false. Harcourt believes that the theory rests on unexamined groupings of "law abiders" and "disorderly people" and of "order" and "disorder," which have no intrinsic reality independent of the techniques of punishment that we implement in our particular society (2001). Other critics contend that defensible space and broken windows constitute instrumentalist policing ideologies founded on environmental determinism that effectively only relocate lawlessness rather than addressing longstanding social inequalities (Rentschler, 2003; Shaftoe, 2006; Vivoni, 2009).

\footnotetext{
${ }^{41}$ James Wilson and George Kelling formulated the broken windows theory of crime in the early 1980s. The broken windows theory's emphasis on policies that crackdown on disorderly conduct and aggressively enforce misdemeanor laws has greatly influenced policing in the US and abroad (Harcourt, 2001).
} 
Additionally, theoretical reflection and empirical evidence bearing on the actual meaning of disorder are remarkably thin (Harcourt, 2001). Research on implicit bias (the cultural stereotypes that operate beneath the radar in society) and cultural stereotyping suggests that Americans hold persistent beliefs linking blacks and poor minorities to crime, violence, disorder, graffiti, welfare, and undesirability as neighbors (Bobo, 2001; Quillian \& Pager, 2001). Dark skin is an easily observable trait that has become a statistical marker in American society, one imbued with meanings and crime and disorder that stigmatize not only people but also the places in which they concentrate (Sampson \& Raudenbush, 2004).

There has been relatively little research done on the social structures that shape perceptions of disorder as a problem (Sampson \& Raudenbush, 2004). Studies in Baltimore and New York City, show that perceptions of disorder vary widely between individuals within the same neighborhood and that perceptions and disorder were not significantly correlated (Sampson \& Raudenbush, 2004). Another study by Lincoln Quillian and Devah Pager (2001) showed that there was a positive association between perceived crime and percentage of young black men. Quillian and Pager underscored that it is important to conceptualize perceived crime and disorder as distinct from actual crime rates. Robert Sampson and Stephen Raudenbush (2004) conducted an extensive neighborhood survey in Chicago focusing on what triggers perceptions of disorder. They hypothesized that perceptions of disorder are socially constructed and are shaped by much more than actual levels of disorder. By combining census and police data, personal interviewers $(\mathrm{N}=3,585)$, and field observations of city streets, they found that 
social structure was a more powerful predictor of perceived disorder than carefully observed disorder. This finding suggests that in shaping perceptions of disorder, residents supplemented their knowledge with prior beliefs informed by the racial stigmatization. This is not due to pure racial prejudice, because blacks were just as likely as whites to be influenced by racial composition in predicting disorder (Sampson \& Raudenbush, 2004).

What this research suggests is that the discomfort people feel about disorder stems from something in addition to actual levels of disorder present around them. There are subconscious cultural influences at work. Also, attempts to remove disorder, such as graffiti, from neighborhoods may be justifiable endeavors supported by residents in some cases, but they may have limited payoffs in reducing fear if the neighborhood is inhabited by a large percentage of poor and minorities. This limitation of effectiveness does not derive from deficiencies in the residents, but is rather due to socialphysiological processes of implicit bias and statistical discrimination as played out in the historic and current racialized context of cities (Sampson \& Raudenbush, 2004).

\section{Research on Graffiti in Portland, Oregon}

Chris Gorsek's (2004) dissertation on graffiti in Portland uncovered many interesting findings. As a former police officer, Gorsek was interested in studying graffiti because he believed that (1) it adversely affected the quality of life of an area, (2) the methods of dealing with it were not scientifically tested, and (3) if current methods were ineffective, scarce tax dollars were being wasted that could be shifted to more promising abatement approaches. Therefore, Gorsek's research focused on how well Portland's graffiti 
removal program worked, how informal social control affected graffiti, and whether there was a specific geography to the location of graffiti.

The broken windows theory implies that rapid removal will eventually lead to an eradication of graffiti. Many cities recommend that property owners should buff graffiti within 24 hours of its appearance (Gorsek, 2004). Through extensive field observations of graffiti removal zones and non-removal zones over 12 weeks in 1999, Gorsek was able to determine that prompt graffiti removal did not prevent the return of graffiti. There was not a significant difference in the amount of graffiti found in the graffiti removal and non-removal areas. In fact, there was an increase in the amount of graffiti in the removal area. These findings directly contradict the broken windows theory.

Gorsek also found that informal social control ${ }^{42}$ was linked to some reduction in graffiti occurrences. However, there was less informal social control in more public areas that were zoned as commercial, and thus these areas had more graffiti. This could explain why Portland graffiti report maps show high concentrations in the inner industrial southeast neighborhoods of Buckman, Kerns, and Hosford-Abernethy.

\section{War on Graffiti}

Kurt Iveson's research (2010) highlights an alarming trend, the ever-expanding number of urban authorities who have declared "war on graffiti." This is problematic because this war on graffiti has played a significant role in the militarization of everyday urban life. It has provided authorities a mechanism to introduce military technologies

\footnotetext{
${ }^{42}$ Informal social control is the control that is exercised by the average citizen, rather than a public official, to control a public space (Gorsek, 2004). This is similar to Jane Jacob's notion of "eyes on the street." Some researchers have said that the most likely person to prevent a crime are not police officers but rather neighbors, friends, relatives, bystanders, or the owner of a property (Clarke \& Felson, 1993).
} 
and operational techniques (e.g., razor wire, chemical washes, CCTV surveillance, acoustic sensors to detect spray cans, GPS locators, real-time paint fume alerts, intelligence, counterintelligence, etc.) into policy and policing (Iveson, 2010). In response to this increased surveillance, Iveson hypothesizes that elaborate and timeconsuming graffiti pieces are becoming less common and are being replaced by quick tags, stencils, posters, stickers and other quickly applied forms. Heinz Steinert (2003) also explains that the use of the word war to describe policy responses to graffiti is significant because it blurs the line between police work and warfare. This also promotes an "us versus them" mentality to anti-graffiti campaigns. It is difficult to know exactly how many, but numerous people have been killed by vigilantes after being caught doing graffiti (Iveson, 2010). ${ }^{43}$

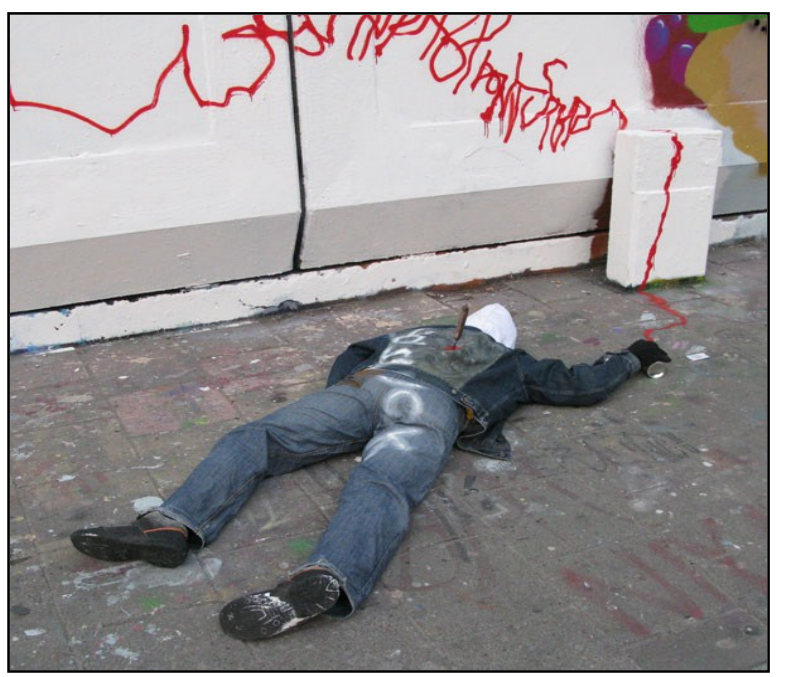

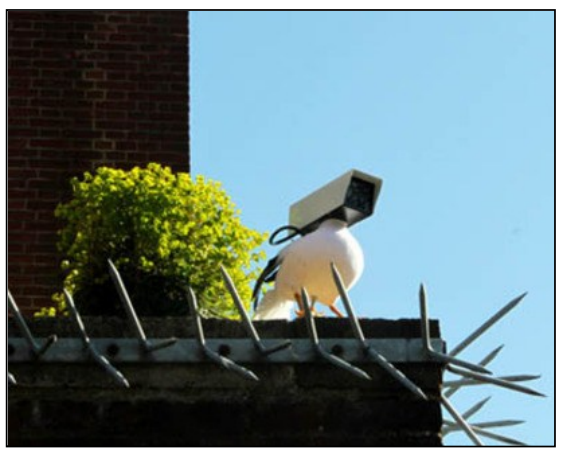

Figure 60 panoptICONS City Surveillance Awareness Project, Utecht Netherlands

Figure 59 "The Last Graffiti Artist," Mark Jenkins, Malmo Sweden 2008

\footnotetext{
${ }^{43}$ Writing of these deaths, Jeff Chang (2002) has observed, "Make no mistake; quality of life campaigns have a body count" (Iveson, 2010, p. 124). For example: in 1983, an African America graffiti artist Michael Stewart was arrested, beaten, and strangled to death by several white New York police officers (Weinberg, 2003). In 1995, William Masters instigated a confrontation with two Latino taggers on a public street in North Hollywood, CA. Masters ended up shooting both, killing 18-year-old Cesar Arce (Weinberg, 2003). In 2008, 15-year-old South Aucklander, Pihema Campbell, was chased and stabbed by a property owner whose fence he was tagging (Iveson, 2010).
} 


\section{Review of Theoretical Literature}

Street Art as Public Interaction

The recent changes occurring in street art represent a new branch of artists interested in not just the art itself, but also how that art directly interacts with the spaces, meanings, and people around it. Some street art installations try to instigate a response and promote interaction with audiences. These installations are moveable, tactical, or designed for easy taking. Sometimes the piece remains for years and passersby introduce additional

pieces, creating a layering of materials and ideas. ${ }^{44} \mathrm{~A}$ worldwide example of this type of intervention are "Locks of Love" installations where padlocks are affixed to a fences, gates, bridges, or similar public fixtures by sweethearts to symbolize their everlasting devotion to one another. Isis Brook (2007) studied several unauthorized 3D artistic interventions and found that there was interplay and elaboration among anonymous citizens. For example, a tree in her study had a natural feature in its bark that was reminiscent of a door. Someone added a small doorknob and a rustic sign overhead that read, "Home Sweet Home." Other people then left small items at the door. Someone even posted a hand-written note saying, "eviction notice” (Brook, 2007). In Brook’s analysis of these interventions, she said that:

A place sparks the imagination and the response is some minimal transformation that others then relate to and join in...these kinds of things cannot be planned or engineered; their improvisational nature is what gives them a specific kind of quality (2007, p. 317).

\footnotetext{
${ }^{44}$ This type of exchange can be seen on the streets of some Portland neighborhoods, where small Buddhist-style shrines are erected in yards and parking strips. People exchange offerings such as toys, flowers, or stones.
} 


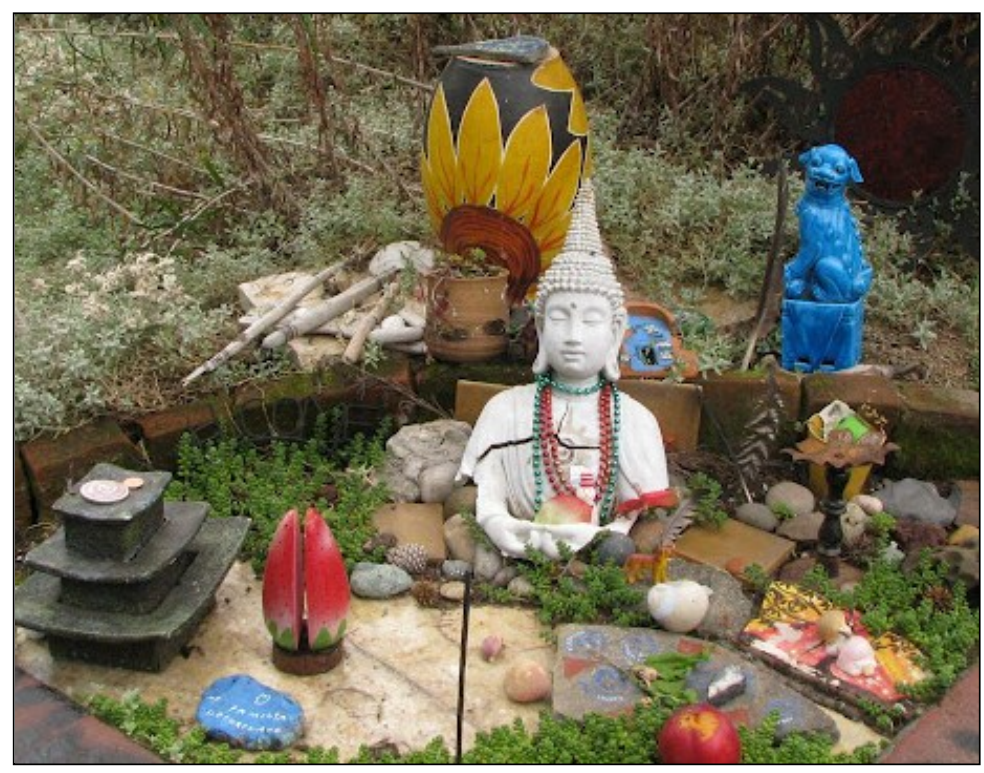

Figure 61 Community-Contributed Shrine, Portland Oregon

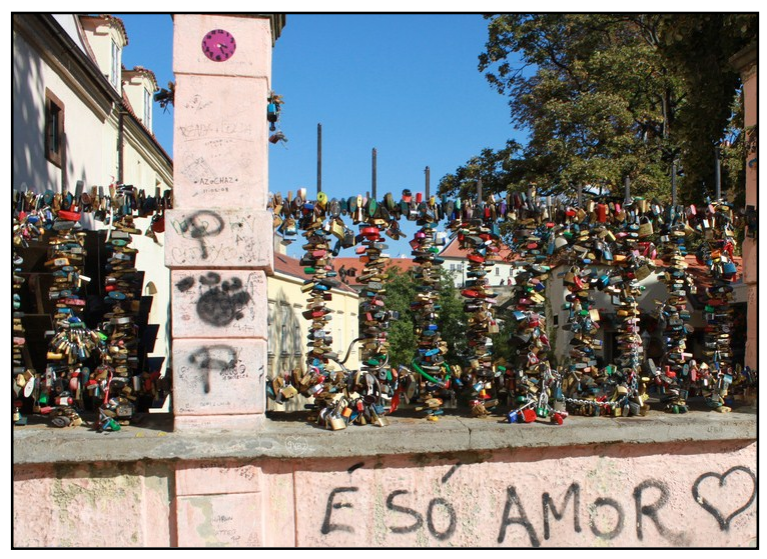

Figure 62 Love Locks Bridge, Prague 2011

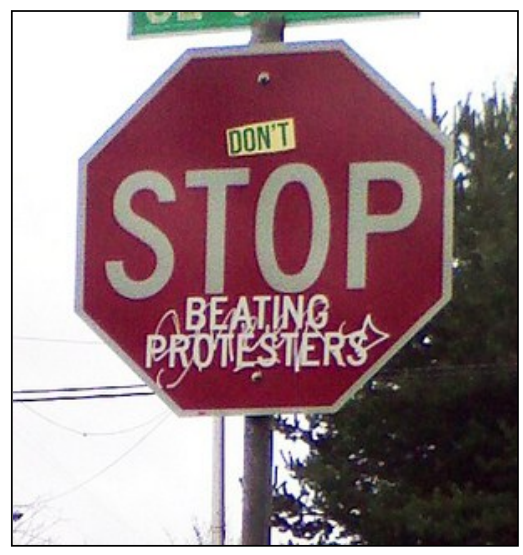

Figure 63 Don't Stop Beating Protestors, Portland Oregon 2012

Furthermore, Rafael Schacter provides a compelling argument that there is a powerful performance aspect to the production and consumption of street art. The heightened emotion the artist feels while producing the illicit work is communicated to spectators through the feeling of the piece (Schacter, 2008). The urban audience is participating in the performance, as they gaze, denounce, laugh, or add their own touches to the artwork. The visualizations created are not just communicating a message, 
but they are an affective process that is actively doing something in the world as "mediators" of activities and communications amongst urbanities (Halsey \& Young, 2006; Schacter, 2008). Street artists transmit a message and then other people in the city can respond. Street art indisputably causes reactions; most people have some sort of opinion concerning its right to exist, its message, artistic merit, legality, etc. Schacter says that street art has "agency," the ability to capture, hold and transform cognitive operations of its spectators and participants (2008).

Street art thus creates "shared narratives" between people, ideas, and the city. Street artists are actively engaging in place-making activities. Keith Basso (1996) believes that place-making is a universal tool of the "historical imagination;" a way of constructing history, inventing it, augmenting and enhancing conceptions of the past. As the artists use urban spaces to fulfill their own desires, they are also constructing a history of their own making. Value and meaning are not inherent in space or place; instead they are continuously created, reproduced, recreated, and defended (Cresswell, 1996). Street artists are augmenting and enhancing conceptions of the past, present, and future for both themselves and others who see the piece. In this way, street art can be seen as a powerful unmediated alternative mode of communication.

Street art can also be viewed as a "cultural practice;" as a form of material culture. For this reason, Hector Orengo, David Robinson (2008) and Melisa Riviere (2005) have approached the study of street art from an archeological perspective. Unsanctioned urban artworks are "artifacts" that sit in direct competition with the sanctioned art displayed in the production of commercial advertisements, signs, and billboards 
(Carrington, 2009). Advertisements are accepted as normal and acceptable uses of public space because capital interests regulate them. Street art, on the other hand, is estranged from the commercial sphere and confronts this rationalized conception of space (Schacter, 2008). Orengo and Robinson (2008) believe that the constructed environments changed and produced by street artists, draw upon the past and provide the material preconditions that influence present-day urban behaviors. This "temporal elasticity" enables materials from the past (like street art) to play active roles in the present (Orengo \& Robinson, 2008). Street art can therefore be viewed as material evidence of the present contestation of past ideologies.

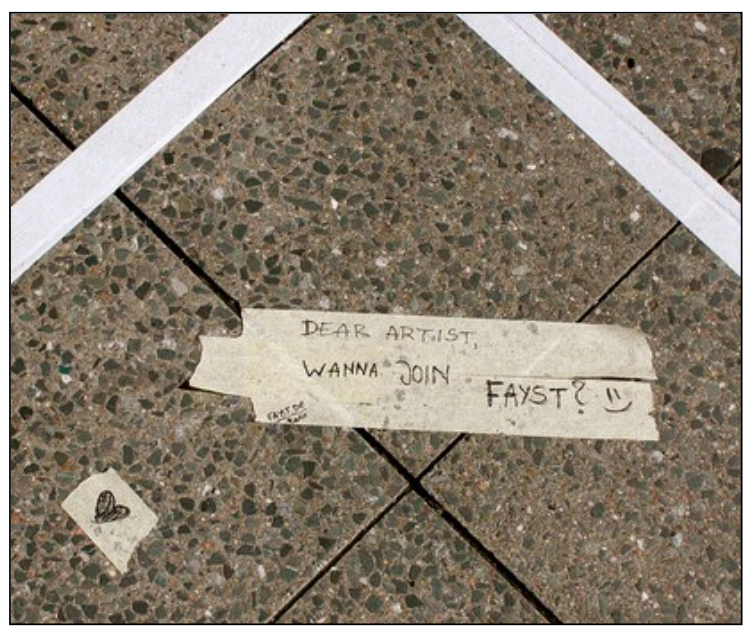

Figure 64 Street Artist Communication, Berlin 2011

Playing with Public Space

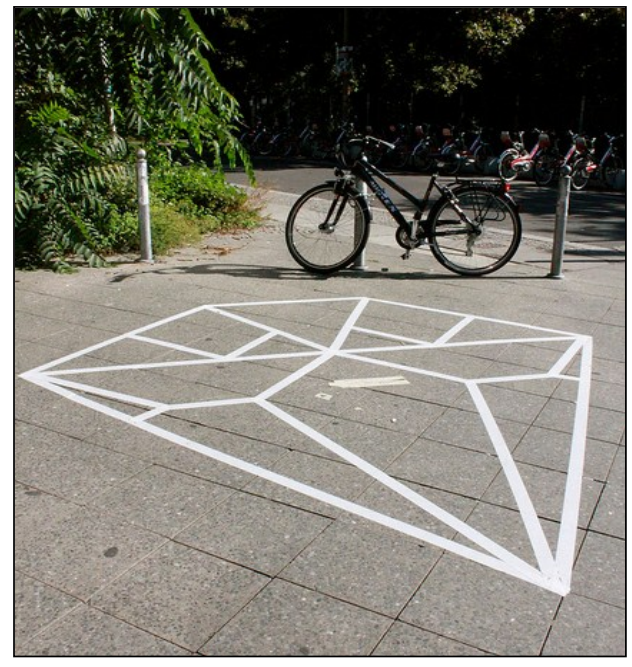

Figure 65 Tape Installation, Berlin 2011

One of the main characteristics of street art is its playful quality. Quentin Stevens (2007) has said that play is an important but largely neglected aspect of human experience in the city. Yi-Fu Tuan (1974) sees playing, especially outside, as an important step in childhood development because a child's ability to navigate through a complicated world begins with learning how to use their senses early in life. Moving 
about and exploring, children touch and manipulate things, and in turn, they learn about the reality of objects and the structuring of space.

By using forms of pleasure (such as art, festivals, carnival, or skateboarding), adults can actively produce their own experiences and interact with their surroundings (Borden, 1996). Quentin Stevens (2007) points out that playing in the urban realm involves controversial expenditures of time and energy and is often looked down upon as an inefficient usage of time. Cities are planned to optimize work and other rational objectives, with leisure space serving well-defined functions (Stevens, 2007). Therefore, spontaneous actions challenge the rigorous timetable of bureaucratic and capitalist production (Bonnett, 1992). Playing in public spaces, especially those not designed for it, reveals new realms of possibilities and embrace space's embedded use-value. Stevens also considers play to be a "lived critique" of rational action, because it discovers new needs and develops new forms of social life illustrating the capacities for social action and expression that the urbanization of society has made possible.

Similarly, street art can also be thought of as a form of carnivalesque behavior. Mikhail Bakhtin (1968) coined the term carnivalesque. These are activities that use playful politics aimed sharply and polemically against the official languages of their time. Carnivalesque activities are a tactical blending of art, play, and life. Similarly, street art often blends art and play to produce counter-spectacles designed to interrupt everyday experiences and provoke reorientation (St John, 2008). A carnival celebrates the temporary liberation from established order, mocks authority, and suspends hierarchies, privilege, norms, and everyday prohibitions (St John, 2008). It is a separate 
autonomous world that is generated in response to the conditions of the official world (Vaneigem, 1972). Similarly, many street art installations are semi-spontaneous engagements that "play with a place" and its elements. These interventions introduce an element of whimsical and quirky distractions from hectic everyday life. They suggest an engagement with the place that, whilst often humorous, is also one of endearment and sharing (Brook, 2007).

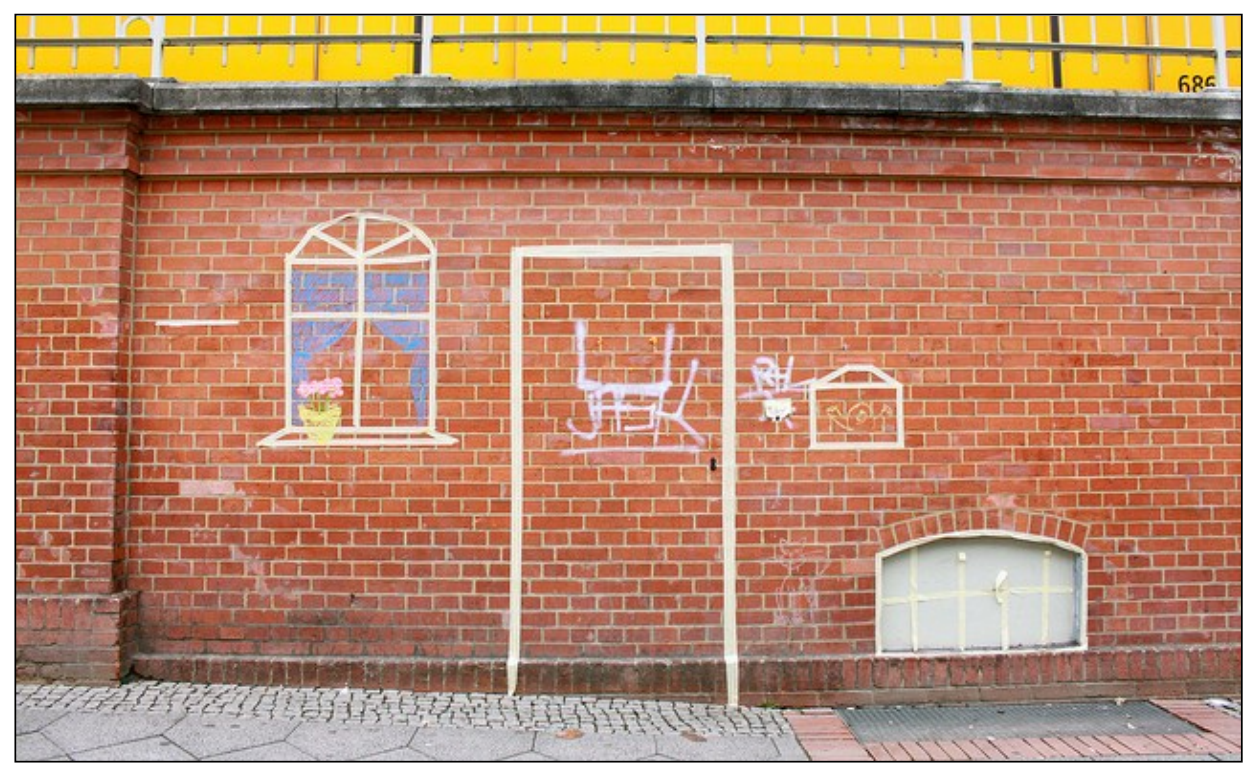

Figure 66 Faux-Front Home, Warschauer Strasse Station Berlin 2011

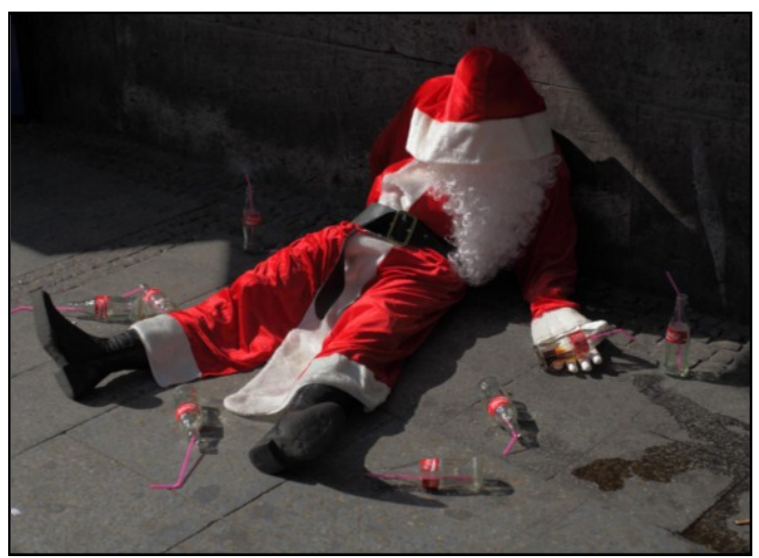

Figure 67 Peter Pink Installation, Berlin-Bahnhof Zoo 2012

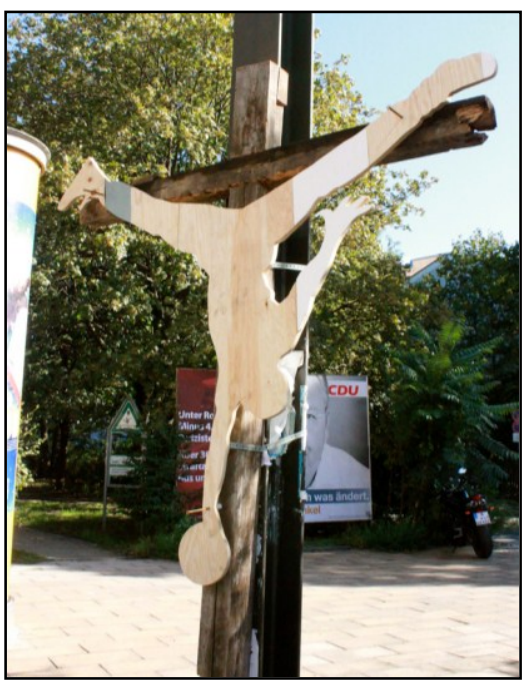

Figure 68 Hung on the Cross Air Jordan, Berlin 2011 


\section{Tactical Urbanism}

A recent survey of the planning and development landscape revealed tactical urbanism as one of the most notable planning trends of 2011 (Planetizen, 2012). ${ }^{45}$ This emerging field of urban interventions (also called temporary, guerrilla, pop-up, ad-hoc, DIY, or open-source) covers a range of projects many of which would also be classified as forms of street art. Arising out of funding challenges brought on by the recent recession, frustrations with the drawn-out approvals process, the organizational opportunities provided by the internet and social media, emerging technologies, and courageous designers, tactical urbanist projects are often defined by their low-cost temporary nature and lack of prior permission (Planetizen, 2012).

These innovative projects aim to activate people and the urban landscape. Sitespecific installations become platforms for social experiences and creative exchange in the city. Pushing the boundaries of art and perception, these events allow for an open exploration of reality in the spaces they create between artist and spectator. These artistic interventions deliberately rediscover performative strategies that reflect the theatrical possibilities of urban space (Feireiss, 2010). It is not just the performance itself that stands out, but is instead the audience's response to it that becomes the main event.

\footnotetext{
${ }^{45}$ The editors of Planetizen, an online public-interest information forum website, reviewed summaries of hundreds of articles, reports, books, studies, and editorials related to planning and urban development (2012).
} 


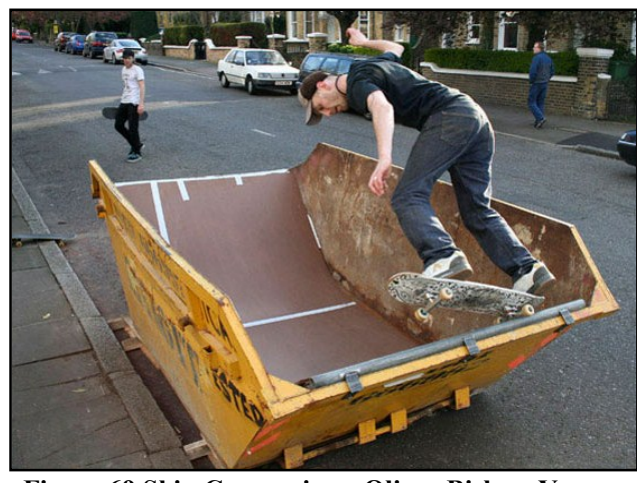

Figure 69 Skip Conversions, Oliver Bishop-Young, London 2008

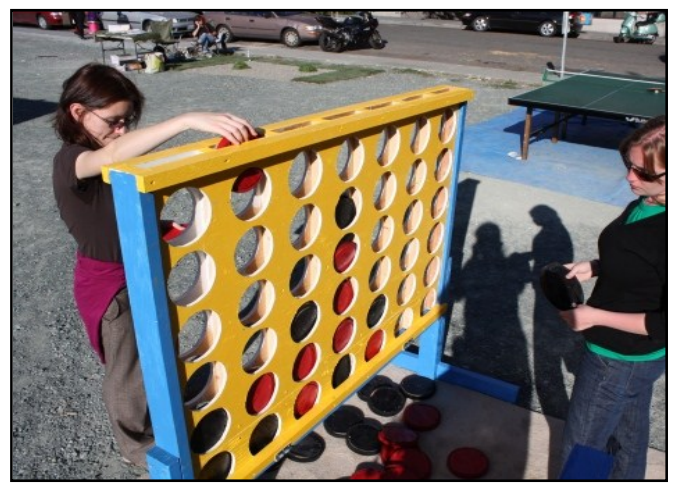

Figure 71 PARK(ing) Day, F.A.D., Lisa Town, and Jason King, Seattle 2009

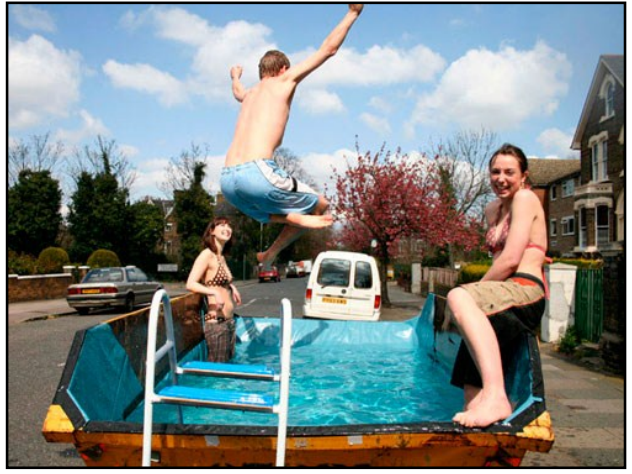

Figure 70 Skip Conversions, Oliver BishopYoung, London 2008

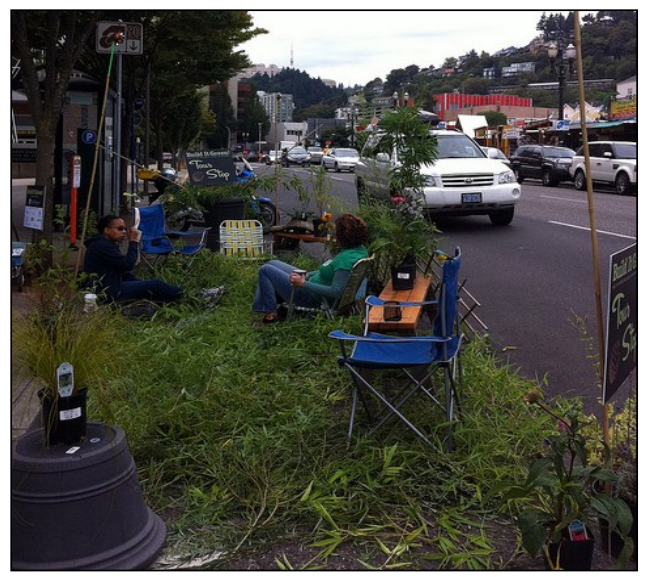

Figure 72 PARK(ing) Day, 4th Avenue Portland Oregon 2011

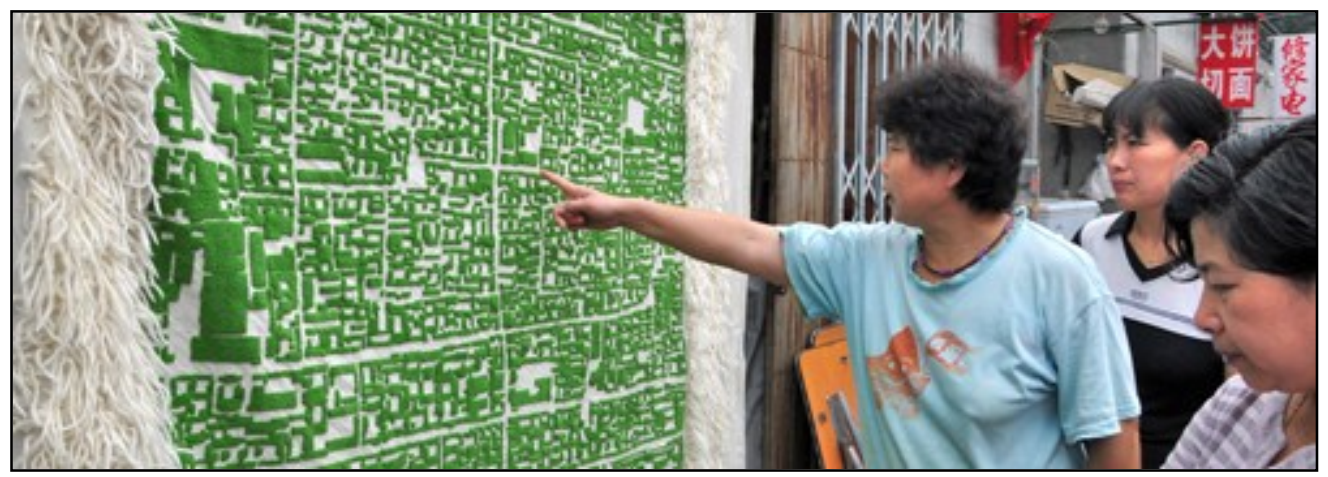

Figure 73 "Instant Hutong," Beijing 2009 - Urban carpets created to record and draw attention to the traditional patterns of neighborhoods, courtyards, and lanes in Beijing, all of which are threatened by urban re-development. 
Situationist International (SI) was one of the first groups to promote and experiment with the idea of tactical urban interventions. SI's tactics of creating "situations" were urban interventions meant to take pedestrians off their predictable paths, outside their habits, and jolt them into a new awareness of the city (Debord, 1955). Their site-specific art and performances were seeking a phenomenological and experimental understanding of the city. One methodology SI used was dérive, or the drift through the city. Paying close attention to the psychogeographical effects of this experience moving through space, SI sought to uncover the hidden "essential ambiences" and "force fields of attraction" so they could understand the various energy flows in and out of places (McGaw, 2008). These tactics questioned the established norms and the hegemonic ideas of their day. The SI sought to counter the spectacle of everyday life by "intervening in the city and experiencing its spaces directly as actors rather than spectators" (Pinder, 2005, p. 149; Dickens, 2008). Thus, a central element in the dérive was using playful-constructive behavior as a means of reclaiming the city, where noncompetitive, inclusive games enhance the freedom of a given environment (Knabb, 1981; Dickens, 2008).

\section{Review of Methods}

Street Art Taxonomies

Several street art studies have focused on the process of classifying graffiti by creating graffiti taxonomies (Gottlieb, 2008; Taylor et al., 2010; Günes \& Yýlmaz, 2006; Gadsby, 1995; Bates \& Martin, 1980; Ferrell, 1993; Gomez, 1993; White, 2000). These authors applied unique taxonomies for their research purposes; therefore the terminology 
used to describe street art forms is highly varied. For example, Taylor et al. (2010) classified based on content (e.g., identity, declaration, obscene, quirky, hate, romantic, memorial, and legal). Günes and Yýlmaz (2006) classified based on general types (gang, tagger, conventional, existential, political, ideological, and piecing). From the 1980s through the 1990s, many researchers tended to form delineations of graffiti based on location (e.g., toilet stall, wall), type (e.g., tag, throw-up, masterpiece); design style (e.g., wildstyle, bubble, 3D); method of production (e.g., stencil, wheatpaste, projection, reverse); legality status (e.g., vandalism, commissioned); and the artists' motivational desires (e.g., protest, political, humor, identity) (Taylor et al., 2010).

\section{Public Perceptions of Street Art}

Rob White (2000) discusses the nature of graffiti production and the different ways in which people might respond to graffiti. White provides a useful overview of the different types of graffiti (categorizing based on intent, form, and location) and graffiti prevention strategies. White believes that graffiti ought not to be condemned, nor celebrated, without due attention given to the ambiguities inherent in its various manifestations. He argues that there is a need for devising appropriate strategies (which include doing nothing) to deal with graffiti at the local neighborhood level.

A recent study by Kim Dovey, Simon Wollan, and Ian Woodcock (2012) asked the question: "What role does graffiti have in the construction and experiences of place?" They sought to look beyond the content of graffiti and focus on the ways it is framed as an urban social practice by residents; how they thought it damaged or contributed to the character of urban places. Their data were collected through a series of in-depth semi- 
structured interviews with residents in two neighborhoods undergoing gentrification in Melbourne, Australia. This was the only research I found in which residents were interviewed directly about their opinions on street art. However, the paper fails to mention the sample size or how respondents were interviewed. Dovey, et al. (2012) did find evidence supporting Mary Douglas' claim (1996) that graffiti is like dirt, and it becomes vandalism when it is "out of place." Respondents made distinctions between good and bad graffiti based on where it was located and based on its artistic merit. Another interesting finding was that residents tended to fall into two categories: longterm residents saw graffiti as an intrusion and newer residents saw it as an inherent part of the character, and even part of what attracted them to live there (Dovey, et al., 2012).

\section{Methodological Contributions}

With my research, I intend to build upon Rob White's study (2000) of public perceptions of street art. The key differences with his approach and mine are that: (1) White hypothesizes about different responses to graffiti; he does not collect data from residents and (2) he focuses on traditional graffiti, and not street art. My survey will collect data from residents about their opinions on both graffiti and street art. Like Dovey, et al. (2012), my research looks beyond the content and intent of graffiti and focuses instead on how the different manifestations of it are perceived by people in the city. I will build upon Dovey's research by systematically surveying all types of people who live in the city (not limiting it to certain neighborhoods) about their opinions on a range of graffiti and street art forms to see what differences in attitudes exist and how people contextualize and justify their opinions regarding these issues. 
As explained, street art can theoretically be used as a "tool" to strengthen and enrich interactions between people and places. Thus, I will test the ability of street art installations to engage with audiences. To do this, I devised several experiments in the city, making interactive and playful pieces of street art myself. Situationist literature and tactics greatly influenced this methodological choice. This research aims to uncover what types of interactions and communications are possible between people and street art. I wanted to create situations designed specifically to take pedestrians off their predictable paths, outside their habits, and jolt them into a new awareness of the spaces and objects around them. 


\section{Chapter 4. Methodology}

The process of choosing appropriate methodology was the most challenging aspect of this research. Describing street art, applying theories about its existence, and postulating its effects, can only do so much to further an understanding of this sociospatial phenomenon. Additionally, it is difficult to describe things such as feelings and "senses of place." These senses are not easily quantifiable, but they have a profound effect on our thoughts and our lived realities and therefore are important to document. Considering these challenges, I chose to use a mixed-methods approach and gather both qualitative and quantitative data. I strove for a balance between the examination of structures and processes on one hand and of individuals and their experiences on the other. An overemphasis on processes could lead to dehumanized research, but an overemphasis on individuals could ignore the fact that people are embedded within powerful societal structures (Hay, 2010).

The lack of existing data on how people react and interact with street art, and what they actually think about different forms of street art, required that I gather new data to answer my research questions. This information is important to collect because we need to first understand what people think about street art in order to accurately evaluate if current policies reflect what people desire. This study will contribute to a more informed discussion about the presence, acceptability, and regulation of different forms of artistic expression in cities, particularly in Portland, Oregon. Two methodological approaches were utilized: (1) participant observations, to uncover what happens when street art is 
placed into public spaces (i.e., people's reactions and interactions) and (2) survey interviews, to gather data about what people think about different forms of street art.

\section{Hypotheses}

This thesis is designed to gather empirical data about how the public reacts, interacts, and feels regarding different forms of street art. A significant body of theory has been devoted to the topic of street art, but there is a lack of information about how the public perceives different forms of street art. My intention with this study is to help clarify these matters by gathering information from the streets and the residents of the City of Portland. Thus, my first research question is: How do people in Portland react to and interact with different forms of street art in the city? To answer this, I conducted street art experiments, placing different forms of street art into public space and then observing what happens in terms of public participation and longevity of the piece. 


\section{During this phase of the research, I will test several hypotheses:}

\begin{tabular}{|c|c|c|}
\hline Hypotheses & Literature & Method/Measurement \\
\hline $\begin{array}{l}\text { 1. People's reactions to someone } \\
\text { placing street art installations in } \\
\text { public space will not be } \\
\text { confrontational. }\end{array}$ & N/A & Participant Observations \\
\hline $\begin{array}{l}\text { 2. Street art installations can } \\
\text { promote interaction with the } \\
\text { piece and surrounding space. } \\
\text { a. Both children and adults } \\
\text { will take a moment out of } \\
\text { their everyday routines and } \\
\text { physically engage with the art } \\
\text { and surrounding space. }\end{array}$ & $\begin{array}{l}\text { Brook, 2007; Dickens, 2009, 2012; } \\
\text { Debord, } 1957\end{array}$ & $\begin{array}{l}\text { Participant Observations - } \\
\text { Presence/Absence of Interactions }\end{array}$ \\
\hline $\begin{array}{l}\text { 3. The amount of time an } \\
\text { installation remains will be } \\
\text { influenced by two factors: its } \\
\text { form and placement. } \\
\text { a. 3D installations will remain } \\
\text { longer than tags, stickers, or } \\
\text { masterpieces. } \\
\text { b. The more noticeable and } \\
\text { 'centrally located' a piece is, } \\
\text { the faster it will be removed. }\end{array}$ & Schacter, 2008 & $\begin{array}{l}\text { Participant Observations - } \\
\text { Presence/Absence of Street Art - } \\
\text { Spatial Analysis }\end{array}$ \\
\hline
\end{tabular}

Table 1 Participant Observation Hypotheses

My second research question is: What do people in Portland think about different forms

of street art? To answer this, I will conduct survey research interviews with residents of

the City of Portland. During this phase of the research, I will test several hypotheses:

\begin{tabular}{|l|l|l|}
\hline \multicolumn{1}{|c|}{ Hypotheses } & \multicolumn{1}{|c|}{ Literature } & \multicolumn{1}{|c|}{ Measurement/Analysis } \\
\hline $\begin{array}{l}\text { 4. Respondents will have more positive opinions } \\
\text { regarding installations than they will towards tags, } \\
\text { stickers and pieces. }\end{array}$ & $\begin{array}{l}\text { Dickens, 2009; } \\
\text { Brook, 2007 }\end{array}$ & $\begin{array}{l}\text { Survey - Composite score } \\
\text { comparison between } \\
\text { installations and other pieces. }\end{array}$ \\
\hline $\begin{array}{l}\text { 5. Street art that attempts to directly engage with } \\
\text { people (i.e., being moveable, playful, tactical, or } \\
\text { interactive) will be rated more positively than those } \\
\text { that do not. }\end{array}$ & $\begin{array}{l}\text { Dickens, 2009; } \\
\text { Brook, 2007; } \\
\text { Schacter, 2008; } \\
\text { Tuan, 1974; } \\
\text { Stevens, 2007 }\end{array}$ & $\begin{array}{l}\text { Survey - Composite score } \\
\text { comparison between chalk box } \\
\text { installation and other pieces. }\end{array}$ \\
\hline $\begin{array}{l}\text { 6. Street art that introduces natural elements to the } \\
\text { urban environment will be rated more positively than } \\
\text { street art that does not. }\end{array}$ & N/A & $\begin{array}{l}\text { Survey- Composite score } \\
\text { comparison between garden } \\
\text { installation and other pieces. }\end{array}$ \\
\hline $\begin{array}{l}\text { 7. Street art that displays iconographical images will } \\
\text { be rated higher than typographical pieces (e.g., those } \\
\text { using traditional graffiti-style letters). }\end{array}$ & $\begin{array}{l}\text { Dickens, 2009; } \\
\text { White, 2000; Von } \\
\text { Lanzenauer, 2011; } \\
\text { Schlecht, 1995 }\end{array}$ & $\begin{array}{l}\text { Survey - Comparisons between } \\
\text { GATS piece and MURG piece. }\end{array}$ \\
\hline
\end{tabular}




\begin{tabular}{|c|c|c|}
\hline Hypotheses & Literature & Measurement/Analysis \\
\hline $\begin{array}{l}\text { 8. Street art that is rated as being more understandable } \\
\text { will be viewed more positively overall than pieces } \\
\text { that are not. }\end{array}$ & $\begin{array}{l}\text { Dickens, 2009, } \\
\text { 2012; Gottlieb, } \\
2008\end{array}$ & $\begin{array}{l}\text { Survey - Comparison of ratings } \\
\text { on 'I understand the intended } \\
\text { message.' }\end{array}$ \\
\hline $\begin{array}{l}\text { 9. Street art that is rated as being more imaginative } \\
\text { will be viewed more positively overall than pieces } \\
\text { that are not. }\end{array}$ & Dickens, 2009, 2012 & $\begin{array}{l}\text { Survey - Comparison of ratings } \\
\text { on 'The person who did this } \\
\text { used their imagination.' }\end{array}$ \\
\hline $\begin{array}{l}\text { 10. Street art that is rated as being more interesting } \\
\text { will be viewed more positively overall than pieces } \\
\text { that are not. }\end{array}$ & N/A & $\begin{array}{l}\text { Survey - Comparison of ratings } \\
\text { on 'It makes the space look } \\
\text { more interesting.' }\end{array}$ \\
\hline $\begin{array}{l}\text { 11. Message-based graffiti will be rated more } \\
\text { positively overall than graffiti promoting someone's } \\
\text { name. }\end{array}$ & Dickens, 2009, 2012 & $\begin{array}{l}\text { Survey - Comparison of } \\
\text { composite score means of the } \\
\text { Fever piece and Long Live } \\
\text { piece. }\end{array}$ \\
\hline $\begin{array}{l}\text { 12. Street art that is less physically damaging to } \\
\text { surfaces will be viewed more positively. }\end{array}$ & $\begin{array}{l}\text { Broken Windows } \\
\text { Theory (general) }\end{array}$ & $\begin{array}{l}\text { Survey - Comparison of ratings } \\
\text { on 'it damaged the surface.' }\end{array}$ \\
\hline $\begin{array}{l}\text { 13. Street art that is less associated with gangs will be } \\
\text { viewed more positively. }\end{array}$ & $\begin{array}{l}\text { Broken Windows } \\
\text { Theory (general); } \\
\text { Glassner, } 1999\end{array}$ & $\begin{array}{l}\text { Survey - Comparison of ratings } \\
\text { on 'it is gang related.' }\end{array}$ \\
\hline $\begin{array}{l}\text { 14. Street art that is associated with making the space } \\
\text { look dirty will be viewed more negatively. }\end{array}$ & $\begin{array}{l}\text { Broken Windows } \\
\text { Theory (general); } \\
\text { Dovey, et al., 2012; } \\
\text { Douglas, } 1996\end{array}$ & $\begin{array}{l}\text { Survey - Comparison of ratings } \\
\text { on 'it makes the space look } \\
\text { dirty.' }\end{array}$ \\
\hline $\begin{array}{l}\text { 15. Respondents will be more willing to have a piece } \\
\text { of street art be in some other part of the city or even in } \\
\text { their neighborhood, before they would be comfortable } \\
\text { with it being on their property. }\end{array}$ & N/A & $\begin{array}{l}\text { Survey - Analysis of 'Would } \\
\text { you be okay if someone placed } \\
\text { something like this (a) on your } \\
\text { property, (b) in your } \\
\text { neighborhood, or (c) in some } \\
\text { other part of the city?' }\end{array}$ \\
\hline $\begin{array}{l}\text { 16. Respondents will prefer that community input is } \\
\text { received regarding the removal of graffiti and street } \\
\text { art. }\end{array}$ & $\mathrm{N} / \mathrm{A}$ & $\begin{array}{l}\text { Survey - Analysis of 'Do you } \\
\text { think that they surrounding } \\
\text { community should have a say } \\
\text { in whether or not it's removed } \\
\text { or left alone?' }\end{array}$ \\
\hline $\begin{array}{l}\text { 17. Respondents will not want public tax money to be } \\
\text { used to pay for graffiti removal. }\end{array}$ & N/A & $\begin{array}{l}\text { Survey - Analysis of 'Do you } \\
\text { think that public tax money } \\
\text { should be spent to pay for its } \\
\text { removal?' }\end{array}$ \\
\hline $\begin{array}{l}\text { 18. Respondents with children living in their home } \\
\text { will rate street art and graffiti (in general) more } \\
\text { negatively than respondents without children in the } \\
\text { home. }\end{array}$ & $\begin{array}{l}\text { Broken Windows } \\
\text { Theory (general); } \\
\text { Glassner, } 1999\end{array}$ & $\begin{array}{l}\text { Survey - Within-subjects t-test, } \\
\text { presence of children in } \\
\text { household on composite score } \\
\text { means. }\end{array}$ \\
\hline $\begin{array}{l}\text { 19. Respondents that own their home will view street } \\
\text { art more negatively than renters because of their } \\
\text { concern about property values and neighborhood } \\
\text { security. }\end{array}$ & Iveson, 2002 & $\begin{array}{l}\text { Survey - Within-subjects t-test, } \\
\text { household tenure on composite } \\
\text { score means. }\end{array}$ \\
\hline $\begin{array}{l}\text { 20. Respondents who have lived in their } \\
\text { neighborhood more than } 5 \text { years will view street art } \\
\text { and graffiti (in general) more negatively than those } \\
\text { living there less than } 5 \text { years. }\end{array}$ & $\begin{array}{l}\text { Dovey, et al., 2012; } \\
\text { Glassner, } 1999\end{array}$ & $\begin{array}{l}\text { Survey - Within-subjects t-test, } \\
\text { length of residency on } \\
\text { composite mean scores. }\end{array}$ \\
\hline $\begin{array}{l}\text { 21. Older respondents will dislike street art and } \\
\text { graffiti (in general) more than younger respondents. }\end{array}$ & $\begin{array}{l}\text { Broken Windows } \\
\text { Theory (general); } \\
\text { Glassner, } 1999\end{array}$ & $\begin{array}{l}\text { Survey - Within-subjects t-test, } \\
\text { age on composite mean scores. }\end{array}$ \\
\hline
\end{tabular}

Table 2 Survey Hypotheses 


\section{Participant Observations}

While conducting informal observations of street art in Portland and Berlin (Discussed in Chapter 2), two factors influenced my decision to conduct participant observations. First, randomly observing pieces of street art and graffiti did not inform me about how long the pieces had been there. Second, without directly asking, it was unclear if people who did not notice the piece, had previously seen it, and at the time were no longer paying attention. Considering this, it was important for my research to document initial encounters. Therefore, participant observations were carried out on new pieces of street art to uncover how people in the city react to and interact with street art encountered. To make this scenario possible, I decided to create street art myself, place them into public space, and then closely observe the aftereffects. This process will be discussed in greater detail shortly.

Participant observations were used to document people's direct and immediate reactions to street art in public space. This information was important to gather in order to understand their perceptions, feelings, and behaviors more fully and intimately (Lofland, et al., 2006). Although not a main objective for this research, this method also provided firsthand knowledge of the work involved and the "rush" 46 of creating street art. Although street artists were not directly interviewed for this research, ${ }^{47}$ I participated in their practices via this involvement. This was an excellent way to understand the "lived

\footnotetext{
${ }^{46}$ Many street artists say that the visceral rush they get while producing their art is a motivating factor. They see the words take shape and feel a connection between their control of the implement and the writing as it appears on the surface (Halsey \& Young, 2006).

${ }^{47} \mathrm{I}$ had informal conversations with street artists (in-person and online) about their work during this research process. This information has greatly contributed to my understandings of the street art world and the people involved in it. Considering their intense desire for anonymity and secrecy, I did not pursue securing interviews with these individuals.
} 
reality" of being a street artist, an insight that helped me more fully understand the phenomenon.

This active participation clearly influenced the situations, considering I created the events under observation. It must be realized, however, that the researcher's presence almost always has some impact on the field of study. Even our choice of what to study and how we study it reflects our values and beliefs (Hay, 2010). Being a reflexive researcher is an important goal to keep in mind. Reflexivity is a process of constant selfconscious scrutiny of the self as research and of the research process (England, 1994). Fieldwork findings are not 'realities' extracted from the field, but are instead 'intersubjective truths' negotiated out of an unfolding iterative process between the researcher, the researched and the environment (Cloke et al., 2010).

Keeping this in mind throughout this research was essential, especially when creating pieces of street art to place in the community. I had the desire to make things that people would enjoy without being offended by. I developed a sense of wanting to "give" something to the spaces, to incorporate the piece into the space, and not make the area look dirty or uncared for in any way. I also had to shift my persona when putting street art out into public space: including getting to know street artists, interacting with strangers, and taking into consideration how I appeared and acted towards others, and how my artwork would be received by the public.

To begin this process, I brainstormed the types of street art that I would feel comfortable making, finally deciding on creating a variety of interactive installations, 
including eight yarn installations, ${ }^{48}$ a tape hopscotch, a connect-the-dots game (using tape and chalk), and a community chalk box (Appendix B). The pieces were designed to pull people off their predicable paths and encourage them to interact and play with the piece and surrounding space. The goal was to test some of the theoretical arguments made about the possibilities of street art presented in the literature (Brook, 2007; Dickens, 2012; Debord, 1957). Additionally, safer forms were chosen over more risky forms of street art (i.e., spray-paint, etching, etc.). These pieces were all non-permanent and non-destructive. The pieces were fairly easy to install, especially when working with a partner.

The street art pieces were constructed at home, or in the field, and then placed into public spaces around Portland. The site locations were selected based on convenience because it was important to be able to observe the pieces on a daily basis. Pieces were placed near my home in a middle-class residential neighborhood (Sunnyside in SE Portland) and at my workplace on the Portland State University campus in downtown Portland. Living in the city, I often walk to the places I go. This may seem like an insignificant factor, but walking allowed me to observe landscapes day after day, notice changes, and identify patterns.

Pieces were observed for various lengths of time, ranging from a few hours to a year and a half (November 2010 to February 2012). Observations took place from various locations, including on-the-ground and overhead. Aerial views were preferred in order to reduce biasing the situation with my presence. Interactions that passersby had with the

\footnotetext{
${ }^{48}$ Yarn installations are also known as yarn bombing, guerilla knitting, yarn storming, urban knitting, or graffiti knitting.
} 
street art and anything overheard referencing the installations were documented.

Depending on the location and context of the piece, methods used to document the situations included: note taking, photography, and videotaping.

The yarn installations were all knitted at home and then placed in a 2-block radius in the Sunnyside neighborhood (Yamhill, 33 ${ }^{\text {rd }}, 34^{\text {th }}$, and Belmont) from November 2010 to July 2011. Some of the installations contained additional materials such as feathers, embroidered messages and designs, beads and ribbon. In January 2012, I replaced two of the yarn installations that had been up since the summer of 2011 because they were dirty and frayed.

The hopscotch tape installation was completed in October 2011 at the Urban Center Plaza at the Portland State University campus in downtown Portland. I created the hopscotch with red tape in the middle of the upper level of this public plaza. While most of the hopscotch was made out of red duct tape, the final home-base was not a square, but was instead a tape heart that said, "Join the Resistance, fall in Love" and pictured a police officer spray-painting red hearts. This piece was chosen because of its playground-like quality. Made mostly of concrete, the plaza is certainly not designed for play. The three existing public art pieces in the plaza are granitite monoliths. ${ }^{49}$ These sculptures are cold, hard, and inaccessible. As discussed in the literature review, playing is an important, but often neglected aspect of our experiences in urban environments.

In November 2011 the connect-the-dot tape installation was completed in a residential area on SE $33^{\text {rd }}$ between Belmont and Yamhill. The game was made with

${ }^{49}$ This project cost a staggering $\$ 225,000$, the city's largest public art commission since the Portland Building's Portlandia (PDC). 
purple duct tape cut into numbered dots, which if outlined, formed a "resistance fist." A bucket of sidewalk chalk was placed on the ground nearby. My intent was for people to use the chalk, tracing the numbered squares, and then the image would appear. This resistance fist image was chosen for a few reasons. First, it was a somewhat simple design. Second, I thought the combination of the fist, a traditional symbol of resistance, and the connect-the-dots, was also interesting theoretically because resistance usually begins when someone "connects the dots" of cause and effect among larger social issues and then acts out against it.

The final piece of street art created was a community chalk box placed on a utility pole at Sunnyside Piazza at the corner of SE $33^{\text {rd }}$ Avenue and Yamhill (Appendix B). This box was created using red spray paint, acrylic paint, stickers, and permanent markers. The box was attached to the pole with two heavy-duty screws. This intervention was carried out late at night and no passers by commented the activity. Several cars passed without any incident.

Overall, participant observation provided invaluable data on what it was like to make and place street art in public, the reactions those activities caused, how long the street art remained, and how people interacted with pieces encountered. This immersive and inductive methodology was helpful in forming a deeper understanding of the relationships between individuals, art, and public space. I now had data to answer my research question about how people interact with street art in the city, but pure observations alone did not reveal what people actually thought about the street art they 
saw. Therefore, an additional method, survey research, was used to uncover people's opinions regarding different forms of street art.

\section{Survey Research}

Survey research was carried out to gather information on how City of Portland residents actually feel about street art and graffiti, a topic not previously studied in this manner. This information is important to gather because of the ongoing controversy surrounding the merits of street art and the city's adherence to zero tolerance graffiti removal strategies. Survey research provides many benefits. Standardized questioning assembles more precise data because all respondents are exposed to the same experience and allows for comparisons between different cases. Most importantly, surveys also help to disseminate empirical data on the opinions of a larger population of people regarding issues, rather than relying on hypothetical or anecdotal evidence.

Street Art Taxonomy and Questionnaire Design

Before creating a survey about street art, it was first necessary to familiarize myself with what types exist. Over the past few decades, countless websites (e.g., Wooster Collective, Endless Canvas, Urban Art Core, etc.) and photography books have meticulously documented street art around the world. ${ }^{50}$ Since there was not an agreed upon classification approach found the literature reviewed (Gottlieb, 2008; Taylor et al., 2010; Günes \& Yýlmaz, 2006; Gadsby, 1995; Bates \& Martin, 1980; Ferrell, 1993;

\footnotetext{
${ }^{50}$ Photographs of street art are acquired in multiple ways by these entities. Some organizations accept photos from anyone. Others use their own team of photographers (Endless Canvas, 2012). These organizations disseminate street art photography through multiple outlets (e.g., websites, magazines, coffee-table books, zines, online social media, art shows, etc.). This documentation usually provides the location of the piece and sometimes an artist's name or pseudonym.
} 
Gomez, 1993; White, 2000), it was decided that the most useful and objective method for my research would be to classify street art based on its form. This focus on form allowed me to experiment and explore emergent reinventions of street art taking place, such as 3D post-graffiti installations, and make distinctions between it and other forms of street art and graffiti. Rafael Schacter's (2008) research findings (and my informal observations) suggest that public audiences and graffiti abatement squads make exceptions for some forms of street art and not others, even when it is all technically illegal. Some forms of graffiti are removed immediately; others are left for years. These findings prompted my interest in how different physical manifestations of street art affect its level of acceptability.

This demarcation of form presented a few methodological issues. First, within each form category there is immense variety. Spray-painted pieces can range from a simple tag of someone's name, to a stencil, or an elaborate mural. Second, inherent to most classification systems (especially ones dealing with a subjective subject such as art) is variance in how items are classified from person to person. For example, the separation between "tags" and "throw-ups" is subject to much variation between personal opinions. Finally, the photos chosen for the survey instrument were not (and could not be) allencompassing or exhaustive. Logistically, the survey had to remain brief to not adversely affect the response and completion rates. Theoretically speaking, while subject matter or form suggests the simple identification of an object, the true significance of that object within the visual context of the artwork and broader societal context 
contributes to the overall meaning of the work (Gottlieb, 2008). Unfortunately, that degree of depth is beyond the scope of this research.

Due to the subject's visual nature, I needed to use photographs in the survey. To begin this selection process, over 1,650 digital photographs that I have taken throughout the United States and Europe were uploaded into a Flickr ${ }^{51}$ database. I then examined each photo and considered its physical properties in order to identify emergent patterns. Asking questions such as: How was this object produced? What materials did the artist use for their medium? What was the piece put on? Each photo was then tagged with a descriptive label (i.e., spray, stencil, sticker, etc.). Since some of the photos consisted of multiple pieces of street art, many were assigned multiple tags. Patterns soon emerged. New codes were created to accommodate forms that were not previously considered. Flickr's "search by tag" and "batch edit" functions made the coding process relatively easy. The images were rearranged and retagged until I was satisfied that the classification system took into account all forms of street art depicted. This pattern analysis informed the formation of a non-hierarchical taxonomy system of current forms of street art. Under each main supertype classification there were subtype classifications that describe in more detail the particular methods of production and the media used. There were three supertype top-level categories: (1) Installation (e.g., 3D objects, knit,

${ }^{51}$ Flickr is an image and video hosting website, web services suite, and online community. Flickr stores photos and offers collaborative tagging, otherwise known as a folksonomy. Flickr is one of the main avenues through which contemporary street artists share their work amongst themselves and audiences. No longer do they have to sit in train yards, watching trains roll by, they can simply access the internet and be exposed to worldwide graffiti. 
gardening, etc.), (2) Paint (e.g., tagging, masterpieces, stencils, etc.), and (3) Appliqué (e.g., stickers, tape, wheatpastes, etc.). ${ }^{52}$

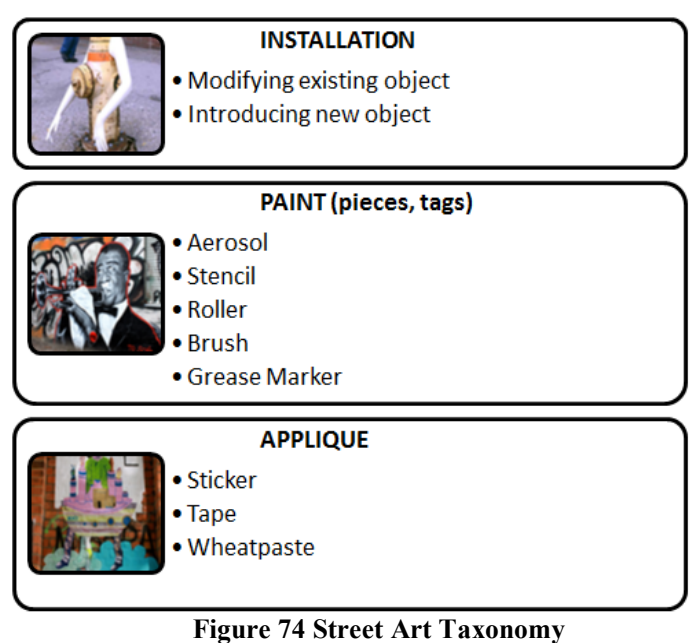

Showing respondents a picture of each of the street art subtypes identified would be far too laborious for this survey. Therefore, selections were made to further narrow down the forms of street art to be used. I decided show four different forms of street art: tags, stickers, masterpieces, and installations. These forms were chosen because they depicted common forms of street art being produced and because of the growing popularity and lack of research on newer forms of street art. In total, eight photographs from the taxonomy I created were used in the survey (Appendix C).

All respondents were informed of: survey's purpose, the average completion time, participation was voluntary and anonymous, they could stop at any time, and if there was a question they would rather not answer, they could skip it. Contact information was

\footnotetext{
${ }^{52}$ A fourth category was identified, reverse graffiti (e.g., clean and dust tagging). Reverse graffiti is a method of production that removes dirt or dust from a surface to expose the lighter-colored wall or object beneath. This method's popularity is not widespread among street artists. The method has co-opted as a tactic for advertisements. This form of art is not always damaging the surface, nor does it leave anything behind (i.e., littering), therefore it is technically not breaking any laws. Due to its lack of popularity amongst street artists and its non-illegality, this form was excluded from this research.
} 
provided for the researcher and the PSU Human Subjects Committee. Respondents were first asked two screening questions to determine eligibility. All respondents were required to confirm that they currently lived in the City of Portland and were 18 years of age or older before taking the survey. The full survey instrument can be found in Appendix D.

The survey design consisted of eight main sections, each containing a picture of a piece street art or graffiti and a series of questions about each photo. These Likert scale questions were meant to gauge the intensity of respondent opinions on a variety of indicator statements regarding the depicted piece's: (1) understandability, (2) damage done, (3) use of imagination, (4) offensiveness, (5) gang-relation, (6) criminality, (7) interest, and (8) dirtiness of the space. Respondents were asked to rate each statement using a five-point scale of strongly disagree, disagree, neither agree nor disagree, agree, and strongly agree. Statements were worded as neutrally as possible. Concepts used in the statements were developed based on participant observations and theories found in the reviewed literature. 
SECT1: In the next few questions, you will be shown 8 pictures of street art and graffiti and asked what you think about each of them. These are all located in public spaces (not on private property). These were all done without permission.

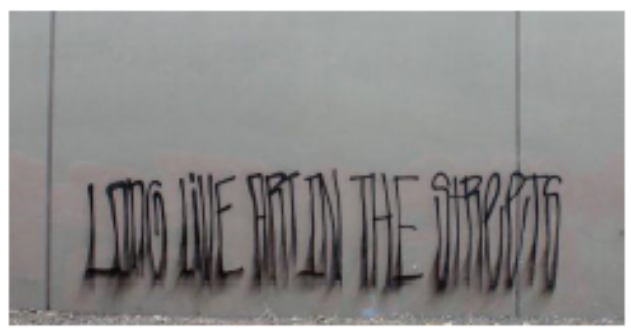

Q1_tag: Please rate your level of agreement with the statements below.

Note: These are in public spaces and were done without permission.

\begin{tabular}{|c|c|c|c|c|c|}
\hline & $\begin{array}{c}\text { (1) } \\
\text { Strongly } \\
\text { Disagree }\end{array}$ & (2) Disagree & $\begin{array}{l}\text { (3) Neither } \\
\text { Agree nor } \\
\text { Disagree }\end{array}$ & (4) Agree & $\begin{array}{l}\text { (5) Strongly } \\
\text { Agree }\end{array}$ \\
\hline $\begin{array}{l}\text { I understand } \\
\text { the intended } \\
\text { message (1) }\end{array}$ & 0 & 0 & 0 & 0 & 0 \\
\hline $\begin{array}{l}\text { It damaged } \\
\text { the surface (2) }\end{array}$ & 0 & 0 & 0 & 0 & 0 \\
\hline $\begin{array}{l}\text { The person } \\
\text { who did this } \\
\text { used their } \\
\text { imagination } \\
\text { (3) }\end{array}$ & 0 & 0 & 0 & 0 & 0 \\
\hline $\begin{array}{l}\text { It is offensive } \\
\text { (4) }\end{array}$ & 0 & 0 & 0 & 0 & 0 \\
\hline $\begin{array}{l}\text { It is gang } \\
\text { related (5) }\end{array}$ & 0 & 0 & 0 & 0 & 0 \\
\hline $\begin{array}{l}\text { It should be } \\
\text { considered a } \\
\text { crime (6) }\end{array}$ & 0 & 0 & 0 & 0 & 0 \\
\hline $\begin{array}{l}\text { It makes the } \\
\text { space more } \\
\text { interesting ( } 7 \text { ) }\end{array}$ & 0 & 0 & 0 & 0 & 0 \\
\hline $\begin{array}{l}\text { It makes the } \\
\text { space look } \\
\text { dirty (8) }\end{array}$ & 0 & 0 & 0 & 0 & 0 \\
\hline
\end{tabular}

Figure 75 Survey Item Example 
Next, respondents were asked if they thought the space shown in the picture was better before or after the street art/graffiti was placed there. They were then asked if they would be okay if something like what was shown was on: (1) their property, (2) in their neighborhood, (3) or in some other part of the city. Respondents were then asked if they had seen something like the piece in the past six months. These items were included to acquire a general sense of how context may explain respondent opinions.

Respondents were then presented a short series of questions asking what they thought should be done about each piece of street art or graffiti. If the respondent thought the piece should be removed, a follow-up question about what removal process they think should be used was asked; specifically, if they thought that the community should have a say in whether or not the piece is removed or left alone, and if public tax money should be spent to pay for its removal. These questions were asked because it is important to know what solutions or outcomes people actually prefer.

After completing the eight main sections, respondents were asked a final general question, not associated with any particular piece of street art or graffiti. Did they think it is generally an act of vandalism or artistic expression, and why? This question was meant to gather information about how respondents' viewed street art and graffiti. This question provided valuable details about respondents' feelings towards the legality and merits of street art and graffiti.

Finally, respondents were asked seven demographic questions. These were standard items that appear on most social research questionnaires. This data were used to compare group characteristics to opinions about street art and graffiti to see if socio- 
economic factors influenced attitudes. At the close of the survey, respondents were provided space to record any additional comments they might have had.

\section{Pilot Testing and Post-Pilot Methodology Changes}

Piloting is the best possible way to test survey questions and methodology. The questionnaire was administered in-person, door-to-door in the Sunnyside neighborhood in Portland in November 2011. The questionnaire design was basically the same as described in the previous section, but instead of showing eight separate pictures of street art and graffiti, pictures were grouped into categories based on form. This difference in survey design will be discussed in greater detail later.

The final sample for the pilot test consisted of 10 surveys, five completed with random households and five completed with acquaintances. ${ }^{53}$ The surveys took between 7 and 11 minutes to complete, slightly longer than anticipated. The response rate using this method was rather low because no one came to the door at many homes. A few “don't know" responses were received, presumably because people did not expect questions about a topic such as this.

A few survey design and methodological changes were implemented following the pilot. Respondents mentioned that they would have different feelings regarding street art depending upon the context (e.g., done on public or privately-owned space, done with or without permission). Since the focus of this research is uncommissioned street art, a statement was added explaining that, "these are in public spaces and were done without

\footnotetext{
${ }^{53}$ Although this was a selection bias, my aim in asking acquaintances to complete the survey was to get critical feedback regarding the questions. Since they knew me, they were not inhibited to tell me how they really felt. I was able to ask them questions about the survey instrument and how well they understood the questions. These respondents were able to provide useful feedback regarding question wording and understandability. Acquaintances surveyed all lived in Portland.
} 
permission." Next, some of the photos shown were substituted to ensure that all pieces were in public space, apparently executed without permission, and were typical examples of street art. ${ }^{54}$ To reduce confusion, it was decided that only one picture was shown at a time, instead of sets of pictures (grouped by form). All the pictures used were photos that I had taken in Portland, Oregon; Tampa, Florida; and Berlin, Germany.

The largest change implemented post-piloting was the survey modality. After testing the in-person method, I decided to instead use a web survey. Social desirability bias was a concern with in-person surveying. People seemed hesitant to speak to me about their opinions about graffiti and street art. If they were able to complete the survey privately, their answers may be more candid. Also, two pilot surveys were completed by acquaintances via email. These emailed surveys had the richest qualitative data in the open-ends. These respondents had time to express their thoughts and explain their answers.

Finally, implementing the survey via the Internet significantly reduces the dissemination time. It took three hours to obtain just five door-to-door surveys. With a web survey, flyers can be passed out far more quickly. Internet survey research has increased dramatically in the last 10 years (Pew, 2012). The increase in the number of Americans who have access to the Internet, and the relatively low cost of conducting Internet-based surveys have contributed to the proliferation of this modality (Pew, 2012). A web survey was the easiest method available to get the most responses with the least

\footnotetext{
${ }^{54}$ For some of the pieces, I had to use my best judgment about whether or not they were in fact in public space and done without permission.
} 
amount of time and cost. Another advantage of web surveys is avoiding the error prone task of data entry (Soloman, 2001).

Web Survey Methodology and Subject Recruitment

Once the survey design was finalized, the instrument was programmed into Qualtrics web survey program for implementation. Testing and revisions were completed to ensure appropriate wording, correct functioning of all skip patterns, and the accurate data recording. The eligible population for the survey included any Portland resident 18 years of age or older. This demographic was chosen for two reasons. First, graffiti and street art are a citywide issue and its presence and removal affect everyone to some degree. Secondly, I was interested in what Portlanders, in general, think about this topic and wanted to obtain a wide range of opinions from across the city.

Since it was impossible to survey the entire population of Portland with the resources I had at my disposal, ten survey areas were chosen in each of Portland's five quadrants: North (Humboldt and Boise neighborhoods), Southeast (Sunnyside, Buckman, Richmond, and Hosford-Abernethy neighborhoods), Northwest (Northwest and Pearl districts), Southwest (Goose Hollow neighborhood), and Northeast (Concordia and Kerns neighborhoods). These areas were selected mostly based on ease of accessibility ${ }^{55}$ and the general proportion of residential vs. commercial properties. Areas with mostly businesses and industrial zones were excluded.

${ }^{55}$ Since I do not have easy access to a motor vehicle, flyer distribution was carried out of foot, using a bicycle, and public transportation. 
Flyers containing a brief survey description, eligibility requirements, and the survey link were distributed directly to households. ${ }^{56}$ Flyers were printed in color on $4 \times 5$ sheets of paper, folded, and placed into plastic Ziploc bags. Holes were punched at the top of the bags and a rubber band was looped through they could be quickly and securely placed on doorknobs, mailboxes, or fences. This arrangement also protected the flyers from getting wet or blowing away. Loose flyers were available for situations where homes had latch handles or if a resident was outside (it could be handed to them directly).
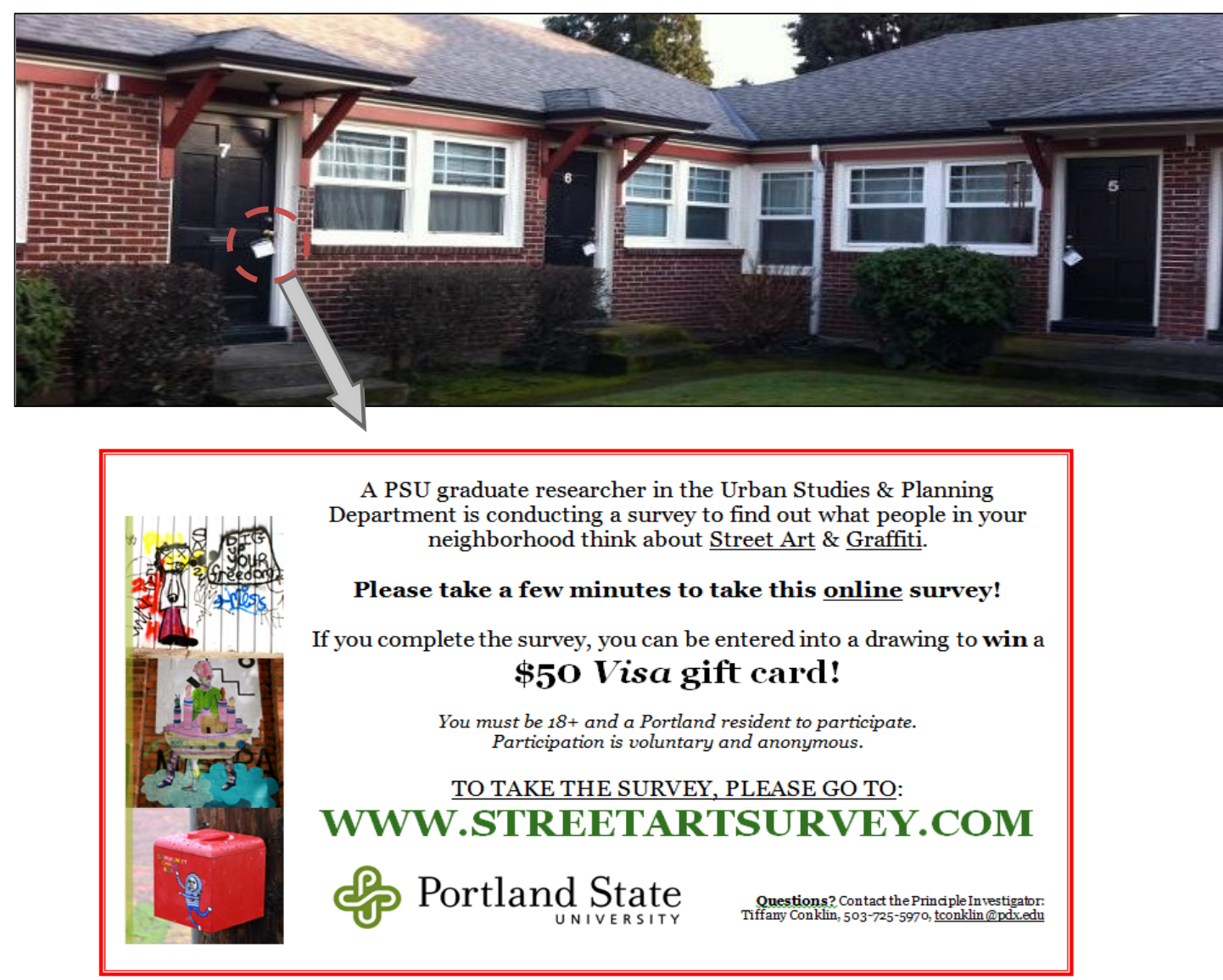

Figure 76 Distributed Flyers

\footnotetext{
${ }^{56}$ The URL www.streetartsurvey.com was used to redirect participants to an anonymous survey hosted on a Qualtrics account. The account was set up so that only one survey could be completed per IP address to minimize the possibility of people completing the survey more than once.
} 
Flyers were left at most homes, even those that had "no soliciting" signs since I was not selling anything or asking for money. Once in certain areas (e.g., downtown and the Pearl), it was realized that flyers could not be passed out at large multi-family complexes, and therefore I had to change the distribution method. Twenty one-page pull-tab flyers were created and posted on public utility boxes and poles near multifamily residences. When I returned to the locations to collect the flyers back (once the survey was completed), many of the pull tabs had been removed suggesting that this recruitment method worked to some extent. Since the survey screened out people who did not verify they were a City of Portland resident and over 18 years old, I felt this was an acceptable recruitment method.

An incentive was offered to those who completed the survey. Flyers informed potential respondents that if they completed the survey, they would have a chance to win a \$50 Visa gift card. Upon completion of the survey, respondents were notified that in order to be entered into the incentive drawing they had to provide a preferred email address or phone number. Those who did not want to be entered into the drawing were thanked for their time and the survey was ended. At the end of the project, respondentprovided contact information was extracted and separated from the survey data. The records were randomized and a winner was identified. Finally, this respondent was contacted to arrange for the gift card to be delivered. 
In total, 1,200 flyers distributed over 19 days (from January 21, 2012 to February 8, 2012). This process took approximately 20 hours to complete. Maps showing areas where flyers were distributed can be found in Appendix E. Since this was a more passive recruitment model, it was only possible to calculate a completion rate and not a response rate. The estimated completion rate for the survey was $7 \% .{ }^{57}$ Over 2.5 weeks, I was able to obtain a total of 161 completed surveys. Due to a data quality issue, caused by unforeseen circumstances, ${ }^{58} \mathrm{I}$ was only able to use 139 surveys for analysis.

\footnotetext{
${ }^{57}$ This completion rate was calculated by diving the number of flyers passed out $(1,200)$ by the total number of completed surveys received (161). Most likely the true completion rate is higher than $7 \%$ because not all flyers were actually seen or read by household members (i.e., immediately thrown away, blown away, not seen, or ignored).

${ }^{58}$ A passerby in the Pearl district noticed one of my pull-tab flyers taped to a public utility box outside of an apartment building. Presumably displeased with this distribution method, they sent a photo of the flyer to a Portland blogger, Jack Bogdanski, a law professor at Lewis \& Clark College. Bogdanski linked and quoted the wrong person as the researcher: (http://www.flickr.com/groups/northweststreetart/discuss/72157626867892090/). Bogdanski did not go to my survey website or fact-check before posting this information. The other 'researcher' who was cited, lives and works in the United Kingdom and did not have an objective approach to their research which angered many people who visited the blog. Some of these visitors went to my survey website and took the survey, thereby significantly biasing my data. It was quite obvious when looking at my data that people were taking my survey because of the blog posting. I split the file and compared the two sets of data (that day verses all other days) for significant differences. Unlike the rest of the survey data, surveys from that day were overtly negative and critical of both the survey method and the topic of street art and graffiti. The difficult decision was made to remove all surveys received that day $(n=22)$ because the quality of the data had been compromised.
} 


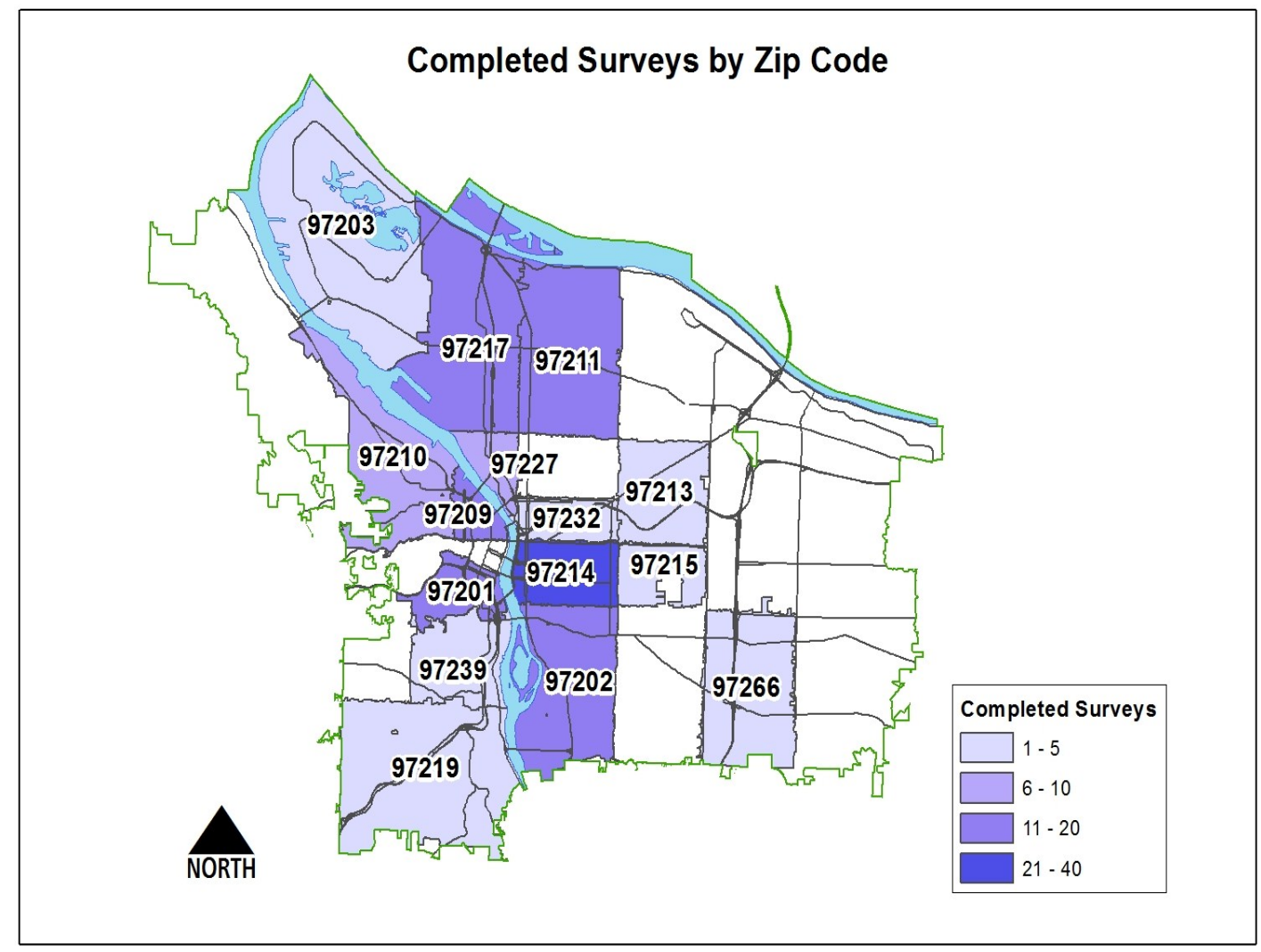

Figure 77 Completed Surveys by Zip Code 


\section{Survey Research Limitations}

The following section briefly describes the limitations of this research that I feel had the greatest impact on my findings. Survey questionnaires must remain relatively simple to be appropriate for different respondents. As discussed, I carefully worded the indicator statements to be as straightforward and neutral as possible. The quantitative nature of survey data can also hide the fact that these are opinions and personal experiences, and not just numbers. To balance this, the open-ended questions were included so that respondents could provide answers in their own words. Surveys are also somewhat inflexible because once implemented they should remain relatively unchanged. Thus, the survey was thoroughly tested before implementation to avoid having to make changes.

Securing an adequate sample size is important for researchers who wish to have a representative sample and generalizable results. In 2010, the City of Portland had a population of 472,253 adults 18 years of age or older (US Census 2010). Therefore, if I was able to do random sampling, a total sample size of at least 384 respondents would have been needed to be $95 \%$ confident that the overall results are those we would expect to find within Portland (Dillman, 2000). With the time and resources available, I was unable to collect a random representative sample of Portland residents. I was also not able to reach certain neighborhoods, especially in the far eastern parts of the city. Realizing that this would significantly limit my ability to make generalizations from the survey results, I hoped to minimize this bias by dispersing the survey flyers to various 
neighborhoods in all five quadrants of the city. Additionally, flyers were passed out to every approachable household along the designated survey routes.

Non-response and self-selection bias are more of a concern with the web modality. This research focuses on a controversial topic which people tend to have strong feelings towards. It is expected that people in the middle, who do not care about street art one way or the other, may be slightly underrepresented. I provided the incentive to minimize these biases.

Another web survey limitation is coverage bias, because it may exclude people who do not have access to the Internet or do not have sufficient computer skills. Nevertheless, coverage bias is also a concern with other survey methods. For instance, contacting people via landline phones also excludes certain demographics (especially young adults, those living with roommates, and low-income populations) because many people now only have cell phones and do not have landlines (Blumberg \& Luke, 2010). ${ }^{59}$ Likewise, in-person surveys exclude anyone who is not present at the exact time and location surveying is taking place. Since survey announcements were delivered directly to households in multiple neighborhoods in each of Portland's five quadrants, (rather than promoting the survey via the web or email) it is hoped that any bias present is evenly distributed throughout the population surveyed. Also, since demographic questions were asked in the survey, during analysis I will be able to determine how representative my sample is compared to the City of Portland.

${ }^{59}$ The representativeness of phone surveys has come under increased scrutiny in recent years (Pew, 2012). 


\section{Chapter 5. Findings and Discussion}

\section{Participant Observations}

Participant observations were carried out to uncover how people react to and interact with street art encountered in the city. I created three types of street art interventions (eight yarn installations, tape hopscotch and connect-the-dots, and a community chalk box) and placed these pieces into public spaces around Portland, Oregon. I directly interacted with several passersby while installing these pieces, but no one was confrontational or had any visible negative reactions to my actions. Although some forms of street art were more successful at promoting interactions than others, results clearly demonstrate that street art designed to promote engagement among people, art, and public space can be successful. Both adult and children paused, and for a brief moment, interacted with the spaces around them in new and unscripted ways.

All but two of the installations created remained longer than most other forms of street art and graffiti in the surrounding area. Tags and stickers were removed monthly or bi-monthly while my yarn and chalk box installations were left. Centrally-located pieces in downtown Portland or on Belmont Avenue (a main thoroughfare with shops and increased auto/foot traffic) were removed more promptly than those located in residential areas. The following three sections describe the findings from these observations. 


\section{Yarn Installations}

I created a total of eight yarn installations for this research (Appendix B). All but one of the installations remained in place as of March $2012 .{ }^{60}$ The Sunnyside Graffiti Abatement crew swept through the area on several occasions during the observation period, but did not remove the yarn. Some yarn installations were more successful at promoting interaction than others. People tended to notice the larger and more centrallylocated pieces rather than the smaller ones in more discrete places. Most interactions were brief. Many people would just touch the yarn as they passed. In some instances, I heard people discuss the piece. For example, a young girl said to someone else in her group, “Look it's a cozy! It makes it look prettier." In another observed instance, a young boy, perhaps 3 or 4 years old was touching the large yarn piece and asked his grandmother, "What is it?" She replied, "I don't know, I've never seen anything like it." They stood there for a few minutes as the child played and pulled at the knitted piece. These positive reactions could indicate that this form of street art is perceived of differently than others. Yarn installations are softer and less threatening than other forms.

During observations, several additions to my yarn installations were made such as the introduction of flowers, small umbrellas, and pamphlet ads for music shows. Like Isis Brook's findings (2007), this research found that unauthorized artistic interventions can promote interplay and elaboration between anonymous citizens. Out of all counterinterventions, the most interesting was another piece of street art added directly below

\footnotetext{
${ }^{60}$ The "Keep on the Sunnyside" tree wrap installation on Belmont Avenue (between SE $33^{\text {rd }}$ and $32^{\text {nd }}$ ) was removed after being in place for almost a year. A crew working in the nearby power sub-station removed the piece when re-planting the surrounding landscaping.
} 
mine. This was a wooden plaque screwed into the telephone pole. It was a trompe-l'oeil optical illusion created by transposing one landscape onto another. The artist photographed the telephone pole from a distance, created a plaque of that picture, and then nailed the plaque to the photographed pole. Interestingly, there was a small black heart drawn on the yarn installation pictured on the plaque. The installation lasted only a few days and was then removed.

The same day the plaque appeared at the Sunnyside Piazza corner, another one was installed one block away on a pole at $33 \mathrm{rd}$ and Belmont. This photo employed the same trompe-l'œil technique. This plaque was also gone after just a few days. Over the following weeks, other similar installations were discovered around the city. In January 2012, I connected with the anonymous artist on Flickr. He turned out to be the wellknown Portland sticker artist, Kanye. Kanye is one of Portland's most prolific "slaptaggers," placing his humorous stickers of celebrity Kayne West "all-city." It was surprising to discover that the same artist was responsible for creating these two very different forms of street art. This illustrates that street artists are flexible and do not restrain themselves to particular forms of street art. They often employ multiple tactics to express themselves in the city. 


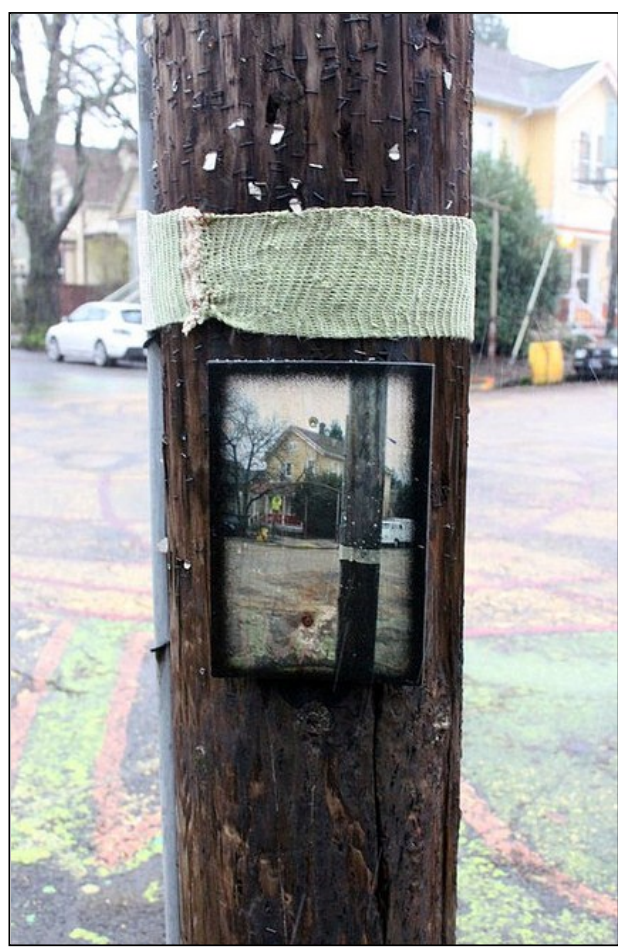

Figure 78 Counter-Intervention Plaque, Sunnyside Piazza 2001

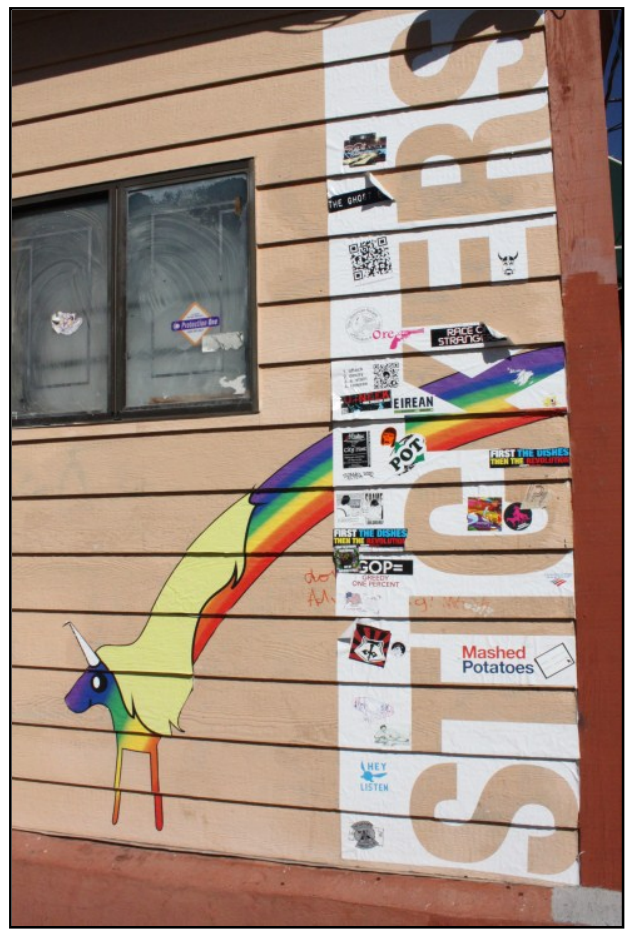

Figure 80 No Limits Stickers Printing Services, NE Alberta Portland, Oregon

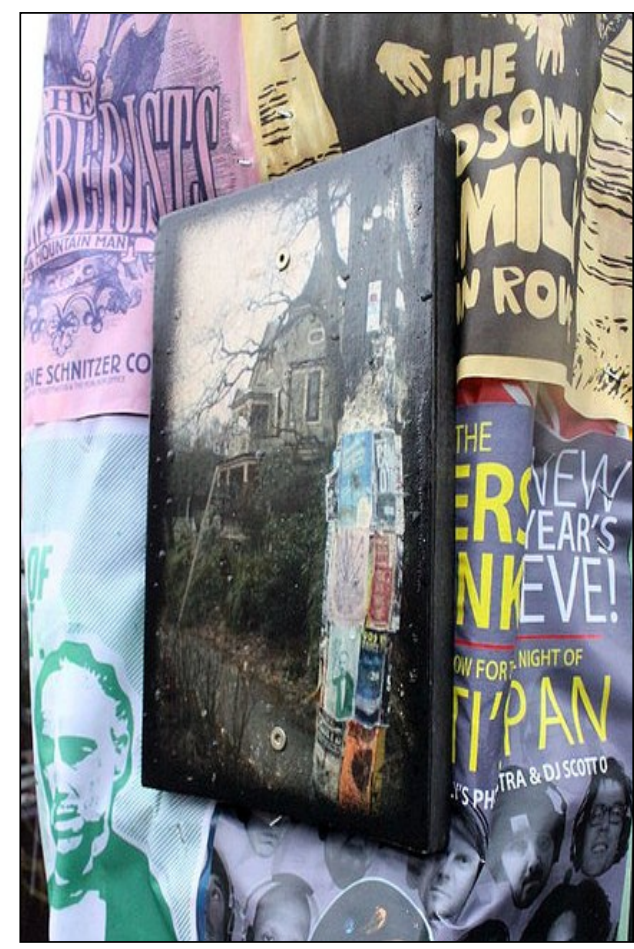

Figure 79 Plaque, Belmont and 33rd 2011

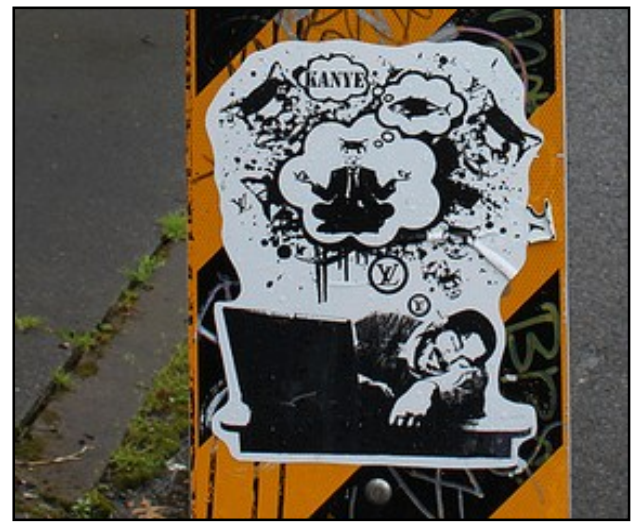

Figure 81 Kanye Sticker, Portland Oregon 2012 


\section{Tape Installations}

While installing the tape hopscotch at the PSU Urban Plaza, two interactions with passersby occurred. A man on a bicycle approached and paused for a few moments. He asked, "What happened to chalk?" I replied, “This is a new waterproof way!" He laughed and rode away. About thirty seconds later, a person wearing a full cow suit (presumably the Ben \& Jerry's mascot), "moo-ed" at me twice. I looked up and the cow waved, turned around and walked away. After laying the tape, I left the scene. I then positioned myself on the second floor of the nearby Urban Building that overlooks the plaza. The intervention was observed for approximately three hours until it was dark and the flow of people dramatically decreased. Extensive notes, photographs, and video were taken during these observations (Appendix B).

The first thing noticed was a Tri-Met security officer approaching the plaza. Initially, I thought he was going to remove the hopscotch or call it in, but he was just being asked to take someone's picture. He glanced in the direction of the hopscotch, but did nothing. In total, out of the hundred or so people that passed through the plaza during observations, 14 people, including adults and children played on the hopscotch. Many hopscotch participants were walking towards the hopscotch in a direction that would allow them to fluidly hop along but still be on their initial trajectory. Most people did not go out of their way to hop. Adults usually played on the hopscotch if they were accompanied by at least one other person. Only three lone adults interacted with hopscotch, including a man who walked over it and then at the very end, before walking completely off it, he hopped the final two squares into the heart. The most interesting 
interaction was a group of five people who each took turns hopping, all standing around watching each other.

Unusual objects in public space, like this hopscotch, produce mixed public reactions. Some passersby appeared to notice the installation (looking at it as they passed), others did not appear to notice at all, and others fully interacted with it. People also tended to look around before hopping on the piece, perhaps to see if other people were looking. These observations suggest that not everyone feels comfortable, wants to, or cares about, breaking from conformity in public spaces. Overall, the hopscotch experiment was very successful at promoting interaction with street art and the surrounding environment.

The next tape installation completed was the connect-the-dots resistance fist. Unfortunately, this piece did not promote interaction as hypothesized. Only one instance was recorded, and this appeared to be a haphazard child-like drawing that did not connect the dots. A few factors could explain this. First, the picture may not have been straightforward enough for people to understand what to do with it. If this installation was recreated, a brief instruction of "connect-the-dots" may help passersby realize the intent. Also, rain could have washed the chalk drawings away before they were documented. Finally, since the piece was done in the fall, leaves eventually covered the image, further decreasing the likelihood and ability for interaction.

\section{Community Chalk Box}

The final street art created was a community chalk box placed at Sunnyside Piazza (Appendix B). Again, the weather played a role in my ability to document interactions. 
In the rain, people did not use the chalk, and if they did the drawings washed away. The chalk art was continuously refreshed in a natural buffing process.

Nevertheless, when it was not raining, this intervention successfully enticed many passersby to use the chalk and write on the pavement. Fifteen separate interactions were recorded over several weeks of daily observations. The drawings consisted of hearts, messages, names, and shapes. All the messages were positive and light-hearted. Some messages provoked others to write messages in response, resulting in an unmediated sharing of thoughts among strangers. Children especially enjoyed the piece. I saw a father lift up his daughter so she could reach into the box and select chalk to use. In general, the chalk box appeared to be well-received by residents and visitors. Someone even left two packs of new sidewalk chalk in the box when it was empty. This donation shows that some people are not only willing to participate in the intervention themselves, but also want to see other people continue to participate.

Overall, most of these street art interventions facilitated people interacting with their environment in a variety of new ways. Some of the interventions even spurred spontaneous social interactions among strangers. Although it would have to be tested on a larger scale, I believe installations like these would have a similar effect in comparable neighborhoods. These street art pieces were a non-permanent and non-threatening way of getting people to interact with the people and places around them. This interaction is important because the limited number of fully-open public spaces available in cities today. Much of the city is designed in a way, or has laws applied to it, that stifle spontaneous socializing and adversely affect interpersonal networks (Semenza \& March, 
2009). Limited opportunities for people to interact can deteriorate mutual understanding, trust and reciprocity, which have been described as a decline in social capital (Bourdieu, 1986; Putman, 1995). I believe that the evidence gathered by these observations show that street art installations can be used as an alternative tool to promote communitybuilding. Street art can be used to inspire and empower communities to creatively transform the spaces around them (Semenza \& March, 2009).

\section{Web Survey}

\section{Analysis Preparation}

To begin analysis, it was first necessary to prepare the data. The web survey data was exported from Qualtrics into SPSS statistical software. Twenty records were removed because the surveys were not fully completed. As mentioned in Chapter 4, an issue occurred during surveying that compromised the quality and randomness of the data received on February $6^{\text {th }}, 2012$, starting at 10:43am. This situation required that an additional 22 records be removed from the file and not used in analysis. The final sample size was 139 .

To prepare the continuous, Likert scale ratings for analysis, the ratings were first recoded so that all the scores were going in the same direction, from negative to positive. For instance, a rating of 1 on "Understanding the message" is negative (least understandable), and a rating of 5 is positive (most understandable). However, on the item "It is offensive," that logic is reversed, so a rating of 1 is positive (least offensive) and a rating of 5 is negative (most offensive), therefore, these scores were recoded to go in the opposite direction, from negative to positive. 
Once the recoding was completed, individual sum scores were calculated by adding up the ratings for each picture for each respondent. These individual sum scores ranged from 8 , representing negative attitudes, to 40 , representing positive attitudes. If a respondent did not provide a rating on all 8 statements for any particular photo, that response set was excluded from analysis since a comparable sum score could not be obtained. ${ }^{61}$ The average of these individual sum scores was then calculated in order to create eight mean scores, one for each picture in the survey. These mean scores will be referred to as "composite scores" (Table 3).

\begin{tabular}{lrr}
\multicolumn{1}{c}{ Composite Score Means } & & \\
\hline Yarn Installation & $\mathrm{N}$ & Mean \\
Chalk Box Installation & 135 & 33.46 \\
Garden Installation & 136 & 32.93 \\
GATS Piece & 138 & 30.56 \\
Murg Piece & 139 & 28.39 \\
Long Live Tag & 136 & 28.20 \\
Stickers & 137 & 25.01 \\
Fever Tag & 136 & 18.95 \\
\hline
\end{tabular}

Table 3 Composite Score Means

Descriptive statistics and frequency distributions were then run to highlight trends in the data. Paired $t$-tests were conducted to determine if the differences between selected variables were significant (Appendix I). Several bar charts were created to visually highlight some of the findings (Appendix F).

Two open-ended survey items allowed respondents space to provide answers in their own words: In general, do you view street art/graffiti as an act of vandalism or artistic

${ }^{61}$ A non-rating (i.e., the respondent skipped a rating) was essentially a zero, which if included, would have artificially lowered their composite score for that picture. 
expression; Do you have any additional comments about this survey. A qualitative coding system was created to categorize the topics discussed in the open-ends. Each response was read and the data was coded into descriptive categories, such as aesthetics, community-building, removal, gangs, etc. (Appendix F). The following section presents the qualitative and quantitative data gathered from 139 Portland residents who completed the survey. Table 4 presents the mean ratings for all of the street art and graffiti pictures shown in the survey. I will discuss these findings in detail.

Survey Photo Mean Ratings

\begin{tabular}{lcccccccc}
\hline & Fever & Long Live & Sticker & Murg & Gats & Chalk Box & Yarn & Garden \\
\hline Understand the & 1.78 & $\mathbf{4 . 3 8}$ & 2.85 & 2.49 & 2.88 & 3.73 & 3.70 & 3.46 \\
message & & & & & & & & \\
It damaged the surface & $\mathbf{3 . 7 0}$ & 3.38 & 3.20 & 2.78 & 2.45 & 2.12 & 1.62 & 2.00 \\
Used their imagination & 2.27 & 3.22 & 2.37 & $\mathbf{4 . 3 9}$ & 4.46 & 4.22 & 4.20 & 3.94 \\
It is offensive & $\mathbf{3 . 1 4}$ & 2.17 & 2.62 & 2.26 & 1.92 & 1.66 & 1.59 & 1.86 \\
It is gang related & $\mathbf{3 . 0 8}$ & 1.53 & 1.89 & 2.40 & 1.88 & 1.51 & 1.53 & 1.49 \\
Considered a crime & $\mathbf{3 . 5 0}$ & 2.80 & 2.64 & 2.89 & 2.53 & 2.04 & 1.87 & 1.97 \\
Space more interesting & 2.24 & 3.32 & 3.28 & 4.05 & 4.11 & $\mathbf{4 . 1 5}$ & 4.04 & 3.80 \\
Makes space look dirty & $\mathbf{3 . 8 4}$ & 2.86 & 3.15 & 2.22 & 2.17 & 1.83 & 1.90 & 2.55 \\
\hline \multicolumn{7}{c}{ Table 4 Survey Photo Mean Ratings }
\end{tabular}


Tags

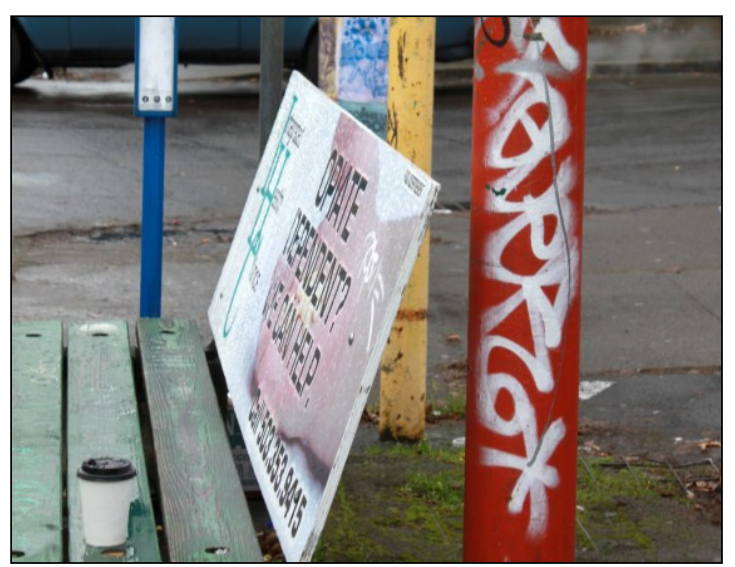

Figure 82 Survey Fever Tag

Mean Ratings for Fever Tag

\begin{tabular}{lll}
\hline & $\mathrm{N}$ & Mean \\
\hline It makes the space look dirty & 138 & 3.84 \\
It damaged the surface & 139 & 3.70 \\
It should be considered a crime & 139 & 3.50 \\
It is offensive & 139 & 3.14 \\
It is gang related & 139 & 3.08 \\
The person who did this used their imagination & 139 & 2.27 \\
It makes the space more interesting & 138 & 2.24 \\
I understand the intended message & 138 & 1.78 \\
\hline
\end{tabular}

Table 5 Mean Ratings for Fever Tag

Overall, respondents felt most negatively towards the "Fever" spray-painted tag on the bus stop pole. The composite score for this photo was 18.95. The Fever tag's composite score was the lowest; in fact it was almost six points lower than stickers, the next lowest score. This piece represents a common type of tagging: fast spray-painted pseudonyms that are difficult to read for those unfamiliar with graffiti typography styles. The tagged pole was rated as being the least understandable out of all pictures shown. This data supports the idea presented the literature (Gottlieb, 2008; Dickens, 2008, 
2012): people tend to dislike graffiti if they do not understand it. The Fever tag was also rated as being the most damaging, the most offensive, the most likely to be gang-related, and the form making the space look the dirtiest. Approximately half of respondents (56\%) thought that this form of graffiti should be considered a crime, more so than any other piece shown in the survey.

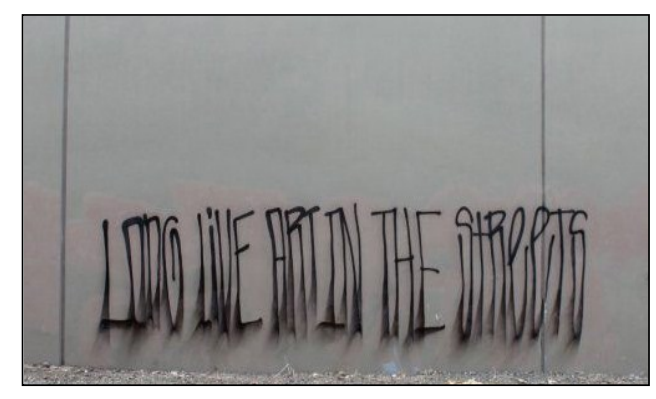

Figure 83 Survey Long Live Art in the Streets

Mean Ratings for Long Live Tag

\begin{tabular}{lrr}
\hline & $\mathrm{N}$ & Mean \\
\hline I understand the intended message & 139 & 4.38 \\
It damaged the surface & 139 & 3.38 \\
It makes the space more interesting & 138 & 3.32 \\
The person who did this used their imagination & 139 & 3.22 \\
It makes the space look dirty & 138 & 2.86 \\
It should be considered a crime & 137 & 2.80 \\
It is offensive & 139 & 2.17 \\
It is gang related & 139 & 1.53 \\
\hline \multicolumn{2}{c}{ Table 6 Mean Ratings for Long Live Tag } \\
\end{tabular}

Table 6 Mean Ratings for Long Live Tag

The next photo shown in the tag category was the "Long Live Art in the Streets" piece. This photo was chosen because unlike the Fever tag, this piece was more readable and had a comprehendible message. The data indicates that respondents felt more positively towards this tag than the Fever tag. The mean composite score was 28.20, nearly ten points higher than the Fever tag. As predicted, the largest rating difference 
between the two types of tags was on their level of understandability. An overwhelming $92 \%$ of respondents agreed that they understood the message of the Long Live tag and only $9 \%$ said they understood the Fever tag. In fact, the Long Live tag was rated the highest on understandability out of all the pieces shown in the survey. Only $34 \%$ of respondents thought the Long Live tag should be considered a crime, versus the 56\% who thought the Fever tag should be considered a crime. Most respondents (86\%) also did not think that the Long Live tag was gang-related. ${ }^{62}$ With the Fever tag, $29 \%$ of respondents thought that the tag was gang-related and $48 \%$ were unsure. When analyzing the open-ended comments it was clear that the question of gang affiliation was a main consideration for some respondents when considering how they felt about tags when compared to other forms of graffiti:

I'm all for graffiti as long as it isn't gang tags.

I view a lot of street art as artistic expression, unless it is just words or gang names quickly written on a wall.

It seems to me that factors such as how good it looks and whether it is truly gangrelated should play into deciding if the street art is actually harmful.

Other respondents spoke about the process of trying to distinguish between gang and non-gang tagging:

The average layman cannot often distinguish the difference between gang messages and graffiti.

I can appreciate graffiti, but not when its gang related or when the individual who's not an artist tagged over other artists beautiful thoughtful work with a mindless name type of tag, etc. or a tag against or for a specific gang... It seems to me it's pretty apparent whether its gang related or artistic expression. I'm pretty sure I can tell the difference.

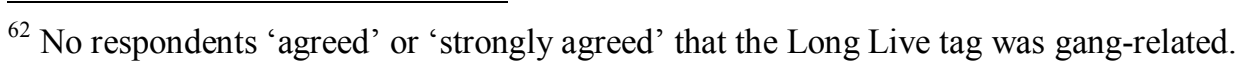


I would have appreciated more info on what constitutes gang tagging and graffiti. I may not have been offended by something in an image because I was unaware that it meant something to a gang or gangs. Tagging is pretty obvious, and is usually related to gang activity, but not always.

Another difference between the Fever and Long Live tags was that $57 \%$ of respondents thought that the Long Live tag made the surrounding space look more interesting and only $22 \%$ of respondents thought the Fever tag made the space look more interesting. Additionally, $84 \%$ of respondents thought the pole looked better before the Fever tag was placed on it, and $52 \%$ thought the grey wall where Long Live tag was painted looked better before. This difference in ratings is interesting because both of these spaces were initially blank (solid color). Respondents' opinions regarding the quality of the space were not only tied to the context and physical properties of the space itself, but were also linked to the feelings they had towards the piece.

When asked how they would feel about these tags being placed in different spaces throughout the city, an overwhelming majority of respondents did not want anything like the Fever tag on their property (96\%), in their neighborhood (77\%), or in some other part of the city (74\%). Similarly, most respondents (86\%) did not want something like the Long Live tag on their property. Respondents were less against the Long Live tag being in other places: $55 \%$ reported that they would be okay with it in their neighborhood and 59\% would be okay with it being in some other part of the city. When analyzing the open-ends, it is clear that context plays a central role in how respondents formed their opinions about street art and graffiti pieces:

To me, context is everything when it comes to street art or graffiti. 
It totally depends to me where it is to determine how I feel about it.

In my opinion, I think it depends on the context of the graffiti in most cases.

\begin{tabular}{|c|c|c|}
\hline & No & Yes \\
\hline Fever Tag & 43 & 61 \\
\hline Stickers & 37 & 18 \\
\hline Long Live Tag & 30 & 41 \\
\hline Murg Piece & 27 & 13 \\
\hline GATS Piece & 26 & 12 \\
\hline Garden Installation & 20 & 21 \\
\hline Chalk Box Installation & 16 & 7 \\
\hline Yarn Installation & 16 & 13 \\
\hline Total & 215 & 186 \\
\hline
\end{tabular}

Considering all these factors, most respondents agreed that both the Fever (77\%) and the Long Live tags (52\%) should be removed. Over half of respondents thought community approval should be received before removal (Long Live 58\%, Fever 59\%). This is surprising because many of other pieces that were rated more positively overall, did not have this many people saying that community approval should be sought. I would have thought that installations would have received the greatest number of people saying community approval is needed, but this was not the case. My only explanation for this is that people who wanted multiple pieces removed may have caught on that this would be asked for each piece and decided to sway their opinion in the other direction to 
reflect a harsher stance on graffiti. If this study is repeated, I would reduce the possibility of rotation group bias by programming the images to appear randomly.

Many respondents expressed strong feelings towards tagging, singling out this type of graffiti, describing it as "mindless, pointless, selfish, and generic." Comments suggested that respondents enjoyed other forms of street art and graffiti, but they did not care for tagging. When pointing out this distinction, some respondents focused on the graffitists' motives and intentions (or lack thereof):

I love street art, but not a huge fan of mindless tagging.

I wish I saw more artistic graffiti and less pointless tagging in my neighborhood.

I view much of street art as a creative expression, but a tag as vandalism, solely for the purposes of making a personal mark on a piece of property.

If it, or the tagger, has something to say other than, "Look, I tagged this," then I can look at it and approach the social question(s) it asks.

Other respondents focused on the lack of artistic merit in tagging when compared to other forms of graffiti:

(It is) artistic expression when it is something more than just a tight stylized scribble of a name or a slogan with lousy calligraphy.

If it is ugly, and in the wrong spaces, then I consider it vandalism. Most tags fit in this category.

Most graffiti tagging lacks artistry and relevance. It is selfish and serves no higher social function.

I hate generic tagging, but something colorful and unique, that is only put on walls or telephone poles (not windows or store signs), adds to the neighborhood in my opinion. 
Most I see falls into the tagging category. Like a dog marking his territory. No regard for the community... When there is some art there I can appreciate it, but I think it's more the exception than the rule.

Some letters quickly sprayed up messily (like the piece going down the pole next to a bus stop) just seems like a selfish territory-marking destructive act whereas some pieces are gorgeous.

Factors of understandability, gang-relation, and criminality influenced respondents' overall attitudes towards tags. The perceived lack of forethought, intent, artistic merit, and consideration for the community and surrounding space contributed to respondents' negative attitudes towards this form of graffiti. Some respondent comments included references to various factors cited in the broken windows theory, including how visual disorder makes the space look dirty, neglected, and uncared for, creating an atmosphere of lawlessness that attracts criminal offenders like gangs. Some comments compared graffiti to trash or dirt:

Garbage on my city's walls looks no different than garbage on my city's streets.

I can see this kind of thing becoming neglected trash.

In most cases graffiti also is unpleasant to eye and really gives off a sense of "scuzzy-ness" to the property.

A few respondents also focused on how graffiti could impact property values:

No consent, adversely affects property value, and most importantly most of it sucks; nothing artistic about it at all.

Most often it is indecipherable, unsightly and can negatively impact the image or property value of surrounding areas.

Other respondents focused on how the presence of graffiti promotes a sense fear about other crimes occurring, including gang activity: 
Graffiti is an expense to home owners, and makes people worried about more serious crime.

Graffiti places citizens in fear of gang activity and degrades the livability of the neighborhood.

I have often seen urban blight begin with graffiti, but have never seen graffiti to be the only manifestation. I see it as a harbinger of broken windows, used syringes, public defecation and urination, firearms discharges, and street crime in general. 


\section{Stickers}

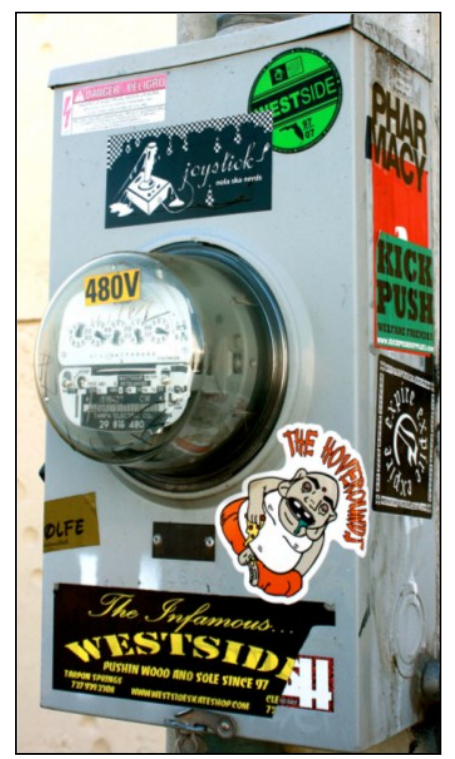

Figure 84 Survey Stickers, Tampa Florida

\section{Mean Ratings for Stickers}

\begin{tabular}{lcc}
\hline & $\mathrm{N}$ & Mean \\
\hline It makes the space more interesting & 137 & 3.28 \\
It damaged the surface & 137 & 3.20 \\
It makes the space look dirty & 137 & 3.15 \\
I understand the intended message & 137 & 2.85 \\
It should be considered a crime & 137 & 2.64 \\
It is offensive & 137 & 2.62 \\
The person who did this used their imagination & 137 & 2.37 \\
It is gang related & 137 & 1.89 \\
\hline
\end{tabular}

Table 8 Mean Ratings for Stickers

The next form of graffiti shown in the survey was stickers. In recent years stickers have become a popular medium for urban artists, especially in Portland. Sticker $\operatorname{art}^{63}$ is a form of graffiti in which an image or message is publicly displayed using stickers.

Sticker artists even have their own specialized language, using words like: cutty spot

${ }^{63}$ Also known as sticker bombing, sticker slapping, slap tagging, and sticker tagging. 
(placing a sticker in a clever inconspicuous spot to create a surprise or discovery),

comboing (creating a collage of stickers), and clipping (stickering over part of a

previous sticker). Stickers can be printed, hand drawn, stenciled, or screen-printed. A

Pacific Northwest College of Art reporter said the following about the sticker art scene:

This genre of street art is marked by sophisticated design with overt (or hidden) messages and concepts behind the work. The illustrations are beautiful and unique and the messages simple. The type on most stickers is rough, hand set, and appropriate to the genre. It recollects the early years of Punk when posters were made by hand from words and letters cut from magazines and then photocopied, the goal being to reproduce the work at the lowest possible cost. It takes skill for these artists to design and produce stickers that will not fade or peel away in rain. Typically, the stickers are screen printed with heavy industrial inks or lead-based paint. It is a painstaking process that takes the knowledge and the acumen of an artist to look great. They are resourceful, preferring to use what they can find available for free. United States Postal Service mailing labels are one of the most common sticker materials (McCracken, 2011).

Stickers had the second lowest mean composite score (25.01) indicating that many respondents felt quite negatively towards this form. Surprisingly, over half of respondents (58\%) did not think sticker artists used their imaginations when creating the pieces. One respondent said, "Simply putting a scribble up or a sticker up to mark that you have been there is unimaginative, degrading to the space, and juvenile.” The idea that all sticker artists fail use their imaginations is incorrect. Respondents may be focusing on the act of placing the sticker on the surface, and not fully considering the work involved behind-the-scenes in creating the sticker. Many sticker artists design and draw the imagines that appear on their stickers. Some use targeted social commentary; others stickers have no meaning and are just for fun. Some sticker artists hand-carve stamps to imprint images onto stickers. A prolific Portland sticker street artist distinguished their work from taggers saying: 
I try to keep a serious variety in my stickers and I don't like to have words or a name on them for anonymity and also because I am trying to spread art to people, not play some graffiti game like 'I was here' kind of thing. I just want there to be art everywhere and make people smile (Private email, February 2012).

Even though respondents had negative feelings towards stickers, many also thought that the presence of stickers made the space look more interesting (56\%). The majority of respondents (77\%) did not agree that the stickers were gang-related. This is interesting because some of the most prolific sticker artists in Portland (e.g., Skam, $\mathrm{R}_{\mathrm{x}}$ Skulls, Kanye, Dr. Rasterbator, and The Lost Cause, etc.) have recently formed a 'crew' called Visual Assault (VA) ${ }^{64}$ Technically, this group of Portland sticker artists would be considered a gang according to police even though their main activity is spreading graffiti, not violence or drugs. If a group of 3 or more people are arrested for graffiti (of any type), they are considered a "gang." They are not only subject to fines for vandalism and damages caused, but also subject to "gang enhancements" and felony charges. Some defendants could face up to 12 to 30 years in prison (Rusk 2011). In Portland, if a lone person is caught "sticker bombing" the penalties are surprisingly high, running \$250 and thirty days in jail per incidence (McCraken, 2011). Nevertheless, actually charging a sticker artist for all instances of their stickers appearing in public spaces would be rather difficult because many artists sell and trade stickers through online trading networks, and then other people put them up (DiStefano, 2012).

Even though they did not think it was gang-related, many respondents thought that stickers made the space look dirty (47\%) and worse than before (58\%). Over half of

\footnotetext{
${ }^{64}$ The VA crew was highlighted in the March 15, 2012 edition of the Portland Tribune. The article discussed the popularity of this form of street art in Portland (DiStefano, 2012). The VA crew members are also curating art shows in Portland which showcase stickers and various other art projects.
} 
respondents did not think placing stickers on public property should be illegal and a little over half of respondents did not think stickers should be removed (59\%). Of the $41 \%$ of people who thought stickers should be removed, over half (57\%) did not think community approval was needed before removal and did not want public tax money being used to pay for its removal (54\%). ${ }^{65}$

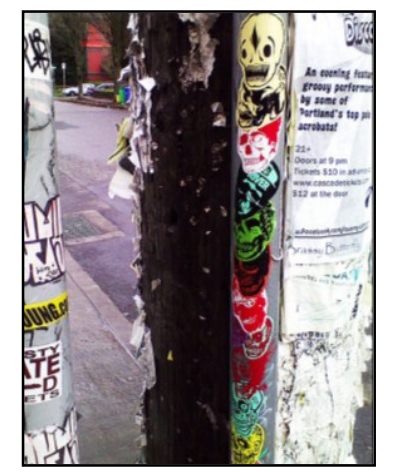

Figure 85 Stickers Portland 2012

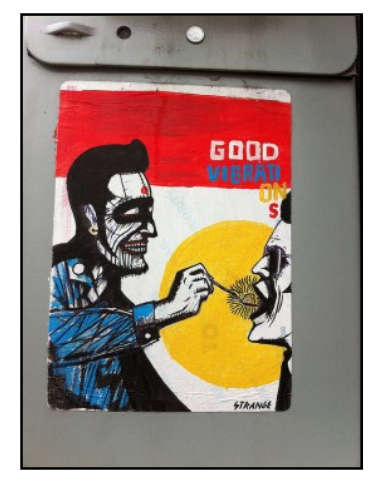

Figure 86 Hand Drawn Sticker Portland 2012

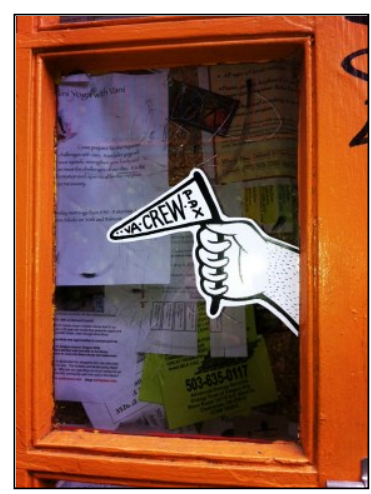

Figure 87 Visual Assault Crew Portland 2012

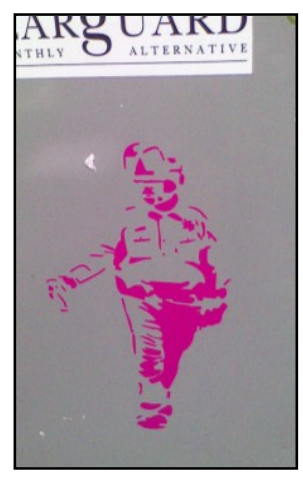

Figure 88 Sticker Art at Portland State University 2012

Marcia Dennis says that stickers are a "property crime that contributes to the negative impact on livability" (DeStefano, 2012). Based on my observations, it appears that volunteer graffiti removal squads focus much of their attention on removing stickers from public and private property. My informal observations of stickers in Portland confirm Chris Gorsek's findings (2004) that removed stickers are quickly replaced. Interestingly, it seems that once an area with a high concentration of stickers is cleaned,

${ }^{65}$ The Office of Neighborhood Involvement (ONI) serves as a communication link between residents, neighborhoods, and City of Portland bureaus. ONI is the leading organization in Portland dealing with graffiti abatement. ONI's Graffiti Abatement Program has recently increased its focus on volunteer recruitment and development. ONI allocated funds starting in 2010 to provide community grants that could provide 'community building' opportunities as well as addressing graffiti abatement and prevention. Funding provided includes $\$ 42,000$ in 2010 and $\$ 40,000$ in 2011 (ONI, 2012). 
new ones reappear much more quickly at that location rather than in other areas, which suggests that there is a targeted effort to replace the lost art. It is not clear why removal teams focus so heavily on stickers rather than other types of graffiti. This data supports other researchers' findings documenting that removal crews subjectively pick and choose which forms of graffiti to remove (Schacter, 2008; Miglavs, 1987). Although this topic is beyond the scope of this research, I suspect that Portland graffiti removal teams focus on stickers because of: (1) the negative perceptions towards stickers (as supported by my data), (2) the sheer number of stickers in the city (due to ease of application or portability), and (3) the relative ease of removal. 
Pieces

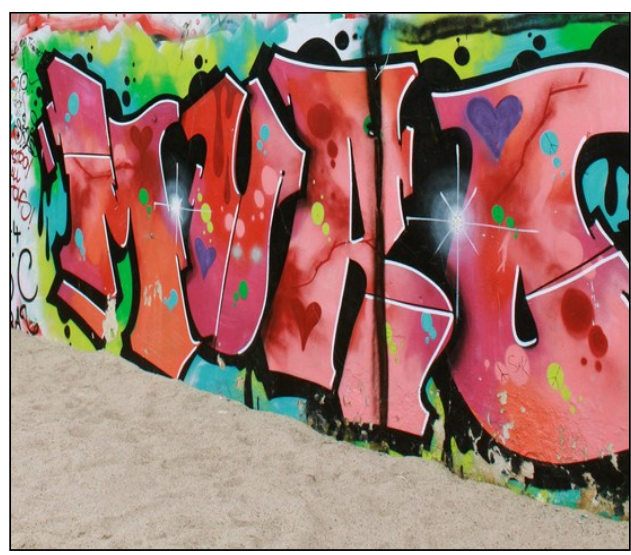

Figure 89 Survey MURG Piece, Berlin Germany

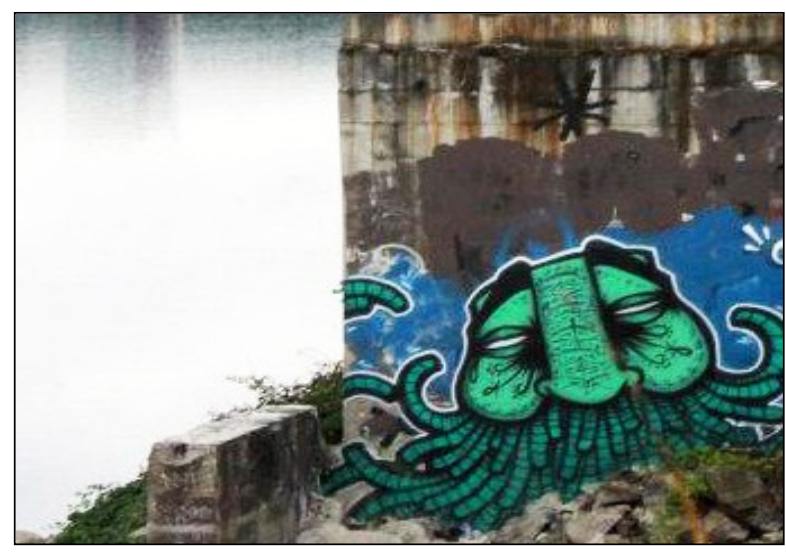

Figure 90 Survey GATS Piece, Portland Oregon

The next street art form presented in the survey was spray-painted pieces. ${ }^{66}$ The first piece was an example of traditional wildstyle that said "Murg." The second piece was a "GATS" (Graffiti against the System) character. This juxtaposition was set up in order to uncover if respondents felt differently towards two equally complex pieces that required refined skills and effort to execute. However, these pieces would generally be classified differently. The Murg piece aligns more with graffiti style and the GATS piece aligns more with street art style. Additionally, the Murg piece promotes a name and the GATS piece promotes an image. I wanted to know if the use of iconography in the GATS piece would impact how it was rated on understandability and other factors.

As predicted, the GATS piece was rated slightly more favorably than the Murg piece on all indicators. The mean composite score was 28.39 for the Murg piece and 30.52 for the GATS piece. The individual mean ratings for the pieces were fairly similar on

\footnotetext{
${ }^{66}$ In this context, "piece" is an abbreviation for "masterpiece," which is a large and labor-intensive graffiti painting.
} 
almost all indicators (understandability, damage to the surface, use of imagination, being considered a crime, making the space more interesting, and making the space look dirty).

\begin{tabular}{lcc} 
Mean Ratings for Murg Piece & & \\
\hline & $\mathrm{N}$ & Mean \\
\hline The person who did this used their imagination & 139 & 4.39 \\
It makes the space more interesting & 139 & 4.05 \\
It should be considered a crime & 139 & 2.89 \\
It damaged the surface & 139 & 2.78 \\
I understand the intended message & 139 & 2.49 \\
It is gang related & 139 & 2.40 \\
It is offensive & 139 & 2.26 \\
It makes the space look dirty & 139 & 2.22 \\
\hline \multicolumn{2}{c}{ Table 9 Mean Ratings for Murg Piece } \\
\end{tabular}

\begin{tabular}{llr} 
Mean Ratings for GATS Piece & & \\
\hline & $\mathrm{N}$ & Mean \\
\hline The person who did this used their imagination & 139 & 4.46 \\
It makes the space more interesting & 139 & 4.11 \\
I understand the intended message & 139 & 2.88 \\
It damaged the surface & 139 & 2.45 \\
It should be considered a crime & 139 & 2.53 \\
It makes the space look dirty & 138 & 2.17 \\
It is offensive & 139 & 1.92 \\
It is gang related & 139 & 1.88 \\
\hline \multicolumn{2}{c}{ Table 10 Mean Ratings for GATS Piece } &
\end{tabular}

It is important to note that an overwhelming majority of respondents (94\%) appreciated both artists' use of imagination in creating these two pieces. In fact, the GATS piece was rated the highest for its use of imagination out of all the items shown in the survey. Respondent comments suggest that people value imagination as manifested through art in the urban environment:

I really do prefer the art that has had some effort and imagination put into it. 
When color is added and people are engaged art can change the perception of the space we live in.

I think graffiti in Portland is pretty poor, all in all. There's often not a lot of imagination or technique involved. That's my criterion: Whether it elevates the environment.

But the other mural piece was beautiful. I grew up in Los Angeles I am used to seeing great murals like on the train tracks in the ghettos and I all for it. It is like ballet and breakdancing, dancing of the imagination and spirit on a surface.

The Murg and GATS pieces ratings that had the most variance were the level of offensiveness and their perceived relationship to gang activity. ${ }^{67}$ The GATS piece was less associated with these negative connotations. This finding again supports the notion that street art is more accepted by the public than traditional styles of graffiti. I believe the main reason that street art is perceived more positively is because of its use of iconography (rather than graffiti typography), which is more understandable to the public, and therefore seen as less offensive and less associated with gang tags.

When asked if the surrounding spaces were better before or after the pieces were introduced, most respondents felt the spaces were better with the GATS and Murg pieces in them rather than without ( $78 \%$ and $74 \%$ respectively). Respondent comments suggested that they thought that colorfully painted walls are more pleasing and a better use of space than "boring" blank walls:

\footnotetext{
${ }^{67}$ Since I do not know the background behind the Murg piece (in Berlin), it is difficult to compare this piece to the GATS piece in terms of their actual relationship to gangs. However, I do know that a sole individual does not paint GATS. GATS is described as "one of the West Coast's most prolific and rampant graffiti artists. Their iconic characters litter the landscape from coast to coast and have been spotted in over half a dozen different countries around the world" (Endless Canvas, 2011). The GATS character is transmitted through many mediums including spray-paint, wheatpaste, screenprints, and stickers. Technically, this could be classified as a street art crew piece, something that most media outlets would label as a graffiti gang although to my knowledge the group that disseminates this image is not a gang, nor is involved in any organized illegal activities other than street art.
} 
Simple concrete and power poles are a draining and dreary view of the city. When color is added and people are engaged, art can change the perception of the space we live in.

A piece of art beats out a boring gray wall any day.

Most of the pieces seemed to be on surfaces that were not really being used anyway for another useful purpose.

If someone wants to brighten up a shabby wall, great.

A person uses their imagination/message and dresses up a blank medium with that.

We live in a very boxed in world, with boxes and blank spaces and blandness all around. These people obviously want to express themselves and try to make the humdrum boring existence a little more tolerable and pleasant to look at.

Respondents also commented on how painted walls can promote uniquely distinct senses of place:

Each piece of work is unique onto itself and the person making the artwork.

If you've ever been to Europe one should realize that graffiti is a universal impulse to place marks in time and space to differentiate one from another (people and places).

Most respondents did not think the GATS piece (72\%) or the Murg piece (69\%) should be removed. Like all other pieces of street art in this survey, the majority of respondents (GATS 73\%, Murg 79\%) would not want these forms of street art to be placed on their property, but would not mind them being placed in their neighborhood (GATS 62\%, Murg 60\%) or some other part of the city (GATS 70\%, Murg 69\%). Out of the respondents who thought the Murg piece should be removed $(n=41)$, most said that community approval was not necessary (68\%), and that they would be okay with public tax money being used for its removal (68\%). Similarly, respondents who thought the GATS piece should be removed $(n=38)$ mostly said that community approval was not 
necessary (68\%) and that they would be okay with public tax money being used for its removal (68\%). This is a high number of respondents saying that they are okay with using public tax money, compared to stickers, where only $46 \%$ wanted public tax money used. Perhaps, since these are mural-like pieces and more difficult to remove, respondents thought that a more intense effort must be used for removal, rather than relying on volunteers that do not have public funding.

Some interesting anomalies occurred when comparing the ratings for tags and pieces. Even though tags and pieces are technically both equally damaging to the surfaces they are applied to, and the pieces shown covered more surface area (thus being more invasive), the tags were generally thought of as more damaging to the surface than the pieces. The same discrepancy appeared when comparing stickers to pieces; as stickers were rated as more damaging to the surface than the pieces. Certainly, the large spraypainted pieces are more permanent, more difficult to remove, and more damaging to the surfaces, than a simple tag or sticker. I believe other factors, such as perceived gangrelation, dirtiness, and offensiveness, (which tags and stickers are more associated with), are influencing people's opinions about these forms of graffiti. 
Installations
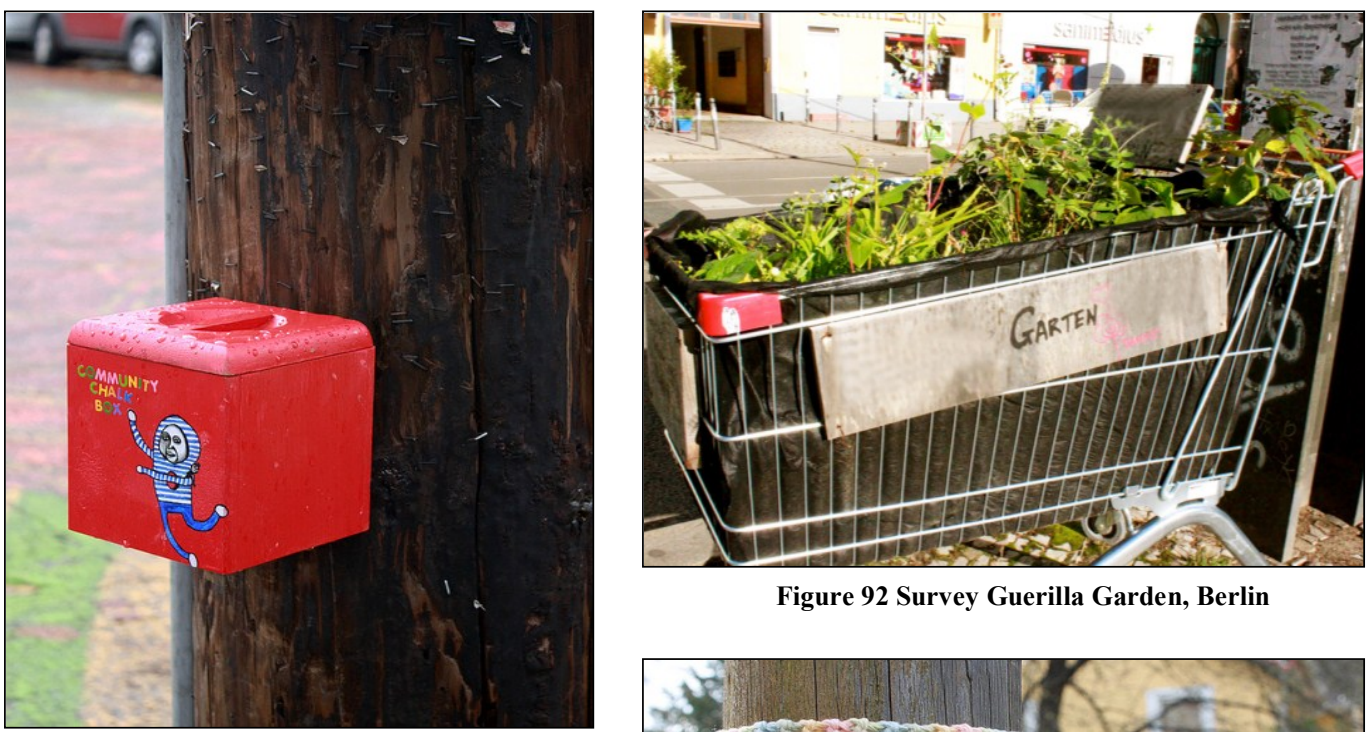

Figure 92 Survey Guerilla Garden, Berlin

Figure 91 Survey Community Chalk Box, Portland

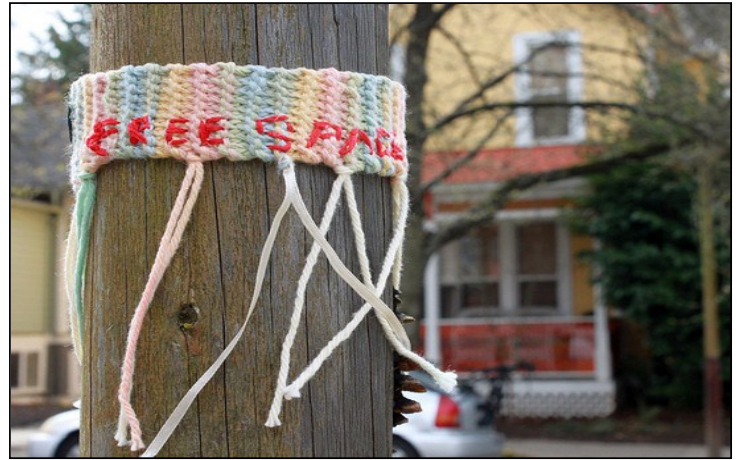

Figure 93 Survey Yarn Installation, Portland

The last form of street art shown to respondents was 3D installations. Overall, these three installations were rated more positively than the rest of the pieces shown in the survey. These ratings also had the least variability between responses. I will first present group statistics for the installations and then look at each individually. The composite scores were: 31.46 for the guerilla garden in a shopping cart, 32.93 for the community chalk box, and 33.46 for the yarn installation. Overall, the installations were scored high on their use of imagination ( $M=4.12)$, making the space look interesting $(M=4.00)$ and their understandability $(\mathrm{M}=3.63)$. Conversely, installations were scored low on damaging the surface $(M=1.91)$, offensiveness $(M=1.70)$, gang-relation $(M=1.51)$, and 
making the space look dirty $(\mathrm{M}=2.09)$. Some respondents spoke directly about

installations in their comments, highlighting how they felt differently towards this form

of street art compared to others:

If it is at least sort of nice to look at, interactive like a chalk box or garden cart, not too messy, imaginative, and fun, then it is street art!

Good (community chalk box, mustache-jellyfish, etc.), bad (tags), or indifferent, street art tends typically involves trespassing and forcing your views on someone else's property.

Some of the other pieces, especially the red box on the phone pole, have a wonderful sense of surprise and discovery. I guess that's my criterion too: If I come around a corner and see a piece of street art, and it makes me smile or go "oooh," or laugh from an appreciation of the artist's concept or delivery, then the graffito has done its job.

Most of the pieces seemed to be on surfaces that were not really being used anyway for another useful purpose, with the exception of the shopping cart with the "Garten" perhaps, though I can definitely see the value of that piece as a political or cultural statement...The "Community Chalk Box" is brilliant and clearly encourages child-like expression and fun amidst dreariness and doesn't hinder the function of the telephone pole. Same with "Free Space".

Additionally, some comments focus on the non-destructive nature of installations:

I personally distinguish between street art and graffiti. I see graffiti (painting surfaces) as vandalism in most cases. Regardless of message, its permanence and the effort it takes to remove it from surfaces is something that I cannot condone. However, street art, other forms of expression, such as stickers on electrical boxes, knitting on trees, and the red chalk box are, are all things that are easily removed. Artistic expression does not have to be damaging to our surroundings.

I think installations like that and the garden shopping cart are in a different league than paints which may damage a surface permanently. 
Mean Ratings for Garden Installation

\begin{tabular}{lrr}
\hline & $\mathrm{N}$ & Mean \\
\hline The person who did this used their imagination & 139 & 3.94 \\
It makes the space more interesting & 138 & 3.80 \\
I understand the intended message & 139 & 3.46 \\
It makes the space look dirty & 139 & 2.55 \\
It damaged the surface & 139 & 2.00 \\
It should be considered a crime & 138 & 1.97 \\
It is offensive & 139 & 1.86 \\
It is gang related & 138 & 1.49 \\
\hline \multicolumn{2}{c}{ Table 11 Mean Rating for Garden Installation } \\
\end{tabular}

The least favored installation was the guerilla garden shopping cart. I had hypothesized that this piece would have been perceived more positively than it was because it introduces natural elements into the urban environment. However, the garden was inside a shopping cart. I believe this factor resulted in $30 \%$ of respondents saying that the piece made the space look dirty. Nevertheless, most respondents thought the garden's creator used their imagination (76\%), and that the garden made the space more interesting (65\%). Respondents also did not think the garden damaged the surface (74\%), was offensive (78\%), gang-related $(90 \%)^{68}$ or should be considered a crime $(73 \%)$. Most respondents (77\%) reported that they had not seen anything like this in the past 6 months, suggesting that many were not familiar with guerilla gardening practices, especially ones of this nature or scale. Most respondents (68\%) did not think the garden should be removed. Of the 42 respondents who said that it should be removed, $51 \%$ thought that community approval should be received before removing the garden and that public tax money should be spent to pay for its removal.

\footnotetext{
${ }^{68}$ No respondents "agreed" or "strongly agreed" that the guerilla garden was gang-related.
} 
The second highest rated piece in the survey was the wooden community chalk box that I created for my field observations. The words "community chalk box" were small, but clear and easy to read. The box was rated by most respondents as being understandable (71\%), imaginative (88\%), and making the space look more interesting $(83 \%)$. Conversely, most respondents did not think the box damaged the surface $(73 \%)$, was offensive $(83 \%)$, gang-related $(89 \%)$, or made the space look dirty $(79 \%)$. It is interesting that so many respondents did not think the box was damaging to the pole. In fact, of all the pieces shown in the survey, this was perhaps the most physically damaging. To secure it, I had to drill several long screws into the wooden pole. To remove the box you would have to use a drill or break the box into pieces. The majority of respondents ( $85 \%)$ thought the surrounding space was better with the chalk box and that it should not be removed (83\%). Interestingly, the chalk box had the most respondents $(n=67)$ say that they would be okay with it being placed on their own private property $(48 \%)$. Like the other pieces, most respondents would tolerate something like this being placed in their neighborhood and in other parts of the city $(83 \%)$.

Mean Ratings for Chalk Box Installation

\begin{tabular}{llc}
\hline & $\mathrm{N}$ & Mean \\
\hline The person who did this used their imagination & 139 & 4.22 \\
It makes the space more interesting & 139 & 4.15 \\
I understand the intended message & 139 & 3.73 \\
It damaged the surface & 139 & 2.12 \\
It should be considered a crime & 139 & 2.04 \\
It makes the space look dirty & 138 & 1.83 \\
It is offensive & 139 & 1.66 \\
It is gang related & 139 & 1.51 \\
\hline \multicolumn{4}{c}{ Table 12 Mean Ratings for Chalk Box Installation } \\
\end{tabular}




\begin{tabular}{lcc} 
Mean Ratings for Yarn Installation & & \\
\hline & $\mathrm{N}$ & Mean \\
\hline The person who did this used their imagination & 138 & 4.20 \\
It makes the space more interesting & 138 & 4.04 \\
I understand the intended message & 138 & 3.70 \\
It makes the space look dirty & 136 & 1.90 \\
It should be considered a crime & 138 & 1.87 \\
It damaged the surface & 138 & 1.62 \\
It is offensive & 137 & 1.59 \\
It is gang related & 138 & 1.53 \\
\hline
\end{tabular}

Table 13 Mean Ratings for Yarn Installations

The highest rated piece in the survey was the yarn installation I made and placed at Sunnyside Piazza. This piece consisted of pastel-colored yarn, tassels, and an embroidered message that read "free space." The majority $(65 \%)$ of respondents reported that they understood the yarn installation's intended message. The words 'free space' were clear and easy to read. Additionally, the yarn installation was rated positively on many other indicators: not damaging to surface $(90 \%)$, use of imagination (88\%), not offensive (89\%), not gang-related (89\%), not considered a crime $(78 \%)$, making the space more interesting (79\%), and not making the space look dirty $(78 \%)$. The majority of respondents (78\%) also thought that the space was better with the piece, and would be okay with it being placed in their neighborhood $(81 \%)$ or in some other part of the city $(82 \%)$. Additionally, $78 \%$ of respondents did not think the yarn should be removed. Other than the indicators in the survey, other reasons why the yarn installation may have been perceived more positively could be due to its feminine nature. It has been said that yarn bombing "takes that most matronly craft (knitting) and that most maternal of gestures (wrapping something cold in a warm blanket) and transfers it to the concrete 
and steel wilds of the urban streetscape" (Wollan, 2011). Yarn's soft and tactile properties heighten this comforting effect. Yarn bombing's non-threatening nature is far different than the gritty male-dominated graffiti world, even though the basic premises of the two crafts are essentially the same. Both types of artists express themselves in public space without permission, adding their own creative handmade touches to the cityscape.

Overall, more respondents in the survey (49\%) thought that street art and graffiti in general should be viewed as an act of artistic expression rather than vandalism (35\%). Respondents did not automatically see graffiti as vandalism; instead they took numerous factors into account when forming opinions about the appropriateness of a piece.

\section{Demographic Characteristics}

Survey respondents provided their age range, level of education, number of household members and children, length of time living in the neighborhood, residential tenure, zip code, and annual household income. The demographic characteristics of the 139 respondents are summarized in Table 14 (page 136). Most respondents were in the 25-34 age group (44\%), followed by the 35-44 age group (20\%). In the City of Portland, most residents are also in the 25-34 age group (19\%), followed by the 35-44 age group (16\%) (US Census, 2010). The majority of survey respondents had completed a bachelor's degree (51\%) followed by a graduate or professional degree (34\%). This is an overrepresentation, because in the City of Portland, only $25 \%$ of residents have completed their bachelor's degree and $15.9 \%$ have a graduate or professional degree (US Census, 2010). Of those surveyed, the average number of people per household 
(including the respondent) was 2.39. This is close to the City of Portland which has an average of 2.25 people per household (US Census, 2010). More respondents rented (53\%) than owned their home (47\%). In the City of Portland, slightly more people own $(55 \%)$ their home rather than rent $(45 \%)$ so renters were slightly over-represented in the survey (US Census, 2010). Finally, most respondent households earned more than $\$ 35,000$ a year (71\%), with " $\$ 50,000$ to less than $\$ 75,000$ " being the most represented income bracket (22\%). This was somewhat representative of the City of Portland, where $63 \%$ of households earn over $\$ 35,000$ a year, and the " $\$ 50,000$ to less than $\$ 75,000 "$ " is also the most represented income bracket (18\%) (US Census, 2010).

Survey Respondent's Household Characteristics $(N=139)$

\begin{tabular}{|l|r|r|}
\hline Number of People in Household & $\%$ & $\#$ \\
\hline 1 person & $20.1 \%$ & 28 \\
\hline 2 people & $42.4 \%$ & 59 \\
\hline 3 people & $18.7 \%$ & 26 \\
\hline 4 people & $15.1 \%$ & 21 \\
\hline 5 people & $0.0 \%$ & 0 \\
\hline 6 people & $1.4 \%$ & 2 \\
\hline Total & $0.7 \%$ & 1 \\
\hline Number of Children Under 18 in Household & $100 \%$ & 137 \\
\hline No children & $53.2 \%$ & $\#$ \\
\hline 1 child & $16.0 \%$ & 74 \\
\hline 2 children & $13.2 \%$ & 17 \\
\hline 5 children & $0.9 \%$ & 14 \\
\hline Total & $100 \%$ & 106 \\
\hline Tenure & $\%$ & $\#$ \\
\hline Rent & $52.6 \%$ & 72 \\
\hline Own & $47.4 \%$ & 65 \\
\hline Total & $100 \%$ & 137 \\
\hline Length of Time in Neighborhood & $\%$ & $\#$ \\
\hline Less than a year & $14.6 \%$ & 20 \\
\hline 1 to less than 3 years & $24.1 \%$ & 33 \\
\hline
\end{tabular}




\begin{tabular}{|c|c|c|}
\hline 3 to less than 5 years & $19.0 \%$ & 26 \\
\hline 5 to less than 10 years & $16.8 \%$ & 23 \\
\hline 10 years or more & $24.1 \%$ & 33 \\
\hline All my life & $1.5 \%$ & 2 \\
\hline Total & $100 \%$ & 137 \\
\hline Age & $\%$ & \# \\
\hline $18-24$ & $7.3 \%$ & 10 \\
\hline $25-34$ & $43.8 \%$ & 60 \\
\hline $35-44$ & $19.7 \%$ & 27 \\
\hline $45-54$ & $12.4 \%$ & 17 \\
\hline $55-64$ & $9.5 \%$ & 13 \\
\hline $65-75$ & $7.3 \%$ & 10 \\
\hline 76 or older & $0.0 \%$ & 0 \\
\hline Total & $100 \%$ & 137 \\
\hline Education & $\%$ & \# \\
\hline High School Diploma or GED & $9.5 \%$ & 13 \\
\hline Associate Degree or Tech/Voc School & $5.1 \%$ & 7 \\
\hline Bachelor's Degree & $51.1 \%$ & 70 \\
\hline Graduate or Professional Degree & $34.3 \%$ & 47 \\
\hline Total & $100 \%$ & 137 \\
\hline Annual Household Income & $\%$ & \# \\
\hline Less than $\$ 15,000$ & $6.2 \%$ & 8 \\
\hline$\$ 15,000$ to less than $\$ 25,000$ & $12.4 \%$ & 16 \\
\hline$\$ 25,000$ to less than $\$ 35,000$ & $10.9 \%$ & 14 \\
\hline$\$ 35,000$ to less than $\$ 50,000$ & $17.1 \%$ & 22 \\
\hline$\$ 50,000$ to less than $\$ 75,000$ & $21.7 \%$ & 28 \\
\hline$\$ 75,000$ to less than $\$ 100,000$ & $12.4 \%$ & 16 \\
\hline$\$ 100,000$ or more & $19.4 \%$ & 25 \\
\hline Total & $100 \%$ & 129 \\
\hline
\end{tabular}


T-tests were conducted to compare the demographic variables to the composite score for each piece of street art in the survey. This analysis provided insight into socioeconomic factors that may be influencing people's attitudes towards street art. There was a significant effect for tenure on the composite score ratings for six out of ten street art pieces. This suggested that owners are more likely than renters to rate street art negatively. Owners may have more invested in their neighborhood and property. Renters are less concerned about property values being affected by negative perceptions of the area.

Difference of Composite Scores between Renters and Owners

$$
\mathrm{t} \text {-test for Equality of Means }
$$

\begin{tabular}{|c|c|c|c|c|c|c|c|}
\hline & \multirow[b]{2}{*}{$\mathrm{t}$} & \multirow[b]{2}{*}{$\mathrm{df}$} & \multirow{2}{*}{$\underset{\text { (2-tailed) }}{\text { Sig. }}$} & \multirow{2}{*}{$\begin{array}{c}\text { Mean } \\
\text { Difference }\end{array}$} & \multirow{2}{*}{$\begin{array}{l}\text { Std. Error } \\
\text { Difference }\end{array}$} & \multicolumn{2}{|c|}{$\begin{array}{c}95 \% \\
\text { Confidence } \\
\text { Interval of the } \\
\text { Difference }\end{array}$} \\
\hline & & & & & & Lower & Upper \\
\hline Long Live Tag & -2.526 & 132 & $.013^{*}$ & -2.904 & 1.150 & -5.178 & -.630 \\
\hline Fever Tag & -3.942 & 132 & $.000 * * *$ & -4.152 & 1.053 & -6.235 & -2.069 \\
\hline Stickers & -3.587 & 133 & $.000 * * *$ & -3.967 & 1.106 & -6.155 & -1.779 \\
\hline Murg Piece & -3.178 & 135 & $.002 * *$ & -3.434 & 1.081 & -5.571 & -1.297 \\
\hline GATS Piece & -2.967 & 134 & $.004 * *$ & -3.372 & 1.136 & -5.619 & -1.124 \\
\hline Chalk Box & -2.486 & 134 & $.014 *$ & -2.715 & 1.092 & -4.876 & -.555 \\
\hline Yarn & -.777 & 131 & .438 & -.751 & .967 & -2.663 & 1.161 \\
\hline Garden & -1.841 & 132 & .068 & -1.861 & 1.011 & -3.861 & .139 \\
\hline
\end{tabular}


Additionally, like Dovey, Wollan, and Woodcock's (2012) qualitative findings, these data suggests that there was a significant effect for length of residency on the ratings for all of the pieces of street art and graffiti shown in the survey. Residents who have lived in their neighborhood more than 5 years were more likely than those who lived there less than 5 years to rate street art negatively.

Difference of Composite Scores between Respondents Living in Neighborhood Less than 5 Years and More than 5 Years

\begin{tabular}{|c|c|c|c|c|c|c|c|}
\hline & \multicolumn{7}{|c|}{ t-test for Equality of Means } \\
\hline & & & & Mean & Std. Error & $\begin{array}{r}95 \\
\text { Confi } \\
\text { Interva } \\
\text { Diffe }\end{array}$ & $\begin{array}{l}\% \\
\text { lence } \\
\text { of the } \\
\text { ence }\end{array}$ \\
\hline & $\mathrm{t}$ & $\mathrm{df}$ & (2-tailed) & Difference & Difference & Lower & Upper \\
\hline Long Live Tag & 3.700 & 132 & $.000^{* * *}$ & 4.185 & 1.131 & 1.948 & 6.422 \\
\hline Fever Tag & 2.733 & 132 & $.007 * *$ & 2.995 & 1.096 & .827 & 5.164 \\
\hline Stickers & 3.057 & 133 & $.003^{* *}$ & 3.454 & 1.130 & 1.219 & 5.690 \\
\hline Murg Piece & 4.179 & 135 & $.000 * * *$ & 4.452 & 1.065 & 2.345 & 6.559 \\
\hline GATS Piece & 3.720 & 134 & $.000^{* * *}$ & 4.203 & 1.130 & 1.968 & 6.437 \\
\hline Chalk Box & 3.793 & 134 & $.000^{* * *}$ & 4.074 & 1.074 & 1.949 & 6.198 \\
\hline Yarn & 3.585 & 131 & $.000^{* * *}$ & 3.346 & .933 & 1.500 & 5.193 \\
\hline Garden & 2.614 & 132 & $.010^{* * *}$ & 2.638 & 1.009 & .641 & 4.635 \\
\hline
\end{tabular}

Again, residents who have lived in their neighborhood longer have more invested in the area than newcomers. Also, respondents who have lived in their neighborhood more than 10 years $(\mathrm{n}=33)$ may look at neighborhood changes negatively if they think the area is being invaded by people unlike them or changed in a way they do not like. These changes may not be directly associated with street art, but if change is occurring, this may make long-term residents apprehensive about alternative ideas coming into their neighborhood, decline, or gentrification. For example, a study of the gentrifying Alberta Art District in Portland, found that long-term Black residents participated less in 
community art events and often felt uncomfortable or unwelcome. The arts-anchored symbolic economy resulted in racial exclusions based on perceptions and experiences of belonging, thereby affecting residents' abilities to identify with the change that the arts were bringing about in their neighborhood (Sullivan \& Shaw, 2011).

There was a significant effect for income on the ratings for all the street art pieces. Respondents making less than $\$ 50,000$ a year were more likely than respondents making over $\$ 50,000$ a year to rate street art positively. This is not enough evidence to state that there are social class differences in tendencies to like or dislike street art. However, street art does arise from the bottom-up and has strong ties to resistance movements. Therefore, it is not surprising that those respondents making higher incomes feel more negatively towards this form of expression, perhaps because they feel threatened by it and the people who propagate it. Respondents earning higher incomes also may be homeowners and thus more concerned about property values.

Difference of Composite Scores between Respondents Earning Less than \$50,000 and More than $\$ 50,000$ per Year

\begin{tabular}{|c|c|c|c|c|c|c|c|}
\hline & \multicolumn{7}{|c|}{ t-test for Equality of Means } \\
\hline & \multirow[b]{2}{*}{$\mathrm{t}$} & \multirow[b]{2}{*}{$\mathrm{df}$} & \multirow{2}{*}{$\begin{array}{c}\text { Sig. } \\
\text { (2-tailed) }\end{array}$} & \multirow{2}{*}{$\begin{array}{c}\text { Mean } \\
\text { Difference }\end{array}$} & \multirow{2}{*}{$\begin{array}{l}\text { Std. Error } \\
\text { Difference }\end{array}$} & \multicolumn{2}{|c|}{$\begin{array}{c}95 \% \\
\text { Confidence } \\
\text { Interval of the } \\
\text { Difference }\end{array}$} \\
\hline & & & & & & Lower & Upper \\
\hline Long Live Tag & 3.772 & 126 & $.000 * * *$ & 4.331 & 1.148 & 2.059 & 6.604 \\
\hline Fever Tag & 2.761 & 125 & $.007 * *$ & 3.100 & 1.123 & .878 & 5.321 \\
\hline Stickers & 3.154 & 125 & $.002 * *$ & 3.626 & 1.149 & 1.351 & 5.901 \\
\hline Murg Piece & 4.449 & 127 & $.000 * * *$ & 4.909 & 1.103 & 2.726 & 7.093 \\
\hline GATS Piece & 3.855 & 126 & $.000 * * *$ & 4.486 & 1.164 & 2.183 & 6.790 \\
\hline Chalk Box & 3.471 & 126 & $.001 * *$ & 3.872 & 1.115 & 1.664 & 6.079 \\
\hline Yarn & 2.362 & 123 & $.020 *$ & 2.377 & 1.006 & .385 & 4.369 \\
\hline Garden & 2.746 & 126 & $.007 * *$ & 2.817 & 1.026 & .787 & 4.847 \\
\hline
\end{tabular}


The data also shows that there was a significant effect of age on the ratings for all the street art pieces, other than the yarn installation. Younger respondents (under 35) were more likely than older respondents $(35+)$ to rate pieces of street art positively. Difference of Composite Scores between Respondents Younger than 35 and 35 and Older

\begin{tabular}{|c|c|c|c|c|c|c|c|}
\hline & \multicolumn{7}{|c|}{ t-test for Equality of Means } \\
\hline & \multirow[b]{3}{*}{$\mathrm{t}$} & \multirow[b]{3}{*}{$\mathrm{df}$} & \multirow{3}{*}{$\underset{\text { Sig. }}{\text { Sitailed) }}$} & \multirow{3}{*}{$\begin{array}{c}\text { Mean } \\
\text { Difference }\end{array}$} & \multirow{3}{*}{$\begin{array}{l}\text { Std. Error } \\
\text { Difference }\end{array}$} & \multirow{2}{*}{\multicolumn{2}{|c|}{$\begin{array}{c}95 \% \\
\text { Confidence } \\
\text { Interval of the } \\
\text { Difference }\end{array}$}} \\
\hline & & & & & & & \\
\hline & & & & & & Lower & Upper \\
\hline Long Live Tag & 2.596 & 132 & $.011 *$ & 3.274 & 1.261 & .779 & 5.770 \\
\hline Fever Tag & 3.667 & 132 & $.000 * * *$ & 4.274 & 1.166 & 1.969 & 6.580 \\
\hline Stickers & 3.160 & 133 & $.002 * *$ & 3.863 & 1.222 & 1.445 & 6.281 \\
\hline Murg Piece & 3.630 & 135 & $.000 * * *$ & 4.263 & 1.174 & 1.940 & 6.585 \\
\hline GATS Piece & 3.581 & 134 & $.000 * * *$ & 4.429 & 1.237 & 1.983 & 6.875 \\
\hline Chalk Box & 3.507 & 134 & $.001 * *$ & 4.139 & 1.180 & 1.805 & 6.473 \\
\hline Yarn & 1.459 & 131 & .147 & 1.539 & 1.055 & -.548 & 3.626 \\
\hline Garden & 2.904 & 132 & $.004 * *$ & 3.165 & 1.090 & 1.009 & 5.320 \\
\hline
\end{tabular}

Note. ${ }^{*} \mathrm{p}<.05,{ }^{* *} \mathrm{p}<.01,{ }^{* * *} \mathrm{p}<.001$

Table 18 Difference of Composite Scores between Respondents Younger than 35 and 35 and Older

This suggests that street art is a generational phenomenon. Younger generations do not associate graffiti with as many negative externalities. This more positive outlook could be due to youth being more open-minded, risky, or generally not having experienced what inner cities were like the 1970s and 1980s when traditional graffiti was at its height. Surprisingly, street art advocates in Berlin are even trying to bridge this generational gap by teaching graffiti to senior citizens through workshops and courses (Kilian, 2011). Across Germany, similar initiatives are encouraging older generations to explore graffiti as a means of self-expression, engagement in their community (to reduce isolation), open up channels of communication with younger generations, and increase their movement, stretching, and hand-eye coordination (Kilian, 
2011). With increasing acceptance of street art in mainstream culture, I predict that older generations will begin to feel less negatively towards these forms of public expression as their exposure to it increases. Conversely, younger generations may feel more negatively (or neutrally) towards street art if becomes so popular it loses "edgy" character and is co-opted and commercialized by corporations. My hypothesis that households' with children under 18 years old would dislike street art and graffiti more than those without children was not substantiated. There was not a significant effect on composite scores for presence of children.

\section{Conclusions}

The results from this survey research indicate that respondents took numerous factors into account when forming opinions about the appropriateness of pieces of street art or graffiti. Opinions were affected by the piece's degree of understandability, offensiveness, imaginativeness, damage, gang-relation, criminality, interest, dirtiness, and its spatial placement. Personal ideologies, aesthetic preferences, and notions regarding the proper use of private and public space also influenced opinions about street art and graffiti. Survey results show that respondents generally preferred installations and masterpieces rather than tagging and stickers. Respondents did not think installations (and to some extent masterpieces) were as offensive, damaging, gangrelated, or dirtying of public space. More respondents considered graffiti to be a form of artistic expression, rather than an act of vandalism. These data suggest that there is a need for more community involvement and input on the issue of street art policy. 
Increased responsibility, social pressure, targeted community support, and free walls were recurring ideas respondents had about how society could handle street art.

Furthermore, direct participant observations indicated that purposefully designed street art has the potential to encourage interaction between people, art, and public space. These experiments show that random urban spectators can become active collaborators; using art and performance to express themselves in public. Overall, these findings contribute to a more informed discussion regarding the regulation, acceptability, and possibilities of unauthorized artistic expression in cities.

\section{Future Survey Research Recommendations}

Considering the limitations of passive surveying, not all questions could be asked. I had to exclude items to shorten the survey to a manageable length (such as asking about wheatpastes or a second set of stickers that modified an urban object). New questions also emerged as I analyzed the data, such as: how acceptable respondents find the amount of advertising they are exposed to on a daily basis, their opinion about zero tolerance graffiti policies, and if they think people should have to pay a fee to the city and/or go through a review process to paint murals. Comments in the survey suggested that if the artist had permission they would feel differently about the piece, therefore, I am interested to know how people would feel about establishing "Free Walls" in Portland to allow for street art in designated areas. Some respondents also mentioned they have had issues with unauthorized graffiti at their businesses or homes. This is a 
factor I did not think to ask about in the survey ${ }^{69}$ In future research, it would be helpful

to know if respondents have had issues with graffiti on any of their properties.

\section{Policy Implications}

Currently, the City of Portland has an ordinance requiring the "removal of graffiti ${ }^{70}$ from buildings, walls and other structures in order to reduce social deterioration within the City and to promote public safety and health" (Auditor's Office, 2012). The aim is to eradicate graffiti completely from the visual landscape. This ordinance is clearly based on the assumptions provided by the broken windows theory, in particular, blight, the collapse of moral values, (i.e., social deterioration), and resulting potential for physical violence and deterioration (i.e., public safety and health). ${ }^{71}$ Owners of a "Graffiti Nuisance Property" must remove graffiti within ten days of its appearance or face search warrants, a fine of up to $\$ 500$, and a jail sentence of up to six months (Auditor's Office, 2012).

\footnotetext{
${ }^{69}$ This question would have to be carefully worded. Biased questions have been used in other research on this topic, such as using the phrase "victim of graffiti" (City of Seattle, 2010). This automatically sets the tone that the researcher thinks that graffiti is an offensive crime.

${ }^{70}$ Under this ordinance graffiti is defined as: "Any unauthorized markings of paint, ink, chalk, dye or other similar substance which is visible from premises open to the public, and that have been placed upon any real or personal property such as buildings, fences, structures, or the unauthorized etching or scratching of such described surfaces where the markings are visible from premises open to the public, such as public rights of way or other publicly owned property" (Auditor's Office, 2012). This definition of graffiti does not take into account newer forms of urban street installations now being experimented with, such as 3D objects placed or adhered to urban fixtures, yarn, or guerilla gardening.

${ }^{71}$ It is necessary to make the distinction between "physical" deterioration and "social" deterioration, which this ordinance does not. The two terms are not synonymous. For example, just because someone lives in a dilapidated neighborhood does not mean they lack of values and are a criminal. Conversely, just because someone lives in a wealthy neighborhood does not mean they are a law-abiding citizen with good values. The idea that physical blight is caused by, or connected to, moral decline is nothing new. This was a popular idea in London in the early 1800s as religious missionaries and others would vilify poverty and focus on the phenomenology of urban deprivation without exploring the larger structural factors that shaped the lives of slum dwellers (Parker, 2004).
} 
Prevalent arguments against zero tolerance policies contend that under these punitive policies there will be fewer large elaborate pieces (like the type that many respondents in my survey rated positively) and more small tags (like the type that many respondents in my survey rated negatively) because tags are quicker and safer for artists to execute (Quin, 2010). Melbourne University criminologist Alison Young said, "It becomes a nowin stand-off and the community misses out on high-quality street art...the policy was not an effective use of money and it antagonized the street art community by showing no interest in understanding the motivations or meaning behind the art" (Quin, 2010).

These data also clearly shows that respondents distinguish between certain forms of street art. Many respondents viewed installations as a positive or neutral form of public expression. Respondents who expressed negative opinions regarding tags, stickers, and pieces, felt more positively towards installations. Generally, respondents did not think installations (and to some extent spray-painted masterpieces) were as offensive, damaging, gang-related, or dirtying of the space.

Although this is not a representative sample of Portland residents, it does suggest that people may not fully support the current laws regulating public artistic expression. There is a need for additional non-biased research into this issue, especially at the local level. Public officials tend to rely on anecdotal accounts from police departments when making decisions about graffiti and street art (City of Seattle, 2010; NoGraffiti.com). Officials often assume that a failure in one city (e.g., a free wall not working to deter all other graffiti in an area) will result in a failure in another. No two cities are the same; each has its own unique mix of people, landscapes, history, and collective cultures. 
Communities need to come together and have informed evidence-based discussions regarding the presence of graffiti in their city, the varying degrees of acceptability towards different forms, and the need for varying levels of regulation. It does not have to be all or nothing.

The data suggests that there is a need for more community involvement and input on the issue of street art removal in Portland. Increased responsibility, informal social controls, targeted community support, and free walls were recurring themes in respondent's ideas about how society should deal with street art. The idea of creating "free walls" in Portland where street artists could paint legally within designated areas was a reoccurring trend in respondent comments:

I'd like to see the city set up a graffiti zone where one could put your message up in an area where only those who want to see graffiti will see it. An area of city owned buildings, maybe an under-bridge area, etc. Everyone would know where to go to vandalize (only it wouldn't be vandalism as it would be sanctioned) and see each other's work.

I wrote graffiti for a little over ten years in the Portland area. Although a few of the artists featured in this survey are from are parts of the country, I appreciate their willingness to contribute to the city of Portland and its distinct lack of interesting public art. Portland is one of the few larger cities with a large creative base to allow "free" or "legal" walls. I strongly believe that many artists do not want to break the law, but come to do so because we do not have legal walls. If a space were provided for artists to let their individual passions flow, there would definitely be less tagging and more murals.

In Europe, there is a noticeable absence of tagging, and much more art. They also have places where you can do street art and not worry about its removal. I wish we had more of that here, as I do believe it can be artistic expression. 
I think that public property maybe that could be a space where people could paint whatever they wanted. Maybe stuff "owned by city" could be like for public and anything could happen there. Having more public spaces for art is important. We need places to communicate ourselves to others; the more of this the better.

The city should take advantage of these people and designate certain areas for street art to limit them going to private property.

Portland should adopt public spaces (walls, blank slates, light poles, etc.) everywhere throughout the city for these artists to express their skills. Not only does this public art show the cultural side of our community but it also connects local and visiting artists. Everyone from tourists to neighborhood residents are offered an enriching experience from observing the artists expressed work.

Besides gang related turf marking, its artists showcasing their talent in interesting and different spaces. I would prefer they were done in designated or allowed spaces but on public property such as bridges, etc., and not personal property then it makes the space more interesting and beautiful to look at.

An argument against free walls is that they send "mixed messages" to people that graffiti is legal, when it is not. I would counter this by saying not cleaning up all graffiti and subjectively choosing which pieces to leave or remove also sends mixed messages. Another argument cited by Portland Police is that in their experience, graffiti on free walls generally expands to exceed the boundaries of the wall and becomes problematic for the surrounding area (City of Seattle, 2010). I was unable to find reliable data or statistics on this issue. I also question whether or not the amount of "spill-over" graffiti is any more or less than what would typically be present in a given area. Free walls are not typically established in areas that did not already have graffiti present. Usually free walls are established in response to a graffiti "problem," to concentrate the markings in certain areas, and to provide youth the opportunity to creatively express themselves in a manner they enjoy. 


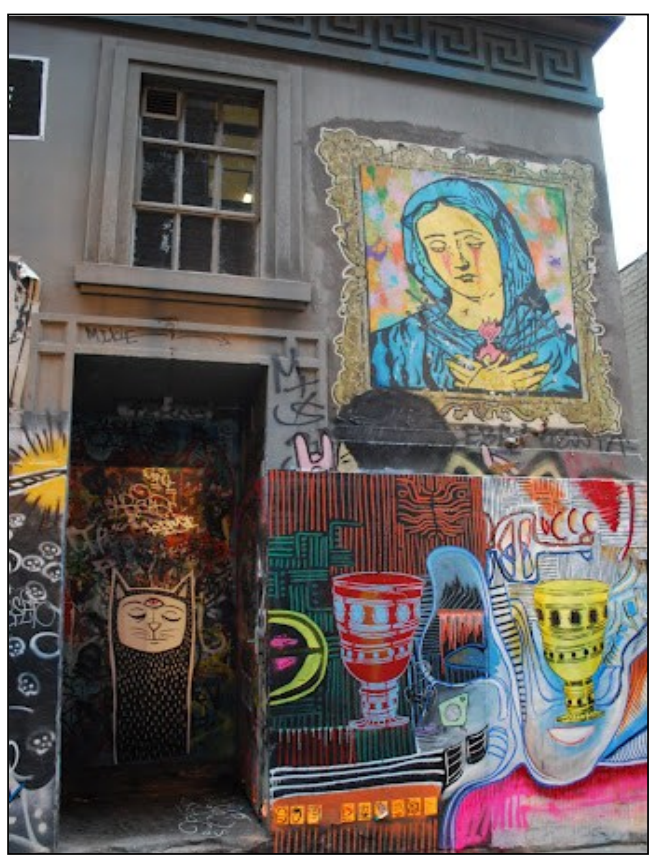

Figure 94 Melbourne Australia

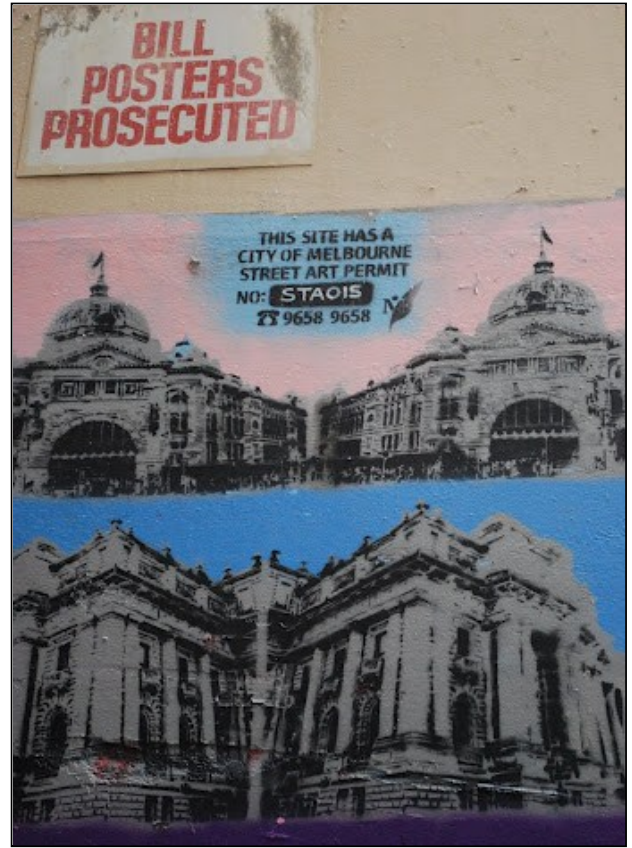

Figure 95 Permitted Wall, Melbourne Australia

Hundreds of cities around the world (especially in Europe and Australia) provide official and unofficial free walls, far more than in the United States (Legal-Walls, 2012). Melbourne Australia has a free wall permitting process that designates specific walls as spaces for street art. The city conducted research and found that many residents actually appreciated street art (especially larger more "artistic' pieces or murals) placed in appropriate locations with permission. Melbourne's graffiti management plan now distinguishes between the need to remove unwanted graffiti applied without permission, and street art applied with permission. The city still takes a strong stance against illegal graffiti. However, the city recognizes that it must take a moderate approach to street art, not just because many residents prefer it, but also because the city's vibrant art scene is driving tourism:

The City of Melbourne recognizes the importance of street art in contributing to a vibrant urban culture. Melbourne's street art has become internationally renowned 
and has become an attraction for local and overseas visitors experiencing Melbourne's creative ambience (City of Melbourne, 2012).

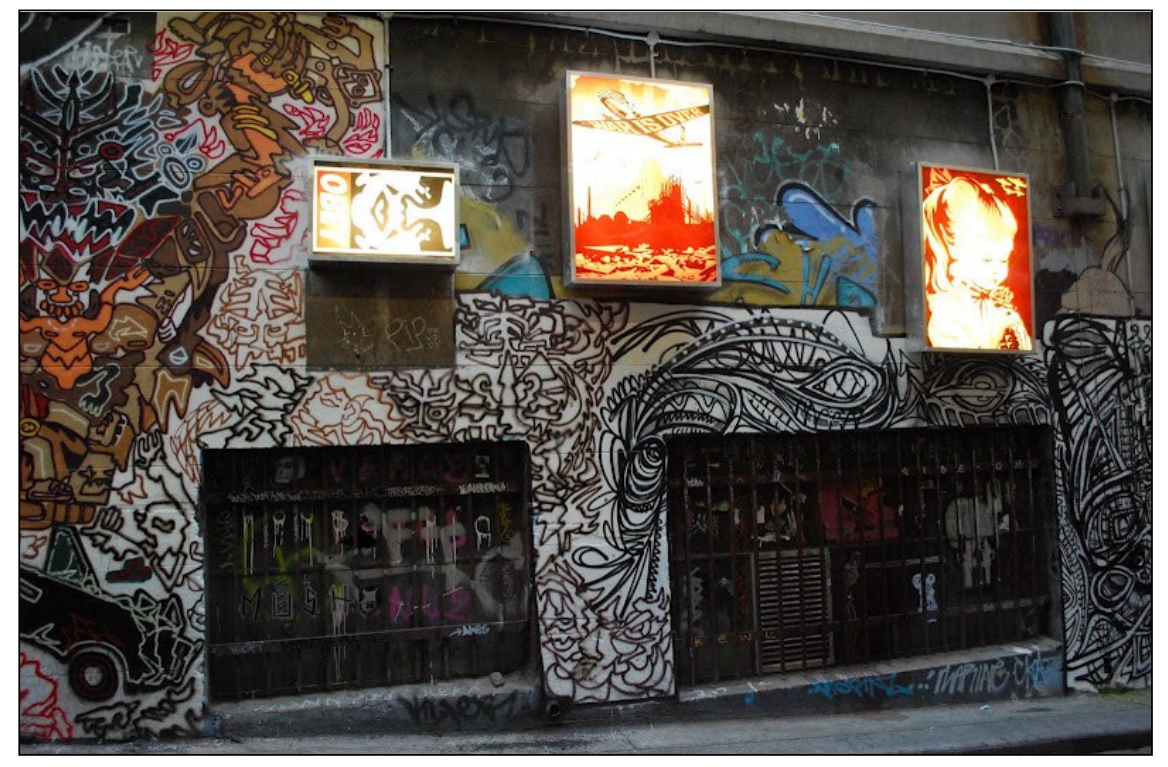

Figure 96 Melbourne Australia

There are only a few dozen walls where street artists can paint legally, for free, in the United States (Legal-Walls, 2012). Miami's Wynwood Walls is one of the best examples. However, these are not technically completely "free" walls, as artists still need to obtain permission to paint there. Most of the Wynwood Walls space is used for rotating commissioned projects, but there is a tolerance of spillover graffiti in the area. In 2009, Tony Goldman was looking for a way to transform this rundown warehouse district; he realized that the large windowless warehouse buildings were excellent canvases (Wynwood, 2012). Goldman successfully created America's first large-scale outdoor street art gallery museum. During the winter of 2011, Miami hosted the 11th annual Art Basel, the most prestigious art show in the Americas (Art Basel, 2012). Over 10,000 people attended the week-long event, which the Wynwood Walls were a main centerpiece alongside with the now 70+ galleries in Wynwood area (Art Basel, 2012). 


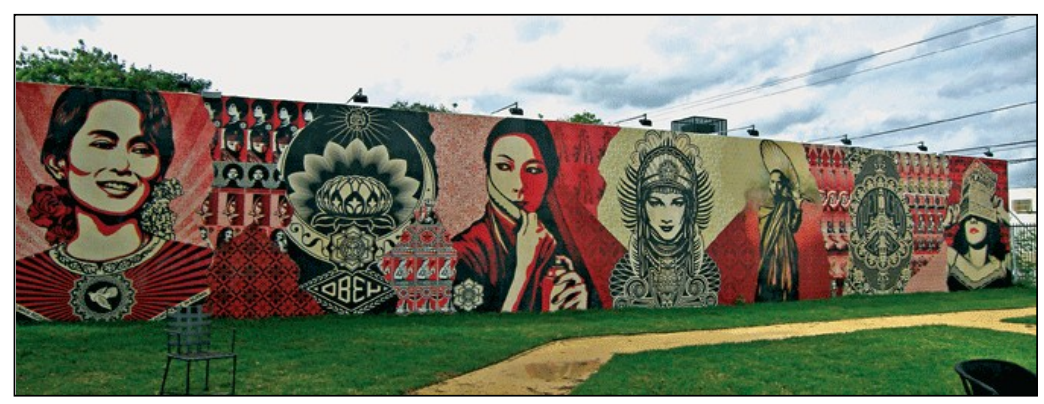

Figure 97 Shepard Fairey, Wynwood Walls Miami Florida 2011

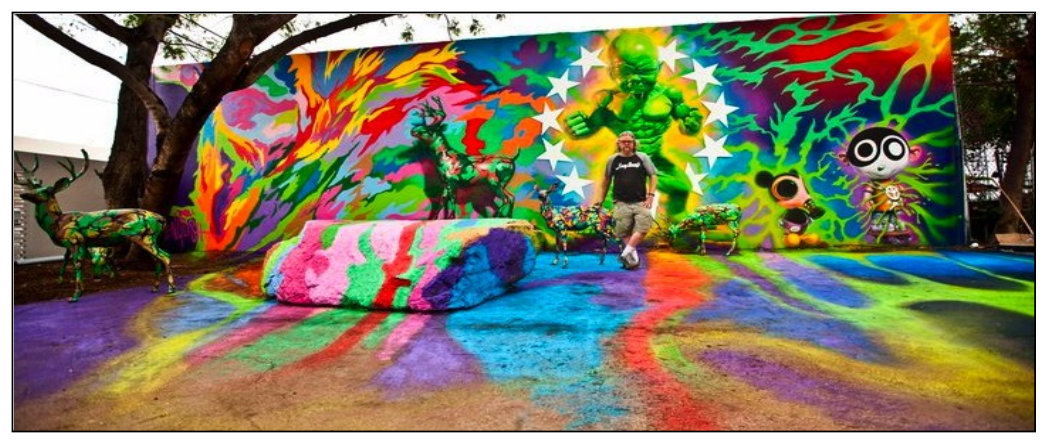

Figure 98 Ron English, Wynwood Walls Miami Florida 2011

Another example of a free wall is 5Pointz in Queens, New York City. The owner granted artists permission to use the outside of his dilapidated warehouse as a makeshift art space. 5Pointz Arts Center has become a mecca for graffiti artists, musicians and break-dancers from the five boroughs and beyond (Finn, 2011). The site is noted in foreign guidebooks as the "hippest" tourist attraction in Queens, an "out-of-doors paean to street art" (Finn, 2011). Nevertheless, in 2011 the building's owner announced their plans to redevelop the property into high-rise condos (McVeigh, 2012). This upset many people because 5Pointz is an important cultural landmark and the center of one of New York's largest and most vibrant artistic communities (McVeigh, 2012). Due to the bourgeoning community surrounding 5Pointz, the property is now worth \$20 million (McVeigh, 2012). 
This process of gentrification is a familiar story. Artists occupy neglected spaces, the new culture that arises attracts more creative types, businesses appear to serve them, property values rise, and then developers descend upon this now valuable area. Artists are effectively priced out and are forced to move on to the next space. Eric Benaim, an owner of a real estate company in Long Island City said this about 5Pointz:

It's a landmark, my favorite building. I'm in real estate. I understand why he (the owner of 5Pointz) wants to rent it, but I wish he would incorporate it into something. Neighborhoods change. Once-desolate areas become occupied by artists because of cheap rent, and then it becomes cool and there are restaurants, and then the developers come. It's like the cycle of life. But I owe a lot to the artists (McVeigh 2012).

There is not an easy solution to the problem of gentrification. Cities initially flourished because they facilitated interaction. People organized themselves into these complex structural systems to support the flow of innovative ideas. As transportation alternatives became more accessible, and cities increasingly crowded and dirty, the population decentralized. Those who could afford to leave the city moved to the periphery. Now, in many cities, the trend is reversing as transportation costs rise and the disillusionment of suburban life sets in. Young professionals want to live in the city, near employment opportunities and amenities. However, these spaces are not always vacant. People who did not want to, or could not afford to leave the city, are still there. The only fair and socially sustainable answer would be to carefully allow these areas to re-develop, but at the same time ensure that the area holds on to its original character by preserving unique architectural features, implementing rent-control for existing residents and businesses, and designating open spaces (preferably free) where temporary uses and creative ventures can still occur. 


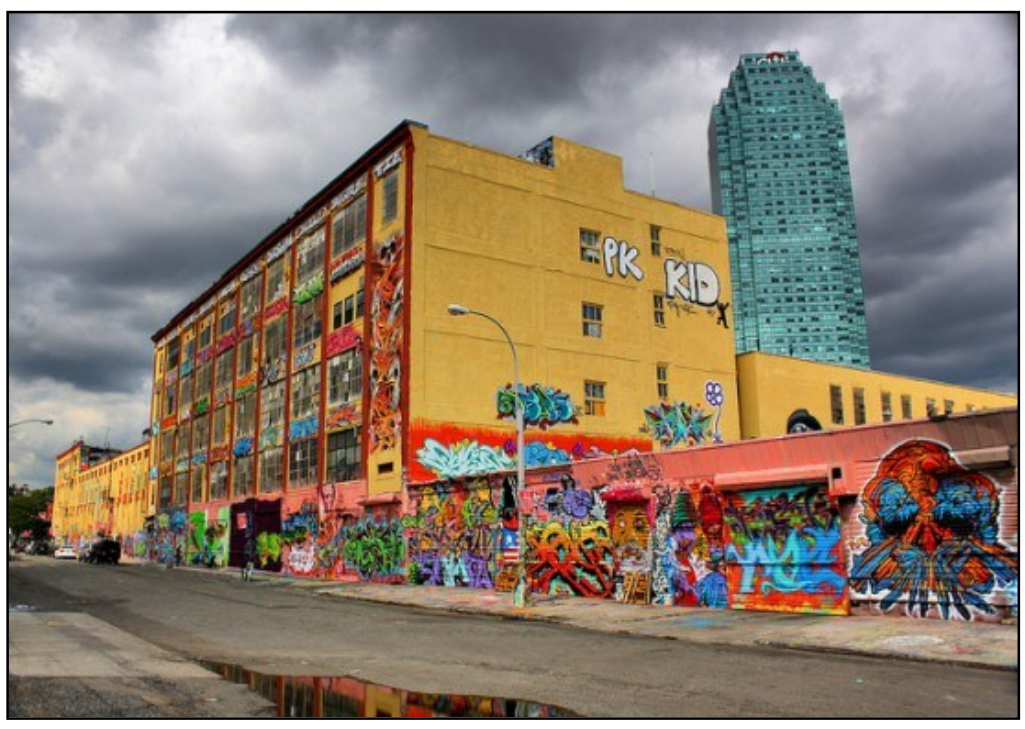

Figure 99 5Pointz, Queens NYC 2010 


\section{Re-evaluating the Broken Windows Theory}

Over the last few decades, graffiti has been theoretically linked to the fear of crime based on the broken windows theory. In 1998, NYC Mayor Rudolph Guiliani, said, "Obviously murder and graffiti are two vastly different crimes. But they are part of the same continuum, and a climate that tolerates one is more likely to tolerate the other" (NBER, 2012). Speaking about the situations on the NYC subways in 1979, Nathan Glazer said that graffiti signified that graffitists, other disorderly persons, and criminals "who rob, rape, assault, and murder passengers...are part of one world of uncontrollable predators" (Kelling \& Cole, 1997, p. 115). These types of comments suggest that if a community allows graffiti to occur they will morally digress and tolerate murders. I do not agree with this reasoning. Take for instance, Germany which certainly boasts some of the world's most impressive displays of graffiti. Despite the United States harsh stance on graffiti, America's murder rate is six times higher than the murder rate in Germany where graffiti is far more abundant (Atlantic Review, 2006).

Surely there are cases that graffiti may be done by people who have committed other more serious crimes, but this is far less prevalent than mainstream media portrays. By far, criminal gangs are not the sole propagators of graffiti. In the City of Portland, it is reported that gang graffiti accounts for only 13-15\% of graffiti (Dennis, 2010). My survey data shows that most respondents did not think the graffiti and street art shown to them was gang-related. In fact, the highest percentage of people thinking that a piece was gang-related was with the tagged bus stop pole, and even then, only $29 \%$ of respondents either agreed (19\%) or strongly agreed (10\%) that the piece had something 
to do with a gang. Not everyone views all graffiti as a symbol of crime or a crime itself; they instead take into consideration the nature of the piece, the context, and intent.

Why do people associate the occurrence of graffiti to other criminal activity? First, graffiti acts as a 'symbolic substitute' (Glassner, 1999) that those in power use to exploit underling cultural anxieties. Research shows that Americans hold persistent beliefs linking blacks and poor minorities to disorder, crime, violence, graffiti, welfare, and undesirability as neighbors (Bobo, 2001; Quillian \& Pager, 2001). People do not often directly fear disarray and dirt itself, but instead fear being near or associated with people that are stereotypically associated with those traits. It is therefore not just the material artifacts left behind that are the problem (i.e., graffiti); it is also the physical presence of these types of people invading the community that is feared. Therefore, the association between graffiti and fear of other crime, very well may be influenced by stereotypes of those thought to be responsible for the rise of graffiti; poor African American youth living in distressed cities. Those in positions of power and influence use the broken windows theory to justify “order-maintenance policing" strategies that forcibly maintain highly controlled and purified environments, restricting undesirable people, aesthetics, and ideas (White, 2000). ${ }^{72}$ It is often the poor and marginalized who are portrayed as the propagators of disorder. James Q. Wilson wrote about these "undesirables:"

The teenager hanging out on a street corner late at night, especially one dressed in an eccentric manner, a Negro wearing a "conk rag", girls in short skirts and boys in long hair parked in a flashy car talking loudly to friends on the curb, or interracial

\footnotetext{
${ }^{72}$ These "quality-of-life initiatives" also provide police legal reason to seize, search, and run checks on persons committing or just suspected of committing minor offenses instead of issuing warnings or implementing alternative problem-solving techniques (Harcourt, 2002). This has led to racial profiling and large prison and jail populations (of disproportionally high African American and minority populations).
} 
couples - all of these are seen by many police officers as persons displaying unconventional and improper behavior (1968, preface).

Additionally, graffiti is upsetting to those in power because it is a form of democratic free expression for people who may have limited opportunities to voice their dissent through mainstream channels (White, 2000). For some, public spaces are the only spaces where they can voice their grievances to a wider audience. Graffiti directly questions the rights of private property, individual land ownership, and state control, and is therefore seen as a threat to orderly society and its ability to safeguard hierarchical authority. Subscribers to the broken windows theory fail to consider other motives behind graffiti, and the fact that it is also used as a tool to propagate dissenting ideas by those struggling to be represented in the city.

Bernard Harcourt (2002) offers an excellent argument against the theoretical underpinnings of the broken windows ideology and how if these same issues are looked at in a different context, the theory does not hold up:

And what exactly is the meaning of neighborhood disorder? Sure it may signal that a community is not in control of crime. But it may also reflect an alternative subculture, political protest, or artistic creativity. An orderly neighborhood may signal commercial sex, wealthy neighbors with personal bodyguards, foreign diplomats, a strong mafia presence, or a large police force. The central claim of the broken windows theory, that disorder causes crime by signaling community breakdown, is flawed. The categories of "disorder" and "the disorderly" lie at the heart of the problem. Those categories do not have well-defined boundaries or settled meanings. When we talk about disorder, we are really referring to certain minor acts that some of us come to view as disorderly mostly because of the punitive strategies that we inflict as a society. We have come to identify certain acts (graffiti spraying, litter, panhandling, turnstile jumping, and prostitution) and not others (police brutality, accounting scams, and tax evasion) as disorderly and connected to broader patterns of serious crime. Hanging out on the front steps of a building or loitering with neighbors only signals that the community is not in control if hanging out or loitering is perceived as violating certain rules of conduct. But, of course, that depends on the neighborhood, and in some it reflects strong 
community bonds and informal modes of social control. Graffiti only signals that the neighborhood is indifferent to crime if graffiti is viewed as violating the rules of the community. But graffiti is sometimes understood to be political or artistic expression or social commentary.

As discussed in the literature review, some researchers question the broken windows theory because it has not been thoroughly tested and lacks empirical verification. Proponents of order-maintenance policing will cite the drop in crime that occurred during the 1990s as evidence that the strategy worked. While it is true that reported blue collar crime in NYC fell dramatically, other cities also experienced significant drops in crime without adopting these types of tactics (Harcourt, 2002). Harcourt cites a number of other factors that contributed to declining crime rates at this time, including a shift in drug use patterns from crack cocaine to heroin, favorable economic conditions, new computerized tracking systems that speed up police responses to crime, a dip in the number of 18-24 year old males, the hiring of more police officers, and shifts in adolescent behavior (2002). Nevertheless, even with all these other contributing factors, the NYPD's order-maintenance strategies received most of the credit for reducing crime. Finally, another reason anti-graffiti sentiment is so pervasive in societies is because the "war on graffiti," like all wars, is good for business. The war on graffiti has contributed to the massive growth of civilian markets; selling security technologies and services to law enforcement agencies and property owners (Iveson, 2010). ${ }^{73}$ As Chris Gorsek (2004) found in his research in Portland, buffing graffiti does not mean that there will be an eradication or reduction of graffiti occurrences in a given area. Instead money, time, and

\footnotetext{
${ }^{73}$ Broken-windows policing has other negative externalities. New York City, for instance, has experienced illegal strip searches, mounting financial liability on police misconduct charges, clogged courts, wasted resources and many traumatic encounters for ordinary citizens (Harcourt, 2002).
} 
effort are continuously expended with little avail. Anti-graffiti media campaigns do little to educate the public regarding the issues, instead these campaigns often serve only to taint public perceptions, further deepening the divide and increasing stereotyping. In order to fully understanding the problem, we must all strive to understand both sides of this heated argument. Opening up a dialogue between pro-graffiti and anti-graffiti activists is the first step to exploring alternative solutions that will serve both interests more justly. 


\section{Chapter 6. Conclusion}

With growing evidence of the global spread and locally diverse range of street art practices, forms, and styles, this research is a timely call for more research to clearly define, contextualize, and understand the rich spectrum of ways the spaces we inhabit are, have been, and can be inscribed (Dickens, 2009). This study presents evidence that zero tolerance policies towards graffiti and street art may, in some cases, be misguided. Further research on public perceptions of street art and graffiti is needed.

Historically, public spaces have not been an automatic or guaranteed public right. They have only been made public because someone takes the space and makes it public (Cresswell, 1996). This act of representation and overthrowing the normative order of the streets, both demands space and creates space (Mitchell, 2003). Existing public space will only remain open if people ensure its continued access by occupying it and consistently pushing its boundaries. Public space is a "city's barometer of justice" and its quality speaks volumes about what a society believes is important (Mitchell, 2003). Access to public space is important because these spaces serve as physical arenas for democratic actions. In uncertain times, when economic, social, and political systems fail to support society, graffiti serves the vital function of communicating grassroots ideas, sympathies, and demands.

Street art invites people to directly participate in the space and in doing so, has the potential to recover a sense of communal purpose and human solidarity (Kingwell \& Turmel, 2009). It is a cultural activity that can establish bonds between individuals, and individuals with features of the urban environment. Street art does not directly ask 
anything of you. It is simply there. The meanings are not always clear; we must use our imaginations and construct our own stories. Its power therein lies in provoking viewers to ask questions, to interact with place, and invent explanations.

The best art challenges us to think differently, provokes our emotions, and encourages healthy debate with other people. I believe this role is best played by street artists who are unencumbered and freely trespass into the everyday world to provoke ideas, embrace the unpredictability of public life, reclaim the streets, and take profound public action (Pasternak, 2010). To reclaim our right to the city, we must directly and imaginatively appropriate the city through collective spatial practices (Dimenberg, 1998). The city should be viewed as an oeuvre, an ongoing work in which all citizens have the right to participate in (Lefebvre, 1992; Mitchell, 2003). In 1845, Karl Marx noted, "humans act upon the world, changing it and themselves; and in doing so they make history." Instead of public spaces and art being produced for us and controlled by distant bodies, citizens must demand the right to the oeuvre, the right to making history in conditions of their own making and participate in the creation of their own realities. 


\section{Works Cited}

Adorno, T. \& Horkheimer, M. (1972). The Dialectic of the Enlightenment. New York: Herder and Herder.

Alcorn, J. (1981). Huastec Noncrop Resource Management: Implications for Prehistoric Rainforest Management. Human Ecology, 9(4), 395-417.

Art Basel. (2012). Art Basel Miami Beach. Retrieved April 24, 2012, from: http://www.artbasel.com/

Artists Initiative East Side Gallery. (2002). Artists Initiative East Side Gallery e.V. International Memorial for Freedom at the Berlin Wall. Retrieved April 24, 2012, from http://www.eastsidegallery.com/\#

Atlantic Review. (2006). Murder Rate in the United States and Germany. Retrieved April 24, 2012, from: http://atlanticreview.org/archives/434-Murder-Rate-in-the-UnitedStates-and-Germany.html

Auditor's Office. (2012). Chapter 14B.80 Graffiti Nuisance Property. City of Portland. Retrieved April 24, 2012, from:

http://www.portlandonline.com/auditor/index.cfm?c=28580

Austin, J. (2001). Taking the Train. New York: Columbia University Press.

B Media Collective. (2011). Create Abate. Video recording. Retrieved April 24, 2012 , from: http://www.youtube.com/watch?v=48gpCe_Wdpo

Bakhtin, M. (1968). Rabelais and His World. Cambridge, MA: MIT Press.

Banksy. (2006). The Writing on the Wall. The Guardian. March 23, 2006. Retrieved April 24, 2012, from: http://www.guardian.co.uk/artanddesign/2006/mar/24/art.australia

Barnwell, A. (2011) Arrest of prolific Portland tagger highlights renewed effort to blot out graffiti. OregonLive.com. October 23, 2011. Retrieved April 24, 2012, from: http://www.oregonlive.com/portland/index.ssf/2011/10/bust_of_prolific_portland_tagg.h tml

Barth, F. (1956). [2008] Ecological Relationships of Ethnic Groups in Swat, North Pakistan. M.R. Dove and C. Carpenter (Eds.), Environmental Anthropology: A Historical Reader. (pp. 181-189). Oxford: Blackwell Publishing. 
Basso, K. (1996). Wisdom Sits in Places: Landscape and Language among the Western Apache. Albuquerque: University of New Mexico Press.

Bates, J.A. \& Martin, M. (1980). The Thematic Content of Graffiti as a Non-reactive Indicator of male and female Attitudes. The Journal of Sex Research. 16, 300-315.

Blumberg \& Luke. (2010). NHIS Wireless Households Update. Retrieved April 24, 2012, from: http://www.cdc.gov/nchs/data/nhis/earlyrelease/wireless201012.htm

Bobo, L. (2001). Racial Attitudes and Relations at the Close of the Twentieth Century. In N. Smelser, W. J. Wilson, \& F. Mitchell (Eds.), America Becoming: Racial Trends and Their Consequences. Washington, DC: National Academy Press.

Bonnett, A. (1992). Art, Ideology, and Everyday Space: Subversive Tendencies from Dada to Postmodernism, Environment and Planning D. Society and Space, 10, 69-86.

Borden, I. (1996). Beneath the Pavement, the Beach: Skateboarding, Architecture and the Urban Dream. In I. Borden (Ed.), Strangely Familiar: Narratives of Architecture in the City (pp. 82-86). London: Routledge.

Bourdieu, P. (1986). The Forms of Capital. In J. Richardson (Ed.), Handbook of Theory and Research for the Sociology of Education (pp. 241-258). New York: Macmillan.

Brighenti, A. (2010). At the Wall: Graffiti Writers, Urban Territoriality, and the Public Domain. Space and Culture, 13(3), 315-332.

Brook, I. (2007). Aesthetic Aspects of Unauthorized Environmental Interventions. Ethics, Place and Environment, 10(3), 307-318.

Carlo, S., M. McCormick \& S. Schiller. (2010). Trespass: A History of Uncommissioned Urban Art. China: Taschen.

Carrington, V. (2009). I Write, Therefore I am: Texts in the City. Visual Communication, Los Angeles: Sage Publications.

Castleman, C. (1984). 'Getting Up': Subway Graffiti in New York. Cambridge, MA: MIT Press.

Chmielewska, E. (2007). Framing [con] text: Graffiti and Place. Space and Culture, 10(2), 145-169.

City of Melbourne. (2012), Street cleaning and graffiti: Graffiti and street art: Street art. Retrieved April 24, 2012, from: 
http://www.melbourne.vic.gov.au/ForResidents/StreetCleaningandGraffiti/GraffitiStreet Art/Pages/Whatisstreetart.aspx

City of Seattle. (2010, July 28). City of Seattle Anti-Graffiti Efforts: Best Practices and Recommendations. Office of City Auditor.

Clarke R. \& M. Felson. (1993). Introduction: Criminology. In R. Clarke \& M. Felson (Eds.), Routine Activity and Rational Choice: Advances in Criminology Theory (pp. 1-14) New Brunswick: Transaction Publications.

Cloke, P., I. Cook, P. Crang, M. Goodwin, J. Painter, \& C. Philo. 2010. (2004). Chapter 6: Doing Ethnographies. In Practicing Human Geography (pp. 169-205), London: Sage Publications.

Cooper, M. \& Chalfant, H. (1984). Subway Art. New York: Henry Holt and Company.

Cresswell, T. (1992). The Crucial Where of Graffiti, A Geographical Analysis of Reactions to Graffiti in New York. Environment \& Planning D: Society \& Space, 10, 329-344.

Cresswell, T. (1996). In Place/out of Place: Geography, Ideology, and Transgression. Minneapolis: University of Minnesota.

Cresswell, T. (2004). Place: A Short Introduction. Oxford: Blackwell.

Daisey, M. (2012). Scoop: Ham Bummer. Willamette Week. March 21, 2012.

Debord, G. (1955). Introduction to a Critique of Urban Geography. In K. Knapp (Ed.), Situationist International Anthology. Berkeley, CA: Bureau of Public Secrets. (Original work published in: Les Lèvres Nues \#6, Sept. 1955).

Debord, G. (1957). Report on the Construction of Situations. In K. Knapp (Ed.), Situationist International Anthology. Berkeley, CA: Bureau of Public Secrets.

Deitch, J. (2010). Art in the Streets. New York: Skira Rizzoli Publications.

DeLanda, M. (2006). A New Philosophy of Society. New York: Continuum.

Deleuze, G. \& Guattari, F. (1987). A Thousand Plateaus. London: Athlone.

Dennis, M. (2010). 'Graffiti: What does it say? What can YOU do about it?' Portland Online Office of Neighborhood Involvement. Retrieved March 21, 2012, from: http://www.portlandonline.com/oni/index.cfm?c=32420 
Dickens, L. (2008). Placing Post-graffiti: the Journey of the Peckham Rock. Cultural Geographies, 15(4), 471-96.

Dickens, L. (2008). "Finders Keepers": Performing the Street, the Gallery and the Spaces In-between. Liminalities: A Journal of Performance Studies, 4(1), 1-30.

Dickens, L. (2009). The Geographies of Post-Graffiti: Art Worlds, Cultural Economy and the City (Doctoral Dissertation, Department of Geography at Royal Holloway University of London 2009). Retrieved March 21, 2012, from:

http://goldsmiths.academia.edu/LukeDickens/Papers/1077743/The_Geographies_of_Pos t-graffiti_Art_Worlds_Cultural_Economy_and_the_City

Dillman, D. (2000). Mail and internet surveys: The tailored design method. New York: Wiley.

DiStefano, A. (2012). Sticking wih Slap Dash Art: Street Artists use Public Spaces for their Sticky Messages. Portland!Life Portland Tribune, March 15, 2012.

Douglas, M. (1996). Purity and Danger: An Analysis of the Concepts of Pollution and Taboo. New York: Routledge.

Dovey, K., S. Wollan, \& I. Woodcock. (2012). Placing Graffiti: Creating and Contesting Character in Inner-city Melbourne. Journal of Urban Design, 17(1), 21-41.

East PDX News. (2006). Westmoreland firefighters help quench 4-alarm fire. East PDX News. Retrieved March 21, 2012, from: http://eastpdxnews.com/fire-andpolice/westmoreland-firefighters-help-quench-4-alarm-fire/

Endless Canvas. (2012). About. Retrieved March 21, 2012, from $\mathrm{http}: / /$ endlesscanvas.com/?page_id=926

England, K. (1994). Getting Personal: Reflexivity, Positionality, and Feminist Research. Professional Geographer, 46, 80-9.

EZ. (2007). Street Art vs. Graffiti. Retrieved March 21, 2012, from http://tagline.blogspot.com/2007/04/evaluations-debates-and-comparisons.html

Ferrante, J. (2011). 'Street art' provides text for understanding cities: Street Art: From Berlin to Brooklyn. Bucknell University. Retrieved March 21, 2012, from: http://www.bucknell.edu/x66537.xml

Ferrell, J. (1993). Crimes of Style: Urban Graffiti and the Politics of Criminality. Current Issues in Criminal Justice 2. New York: Garland. 
Finn, R. (2011, August 21). "Writing's on the Wall (Art Is, Too, for Now)." New York Times, Retrieved March 21, 2012, from:

http://www.nytimes.com/2011/08/28/nyregion/5pointz-arts-center-and-its-graffiti-is-onborrowed-time.html?_r=1\&pagewanted=all

Freeman, C. (2010). Tacheles Art House battles with banks for survival. Retrieved March 21, 2012, from:

http://news.monstersandcritics.com/europe/features/article_1578551.php/Tacheles-ArtHouse-battles-with-banks-for-survival-Feature

Freke, T. (2009). How Long Is Now?: A Journey to Enlightenment... and Beyond. London: Hay House.

Gadsby, J. (1995). Looking at the Writing on the Wall: A Critical Review and Taxonomy of Graffiti Texts. Art Crimes. Retrieved March 21, 2012, from http://www.graffiti.org/faq/critical.review.html

Glassner, B. (1999). The Culture of Fear: Why Americans Are Afraid of the Wrong Things. New York: Basic Books.

Goetze, J. (1982, September 23). Fruit Looms on Blank Wall as First Sign of Attack on Blandness. The Oregonian.

Goetze, J. (2012, March 23). Rules trump creativity as a bright, comic-book style mural outside Hamburger Mary's in Northwest Portland is covered with beige paint. The Oregonian.

Gomez, M. (1993). The writing on our walls: Finding solutions through distinguishing graffiti art from graffiti vandalism. Journal of Law Reform, 26, 6333-6707.

Goode, R. (2007). The Politics of Pasting: A Spatial Inquiry into the Practice(s) of Wheatpasting, Power, and Representation. (Master's Thesis, California State University, Department of Geography). (Publication No. 1451173)

Gorilla Wallflare. (1982, August 5). Press Release. Retrieved April 14, 2012, from: https://www.facebook.com/media/set/?set=a.147965628575229.22804.14796434190869 $1 \&$ type $=3$

Gorsek, C. (2004). The Effect of Informal Social Control on the Presence and Geographic Distribution of Graffiti on City Streets. (Doctoral Dissertation, Portland State University, Department of Urban Studies and Planning). (UMI Number: 3150613)

Gottlieb, L. (2008). Graffiti Art Styles: a Classification System and Theoretical Analysis. Jefferson, NC: McFarland. 
Graffiti 911. (2008). Graffiti Facts: Costs of Graffiti. Retrieved April 14, 2012, from: http://www.graffiti911.com/costs.php

Graffiti Hurts. (2011) Sheriff's Office of Washington County. Retrieved April 14, 2012, from http://www.co.washington.or.us/Sheriff/OtherServices/GangsGraffiti/graffiti-hurtsprogram.cfm

GrafRank. (2012). Global Graffiti Statistics. Retrieved April 14, 2012, from: http://www.grafrank.com/citiesindex.html

Günes, S. \& G. Yýlmaz. (2006). Understanding Graffiti in the built Environment: The case in Ankara, Turkey. Case Study presented on the ISOCARP Congress 2006: Cities between Integration and Disintegration. Retrieved April 14, 2012, from http://www.isocarp.net/projects/case_studies/cases/cs_info.asp?ID=724

Hall, S., Clarke, J. \& Jefferson, T. (1976). Resistance through Rituals: Youth Subcultures in Post-War Britain. London: University of Birmingham.

Halsey, M. \& A. Young. (2006). Our Desires are Ungovernable: Writing Graffiti in Urban Space. Theoretical Criminology, 10(3), 275-299.

Harcourt, B. (2001). Illusion of Order: the False Promise of Broken Windows Policing. Cambridge, MA: Harvard UP.

Harcourt, B. (2002). Policing Disorder: Can we reduce serious crime by punishing petty offenses? Boston Review. Retrieved April 14, 2012, from:

http://bostonreview.net/BR27.2/harcourt.html

Hay, I. (2010). Qualitative Research Methods in Human Geography. Oxford: Oxford UP.

Hardin G. (1968). The Tragedy of the Commons. Science, 162(3859), 1243-1248.

hooks, b. (1995). Art on my Mind: Visual Politics. New York: New Press.

horseproject.net. (2008). Portland Horse Project. Retrieved April 14, 2012, from http://www.horseproject.net/thieves.htm

Hou, J. (2010). Insurgent Public Space: Guerilla Urbanism and the Remaking of Contemporary Cities. New York: Routledge.

Iveson, K. (2002). Call to the Streets II: London. Graphotism 27. 
Iveson, K. (2007). Publics in the City. Oxford: Wiley-Blackwell.

Iveson, K. (2010) The Wars on Graffiti and the New Military Urbanism. City, (14)1-2, 115-134.

Jakob, K. (2008). Street Art in Berlin. Berlin: Jaron.

Kelling, G. \& C. Coles. (1997). Fixing Broken Windows: Restoring Order and Reducing Crime in Our Communities. New York: Free Press.

Kendall, D. (2011, April 14). Street Art: A Window to a City's Soul. Huffington Post. Retrieved April 14, 2012, from http://www.huffingtonpost.com/dylan-kendall/street-arta-window-to-a-_b_823592.html?ir=Los\%20Angeles

Kilian, A. (2011). Seniors with Spray Cans: Germany's Older Generations Take Up Graffiti. Spiegel Online. Retrieved from:

http://www.spiegel.de/international/0,1518,778978,00.html

Kingwell, M., \& P. Turmel. (2009). Rites of Way: the Politics and Poetics of Public Space. Waterloo, Ont.: Wilfrid Laurier UP.

Knabb, K., ed. (1981). Situationist International: Anthology. California: Bureau of Public Secrets.

Kwon, M. (2002). One Place after Another: Site-Specific Art and Locational Identity. Cambridge MA: MIT Press.

Ladd, B. (1997). The Ghosts of Berlin: Confronting German History in the Urban Landscape. Chicago: University of Chicago.

Lefebvre, H. (1992). The Production of Space. Massachusetts: Wiley-Blackwell.

Legal-Walls. (2012). Find Legal Walls around the World. Retrieved April 14, 2012, from: http://legal-walls.net/\#lat=47.5378\&lng=8.773270000000025\&zoom=2

Leonard, R. (2006, September 6). Teeny Weeny Horses Run Rings around S.E. Portland History. The Bee Community Newspaper.

Lofland, J., D. Snow, L. Anderson, \& L. Lofland. (2006). Analyzing Social Settings: A Guide to Qualitative Observation and Analysis. Belmont, CA: Wadsworth/Thomson Learning.

MacDonald, N. (2001). The Graffiti Subculture. New York: Palgrave Macmillan. 
MacDonald, N. (2005). The Graffiti Subculture: Making A World of Difference. In K. Gelder (Ed.), The Subcultures Reader, New York: Routledge.

MacPhee, J. (2004). Stencil Pirates: A Global Study of the Street Stencil. Brooklyn NY: Sof Skull Press.

Marx, K. (1845). The German Ideology. Feuerbach: Opposition of the Materialist and Idealist Outlook: Idealism and Materialism. Retrieved November 15, 2010, from http://www.marxists.org/archive/marx/works/1845/german-ideology/ch01a.htm

MASS MoCa. (2011). The Interventionists: Art in the Social Sphere. Massachusetts Museum of Contemporary Art. Retrieved April 10, 2012, from http://www.massmoca.org/event_details.php?id=38

Massey, D. (1994). Space, Place and Gender. Cambridge: Polity.

Massey, D. (2005). For Space. London: SAGE.

Massumi, B. (2002). Navigating Movements: A Conversation with Brian Massumi. In M. Zournazi (Ed.), Hope: New Philosophies for Change (pp. 210-43). Annandale: Pluto Press.

McCracken, P. (2011). Type Talk: Typographic Terrorism. Pacific Northwest College of Art Online Magazine. Retrieved April 10, 2012, from:

http://untitled.pnca.edu/articles/show/5329/

McGaw, J. (2008). Complex Relationships between Détournement and Recuperation in Melbourne's Street (Graffiti and Stencil) Art Scene. Architectural Theory Review, 13(2), 222-239.

McVeigh, K. (2012, January 17). 5Pointz: New Yorkers Prepare to Say Goodbye to a Slice of Hip-Hop History. The Guardian. Retrieved March 2, 2012, from:

http://www.guardian.co.uk/world/2012/jan/17/5pointz-new-york-hip-hop-history

MetMuseum. (2011). Chauvet Cave. The Metropolitan Museum of Art in New York City. Retrieved March 19, 2012, from

http://www.metmuseum.org/toah/hd/chav/hd_chav.htm

Miglavs, J. (1987) “Off the Wall.” Northwest Magazine. Sunday April 12, 1987. pp.18, 22.

Mirk, S. (2011, August 25). Graffiti Police Crack Down on Gallery for Hosting Street Art Show. Portland Mercury. Retrieved August 25, 2011, from: 
http://blogtown.portlandmercury.com/BlogtownPDX/archives/2011/08/25/graffitipolice-crack-down-on-gallery-for-hosting-street-art-show

Mitchell, D. (2003). The Right to the City: Social Justice and the Fight for Public Space. New York: Guilford.

MOCA. (2011). Outside In: The Story of Art in the Streets. Retrieved April 20, 2012, from: http://www.hulu.com/watch/295710/outside-in-the-story-of-art-in-the-streets Moore, M., \& L. Prain. (2009). Yarn Bombing: the Art of Crochet and Knit Graffiti. Vancouver: Arsenal Pulp.

National Bureau of Economic Research (NBER). (2012). What Reduced Crime in New York City. Retrieved January 11, 2012, from:

http://www.nber.org/digest/jan03/w9061.html

Neighborhood Business Districts (2012). It's Not Just About Neighborhood Pride: Murals Prevent Graffiti AND Drive Retail Sales. Neighborhood Business Districts. Retrieved April 2, 2012, from: http://www.uptowngr.org/its-not-just-aboutneighborhood-pride-murals-prevent-graffiti-and-drive-retail-sales.html/

NoGraffiti.com. (n.d.). Graffiti "Free" or "Sanctioned" Walls Vignettes from All Over. Retrieved on April 4, 2012, from: http://www.nograffiti.com/files/freewalls.htm

Office of Neighborhood Improvement (ONI). (2012). Graffiti Abatement Community Grant Program Grant Applications in Process. Retrieved April 19, 2012, from: http://www.portlandonline.com/oni/index.cfm?c=53260\&

Ostrom, E. (1990). Governing the Commons: the Evolution of Institutions for Collective Action. Cambridge: Cambridge UP.

Orengo, H., \& D. Robinson. (2008). Contemporary Engagements Within Corridors of the Past: Temporal Elasticity, Graffiti and the Materiality of St Rock Street, Barcelona. Journal of Material Culture, 13(3), 267-86.

Parker, S. (2004). Urban Theory and the Urban Experience: Encountering the City. New York: Routledge.

Pasternak, A., (2010). Just Do It. In E. Seno (Ed.), Trespass: A History of Uncommissioned Urban Art. China: Taschen.

Pew Research Center. (2012). Internet Surveys. Retrieved February 20, 2012, from: http://www.people-press.org/methodology/collecting-survey-data/internet-surveys/ 
Pinder, D. (2005). Visions of the City: Utopianism, Power and Politics in TwentiethCentury Urbanism. Edinburgh: Edinburgh University Press.

Planetizen. (2012). Top Planning Trends of 2011-2012. Planetizen. Retrieved April 24, 2012, from: http://www.planetizen.com/node/54838

Portland Development Commission. University Plaza: The Urban Center. Retrieved April 4, 2012 from: http://vmw.pdc.us/pdf/dev_serv/pubs/dev_proj_fs_psu.pdf

Portland Horse Project. (n.d.). In Facebook (Fan Page). Retrieved March 28, 2012, from: https://www.facebook.com/PortlandHorseProject

Portland Police. (2012). Graffiti. Portland, Maine Police Department (Website). Retrieved March 20, 2012, from: http://www.portland-police.com/graffiti.asp

Portland Maps. (2012). 4511 SE 23rd Ave Reed Portland. Permit Case Report. Retrieved March 1, 2012, from: http://portlandmaps.com

Posey, D. (1985). Indigenous Management of Tropical Forest Ecosystems: The Case of the Kayapó Indians of the Brazilian Amazon. Agroforestry Systems, 3, 139-158.

Putman, R. (1995). Bowling Alone: America's Declining Social Capital. Journal of Democracy, 6, 65-78.

Quillian, L. \& D. Pager. (2001). Black Neighbors, Higher Crime? The Role of Racial Stereotypes in Evaluations of Neighborhood Crime. American Journal of Sociology, 107, 717-67.

Quin, M. (2010). Zero-tolerance graffiti plan cops a spray. Melbourne Times Weekly. Retrieved March 21, 2011, from:

http://www.melbournetimesweekly.com.au/news/local/news/general/zerotolerancegraffiti-plan-cops-a-spray/2025209.aspx

Rahn, J. (2001). Painting without Permission. Basingstoke: Palgrave.

Rappaport, R. (1967). [2008] Ritual Regulation of Environmental Relations among a New Guinea People. In M.R. Dove \& C. Carpenter (Eds.), Environmental Anthropology: A Historical Reader (pp. 254-264). Oxford: Blackwell Publishing.

Rentschler, C. A. (2003). Designing Fear: How Environmental Security Protects Property at the Expense of People. In J. Z. Bratich, J. Packer, \& C. McCarthy (Eds.), Foucault, Cultural Studies, and Governmentality (pp. 243-271). Albany: State University of New York Press. 
Riviere, M. (2005). The Dynamics of a Canvas: Graffiti and Aerosol Art. Public Art Review, 17(33), 24-27.

Rose, C. (1999). Agitprop art: From the Spraycan to the CD-ROM in Trade Secrets. Young British Talents Talk Business. London: Thames and Hudson.

Rusk, K. (2011, December 15). Dozens arrested in San Jose graffiti crackdown. South Bay News ABC. Retrieved January 11, 2012, from:

http://abclocal.go.com/kgo/story?section=news/local/south_bay\&id=8469021

Sampson, R. \& S. Raudenbush. (2004) Seeing Disorder: Neighborhood Stigma and the Social Construction of "Broken Windows." Social Psychology Quarterly, 67(4), 319342.

Sanders, B. (2005). Youth Crime and Youth Culture in the Inner City. London:

Routledge.

Schacter, R. (2008). An Ethnography of Iconoclash. Journal of Material Culture, 13(1), $35-61$.

Schlecht, N. (1995). Resistance and Appropriation in Brazil: How the Media and 'Official Culture' Institutionalized Paulo's Grafite. Studies in Latin American Popular Culture, 14, 37-67.

Semenza, J. (2006). The City Repair Project. Retrieved April 1, 2012, from: http://www.inthefield.info/city_repair.pdf

Semenza, J. \& T. March. (2009). An Urban Community-Based Intervention to Advance Social Interactions. Environment and Behavior, 41(1), 22-42.

Shaftoe, H. (2006). Behaving badly in public places. Urban Design, 97, 19-21.

Shane. (2009). Interview with 'Shane' of the Anarchist Media Group in Berlin. Retrieved March 1, 2010, from: http://anarchism.pageabode.com/andrewnflood/torturedgeography-berlin

Shanti, D. (2012). Street Art vs. Graffiti. Vimeo. Retrieved April 24, 2012, from: http://vimeo.com/20047963

Sibley, D. (1995). Geographies of Exclusion: Society and Difference in the West. London: New York.

Solomon, D. (2001). Conducting web-based surveys. Practical Assessment. Research \& Evaluation, 7(19). 
Speer, R. (2004, November 10). Pillars of the Community: The Lovejoy Columns, Urban Landmark. Willamette Week. Retrieved March 19, 2012, from:

http://www.wweek.com/portland/article-3815-pillars_of_the_community.html

Spidertag. (2011). Yarn-bombing that doesn't suck. Vandalog. Retrieved December 28, 2011, from: http://blog.vandalog.com/2011/10/yarn-bombing-that-doesnt-suck/

St John, G. (2008). Protestival: Global Days of Action and Carnivalized Politics in the Present. Social Movement Studies, 7(2), 167-190.

Steinert, H. (2003). The Indispensable Metaphor of War on Populist Politics and the Contradictions of the State's Monopoly of Force. Theoretical Criminology, 7(3), 265291.

Steward, J. (1955). [2008] The Great Basin Shoshonean Indians: An Example of a Family Level of Sociocultural Integration. In M.R. Dove \& C. Carpenter (Eds.), Environmental Anthropology: A Historical Reader. Oxford: Blackwell Publishing.

Stevens, Q. (2007). The Ludic City: Exploring the Potential of Public Spaces. New York: Routledge.

Sullivan, D. \& S. Shaw. (2011). "White Night": Gentrification, Racial Exclusion, and Perceptions and Participation in the Arts. City \& Community, 10(3), 241-264.

Sunnyside Neighborhood Newsletter (2011). Crime Prevention Month Activities. Retrieved March 20, 2012, from: http://sunnysideneighborhood.wordpress.com/ taki183.net. (2012). TAKI 183. Retrieved November 16, 2011, from: http://www.taki183.net/\#

Taylor, M., R. Cordin, \& J. Njiru. (2010). A Twenty-first Century Graffiti Classification System: A Typological Tool for Prioritizing Graffiti Removal. Crime Prevention and Community Safety, 12(3), 137-155.

Thompson, N., (2004). Interventionists: Users' Manual for the Creative Disruption of Everyday Life. North Adams, MA: MASS MoCA.

Tracy, A. (2008, May 29). Stumptown Stumper. Portland Tribune. Retrieved May 1, 2011 from:

http://www.portlandtribune.com/news/story.php?story_id=121200820449860100

Tuan, Y. (1977). Space and Place: the Perspective of Experience. Minneapolis: University of Minnesota. 
Tuan, Y. (1974). Topophilia: A Study of Environmental Perception, Attitudes, and Values. New York: Columbia University Press.

US Census Bureau (2010) FactFinder Portland, Oregon. Retrieved March 19, 2012, from: http://factfinder2.census.gov

Vaneigem, R. (1972). The Revolution of Everyday Life. Trans. J. Fullerton \& P. Sieveking: Practical Paradise.

Vivoni, F. (2009). Spots of Spatial Desire: Skateparks, Skateplazas, and Urban Politics. Journal of Sport \& Social Issues, 33(2), 130-49.

Von Lanzenauer, J. (2011). Berlin Street Art: The Quest for Golden Garbage. The Washington Times. Retrieved December 1, 2011, from:

http://communities.washingtontimes.com/neighborhood/donnesworld/2011/sep/10/berlin-street-art-quest-golden-garbage/

Waymaking. (2012). Brooklyn Intermodal Rail Yard, Portland, Oregon. Groundspeak, Inc. Retrieved January 12, 2012, from:

http://www.waymarking.com/waymarks/WMC7QA_Brooklyn_Intermodal_Rail_Yard_ Portland_Oregon

Weinberg, R. (2003, December 8). Shooting the Messenger: Rethinking Confrontation in the War against Graffiti. Spindrift. Retrieved April 2, 2012, from: http://www.spindrift.org/graffiti.pdf

Wendl, P. (2011). The Mythological City. Eurozine. Retrieved November 3, 2011, from: http://www.eurozine.com/articles/2011-07-25-wendl-en.html

West, R. (2012). Hoyt Street Yard \& Lovejoy Columns. Portland Places. Retrieved January 25, 2012, from: http://myweb.msoe.edu/ westr/pdxlovejoycolumns.htm

White, R. (2000). Graffiti, crime prevention and cultural space. Current Issues in Criminal Justice, 12, 253-266.

Wilson, J. Q. (1968). Varieties of Police Behavior; the Management of Law and Order in Eight Communities. Cambridge, MA: Harvard UP.

Wilson, J. \& G. Kelling. (1982). The Police and Neighborhood Safety: Broken Windows. The Atlantic Monthly, 127, 29-38. 
Wilson, R. (1986). Experiencing Creativity. In The Sociology and Psychology of Art. New Brunswick, New York: Transaction Books.

Wollan, W. (2011, May 18). Graffiti's Cozy, Feminine Side. New York Times. Retrieved May 18, 2011, from: http://www.nytimes.com/2011/05/19/fashion/creating-graffiti-withyarn.html?_r=1\&adxnnl=1\&adxnnlx=1329699982-5zUy/CMBwJn6a77FAtH+gA

Wynwood Walls. (2012). About Wynwood Walls. Retrieved March 1, 2012, from: http://thewynwoodwalls.com/About/ 


\section{Photograph Citations}

\section{All photographs not cited below where taken by the author.}

Figure 2: GrafRank Global Graffiti Concentration as of March 2012:

Dobkin, J. (Website Creator). (2012). Worldwide GrafMap. [Map], Retrieved March 16, 2012, from: URL (http://www.grafrank.com/index.html)

Figure 4: Lovejoy Column (Present Day):

Jeffers, L. (Photographer). (2012). Lovejoy Column [Photo], Retrieved March 16, 2012, from: URL (http://www.flickr.com/photos/portland_urban_living/5045242539/)

Figure 5: Lovejoy Column (Pre-Re-Development):

Tgd1220. (Photographer). (Unknown Date). No Parking Any Time [Photo], Retrieved March 16, 2012, from: URL

[http://www.flickr.com/photos/maxwells_demon/2173043557/)

Figure 6: “Oh No!" Gorilla Wallflare:

Gorilla Wallflare. (2012). Oh No Mural [Photo], Retrieved March 16, 2012, from: URL (https://www.facebook.com/pages/Gorilla-Wallflare/147964341908691)

Figure 7: "Art Fills the Void" GorillaWallflare:

Gorilla Wallflare. (2012). Art Fills the Void Mural [Photo], Retrieved March 16, 2012, from: URL (https:/www.facebook.com/pages/Gorilla-Wallflare/147964341908691)

Figure 11: Reported Graffiti in Portland 2005-2006:

City of Portland. (2006). Graffiti Maps 2005-2006, Citywide [Map], Retrieved March 16, 2012 from: URL (http://www.portlandonline.com/oni/index.cfm?c=39978\&)

Figure 37: Subway NYC 1980s:

Unknown. (1980s). Unknown Title [Photo], Classic Hits: New York's Pioneering Subway Graffiti Writers' Book. Retrieved March 16, 2012, from: URL (http://www.notorietyinc.com/blog/\%E2\%80\%98classic-hits-\%E2\%80\%93-newyork $\% \mathrm{E} 2 \% 80 \% 99$ s-pioneering-subway-graffiti-writers $\% \mathrm{E} 2 \% 80 \% 99$-book)

Figure 38: Lower Eastside NYC 1970s:

Cooper, M. (Photographer). (1970s). Martha Cooper x Obey 'Street Play' Collection [Photo], Retrieved March 16, 2012 from: URL (http://popieces.blogspot.com/2009/02/martha-cooper-X-obey-street-play.html)

Figure 39: Happy Holiday by Richie and Jason, South Bronx 1982:

Cooper, M. (Photographer). (1984). Happy Holiday by Richie and Jason [Photo], Subway Art. New York: Henry Holt and Company. 
Figure 40: MIDG, South Bronx 1983:

Cooper, M. (Photographer). (1984). MIDG, South Bronx 1983 [Photo], Subway Art. New York: Henry Holt and Company.

Figure 41: 1980 "Minotaur Brooklyn Bridge," Paolo Buggiani 1980:

Buggiani, P. (Photographer). (1980). Minotaur Brooklyn Bridge [Photo], Carlo, S., M. McCormick and S. Schiller. (eds.). (2010). Trespass: A History of Uncommissioned Urban Art. China: Taschen.

Figure 42: 1992 "Portofess," Joey Skaggs 1992:

Skaggs, J. (Artist). (1992). Portofess [Photo], Retrieved March 16, 2012, from: URL (http://www.joeyskaggs.com/html/port.html)

Figure 43: Stacy Peralta Photographed by Craig Stecyk 1976:

Stecyk, C. (Photographer). (1972). Stacy Peralta [Photo], Nikki Columbus (ed.). (2010). Art in the Streets. The Museum of Contemporary Art. New York: Skira Rizzoli Publications.

Figure 44: Blending of Graffiti and Street Art Styles:

PakOne. (Artist). (2012). "Cerisier" (Brest) [Photo], Retrieved March 16, 2012, from: URL (http://www.flickr.com/photos/b-z-hasch/6910530025/)

Figure 45: Spidertag:

Spidertag. (Artist). (2011). Masterpieces [Photo], Retrieved March 16, 2012, from: URL (http://spidertag.wordpress.com/masterpieces/)

Figure 46: "The Joy of Not Being Sold Anything," Banksy, London 2005:

Banksy. (Artist). (2005). Title Unknown [Photo], Retrieved March 28, 2012, from: URL (http://thequirkyinventor.tumblr.com/post/12596627470/the-joy-of-not-being-soldanything)

Figure 47: Mentalgassi Wheatpaste, Berlin:

Mentalgassi. (Artist). (2009). Ticket Machine Man in Berlin [Photo], Retrieved March 16, 2012, from: URL (http://laughingsquid.com/berlin-street-art-by-mentalgassi/)

Figure 48: "Pedestrian Shuffle," Leon Reid, Brooklyn 2011:

Reid, L. (Artist). (2011). Pedestrian Shuffle [Photo], Retrieved March 16, 2012, from: URL (http://www.woostercollective.com/post/leon-reid-ivs-pedestrian-shuffle)

Figure 49: Revs Metal Sculptures, New York City:

Revs. (Artist). (unknown). Revs Metal Sculptures [Photo], Retrieved March 16, 2012, from: URL (http://www.juxtapoz.com/Street-Art/revs-metal-sculptures) 
Figure 50: Moss Girl, Brooklyn:

Tokodi, T. (Artist). (2008). Moss Stencil [Photo], Retrieved March 16, 2012, from: URL (http://mosstika.com/)

Figure 51: Mark Jenkins, Baltimore:

Jenkins, M. (Artist). (2008). Dogs on Trash [Photo], Fresh Air Smells Funny Urban Art. Kunsthalle Dominikanerkirche (ed.). rik reinking: Germany.

Figure 52: Haas \& Hahn, Favela Rio de Janeiro 2006:

Haas \& Hahn. (Artists). (2010). Favela Paining [Photo], Retrieved March 28, 2012, from: URL (http://www.dutchartevents.com/tag/favela-painting/)

Figure 53: Walking Man, Bergen Norway:

Unknown. (2006). Walking Man in Norway [Photo], Retrieved March 16, 2012, from:

URL (http://www.woostercollective.com/post/walking-man-in-norway)

Figure 54: Yaron's Favela, Czech Republic:

Yaron. (Artist). (2010). Yaron's Favela [Photo], Retrieved March 28, 2012, from: URL (http://cwoca.com/architecture/cardboard-street-art-yarons-favela-in-czech-republic)

Figure 55: "Drinking Water Running through the Streets," Spain 2012:

Luzinterruptus. (Artist). (2012). Drinking Water Running through the Streets [Photo], Retrieved March 28, 2012, from: URL (http://www.woostercollective.com/post/luzinterruptus-drinking-water-running-throughthe-streets)

Figure 56: "Fake Bird Twitters at Real People," NYC:

Unknown. (2010). Fake Bird Twitters at Real People [Photo], Retrieved March 28, 2012, from: URL (http://www.woostercollective.com/post/seen-on-mott-street-in-nyc-mottstreet-fake-bird-twitters-at-real-people)

Figure 57: "Protesting Potatoes in front of McDonalds" Berlin 2012:

Peter Pink. (Artist). (2012). Protesting Potatoes in front of McDonalds [Photo], Retrieved March 28, 2012, from: URL (https://www.facebook.com/pages/PeterPink/376915795652764)

Figure 58: Subway Police, NYC 1980s:

Unknown. (1980s). Title Unknown [Photo], Cooper, M. and Chalfant, H. (1984).

Subway Art. New York: Henry Holt and Company.

Figure 59: "The Last Graffiti Artist," Mark Jenkins, Malmo Sweden 2008:

Jenkins, M. (Artist). (2008). The Last Graffiti Artist [Photo], Retrieved April 6, 2012, from: URL (http://www.xmarkjenkinsx.com/lastgraffitiartist.html) 
Figure 60: panoptICONS City Surveillance Awareness Project, Utrecht Netherlands: voor 't Hekke and van Oerle. (Artists). (2010). PANOPTICONS 2010 [Photo], Retrieved March 16, 2012, from: URL (http://www.thomasvoorthekke.com/?cat=12)

Figure 61: Community-Contributed Shrine Portland, Oregon:

Island Woman MJ. (Photographer). (2010). A shrine someone made on the corner in the neighborhood [Photo], Retrieved March 16, 2012, from: URL

(http://islandwomanculebra.blogspot.com/2010_09_01_archive.html)

Figure 68: Peter Pink Installation, Berlin 2011:

Peter Pink. (Artist). (2011). Title Unknown [Photo], Retrieved April 11, 2012, from:

URL (https://www.facebook.com/pages/Peter-Pink/376915795652764?ref=ts)

Figures 69 and 70: Skip Conversions, London 2008:

Bishop-Young, O. (Artist). (2008). Skip Conversions [Photo], Urban Interventions:

Personal Projects in Public Spaces. R. Klanten and M. Hubner. (eds.). Berlin: Gestalten.

Figure 71: PARK(ing) Day, F.A.D., Lisa Town, and Jason King, Seattle2009:

F.A.D., Town, L. and King, J. (Artists). (2009). Four Play [Photo], Retrieved March 28, 2012, from: URL (http://freeassociationdesign.wordpress.com/tag/tactical-urbanism/)

Figure 73: "Instant Hutong," Beijing 2009:

Campa, M. and Avesani. S. (Artists). (2009). Instant Hutong [Photo], Urban

Interventions: Personal Projects in Public Spaces. R. Klanten and M. Hubner. (eds.)

Berlin: Gestalten. pp. 198-199

Figures 94, 95 and 96: Street Art, Melbourne Australia:

Dill, J. (Photographer). (2010). Melbourne Graffiti Picasa Album [Photo], Retrieved March 16, 2012, from: URL

(https://picasaweb.google.com/jenniferlynndill/MelbourneGraffiti?authuser=0\&authkey

$=$ Gv1sRgCMXn_6jqlZXyVg\&feat=directlink)

Figure 97: Shepard Fairey, Wynwood Walls, Miami Florida 2011:

Fairey, S. (Artist). (2011). Title Unknown [Photo], Retrieved March 16, 2012, from:

URL (http://thewynwoodwalls.com/)

Figure 98: Ron English, Wynwood Walls, Miami Florida 2011:

English, R. (Artist). (2011). Title Unknown [Photo], Retrieved March 16, 2012, from:

URL (http://thewynwoodwalls.com/)

Figure 99: 5Pointz, Queens NYC 2010:

Blough, J. (Photographer). (2010). 5pointz [Photo], Retrieved March 16, 2012, from:

URL (http://www.flickr.com/photos/jblough/5004531901/) 


\section{Appendix A. Graffiti and Street Art Evolution}

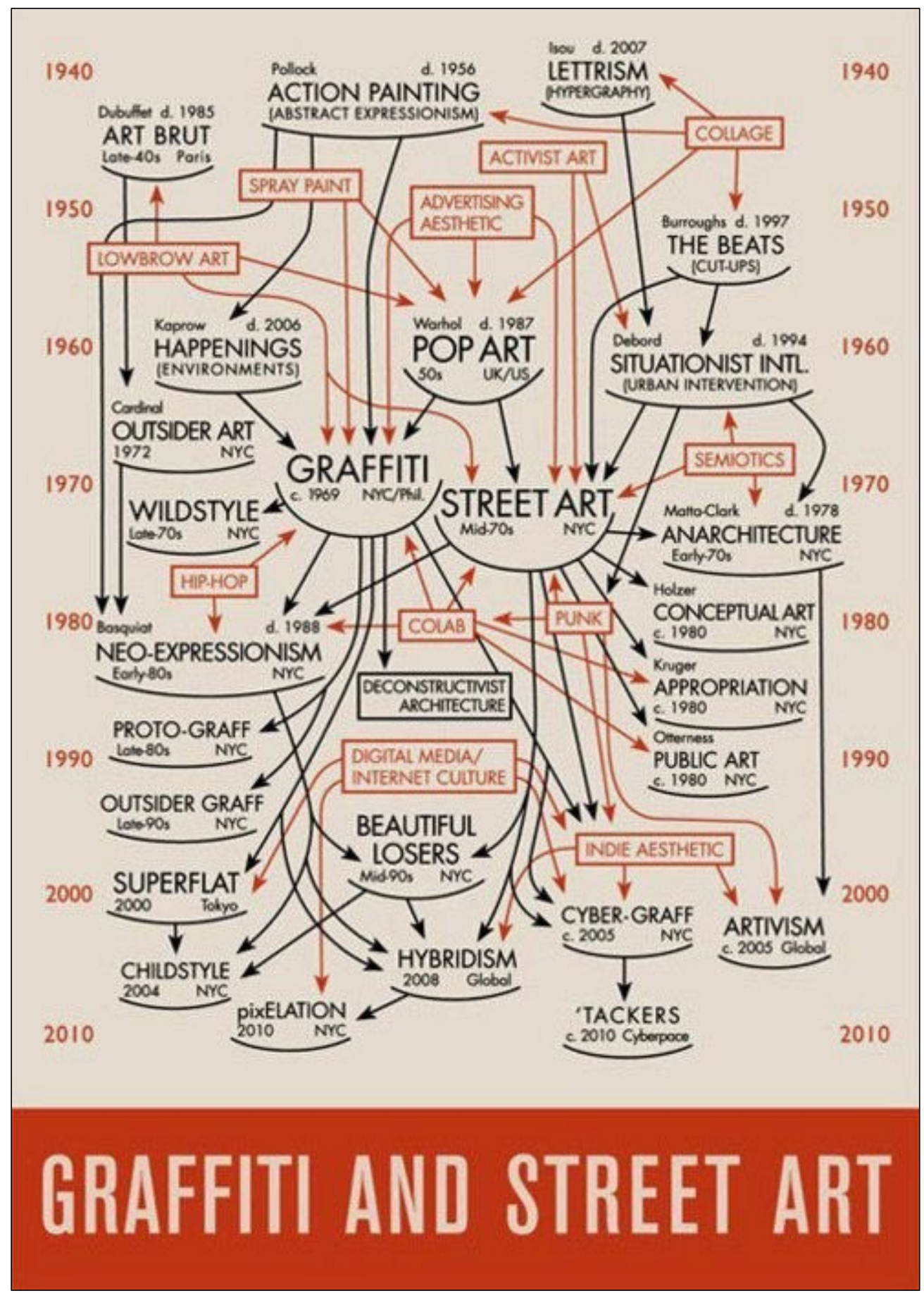

Feral, D. (2011). Graffiti and Street Art. Retrieved from:

http://www.abstractmodem.com/2011/04/graffiti-and-street-art.html 


\section{Appendix B. My Interventions}

\section{Community ChaLK Box InStallation}

Location: SE 33rd and Yamhill, Portland Oregon

Created: Thursday, November $17^{\text {th }}, 2011$ at $11: 00 \mathrm{pm}$

Status: Removed February 2012 due to disrepair.
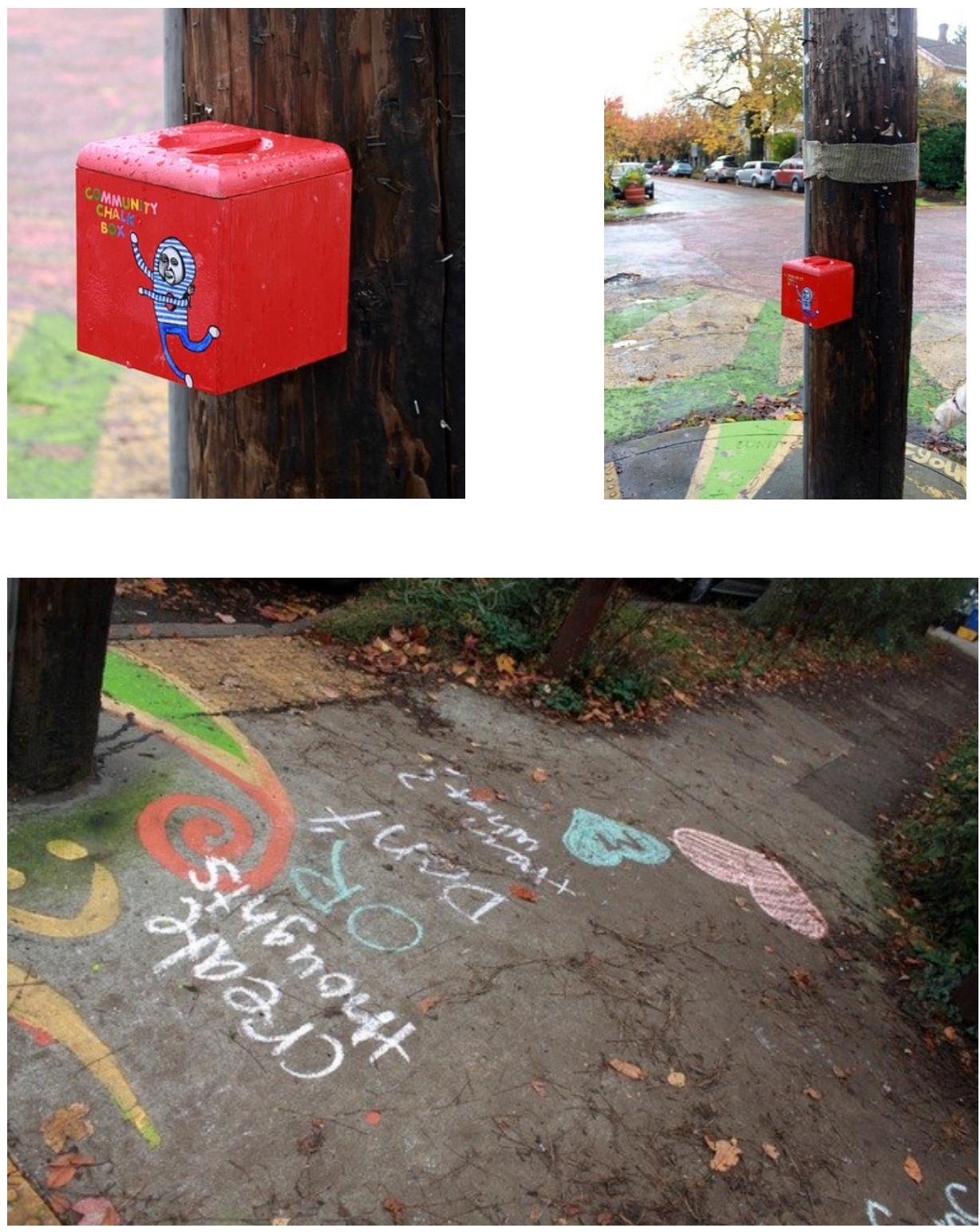

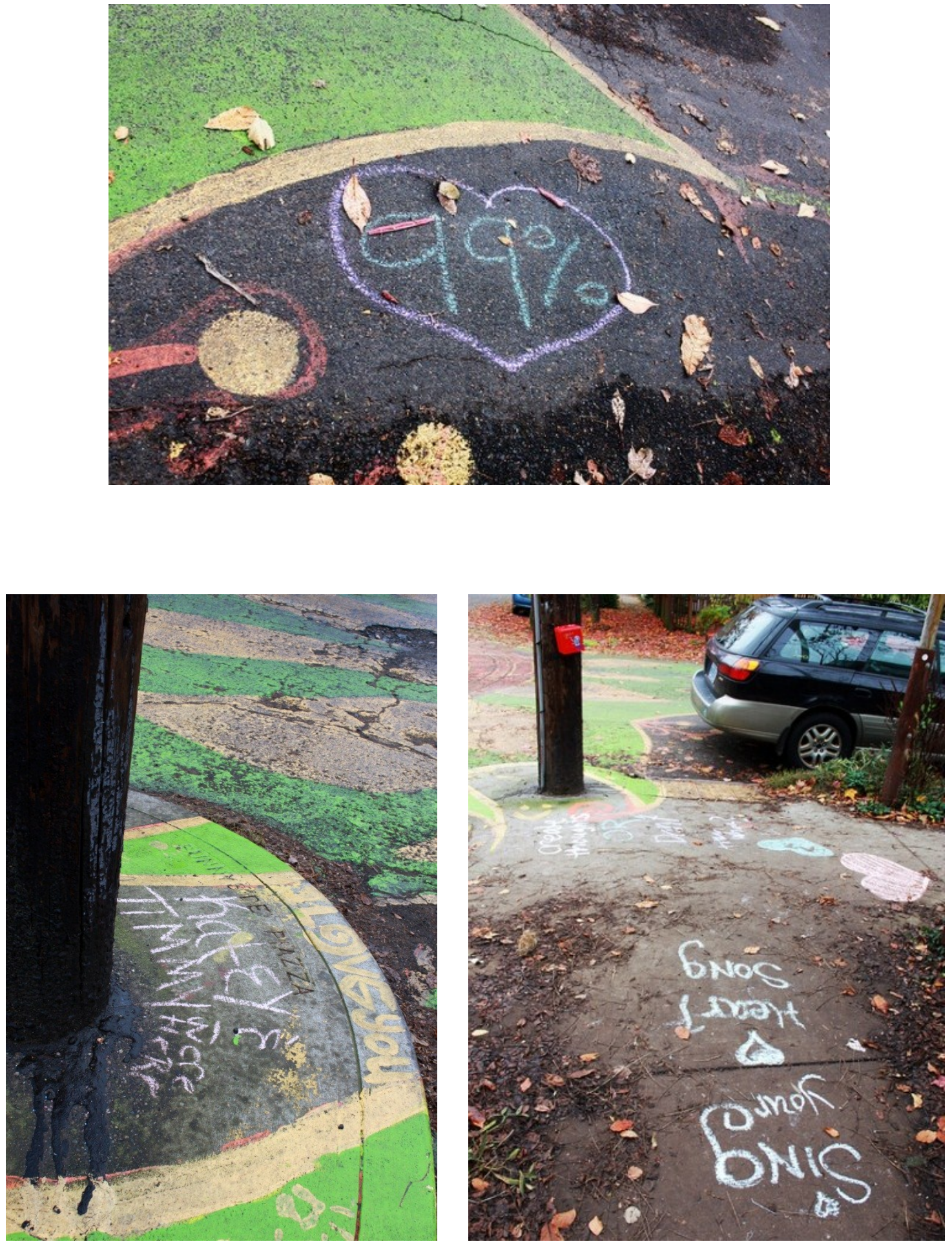

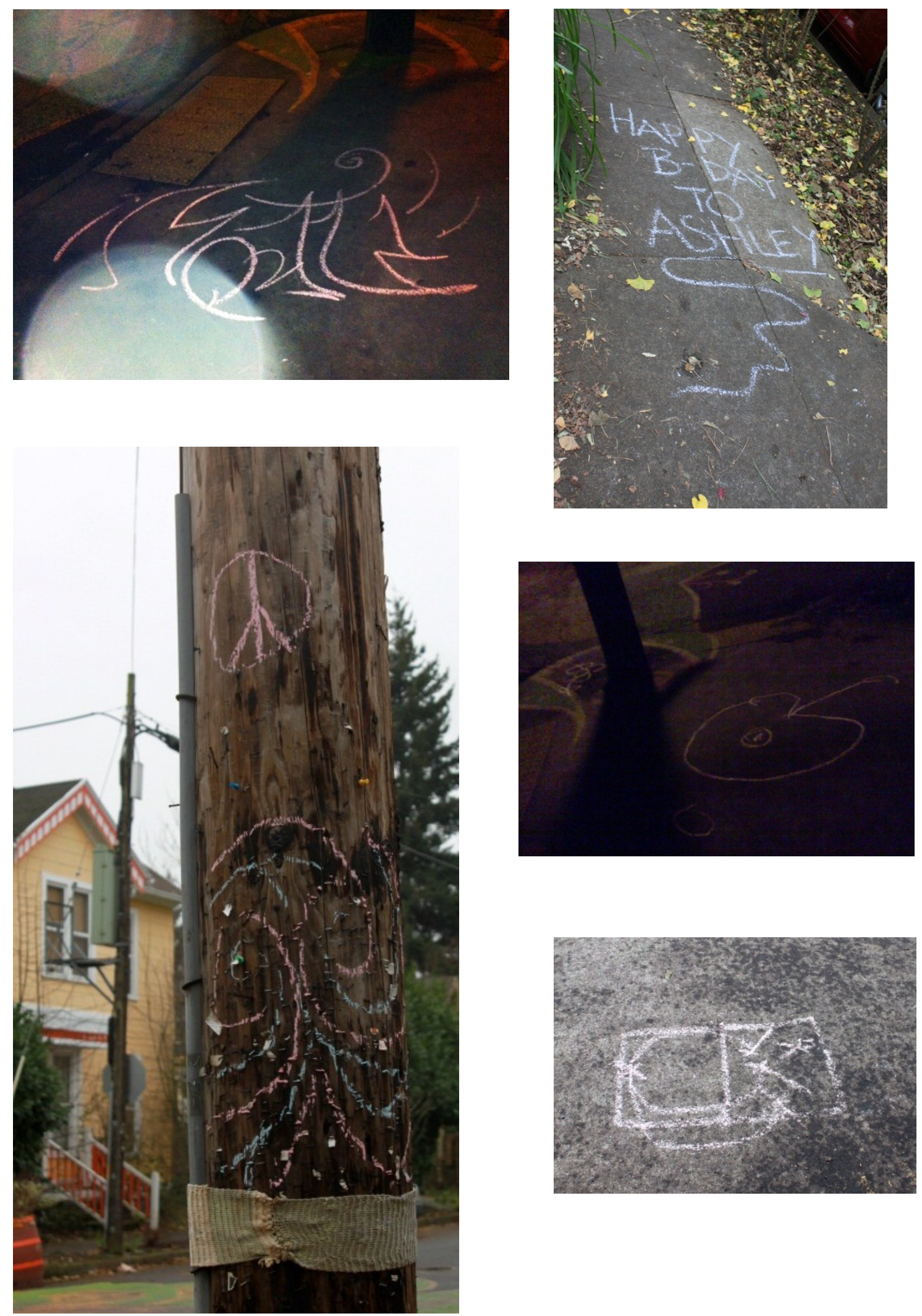


\section{RESISTANCE FIST TAPE INTERVENTION}

Location: SE $33^{\text {rd }}$ between Belmont and Yamhill, Portland Oregon

Created: Friday, November $4^{\text {th }}, 2011$

Status: It was removed on November $15^{\text {th }}, 2011$ due to non-use and peeling tape.
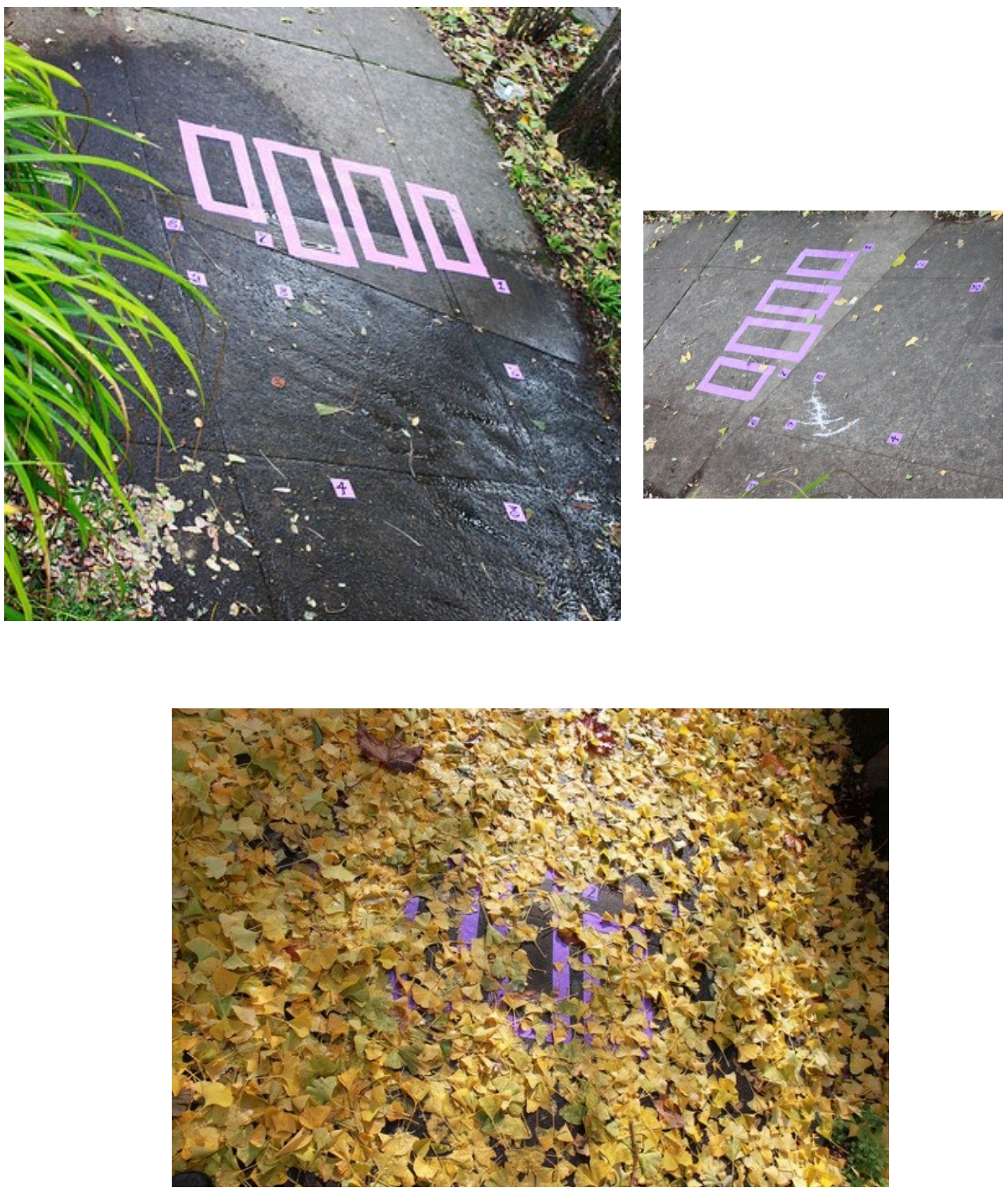


\section{HOP-SCOTCH INTERVENTION}

Location: Portland State University Urban Center Plaza, Portland Oregon Created: October $8^{\text {th }}, 2011$

Status: Removed by unknown person on October $9^{\text {th }}, 2011$
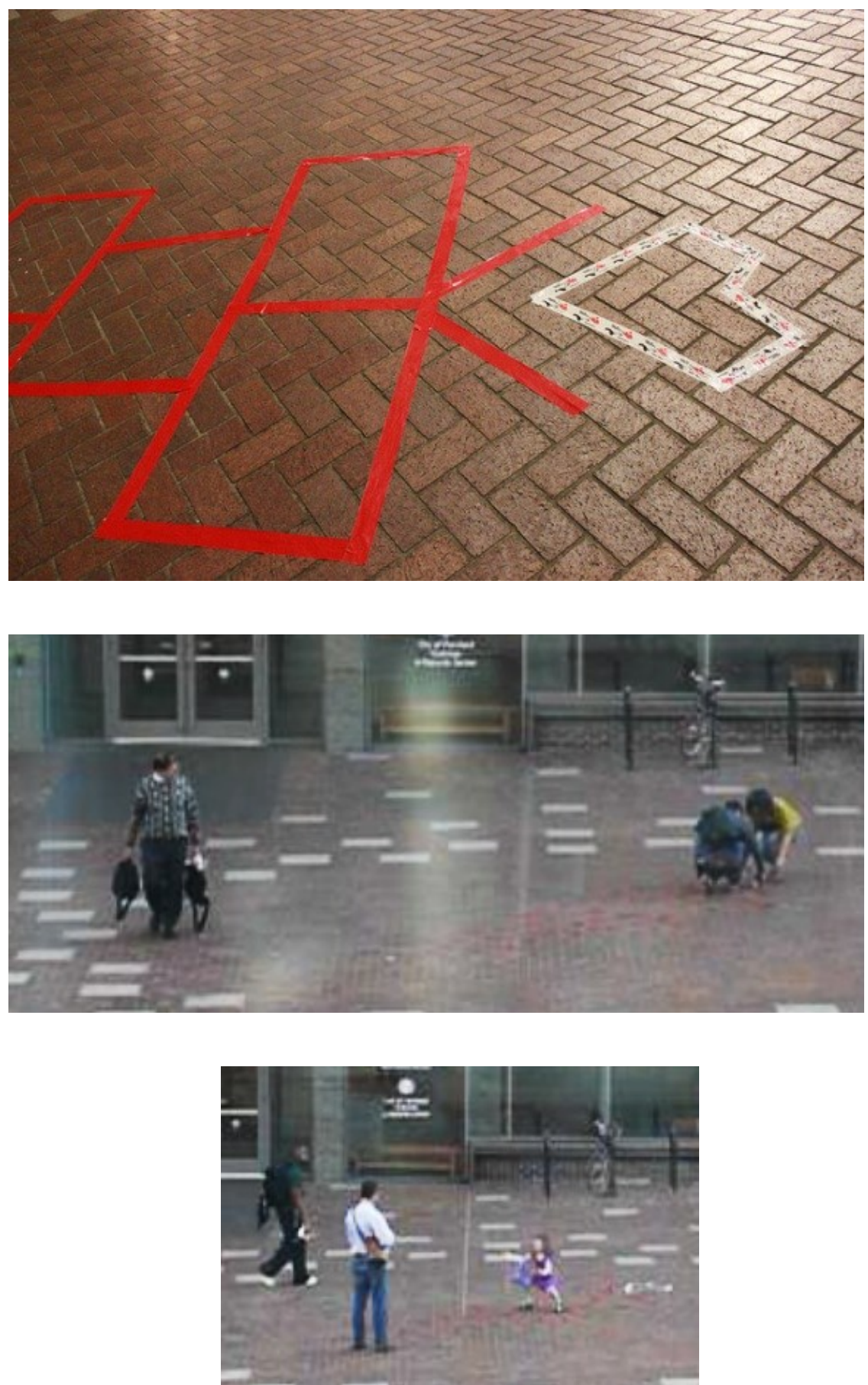

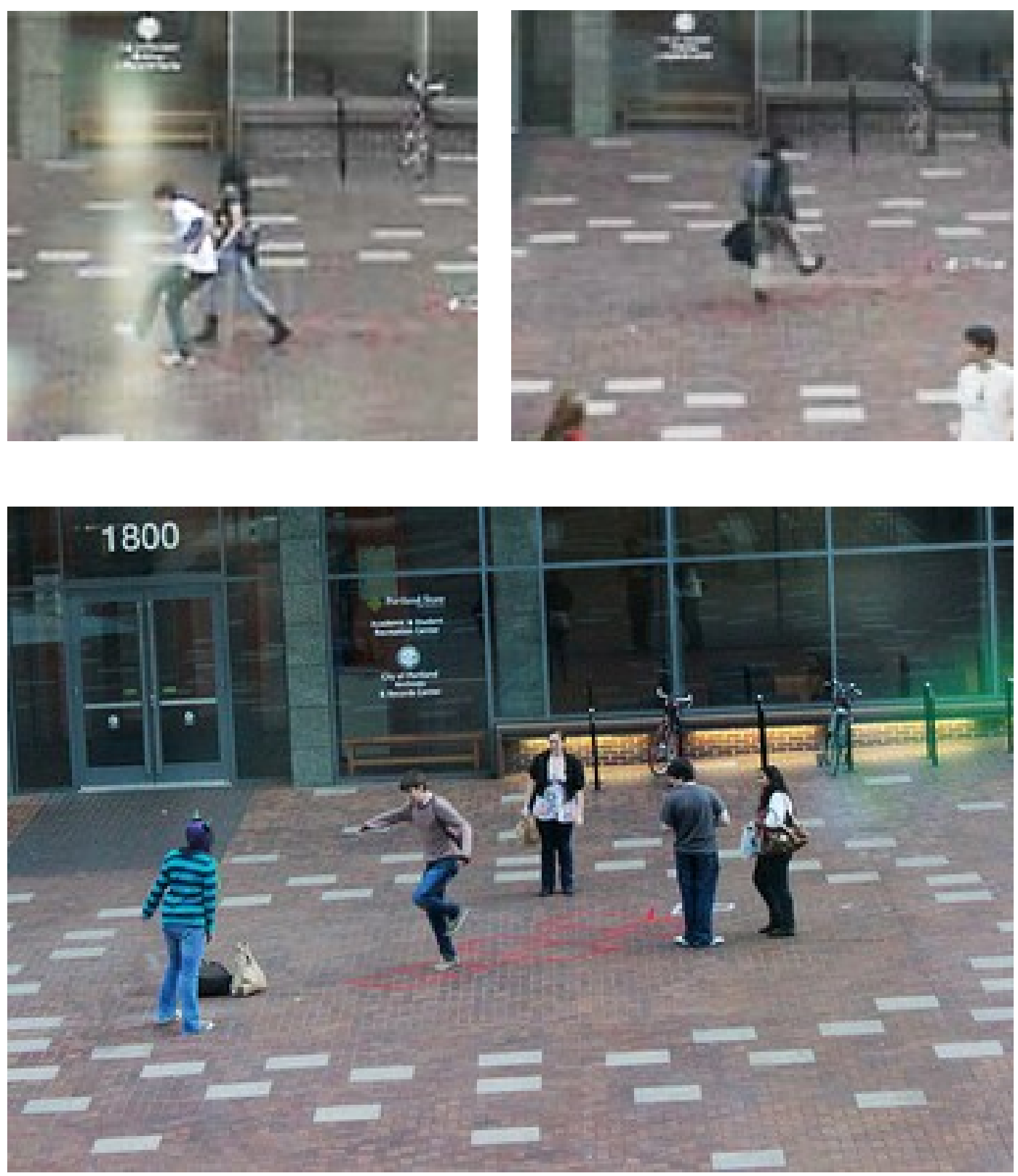


\section{YARN INSTALLATIONS}

Created: Various 2010, 2011, 2012, Sunnyside Portland Oregon Status: Various

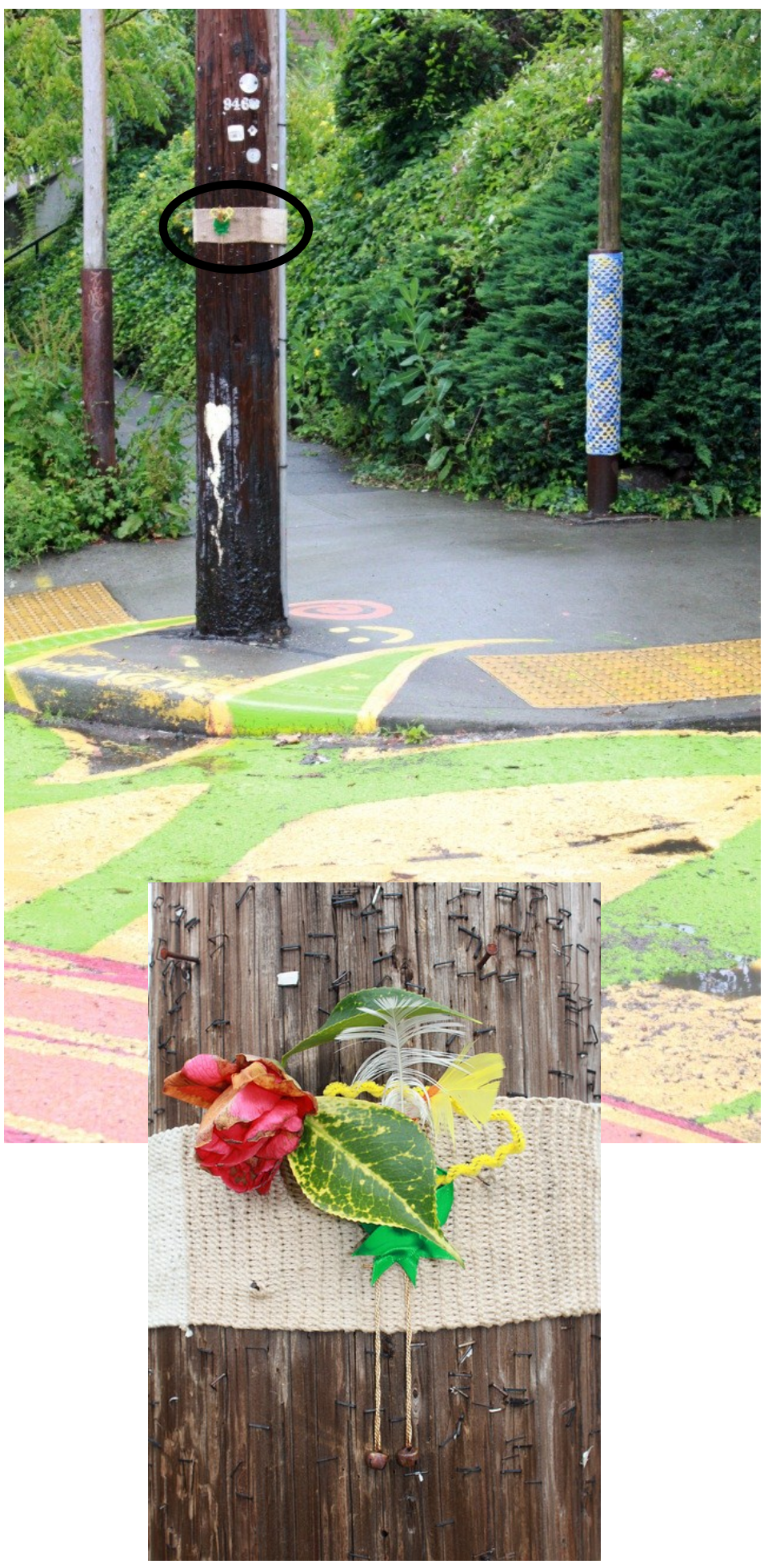




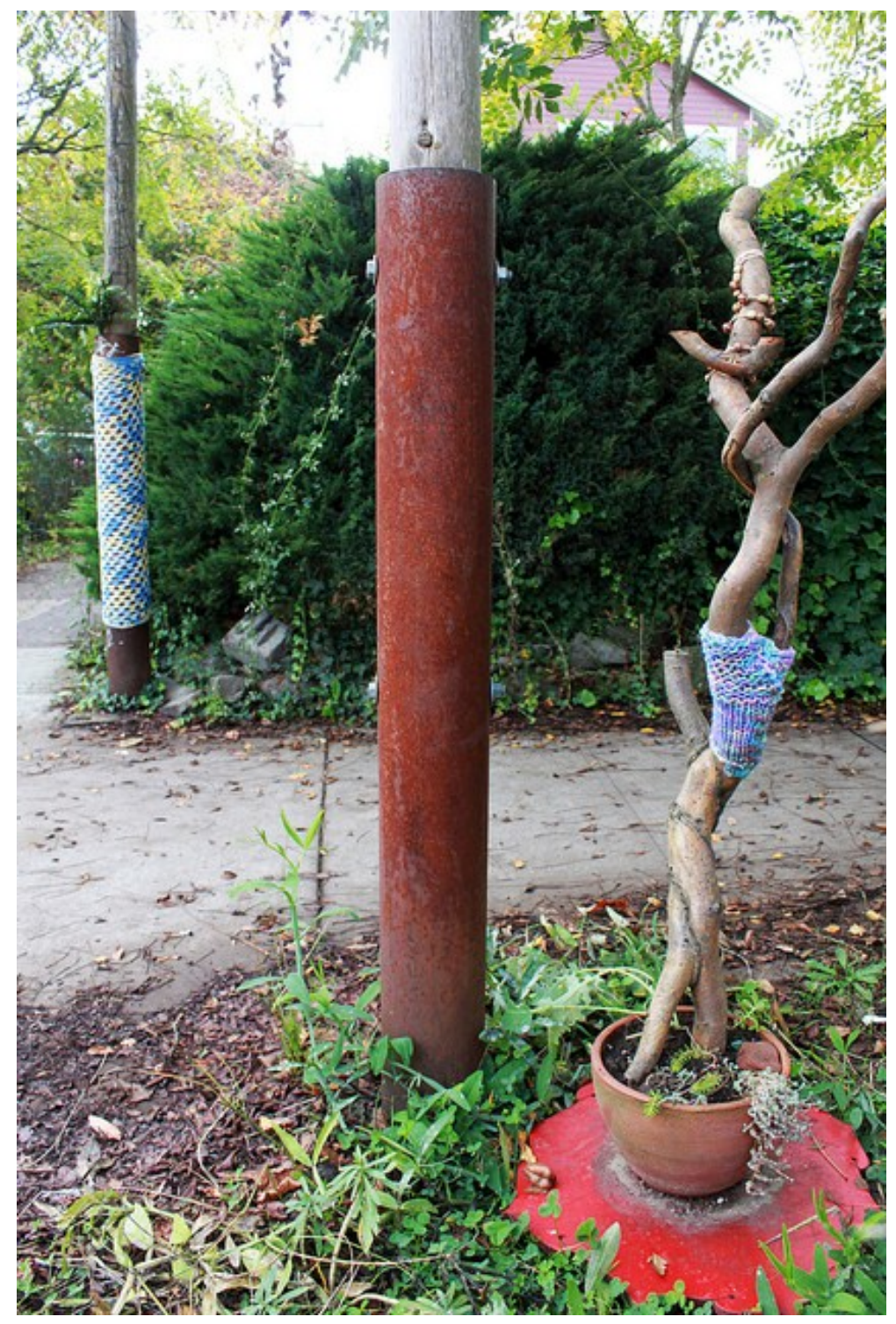



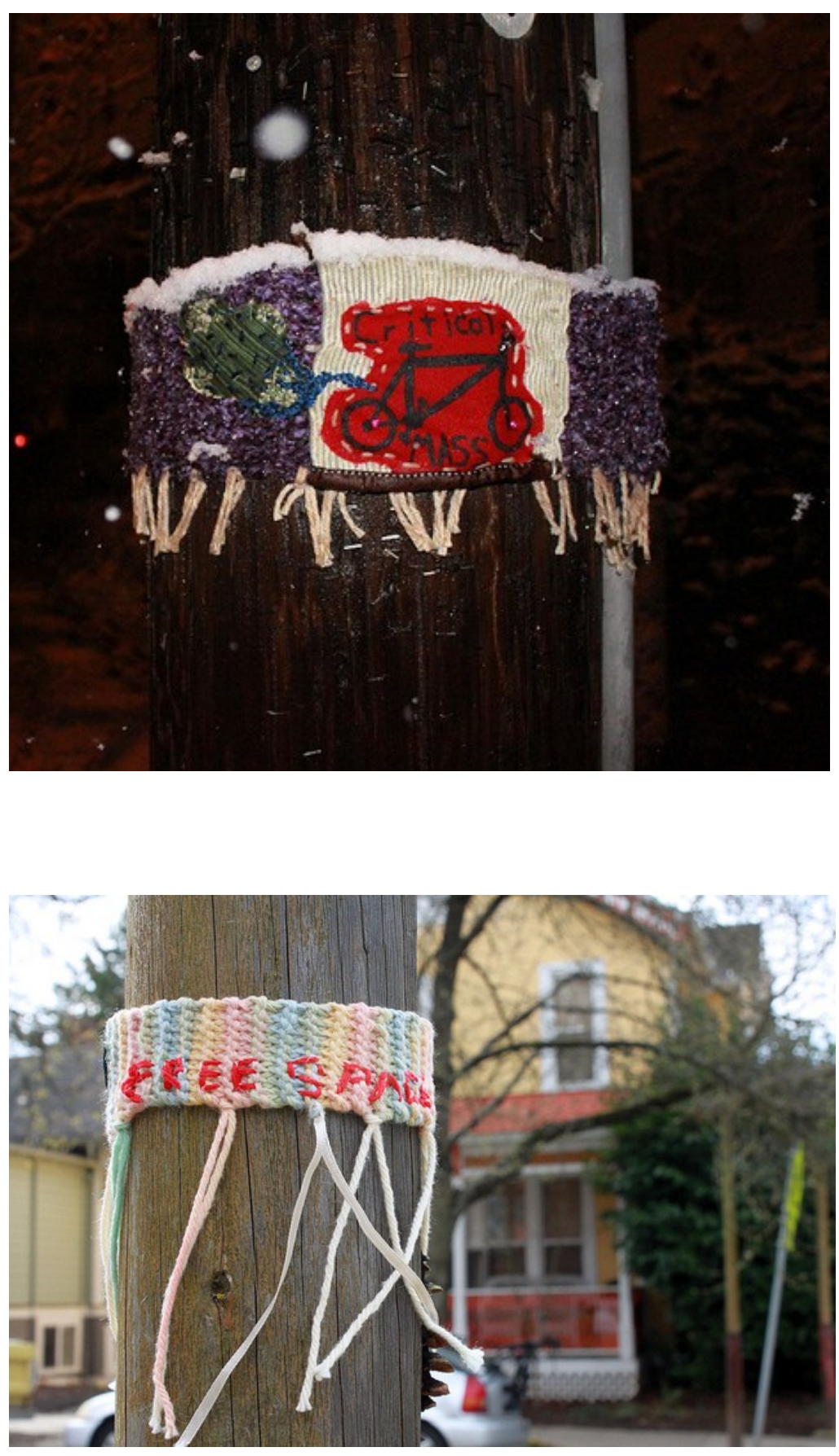

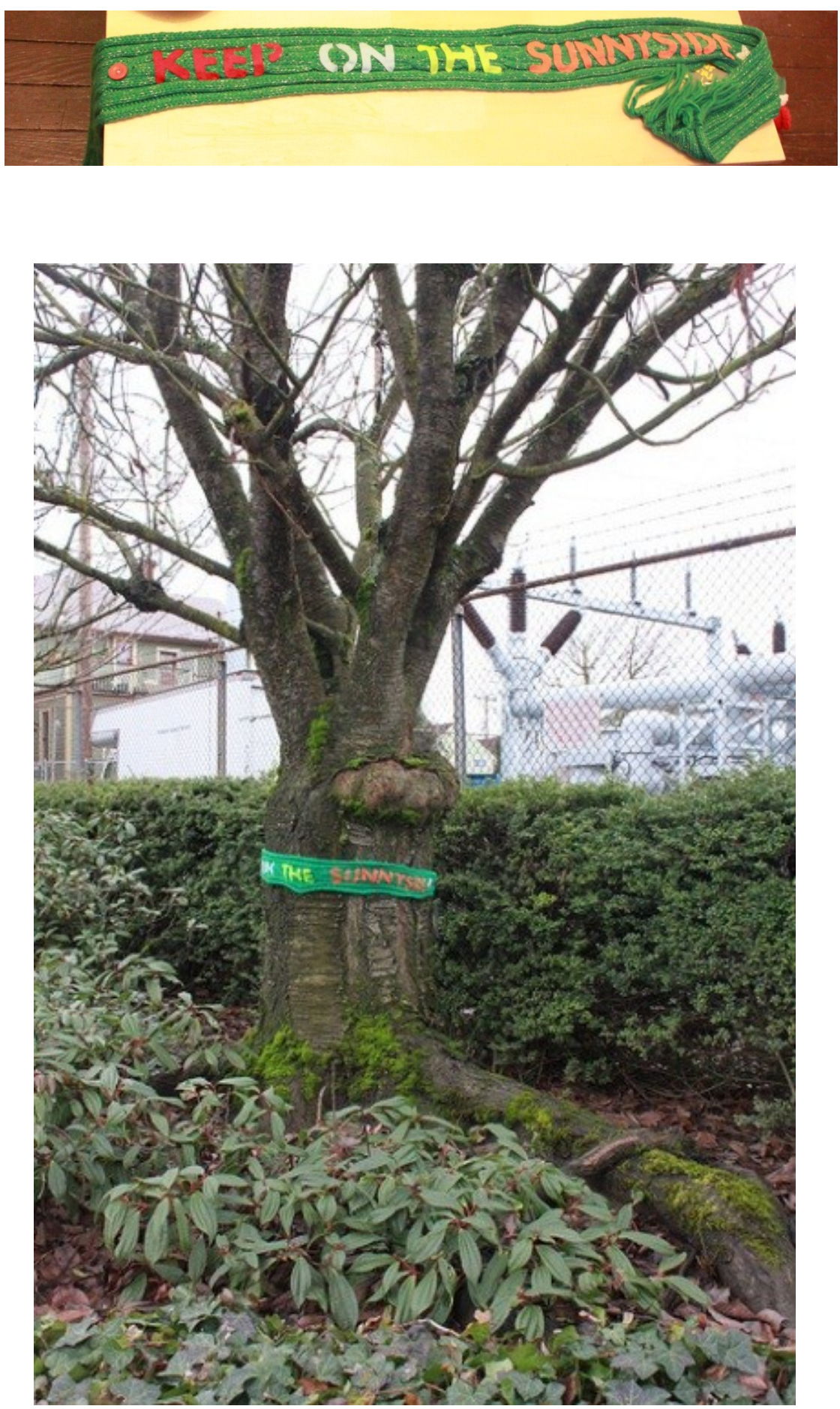


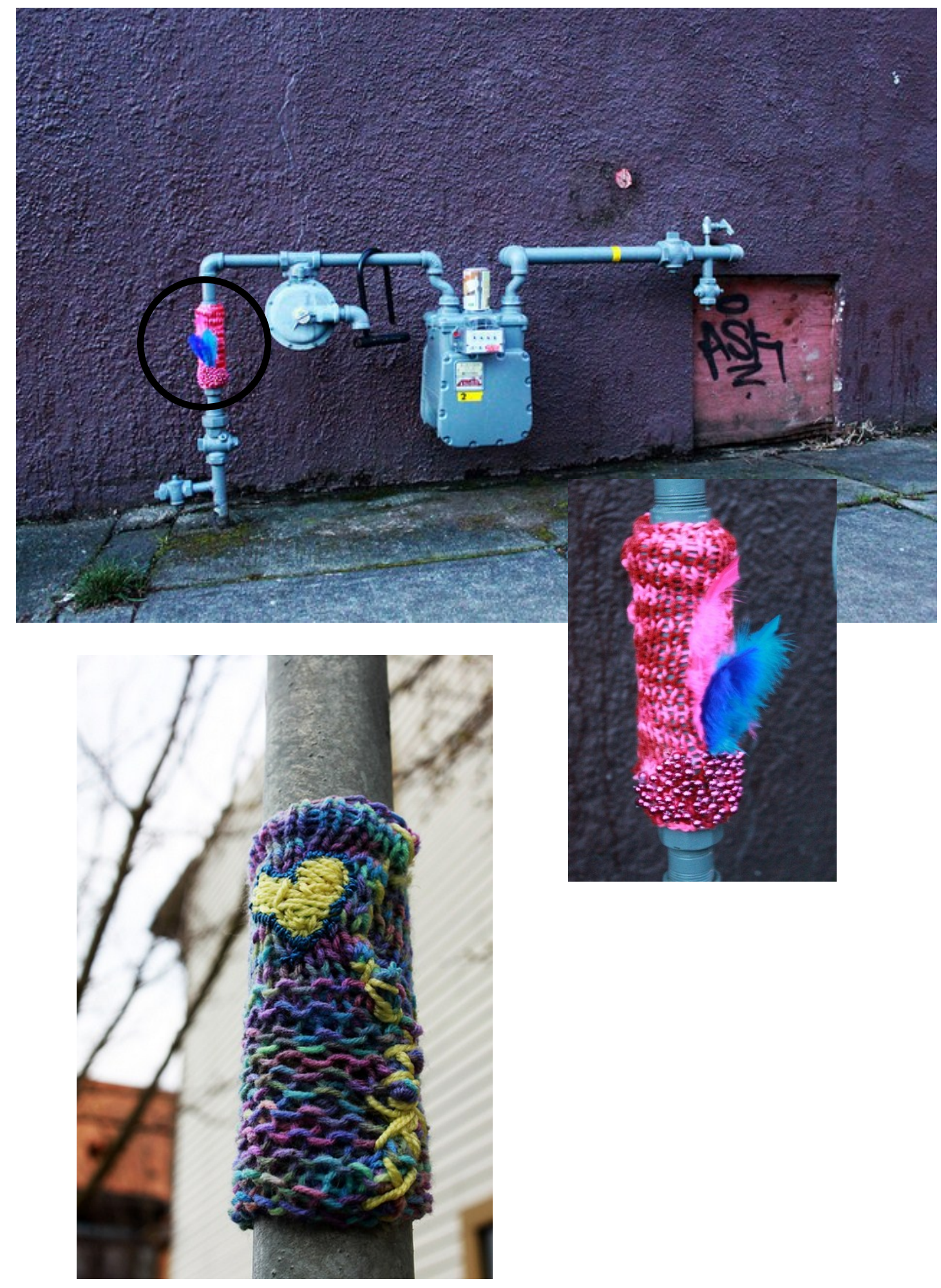




\section{Appendix C. Survey Photograph Details}

\section{Long Live Art in the Streets Tag:}

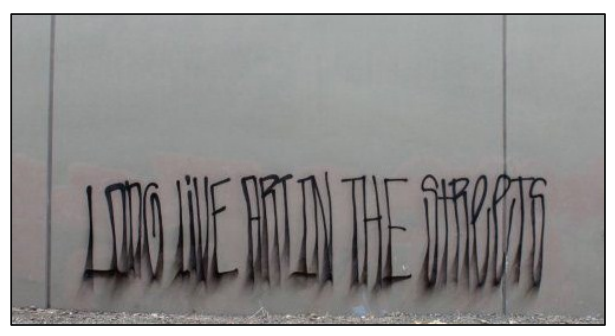

This photograph was taken in Portland, Oregon on October 23, 2011. This spray-painted piece was located along the train tracks in the inner industrial area near SE Yamhill and Water Avenue. This simple piece was created using black spray-paint and a fat cap. I chose this piece because it was a simple tag-like piece that transmitted an understandable message to viewers. Directly across the tracks from this piece is a large commissioned mural on the Refuge building. Train tracks are a likely place to find street art and graffiti.

\section{Fever Tag:}

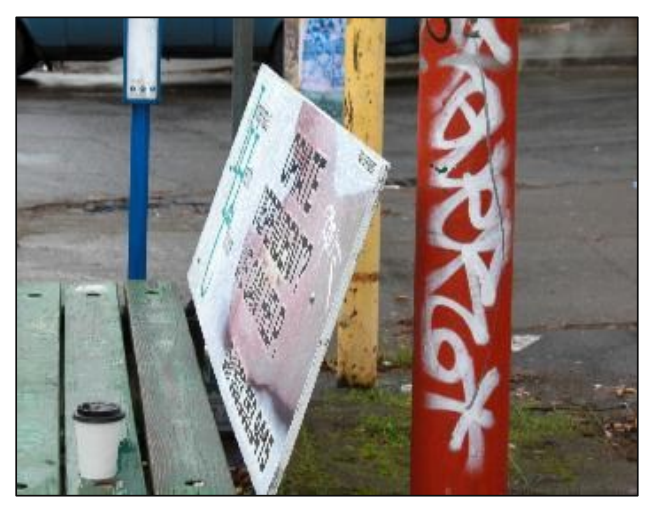

This photograph was taken in Portland, Oregon on January 14, 2012. This piece was at a bus stop on SE Belmont Avenue. This simple piece was created using silver spray paint. It appears to say "Fever." I chose this piece because it represents traditional tagging style, most likely someone's plum de nom. 


\section{Stickers:}

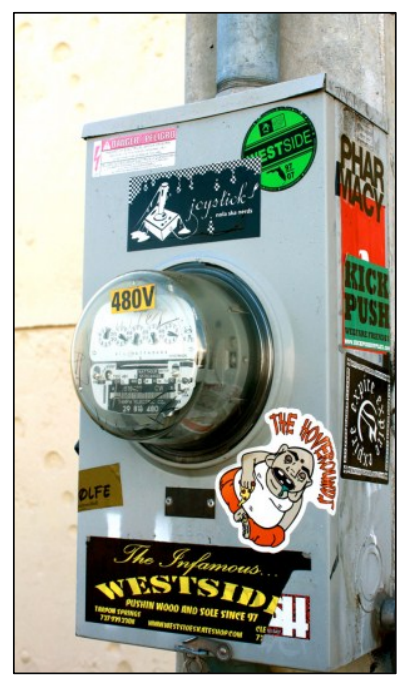

This photograph was taken in Tampa, Florida on January 6, 2012. This example of sticker art (also known as slap tagging) was behind the Skatepark of Tampa's (SPOT) parking lot. I chose this piece because it represents the new trend of sticker street art. Stickers are fast and easy to apply. Stickers are not permanently damaging the surface onto which they are adhered. However, graffiti abatement crews seem to focus much of their time and resources removing these pieces from public space.

\section{MURG Traditional Wildstyle Piece:}

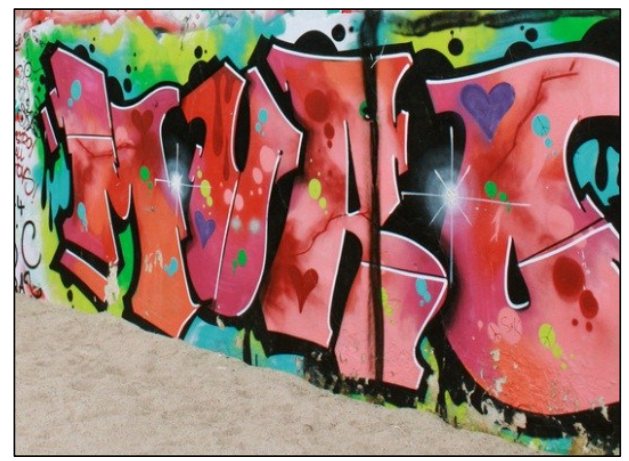

This photograph was taken in Berlin, Germany on September 9, 2011. This spray-painted wildstyle 'masterpiece' was located in Görlitzer Park in the Friedrichshain-Kreuzberg neighborhood. This piece was chosen because it is an elaborate piece that required specialized skill to execute. It represents some characteristics of traditional graffiti, but also incorporates newer styles. This piece appears to be someone's plum de nom (MURG), making it characteristic of the graffiti tradition. 


\section{GATS Street Art Character Piece:}

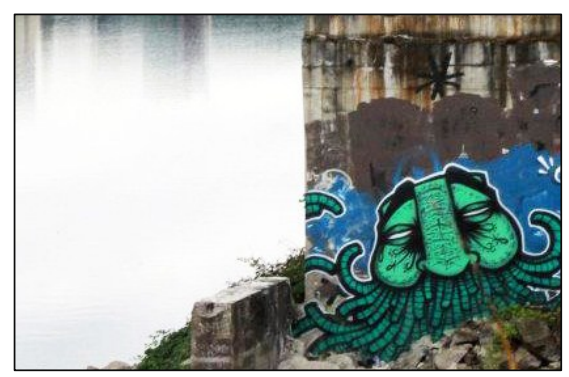

This photograph was taken in Portland, Oregon on October 9, 2011. This piece was located along the banks of the Willamette River, north of downtown in the Pearl District. I chose this piece because like the traditional wild-style masterpiece (above) it required specialized skills to execute, but instead of promoting a name, it promotes an image. In this case it is the character GATS, which stands for 'Graffiti Against The System.' This piece is representative of 'street art' style.

\section{Community Chalk Box Installation:}

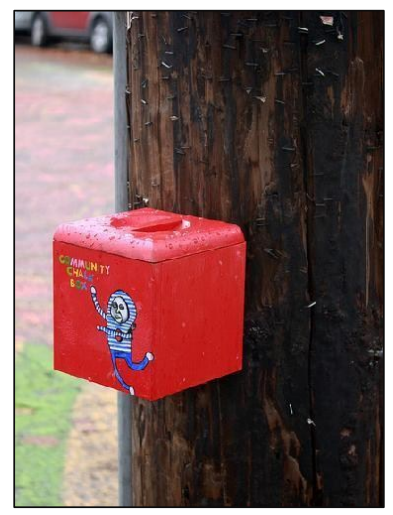

This photograph was taken in Portland, Oregon on November 18, 2011. It was located in the Sunnyside neighborhood at Sunnyside Piazza City Repair Intersection. I created this piece for my participant observation experiments. It was a wooden box filled with sidewalk chalk. The purpose of the piece was to encourage community members and visitors to use the chalk to create their own art and slogans on the sidewalk. 


\section{“Free Space" Yarn Installation:}

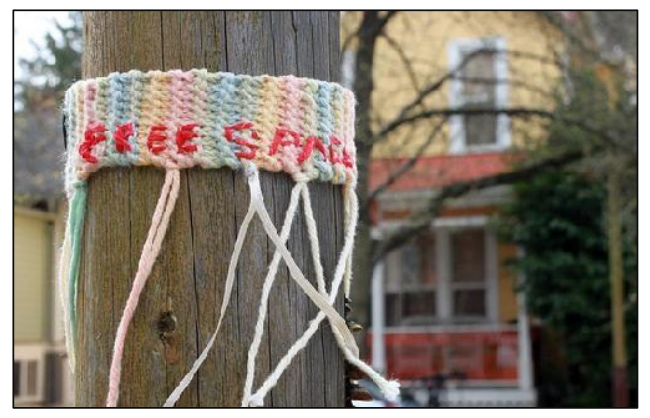

This photograph was taken in Portland, Oregon on April 3, 2011. This is a yarn installation (also known as yarn bombing and guerilla knitting). This is one of the pieces that I created myself as part of my participant observation experiments. It is an example of traditional yarn bombing style of wrapping a knitted piece around a street object.

\section{Guerilla Garden Installation:}

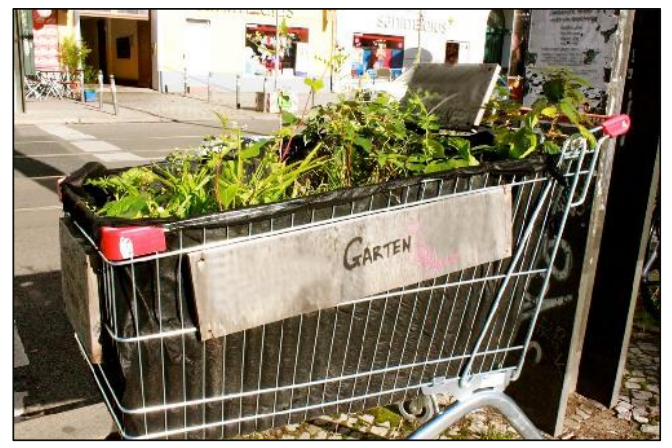

This photograph was taken in a residential neighborhood in Berlin, Germany on September 6, 2011. This piece is an example of guerrilla gardening. This simple piece was created using plants, dirt, a thick tarp, and a shopping cart. I chose this piece because many people do not think of gardening in public without permission as a form of street art or graffiti, but the basic guiding principles behind the act are similar to other street art. 


\section{Appendix D. Street Art and Graffiti Survey}

INTRO: Welcome to the Street Art and Graffiti Survey. Thank you for your willingness to participate! This survey is being done as part of a master's thesis in Urban Studies. The information gathered will be used to better understand what people in Portland think about street art and graffiti. This survey should take about 10 minutes to complete. Your participation is voluntary and anonymous. You may stop the survey at any time without penalty. If there's a question you would rather not answer, you can skip over it.

Note: If you need to stop the survey, but want to finish at a later time, just return to this website using the same computer and you should be able to start where you left off.

Questions? Tiffany Conklin PSU School of Urban Studies \& Planning Office: 503-725-5970 Email: tconklin@pdx.edu.

If you have concerns or questions about your rights as a research subject or your privacy protection, please contact the PSU Research and Strategic Partnerships at 503-725-4288.

ELIG1: First, to verify if you are eligible to complete the survey, please answer the following two questions. Are you 18 years of age or older?

Yes (1)

No (2)

If 'No' Is Selected, Then Skip To: "I'm sorry but you are not eligible to complete this survey. Thank you for your time and willingness to participate." [Then Skip To End of Survey]

ELIG2: Do you currently live in the City of Portland?
Yes (1)
No (2)

If 'No' Is Selected, Then Skip To: "I'm sorry but you are not eligible to complete this survey. Thank you for your time and willingness to participate." [Then Skip To End of Survey] 
SECT1: In the next few questions, you will be shown 8 pictures of street art and graffiti and asked what you think about each of them. These are all located in public spaces (not on private property). These were all done without permission.

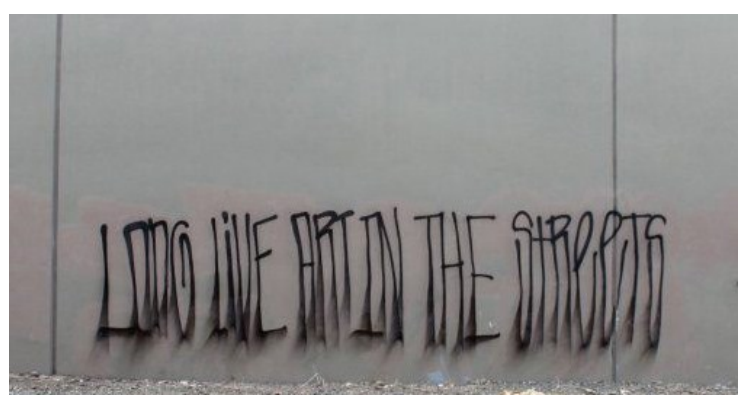

Q1_tag: Please rate your level of agreement with the statements below.

Note: These are in public spaces and were done without permission.

\begin{tabular}{|c|c|c|c|c|c|}
\hline & $\begin{array}{c}\text { (1) } \\
\text { Strongly } \\
\text { Disagree }\end{array}$ & (2) Disagree & $\begin{array}{l}\text { (3) Neither } \\
\text { Agree nor } \\
\text { Disagree }\end{array}$ & (4) Agree & $\begin{array}{l}\text { (5) Strongly } \\
\text { Agree }\end{array}$ \\
\hline $\begin{array}{l}\text { I understand } \\
\text { the intended } \\
\text { message (1) }\end{array}$ & $\mathrm{O}$ & $\mathrm{O}$ & $\mathrm{O}$ & $\mathrm{O}$ & O \\
\hline $\begin{array}{l}\text { It damaged } \\
\text { the surface (2) }\end{array}$ & $\mathrm{O}$ & 0 & 0 & 0 & 0 \\
\hline $\begin{array}{l}\text { The person } \\
\text { who did this } \\
\text { used their } \\
\text { imagination } \\
\text { (3) }\end{array}$ & $\mathrm{O}$ & 0 & 0 & O & $\mathrm{O}$ \\
\hline $\begin{array}{l}\text { It is offensive } \\
\text { (4) }\end{array}$ & 0 & 0 & 0 & $\mathrm{O}$ & O \\
\hline $\begin{array}{l}\text { It is gang } \\
\text { related (5) }\end{array}$ & O & $\mathrm{O}$ & O & 0 & O \\
\hline $\begin{array}{l}\text { It should be } \\
\text { considered a } \\
\text { crime (6) }\end{array}$ & 0 & 0 & 0 & 0 & 0 \\
\hline $\begin{array}{l}\text { It makes the } \\
\text { space more } \\
\text { interesting (7) }\end{array}$ & $\mathrm{O}$ & 0 & $\mathrm{O}$ & $\mathrm{O}$ & $\mathrm{O}$ \\
\hline $\begin{array}{l}\text { It makes the } \\
\text { space look } \\
\text { dirty (8) }\end{array}$ & 0 & $\mathrm{O}$ & $\mathrm{O}$ & $\mathrm{O}$ & $\mathrm{O}$ \\
\hline
\end{tabular}


Q1a_tag: In general, was this space better before or after the street art/graffiti was put there?

Before (1)

After (2)

Q1b_tag: Would you be okay if someone placed something like this...

\begin{tabular}{|c|c|c|}
\hline & Yes (1) & No (2) \\
\hline On your property (1) & 0 & 0 \\
In your neighborhood (2) & 0 & 0 \\
Some other part of the city (3) & 0 & 0 \\
\hline
\end{tabular}

Q1c_tag: Have you seen something like this in the past 6 months?

Yes (1)

O No (2)

Q1d_tag: Do you think this should be removed?

O No (1)

Yes (2)

If 'No' Is Selected, Then Skip To End of Block 
Answer If "Do you think this should be removed?" 'Yes' Is Selected

Q1d1_tag: Do you think that the surrounding community should have a say in whether or not it's removed or left alone?

No (Community input is not needed) (1)

Yes (Community input should be received) (2)

Answer If "Do you think this should be removed?" 'Yes' Is Selected

Q1d2_tag: Do you think that public tax money should be spent to pay for its removal?

Note: This would tax money being spent on both removal labor and cost of supplies.

O No (1)

Yes (2) 


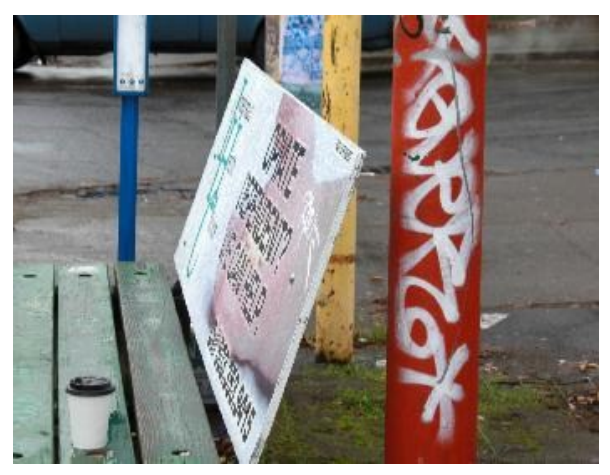

Q2_tag: Please rate your level of agreement with the statements below.

Note: These are in public spaces and were done without permission.

\begin{tabular}{|c|c|c|c|c|c|}
\hline & $\begin{array}{c}\text { (1) } \\
\text { Strongly } \\
\text { Disagree }\end{array}$ & (2) Disagree & $\begin{array}{c}\text { (3) Neither } \\
\text { Agree nor } \\
\text { Disagree }\end{array}$ & (4) Agree & $\begin{array}{l}\text { (5) Strongly } \\
\text { Agree }\end{array}$ \\
\hline $\begin{array}{l}\text { I understand the } \\
\text { intended message } \\
\text { (1) }\end{array}$ & $\mathrm{O}$ & $\mathrm{O}$ & $\mathrm{O}$ & $\mathrm{O}$ & ○ \\
\hline $\begin{array}{l}\text { It damaged the } \\
\text { surface (2) }\end{array}$ & $\mathrm{O}$ & $\mathrm{O}$ & $\mathrm{O}$ & O & $\mathrm{O}$ \\
\hline $\begin{array}{l}\text { The person who did } \\
\text { this used their } \\
\text { imagination (3) }\end{array}$ & $\mathrm{O}$ & $\mathrm{O}$ & $\mathrm{O}$ & $\mathrm{O}$ & $\mathrm{O}$ \\
\hline It is offensive (4) & $\mathrm{O}$ & $\mathrm{O}$ & O & O & $\mathrm{O}$ \\
\hline It is gang related (5) & $\mathrm{O}$ & O & $\mathrm{O}$ & $\mathrm{O}$ & $\mathrm{O}$ \\
\hline $\begin{array}{l}\text { It should be } \\
\text { considered a crime } \\
\text { (6) }\end{array}$ & O & O & O & O & O \\
\hline $\begin{array}{l}\text { It makes the space } \\
\text { more interesting } \\
\text { (7) }\end{array}$ & $\mathrm{O}$ & $\mathrm{O}$ & $\mathrm{O}$ & $\mathrm{O}$ & $\mathrm{O}$ \\
\hline $\begin{array}{l}\text { It makes the space } \\
\text { look dirty (8) }\end{array}$ & O & O & $\mathrm{O}$ & $\mathrm{O}$ & $\mathrm{O}$ \\
\hline
\end{tabular}

Q2a_tag: In general, was this space better before or after the street art/graffiti was put there?

Before (1)

After (2) 
Q2b_tag: Would you be okay if someone placed something like this...

\begin{tabular}{|c|c|c|}
\hline & Yes (1) & No (2) \\
\hline On your property (1) & 0 & 0 \\
In your neighborhood (2) & 0 & 0 \\
Some other part of the city (3) & 0 & 0 \\
\hline
\end{tabular}

Q2c_tag: Have you seen something like this in the past 6 months?

Yes (1)

O No (2)

Q2d_tag: Do you think this should be removed?

O No (1)

Yes (2)

If 'No' Is Selected, Then Skip To End of Block

Answer If "Do you think this should be removed?" 'Yes' Is Selected

Q2d1_tag: Do you think that the surrounding community should have a say in whether or not it's removed or left alone?

No (Community input is not needed) (1)

Y Yes (Community input should be received) (2)

Answer If "Do you think this should be removed?" 'Yes' Is Selected

Q2d2_tag: Do you think that public tax money should be spent to pay for its removal?

Note: This would tax money being spent on both removal labor and cost of supplies.

O No (1)

Yes (2) 


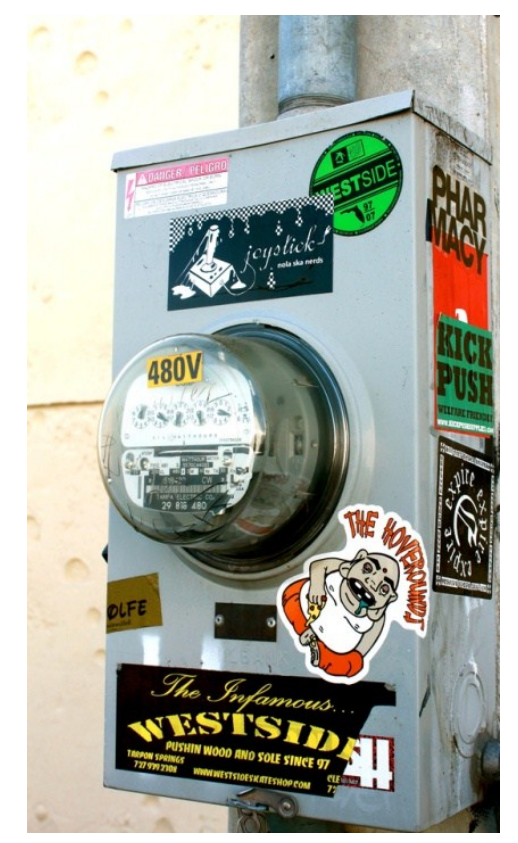

Q3_sticker: Please rate your level of agreement with the statements below.

Note: These are in public spaces and were done without permission.

\begin{tabular}{|c|c|c|c|c|c|}
\hline & $\begin{array}{c}\text { (1) } \\
\text { Strongly } \\
\text { Disagree }\end{array}$ & (2) Disagree & $\begin{array}{l}\text { (3) Neither } \\
\text { Agree nor } \\
\text { Disagree }\end{array}$ & (4) Agree & $\begin{array}{l}\text { (5) Strongly } \\
\text { Agree }\end{array}$ \\
\hline $\begin{array}{l}\text { I understand the } \\
\text { intended message } \\
\text { (1) }\end{array}$ & O & $\mathrm{O}$ & $\mathrm{O}$ & $\mathrm{O}$ & $\mathrm{O}$ \\
\hline $\begin{array}{l}\text { It damaged the } \\
\text { surface (2) }\end{array}$ & O & O & $\mathrm{O}$ & O & O \\
\hline $\begin{array}{l}\text { The person who did } \\
\text { this used their } \\
\text { imagination (3) }\end{array}$ & O & O & O & O & O \\
\hline It is offensive (4) & O & $\mathrm{O}$ & O & O & O \\
\hline It is gang related (5) & $\mathrm{O}$ & $\mathrm{O}$ & $\mathrm{O}$ & $\mathrm{O}$ & $\mathrm{O}$ \\
\hline $\begin{array}{l}\text { It should be } \\
\text { considered a crime } \\
\text { (6) }\end{array}$ & O & O & O & O & O \\
\hline $\begin{array}{l}\text { It makes the space } \\
\text { more interesting } \\
\text { (7) }\end{array}$ & O & O & $\mathrm{O}$ & $\mathrm{O}$ & $\mathrm{O}$ \\
\hline $\begin{array}{l}\text { It makes the space } \\
\text { look dirty (8) }\end{array}$ & O & O & $\mathrm{O}$ & $\mathrm{O}$ & O \\
\hline
\end{tabular}


Q3a_sticker: In general, was this space better before or after the street art/graffiti was put there?

Before (1)

After (2)

Q3b_sticker: Would you be okay if someone placed something like this...

\begin{tabular}{|c|c|c|}
\hline & Yes (1) & No (2) \\
\hline On your property (1) & 0 & 0 \\
In your neighborhood (2) & 0 & 0 \\
Some other part of the city (3) & 0 & 0 \\
\hline
\end{tabular}

Q3c_sticker: Have you seen something like this in the past 6 months?

Yes (1)

O No (2)

Q3d_sticker: Do you think this should be removed?

No (1)

O Yes (2)

If 'No' Is Selected, Then Skip To End of Block 
Answer If "Do you think this should be removed?" 'Yes' Is Selected

Q3d1_sticker: Do you think that the surrounding community should have a say in whether or not it's removed or left alone?

No (Community input is not needed) (1)

Yes (Community input should be received) (2)

Answer If "Do you think this should be removed?" 'Yes' Is Selected

Q3d2_sticker: Do you think that public tax money should be spent to pay for its removal?

Note: This would tax money being spent on both removal labor and cost of supplies.

O No (1)

Yes (2) 


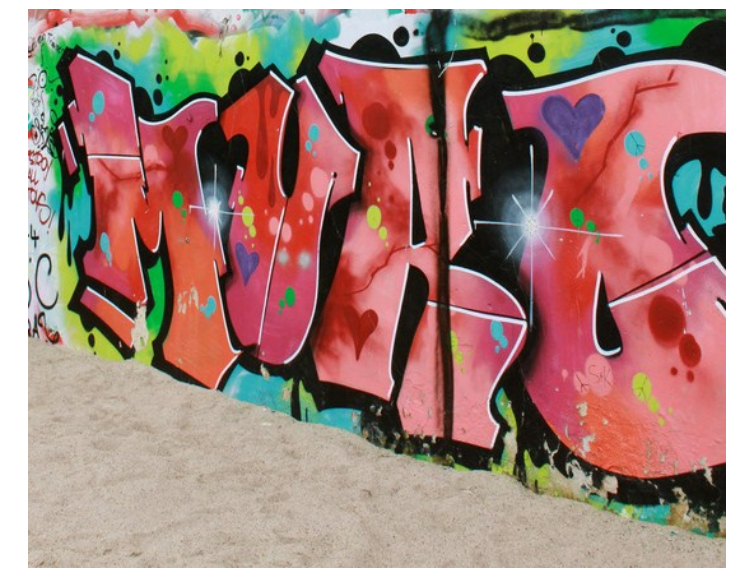

Q4_piece: Please rate your level of agreement with the statements below.

Note: These are in public spaces and were done without permission.

\begin{tabular}{|c|c|c|c|c|c|}
\hline & $\begin{array}{c}\text { (1) } \\
\text { Strongly } \\
\text { Disagree }\end{array}$ & (2) Disagree & $\begin{array}{l}\text { (3) Neither } \\
\text { Agree nor } \\
\text { Disagree }\end{array}$ & (4) Agree & $\begin{array}{l}\text { (5) Strongly } \\
\text { Agree }\end{array}$ \\
\hline $\begin{array}{l}\text { I understand the } \\
\text { intended message } \\
\text { (1) }\end{array}$ & $\mathrm{O}$ & $\mathrm{O}$ & $\mathrm{O}$ & $\mathrm{O}$ & $\mathrm{O}$ \\
\hline $\begin{array}{l}\text { It damaged the } \\
\text { surface (2) }\end{array}$ & 0 & 0 & O & O & 0 \\
\hline $\begin{array}{c}\text { The person who did } \\
\text { this used their } \\
\text { imagination (3) }\end{array}$ & 0 & 0 & O & $\mathrm{O}$ & 0 \\
\hline It is offensive (4) & $\mathrm{O}$ & 0 & $\mathrm{O}$ & 0 & 0 \\
\hline It is gang related (5) & $\mathrm{O}$ & $\mathrm{O}$ & O & O & $\mathrm{O}$ \\
\hline $\begin{array}{l}\text { It should be } \\
\text { considered a crime } \\
\text { (6) }\end{array}$ & O & O & $\mathrm{O}$ & O & O \\
\hline $\begin{array}{l}\text { It makes the space } \\
\text { more interesting } \\
\text { (7) }\end{array}$ & $\mathrm{O}$ & $\mathrm{O}$ & $\mathrm{O}$ & $\mathrm{O}$ & $\mathrm{O}$ \\
\hline $\begin{array}{l}\text { It makes the space } \\
\text { look dirty (8) }\end{array}$ & 0 & 0 & 0 & $\mathrm{O}$ & 0 \\
\hline
\end{tabular}

Q4a_piece: In general, was this space better before or after the street art/graffiti was put there? 
Before (1)

After (2)

Q4b_piece: Would you be okay if someone placed something like this...

\begin{tabular}{|c|c|c|}
\hline & Yes (1) & No (2) \\
\hline On your property (1) & 0 & 0 \\
In your neighborhood (2) & 0 & 0 \\
Some other part of the city (3) & 0 & 0 \\
\hline
\end{tabular}

Q4c_piece: Have you seen something like this in the past 6 months?

Yes (1)

O No (2)

Q4d_piece: Do you think this should be removed?

No (1)

Y Yes (2)

If 'No' Is Selected, Then Skip To End of Block

Answer If "Do you think this should be removed?" Yes Is Selected

Q4d1_piece: Do you think that the surrounding community should have a say in whether or not it's removed or left alone?

No (Community input is not needed) (1)

Yes (Community input should be received) (2)

\section{Answer If "Do you think this should be removed?" 'Yes' Is Selected}

Q4d2_piece: Do you think that public tax money should be spent to pay for its removal?

Note: This would tax money being spent on both removal labor and cost of supplies.

No (1)

Yes (2) 


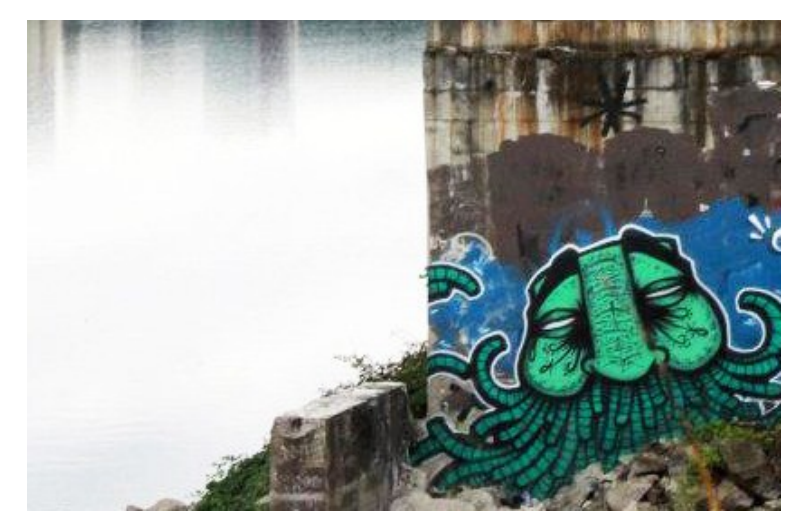

Q5_piece: Please rate your level of agreement with the statements below.

Note: These are in public spaces and were done without permission.

\begin{tabular}{|c|c|c|c|c|c|}
\hline & $\begin{array}{c}\text { (1) } \\
\text { Strongly } \\
\text { Disagree }\end{array}$ & (2) Disagree & $\begin{array}{l}\text { (3) Neither } \\
\text { Agree nor } \\
\text { Disagree }\end{array}$ & (4) Agree & $\begin{array}{l}\text { (5) Strongly } \\
\text { Agree }\end{array}$ \\
\hline $\begin{array}{l}\text { I understand the } \\
\text { intended message } \\
\text { (1) }\end{array}$ & $\mathrm{O}$ & $\mathrm{O}$ & $\mathrm{O}$ & O & $\mathrm{O}$ \\
\hline $\begin{array}{l}\text { It damaged the } \\
\text { surface (2) }\end{array}$ & O & O & $\mathrm{O}$ & O & O \\
\hline $\begin{array}{l}\text { The person who did } \\
\text { this used their } \\
\text { imagination (3) }\end{array}$ & O & O & $\mathrm{O}$ & $\mathrm{O}$ & $\mathrm{O}$ \\
\hline It is offensive (4) & O & O & O & $\mathrm{O}$ & $\mathrm{O}$ \\
\hline It is gang related (5) & O & $\mathrm{O}$ & O & O & $\mathrm{O}$ \\
\hline $\begin{array}{l}\text { It should be } \\
\text { considered a crime } \\
\text { (6) }\end{array}$ & $\mathrm{O}$ & O & $\mathrm{O}$ & O & O \\
\hline $\begin{array}{l}\text { It makes the space } \\
\text { more interesting } \\
\text { (7) }\end{array}$ & $\mathrm{O}$ & $\mathrm{O}$ & $\mathrm{O}$ & $\mathrm{O}$ & $\mathrm{O}$ \\
\hline $\begin{array}{l}\text { It makes the space } \\
\text { look dirty (8) }\end{array}$ & O & O & $\mathrm{O}$ & $\mathrm{O}$ & O \\
\hline
\end{tabular}

Q5a_piece: In general, was this space better before or after the street art/graffiti was put there?

Before (1) 
After (2)

Q5b_piece: Would you be okay if someone placed something like this...

\begin{tabular}{|c|c|c|}
\hline & Yes (1) & No (2) \\
\hline On your property (1) & 0 & 0 \\
In your neighborhood (2) & 0 & 0 \\
Some other part of the city (3) & 0 & 0 \\
\hline
\end{tabular}

Q5c_piece: Have you seen something like this in the past 6 months?

Yes (1)

No (2)

Q5d_piece: Do you think this should be removed?

O No (1)

O Yes (2)

If 'No' Is Selected, Then Skip To End of Block

Answer If "Do you think this should be removed?" 'Yes' Is Selected

Q5d1_piece: Do you think that the surrounding community should have a say in whether or not it's removed or left alone?

No (Community input is not needed) (1)

Yes (Community input should be received) (2)

Answer If "Do you think this should be removed?" 'Yes' Is Selected

Q5d2_piece: Do you think that public tax money should be spent to pay for its removal?

Note: This would tax money being spent on both removal labor and cost of supplies.

O No (1)

Yes (2) 


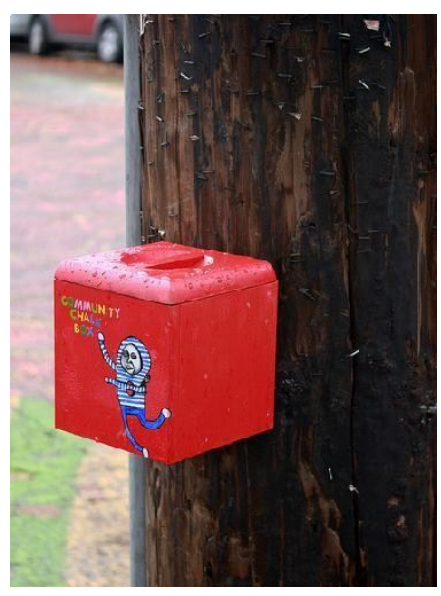

Q6_install: Please rate your level of agreement with the statements below.

Note: These are in public spaces were done without permission.

\begin{tabular}{|c|c|c|c|c|c|}
\hline & $\begin{array}{c}\text { (1) } \\
\text { Strongly } \\
\text { Disagree }\end{array}$ & (2) Disagree & $\begin{array}{l}\text { (3) Neither } \\
\text { Agree nor } \\
\text { Disagree }\end{array}$ & (4) Agree & $\begin{array}{l}\text { (5) Strongly } \\
\text { Agree }\end{array}$ \\
\hline $\begin{array}{l}\text { I understand the } \\
\text { intended message } \\
\text { (1) }\end{array}$ & ○ & ○ & $\mathrm{O}$ & O & ○ \\
\hline $\begin{array}{l}\text { It damaged the } \\
\text { surface (2) }\end{array}$ & ○ & $\mathrm{O}$ & $\mathrm{O}$ & $\mathrm{O}$ & O \\
\hline $\begin{array}{l}\text { The person who did } \\
\text { this used their } \\
\text { imagination (3) }\end{array}$ & $\mathrm{O}$ & $\mathrm{O}$ & $\mathrm{O}$ & $\mathrm{O}$ & $\mathrm{O}$ \\
\hline It is offensive (4) & $\mathrm{O}$ & O & O & O & $\mathrm{O}$ \\
\hline It is gang related (5) & $\mathrm{O}$ & $\mathrm{O}$ & $\mathrm{O}$ & $\mathrm{O}$ & $\mathrm{O}$ \\
\hline $\begin{array}{l}\text { It should be } \\
\text { considered a crime } \\
\text { (6) }\end{array}$ & O & O & $\mathrm{O}$ & O & O \\
\hline $\begin{array}{l}\text { It makes the space } \\
\text { more interesting } \\
\text { (7) }\end{array}$ & $\mathrm{O}$ & $\mathrm{O}$ & $\mathrm{O}$ & 0 & O \\
\hline $\begin{array}{l}\text { It makes the space } \\
\text { look dirty (8) }\end{array}$ & O & O & $\mathrm{O}$ & $\mathrm{O}$ & $\mathrm{O}$ \\
\hline
\end{tabular}

Q6a_install: In general, was this space better before or after the street art/graffiti was put there? 
Before (1)

O After (2)

Q6b_install: Would you be okay if someone placed something like this...

\begin{tabular}{|c|c|c|}
\hline & Yes (1) & No (2) \\
\hline On your property (1) & 0 & 0 \\
In your neighborhood (2) & 0 & 0 \\
Some other part of the city (3) & 0 & 0 \\
\hline
\end{tabular}

Q6c_install: Have you seen something like this in the past 6 months?

Yes (1)

O No (2)

Q6d_install: Do you think this should be removed?

O No (1)

Yes (2)

If 'No' Is Selected, Then Skip To End of Block

Answer If "Do you think this should be removed?" 'Yes' Is Selected

Q6d1_install: Do you think that the surrounding community should have a say in whether or not it's removed or left alone?

No (Community input is not needed) (1)

O Yes (Community input should be received) (2)

Answer If "Do you think this should be removed?" 'Yes' Is Selected

Q6d2_install: Do you think that public tax money should be spent to pay for its removal?

Note: This would tax money being spent on both removal labor and cost of supplies.

O No (1)

Yes (2) 


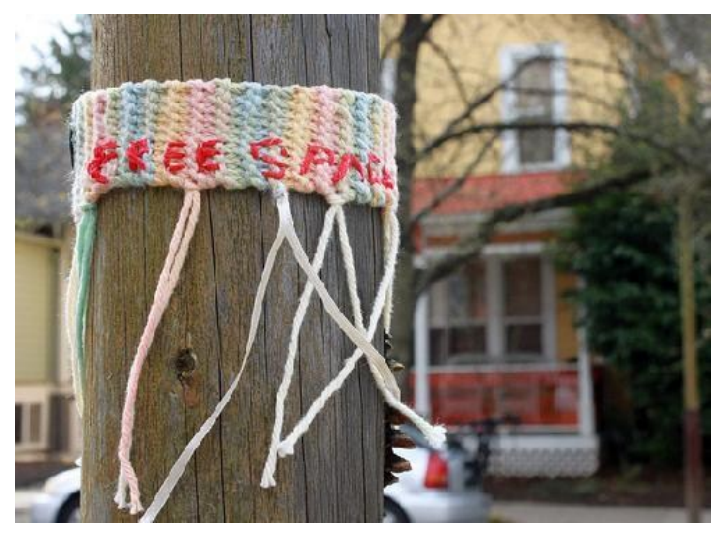

Q7_install: Please rate your level of agreement with the statements below.

Note: These are in public spaces and were done without permission.

\begin{tabular}{|c|c|c|c|c|c|}
\hline & $\begin{array}{c}\text { (1) } \\
\text { Strongly } \\
\text { Disagree }\end{array}$ & (2) Disagree & $\begin{array}{l}\text { (3) Neither } \\
\text { Agree nor } \\
\text { Disagree }\end{array}$ & (4) Agree & $\begin{array}{l}\text { (5) Strongly } \\
\text { Agree }\end{array}$ \\
\hline $\begin{array}{l}\text { I understand the } \\
\text { intended message } \\
\text { (1) }\end{array}$ & O & O & O & O & O \\
\hline $\begin{array}{l}\text { It damaged the } \\
\text { surface (2) }\end{array}$ & $\mathrm{O}$ & $\mathrm{O}$ & $\mathrm{O}$ & 0 & $\mathrm{O}$ \\
\hline $\begin{array}{c}\text { The person who did } \\
\text { this used their } \\
\text { imagination (3) }\end{array}$ & O & O & O & O & O \\
\hline It is offensive (4) & $\mathrm{O}$ & $\mathrm{O}$ & $\mathrm{O}$ & $\mathrm{O}$ & $\mathrm{O}$ \\
\hline It is gang related (5) & O & O & $\mathrm{O}$ & O & 0 \\
\hline $\begin{array}{l}\text { It should be } \\
\text { considered a crime } \\
\text { (6) }\end{array}$ & O & O & O & O & O \\
\hline $\begin{array}{l}\text { It makes the space } \\
\text { more interesting } \\
\text { (7) }\end{array}$ & O & O & $\mathrm{O}$ & O & $\mathrm{O}$ \\
\hline $\begin{array}{l}\text { It makes the space } \\
\text { look dirty (8) }\end{array}$ & O & O & $\mathrm{O}$ & O & 0 \\
\hline
\end{tabular}

Q7a_install: In general, was this space better before or after the street art/graffiti was put there?

Before (1) 
After (2)

Q7b_install: Would you be okay if someone placed something like this...

\begin{tabular}{|c|c|c|}
\hline On your property (1) & Yes (1) & No (2) \\
\hline In your neighborhood (2) & 0 & 0 \\
Some other part of the city (3) & 0 & 0 \\
\hline
\end{tabular}

Q7c_install: Have you seen something like this in the past 6 months?

Yes (1)

O No (2)

Q7d_install: Do you think this should be removed?

O No (1)

Y Yes (2)

If 'No' Is Selected, Then Skip To End of Block

Answer If "Do you think this should be removed?" 'Yes' Is Selected

Q7d1_install: Do you think that the surrounding community should have a say in whether or not it's removed or left alone?

No (Community input is not needed) (1)

Yes (Community input should be received) (2)

Answer If "Do you think this should be removed?" 'Yes' Is Selected

Q7d2_install: Do you think that public tax money should be spent to pay for its removal?

Note: This would tax money being spent on both removal labor and cost of supplies.

O No (1)

Y Yes (2) 


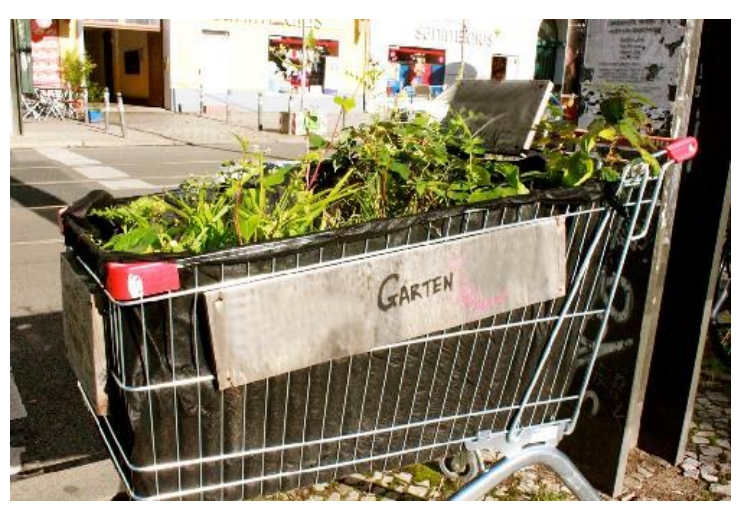

Q8_install: Please rate your level of agreement with the statements below.

Note: These are in public spaces and were done without permission.

\begin{tabular}{|c|c|c|c|c|c|}
\hline & $\begin{array}{c}\text { (1) } \\
\text { Strongly } \\
\text { Disagree }\end{array}$ & (2) Disagree & $\begin{array}{l}\text { (3) Neither } \\
\text { Agree nor } \\
\text { Disagree }\end{array}$ & (4) Agree & $\begin{array}{l}\text { (5) Strongly } \\
\text { Agree }\end{array}$ \\
\hline $\begin{array}{l}\text { I understand the } \\
\text { intended message } \\
\text { (1) }\end{array}$ & $\mathrm{O}$ & $\mathrm{O}$ & $\mathrm{O}$ & 0 & $\mathrm{O}$ \\
\hline $\begin{array}{l}\text { It damaged the } \\
\text { surface (2) }\end{array}$ & $\mathrm{O}$ & $\mathrm{O}$ & $\mathrm{O}$ & $\mathrm{O}$ & $\mathrm{O}$ \\
\hline $\begin{array}{l}\text { The person who did } \\
\text { this used their } \\
\text { imagination (3) }\end{array}$ & $\mathrm{O}$ & 0 & 0 & O & 0 \\
\hline It is offensive (4) & $\mathrm{O}$ & 0 & $\mathrm{O}$ & 0 & $\mathrm{O}$ \\
\hline It is gang related (5) & O & O & O & O & O \\
\hline $\begin{array}{l}\text { It should be } \\
\text { considered a crime } \\
\text { (6) }\end{array}$ & 0 & 0 & $\mathrm{O}$ & $\mathrm{O}$ & 0 \\
\hline $\begin{array}{l}\text { It makes the space } \\
\text { more interesting } \\
\text { (7) }\end{array}$ & $\mathrm{O}$ & $\mathrm{O}$ & $\mathrm{O}$ & $\mathrm{O}$ & $\mathrm{O}$ \\
\hline $\begin{array}{l}\text { It makes the space } \\
\text { look dirty (8) }\end{array}$ & $\mathrm{O}$ & $\mathrm{O}$ & $\mathrm{O}$ & O & 0 \\
\hline
\end{tabular}

Q8a_install: In general, was this space better before or after the street art/graffiti was put there?
Before (1)
O After (2) 
Q8b_install: Would you be okay if someone placed something like this...

\begin{tabular}{|c|c|c|}
\hline & Yes (1) & No (2) \\
\hline On your property (1) & 0 & 0 \\
In your neighborhood (2) & 0 & 0 \\
Some other part of the city (3) & 0 & 0 \\
\hline
\end{tabular}

Q8c_install: Have you seen something like this in the past 6 months?

Yes (1)

O No (2)

Q8d_install: Do you think this should be removed?

O No (1)

Yes (2)

If 'No' Is Selected, Then Skip To End of Block

Answer If "Do you think this should be removed?" 'Yes' Is Selected

Q8d1_install: Do you think that the surrounding community should have a say in whether or not it's removed or left alone?

No (Community input is not needed) (1)

Y Yes (Community input should be received) (2)

Answer If "Do you think this should be removed?" 'Yes' Is Selected

Q8d2_install: Do you think that public tax money should be spent to pay for its removal?

Note: This would tax money being spent on both removal labor and cost of supplies.

O No (1)

Yes (2) 
VANDART: In general, do you view street art/graffiti as an act of vandalism or artistic expression?

Vandalism (Why?) (1)

O Artistic Expression (Why?) (2)

O Don't Know (3)

DEMO: The next few questions are for demographic purposes only. Please remember that this survey is anonymous. If there is a question you would rather not answer, you can skip over it by leaving it blank and clicking the button.

HHMS: Including yourself, how many people live in your household?

Enter number including yourself: (1)

One - I live alone (2)

Answer If "Including yourself, how many people live in your household?" 'One - I live alone' Is Not Selected

CHILD: How many children under the age of 18 live in your household?

Number of children under 18: (1)

O None (2)

RENT/OWN: Do you currently own or rent your home?

O Own (1)

O Rent (2)

TIME: How long have you lived in your current neighborhood?

Less than a year (1)

1 to less than 3 years (2)

O 3 to less than 5 years ( 3 )

5 to less than 10 years (4)

10 years or more (5)

All my life (6)

ZIP: What is your home zip code? 
AGE: Which of the following age groups are you in?
O $18-24(1)$
O $25-34(2)$
O $35-44(3)$
O $45-54$ (4)
O $55-64(5)$
O $65-75(6)$
O 76 or over (7)

EDUCATION: What is the highest level of education you have completed?

Some High School, without a Diploma (1)

High School Diploma or GED (2)

O Associate Degree or Technical/Vocational School (3)

O Bachelor's Degree (4)

Graduate or Professional Degree (5)

INCOME: Finally, which category best describes your yearly total household income before taxes?

Note: Your best estimate is fine.

Less than $\$ 15,000$ (1)

O $\$ 15,000$ to less than $\$ 25,000(2)$

O $\$ 25,000$ to less than $\$ 35,000$ (3)

O $\$ 35,000$ to less than $\$ 50,000$ (4)

O $\$ 50,000$ to less than $\$ 75,000(5)$

O $\$ 75,000$ to less than $\$ 100,000(6)$

O $\$ 100,000$ or more $(7)$

COMMENTS: Do you have any additional comments about this survey?

Yes (Please specify): (1)

O No (2)

DRAWING: Thank you for your help with this research. If you would like to be entered into the drawing to win a $\$ 50$ Visa gift card, please provide your contact e-mail address and/or phone number below. The winner will be contacted once this survey is complete.

Enter e-mail and/or phone number: (1)

No thanks (2) 


\section{Appendix E. Flyer Distribution Areas}

\section{NORTH PORTLAND}

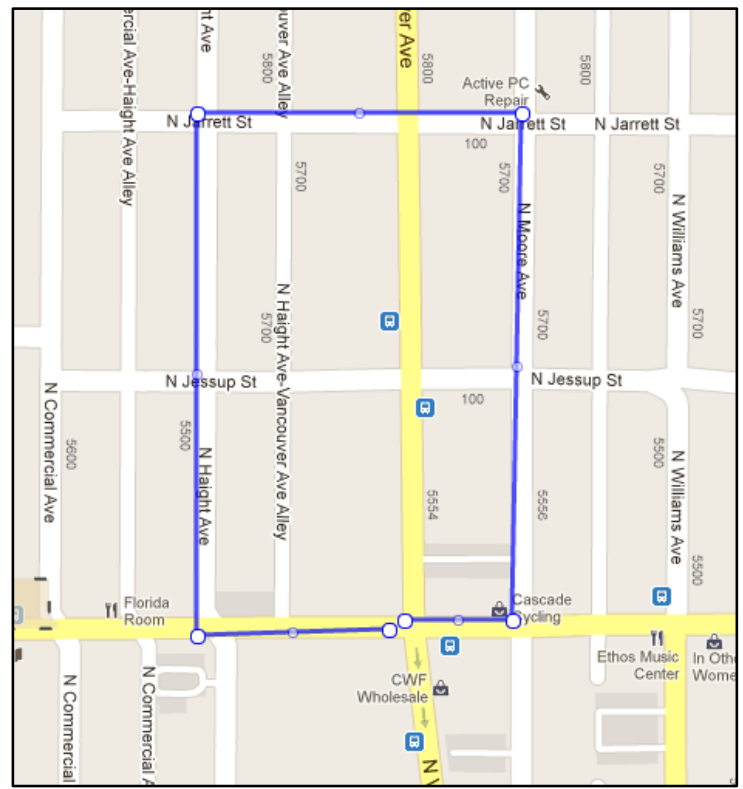

Humboldt: Killingsworth, Haight, Jarrett, Moore

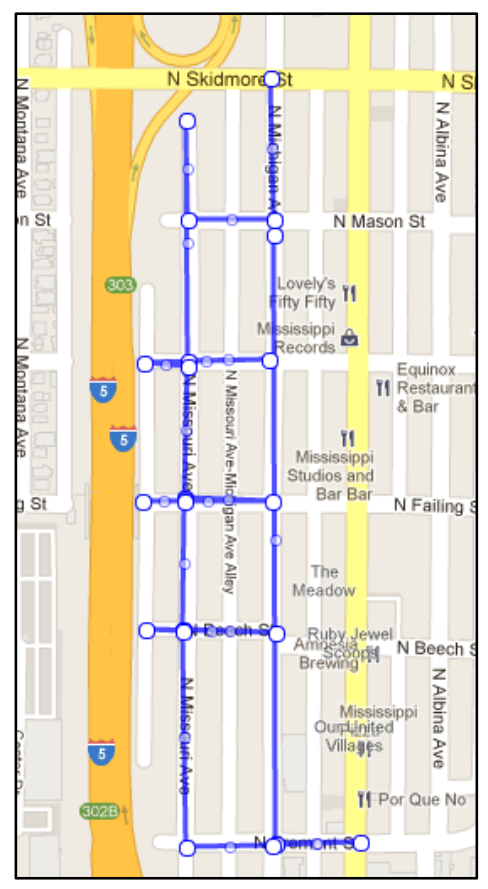

Boise: Missouri, Michigan, Falling, Beech, Fremont, Shaver, Mason 


\section{SOUTHEAST PORTLAND}

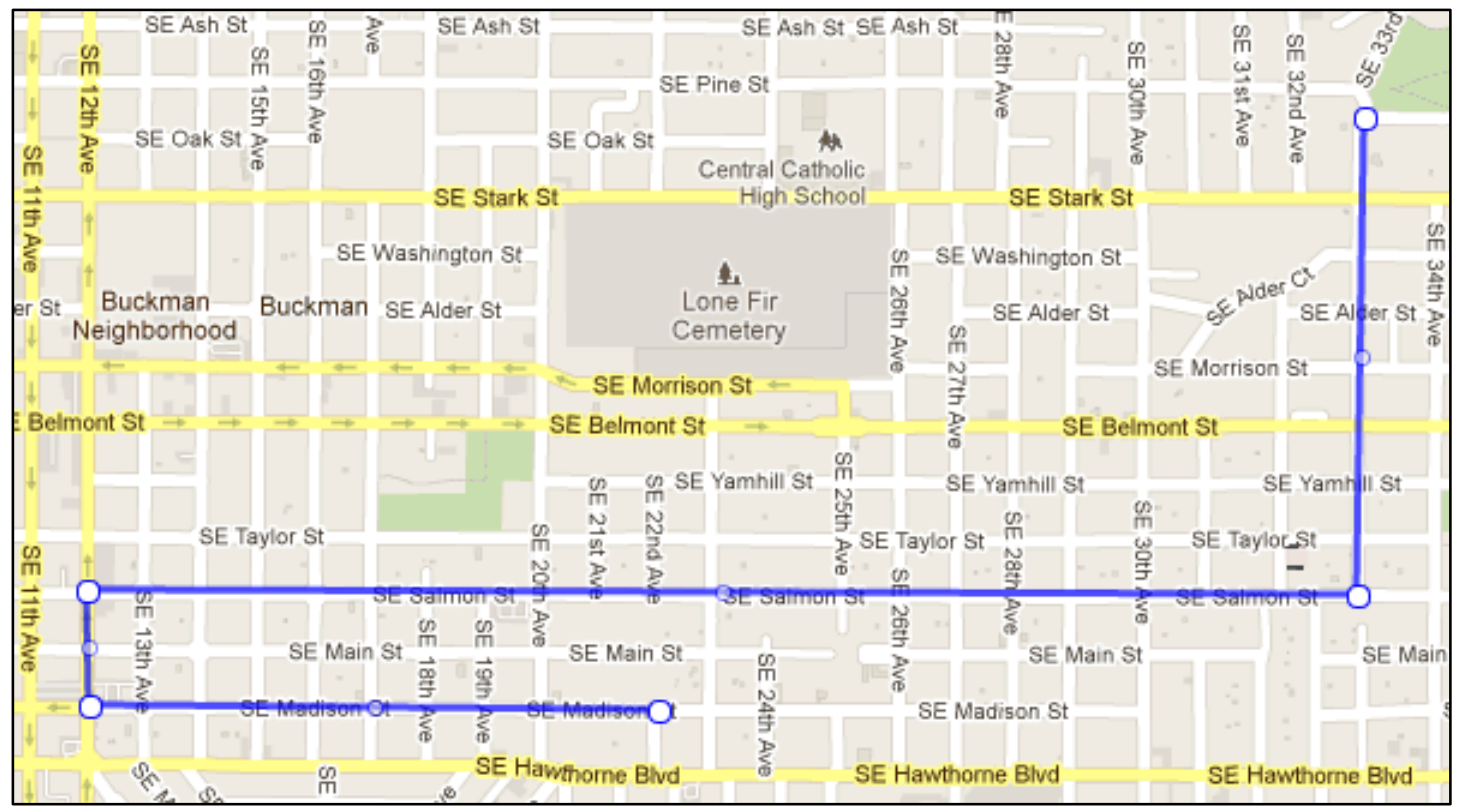

Sunnyside and Buckman: Madison, Salmon, 33rd

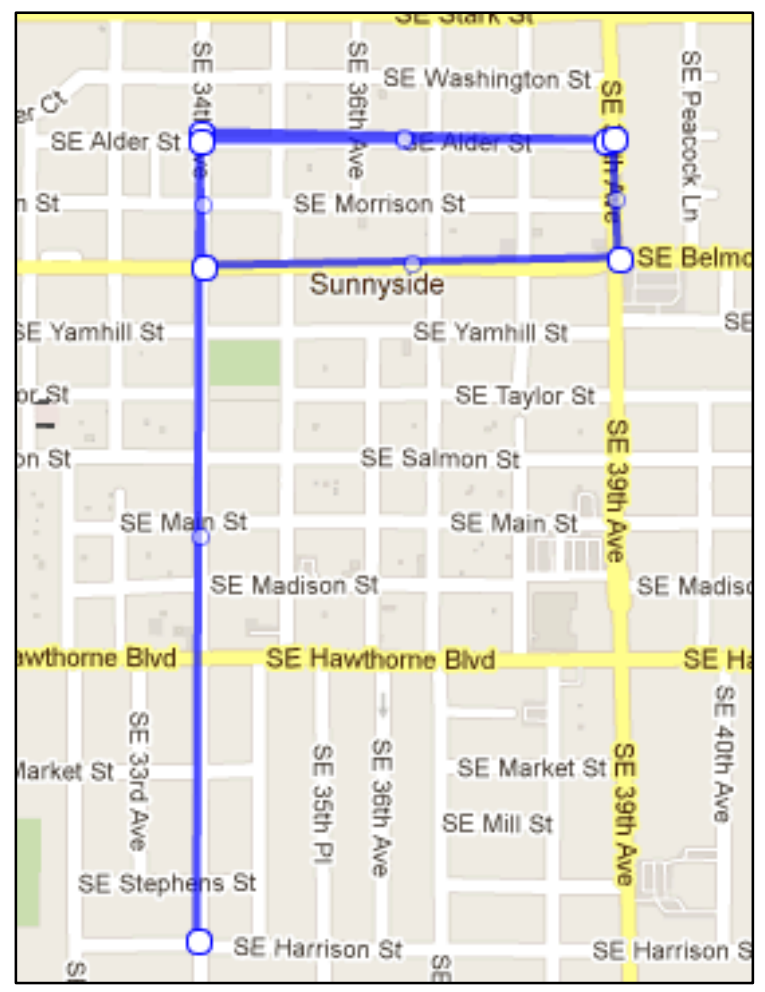

Sunnyside and Richmond: $34^{\text {th }}$, Belmont, Alder, $39^{\text {th }}$ 


\section{SOUTHEAST PORTLAND}

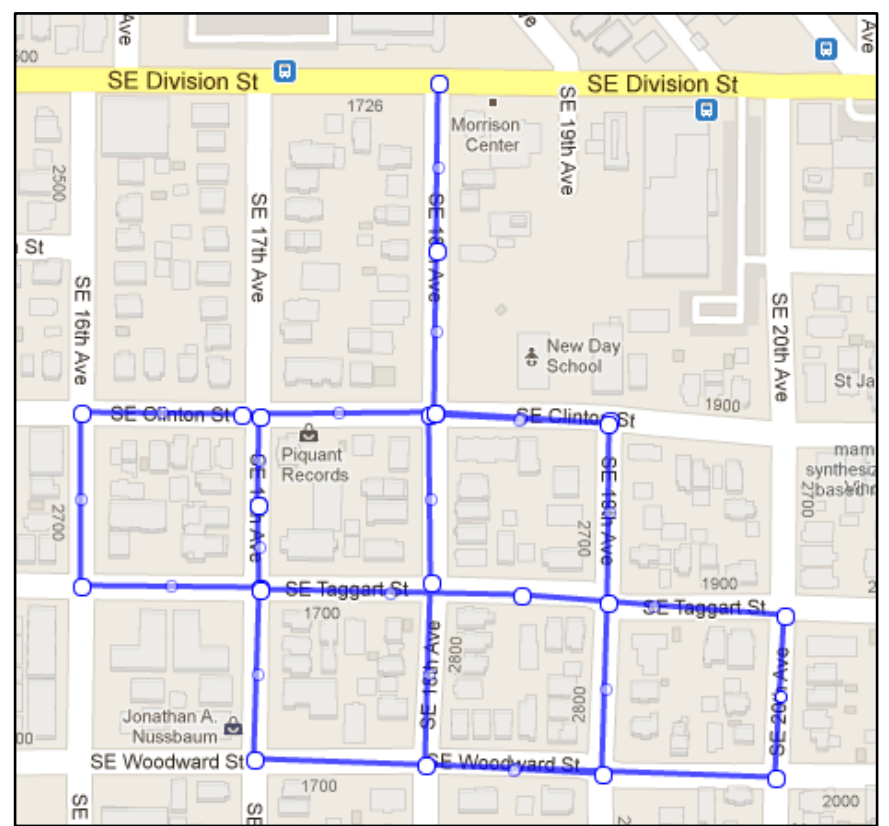

Hosford-Abernethy: Woodward, Taggart, Clinton, $16^{\text {th }}, 17^{\text {th }}, 18^{\text {th }}, 19^{\text {th }}, 20^{\text {th }}$

\section{NORTHWEST PORTLAND}

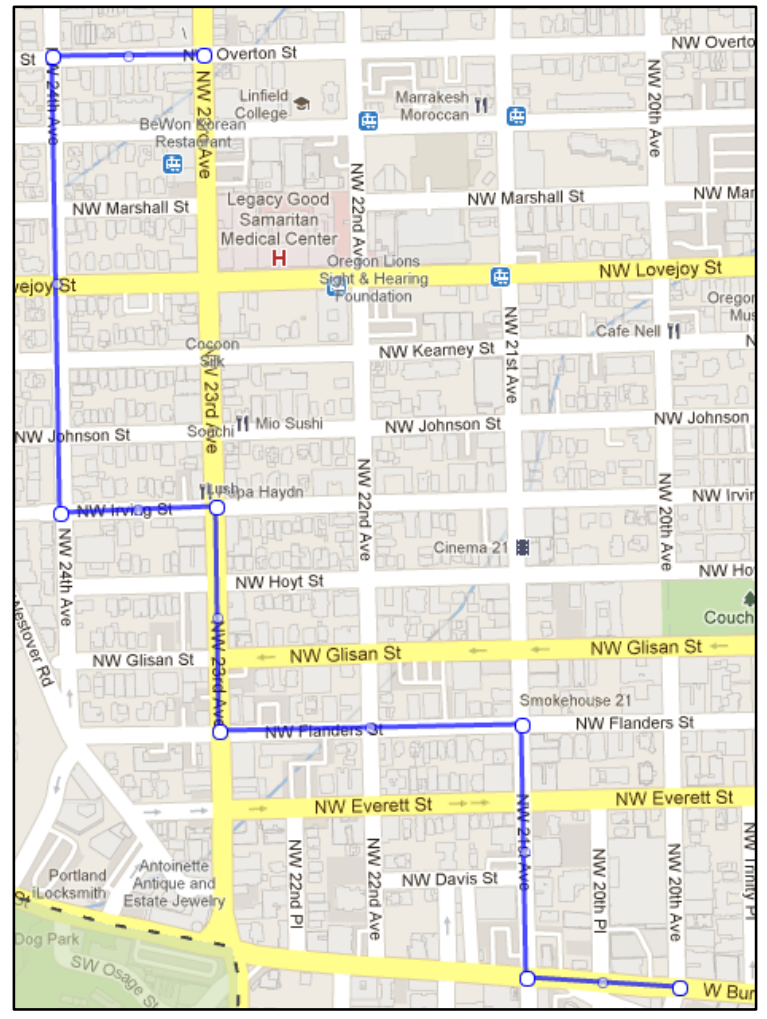

Northwest District: Overton, $24^{\text {th }}$, Irving, $23^{\text {rd }}$, Flanders, $21^{\text {st }}$ 


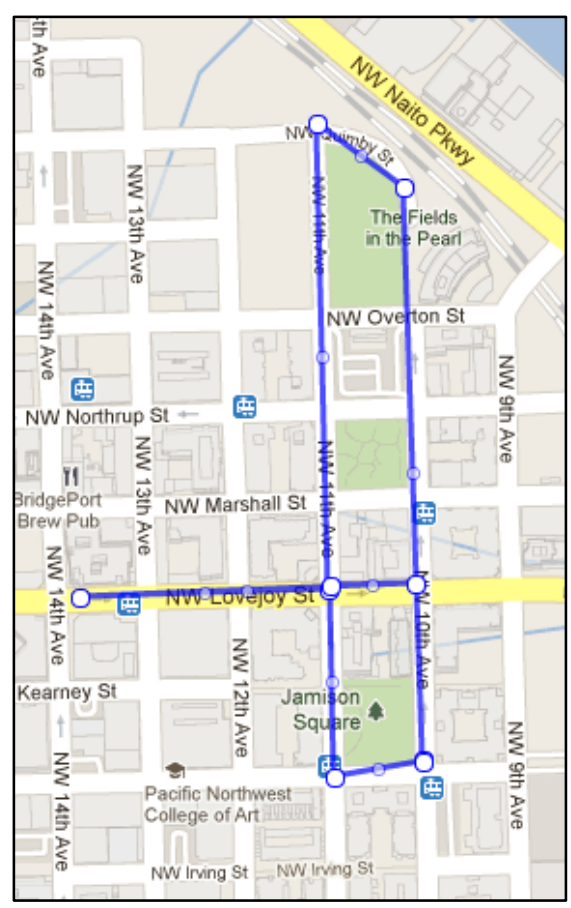

Pearl District: Lovejoy, $11^{\text {th }}, 10^{\text {th }}$ 


\section{SOUTHWEST PORTLAND}

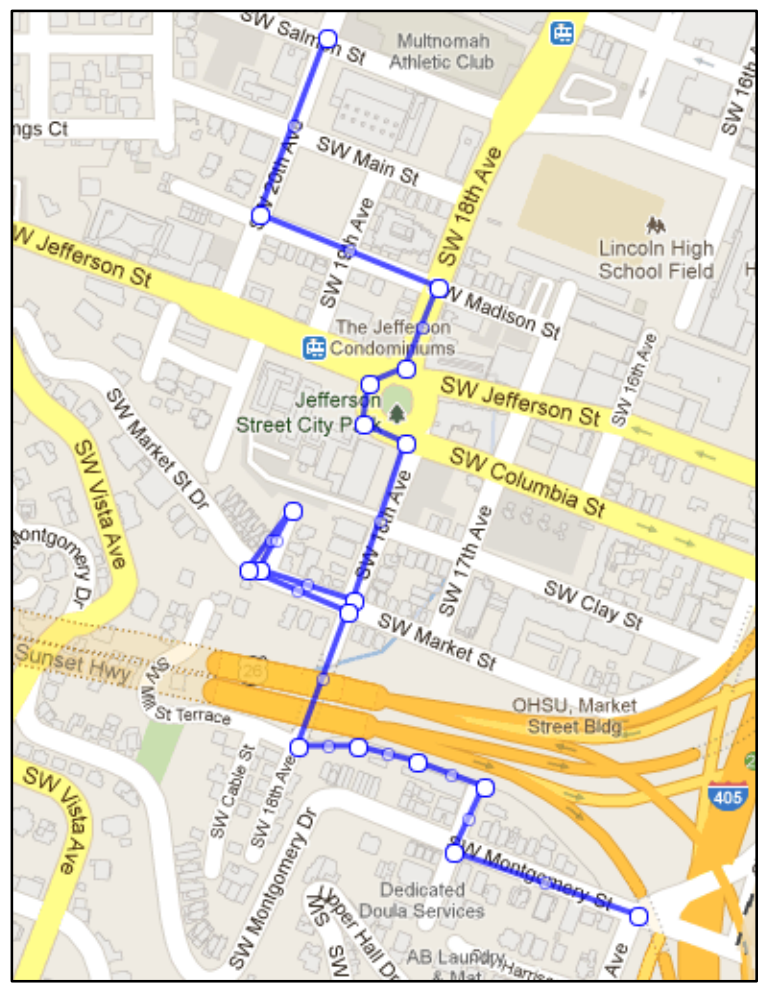

Goose Hollow: $20^{\text {th }}$, Madison, $18^{\text {th }}$, Market, Montgomery 


\section{NORTHEAST PORTLAND}

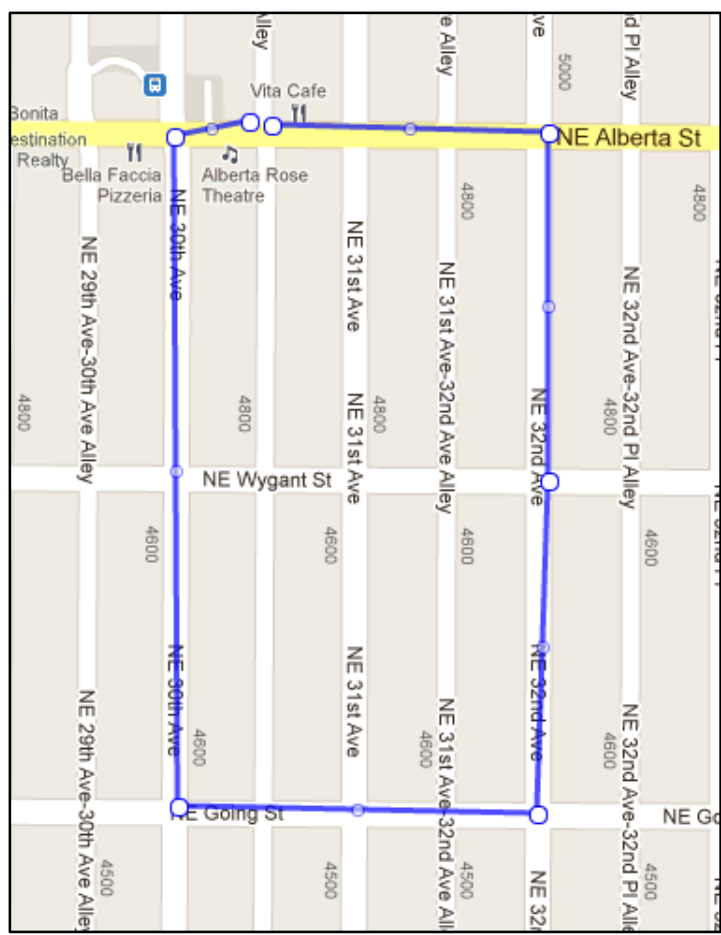

Concordia: Going, 32nd, Alberta, 30th

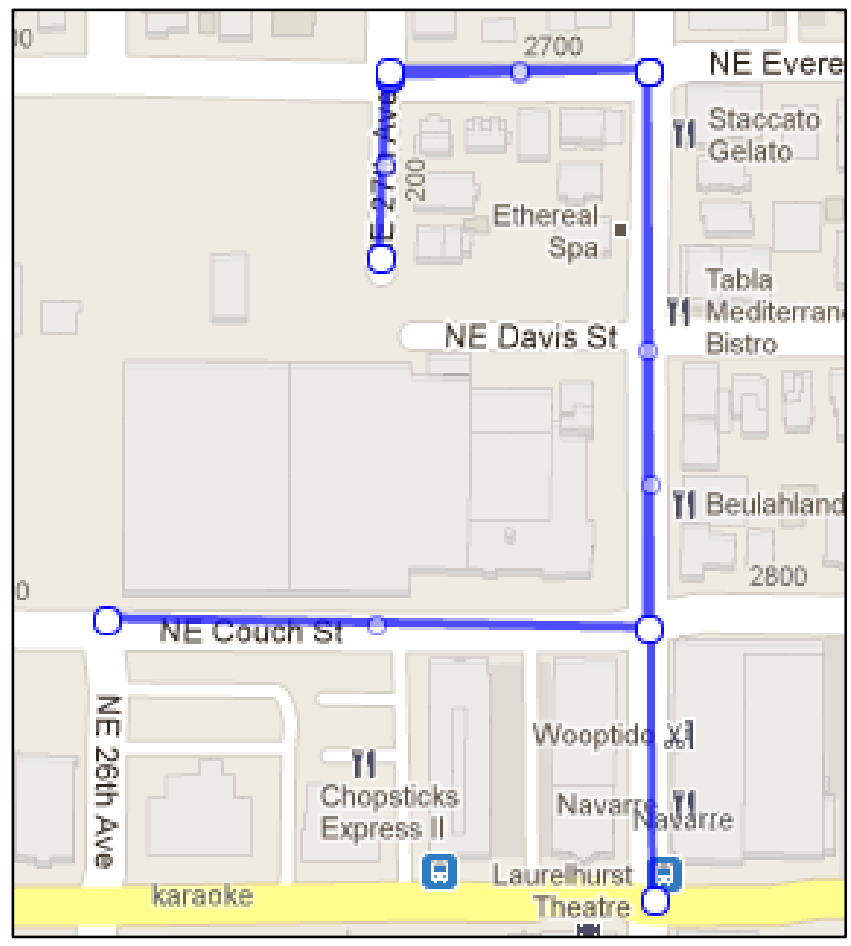

Kerns: Burnside, Couch, $28^{\text {th }}$, Everett, $27^{\text {th }}$ 


\section{Appendix F. Survey Open Ends}

\section{ACCESSABLE TO EVERYONE (PUBLIC MUSEUM)}

I think some of the street art featured in this survey was better than things you might see in a museum. It is interesting to see different people's ideas and thoughts in a public space.

I think it's a forum for artists to express themselves on spaces that are accessible for everybody.

Not only does this public art show the cultural side of our community, but it also connects local and visiting artists. Everyone from tourists to neighborhood residents is offered an enriching experience from observing the artists expressed work.

The fact that you encounter street art unexpectedly, while you're in the middle of your day going place to place is what makes it so meaningful. The risk that the artist takes by putting it out in public makes it that much better. No kind of art is like street art, and it is without a doubt an expression of art.

Besides gang related turf marking, its artists showcasing their talent in interesting and different spaces.

I'm sorry there aren't places where this type of work can be done as public art and be on view for people to enjoy.

I should not be forced to look at graffiti while I walk out of the house, or to the market. If I want to see this, I will go to a gallery or a graffiti show.

\section{ADVERTISTING}

Above all, I believe that street art will continue to expand, despite measures taken against them such as cameras, fences or guard patrol, because as the world grows, so does advertising and the reign of billboards, paid advertisements, LED billboards until... what, every major US city comes to look like a synaptic flashing Tokyo? Instead of graffiti, yarn bombing, murals, wheatpasting and other related forms of street art, we'll be surrounded by the other thing we didn't choose to see and digest, advertising? How is that better?

\section{AESTHETICS}

Art and vandalism cannot be separated by aesthetics (if it looks good or not) it boils down to permission. 
These can be artistic expression if done tastefully. Simply putting a scribble up or a sticker up to mark that you have been there is unimaginative, degrading to the space, and juvenile. When thought and feelings go into creation and community building through the shared enjoyment of the artist and viewers then these small and large projects can create space within a city. Simple concrete and power poles are a draining and dreary view of the city. When color is added and people are engaged art can change the perception of the space we live in.

If it is at least sort of nice to look at, interactive like a chalk box or garden cart, not too messy, imaginative, and fun, then it is street art!

It does really depend on the appearance. The difference for me lies in the amount of time and thought I think the person put into the piece. Some letters quickly sprayed up messily (like the piece going down the pole next to a bus stop) just seems like a selfish territory-marking destructive act whereas some pieces are gorgeous.

It's ugly and doesn't contribute to the overall look/feel of the community. While someone may have thought they were supporting community-building, it's ugly and in bad taste.

Something is art if it is easily understood, is interesting, and/or has socially redeeming value.

Most of the images appear to have damaged the surfaces but the last 3 images were interesting, artistic and not damaging (vandalism).

No consent, adversely affects property value, and most importantly most of it sucks. Nothing artistic about it at all. Art is a pretty big umbrella for lots of crap. Most graffiti in Portland doesn't make the cut.

While plain tags seem to be ugly to me, larger, brighter murals and art pieces make me smile.

Street art is inspiring and impactful. There should be a raised standard among writers so the 'trash' graffiti is not accepted and people strive for more.

\section{ART + THE CITY}

I've been trying to get a handle on Portland graffiti since moving here from New York five years ago. There's a strong graffiti tradition in NYC. Here, it seems, not so much. In general it seems very amateurish to me, without a strong sense of identity. With few exceptions, I've never been able to identify the work of a particular street artist from piece to piece.

I have some experience with graffiti "artists" and other street artists over the past few years. My neighborhood, the NW Nob Hill area, has a large contingent of these creative sorts of people and street art is part of what makes the neighborhood notable. However, there is group of artist wannabes who have not matured in their understanding of what is a creative self-expression byway of performing public are, in a non-destructive way. 
Street art has become a much larger part of the arts world and I think in certain regards, it should be respected.

Simple concrete and power poles are a draining and dreary view of the city. When color is added and people are engaged art can change the perception of the space we live in.

I want to live somewhere where there is street art and graffiti.

When it's done in the right places and in a creative way, it enlivens the city.

A person uses their imagination/message and dresses up a blank medium with that.

I think it is important to acknowledge some graffito to be artists. Their best work is done for the public. Portland should adopt public spaces (walls, blank slates, light poles, etc.) everywhere throughout the city for these artists to express their skills. Not only does this public art show the cultural side of our community but it also connects local and visiting artists.

There's often not a lot of imagination or technique involved. That's my criterion: Whether it elevates the environment.

The fact that you encounter street art unexpectedly, while you're in the middle of your day going place to place is what makes it so meaningful.

The more color we have in our daily lives the better! It makes each neighborhood within our city and each city itself more unique.

In general I think graffiti livens up public spaces and in some cases, is downright beautiful and should not be illegal, but embraced as art

We live in a very boxed in world, with boxes and blank spaces and blandness all around. These people obviously want to express themselves and try to make the humdrum boring existence a little more tolerable and pleasant to look at. Each piece of work is unique onto itself and the person making the artwork. Street art is a way of life in any city or urban area.

It's shown by graffiti or music players on the street, there's no problem with is, it makes people feel good and changes the energy in the air, why is there artistic energy? Because it can be used as an outlet for people to get their anger of the economy and it could be do what you do for work.

A piece of art beats out a boring gray wall any day....The city should take advantage of these people and designate certain areas for street art to limit them going to private property. Even then, the majority of the private property they hit up is abandoned or bank owned I feel this survey has left out a lot of information that could have not only let people express their opinions, but educated them in the street art etiquette that goes on. 


\section{BLANK WALLS: MAKING SPACE MORE INTERESTING OR UNIQUE}

Most graffiti seems intent on amusing passersby, making a space more interesting, or conveying a message in my opinion.

I think if you're going to put something on a wall, it has to improve on that wall, and I don't see that the majority of the time with the graffiti here. If the wall's better without your work on it, you need to step up your game or fine another one.

Simple concrete and power poles are a draining and dreary view of the city. When color is added and people are engaged art can change the perception of the space we live in.

A piece of art beats out a boring gray wall any day.

They are taking a blank canvas and making it their own. I don't think people are out to tag a particular building, I think they just see a big open space and see opportunity, no matter where its location. If someone is writing something bad on a space which they are intentionally targeting, then I would consider that vandalism.

Most of the pieces seemed to be on surfaces that were not really being used anyway for another useful purpose.

Cities all have areas of urban decay. I believe that artists should be able to express themselves in these areas.

If someone wants to brighten up a shabby wall, great. It only seems a problem to me when they cover someone else's art.

A person uses their imagination/message and dresses up a blank medium with that.

We live in a very boxed in world, with boxes and blank spaces and blandness all around. These people obviously want to express themselves and try to make the humdrum boring existence a little more tolerable and pleasant to look at. Each piece of work is unique onto itself and the person making the artwork.

If you've ever been to Europe one should realize that graffiti is a universal impulse to place marks in time and space to differentiate one from another (people and places).

\section{BOTH LIKE AND DISLIKE - BOTH VANDALISM AND ART}

I understand and appreciate some forms of graffiti and would consider them art (e.g. I'm a fan on Banksy and he can tag any area in my neighborhood - it would help property values increase!) but 
I see tags on buildings in my neighborhood of Mississippi ad it drives me nuts. Every time I drive past it, it angers me than some idiot feels that he or she has the right to just spray paint junk messages on someone else's property.

I hate tagging, but I like street art so I understand it's difficult to draw the line. But if I were forced to choose, I would rather have a city with no unauthorized street art than a city with tagging and gang graffiti mixed in. Garbage on my city's walls looks no different than garbage on my city's streets.

I liked the decorated telephone poles in NW Portland and was sorry people got so fired up and ripped them off. But I truly do not like any painted graffiti on anything. It's ugly and hard to remove.

I see the artistic expression element of the work in these photos, but painting on property that is not yours, be it public or private is vandalism.

Tagging and other gang-related activity should be removed immediately, using public funds if necessary, to prevent giving the gangs credence. However, I appreciate artistic expression and enjoy colorful well-done artistic messages and graffiti.

If it is ugly, and in the wrong spaces, then I consider it vandalism. Most tags fit in this category. If it is not ugly, is imaginative and is not defacing something (like the Colonel Summers Park sign), I consider it artistic expression.

Definitely vandalism, but why can't it be artistic expression too?

It's vandalism because it's done without permission. It is also artistic expression. If it weren't illegal, everyone would do it.

It's mostly artistic expression. I hate generic tagging, but something colorful and unique, that is only put on walls or telephone poles (not windows or store signs), adds to the neighborhood in my opinion. I really sit more in the middle on this question. It's not fair, I know, but when the art is terrible, I think of it as vandalism. When it's good, it's artistic expression.

It depends on the context and art/graffiti subject. Tags are omnipresent and not particularly attractive. Stencils, pictures, statements are interesting and seem more a form of artistic expression.

If it, or the tagger, has something to say other than, "Look, I tagged this," then I can look at it and approach the social question(s) it asks. It enters the realm of editorial or commentary. Otherwise, if they just want to tag for tagging sake or bragging rights, they can keep the spray paint and markers up their nose.

Street art/graffiti is vandalism if it is performed without consent or permission, and the owner of the property wants it removed. In addition, the street art must modify an existing surface. That 
being said, the street art/graffiti is also artistic expression. The artistic expression varies in degrees of quality based on the perspective of the observer.

Good (community chalk box, mustache-jellyfish, etc.), bad (tags), or indifferent, street art tends typically involves trespassing and forcing your views on someone else's property. I find a lot of street art to be very interesting, beautiful, and thought-provoking and I would probably support such art on my property.

Graffiti are sometimes beautiful art but are always an advertisement that anything is permitted in that common space. I do not feel badly that the tiny percentage of beautiful art gets scrubbed along with the tags and blight.

The photos of some of street art on this survey show nice work that I like to look at, but I still wouldn't want any of it on my house or on the fence in front of my yard.

I encourage to a degree, the reason being it could be offensive to one and not to the other. Anything that glorifies Satan I'm not for, but positive art I am for and demonic art that is influenced by demonic spirits and "new age" I am against completely. Yet some things are just vandalism, like the one that said 'long live art' that is vandalism and then there are stickers too. But the other mural piece was beautiful.

\section{BROKEN WINDOWS}

Garbage on my city's walls looks no different than garbage on my city's streets.

Graffiti is an expense to home owners, and makes people worried about more serious crime. However, tons of band posters on power poles don't bother me.

Graffiti places citizens in fear of gang activity and degrades the livability of the neighborhood.

Stuff in the public right of way, is still stuff in the public right of way. Rules and regulations are set up for public safety and welfare. I can see this kind of thing becoming neglected trash.

No consent, adversely affects property value, and most importantly most of it sucks; nothing artistic about it at all.

Looks like litter.

The majority of the time I see it as vandalism. Most often it is indecipherable, unsightly and can negatively impact the image or property value of surrounding areas. Even though sometimes the graffiti/art is creative and artful, it has negative connotations associated with it, especially if gang related and does not improve the location or area.

I personally find graffiti depressing and have had to deal with it myself when I had a retail shop. 
Ultimately, its different color paint on an already painted surface and not a broken window.

Unchecked it spreads from public property to private property.

For the most part, I would consider that most street art is vandalism due to the fact that it defaces and devalues public property. In most cases graffiti also is unpleasant to eye and really gives off a sense of "scuzzy-ness" to the property. Street artists are criminals and they should be fined, thrown in jail for an evening, or punched in the face.

I understand that asking permission would probably make things better, but if the social construct didn't create street art as a dirty/gang related crime I'm sure more property owners would graciously welcome free art and murals expressing some of the culture that makes Portland the awesome-weird place it is.

On private property - the owners don't want to see it. If they don't go through the expense of removing it, it attracts more (i.e., if someone tags your property and you don't clean it up, other folks come along and tag over it or next to it, and so you have a mess). The cleaners don't work on the garbage cans, just smear it and looks bad.

I have often seen urban blight begin with graffiti, but have never seen graffiti to be the only manifestation. I see it as a harbinger of broken windows, used syringes, public defecation and urination, firearms discharges, and street crime in general.

Most "contributions" are eyesores and gang related ones seem threatening. Even though some are clever and seem to decorate rather than deface, leaving them only encourages more.

I also think property owners should be able to make the decision if they wish graffiti to be removed or retained to add value to their property.

\section{COMMUNICATION}

Most graffiti seems intent on amusing passersby, making a space more interesting, or conveying a message in my opinion.

Main motivation is to communicate, express, not to harm or damage.

It is interesting to see different people's ideas and thoughts in a public space.

Having more public spaces for art is important. We need places to communicate ourselves to others; the more of this the better.

It is a public forum for political commentary.

I think it is important to acknowledge some graffito to be artists. Their best work is done for the public. Not only does this public art show the cultural side of our community but it also connects 
local and visiting artists. Everyone from tourists to neighborhood residents are offered an enriching experience from observing the artists expressed work.

\section{COMMUNITY-BUILDING}

When thought and feelings go into creation and community building through the shared enjoyment of the artist and viewers then these small and large projects can create space within a city. Simple concrete and power poles are a draining and dreary view of the city. When color is added and people are engaged art can change the perception of the space we live in.

The two as I said above are not contradictory. This is important and crucial to maintain community, to grow as society or as individuals. It being in public, makes it all the stronger, in terms of its positive healing properties, in terms of its ability to connect, communicate, etc. Artistic expression is great, but it also needs to realistically fit framework of positive communication, which means respecting the fact that different people have different projects (which extends to spaces).

I think it is important to acknowledge some graffito to be artists. Their best work is done for the public. Portland should adopt public spaces (walls, blank slates, light poles, etc.) everywhere throughout the city for these artists to express their skills. Not only does this public art show the cultural side of our community but it also connects local and visiting artists. Everyone from tourists to neighborhood residents are offered an enriching experience from observing the artists expressed work.

It's ugly and doesn't contribute to the overall look/feel of the community. While someone may have thought they were supporting community-building, it's ugly and in bad taste.

I believe if the community comes together and designates space/spaces then it will be taken care of, planned and protected. If it is just random spots than it is a disservice to the community for public spaces should be free of individual personal expression for it is for all. This does not mean that there can't be artwork, but it is the randomness of what is put and where.

Something is art if it is easily understood, is interesting, and/or has socially redeeming value.

When thought and feelings go into creation and community building through the shared enjoyment of the artist and viewers then these small and large projects can create space within a city.

\section{COMMUNITY APPROVAL - AN ISSUE OF PERMISSION}

I believe if the community comes together and designates space/spaces then it will be taken care of, planned and protected. If it is just random spots than it is a disservice to the community for public spaces should be free of individual personal expression for it is for all. 
As an observer, I'm fine with street art as long as I like it (if some effort/creativity was put into it) but if I don't I think it should be removed. Who gets to decide that line? The community I suppose.

Interesting; it made me think about the subjectivity of the subject. That's why I like the idea of a vote on major pieces that are difficult to remove.

Taxpayer money should not be used to remove street art. We should promote those with truly artistic intentions to "go over" vandalism.

I like artwork, but only if it is approved by the owner or community.

In the instances where I said the graffiti/art should be removed, I meant that it should be eventually removed after community input deems it to be time. I think most of these expressions should be somewhat temporary, not permanent.

Do it to your own property.

Public property should have the right to have people freely express themselves.

No one should have permission to use the shared public right of way as their own personal canvas.

Modifying something that isn't yours because you "feel like it looks better," is vandalism pure and simple. Feel free to decorate your own property as you see fit. But community property or taxpayer-funded property should be left alone.

Decorating the community should be a community decision.

The majority of photos shown are on applied on private or public property, what is not said is if there was permission. [INACCURATE - Survey said all pieces were executed without permission.]

I see the artistic expression element of the work in these photos, but painting on property that is not yours, be it public or private, is vandalism.

No consent, adversely affects property value, and most importantly most of it sucks; nothing artistic about it at all.

Property owners must retain the right to remove the graffiti, and the community needs to have some say in what level or types of graffiti should be acceptable.

I believe that artistic graffiti is an acceptable form of art, but if it's on someone else's property, funds should be made available to the property owner to allow for removal. Unless the taxpayers agree to allow graffiti in public spaces and graffiti remains illegal then I think it is an act of vandalism. 
It should be illegal to vandalize someone's (even public) property without permission, just like it should be illegal to shoot a serial killer without due process. Why not ask? Why is "without permission" so important to the artistic expression.

I also think property owners should be able to make the decision if they wish graffiti to be removed or retained to add value to their property.

I'm okay with it as long as it isn't on someone's personal home or business without their permission.

It is done on someone else's property without permission and with no regard to how it will affect others in community.

(They) did not seek approval from land owner or the city.

We need to ask before we paint on someone's wall. They are entitled to express that space, as they would like. This is like protecting peoples' basic liberties. It is asking to paint everywhere and then not letting anyone else paint. We need to respect the spaces that each other use to express.

In the end they are damaging someone else's property and forcing a message on that owner. Regardless of whether or not it makes the space better they placed it there without permission.

It's an act of vandalism. It's usually done on private property without the owner's permission, thus its vandalism. If it's done on community property (phone pole, street, sidewalk), again, it's vandalism. The graffitist did not get permission from the community (in most cases this would be the city) to deface the area.

Vandalism; anything done to public or private property without the permission of the owner or facility/resource manager is a crime of trespass at the very start.

Street art/graffiti is vandalism if it is performed without consent or permission, and the owner of the property wants it removed.

I do not agree that it is okay for anyone to place their idea of "art" on surfaces that do not belong to them without permission.

Good (community chalk box, mustache-jellyfish, etc.), bad (tags), or indifferent, street art tends typically involves trespassing and forcing your views on someone else's property. I find a lot of street art to be very interesting, beautiful, and thought-provoking and I would probably support such art on my property. However, no matter how great it is, nobody has the right to choose how my space is decorated. Also, nobody should be forced to remove/cover your work at their own expense/time, but they are when art is forced upon them.

Because property owners aren't asked by the 'artist' or given the choice to have the graffiti put on their property. Then it becomes the property owner's responsibility to clean it up or they can face fines from the city. It is no different than spray-painting someone's vehicle without their consent, 
or dumping your trash on someone's lawn. You are leaving a mess that may or may not look artistic, but which still has to be cleaned up by the person/people you left it with. It is selfish to assume that your own version of 'art' or self-expression is wanted or appreciated without asking first. The photos of some of street art on this survey show nice work that I like to look at, but I still wouldn't want any of it on my house or on the fence in front of my yard And I would be irate if I ever caught someone putting their 'art' on my property without my permission.

As long as it's on public spaces (bridges, telephone poles, sidewalks, etc.) and not on a private property owned by an individual (not a corporation or government), I love street art! I love it on private property too, as long as the owner allows it.

I don't like it when property is damaged or something is done without some permission or intention.

\section{CONTEXT}

This survey does a poor job of putting the photos into context. To me, context is everything when it comes to street art, or graffiti.

The photos do not depict their true location or surrounding area.

It's hard to decide if something/art is making an area better or not without a larger view of the area.

It is difficult to decide if property is better/worse than before without seeing the context, without seeing a larger photo of the building/property.

For some of the pictures, including the tag and the cart garden, there was not enough context to know if the installation made the space better or dirtier.

Sometimes understanding the context of the space could have informed the decision of "better before or after." For some reason (in my head) graffiti is "more ok" when it occurs on public property or a commercial space and not ok if it is on someone's home/car/etc.

In my opinion I think it depends on the context of the graffiti itself in most cases. In some instances it's simply that I do not prefer the style of art. However, I don't think that should determine whether or not the environment is made more interesting with the use of non-gang related graffiti - especially if it is on public property done anonymously or private property by the owner.

I would like to have had more info about some of the specific pieces because I could not tell what they were - for example, the shopping cart. Is the cart full of plants the vandalism? Is it the sign placed on the cart? Is it on a sidewalk, in a park or what?

Do it to your own property. 
Quality of the work and placement are crucial in my judgment: art or littering? If windows are covered up, obviously that's a crime.

It depends on the context and art/graffiti subject. Tags are omnipresent and not particularly attractive.

When it's done in the right places and in a creative way, it enlivens the city.

Cities all have areas of urban decay. I believe that artists should be able to express themselves in these areas.

This survey is very challenging to answer because I don't know where the art is or one what type of property. With the garden shopping cart, it totally depends to me where it is to determine how I feel about it.

If someone wants to brighten up a shabby wall, great. It only seems a problem to me when they cover someone else's art.

We live in a very boxed in world, with boxes and blank spaces and blandness all around. These people obviously want to express themselves and try to make the humdrum boring existence a little more tolerable and pleasant to look at. Each piece of work is unique onto itself and the person making the artwork. Street art is a way of life in any city or urban area.

As long as it's on public spaces (bridges, telephone poles, sidewalks, etc) and not on a private property owned by an individual (not a corporation or government), I love street art! I love it on private property too, as long as the owner allows it.

\section{DESTRUCTIVE}

Wheatpaste was not presented here, but it is another great form of street art because it is water soluble and can show more graphics and design than paint.

The only thing that separates street art and graffiti from vandalism is if thing are broken.

I have some experience with graffiti "artists" and other street artists over the past few years. My neighborhood, the NW Nob Hill area, has a large contingent of these creative sorts of people and street art is part of what makes the neighborhood notable. However, there is group of artist wannabes who have not matured in their understanding of what is a creative self-expression byway of performing public are, in a non-destructive way.

I think installations like that and the garden shopping cart are in a different league than paints which may damage a surface permanently. Personally, the knit "graffiti" is a bit annoying - you know there are people in the city that could use scarves and blankets so it seems like a waste on a tree or pole. Again, though, it doesn't do any permanent damage so it is mostly a nuisance and perhaps litter. 
I don't like it when property is damaged or something is done without some permission or intention.

Most of the images appear to have damaged the surfaces but the last 3 images were interesting, artistic and not damaging (vandalism).

No one should ruin a building, seen it too many times.

In the end they are damaging someone else's property and forcing a message on that owner. Regardless of whether or not it makes the space better they placed it there without permission.

Regardless of message, its permanence and the effort it takes to remove it from surfaces is something that I cannot condone. However, street art, other forms of expression, such as stickers on electrical boxes, knitting on trees, and the red chalk box are, are all things that are easily removed. Artistic expression does not have to be damaging to our surroundings.

Some letters quickly sprayed up messily (like the piece going down the pole next to a bus stop) just seems like a selfish territory-marking destructive act whereas some pieces are gorgeous.

\section{EUROPE}

If you've ever been to Europe one should realize that graffiti is a universal impulse to place marks in time and space to differentiate one from another (people and places).

In Europe, there is a noticeable absence of tagging, and much more art. They also have places where you can o street art and not worry about its removal. I wish we had more of that here, as I do believe it can be artistic expression.

I want to see more art that resembles European-style graffiti; graffiti with thought behind it. That, I wouldn't be opposed to.

When I was in High school my family had a German exchange student live with us for six months. Not long after his arrival I learned that he was a street artist. Spending lots of time with him while he made art, I was turned onto this new type of expression. The fact that you encounter street art unexpectedly, while you're in the middle of your day going place to place is what makes it so meaningful. The risk that the artist takes by putting it out in public makes it that much better.

\section{LEGALIZE (PARTIAL OR COMPLETE)}

Legalize graffiti!

Art should be allowed to live wherever it resides. 
Some should be considered a crime "don't know" answers are "this should be illegal, but generally unprosecuted"

In the instances where I said the graffiti/art should be removed, I meant that it should be eventually removed after community input deems it to be time. I think most of these expressions should be somewhat temporary, not permanent.

Public property should have the right to have people freely express themselves.

What if there was a rule to let a piece on public property stay for three months and then remove? If it took some time and talent, $\mathrm{i}$ think it should be allowed to stay for a bit.

Something I think would be cool is if maybe sides of buildings could be public, some businesses wouldn't need to take responsibility to "keep up" a side of building. People would not associate that side of building with the business inside.

\section{FREE/LEGAL WALLS}

I'd like to see the city set up a graffiti zone where one could put your message up in an area where only those who want to see graffiti will see it. An area of city owned buildings, maybe an underbridge area, etc. Everyone would know where to go to vandalize (only it wouldn't be vandalism as it would be sanctioned) and see each other's work.

I wrote graffiti for a little over ten years in the Portland area. Although a few of the artists featured in this survey are from are parts of the country, I appreciate their willingness to contribute to the city of Portland and its distinct lack of interesting public art. Portland is one of the few larger cities with a large creative base to allow "free" or "legal" walls. I strongly believe that many artists do not want to break the law, but come to do so because we do not have legal walls. If a space were provided for artists to let their individual passions flow, there would definitely be less tagging and more murals.

In Europe, there is a noticeable absence of tagging, and much more art. They also have places where you can do street art and not worry about its removal. I wish we had more of that here, as I do believe it can be artistic expression.

I think that public property maybe that could be a space where people could paint whatever they wanted. Maybe stuff "owned by city" could be like for public and anything could happen there. Having more public spaces for art is important. We need places to communicate ourselves to others; the more of this the better.

The city should take advantage of these people and designate certain areas for street art to limit them going to private property.

Cities all have areas of urban decay. I believe that artists should be able to express themselves in these areas. 
Some of it is very pleasant. I feel the street art in Portland is sparse and lacking in certain respects, compared to other cities. Art should be allowed to live wherever it resides.

I think it is important to acknowledge some graffito to be artists. Their best work is done for the public. Portland should adopt public spaces (walls, blank slates, light poles, etc.) everywhere throughout the city for these artists to express their skills. Not only does this public art show the cultural side of our community but it also connects local and visiting artists. Everyone from tourists to neighborhood residents are offered an enriching experience from observing the artists expressed work.

The writing on the pole, I'd say, is graffiti \& it doesn't seem intelligible to read or your average person who is not familiar with graffiti art. This type of stuff should be expressed somewhere else, say under a bridge or in a specific spot set aside for graffiti artists, though for those artists that probably defeats the point somewhat.

Besides gang related turf marking, its artists showcasing their talent in interesting and different spaces. I would prefer they were done in designated or allowed spaces but on public property such as bridges, etc., and not personal property then it makes the space more interesting and beautiful to look at.

\section{REMOVAL - FUNDING}

It's even more maddening when I see the space get repainted using someone else's hard earned money and time, and then the following weekend *bam* there's another tag. Every once in a while I am amused with what I see, and I do appreciate good graffiti, but I feel it's not entirely fair to discriminate between what I may subjectively find attractive and ugly. I would have to stay consistent - a zero tolerance policy, if you will - and clean up everything, even if it takes tax payer dollars and "look better after than before" (though I would probably prioritize the clean up to first attack "the ugly stuff".

One in particular (tax \$) should not pay for cleanup although if no one else steps up (such as a neighborhood association) I'm fine with paying for it.

The tax dollar for removal question is hard to answer. I feel the owner of the property should maintain the property (which in my opinion means removing most graffiti) and public spaces would be maintained by tax dollars. However I do not believe tax dollars should be used for private property maintenance.

I felt that the statement that the graffiti was in public spaces was misleading. Did that mean that the buildings, utility poles, etc. that were defaced were publicly owned or just publicly accessible. It made the "taxpayer money spent to remove" question ambiguous. For example, I answered yes, but would not want public money spent to remove graffiti from private buildings.

Taxpayer money should not be used to remove street art. We should promote those with truly artistic intentions to "go over" vandalism. 
There is a jolt to the illicitness of the act also, so it may not be as easy as putting up a graffiti wall, but in my humble opinion there is way too much effort and money spent trying to eradicate something universal!

Feel free to decorate your own property as you see fit. But community property or taxpayerfunded property should be left alone.

I believe that artistic graffiti is an acceptable form of art, but if it's on someone else's property, funds should be made available to the property owner to allow for removal (i.e., people completing community service could provide the labor; there could be money available to neighborhood associations to assist in supplies for removal).

On private property - the owners don't want to see it. If they don't go through the expense of removing it, it attracts more (i.e., if someone tags your property and you don't clean it up, other folks come along and tag over it or next to it, and so you have a mess).

Removing them is expensive and limited resources call for imaginative removal ideas like putting those caught to work cleaning off graffiti and encouraging other groups to take on graffiti removal projects.

Because property owners aren't asked by the 'artist' or given the choice to have the graffiti put on their property. Then it becomes the property owner's responsibility to clean it up or they can face fines from the city. It is no different than spray-painting someone's vehicle without their consent, or dumping your trash on someone's lawn. You are leaving a mess that may or may not look artistic, but which still has to be cleaned up by the person/people you left it with.

I also think property owners should be able to make the decision for themselves if they wish graffiti to be removed or retained to add value to their property.

Vandals should pay for and clean up the graffiti (pay by labor of any sort pick up litter, etc.).

Graffiti is an expense to home owners, and makes people worried about more serious crime.

\section{NEGATIVE PERCEPTIONS (GENERAL)}

I understand that some people view vandalism as art, but that's an arrogant attitude. What if I spray-painted the words "Gay $=$ Sin" on public property? Would that be protected art? Of course not; this is no different.

But I truly do not like any painted graffiti on anything. It's ugly and hard to remove.

Public art is a blessing. Free-lance graffiti becomes something else, and quickly. I have zero tolerance. 
Graffiti is an expense to home owners, and makes people worried about more serious crime. However, tons of band posters on power poles don't bother me.

I hope this survey results in the overall conclusion that most people in our community view graffiti as criminal in nature and very unpleasant.

I consider gang related graffiti to be something that supports a culture that is very detrimental to neighborhoods and should be viewed as vandalism. I also think the random spray painting of spaces is vandalism since it is done by people who show little creativity and seem to have no thought or purpose other than to make a public mark.

Violation of private and public property. Often contains profanity and/or obscenity.

Most "contributions" are eyesores and gang related ones seem threatening.

No one should have permission to use the shared public right of way as their own personal canvas.

Most I see falls into the tagging category. Like a dog marking his territory. No regard for the community.

Unless it's legalized, I don't see any difference whether it's done in a public space or privately owned space.

No one should have permission to use the shared public right of way as their own personal canvas.

Violation of private and public property. Often contains profanity and/or obscenity.

Most graffiti tagging lacks artistry and relevance. It is selfish and serves no higher social function.

Because it is done without owners' permission, often (usually) against owners' wishes and must often be removed at owners' time and expense. This includes both public and private owners. Read a dictionary definition of "vandalism": "Willful or malicious destruction or defacement of public or private property." Of course, something may be vandalism and artistic expression at the same time. This is, of course, an observation, not justification.

Stuff in the public right of way, is still stuff in the public right of way. Rules and regulations are set up for public safety and welfare. I can see this kind of thing becoming neglected trash.

\section{GANGS}

Graffiti places citizens in fear of gang activity and degrades the livability of the neighborhood. 
Besides gang related turf marking, its artists showcasing their talent in interesting and different spaces.

I consider gang related graffiti to be something that supports a culture that is very detrimental to neighborhoods and should be viewed as vandalism.

Even though sometimes the graffiti/art is creative and artful, it has negative connotations associated with it, especially if gang related and does not improve the location or area.

I don't know what's gang related on graffiti or not, but some things are visually compelling and it's appealing.

Tagging and other gang-related activity should be removed immediately, using public funds if necessary, to prevent giving the gangs credence.

It seems to me that factors such as how good it looks and whether it is truly gang-related should play into deciding if the street art is actually harmful.

I can appreciate graffiti, but not when it's gang related or when the individual whose not an artist tagged over another artists beautiful thoughtful work with a mindless name type of tag, etc. or a tag against or for a specific gang (i.e., I'm getting pretty tired of SNEAK \& XV3 in NoPo). It seems to me it's pretty apparent whether its gang related or artistic expression. I'm pretty sure I can tell the difference.

Often gang related in our area of North Portland. When there is some art there I can appreciate it, but I think it's more the exception than the rule.

Gang tags promote more gang tags.

Most "contributions" are eyesores and gang related ones seem threatening. Even though some are clever and seem to decorate rather than deface, leaving them only encourages more. Removing them is expensive and limited resources call for imaginative removal ideas like putting those caught to work cleaning off graffiti and encouraging other groups to take on graffiti removal projects.

I don't know what's gang related on graffiti or not, but some things are visually compelling and it's appealing.

I don't know enough about gang tagging to identify when it's confrontational.

I marked "neither agree nor disagree" for "is it gang-related" on pretty much all the slides, because I don't know enough about gang tags to recognize them. 


\section{IMAGINATION}

That said, I really do prefer the art that has had some effort and imagination put into it.

Probably the most artistic thing I see regularly on Portland's streets is the weave of thumbtacks and ripped corners of paper that wrap a lot of the phone poles, lots of mystery and history there.

When color is added and people are engaged art can change the perception of the space we live in.

A person uses their imagination/message and dresses up a blank medium with that.

I think graffiti in Portland is pretty poor, all in all. There's often not a lot of imagination or technique involved. That's my criterion: Whether it elevates the environment. Some of the other pieces, especially the red box on the phone pole, have a wonderful sense of surprise and discovery. I guess that's my criterion too: If I come around a corner and see a piece of street art, and it makes me smile or go "oooh," or laugh from an appreciation of the artist's concept or delivery, then the graffito has done its job.

But the other mural piece was beautiful. I grew up in Los Angeles I am used to seeing great murals like on the train tracks in the ghettos and I all for it. It is like ballet and breakdancing, dancing of the imagination and spirit on a surface.

\section{INTERACTION}

I think street art/graffiti can really make a dull area pop! I love when I come across something interesting like this. It is fun to try and decipher the artist's message. I have great respect for street art/graffiti artists!

Some of the other pieces, especially the red box on the phone pole, have a wonderful sense of surprise and discovery. I guess that's my criterion too: If I come around a corner and see a piece of street art, and it makes me smile or go "oooh," or laugh from an appreciation of the artist's concept or delivery, then the graffito has done its job.

Street Art is $100 \%$ artistic expression, and to me is my favorite and most meaningful type of art. When I was in High school my family had a German exchange student live with us for six months. Not long after his arrival I learned that he was a street artist. Spending lots of time with him while he made art, I was turned onto this new type of expression. The fact that you encounter street art unexpectedly, while you're in the middle of your day going place to place is what makes it so meaningful.

The "Community Chalk Box" is brilliant and clearly encourages child-like expression and fun amidst dreariness and doesn't hinder the function of the telephone pole. Same with "Free Space". 
When color is added and people are engaged art can change the perception of the space we live in.

\section{ARTIST'S INTENTIONS}

Got me thinking about the philosophical issues/pre-conceived notions about graffiti and street art.

When I see street art or graffiti, it's generally clear to me what the person's intentions were. With a lot of tags that you see, it looks like something that took a minute at most and was done to put their name on something. With more elaborate art, it's clear that they were much more considerate about what they were putting out into the world and cared more about its receiving positive attention.

It is done on someone else's property without permission and with no regard to how it will affect others in community.

Most of the time, the intent is an aesthetic maneuver on part of the artist, rather than damage to property.

As long as the intention is to express yourself, then its artistic expression. It's only vandalism if the intent is to damage (not improve through art).

The difference for me lies in the amount of time and thought I think the person put into the piece. Some letters quickly sprayed up messily (like the piece going down the pole next to a bus stop) just seems like a selfish territory-marking destructive act whereas some pieces are gorgeous.

I don't think people are out to tag a particular building, I think they just see a big open space and see opportunity, no matter where its location. If someone is writing something bad on a space which they are intentionally targeting, then I would consider that vandalism.

\section{OBEY THE LAW}

Unless the taxpayers agree to allow graffiti in public spaces and graffiti remains illegal then I think it is an act of vandalism.

Stuff in the public right of way, is still stuff in the public right of way. Rules and regulations are set up for public safety and welfare. I can see this kind of thing becoming neglected trash.

The person who put it there was trespassing on someone else's property. 


\section{MY INTERVENTIONS}

Clever decoration (knit rings, toy horses attached to horse rings, community-building free boxes) I find appealing though.

I think it is interesting that the red community box was included. I have something similar in my neighborhood and have never considered it graffiti but i guess street art is a good term. I think installations like that and the garden shopping cart are in a different league than paints which may damage a surface permanently. Personally, the knit "graffiti" is a bit annoying - you know there are people in the city that could use scarves and blankets so it seems like a waste on a tree or pole. Again, though, it doesn't do any permanent damage so it is mostly a nuisance and perhaps litter.

If it is at least sort of nice to look at, interactive like a chalk box or garden cart, not too messy, imaginative, and fun, then it is street art!

I personally distinguish between street art and graffiti. I see graffiti (painting surfaces) as vandalism in most cases. Regardless of message, its permanence and the effort it takes to remove it from surfaces is something that I cannot condone. However, street art, other forms of expression, such as stickers on electrical boxes, knitting on trees, and the red chalk box are, are all things that are easily removed. Artistic expression does not have to be damaging to our surroundings.

Good (community chalk box, mustache-jellyfish, etc.), bad (tags), or indifferent, street art tends typically involves trespassing and forcing your views on someone else's property. I find a lot of street art to be very interesting, beautiful, and thought-provoking and I would probably support such art on my property. However, no matter how great it is, nobody has the right to choose how my space is decorated. Also, nobody should be forced to remove/cover your work at their own expense/time, but they are when art is forced upon them.

I think graffiti in Portland is pretty poor, all in all. There's often not a lot of imagination or technique involved. That's my criterion: Whether it elevates the environment. The first slide, "Long live street art," is just dumb; it's making a statement about the value of a medium without actually rising to the potential of the medium. It makes me say, "Why?" Some of the other pieces, especially the red box on the phone pole, have a wonderful sense of surprise and discovery. I guess that's my criterion too: If I come around a corner and see a piece of street art, and it makes me smile or go "oooh," or laugh from an appreciation of the artist's concept or delivery, then the graffito has done its job. I marked "neither agree nor disagree" for "is it gang-related" on pretty much all the slides, because I don't know enough about gang tags to recognize them.

The majority of the works displayed are clearly art, not vandalism. Only one that I noticed was poorly thought through and not executed well was the spray paint on red pole. Most of the pieces seemed to be on surfaces that were not really being used anyway for another useful purpose, with the exception of the shopping cart with the "Garten" perhaps, though I can definitely see the value of that piece as a political or cultural statement. (e.g. Why do we go shopping with huge carts made of metal and plastic in China when we could grow our own food? Are we as a society really food and energy secure? ) Or perhaps the cart was abandoned and this project made the 
public space more beautiful and pleasant. I am not saying that people should steal shopping arts or that stealing should generally be culturally acceptable, but also think this should not be considered a crime, especially if it is being used for an interesting purpose and perhaps also if the community agrees it should stay. The "Community Chalk Box" is brilliant and clearly encourages child-like expression and fun amidst dreariness and doesn't hinder the function of the telephone pole. Same with "Free Space". The writing on the pole, I'd say, is graffiti \& it doesn't seem intelligible to read or your average person who is not familiar with graffiti art. This type of stuff should be expressed somewhere else, say under a bridge or in a specific spot set aside for graffiti artists, though for those artists that probably defeats the point somewhat. Most of the artworks did not seem gang related to me, but I am ill-informed on the issue. There may have been one or two gang references perhaps, but if so it was not clear to me.

\section{MURALS}

I hate to see interesting and good art covered up/taken down, but I would rather have artistic talent be put to use in the way of murals that are enjoyed by all o other artful pursuits.

There are murals in PDX that promote artistic expression and enhance community, regardless of my opinion of the quality of the talent.

But the other mural piece was beautiful. I grew up in Los Angeles I am used to seeing great murals like on the train tracks in the ghettos and I all for it. It is like ballet and breakdancing, dancing of the imagination and spirit on a surface.

While plain tags seem to be ugly to me, larger, brighter murals and art pieces make me smile. They're beautiful.

I understand that asking permission would probably make things better, but if the social construct didn't create street art as a dirty/gang related crime, I'm sure more property owners would graciously welcome free art and murals expressing some of the culture that makes Portland the awesome-weird place it is.

\section{OFFENSIVE}

I like to see splashes of creativity in my neighborhood, but I don't approve and think it is vandalism if it is demeaning or hateful or damaging.

This survey is very challenging to answer because I don't know where the art is or one what type of property. With the garden shopping cart it totally depends to me where it is to determine how I feel about it. I suggest you include more "offensive" street art on this survey such as "Fuck the Police" to give us a range of art to respond to. 


\section{POLE POSTERS}

Although I understand how it detrimentally affected the street poles, I was a fan of bands flyering every corner pole. There was an intriguing, alluring, aggressiveness to it (covering up another band's flyer, coming up with eye catching layouts) that I don't think tagging quite achieves for me.

Graffiti is an expense to home owners, and makes people worried about more serious crime. However, tons of band posters on power poles don't bother me.

\section{MY METHOD}

I observe that you appeared to utilize doorstop littering as at least one of your methods of soliciting response.

Glad to see the survey in my mailbox.

Interesting survey and I like the way you put the posting in the city. I actually read one of them.

\section{PORTLAND STREET ART}

Street art is beautiful, one of the reasons I moved to Portland is because it is so abundant here.

I liked the decorated telephone poles in NW Portland and was sorry people got so fired up and ripped them off. But I truly do not like any painted graffiti on anything. It's ugly and hard to remove.

Probably the most artistic thing I see regularly on Portland's streets is the weave of thumbtacks and ripped corners of paper that wrap a lot of the phone poles, lots of mystery and history there.

Portland has had a history of street art which is very creative and definitely qualifies as artistic expression. The oldest example I know of was art work on the support pillars of the old Lovejoy Bridge which may have been done in the 1930s (I hope these are being preserved somewhere). There are other surviving examples around Portland which show imagination and creativity.

I feel the street art in Portland is sparse and lacking in certain respects, compared to other cities.

I understand that asking permission would probably make things better, but if the social construct didn't create street art as a dirty/gang related crime, I'm sure more property owners would graciously welcome free art and murals expressing some of the culture that makes Portland the awesome-weird place it is. 
I think graffiti in Portland is pretty poor, all in all. There's often not a lot of imagination or technique involved.

\section{PLAY}

If I come around a corner and see a piece of street art, and it makes me smile or go "oooh," or laugh from an appreciation of the artist's concept or delivery, then the graffito has done its job.

\section{PROTEST}

There is a lot of power to the influence of street art.

At same time, the issue of respect, we need to learn how to protest in peaceful ways, rather than thinking we are peaceful (by protesting a war), but in actuality, simply furthering violence and aggression. It is difficult to truly not pass on aggression when protesting, the same applies to art. If we really follow a path of peace, then art does not need to be censored (perhaps). I really think this is to some degree (although this requires understanding of others and respect) a balance. There needs to be places to process feelings (before reaching full respect), and maybe there could be a public place to do this. Then again, lots of art is not necessarily protest but simply expression, of a certain message, same applies. Definitely it is all artistic expression.

It is a public forum for political commentary.

It's part of the art to be disobedient.

If it, or the tagger, has something to say other than, "Look, I tagged this," then I can look at it and approach the social question(s) it asks. It enters the realm of editorial or commentary. Otherwise, if they just want to tag for tagging sake or bragging rights, they can keep the spray paint and markers up their nose.

It is a cool way to convey social or political statements.

\section{RESPECT}

I do think that street artists need to be respectful of each other's work. I have seen people tag over amazing murals, and to me, that is just bad manners.

Most I see falls into the tagging category. Like a dog marking his territory. No regard for the community. Often gang related in our area of North Portland. When there is some art there I can appreciate it, but I think it's more the exception than the rule. 
Because property owners aren't asked by the 'artist' or given the choice to have the graffiti put on their property. Then it becomes the property owner's responsibility to clean it up or they can face fines from the city. It is no different than spray-painting someone's vehicle without their consent, or dumping your trash on someone's lawn. You are leaving a mess that may or may not look artistic, but which still has to be cleaned up by the person/people you left it with. It is selfish to assume that your own version of 'art' or self-expression is wanted or appreciated without asking first. The photos of some of street art on this survey show nice work that I like to look at, but I still wouldn't want any of it on my house or on the fence in front of my yard And I would be irate if I ever caught someone putting their 'art' on my property without my permission.

\section{REMOVAL - BUFF LOOKS BAD}

Street art is a contentious issue. Even though I appreciate much of the art, I still support removal of unauthorized works. To those who claim that graffiti is not art, I've tell the story of the graffiti cleanup crew working in a French park. One day while removing graffiti, they accidentally damaged ancient cave paintings. They couldn't tell the difference. On the other hand, witness what happened in the Margot Cave in France. In Margot, ancient cave art was obliterated by modern graffiti artists. That is truly a criminal act.

I think the methods of removal (i.e., paint colors, sandblasting) often leaves a graffiti surface looking much worse.

On private property - the owners don't want to see it. If they don't go through the expense of removing it, it attracts more (i.e., if someone tags your property and you don't clean it up, other folks come along and tag over it or next to it, and so you have a mess). The cleaners don't work on the garbage cans, just smear it and looks bad. Not as interesting as some of the samples you showed.

\section{SENSE OF PLACE - NEIGHBORHOOD ART/COLOR}

In my opinion I think it depends on the context of the graffiti itself in most cases. In some instances it's simply that I do not prefer the style of art. However, I don't think that should determine whether or not the environment is made more interesting with the use of non-gang related graffiti - especially if it is on public property done anonymously or private property by the owner.

Although I understand how it detrimentally affected the street poles, I was a fan of bands flyering every corner pole. There was an intriguing, alluring, aggressiveness to it (covering up another band's flyer, coming up with eye catching layouts) that I don't think tagging quite achieves for me.

Besides gang related turf marking, its artists showcasing their talent in interesting and different spaces. I would prefer they were done in designated or allowed spaces but on public property 
such as bridges, etc., and not personal property then it makes the space more interesting and beautiful to look at.

I like to see splashes of creativity in my neighborhood, but I don't approve and think it is vandalism if it is demeaning or hateful or damaging.

The more color we have in our daily lives the better! It makes each neighborhood within our city and each city itself more unique.

I think street art/graffiti can really make a dull area pop! I love when I come across something interesting like this. It is fun to try and decipher the artist's message. I have great respect for street art/graffiti artists!

Mostly artistic expression. I hate generic tagging, but something colorful and unique, that is only put on walls or telephone poles (NOT windows or store signs), adds to the neighborhood in my opinion.

When it's done in the right places and in a creative way, it enlivens the city.

It's ugly and doesn't contribute to the overall look/feel of the community. While someone may have thought they were supporting community-building, it's ugly and in bad taste.

The fact that you encounter street art unexpectedly, while you're in the middle of your day going place to place is what makes it so meaningful. The risk that the artist takes by putting it out in public makes it that much better. No kind of art is like street art, and it is without a doubt an expression of art.

It's shown by graffiti or music players on the street, there's no problem with is, it makes people feel good and changes the energy in the air, why is there artistic energy? Because it can be used as an outlet for people to get their anger of the economy and it could be do what you do for work.

If you've ever been to Europe one should realize that graffiti is a universal impulse to place marks in time and space to differentiate one from another (people and places).

\section{SUBJECTIVE ART}

Street art is a contentious issue. Even though I appreciate much of the art, I still support removal of unauthorized works. To those who claim that graffiti is not art, I've tell the story of the graffiti cleanup crew working in a French park. One day while removing graffiti, they accidentally damaged ancient cave paintings. They couldn't tell the difference. On the other hand, witness what happened in the Margot Cave in France. In Margot, ancient cave art was obliterated by modern graffiti artists. That is truly a criminal act.

As an observer I'm fine with street art as long as I like it (if some effort/creativity was put into it) but if I don't I think it should be removed. 
In my opinion I think it depends on the context of the graffiti itself in most cases. In some instances it's simply that I do not prefer the style of art. However, I don't think that should determine whether or not the environment is made more interesting with the use of non-gang related graffiti - especially if it is on public property done anonymously or private property by the owner.

Interesting, it made me think about the subjectivity of the subject.

Art/beauty is in the eye of the beholder. I'm getting annoyed with the proliferation of tags around my neighborhood. Clever decoration (knit rings, toy horses attached to horse rings, communitybuilding free boxes) I find appealing though.

Public property should have the right to have people freely express themselves. There is a fine line between art and trash graffiti. Graffiti is art but not everyone who writes graffiti is an artist. There should be a higher standard among writers for what goes up in the city. Portland, compared to other cities, has a lot of trash graffiti up, seemingly from kids doing it for the thrill. There is a lot of power to the influence of street art.

If it is ugly, and in the wrong spaces, then I consider it vandalism. Most tags fit in this category. If it is not ugly, is imaginative and is not defacing something (like the Colonel Summers Park sign), I consider it artistic expression.

I really sit more in the middle on this question. It's not fair, I know, but when the art is terrible, I think of it as vandalism. When it's good, it's artistic expression.

Art is subjective. Art/graffiti is art when I like it and vandalism when I don't.

In either case it will always be a matter of opinion: no one is right and no one is wrong and there will always be a fighting over the concept of "art" versus "vandalism" and the belief amongst taggers that perhaps no one really owns anything.

\section{TAGGING (SELFISH)}

There should be a raised standard among writers so the 'trash' graffiti is not accepted and people strive for more.

I understand and appreciate some forms of graffiti and would consider them art (e.g. I'm a fan on Banksy and he can tag any area in my neighborhood - it would help property values increase!) but I see tags on buildings in my neighborhood of Mississippi ad it drives me nuts. Every time I drive past it, it angers me than some idiot feels that he or she has the right to just spray paint junk messages on someone else's property. If you want free expression, do it on your own property or get permission ahead of time. It's even more maddening when I see the space get repainted using someone else's hard earned money and time, and then the following weekend *bam* there's another tag. Every once in a while I am amused with what I see, and I do appreciate good graffiti, but I feel it's not entirely fair to discriminate between what I may subjectively find attractive and 
ugly. I would have to stay consistent - a zero tolerance policy, if you will - and clean up everything, even if it takes tax payer dollars and "look better after than before" (though I would probably prioritize the clean up to first attack "the ugly stuff". This survey makes me recall the NYC cleanup in the 80's when the governor would clean up every single subway car before it would go on the track. Eventually the taggers got the message that if they tagged that evening, their hard work would just be swiped away the following morning. As time went on, they got the message, and tagging went down dramatically. It helped clean up the NYC subways tremendously.

Although I understand how it detrimentally affected the street poles, I was a fan of bands flyering every corner pole. There was an intriguing, alluring, aggressiveness to it (covering up another band's flyer, coming up with eye catching layouts) that I don't think tagging quite achieves for me.

I love street art, but not a huge fan of mindless tagging.

Also, I would have appreciated more info on what constitutes gang tagging and graffiti. I may not have been offended by something in an image because I was unaware that it meant something to a gang or gangs. Tagging is pretty obvious, and is usually related to gang activity, but not always, but was some of the other images? I don't know.

Tagging with a name or nickname is vandalism, not art.

I wish I saw more artistic graffiti and less pointless tagging in my neighborhood, one would add value and the other detracts.

I view much of street art as a creative expression, but a tag as vandalism, solely for the purposes of making a personal mark on a piece of property.

Tagging and other gang-related activity should be removed immediately, using public funds if necessary, to prevent giving the gangs credence.

With a lot of tags that you see, it looks like something that took a minute at most and was done to put their name on something.

If it is ugly, and in the wrong spaces, then I consider it vandalism. Most tags fit in this category.

(Artistic Expression) when it is something more than just a tight stylized scribble of a name or a slogan with lousy calligraphy. If there's an actual graphic element to it then I enjoy it.

I view a lot of street art as artistic expression, unless it is just words or gang names quickly written on a wall.

It seems to me that factors such as how good it looks and whether it is truly gang-related should play into deciding if the street art is actually harmful. 
I guess sometimes I draw a distinction between people simply "tagging" a wall and someone taking the time to make a beautiful mural or image. It is subjective, I suppose.

I hate generic tagging, but something colorful and unique, that is only put on walls or telephone poles (not windows or store signs), adds to the neighborhood in my opinion.

Most graffiti tagging lacks artistry and relevance. It is selfish and serves no higher social function.

I'm all for graffiti as long as it isn't gang tags.

The average layman cannot often distinguish the difference between gang messages and graffiti.

Tags are omnipresent and not particularly attractive.

If it, or the tagger, has something to say other than, "Look, I tagged this," then I can look at it and approach the social question(s) it asks. It enters the realm of editorial or commentary. Otherwise, if they just want to tag for tagging sake or bragging rights, they can keep the spray paint and markers up their nose.

The belief amongst taggers that perhaps no one really owns anything.

Absolutely artistic expression, even in the case of most graffiti. I am an artist myself. I can appreciate graffiti, but not when its gang related or when the individual who's not an artist tagged over other artists beautiful thoughtful work with a mindless name type of tag, etc. or a tag against or for a specific gang (i.e., I'm getting pretty tired of SNEAK \& XV3 in NoPo). It seems to me it's pretty apparent whether its gang related or artistic expression. I'm pretty sure I can tell the difference.

Most I see falls into the tagging category. Like a dog marking his territory. No regard for the community. Often gang related in our area of North Portland. When there is some art there I can appreciate it, but I think it's more the exception than the rule.

But it does really depend on the appearance. The difference for me lies in the amount of time and thought I think the person put into the piece. Some letters quickly sprayed up messily (like the piece going down the pole next to a bus stop) just seems like a selfish territory-marking destructive act whereas some pieces are gorgeous.

They are taking a blank canvas and making it their own. I don't think people are out to tag a particular building, I think they just see a big open space and see opportunity, no matter where its location. If someone is writing something bad on a space which they are intentionally targeting, then I would consider that vandalism.

It is selfish to assume that your own version of 'art' or self-expression is wanted or appreciated without asking first. 


\section{TRASH/DIRT}

Looks like litter.

Garbage on my city's walls looks no different than garbage on my city's streets.

I can see this kind of thing becoming neglected trash.

\section{QUALITY OF SPACE INTIALLY}

Also, we must take into account how the space looked before and after.

In the end they are damaging someone else's property and forcing a message on that owner. Regardless of whether or not it makes the space better they placed it there without permission.

But I think that we have a lot of gross concrete in the city, there to create infrastructure. If people can take little steps to make that concrete a little bit more beautiful, more power to them. When it's done in the right places and in a creative way, it enlivens the city.

A person uses their imagination/message and dresses up a blank medium with that.

\section{UNDERSTANDABILITY}

Something is art if it is easily understood, is interesting, and/or has socially redeeming value.

\section{VENUE FOR ART}

I think for people who are artistically talented it is not necessary to demonstrate that through vandalism nor is "tagging" public surfaces without permission necessary for pure expression of one's creative vision.

Besides gang related turf marking, its artists showcasing their talent in interesting and different spaces. I would prefer they were done in designated or allowed spaces but on public property such as bridges, etc., and not personal property then it makes the space more interesting and beautiful to look at. Also, a cool way to convey social or political statements.

There are some really great artists, it's a shame they must use graffiti to express themselves.

Public property should have the right to have people freely express themselves. 


\section{VANDALISM}

Tagging with a name or nickname is vandalism, not art.

It's an act of vandalism. It's usually done on private property without the owner's permission, thus its vandalism. If it's done on community property (phone pole, street, sidewalk), again, it's vandalism. The graffitist did not get permission from the community (in most cases this would be the city) to deface the area.

Vandalism. Anything done to public or private property without the permission of the owner or facility/resource manager is a crime of trespass at the very start.

For the most part, I would consider that most street art is vandalism due to the fact that it defaces and devalues public property. In most cases graffiti also is unpleasant to eye and really gives off a sense of "scuzzy-ness" to the property. Street artists are criminals and they should be fined, thrown in jail for an evening, or punched in the face.

Because it is done without owners' permission, often (usually) against owners' wishes and must often be removed at owners' time and expense. This includes both public and private owners. Read a dictionary definition of "vandalism": "Willful or malicious destruction or defacement of public or private property." Of course, something may be vandalism and artistic expression at the same time. This is, of course, an observation, not justification.

The person does not have permission. There is a difference between graffiti on the side of a train car and the tag on the church down the street. Gang tags promote more gang tags. Vandals should pay for and clean up the graffiti (pay by labor of any sort pick up litter, etc.). There are murals in PDX that promote artistic expression and enhance community, regardless of my opinion of the quality of the talent.

I see the artistic expression element of the work in these photos, but painting on property that is not yours, be it public or private is vandalism.

The person who put it there was trespassing on someone else's property.

I would like to have had more info about some of the specific pieces because I could not tell what they were - for example, the shopping cart. Is the cart full of plants the vandalism? Is it the sign placed on the cart? Is it on a sidewalk, in a park or what? I could not tell what made this vandalism/graffiti/art. Also, I would have appreciated more info on what constitutes gang tagging and graffiti. I may not have been offended by something in an image because I was unaware that it meant something to a gang or gangs. Tagging is pretty obvious, and is usually related to gang activity, but not always, but were some of the other images? I don't know.

This survey is obviously geared more toward 'street art' to get people to question whether it is truly a crime that should be equated with vandalism like gang graffiti. I hate tagging, but I like street art so I understand it's difficult to draw the line. But if I were forced to choose, I would 
rather have a city with no unauthorized street art than a city with tagging and gang graffiti mixed in. Garbage on my city's walls looks no different than garbage on my city's streets.

The only thing that separates street art and graffiti from vandalism is if thing are broken. 
Appendix G. Bar Charts of Survey Data Mean Ratings of All Pieces Art Forms

WIIII

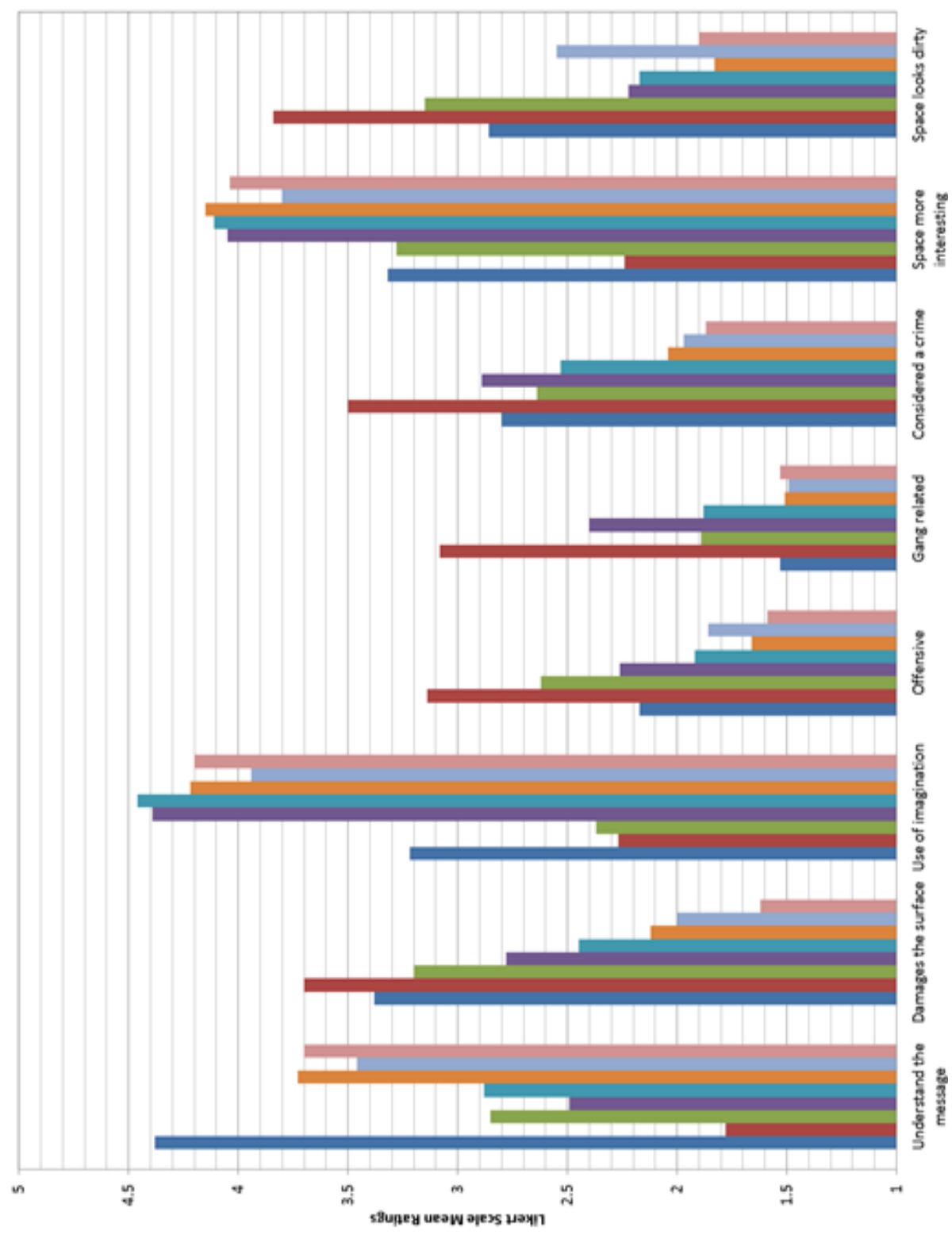




\section{Mean Ratings of Pieces Grouped by Form}

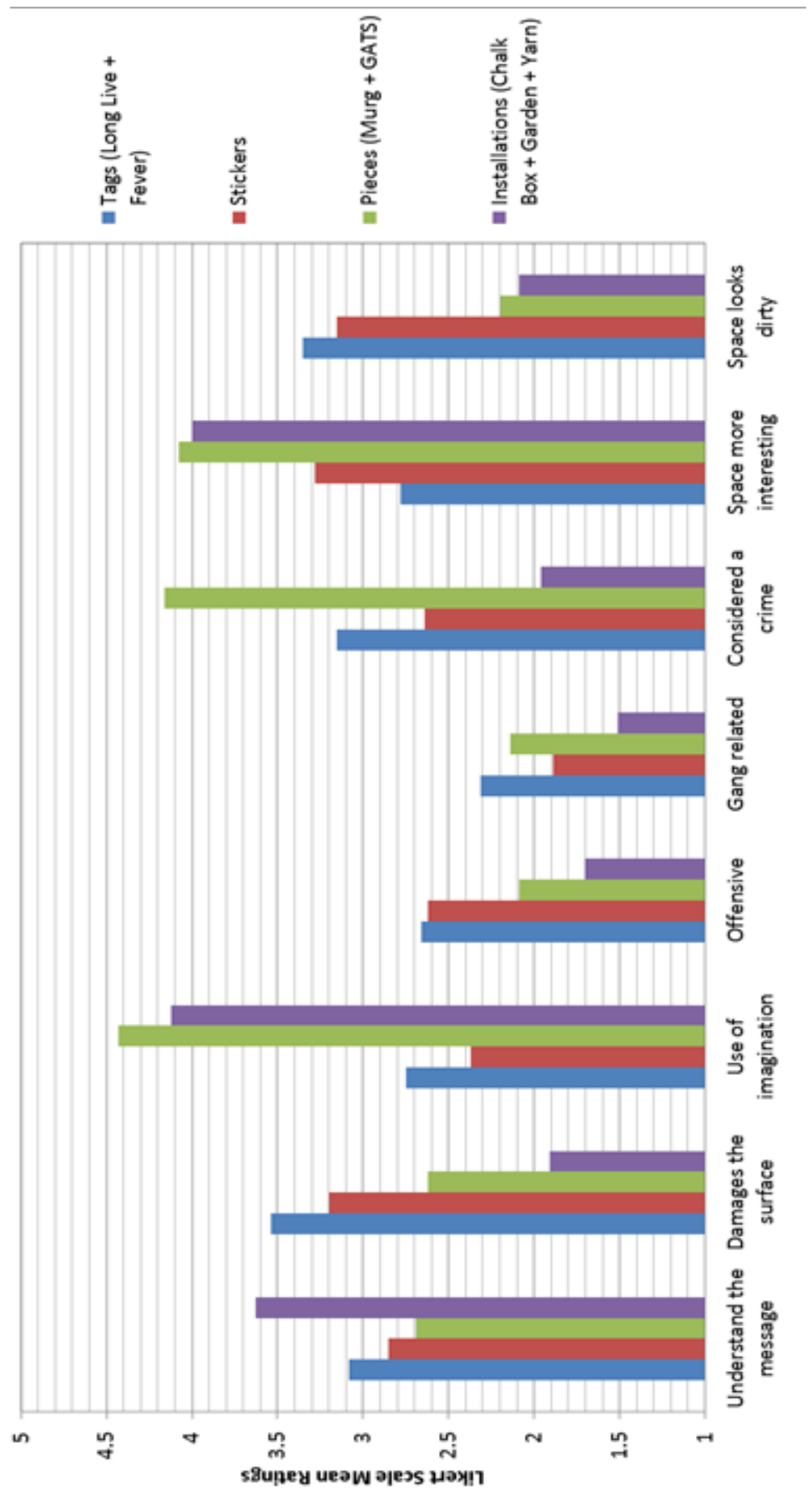




\section{Removal Preference}

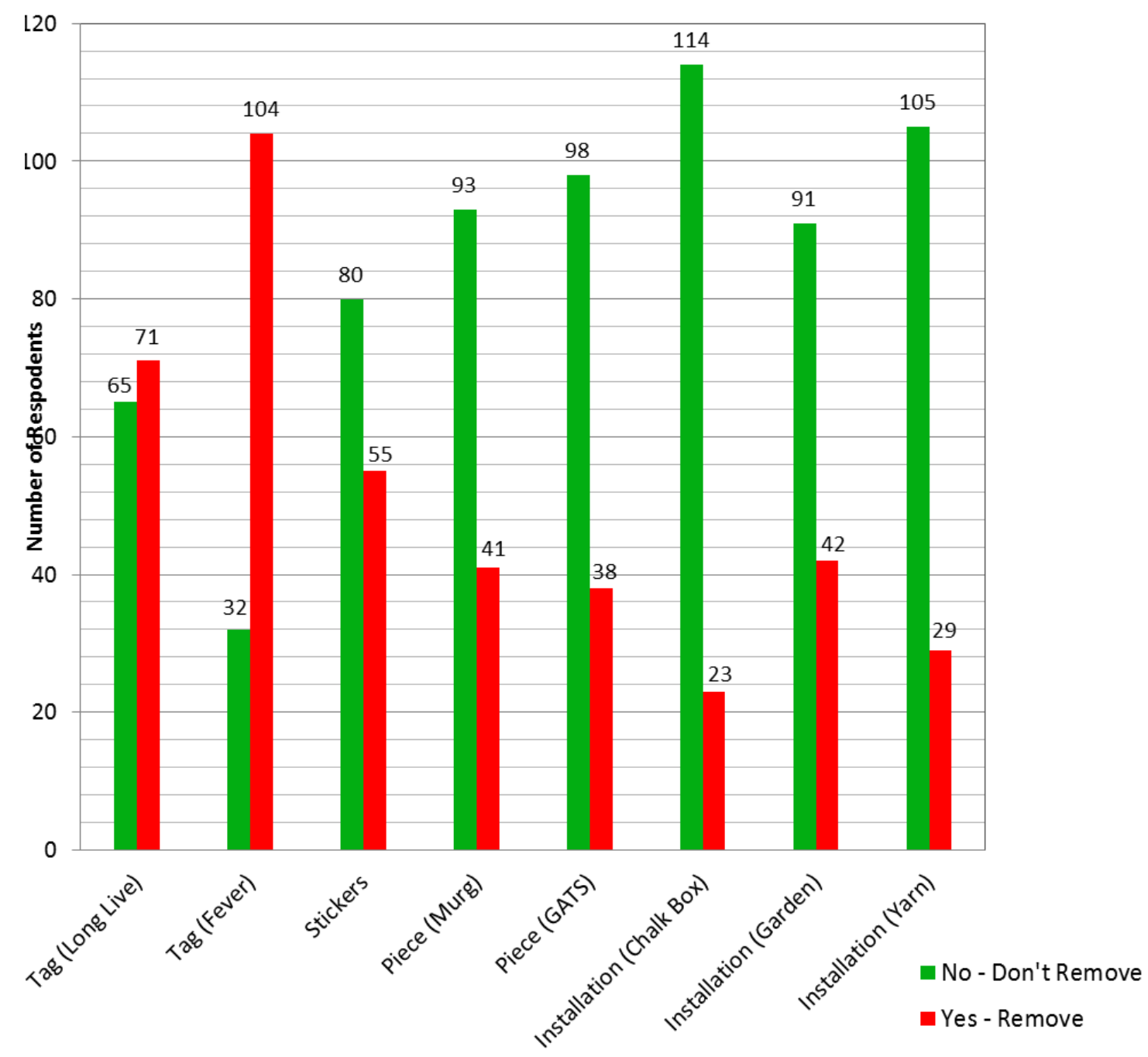




\section{Spatial Preferences}

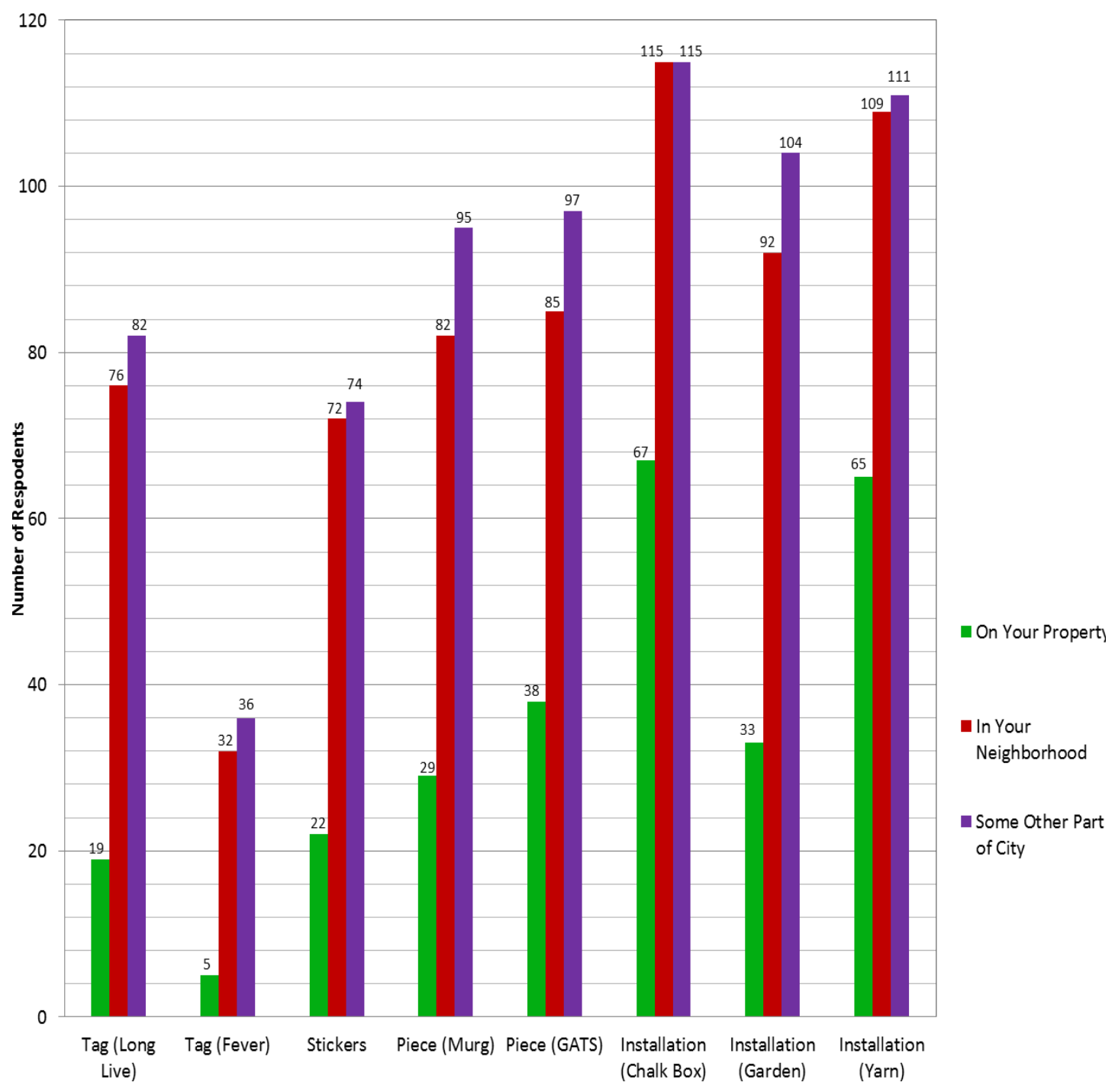




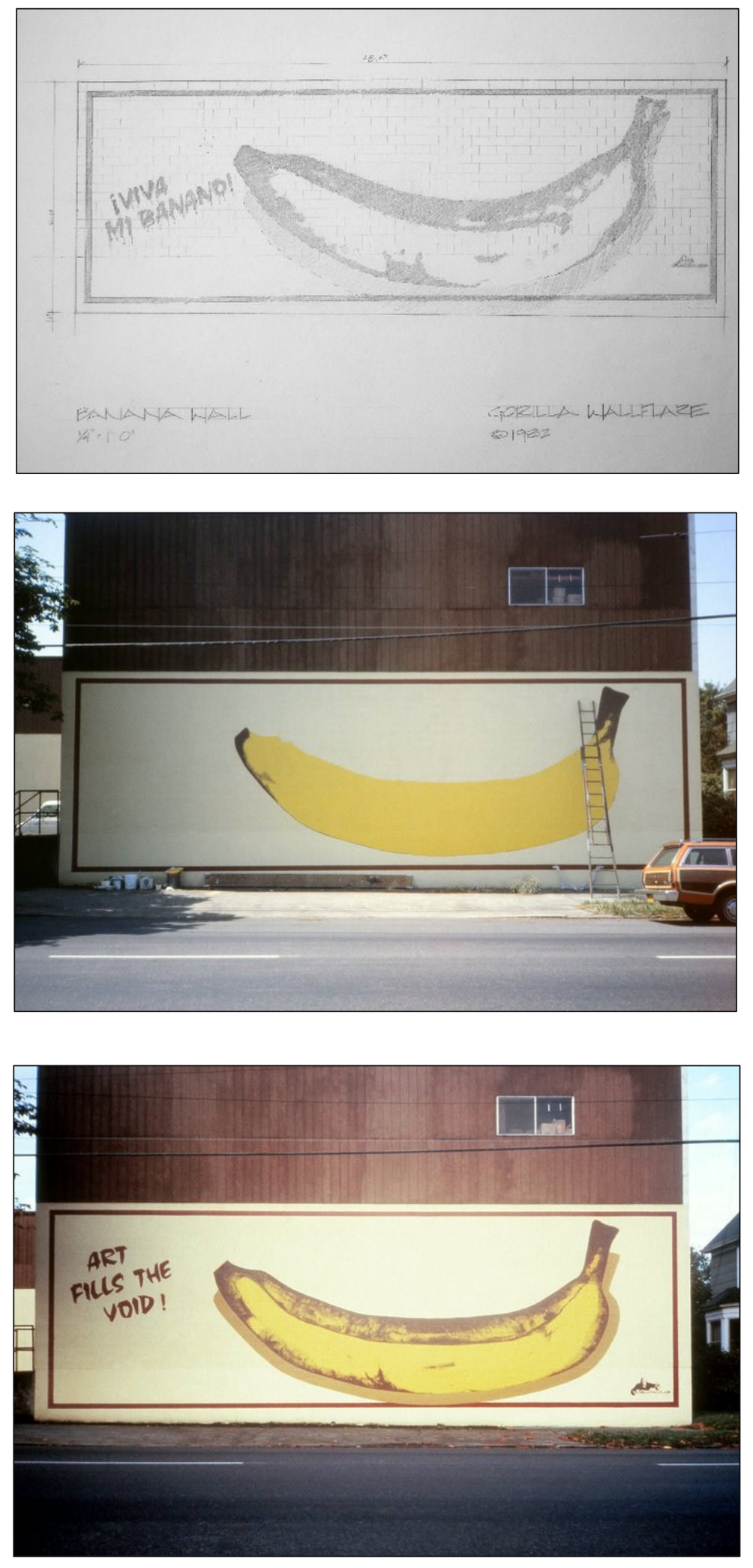

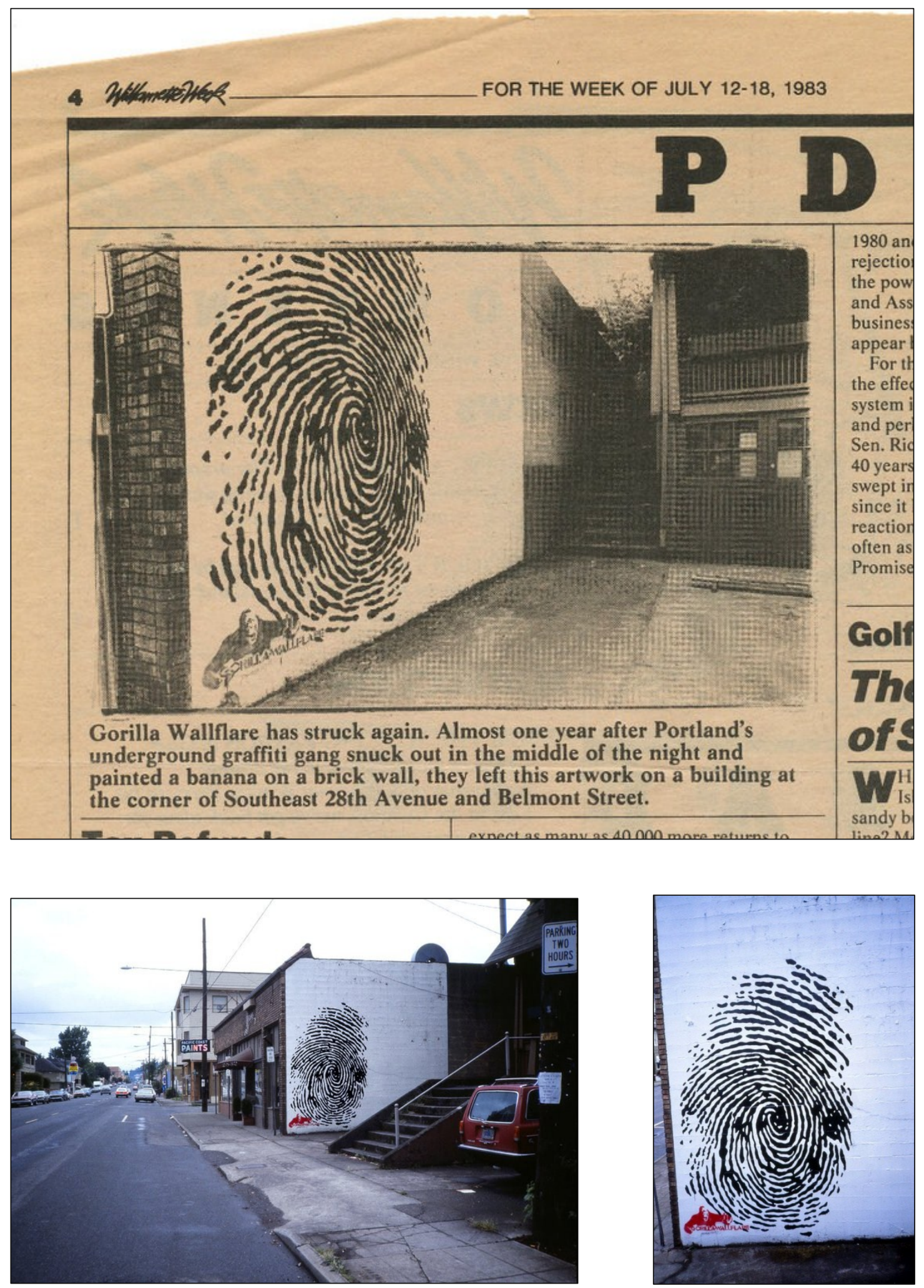

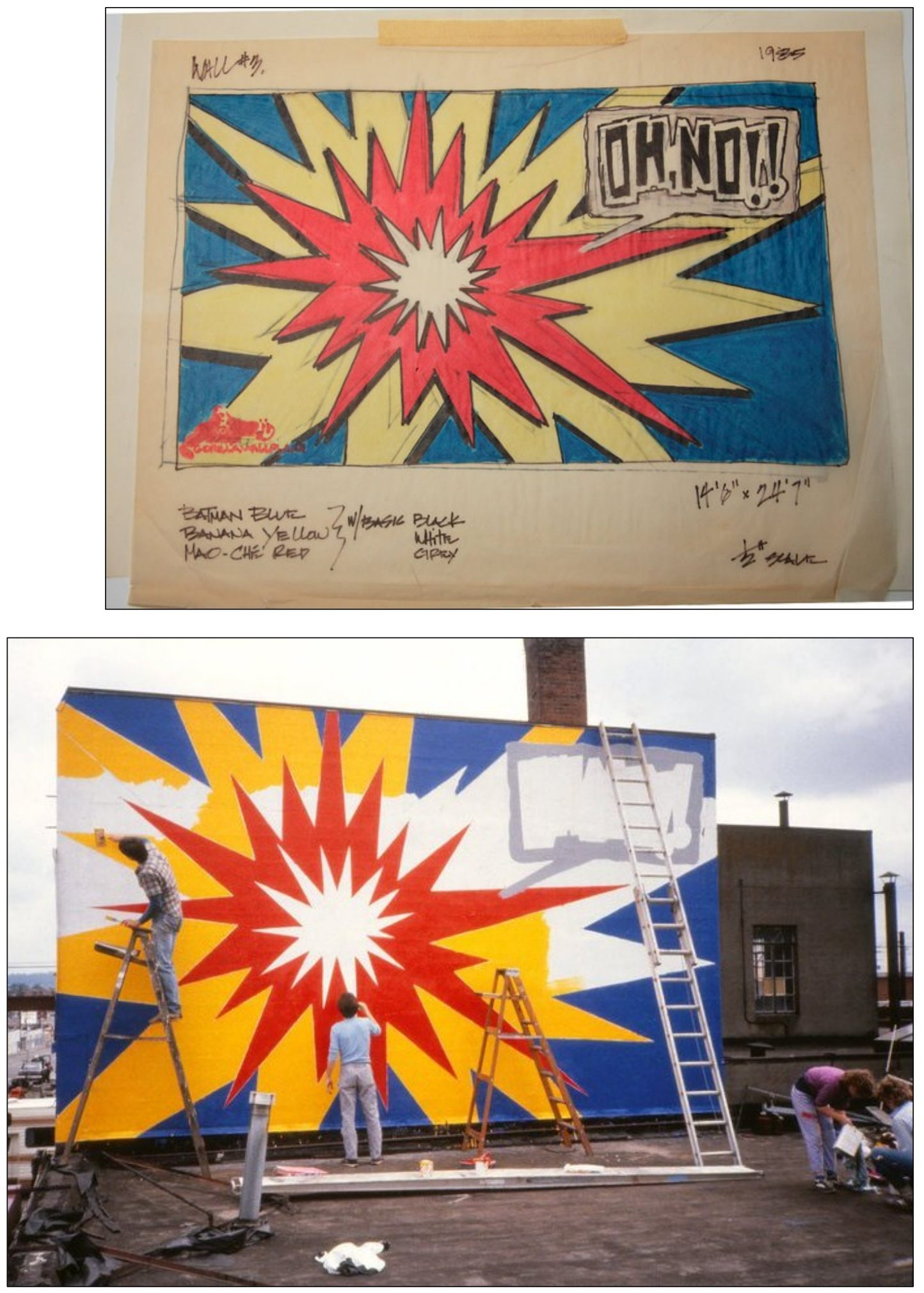
May, 1985

Gorilla Wallflare took matters into their own hands again for attack \#3 on Portland's grey walls.

In less time than ever, a design was concieved, a date decided upon and supplies and materials collected. The wall was painted in one day: Sunday, May 26 (or was $1 t$ night?). There was no financial compensation or authorization from the wall owners.

Not a butterfly, not a rose, not a sign: it's a painted landmark, a political statement, graffitti, a spoof.

Our first attack, July 1982, produced Portland's largest and most famous banana as we set out to fill the vold.

We left our mark on Genoa Restaurant in July of 1983. It is now only a memory in the minds of many.

This our third attack could very well be our last. Maybe it's the night blindness, maybe 1t's an overdose of adrenilin rushes -- 1 t certainly won't be from lack of 'vold'.
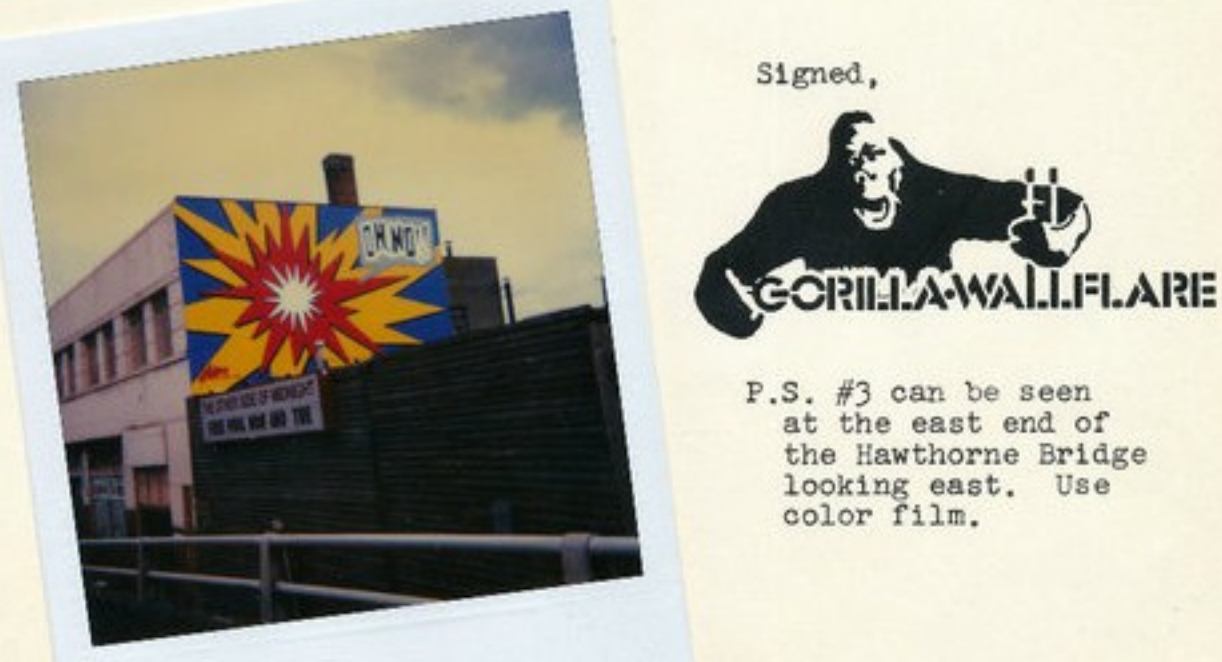

P.S. \#3 can be seen at the east end of the Hawthorne Briage looking east. Use color film. 


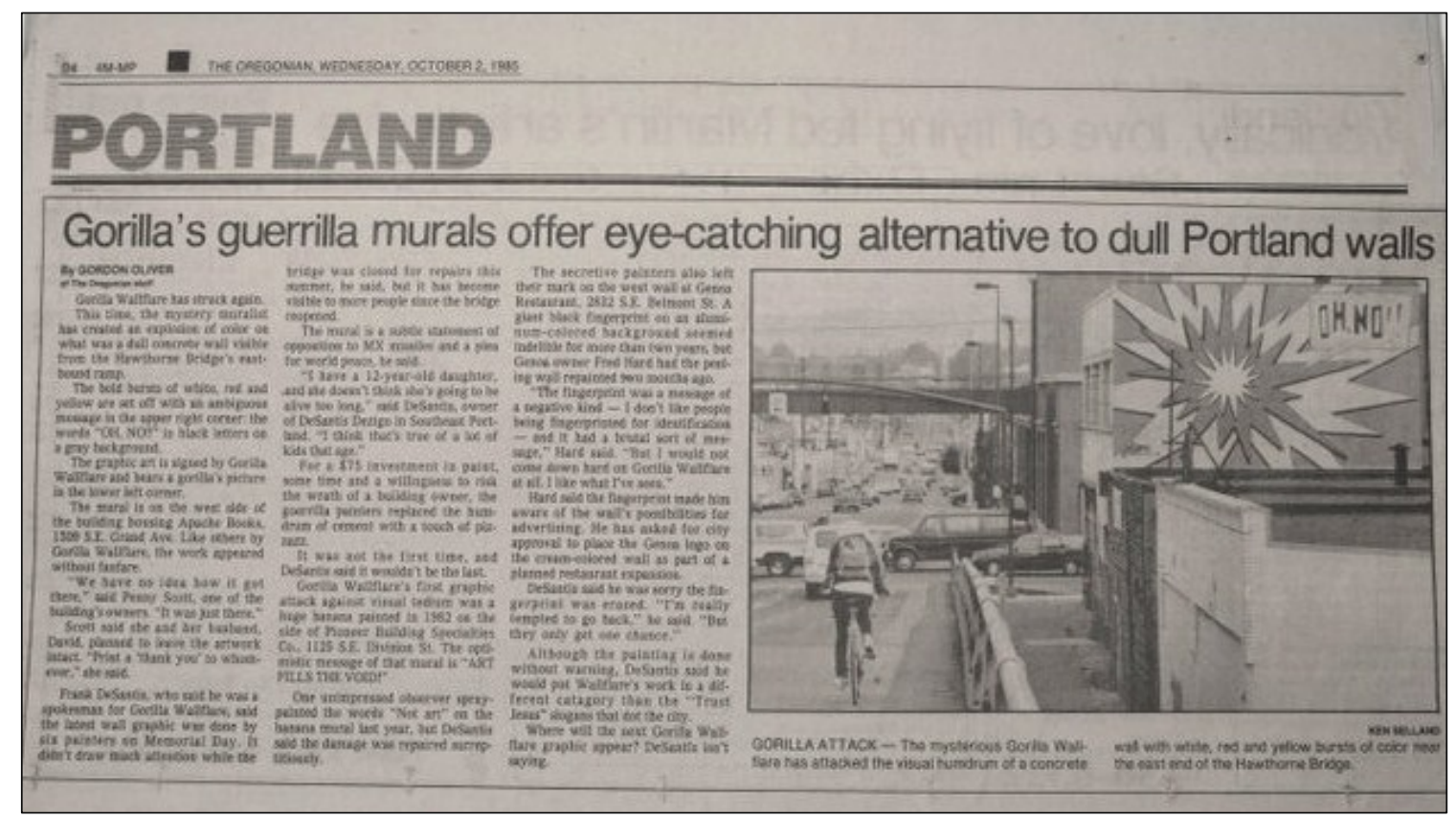

Gorilla Wallflare. (2012). “Gorilla Wallflare Albums.” Facebook. Retrieved on March 28, 2012, from: URL (https://www.facebook.com/pages/Gorilla-Wallflare/147964341908691)

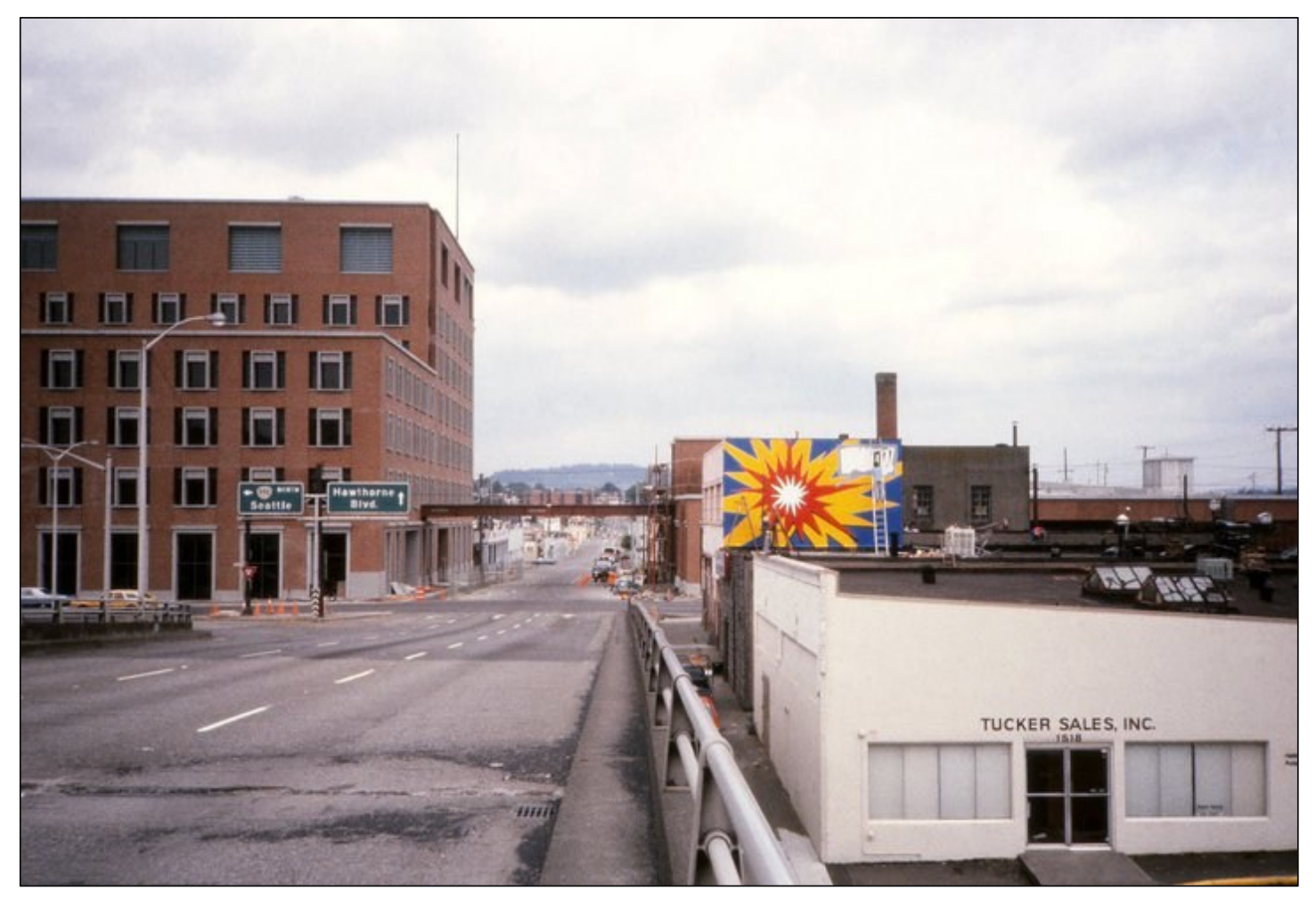




\section{Appendix I. Survey Data Frequencies and Statistical Tests}

\section{Q1: Tag - Long Live Art in the Streets}

Q1_tag_artinstreets_understand I understand the intended message

\begin{tabular}{|c|c|c|c|c|c|}
\hline & & Frequency & Percent & Valid Percent & $\begin{array}{c}\text { Cumulative } \\
\text { Percent }\end{array}$ \\
\hline \multirow{6}{*}{ Valid } & Strongly Disagree & 3 & 2.2 & 2.2 & 2.2 \\
\hline & Disagree & 5 & 3.6 & 3.6 & 5.8 \\
\hline & Neither Agree nor Disagree & 3 & 2.2 & 2.2 & 7.9 \\
\hline & Agree & 53 & 38.1 & 38.1 & 46.0 \\
\hline & Strongly Agree & 75 & 54.0 & 54.0 & 100.0 \\
\hline & Total & 139 & 100.0 & 100.0 & \\
\hline
\end{tabular}

Q1_tag_artinstreets_damaged It damaged the surface

\begin{tabular}{|c|c|c|c|c|c|}
\hline & & Frequency & Percent & Valid Percent & $\begin{array}{c}\text { Cumulative } \\
\text { Percent }\end{array}$ \\
\hline \multirow{6}{*}{ Valid } & Strongly Disagree & 13 & 9.4 & 9.4 & 9.4 \\
\hline & Disagree & 21 & 15.1 & 15.1 & 24.5 \\
\hline & Neither Agree nor Disagree & 31 & 22.3 & 22.3 & 46.8 \\
\hline & Agree & 48 & 34.5 & 34.5 & 81.3 \\
\hline & Strongly Agree & 26 & 18.7 & 18.7 & 100.0 \\
\hline & Total & 139 & 100.0 & 100.0 & \\
\hline
\end{tabular}

Q1_tag_artinstreets_imagination The person who did this used their imagination

\begin{tabular}{|l|r|r|r|r|}
\hline & Frequency & Percent & Valid Percent & $\begin{array}{c}\text { Cumulative } \\
\text { Percent }\end{array}$ \\
\hline \multirow{2}{*}{ Strongly Disagree } & 13 & 9.4 & 9.4 & 9.4 \\
Disagree & 25 & 18.0 & 18.0 & 27.3 \\
Veither Agree nor Disagree & 31 & 22.3 & 22.3 & 49.6 \\
Valid & 59 & 42.4 & 42.4 & 92.1 \\
Agree & 11 & 7.9 & 7.9 & 100.0 \\
Strongly Agree & 139 & 100.0 & 100.0 & \\
Total & &
\end{tabular}


Q1 tag artinstreets offensive It is offensive

\begin{tabular}{|l|r|r|r|r|}
\hline & Frequency & Percent & Valid Percent & $\begin{array}{c}\text { Cumulative } \\
\text { Percent }\end{array}$ \\
\hline Strongly Disagree & 52 & 37.4 & 37.4 & 37.4 \\
Disagree & 39 & 28.1 & 28.1 & 65.5 \\
Veither Agree nor Disagree & 29 & 20.9 & 20.9 & 86.3 \\
Valid & 11 & 7.9 & 7.9 & 94.2 \\
Agree & 8 & 5.8 & 5.8 & 100.0 \\
Strongly Agree & 139 & 100.0 & 100.0 & \\
Total & & &
\end{tabular}

Q1 tag artinstreets gang It is gang related

\begin{tabular}{|c|c|c|c|c|c|}
\hline & & Frequency & Percent & Valid Percent & $\begin{array}{c}\text { Cumulative } \\
\text { Percent }\end{array}$ \\
\hline \multirow{4}{*}{ Valid } & Strongly Disagree & 85 & 61.2 & 61.2 & 61.2 \\
\hline & Disagree & 34 & 24.5 & 24.5 & 85.6 \\
\hline & Neither Agree nor Disagree & 20 & 14.4 & 14.4 & 100.0 \\
\hline & Total & 139 & 100.0 & 100.0 & \\
\hline
\end{tabular}

Q1 tag artinstreets crime It should be considered a crime

\begin{tabular}{|ll|r|r|r|r|}
\hline & Frequency & Percent & Valid Percent & $\begin{array}{c}\text { Cumulative } \\
\text { Percent }\end{array}$ \\
\hline & Strongly Disagree & 34 & 24.5 & 24.8 & 24.8 \\
& Disagree & 21 & 15.1 & 15.3 & 40.1 \\
& Neither Agree nor Disagree & 35 & 25.2 & 25.5 & 65.7 \\
Valid & Agree & 32 & 23.0 & 23.4 & 89.1 \\
& Strongly Agree & 15 & 10.8 & 10.9 & 100.0 \\
& Total & 137 & 98.6 & 100.0 & \\
Missing & -99 & 2 & 1.4 & & \\
Total & & 139 & 100.0 & & \\
\hline
\end{tabular}


Q1_tag_artinstreets_interesting It makes the space more interesting

\begin{tabular}{|c|c|c|c|c|c|}
\hline & & Frequency & Percent & Valid Percent & $\begin{array}{c}\text { Cumulative } \\
\text { Percent }\end{array}$ \\
\hline \multirow{6}{*}{ Valid } & Strongly Disagree & 19 & 13.7 & 13.8 & 13.8 \\
\hline & Disagree & 20 & 14.4 & 14.5 & 28.3 \\
\hline & Neither Agree nor Disagree & 20 & 14.4 & 14.5 & 42.8 \\
\hline & Agree & 56 & 40.3 & 40.6 & 83.3 \\
\hline & Strongly Agree & 23 & 16.5 & 16.7 & 100.0 \\
\hline & Total & 138 & 99.3 & 100.0 & \\
\hline Missing & -99 & 1 & .7 & & \\
\hline Total & & 139 & 100.0 & & \\
\hline
\end{tabular}

Q1_tag_artinstreets_dirty It makes the space look dirty

\begin{tabular}{|ll|r|r|r|r|}
\hline & Frequency & Percent & Valid Percent & $\begin{array}{c}\text { Cumulative } \\
\text { Percent }\end{array}$ \\
\hline \multirow{2}{*}{ Strongly Disagree } & 27 & 19.4 & 19.6 & 19.6 \\
& Disagree & 35 & 25.2 & 25.4 & 44.9 \\
& Neither Agree nor Disagree & 24 & 17.3 & 17.4 & 62.3 \\
Valid & Agree & 35 & 25.2 & 25.4 & 87.7 \\
& Strongly Agree & 17 & 12.2 & 12.3 & 100.0 \\
& Total & 138 & 99.3 & 100.0 & .7 \\
Missing & -99 & 1 & 139 & & \\
Total & & 100.0 & & \\
\hline
\end{tabular}

Q1a_tag_artinstreets_beforeafter In general, was this space better before or after the street art/graffiti was put there?

\begin{tabular}{|ll|r|r|r|r|}
\hline & Frequency & Percent & Valid Percent & $\begin{array}{c}\text { Cumulative } \\
\text { Percent }\end{array}$ \\
\hline & Before & 70 & 50.4 & 51.9 & 51.9 \\
Valid & After & 65 & 46.8 & 48.1 & 100.0 \\
& Total & 135 & 97.1 & 100.0 & \\
Missing & -99 & 4 & 2.9 & & \\
Total & & 139 & 100.0 & & \\
\hline
\end{tabular}


Q1b_tag_1_artinstreets_yourproperty Would you be okay if someone placed something like this - On your property

\begin{tabular}{|ll|r|r|r|r|}
\hline & Frequency & Percent & Valid Percent & $\begin{array}{c}\text { Cumulative } \\
\text { Percent }\end{array}$ \\
\hline & Yes & 19 & 13.7 & 13.8 & 13.8 \\
Valid & No & 119 & 85.6 & 86.2 & 100.0 \\
& Total & 138 & 99.3 & 100.0 & \\
Missing & -99 & 1 & .7 & & \\
Total & & 139 & 100.0 & & \\
\hline
\end{tabular}

Q1b_tag_2_artinstreets_neighborhood Would you be okay if someone placed something like this - In your neighborhood

\begin{tabular}{|c|c|c|c|c|c|}
\hline & & Frequency & Percent & Valid Percent & $\begin{array}{c}\text { Cumulative } \\
\text { Percent }\end{array}$ \\
\hline \multirow{3}{*}{ Valid } & Yes & 76 & 54.7 & 54.7 & 54.7 \\
\hline & No & 63 & 45.3 & 45.3 & 100.0 \\
\hline & Total & 139 & 100.0 & 100.0 & \\
\hline
\end{tabular}

Q1b_tag_3_artinstreets_city Would you be okay if someone placed something like this

\begin{tabular}{|lc|r|r|r|r|}
\hline & Frequency & Percent & Valid Percent & $\begin{array}{c}\text { Cumulative } \\
\text { Percent }\end{array}$ \\
\hline & Yes & 82 & 59.0 & 59.4 & 59.4 \\
Valid & No & 56 & 40.3 & 40.6 & 100.0 \\
& Total & 138 & 99.3 & 100.0 & \\
Missing & -99 & 1 & .7 & & \\
Total & & 139 & 100.0 & & \\
\hline
\end{tabular}


Q1c_tag_artinstreets_6months Have you seen something like this in the past 6

\begin{tabular}{|lc|r|r|r|r|}
\hline & & months? & \\
& & Frequency & Percent & Valid Percent & $\begin{array}{c}\text { Cumulative } \\
\text { Percent }\end{array}$ \\
\hline & Yes & 112 & 80.6 & 81.2 & 81.2 \\
Valid & No & 26 & 18.7 & 18.8 & 100.0 \\
& Total & 138 & 99.3 & 100.0 & \\
Missing & -99 & 1 & .7 & & \\
Total & & 139 & 100.0 & & \\
\hline
\end{tabular}

Q1d tag_artinstreets_removed Do you think this should be removed?

\begin{tabular}{|lc|r|r|r|r|}
\hline & Frequency & Percent & Valid Percent & $\begin{array}{c}\text { Cumulative } \\
\text { Percent }\end{array}$ \\
\hline & No & 65 & 46.8 & 47.8 & 47.8 \\
Valid & Yes & 71 & 51.1 & 52.2 & 100.0 \\
& Total & 136 & 97.8 & 100.0 & \\
Missing & -99 & 3 & 2.2 & & \\
Total & & 139 & 100.0 & & \\
\hline
\end{tabular}

Q1d1_tag_artinstreets_communityinput Do you think that the surrounding community should have a say in whether or not it's removed or left alone?

\begin{tabular}{|ll|r|r|r|r|}
\hline & & Frequency & Percent & Valid Percent & $\begin{array}{c}\text { Cumulative } \\
\text { Percent }\end{array}$ \\
\hline & No (Community input is not & 30 & 21.6 & 42.3 & \\
& needed) & & & \\
Valid & Yes (Community input should & 41 & 29.5 & 52.3 \\
& be received) & & & \\
& Total & 71 & 51.1 & 100.0 & \\
Missing & System & 68 & 48.9 & & \\
Total & & 139 & 100.0 & & \\
\hline
\end{tabular}


Q1d2_tag_artinstreets_tax Do you think that public tax money should be spent to pay

\begin{tabular}{|ll|r|r|r|r|}
\hline & & Frequency & Percent & Valid Percent & $\begin{array}{c}\text { Cumulative } \\
\text { Percent }\end{array}$ \\
\hline & No & 29 & 20.9 & 40.8 & 40.8 \\
Valid & Yes & 42 & 30.2 & 59.2 & 100.0 \\
& Total & 71 & 51.1 & 100.0 & \\
Missing & System & 68 & 48.9 & & \\
Total & & 139 & 100.0 & & \\
\hline
\end{tabular}

\section{Q2: Tag - Fever Pole}

Q2 tag_pole_understand I understand the intended message

\begin{tabular}{|c|c|c|c|c|c|}
\hline & & Frequency & Percent & Valid Percent & $\begin{array}{c}\text { Cumulative } \\
\text { Percent }\end{array}$ \\
\hline \multirow{6}{*}{ Valid } & Strongly Disagree & 68 & 48.9 & 49.3 & 49.3 \\
\hline & Disagree & 49 & 35.3 & 35.5 & 84.8 \\
\hline & Neither Agree nor Disagree & 8 & 5.8 & 5.8 & 90.6 \\
\hline & Agree & 10 & 7.2 & 7.2 & 97.8 \\
\hline & Strongly Agree & 3 & 2.2 & 2.2 & 100.0 \\
\hline & Total & 138 & 99.3 & 100.0 & \\
\hline Missing & -99 & 1 & .7 & & \\
\hline Total & & 139 & 100.0 & & \\
\hline
\end{tabular}

Q2_tag_pole_damaged It damaged the surface

\begin{tabular}{|c|c|c|c|c|c|}
\hline & & Frequency & Percent & Valid Percent & $\begin{array}{c}\text { Cumulative } \\
\text { Percent }\end{array}$ \\
\hline \multirow{6}{*}{ Valid } & Strongly Disagree & 6 & 4.3 & 4.3 & 4.3 \\
\hline & Disagree & 21 & 15.1 & 15.1 & 19.4 \\
\hline & Neither Agree nor Disagree & 24 & 17.3 & 17.3 & 36.7 \\
\hline & Agree & 46 & 33.1 & 33.1 & 69.8 \\
\hline & Strongly Agree & 42 & 30.2 & 30.2 & 100.0 \\
\hline & Total & 139 & 100.0 & 100.0 & \\
\hline
\end{tabular}


Q2_tag_pole_imagination The person who did this used their imagination

\begin{tabular}{|c|c|c|c|c|c|}
\hline & & Frequency & Percent & Valid Percent & $\begin{array}{c}\text { Cumulative } \\
\text { Percent }\end{array}$ \\
\hline \multirow{6}{*}{ Valid } & Strongly Disagree & 44 & 31.7 & 31.7 & 31.7 \\
\hline & Disagree & 41 & 29.5 & 29.5 & 61.2 \\
\hline & Neither Agree nor Disagree & 29 & 20.9 & 20.9 & 82.0 \\
\hline & Agree & 23 & 16.5 & 16.5 & 98.6 \\
\hline & Strongly Agree & 2 & 1.4 & 1.4 & 100.0 \\
\hline & Total & 139 & 100.0 & 100.0 & \\
\hline
\end{tabular}

Q2_tag_pole_offensive It is offensive

\begin{tabular}{|c|c|c|c|c|c|}
\hline & & Frequency & Percent & Valid Percent & $\begin{array}{c}\text { Cumulative } \\
\text { Percent }\end{array}$ \\
\hline \multirow{6}{*}{ Valid } & Strongly Disagree & 15 & 10.8 & 10.8 & 10.8 \\
\hline & Disagree & 27 & 19.4 & 19.4 & 30.2 \\
\hline & Neither Agree nor Disagree & 50 & 36.0 & 36.0 & 66.2 \\
\hline & Agree & 18 & 12.9 & 12.9 & 79.1 \\
\hline & Strongly Agree & 29 & 20.9 & 20.9 & 100.0 \\
\hline & Total & 139 & 100.0 & 100.0 & \\
\hline
\end{tabular}

Q2_tag_pole_gang It is gang related

\begin{tabular}{|c|c|c|c|c|c|}
\hline & & Frequency & Percent & Valid Percent & $\begin{array}{c}\text { Cumulative } \\
\text { Percent }\end{array}$ \\
\hline \multirow{6}{*}{ Valid } & Strongly Disagree & 11 & 7.9 & 7.9 & 7.9 \\
\hline & Disagree & 21 & 15.1 & 15.1 & 23.0 \\
\hline & Neither Agree nor Disagree & 67 & 48.2 & 48.2 & 71.2 \\
\hline & Agree & 26 & 18.7 & 18.7 & 89.9 \\
\hline & Strongly Agree & 14 & 10.1 & 10.1 & 100.0 \\
\hline & Total & 139 & 100.0 & 100.0 & \\
\hline
\end{tabular}


Q2_tag_pole_crime It should be considered a crime

\begin{tabular}{|c|c|c|c|c|c|}
\hline & & Frequency & Percent & Valid Percent & $\begin{array}{c}\text { Cumulative } \\
\text { Percent }\end{array}$ \\
\hline \multirow{6}{*}{ Valid } & Strongly Disagree & 12 & 8.6 & 8.6 & 8.6 \\
\hline & Disagree & 18 & 12.9 & 12.9 & 21.6 \\
\hline & Neither Agree nor Disagree & 31 & 22.3 & 22.3 & 43.9 \\
\hline & Agree & 44 & 31.7 & 31.7 & 75.5 \\
\hline & Strongly Agree & 34 & 24.5 & 24.5 & 100.0 \\
\hline & Total & 139 & 100.0 & 100.0 & \\
\hline
\end{tabular}

Q2 tag pole interesting It makes the space more interesting

\begin{tabular}{|ll|r|r|r|r|}
\hline & Frequency & Percent & Valid Percent & $\begin{array}{c}\text { Cumulative } \\
\text { Percent }\end{array}$ \\
\hline & Strongly Disagree & 52 & 37.4 & 37.7 & 37.7 \\
& Disagree & 40 & 28.8 & 29.0 & 66.7 \\
& Neither Agree nor Disagree & 15 & 10.8 & 10.9 & 77.5 \\
Valid & Agree & 23 & 16.5 & 16.7 & 94.2 \\
& Strongly Agree & 8 & 5.8 & 5.8 & 100.0 \\
& Total & 138 & 99.3 & 100.0 & .7 \\
Missing & -99 & 1 & 139 & & \\
Total & & & 100.0 & \\
\hline
\end{tabular}

Q2_tag_pole_dirty It makes the space look dirty

\begin{tabular}{|ll|r|r|r|r|}
\hline & & Frequency & Percent & Valid Percent & $\begin{array}{c}\text { Cumulative } \\
\text { Percent }\end{array}$ \\
\hline \multirow{2}{*}{ Strongly Disagree } & & 11 & 7.9 & 8.0 & 8.0 \\
& Disagree & 13 & 9.4 & 9.4 & 17.4 \\
& Neither Agree nor Disagree & 13 & 9.4 & 9.4 & 26.8 \\
Valid & Agree & 51 & 36.7 & 37.0 & 63.8 \\
& Strongly Agree & 50 & 36.0 & 36.2 & 100.0 \\
& Total & 138 & 99.3 & 100.0 & .7 \\
Missing & -99 & 1 & 139 & 100.0 & \\
Total & & & & \\
\hline
\end{tabular}


Q2a_tag_pole_beforeafter In general, was this space better before or after the street art/graffiti was put there?

\begin{tabular}{|ll|r|r|r|r|}
\hline & Frequency & Percent & Valid Percent & $\begin{array}{c}\text { Cumulative } \\
\text { Percent }\end{array}$ \\
\hline & Before & 111 & 79.9 & 83.5 & 83.5 \\
Valid & After & 22 & 15.8 & 16.5 & 100.0 \\
& Total & 133 & 95.7 & 100.0 & \\
Missing & -99 & 6 & 4.3 & & \\
Total & & 139 & 100.0 & & \\
\hline
\end{tabular}

Q2b_tag_1_pole_yourproperty Would you be okay if someone placed something like this - On your property

\begin{tabular}{|c|c|c|c|c|c|}
\hline & & Frequency & Percent & Valid Percent & $\begin{array}{c}\text { Cumulative } \\
\text { Percent }\end{array}$ \\
\hline \multirow{3}{*}{ Valid } & Yes & 5 & 3.6 & 3.6 & 3.6 \\
\hline & No & 134 & 96.4 & 96.4 & 100.0 \\
\hline & Total & & 100.0 & 100.0 & \\
\hline
\end{tabular}

Q2b_tag_2_pole_neighborhood Would you be okay if someone placed something like this - In your neighborhood

\begin{tabular}{|c|c|c|c|c|c|}
\hline & & Frequency & Percent & Valid Percent & $\begin{array}{c}\text { Cumulative } \\
\text { Percent }\end{array}$ \\
\hline \multirow{3}{*}{ Valid } & Yes & 32 & 23.0 & 23.0 & 23.0 \\
\hline & No & 107 & 77.0 & 77.0 & 100.0 \\
\hline & Total & 139 & 100.0 & 100.0 & \\
\hline
\end{tabular}

Q2b_tag_3_pole_city Would you be okay if someone placed something like this -

Some other part of the city

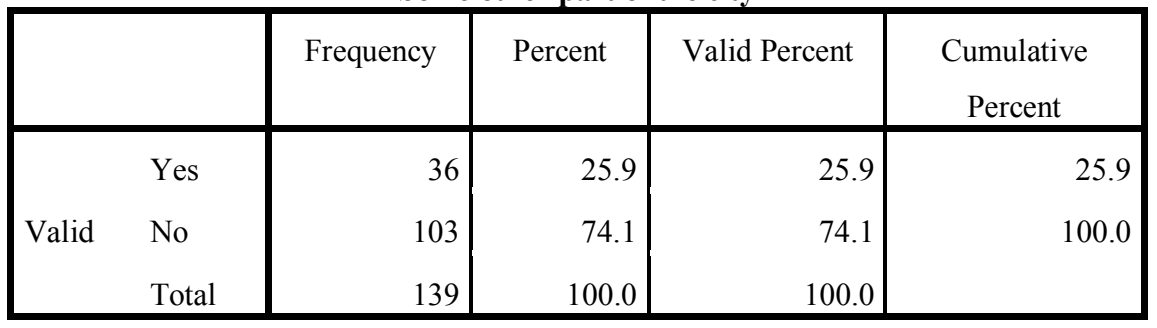


Q2c tag pole 6months Have you seen something like this in the past 6 months?

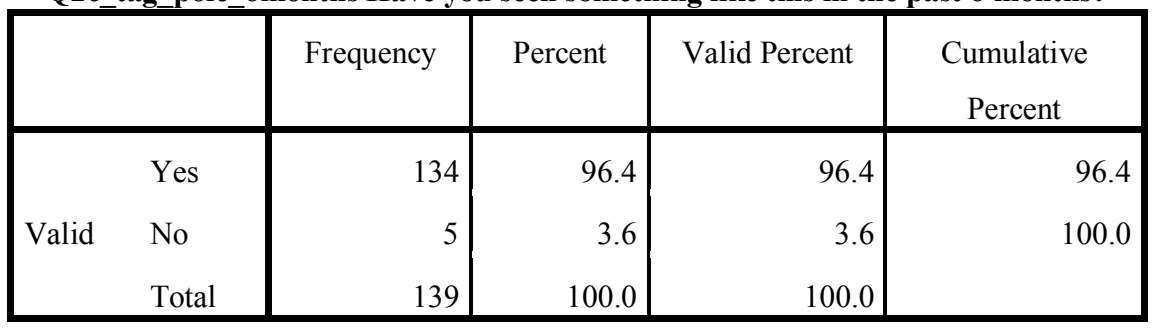

Q2d_tag_pole_removed Do you think this should be removed?

\begin{tabular}{|lc|r|r|r|r|}
\hline & & Frequency & Percent & Valid Percent & $\begin{array}{c}\text { Cumulative } \\
\text { Percent }\end{array}$ \\
\hline & No & 32 & 23.0 & 23.5 & 23.5 \\
Valid & Yes & 104 & 74.8 & 76.5 & 100.0 \\
& Total & 136 & 97.8 & 100.0 & \\
Missing & -99 & 3 & 2.2 & & \\
Total & & 139 & 100.0 & & \\
\hline
\end{tabular}

Q2d1_tag_pole_communityinput Do you think that the surrounding community should have a say in whether or not it's removed or left alone?

\begin{tabular}{|c|c|c|c|c|c|}
\hline & & Frequency & Percent & Valid Percent & $\begin{array}{c}\text { Cumulative } \\
\text { Percent }\end{array}$ \\
\hline \multirow{3}{*}{ Valid } & $\begin{array}{l}\text { No (Community input is not } \\
\text { needed) }\end{array}$ & 43 & 30.9 & 41.3 & 41.3 \\
\hline & $\begin{array}{l}\text { Yes (Community input should } \\
\text { be received) }\end{array}$ & 61 & 43.9 & 58.7 & 100.0 \\
\hline & Total & 104 & 74.8 & 100.0 & \\
\hline Missing & System & 35 & 25.2 & & \\
\hline Total & & 139 & 100.0 & & \\
\hline
\end{tabular}


Q2d2_tag_pole_tax Do you think that public tax money should be spent to pay for its

\begin{tabular}{|c|c|c|c|c|c|}
\hline & & Frequency & Percent & Valid Percent & $\begin{array}{c}\text { Cumulative } \\
\text { Percent }\end{array}$ \\
\hline \multirow{3}{*}{ Valid } & No & 33 & 23.7 & \multirow{7}{*}{$\begin{array}{r}32.0 \\
68.0 \\
100.0\end{array}$} & \multirow{7}{*}{$\begin{array}{r}32.0 \\
100.0\end{array}$} \\
\hline & Yes & 70 & 50.4 & & \\
\hline & Total & 103 & 74.1 & & \\
\hline & -99 & 1 & .7 & & \\
\hline Missing & System & 35 & 25.2 & & \\
\hline & Total & 36 & 25.9 & & \\
\hline Total & & 139 & 100.0 & & \\
\hline
\end{tabular}

\section{Q3: Sticker}

Q3 sticker 1 understand I understand the intended message

\begin{tabular}{|ll|r|r|r|r|}
\hline & Frequency & Percent & Valid Percent & $\begin{array}{c}\text { Cumulative } \\
\text { Percent }\end{array}$ \\
\hline & Strongly Disagree & 16 & 11.5 & 11.7 & 11.7 \\
& Disagree & 41 & 29.5 & 29.9 & 41.6 \\
& Neither Agree nor Disagree & 34 & 24.5 & 24.8 & 66.4 \\
Valid & Agree & 39 & 28.1 & 28.5 & 94.9 \\
& Strongly Agree & 7 & 5.0 & 5.1 & 100.0 \\
& Total & 137 & 98.6 & 100.0 & \\
Missing & -99 & 2 & 1.4 & & \\
Total & & 139 & 100.0 & \\
\hline
\end{tabular}

Q3 sticker 2 damaged It damaged the surface

\begin{tabular}{|ll|r|r|r|r|}
\hline & & Frequency & Percent & Valid Percent & $\begin{array}{c}\text { Cumulative } \\
\text { Percent }\end{array}$ \\
\hline \multirow{2}{*}{ Strongly Disagree } & 12 & 8.6 & 8.8 & 8.8 \\
& Disagree & 39 & 28.1 & 28.5 & 37.2 \\
& Neither Agree nor Disagree & 21 & 15.1 & 15.3 & 52.6 \\
Valid & Agree & 40 & 28.8 & 29.2 & 81.8 \\
& Strongly Agree & 25 & 18.0 & 18.2 & 100.0 \\
& Total & 137 & 98.6 & 100.0 & \\
Missing & -99 & 2 & 1.4 & 100.0 & \\
Total & & 139 & & \\
\hline
\end{tabular}


Q3 sticker 3 imagination The person who did this used their imagination

\begin{tabular}{|ll|r|r|r|r|}
\hline & & Frequency & Percent & Valid Percent & $\begin{array}{c}\text { Cumulative } \\
\text { Percent }\end{array}$ \\
\hline \multirow{2}{*}{ Strongly Disagree } & 34 & 24.5 & 24.8 & 24.8 \\
& Disagree & 46 & 33.1 & 33.6 & 58.4 \\
& Neither Agree nor Disagree & 37 & 26.6 & 27.0 & 85.4 \\
Valid & Agree & 12 & 8.6 & 8.8 & 94.2 \\
& Strongly Agree & 8 & 5.8 & 5.8 & 100.0 \\
& Total & 137 & 98.6 & 100.0 & \\
Missing & -99 & 2 & 1.4 & 100.0 & \\
Total & & & &
\end{tabular}

Q3 sticker 4 offensive It is offensive

\begin{tabular}{|ll|r|r|r|r|}
\hline & & Frequency & Percent & Valid Percent & $\begin{array}{c}\text { Cumulative } \\
\text { Percent }\end{array}$ \\
\hline & Strongly Disagree & 24 & 17.3 & 17.5 & 17.5 \\
& Disagree & 44 & 31.7 & 32.1 & 49.6 \\
& Neither Agree nor Disagree & 41 & 29.5 & 29.9 & 79.6 \\
Valid & Agree & 16 & 11.5 & 11.7 & 91.2 \\
& Strongly Agree & 12 & 8.6 & 8.8 & 100.0 \\
& Total & 137 & 98.6 & 100.0 & 1.4 \\
Missing & -99 & 2 & 139 & & \\
Total & & & 100.0 & \\
\hline
\end{tabular}

Q3_sticker_5_gang It is gang related

\begin{tabular}{|ll|r|r|r|r|}
\hline & & Frequency & Percent & Valid Percent & $\begin{array}{c}\text { Cumulative } \\
\text { Percent }\end{array}$ \\
\hline \multirow{2}{*}{ Strongly Disagree } & & 50 & 36.0 & 36.5 & 36.5 \\
& Disagree & 55 & 39.6 & 40.1 & 76.6 \\
& Neither Agree nor Disagree & 30 & 21.6 & 21.9 & 98.5 \\
Valid & Agree & 1 & .7 & .7 & 99.3 \\
& Strongly Agree & 1 & .7 & .7 & 100.0 \\
& Total & 137 & 98.6 & 100.0 & \\
Missing & -99 & 2 & 1.4 & 100.0 & \\
Total & & & &
\end{tabular}


Q3_sticker_6_crime It should be considered a crime

\begin{tabular}{|ll|r|r|r|r|}
\hline & Frequency & Percent & Valid Percent & $\begin{array}{c}\text { Cumulative } \\
\text { Percent }\end{array}$ \\
\hline \multirow{2}{*}{ Strongly Disagree } & 28 & 20.1 & 20.4 & 20.4 \\
& Disagree & 40 & 28.8 & 29.2 & 49.6 \\
& Neither Agree nor Disagree & 30 & 21.6 & 21.9 & 71.5 \\
Valid & Agree & 31 & 22.3 & 22.6 & 94.2 \\
& Strongly Agree & 8 & 5.8 & 5.8 & 100.0 \\
& Total & 137 & 98.6 & 100.0 & \\
Missing & -99 & 2 & 1.4 & & \\
Total & & & 100.0 & \\
\end{tabular}

Q3 sticker 7 interesting It makes the space more interesting

\begin{tabular}{|ll|r|r|r|r|}
\hline & & Frequency & Percent & Valid Percent & $\begin{array}{c}\text { Cumulative } \\
\text { Percent }\end{array}$ \\
\hline \multirow{2}{*}{ Strongly Disagree } & 21 & 15.1 & 15.3 & 15.3 \\
& Disagree & 19 & 13.7 & 13.9 & 29.2 \\
& Neither Agree nor Disagree & 20 & 14.4 & 14.6 & 43.8 \\
Valid & Agree & 54 & 38.8 & 39.4 & 83.2 \\
& Strongly Agree & 23 & 16.5 & 16.8 & 100.0 \\
& Total & 137 & 98.6 & 100.0 & \\
Missing & -99 & 2 & 1.4 & 100.0 & \\
Total & & 139 & & \\
\hline
\end{tabular}

Q3 sticker 8 dirty It makes the space look dirty

\begin{tabular}{|c|c|c|c|c|c|}
\hline & & Frequency & Percent & Valid Percent & $\begin{array}{c}\text { Cumulative } \\
\text { Percent }\end{array}$ \\
\hline \multirow{6}{*}{ Valid } & Strongly Disagree & 16 & 11.5 & 11.7 & 11.7 \\
\hline & Disagree & 33 & 23.7 & 24.1 & 35.8 \\
\hline & Neither Agree nor Disagree & 23 & 16.5 & 16.8 & 52.6 \\
\hline & Agree & 44 & 31.7 & 32.1 & 84.7 \\
\hline & Strongly Agree & 21 & 15.1 & 15.3 & 100.0 \\
\hline & Total & 137 & 98.6 & 100.0 & \\
\hline Missing & -99 & 2 & 1.4 & & \\
\hline Total & & 139 & 100.0 & & \\
\hline
\end{tabular}


Q3a_sticker_beforeafter In general, was this space better before or after the street art/graffiti was put there?

\begin{tabular}{|ll|r|r|r|r|}
\hline & Frequency & Percent & Valid Percent & \multicolumn{2}{|c|}{$\begin{array}{c}\text { Cumulative } \\
\text { Percent }\end{array}$} \\
\hline & Before & 78 & 56.1 & 58.2 & 58.2 \\
Valid & After & 56 & 40.3 & 41.8 & 100.0 \\
& Total & 134 & 96.4 & 100.0 & \\
Missing & -99 & 5 & 3.6 & & \\
Total & & 139 & 100.0 & & \\
\hline
\end{tabular}

Q3b_sticker_1_yourproperty Would you be okay if someone placed something like this - On your property

\begin{tabular}{|ll|r|r|r|r|}
\hline & Frequency & Percent & Valid Percent & $\begin{array}{c}\text { Cumulative } \\
\text { Percent }\end{array}$ \\
\hline & Yes & 22 & 15.8 & 16.2 & 16.2 \\
Valid & No & 114 & 82.0 & 83.8 & 100.0 \\
& Total & 136 & 97.8 & 100.0 & \\
Missing & -99 & 3 & 2.2 & & \\
Total & & 139 & 100.0 & & \\
\hline
\end{tabular}

Q3b_sticker_2_neighborhood Would you be okay if someone placed something like this - In your neighborhood

\begin{tabular}{|ll|r|r|r|r|}
\hline & Frequency & Percent & Valid Percent & $\begin{array}{c}\text { Cumulative } \\
\text { Percent }\end{array}$ \\
\hline & Yes & 72 & 51.8 & 52.9 & 52.9 \\
Valid & No & 64 & 46.0 & 47.1 & 100.0 \\
& Total & 136 & 97.8 & 100.0 & \\
Missing & -99 & 3 & 2.2 & & \\
Total & & 139 & 100.0 & & \\
\hline
\end{tabular}


Q3b_sticker_3_city Would you be okay if someone placed something like this - Some other part of the city

\begin{tabular}{|lc|r|r|r|r|}
\hline & Frequency & Percent & Valid Percent & \multicolumn{2}{|c|}{$\begin{array}{c}\text { Cumulative } \\
\text { Percent }\end{array}$} \\
\hline & Yes & 74 & 53.2 & 54.0 & 54.0 \\
Valid & No & 63 & 45.3 & 46.0 & 100.0 \\
& Total & 137 & 98.6 & 100.0 & \\
Missing & -99 & 2 & 1.4 & & \\
Total & & 139 & 100.0 & & \\
\hline
\end{tabular}

Q3c_sticker_6months Have you seen something like this in the past 6 months?

\begin{tabular}{|ll|r|r|r|r|}
\hline & Frequency & Percent & Valid Percent & $\begin{array}{c}\text { Cumulative } \\
\text { Percent }\end{array}$ \\
\hline & Yes & 131 & 94.2 & 97.0 & 97.0 \\
Valid & No & 4 & 2.9 & 3.0 & 100.0 \\
& Total & 135 & 97.1 & 100.0 & \\
Missing & -99 & 4 & 2.9 & & \\
Total & & 139 & 100.0 & & \\
\hline
\end{tabular}

Q3d_sticker_removed Do you think this should be removed?

\begin{tabular}{|lc|r|r|r|r|}
\hline & Frequency & Percent & Valid Percent & $\begin{array}{c}\text { Cumulative } \\
\text { Percent }\end{array}$ \\
\hline & No & 80 & 57.6 & 59.3 & 59.3 \\
Valid & Yes & 55 & 39.6 & 40.7 & 100.0 \\
& Total & 135 & 97.1 & 100.0 & \\
Missing & -99 & 4 & 2.9 & & \\
Total & & 139 & 100.0 & & \\
\hline
\end{tabular}


Q3d1_sticker_communityinput Do you think that the surrounding community should have a say in whether or not it's removed or left alone?

\begin{tabular}{|ll|r|r|r|r|}
\hline & & Frequency & Percent & Valid Percent & $\begin{array}{c}\text { Cumulative } \\
\text { Percent }\end{array}$ \\
\hline & No (Community input is not & 37 & 26.6 & 67.3 & 67.3 \\
needed) & & & \\
Valid & Yes (Community input should & 18 & 12.9 & 32.7 & 100.0 \\
& be received) & & & \\
& Total & 55 & 39.6 & 100.0 & \\
Missing & System & 84 & 60.4 & & \\
Total & & 139 & 100.0 & & \\
\hline
\end{tabular}

Q3d2_sticker_tax Do you think that public tax money should be spent to pay for its

\begin{tabular}{|ll|r|r|r|r|}
\hline & & Frequency & Percent & Valid Percent & $\begin{array}{c}\text { Cumulative } \\
\text { Percent }\end{array}$ \\
\hline \multirow{4}{*}{ Valid } & No & 29 & 20.9 & 53.7 & 53.7 \\
& Yes & 25 & 18.0 & 46.3 & 100.0 \\
& Total & 54 & 38.8 & 100.0 & \\
& -99 & 1 & .7 & & \\
Missing & System & 84 & 60.4 & & \\
& Total & 85 & 61.2 & & \\
Total & & 139 & 100.0 & & \\
\hline
\end{tabular}




\section{Q4: Piece - Murg Wildstyle}

Q4_wildstylepiece_1_understand I understand the intended message

\begin{tabular}{|c|c|c|c|c|c|}
\hline & & Frequency & Percent & Valid Percent & $\begin{array}{c}\text { Cumulative } \\
\text { Percent }\end{array}$ \\
\hline \multirow{6}{*}{ Valid } & Strongly Disagree & 21 & 15.1 & 15.1 & 15.1 \\
\hline & Disagree & 63 & 45.3 & 45.3 & 60.4 \\
\hline & Neither Agree nor Disagree & 30 & 21.6 & 21.6 & 82.0 \\
\hline & Agree & 16 & 11.5 & 11.5 & 93.5 \\
\hline & Strongly Agree & 9 & 6.5 & 6.5 & 100.0 \\
\hline & Total & 139 & 100.0 & 100.0 & \\
\hline
\end{tabular}

Q4_wildstylepiece_2_damaged It damaged the surface

\begin{tabular}{|c|c|c|c|c|c|}
\hline & & Frequency & Percent & Valid Percent & $\begin{array}{c}\text { Cumulative } \\
\text { Percent }\end{array}$ \\
\hline \multirow{6}{*}{ Valid } & Strongly Disagree & 29 & 20.9 & 20.9 & 20.9 \\
\hline & Disagree & 38 & 27.3 & 27.3 & 48.2 \\
\hline & Neither Agree nor Disagree & 25 & 18.0 & 18.0 & 66.2 \\
\hline & Agree & 29 & 20.9 & 20.9 & 87.1 \\
\hline & Strongly Agree & 18 & 12.9 & 12.9 & 100.0 \\
\hline & Total & 139 & 100.0 & 100.0 & \\
\hline
\end{tabular}

Q4_wildstylepiece_3_imagination The person who did this used their imagination

\begin{tabular}{|c|c|c|c|c|c|}
\hline & & Frequency & Percent & Valid Percent & $\begin{array}{c}\text { Cumulative } \\
\text { Percent }\end{array}$ \\
\hline \multirow{5}{*}{ Valid } & Strongly Disagree & 1 & .7 & .7 & .7 \\
\hline & Neither Agree nor Disagree & 8 & 5.8 & 5.8 & 6.5 \\
\hline & Agree & 65 & 46.8 & 46.8 & 53.2 \\
\hline & Strongly Agree & 65 & 46.8 & 46.8 & 100.0 \\
\hline & Total & 139 & 100.0 & 100.0 & \\
\hline
\end{tabular}


Q4 wildstylepiece 4 offensive It is offensive

\begin{tabular}{|l|r|r|r|r|}
\hline & Frequency & Percent & Valid Percent & $\begin{array}{c}\text { Cumulative } \\
\text { Percent }\end{array}$ \\
\hline Strongly Disagree & 43 & 30.9 & 30.9 & 30.9 \\
Disagree & 45 & 32.4 & 32.4 & 63.3 \\
Neither Agree nor Disagree & 33 & 23.7 & 23.7 & 87.1 \\
Valid & 8 & 5.8 & 5.8 & 92.8 \\
Agree & 10 & 7.2 & 7.2 & 100.0 \\
Strongly Agree & 139 & 100.0 & 100.0 & \\
Total & &
\end{tabular}

Q4_wildstylepiece_5_gang It is gang related

\begin{tabular}{|c|c|c|c|c|c|}
\hline & & Frequency & Percent & Valid Percent & $\begin{array}{c}\text { Cumulative } \\
\text { Percent }\end{array}$ \\
\hline \multirow{6}{*}{ Valid } & Strongly Disagree & 33 & 23.7 & 23.7 & 23.7 \\
\hline & Disagree & 28 & 20.1 & 20.1 & 43.9 \\
\hline & Neither Agree nor Disagree & 69 & 49.6 & 49.6 & 93.5 \\
\hline & Agree & 8 & 5.8 & 5.8 & 99.3 \\
\hline & Strongly Agree & 1 & .7 & .7 & 100.0 \\
\hline & Total & 139 & 100.0 & 100.0 & \\
\hline
\end{tabular}

Q4_wildstylepiece_6_crime It should be considered a crime

\begin{tabular}{|c|c|c|c|c|c|}
\hline & & Frequency & Percent & Valid Percent & $\begin{array}{c}\text { Cumulative } \\
\text { Percent }\end{array}$ \\
\hline \multirow{6}{*}{ Valid } & Strongly Disagree & 29 & 20.9 & 20.9 & 20.9 \\
\hline & Disagree & 25 & 18.0 & 18.0 & 38.8 \\
\hline & Neither Agree nor Disagree & 34 & 24.5 & 24.5 & 63.3 \\
\hline & Agree & 34 & 24.5 & 24.5 & 87.8 \\
\hline & Strongly Agree & 17 & 12.2 & 12.2 & 100.0 \\
\hline & Total & 139 & 100.0 & 100.0 & \\
\hline
\end{tabular}


Q4_wildstylepiece_7_interesting It makes the space more interesting

\begin{tabular}{|c|c|c|c|c|c|}
\hline & & Frequency & Percent & Valid Percent & $\begin{array}{c}\text { Cumulative } \\
\text { Percent }\end{array}$ \\
\hline \multirow{6}{*}{ Valid } & Strongly Disagree & 7 & 5.0 & 5.0 & 5.0 \\
\hline & Disagree & 7 & 5.0 & 5.0 & 10.1 \\
\hline & Neither Agree nor Disagree & 12 & 8.6 & 8.6 & 18.7 \\
\hline & Agree & 59 & 42.4 & 42.4 & 61.2 \\
\hline & Strongly Agree & 54 & 38.8 & 38.8 & 100.0 \\
\hline & Total & 139 & 100.0 & 100.0 & \\
\hline
\end{tabular}

Q4 wildstylepiece 8 dirty It makes the space look dirty

\begin{tabular}{|c|c|c|c|c|c|}
\hline & & Frequency & Percent & Valid Percent & $\begin{array}{c}\text { Cumulative } \\
\text { Percent }\end{array}$ \\
\hline \multirow{6}{*}{ Valid } & Strongly Disagree & 47 & 33.8 & 33.8 & 33.8 \\
\hline & Disagree & 49 & 35.3 & 35.3 & 69.1 \\
\hline & Neither Agree nor Disagree & 17 & 12.2 & 12.2 & 81.3 \\
\hline & Agree & 18 & 12.9 & 12.9 & 94.2 \\
\hline & Strongly Agree & 8 & 5.8 & 5.8 & 100.0 \\
\hline & Total & 139 & 100.0 & 100.0 & \\
\hline
\end{tabular}

Q4a_wildstylepiece In general, was this space better before or after the street art/graffiti was put there?

\begin{tabular}{|ll|r|r|r|r|}
\hline & Frequency & Percent & Valid Percent & $\begin{array}{c}\text { Cumulative } \\
\text { Percent }\end{array}$ \\
\hline & Before & 35 & 25.2 & 26.5 & 26.5 \\
Valid & After & 97 & 69.8 & 73.5 & 100.0 \\
& Total & 132 & 95.0 & 100.0 & \\
Missing & -99 & 7 & 5.0 & & \\
Total & & 139 & 100.0 & & \\
\hline
\end{tabular}


Q4b_wildstylepiece_1 Would you be okay if someone placed something like this - On

\begin{tabular}{|ll|r|r|r|r|}
\hline & & Frequency & Percent & Valid Percent & $\begin{array}{c}\text { Cumulative } \\
\text { Percent }\end{array}$ \\
\hline & Yes & 29 & 20.9 & 21.0 & 21.0 \\
Valid & No & 109 & 78.4 & 79.0 & 100.0 \\
& Total & 138 & 99.3 & 100.0 & \\
Missing & -99 & 1 & .7 & & \\
Total & & 139 & 100.0 & & \\
\hline
\end{tabular}

Q4b_wildstylepiece_2 Would you be okay if someone placed something like this - In

your neighborhood

\begin{tabular}{|lc|r|r|r|r|}
\hline & Frequency & Percent & Valid Percent & $\begin{array}{c}\text { Cumulative } \\
\text { Percent }\end{array}$ \\
\hline & Yes & 82 & 59.0 & 59.9 & 59.9 \\
Valid & No & 55 & 39.6 & 40.1 & 100.0 \\
& Total & 137 & 98.6 & 100.0 & \\
Missing & -99 & 2 & 1.4 & & \\
Total & & 139 & 100.0 & & \\
\hline
\end{tabular}

Q4b_wildstylepiece_3 Would you be okay if someone placed something like this -

Some other part of the city

\begin{tabular}{|ll|r|r|r|r|}
\hline & Frequency & Percent & Valid Percent & \multicolumn{2}{|c|}{$\begin{array}{c}\text { Cumulative } \\
\text { Percent }\end{array}$} \\
\hline & Yes & 95 & 68.3 & 68.8 & 68.8 \\
Valid & No & 43 & 30.9 & 31.2 & 100.0 \\
& Total & 138 & 99.3 & 100.0 & \\
Missing & -99 & 1 & .7 & & \\
Total & & 139 & 100.0 & & \\
\hline
\end{tabular}

Q4c wildstylepiece Have you seen something like this in the past 6 months?

\begin{tabular}{|c|c|c|c|c|c|}
\hline & & Frequency & Percent & Valid Percent & $\begin{array}{c}\text { Cumulative } \\
\text { Percent }\end{array}$ \\
\hline \multirow{3}{*}{ Valid } & Yes & 110 & 79.1 & 80.9 & 80.9 \\
\hline & No & 26 & 18.7 & 19.1 & 100.0 \\
\hline & Total & 136 & 97.8 & 100.0 & \\
\hline Missing & -99 & 3 & 2.2 & & \\
\hline Total & & 139 & 100.0 & & \\
\hline
\end{tabular}


Q4d wildstylepiece Do you think this should be removed?

\begin{tabular}{|ll|r|r|r|r|}
\hline & Frequency & Percent & Valid Percent & $\begin{array}{c}\text { Cumulative } \\
\text { Percent }\end{array}$ \\
\hline & No & 93 & 66.9 & 69.4 & 69.4 \\
Valid & Yes & 41 & 29.5 & 30.6 & 100.0 \\
& Total & 134 & 96.4 & 100.0 & \\
Missing & -99 & 5 & 3.6 & & \\
Total & & 139 & 100.0 & & \\
\hline
\end{tabular}

Q4d1_wildstylepiece Do you think that the surrounding community should have a say in whether or not it's

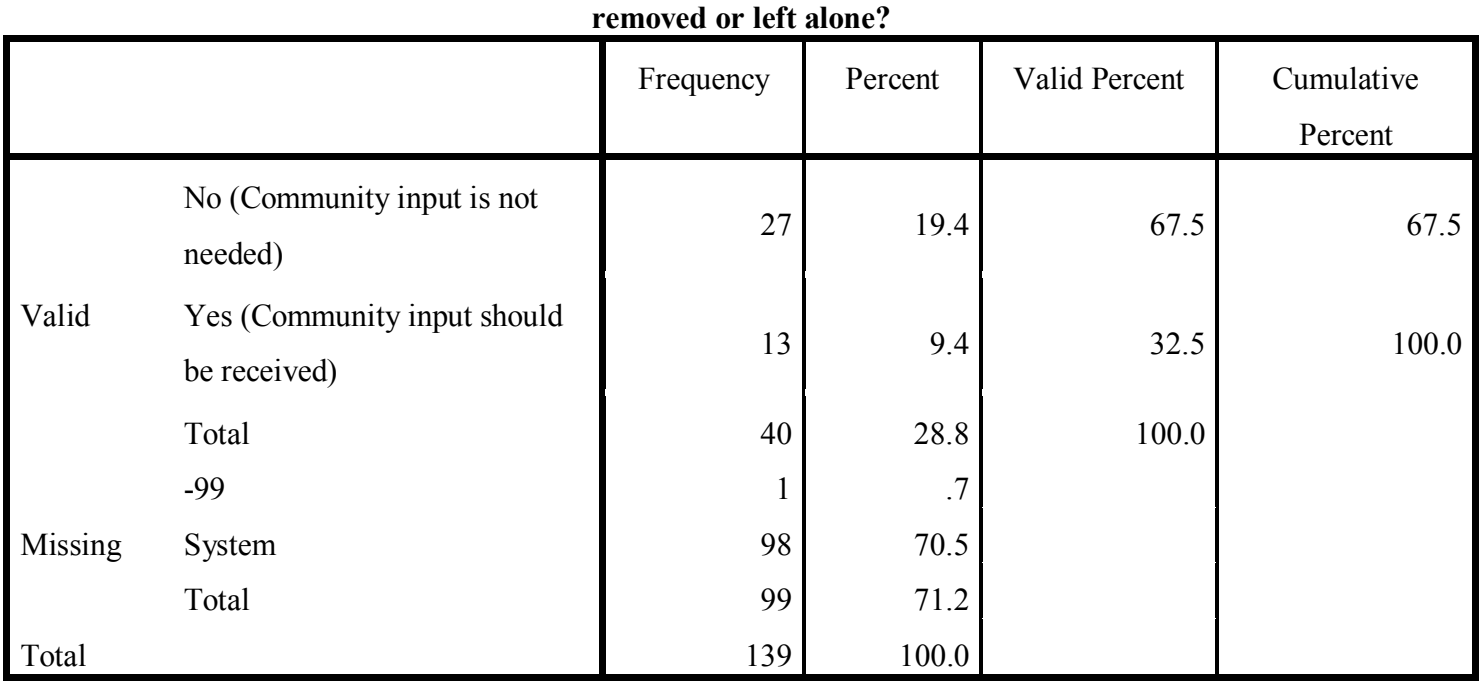

Q4d2_wildstylepiece Do you think that public tax money should be spent to pay for its

\begin{tabular}{|ll|r|r|r|r|}
\hline & & Frequency & Percent & Valid Percent & $\begin{array}{c}\text { Cumulative } \\
\text { Percent }\end{array}$ \\
\hline \multirow{4}{*}{ Valid } & No & 13 & 9.4 & 32.5 & 32.5 \\
& Yes & 27 & 19.4 & 67.5 & 100.0 \\
& Total & 40 & 28.8 & 100.0 & \\
Missing & System & 1 & .7 & & \\
& Total & 98 & 70.5 & & \\
Total & & 99 & 71.2 & & \\
\hline
\end{tabular}




\section{Q5: Piece - GATS Character}

Q5_GATSpiece_1_understand I understand the intended message

\begin{tabular}{|l|r|r|r|r|}
\hline & Frequency & Percent & Valid Percent & $\begin{array}{c}\text { Cumulative } \\
\text { Percent }\end{array}$ \\
\hline \multirow{2}{*}{ Strongly Disagree } & 15 & 10.8 & 10.8 & 10.8 \\
Disagree & 37 & 26.6 & 26.6 & 37.4 \\
Veither Agree nor Disagree & 49 & 35.3 & 35.3 & 72.7 \\
Valid & 25 & 18.0 & 18.0 & 90.6 \\
& 13 & 9.4 & 9.4 & 100.0 \\
Strongly Agree & 139 & 100.0 & 100.0 & \\
Total & & &
\end{tabular}

Q5 GATSpiece_2_damaged It damaged the surface

\begin{tabular}{|c|c|c|c|c|c|}
\hline & & Frequency & Percent & Valid Percent & $\begin{array}{c}\text { Cumulative } \\
\text { Percent }\end{array}$ \\
\hline \multirow{6}{*}{ Valid } & Strongly Disagree & 37 & 26.6 & 26.6 & 26.6 \\
\hline & Disagree & 45 & 32.4 & 32.4 & 59.0 \\
\hline & Neither Agree nor Disagree & 28 & 20.1 & 20.1 & 79.1 \\
\hline & Agree & 16 & 11.5 & 11.5 & 90.6 \\
\hline & Strongly Agree & 13 & 9.4 & 9.4 & 100.0 \\
\hline & Total & 139 & 100.0 & 100.0 & \\
\hline
\end{tabular}

Q5_GATSpiece_3_imagination The person who did this used their imagination

\begin{tabular}{|l|r|r|r|r|}
\hline & Frequency & Percent & Valid Percent & $\begin{array}{c}\text { Cumulative } \\
\text { Percent }\end{array}$ \\
\hline \multirow{2}{*}{ Strongly Disagree } & 1 & .7 & .7 & .7 \\
Disagree & 1 & .7 & .7 & 1.4 \\
Valid & 7 & 5.0 & 5.0 & 6.5 \\
Neither Agree nor Disagree & 54 & 38.8 & 38.8 & 45.3 \\
Agree & 76 & 54.7 & 54.7 & 100.0 \\
Strongly Agree & 139 & 100.0 & 100.0 & \\
Total & & &
\end{tabular}


Q5 GATSpiece 4 offensive It is offensive

\begin{tabular}{|c|c|c|c|c|c|}
\hline & & Frequency & Percent & Valid Percent & $\begin{array}{c}\text { Cumulative } \\
\text { Percent }\end{array}$ \\
\hline \multirow{6}{*}{ Valid } & Strongly Disagree & 60 & 43.2 & 43.2 & 43.2 \\
\hline & Disagree & 48 & 34.5 & 34.5 & 77.7 \\
\hline & Neither Agree nor Disagree & 19 & 13.7 & 13.7 & 91.4 \\
\hline & Agree & 6 & 4.3 & 4.3 & 95.7 \\
\hline & Strongly Agree & 6 & 4.3 & 4.3 & 100.0 \\
\hline & Total & 139 & 100.0 & 100.0 & \\
\hline
\end{tabular}

Q5_GATSpiece_5_gang It is gang related

\begin{tabular}{|c|c|c|c|c|c|}
\hline & & Frequency & Percent & Valid Percent & $\begin{array}{c}\text { Cumulative } \\
\text { Percent }\end{array}$ \\
\hline \multirow{5}{*}{ Valid } & Strongly Disagree & 59 & 42.4 & 42.4 & 42.4 \\
\hline & Disagree & 38 & 27.3 & 27.3 & 69.8 \\
\hline & Neither Agree nor Disagree & 41 & 29.5 & 29.5 & 99.3 \\
\hline & Agree & 1 & .7 & .7 & 100.0 \\
\hline & Total & 139 & 100.0 & 100.0 & \\
\hline
\end{tabular}

Q5 GATSpiece 6 crime It should be considered a crime

\begin{tabular}{|c|c|c|c|c|c|}
\hline & & Frequency & Percent & Valid Percent & $\begin{array}{c}\text { Cumulative } \\
\text { Percent }\end{array}$ \\
\hline \multirow{6}{*}{ Valid } & Strongly Disagree & 41 & 29.5 & 29.5 & 29.5 \\
\hline & Disagree & 31 & 22.3 & 22.3 & 51.8 \\
\hline & Neither Agree nor Disagree & 31 & 22.3 & 22.3 & 74.1 \\
\hline & Agree & 24 & 17.3 & 17.3 & 91.4 \\
\hline & Strongly Agree & 12 & 8.6 & 8.6 & 100.0 \\
\hline & Total & 139 & 100.0 & 100.0 & \\
\hline
\end{tabular}


Q5_GATSpiece 7_interesting It makes the space more interesting

\begin{tabular}{|c|c|c|c|c|c|}
\hline & & Frequency & Percent & Valid Percent & $\begin{array}{c}\text { Cumulative } \\
\text { Percent }\end{array}$ \\
\hline \multirow{6}{*}{ Valid } & Strongly Disagree & 10 & 7.2 & 7.2 & 7.2 \\
\hline & Disagree & 5 & 3.6 & 3.6 & 10.8 \\
\hline & Neither Agree nor Disagree & 11 & 7.9 & 7.9 & 18.7 \\
\hline & Agree & 47 & 33.8 & 33.8 & 52.5 \\
\hline & Strongly Agree & 66 & 47.5 & 47.5 & 100.0 \\
\hline & Total & 139 & 100.0 & 100.0 & \\
\hline
\end{tabular}

Q5 GATSpiece 8 dirty It makes the space look dirty

\begin{tabular}{|ll|r|r|r|r|}
\hline & Frequency & Percent & Valid Percent & $\begin{array}{c}\text { Cumulative } \\
\text { Percent }\end{array}$ \\
\hline & Strongly Disagree & 57 & 41.0 & 41.3 & 41.3 \\
& Disagree & 38 & 27.3 & 27.5 & 68.8 \\
& Neither Agree nor Disagree & 15 & 10.8 & 10.9 & 79.7 \\
Valid & Agree & 19 & 13.7 & 13.8 & 93.5 \\
& Strongly Agree & 9 & 6.5 & 6.5 & 100.0 \\
& Total & 138 & 99.3 & 100.0 & .7 \\
Missing & -99 & 1 & 139 & 100.0 & \\
Total & & & & \\
\hline
\end{tabular}

Q5a_GATSpiece_beforeafter In general, was this space better before or after the street art/graffiti was put there?

\begin{tabular}{|ll|r|r|r|r|}
\hline & Frequency & Percent & Valid Percent & $\begin{array}{c}\text { Cumulative } \\
\text { Percent }\end{array}$ \\
\hline & Before & 29 & 20.9 & 21.6 & 21.6 \\
Valid & After & 105 & 75.5 & 78.4 & 100.0 \\
& Total & 134 & 96.4 & 100.0 & \\
Missing & -99 & 5 & 3.6 & & \\
Total & & 139 & 100.0 & & \\
\hline
\end{tabular}


Q5b_GATSpiece_1_yourproperty Would you be okay if someone placed something

like this - On your property

\begin{tabular}{|ll|r|r|r|r|}
\hline & Frequency & Percent & Valid Percent & $\begin{array}{c}\text { Cumulative } \\
\text { Percent }\end{array}$ \\
\hline & Yes & 38 & 27.3 & 27.5 & 27.5 \\
Valid & No & 100 & 71.9 & 72.5 & 100.0 \\
& Total & 138 & 99.3 & 100.0 & \\
Missing & -99 & 1 & .7 & & \\
Total & & 139 & 100.0 & & \\
\hline
\end{tabular}

Q5b_GATSpiece_2_neighborhood Would you be okay if someone placed something like this - In your neighborhood

\begin{tabular}{|ll|r|r|r|r|}
\hline & Frequency & Percent & Valid Percent & $\begin{array}{c}\text { Cumulative } \\
\text { Percent }\end{array}$ \\
\hline & Yes & 85 & 61.2 & 61.6 & 61.6 \\
Valid & No & 53 & 38.1 & 38.4 & 100.0 \\
& Total & 138 & 99.3 & 100.0 & \\
Missing & -99 & 1 & .7 & & \\
Total & & 139 & 100.0 & & \\
\hline
\end{tabular}

Q5b_GATSpiece_3_city Would you be okay if someone placed something like this -

Some other part of the city

\begin{tabular}{|ll|r|r|r|r|}
\hline & Frequency & Percent & Valid Percent & $\begin{array}{c}\text { Cumulative } \\
\text { Percent }\end{array}$ \\
\hline & Yes & 97 & 69.8 & 70.3 & 70.3 \\
Valid & No & 41 & 29.5 & 29.7 & 100.0 \\
& Total & 138 & 99.3 & 100.0 & \\
Missing & -99 & 1 & .7 & & \\
Total & & 139 & 100.0 & & \\
\hline
\end{tabular}

Q5c_GATSpiece 6months Have you seen something like this in the past 6 months?

\begin{tabular}{|ll|r|r|r|r|}
\hline & Frequency & Percent & Valid Percent & $\begin{array}{c}\text { Cumulative } \\
\text { Percent }\end{array}$ \\
\hline & Yes & 100 & 71.9 & 72.5 & 72.5 \\
Valid & No & 38 & 27.3 & 27.5 & 100.0 \\
& Total & 138 & 99.3 & 100.0 & \\
Missing & -99 & 1 & .7 & & \\
Total & & 139 & 100.0 & & \\
\hline
\end{tabular}


Q5d_GATSpiece_removed Do you think this should be removed?

\begin{tabular}{|ll|r|r|r|r|}
\hline & \multicolumn{1}{|c|}{ Frequency } & Percent & Valid Percent & $\begin{array}{c}\text { Cumulative } \\
\text { Percent }\end{array}$ \\
\hline & No & 98 & 70.5 & 72.1 & 72.1 \\
Valid & Yes & 38 & 27.3 & 27.9 & 100.0 \\
& Total & 136 & 97.8 & 100.0 & \\
Missing & -99 & 3 & 2.2 & & \\
Total & & 139 & 100.0 & & \\
\hline
\end{tabular}

Q5d1_GATSpiece_communityinput Do you think that the surrounding community should have a say in whether or not it's removed or left alone?

\begin{tabular}{|ll|r|r|r|r|}
\hline & & Frequency & Percent & Valid Percent & $\begin{array}{c}\text { Cumulative } \\
\text { Percent }\end{array}$ \\
\hline & No (Community input is not & 26 & 18.7 & 68.4 & \\
& needed) & & & \\
Valid & Yes (Community input should & 12 & 8.6 & 31.6 & \\
& be received) & & & \\
& Total & 38 & 27.3 & 100.0 & \\
Missing & System & 101 & 72.7 & & \\
Total & & 139 & 100.0 & & \\
\hline
\end{tabular}

Q5d2_GATSpiece_tax Do you think that public tax money should be spent to pay for its

\begin{tabular}{|ll|r|r|r|r|}
\hline & & Frequency & Percent & Valid Percent & $\begin{array}{c}\text { Cumulative } \\
\text { Percent }\end{array}$ \\
\hline & No & 12 & 8.6 & 31.6 & 31.6 \\
Valid & Yes & 26 & 18.7 & 68.4 & 100.0 \\
& Total & 38 & 27.3 & 100.0 & \\
Missing & System & 101 & 72.7 & & \\
Total & & 139 & 100.0 & & \\
\hline
\end{tabular}




\section{Q6: Installation - Community Chalk Box}

Q6_Chalk_install_1_understand I understand the intended message

\begin{tabular}{|c|c|c|c|c|c|}
\hline & & Frequency & Percent & Valid Percent & $\begin{array}{c}\text { Cumulative } \\
\text { Percent }\end{array}$ \\
\hline \multirow{6}{*}{ Valid } & Strongly Disagree & 11 & 7.9 & 7.9 & 7.9 \\
\hline & Disagree & 15 & 10.8 & 10.8 & 18.7 \\
\hline & Neither Agree nor Disagree & 14 & 10.1 & 10.1 & 28.8 \\
\hline & Agree & 60 & 43.2 & 43.2 & 71.9 \\
\hline & Strongly Agree & 39 & 28.1 & 28.1 & 100.0 \\
\hline & Total & 139 & 100.0 & 100.0 & \\
\hline
\end{tabular}

Q6_Chalk_install_2_damaged It damaged the surface

\begin{tabular}{|l|r|r|r|r|}
\hline & Frequency & Percent & Valid Percent & $\begin{array}{c}\text { Cumulative } \\
\text { Percent }\end{array}$ \\
\hline Strongly Disagree & 51 & 36.7 & 36.7 & 36.7 \\
Disagree & 51 & 36.7 & 36.7 & 73.4 \\
Veither Agree nor Disagree & 15 & 10.8 & 10.8 & 84.2 \\
Agree & 14 & 10.1 & 10.1 & 94.2 \\
Strongly Agree & 8 & 5.8 & 5.8 & 100.0 \\
Total & 139 & 100.0 & 100.0 & \\
\hline
\end{tabular}

Q6_Chalk_install_3_imagination The person who did this used their imagination

\begin{tabular}{|l|r|r|r|r|}
\hline & Frequency & Percent & Valid Percent & $\begin{array}{c}\text { Cumulative } \\
\text { Percent }\end{array}$ \\
\hline Strongly Disagree & 3 & 2.2 & 2.2 & 2.2 \\
Disagree & 3 & 2.2 & 2.2 & 4.3 \\
Veither Agree nor Disagree & 11 & 7.9 & 7.9 & 12.2 \\
Valid & 65 & 46.8 & 46.8 & 59.0 \\
Agree & 57 & 41.0 & 41.0 & 100.0 \\
Strongly Agree & 139 & 100.0 & 100.0 & \\
Total & &
\end{tabular}


Q6 Chalk install 4 offensive It is offensive

\begin{tabular}{|c|c|c|c|c|c|}
\hline & & Frequency & Percent & Valid Percent & $\begin{array}{c}\text { Cumulative } \\
\text { Percent }\end{array}$ \\
\hline \multirow{6}{*}{ Valid } & Strongly Disagree & 73 & 52.5 & 52.5 & 52.5 \\
\hline & Disagree & 47 & 33.8 & 33.8 & 86.3 \\
\hline & Neither Agree nor Disagree & 15 & 10.8 & 10.8 & 97.1 \\
\hline & Agree & 1 & .7 & .7 & 97.8 \\
\hline & Strongly Agree & 3 & 2.2 & 2.2 & 100.0 \\
\hline & Total & 139 & 100.0 & 100.0 & \\
\hline
\end{tabular}

Q6_Chalk_install_5 gang It is gang related

\begin{tabular}{|c|c|c|c|c|c|}
\hline & & Frequency & Percent & Valid Percent & $\begin{array}{c}\text { Cumulative } \\
\text { Percent }\end{array}$ \\
\hline \multirow{4}{*}{ Valid } & Strongly Disagree & 84 & 60.4 & 60.4 & 60.4 \\
\hline & Disagree & 39 & 28.1 & 28.1 & 88.5 \\
\hline & Neither Agree nor Disagree & 16 & 11.5 & 11.5 & 100.0 \\
\hline & Total & 139 & 100.0 & 100.0 & \\
\hline
\end{tabular}

Q6_Chalk_install_6_crime It should be considered a crime

\begin{tabular}{|l|r|r|r|r|}
\hline & Frequency & Percent & Valid Percent & $\begin{array}{c}\text { Cumulative } \\
\text { Percent }\end{array}$ \\
\hline \multirow{2}{*}{ Strongly Disagree } & 62 & 44.6 & 44.6 & 44.6 \\
Disagree & 36 & 25.9 & 25.9 & 70.5 \\
Valid & 23 & 16.5 & 16.5 & 87.1 \\
Neither Agree nor Disagree & 10 & 7.2 & 7.2 & 94.2 \\
Agree & 8 & 5.8 & 5.8 & 100.0 \\
Strongly Agree & 139 & 100.0 & 100.0 & \\
Total & &
\end{tabular}

Q6_Chalk_install_7_interesting It makes the space more interesting

\begin{tabular}{|c|c|c|c|c|c|}
\hline & & Frequency & Percent & Valid Percent & $\begin{array}{c}\text { Cumulative } \\
\text { Percent }\end{array}$ \\
\hline \multirow{6}{*}{ Valid } & Strongly Disagree & 5 & 3.6 & 3.6 & 3.6 \\
\hline & Disagree & 11 & 7.9 & 7.9 & 11.5 \\
\hline & Neither Agree nor Disagree & 8 & 5.8 & 5.8 & 17.3 \\
\hline & Agree & 49 & 35.3 & 35.3 & 52.5 \\
\hline & Strongly Agree & 66 & 47.5 & 47.5 & 100.0 \\
\hline & Total & 139 & 100.0 & 100.0 & \\
\hline
\end{tabular}


Q6_Chalk install 8_dirty It makes the space look dirty

\begin{tabular}{|ll|r|r|r|r|}
\hline & Frequency & Percent & Valid Percent & $\begin{array}{c}\text { Cumulative } \\
\text { Percent }\end{array}$ \\
\hline & Strongly Disagree & 66 & 47.5 & 47.8 & 47.8 \\
& Disagree & 44 & 31.7 & 31.9 & 79.7 \\
& Neither Agree nor Disagree & 17 & 12.2 & 12.3 & 92.0 \\
Valid & Agree & 8 & 5.8 & 5.8 & 97.8 \\
& Strongly Agree & 3 & 2.2 & 2.2 & 100.0 \\
& Total & 138 & 99.3 & 100.0 & .7 \\
Missing & -99 & 1 & 139 & & \\
Total & & & &
\end{tabular}

Q6a_Chalk_install_beforeafter In general, was this space better before or after the street art/graffiti was put there?

\begin{tabular}{|ll|r|r|r|r|}
\hline & Frequency & Percent & Valid Percent & $\begin{array}{c}\text { Cumulative } \\
\text { Percent }\end{array}$ \\
\hline & Before & 20 & 14.4 & 14.8 & 14.8 \\
Valid & After & 115 & 82.7 & 85.2 & 100.0 \\
& Total & 135 & 97.1 & 100.0 & \\
Missing & -99 & 4 & 2.9 & & \\
Total & & 139 & 100.0 & & \\
\hline
\end{tabular}

Q6b_Chalk_install_1_yourproperty Would you be okay if someone placed something like this - On your property

\begin{tabular}{|c|c|c|c|c|c|}
\hline & & Frequency & Percent & Valid Percent & $\begin{array}{c}\text { Cumulative } \\
\text { Percent }\end{array}$ \\
\hline \multirow{3}{*}{ Valid } & Yes & 67 & 48.2 & 48.2 & 48.2 \\
\hline & No & 72 & 51.8 & 51.8 & 100.0 \\
\hline & Total & 139 & 100.0 & 100.0 & \\
\hline
\end{tabular}


Q6b_Chalk_install_2_neighborhood Would you be okay if someone placed

\begin{tabular}{|c|c|c|c|c|c|}
\hline & & Frequency & Percent & Valid Percent & $\begin{array}{c}\text { Cumulative } \\
\text { Percent }\end{array}$ \\
\hline \multirow{3}{*}{ Valid } & Yes & 115 & 82.7 & 82.7 & 82.7 \\
\hline & No & 24 & 17.3 & 17.3 & 100.0 \\
\hline & Total & 139 & 100.0 & 100.0 & \\
\hline
\end{tabular}

Q6b_Chalk_install_3_city Would you be okay if someone placed something like this -

Some other part of the city

\begin{tabular}{|lc|r|r|r|r|}
\hline & Frequency & Percent & Valid Percent & $\begin{array}{c}\text { Cumulative } \\
\text { Percent }\end{array}$ \\
\hline & Yes & 115 & 82.7 & 83.3 & 83.3 \\
Valid & No & 23 & 16.5 & 16.7 & 100.0 \\
& Total & 138 & 99.3 & 100.0 & \\
Missing & -99 & 1 & .7 & & \\
Total & & 139 & 100.0 & & \\
\hline
\end{tabular}

Q6c Chalk install 6months Have you seen something like this in the past 6 months?

\begin{tabular}{|lc|r|r|r|r|}
\hline & Frequency & Percent & Valid Percent & $\begin{array}{c}\text { Cumulative } \\
\text { Percent }\end{array}$ \\
\hline & Yes & 51 & 36.7 & 37.0 & 37.0 \\
Valid & No & 87 & 62.6 & 63.0 & 100.0 \\
& Total & 138 & 99.3 & 100.0 & \\
Missing & -99 & 1 & .7 & & \\
Total & & 139 & 100.0 & & \\
\hline
\end{tabular}

Q6d_Chalk_install_removed Do you think this should be removed?

\begin{tabular}{|ll|r|r|r|r|}
\hline & Frequency & Percent & Valid Percent & $\begin{array}{c}\text { Cumulative } \\
\text { Percent }\end{array}$ \\
\hline & No & 114 & 82.0 & 83.2 & 83.2 \\
Valid & Yes & 23 & 16.5 & 16.8 & 100.0 \\
& Total & 137 & 98.6 & 100.0 & \\
Missing & -99 & 2 & 1.4 & & \\
Total & & 139 & 100.0 & & \\
\hline
\end{tabular}


Q6d1_Chalk_install_communityinput Do you think that the surrounding community should have a say in whether or not it's removed or left alone?

\begin{tabular}{|c|c|c|c|c|c|}
\hline & & Frequency & Percent & Valid Percent & $\begin{array}{c}\text { Cumulative } \\
\text { Percent }\end{array}$ \\
\hline \multirow{3}{*}{ Valid } & $\begin{array}{l}\text { No (Community input is not } \\
\text { needed) }\end{array}$ & 16 & 11.5 & 69.6 & 69.6 \\
\hline & $\begin{array}{l}\text { Yes (Community input should } \\
\text { be received) }\end{array}$ & 7 & 5.0 & 30.4 & 100.0 \\
\hline & Total & 23 & 16.5 & 100.0 & \\
\hline Missing & System & 116 & 83.5 & & \\
\hline Total & & 139 & 100.0 & & \\
\hline
\end{tabular}

Q6d2_Chalk_install_tax Do you think that public tax money should be spent to pay for

\begin{tabular}{|c|c|c|c|c|c|}
\hline & & Frequency & Percent & Valid Percent & $\begin{array}{c}\text { Cumulative } \\
\text { Percent }\end{array}$ \\
\hline \multirow{3}{*}{ Valid } & No & 9 & 6.5 & 40.9 & 40.9 \\
\hline & Yes & 13 & 9.4 & 59.1 & 100.0 \\
\hline & Total & 22 & 15.8 & 100.0 & \\
\hline \multirow{3}{*}{ Missing } & -99 & 1 & .7 & & \\
\hline & System & 116 & 83.5 & & \\
\hline & Total & 117 & 84.2 & & \\
\hline Total & & 139 & 100.0 & & \\
\hline
\end{tabular}




\section{Q7: Installation - Yarn Free Space}

Q7_Yarn install_1_understand I understand the intended message

\begin{tabular}{|ll|r|r|r|r|}
\hline & & Frequency & Percent & Valid Percent & $\begin{array}{c}\text { Cumulative } \\
\text { Percent }\end{array}$ \\
\hline \multirow{2}{*}{ Strongly Disagree } & & 6 & 4.3 & 4.3 & 4.3 \\
& Disagree & 15 & 10.8 & 10.9 & 15.2 \\
& Neither Agree nor Disagree & 27 & 19.4 & 19.6 & 34.8 \\
Valid & Agree & 57 & 41.0 & 41.3 & 76.1 \\
& Strongly Agree & 33 & 23.7 & 23.9 & 100.0 \\
& Total & 138 & 99.3 & 100.0 & .7 \\
Missing & -99 & 1 & 139 & 100.0 & \\
Total & & & & \\
\hline
\end{tabular}

Q7_Yarn_install_2_damaged It damaged the surface

\begin{tabular}{|c|c|c|c|c|c|}
\hline & & Frequency & Percent & Valid Percent & $\begin{array}{c}\text { Cumulative } \\
\text { Percent }\end{array}$ \\
\hline \multirow{6}{*}{ Valid } & Strongly Disagree & 75 & 54.0 & 54.3 & 54.3 \\
\hline & Disagree & 49 & 35.3 & 35.5 & 89.9 \\
\hline & Neither Agree nor Disagree & 8 & 5.8 & 5.8 & 95.7 \\
\hline & Agree & 4 & 2.9 & 2.9 & 98.6 \\
\hline & Strongly Agree & 2 & 1.4 & 1.4 & 100.0 \\
\hline & Total & 138 & 99.3 & 100.0 & \\
\hline Missing & -99 & 1 & .7 & & \\
\hline Total & & 139 & 100.0 & & \\
\hline
\end{tabular}

Q7 Yarn install 3 imagination The person who did this used their imagination

\begin{tabular}{|ll|r|r|r|r|}
\hline & & Frequency & Percent & Valid Percent & $\begin{array}{c}\text { Cumulative } \\
\text { Percent }\end{array}$ \\
\hline \multirow{2}{*}{ Strongly Disagree } & & 2 & 1.4 & 1.4 & 1.4 \\
& Disagree & 4 & 2.9 & 2.9 & 4.3 \\
& Neither Agree nor Disagree & 11 & 7.9 & 8.0 & 12.3 \\
Valid & Agree & 69 & 49.6 & 50.0 & 62.3 \\
& Strongly Agree & 52 & 37.4 & 37.7 & 100.0 \\
& Total & 138 & 99.3 & 100.0 & .7 \\
Missing & -99 & 1 & 139 & & \\
Total & & & 100.0 & \\
\hline
\end{tabular}


Q7 Yarn install 4 offensive It is offensive

\begin{tabular}{|ll|r|r|r|r|}
\hline & & Frequency & Percent & Valid Percent & $\begin{array}{c}\text { Cumulative } \\
\text { Percent }\end{array}$ \\
\hline & Strongly Disagree & 76 & 54.7 & 55.5 & 55.5 \\
& Disagree & 46 & 33.1 & 33.6 & 89.1 \\
& Neither Agree nor Disagree & 12 & 8.6 & 8.8 & 97.8 \\
Valid & Agree & 1 & .7 & .7 & 98.5 \\
& Strongly Agree & 2 & 1.4 & 1.5 & 100.0 \\
& Total & 137 & 98.6 & 100.0 & \\
Missing & -99 & 2 & 1.4 & 100.0 & \\
Total & & 139 & & \\
\hline
\end{tabular}

Q7_Yarn install 5_gang It is gang related

\begin{tabular}{|c|c|c|c|c|c|}
\hline & & Frequency & Percent & Valid Percent & $\begin{array}{c}\text { Cumulative } \\
\text { Percent }\end{array}$ \\
\hline \multirow{5}{*}{ Valid } & Strongly Disagree & 84 & 60.4 & 60.9 & 60.9 \\
\hline & Disagree & 39 & 28.1 & 28.3 & 89.1 \\
\hline & Neither Agree nor Disagree & 13 & 9.4 & 9.4 & 98.6 \\
\hline & Strongly Agree & 2 & 1.4 & 1.4 & 100.0 \\
\hline & Total & 138 & 99.3 & 100.0 & \\
\hline Missing & -99 & 1 & .7 & & \\
\hline Total & & 139 & 100.0 & & \\
\hline
\end{tabular}

Q7_Yarn_install_6_crime It should be considered a crime

\begin{tabular}{|c|c|c|c|c|c|}
\hline & & Frequency & Percent & Valid Percent & $\begin{array}{c}\text { Cumulative } \\
\text { Percent }\end{array}$ \\
\hline \multirow{6}{*}{ Valid } & Strongly Disagree & 66 & 47.5 & 47.8 & 47.8 \\
\hline & Disagree & 41 & 29.5 & 29.7 & 77.5 \\
\hline & Neither Agree nor Disagree & 19 & 13.7 & 13.8 & 91.3 \\
\hline & Agree & 7 & 5.0 & 5.1 & 96.4 \\
\hline & Strongly Agree & 5 & 3.6 & 3.6 & 100.0 \\
\hline & Total & 138 & 99.3 & 100.0 & \\
\hline Missing & -99 & 1 & .7 & & \\
\hline Total & & 139 & 100.0 & & \\
\hline
\end{tabular}


Q7 Yarn install 7 interesting It makes the space more interesting

\begin{tabular}{|c|c|c|c|c|c|}
\hline & & Frequency & Percent & Valid Percent & $\begin{array}{c}\text { Cumulative } \\
\text { Percent }\end{array}$ \\
\hline \multirow{6}{*}{ Valid } & Strongly Disagree & 5 & 3.6 & 3.6 & 3.6 \\
\hline & Disagree & 10 & 7.2 & 7.2 & 10.9 \\
\hline & Neither Agree nor Disagree & 14 & 10.1 & 10.1 & 21.0 \\
\hline & Agree & 55 & 39.6 & 39.9 & 60.9 \\
\hline & Strongly Agree & 54 & 38.8 & 39.1 & 100.0 \\
\hline & Total & 138 & 99.3 & 100.0 & \\
\hline Missing & -99 & 1 & .7 & & \\
\hline Total & & 139 & 100.0 & & \\
\hline
\end{tabular}

Q7_Yarn install 8 dirty It makes the space look dirty

\begin{tabular}{|ll|r|r|r|r|}
\hline & Frequency & Percent & Valid Percent & $\begin{array}{c}\text { Cumulative } \\
\text { Percent }\end{array}$ \\
\hline \multirow{2}{*}{ Strongly Disagree } & 62 & 44.6 & 45.6 & 45.6 \\
& Disagree & 44 & 31.7 & 32.4 & 77.9 \\
& Neither Agree nor Disagree & 16 & 11.5 & 11.8 & 89.7 \\
Valid & Agree & 10 & 7.2 & 7.4 & 97.1 \\
& Strongly Agree & 4 & 2.9 & 2.9 & 100.0 \\
& Total & 136 & 97.8 & 100.0 & \\
Missing & -99 & 3 & 139 & 100.0 & \\
Total & & & & \\
\hline
\end{tabular}

Q7a_Yarn_install_beforeafter In general, was this space better before or after the street art/graffiti was put there?

\begin{tabular}{|ll|r|r|r|r|}
\hline & Frequency & Percent & Valid Percent & $\begin{array}{c}\text { Cumulative } \\
\text { Percent }\end{array}$ \\
\hline & Before & 29 & 20.9 & 21.6 & 21.6 \\
Valid & After & 105 & 75.5 & 78.4 & 100.0 \\
& Total & 134 & 96.4 & 100.0 & \\
Missing & -99 & 5 & 3.6 & & \\
Total & & 139 & 100.0 & & \\
\hline
\end{tabular}


Q7b_Yarn_install_1_yourproperty Would you be okay if someone placed something

like this - On your property

\begin{tabular}{|lc|r|r|r|r|}
\hline & Frequency & Percent & Valid Percent & $\begin{array}{c}\text { Cumulative } \\
\text { Percent }\end{array}$ \\
\hline & Yes & 65 & 46.8 & 47.8 & 47.8 \\
Valid & No & 71 & 51.1 & 52.2 & 100.0 \\
& Total & 136 & 97.8 & 100.0 & \\
Missing & -99 & 3 & 2.2 & & \\
Total & & 139 & 100.0 & & \\
\hline
\end{tabular}

Q7b_Yarn_install_2_neighborhood Would you be okay if someone placed something like this - In your neighborhood

\begin{tabular}{|lc|r|r|r|r|}
\hline & Frequency & Percent & Valid Percent & $\begin{array}{c}\text { Cumulative } \\
\text { Percent }\end{array}$ \\
\hline & Yes & 109 & 78.4 & 80.7 & 80.7 \\
Valid & No & 26 & 18.7 & 19.3 & 100.0 \\
& Total & 135 & 97.1 & 100.0 & \\
Missing & -99 & 4 & 2.9 & & \\
Total & & 139 & 100.0 & & \\
\hline
\end{tabular}

Q7b_Yarn_install_3_city Would you be okay if someone placed something like this -

Some other part of the city

\begin{tabular}{|ll|r|r|r|r|}
\hline & Frequency & Percent & Valid Percent & $\begin{array}{c}\text { Cumulative } \\
\text { Percent }\end{array}$ \\
\hline & Yes & 111 & 79.9 & 82.2 & 82.2 \\
Valid & No & 24 & 17.3 & 17.8 & 100.0 \\
& Total & 135 & 97.1 & 100.0 & \\
Missing & -99 & 4 & 2.9 & & \\
Total & & 139 & 100.0 & & \\
\hline
\end{tabular}


Q7c_Yarn_install_6months Have you seen something like this in the past 6 months?

\begin{tabular}{|lc|r|r|r|r|}
\hline & Frequency & Percent & Valid Percent & $\begin{array}{c}\text { Cumulative } \\
\text { Percent }\end{array}$ \\
\hline & Yes & 71 & 51.1 & 52.6 & 52.6 \\
Valid & No & 64 & 46.0 & 47.4 & 100.0 \\
& Total & 135 & 97.1 & 100.0 & \\
Missing & -99 & 4 & 2.9 & & \\
Total & & 139 & 100.0 & & \\
\hline
\end{tabular}

Q7d_Yarn_install_removed Do you think this should be removed?

\begin{tabular}{|ll|r|r|r|r|}
\hline & Frequency & Percent & Valid Percent & $\begin{array}{c}\text { Cumulative } \\
\text { Percent }\end{array}$ \\
\hline & No & 105 & 75.5 & 78.4 & 78.4 \\
Valid & Yes & 29 & 20.9 & 21.6 & 100.0 \\
& Total & 134 & 96.4 & 100.0 & \\
Missing & -99 & 5 & 3.6 & & \\
Total & & 139 & 100.0 & & \\
\hline
\end{tabular}

Q7d1_Yarn_install_communityinput Do you think that the surrounding community should have a say in whether or not it's removed or left alone?

\begin{tabular}{|ll|r|r|r|r|}
\hline & & Frequency & Percent & Valid Percent & $\begin{array}{c}\text { Cumulative } \\
\text { Percent }\end{array}$ \\
\hline & No (Community input is not & 16 & 11.5 & 55.2 & 55.2 \\
& needed) & & & \\
Valid $\quad$ Yes (Community input should & be received) & 13 & 9.4 & 100.0 \\
& Total & 29 & 20.9 & \\
& System & 110 & 79.1 & 100.0 & \\
Missing & & 139 & 100.0 & & \\
Total & & & & \\
\hline
\end{tabular}


Q7d2_Yarn_install_tax Do you think that public tax money should be spent to pay for

\begin{tabular}{|ll|r|r|r|r|}
\hline & & Frequency & Percent & Valid Percent & $\begin{array}{c}\text { Cumulative } \\
\text { Percent }\end{array}$ \\
\hline & No & 15 & 10.8 & 51.7 & 51.7 \\
Valid & Yes & 14 & 10.1 & 48.3 & 100.0 \\
& Total & 29 & 20.9 & 100.0 & \\
Missing & System & 110 & 79.1 & & \\
Total & & 139 & 100.0 & & \\
\hline
\end{tabular}

\section{Q8: Installation - Guerilla Garden}

Q8_Garden_install_1_understand I understand the intended message

\begin{tabular}{|l|r|r|r|r|}
\hline & Frequency & Percent & Valid Percent & $\begin{array}{c}\text { Cumulative } \\
\text { Percent }\end{array}$ \\
\hline \multirow{2}{*}{ Strongly Disagree } & 11 & 7.9 & 7.9 & 7.9 \\
Disagree & 24 & 17.3 & 17.3 & 25.2 \\
Valid & 21 & 15.1 & 15.1 & 40.3 \\
Neither Agree nor Disagree & 56 & 40.3 & 40.3 & 80.6 \\
Agree & 27 & 19.4 & 19.4 & 100.0 \\
Strongly Agree & 139 & 100.0 & 100.0 & \\
Total & & &
\end{tabular}

Q8_Garden install 2 damaged It damaged the surface

\begin{tabular}{|l|r|r|r|r|}
\hline & Frequency & Percent & Valid Percent & $\begin{array}{c}\text { Cumulative } \\
\text { Percent }\end{array}$ \\
\hline \multirow{2}{*}{ Strongly Disagree } & 48 & 34.5 & 34.5 & 34.5 \\
Disagree & 55 & 39.6 & 39.6 & 74.1 \\
Valid & 26 & 18.7 & 18.7 & 92.8 \\
Neither Agree nor Disagree & 8 & 5.8 & 5.8 & 98.6 \\
Agree & 2 & 1.4 & 1.4 & 100.0 \\
Strongly Agree & 139 & 100.0 & 100.0 & \\
Total & & &
\end{tabular}


Q8_Garden_install_3_imagination The person who did this used their imagination

\begin{tabular}{|c|c|c|c|c|c|}
\hline & & Frequency & Percent & Valid Percent & $\begin{array}{c}\text { Cumulative } \\
\text { Percent }\end{array}$ \\
\hline \multirow{6}{*}{ Valid } & Strongly Disagree & 1 & .7 & .7 & .7 \\
\hline & Disagree & 7 & 5.0 & 5.0 & 5.8 \\
\hline & Neither Agree nor Disagree & 25 & 18.0 & 18.0 & 23.7 \\
\hline & Agree & 72 & 51.8 & 51.8 & 75.5 \\
\hline & Strongly Agree & 34 & 24.5 & 24.5 & 100.0 \\
\hline & Total & 139 & 100.0 & 100.0 & \\
\hline
\end{tabular}

Q8 Garden install 4 offensive It is offensive

\begin{tabular}{|l|r|r|r|r|}
\hline & Frequency & Percent & Valid Percent & $\begin{array}{c}\text { Cumulative } \\
\text { Percent }\end{array}$ \\
\hline Strongly Disagree & 58 & 41.7 & 41.7 & 41.7 \\
Disagree & 50 & 36.0 & 36.0 & 77.7 \\
Neither Agree nor Disagree & 25 & 18.0 & 18.0 & 95.7 \\
Valid & 4 & 2.9 & 2.9 & 98.6 \\
Agree & 2 & 1.4 & 1.4 & 100.0 \\
Strongly Agree & 139 & 100.0 & 100.0 & \\
Total & & &
\end{tabular}


Q8_Garden_install_5_gang It is gang related

\begin{tabular}{|ll|r|r|r|r|}
\hline & & Frequency & Percent & Valid Percent & $\begin{array}{c}\text { Cumulative } \\
\text { Percent }\end{array}$ \\
\hline \multirow{2}{*}{} & Strongly Disagree & 84 & 60.4 & 60.9 & 60.9 \\
& Disagree & 40 & 28.8 & 29.0 & 89.9 \\
Valid & Neither Agree nor Disagree & 14 & 10.1 & 10.1 & 100.0 \\
& Total & 138 & 99.3 & 100.0 & .7 \\
Missing & -99 & 1 & 139 & 100.0 & \\
Total & & & & \\
\hline
\end{tabular}

Q8_Garden_install_6_crime It should be considered a crime

\begin{tabular}{|c|c|c|c|c|c|}
\hline & & Frequency & Percent & Valid Percent & $\begin{array}{c}\text { Cumulative } \\
\text { Percent }\end{array}$ \\
\hline \multirow{6}{*}{ Valid } & Strongly Disagree & 55 & 39.6 & 39.9 & 39.9 \\
\hline & Disagree & 45 & 32.4 & 32.6 & 72.5 \\
\hline & Neither Agree nor Disagree & 27 & 19.4 & 19.6 & 92.0 \\
\hline & Agree & 9 & 6.5 & 6.5 & 98.6 \\
\hline & Strongly Agree & 2 & 1.4 & 1.4 & 100.0 \\
\hline & Total & 138 & 99.3 & 100.0 & \\
\hline Missing & -99 & 1 & .7 & & \\
\hline Total & & 139 & 100.0 & & \\
\hline
\end{tabular}

Q8_Garden install 7 interesting It makes the space more interesting

\begin{tabular}{|ll|r|r|r|r|}
\hline & & Frequency & Percent & Valid Percent & $\begin{array}{c}\text { Cumulative } \\
\text { Percent }\end{array}$ \\
\hline \multirow{2}{*}{ Strongly Disagree } & 5 & 3.6 & 3.6 & 3.6 \\
& Disagree & 13 & 9.4 & 9.4 & 13.0 \\
& Neither Agree nor Disagree & 30 & 21.6 & 21.7 & 34.8 \\
Valid & Agree & 46 & 33.1 & 33.3 & 68.1 \\
& Strongly Agree & 44 & 31.7 & 31.9 & 100.0 \\
& Total & 138 & 99.3 & 100.0 & .7 \\
Missing & -99 & 1 & 139 & & \\
Total & & & 100.0 &
\end{tabular}


Q8_Garden install 8 dirty It makes the space look dirty

\begin{tabular}{|c|c|c|c|c|c|}
\hline & & Frequency & Percent & Valid Percent & $\begin{array}{c}\text { Cumulative } \\
\text { Percent }\end{array}$ \\
\hline \multirow{6}{*}{ Valid } & Strongly Disagree & 37 & 26.6 & 26.6 & 26.6 \\
\hline & Disagree & 37 & 26.6 & 26.6 & 53.2 \\
\hline & Neither Agree nor Disagree & 23 & 16.5 & 16.5 & 69.8 \\
\hline & Agree & 35 & 25.2 & 25.2 & 95.0 \\
\hline & Strongly Agree & 7 & 5.0 & 5.0 & 100.0 \\
\hline & Total & 139 & 100.0 & 100.0 & \\
\hline
\end{tabular}

Q8a_Garden_install_beforeafter In general, was this space better before or after the street art/graffiti was put there?

\begin{tabular}{|ll|r|r|r|r|}
\hline & Frequency & Percent & Valid Percent & $\begin{array}{c}\text { Cumulative } \\
\text { Percent }\end{array}$ \\
\hline & Before & 50 & 36.0 & 37.9 & 37.9 \\
Valid & After & 82 & 59.0 & 62.1 & 100.0 \\
& Total & 132 & 95.0 & 100.0 & \\
Missing & -99 & 7 & 5.0 & & \\
Total & & 139 & 100.0 & & \\
\hline
\end{tabular}

Q8b_Garden_install_1_yourproperty Would you be okay if someone placed

\begin{tabular}{|ll|r|r|r|r|}
\hline & & Something like this - On your property & \\
& & Frequency & Percent & Valid Percent & $\begin{array}{c}\text { Cumulative } \\
\text { Percent }\end{array}$ \\
\hline & Yes & 33 & 23.7 & 24.4 & 24.4 \\
Valid & No & 102 & 73.4 & 75.6 & 100.0 \\
& Total & 135 & 97.1 & 100.0 & \\
Missing & -99 & 4 & 2.9 & & \\
Total & & 139 & 100.0 & & \\
\hline
\end{tabular}


Q8b_Garden_install_2_neighborhood Would you be okay if someone placed something like this - In your neighborhood

\begin{tabular}{|lc|r|r|r|r|}
\hline & Frequency & Percent & Valid Percent & \multicolumn{2}{|c|}{$\begin{array}{c}\text { Cumulative } \\
\text { Percent }\end{array}$} \\
\hline & Yes & 92 & 66.2 & 67.6 & 67.6 \\
Valid & No & 44 & 31.7 & 32.4 & 100.0 \\
& Total & 136 & 97.8 & 100.0 & \\
Missing & -99 & 3 & 2.2 & & \\
Total & & 139 & 100.0 & & \\
\hline
\end{tabular}

Q8b_Garden_install_3_city Would you be okay if someone placed something like this - Some other part of the city

\begin{tabular}{|ll|r|r|r|r|}
\hline & Frequency & Percent & Valid Percent & $\begin{array}{c}\text { Cumulative } \\
\text { Percent }\end{array}$ \\
\hline & Yes & 104 & 74.8 & 76.5 & 76.5 \\
Valid & No & 32 & 23.0 & 23.5 & 100.0 \\
& Total & 136 & 97.8 & 100.0 & \\
Missing & -99 & 3 & 2.2 & & \\
Total & & 139 & 100.0 & & \\
\hline
\end{tabular}

Q8c_Garden_install_6months Have you seen something like this in the past 6 months?

\begin{tabular}{|ll|r|r|r|r|}
\hline & Frequency & Percent & Valid Percent & $\begin{array}{c}\text { Cumulative } \\
\text { Percent }\end{array}$ \\
\hline & Yes & 31 & 22.3 & 23.1 & 23.1 \\
Valid & No & 103 & 74.1 & 76.9 & 100.0 \\
& Total & 134 & 96.4 & 100.0 & \\
Missing & -99 & 5 & 3.6 & & \\
Total & & 139 & 100.0 & & \\
\hline
\end{tabular}


Q8d_Garden_install_removed Do you think this should be removed?

\begin{tabular}{|lc|r|r|r|r|}
\hline & Frequency & Percent & Valid Percent & \multicolumn{2}{|c|}{$\begin{array}{c}\text { Cumulative } \\
\text { Percent }\end{array}$} \\
\hline & No & 91 & 65.5 & 68.4 & 68.4 \\
Valid & Yes & 42 & 30.2 & 31.6 & 100.0 \\
& Total & 133 & 95.7 & 100.0 & \\
Missing & -99 & 6 & 4.3 & & \\
Total & & 139 & 100.0 & & \\
\hline
\end{tabular}

Q8d1_Garden_install_communityinput Do you think that the surrounding community should have a say in whether or not it's removed or left alone?

\begin{tabular}{|c|c|c|c|c|c|}
\hline & & Frequency & Percent & Valid Percent & $\begin{array}{c}\text { Cumulative } \\
\text { Percent }\end{array}$ \\
\hline \multirow{4}{*}{ Valid } & $\begin{array}{l}\text { No (Community input is not } \\
\text { needed) }\end{array}$ & 20 & 14.4 & 48.8 & 48.8 \\
\hline & $\begin{array}{l}\text { Yes (Community input should } \\
\text { be received) }\end{array}$ & 21 & 15.1 & 51.2 & 100.0 \\
\hline & Total & 41 & 29.5 & 100.0 & \\
\hline & -99 & 1 & .7 & & \\
\hline \multirow[t]{2}{*}{ Missing } & System & 97 & 69.8 & & \\
\hline & Total & 98 & 70.5 & & \\
\hline Total & & 139 & 100.0 & & \\
\hline
\end{tabular}

Q8d2_Garden_install_tax Do you think that public tax money should be spent to pay

\begin{tabular}{|ll|r|r|r|r|}
\hline & & for its removal? & \\
& & Frequency & Percent & Valid Percent & $\begin{array}{c}\text { Cumulative } \\
\text { Percent }\end{array}$ \\
\hline \multirow{3}{*}{ Valid } & No & 20 & 14.4 & 48.8 & 48.8 \\
& Yes & 21 & 15.1 & 51.2 & 100.0 \\
& Total & 41 & 29.5 & 100.0 & \\
Missing & System & 1 & .7 & & \\
& Total & 97 & 69.8 & & \\
Total & & 98 & 70.5 & & \\
\hline
\end{tabular}


VANDART_ORIG In general, do you view street art/graffiti as an act of vandalism or artistic expression?

\begin{tabular}{|ll|r|r|r|r|}
\hline & Frequency & Percent & Valid Percent & $\begin{array}{c}\text { Cumulative } \\
\text { Percent }\end{array}$ \\
\hline \multirow{2}{*}{ Valid } & Vandalism & 46 & 33.1 & 34.8 & 34.8 \\
& Artistic Expression & 64 & 46.0 & 48.5 & 83.3 \\
& Don't Know & 22 & 15.8 & 16.7 & 100.0 \\
& Total & 132 & 95.0 & 100.0 & \\
Missing & System & 6 & 4.3 & & \\
& Total & 1 & 7 & & \\
Total & & 139 & 100.0 & & \\
\hline
\end{tabular}

VANDART_CLEANED In general, do you view street art/graffiti as an act of vandalism or artistic expression?

\begin{tabular}{|c|c|c|c|c|c|}
\hline & & Frequency & Percent & Valid Percent & $\begin{array}{c}\text { Cumulative } \\
\text { Percent }\end{array}$ \\
\hline \multirow{5}{*}{ Valid } & Vandalism & 26 & 18.7 & 18.7 & 18.7 \\
\hline & Artistic Expression & 58 & 41.7 & 41.7 & 60.4 \\
\hline & Don't Know & 44 & 31.7 & 31.7 & 92.1 \\
\hline & Both (New Code) & 11 & 7.9 & 7.9 & 100.0 \\
\hline & Total & 139 & 100.0 & 100.0 & \\
\hline
\end{tabular}

HHMSTotal Including yourself, how many people live in your household?

\begin{tabular}{|r|r|r|r|r|}
\hline & Frequency & Percent & Valid Percent & \multicolumn{2}{c|}{$\begin{array}{c}\text { Cumulative } \\
\text { Percent }\end{array}$} \\
\hline & & & & 1.4 \\
1 & 2 & 1.4 & 20.1 & 21.6 \\
& 28 & 20.1 & 42.4 & 64.0 \\
& 59 & 42.4 & 18.7 & 82.7 \\
Valid & 26 & 18.7 & 15.1 & 97.8 \\
& 21 & 15.1 & 1.4 & 99.3 \\
& 2 & 1.4 & .7 & 100.0 \\
6 & 1 & .7 & 100.0 & \\
\hline
\end{tabular}


Descriptive Statistics: Household Members

\begin{tabular}{|c|c|c|c|c|c|}
\hline & $\mathrm{N}$ & Minimum & Maximum & Mean & Std. Deviation \\
\hline $\begin{array}{l}\text { Including yourself, how many } \\
\text { people live in your household? }\end{array}$ & 139 & -99 & 7 & .93 & 12.169 \\
\hline
\end{tabular}

CHILD How many children under the age of 18 live in your household?

\begin{tabular}{|ll|r|r|r|r|}
\hline & & Frequency & Percent & Valid Percent & $\begin{array}{c}\text { Cumulative } \\
\text { Percent }\end{array}$ \\
\hline \multirow{3}{*}{ Valid } & Number of children under 18: & 34 & 24.5 & 31.5 & 31.5 \\
& None & 74 & 53.2 & 68.5 & 100.0 \\
& Total & 108 & 77.7 & 100.0 & \\
\multirow{2}{*}{ Missing } & System & 1 & .7 & & \\
& Total & 30 & 21.6 & & \\
Total & & 31 & 22.3 & \\
\hline
\end{tabular}

CHILD_TEXT How many children under the age of 18 live in your household?

\begin{tabular}{|ll|r|r|r|r|}
\hline & Frequency & Percent & Valid Percent & $\begin{array}{c}\text { Cumulative } \\
\text { Percent }\end{array}$ \\
\hline & 1 & 17 & 12.2 & 53.1 & 53.1 \\
Valid & 2 & 14 & 10.1 & 43.8 & 96.9 \\
& 5 & 1 & .7 & 3.1 & 100.0 \\
& Total & 32 & 23.0 & 100.0 & \\
Missing & System & 107 & 77.0 & & \\
Total & & 139 & 100.0 & & \\
\hline
\end{tabular}

Descriptive Statistics: Children

\begin{tabular}{|l|r|r|r|r|r|}
\hline & $\mathrm{N}$ & Minimum & Maximum & Mean & Std. Deviation \\
\hline How many children under the & & & & & \\
age of 18 live in your & 32 & 1 & 5 & 1.56 & \\
household? & & & & & \\
Valid N (listwise) & 32 & & & & \\
\hline
\end{tabular}


RENT_OWN Do you currently own or rent your home?

\begin{tabular}{|ll|r|r|r|r|}
\hline & Frequency & Percent & Valid Percent & $\begin{array}{c}\text { Cumulative } \\
\text { Percent }\end{array}$ \\
\hline & Own & 65 & 46.8 & 47.4 & 47.4 \\
Valid & Rent & 72 & 51.8 & 52.6 & 100.0 \\
& Total & 137 & 98.6 & 100.0 & \\
Missing & System & 2 & 1.4 & & \\
Total & & 139 & 100.0 & & \\
\hline
\end{tabular}

TIME How long have you lived in your current neighborhood?

\begin{tabular}{|c|c|c|c|c|c|}
\hline & & Frequency & Percent & Valid Percent & $\begin{array}{c}\text { Cumulative } \\
\text { Percent }\end{array}$ \\
\hline \multirow{7}{*}{ Valid } & Less than a year & 20 & 14.4 & 14.6 & 14.6 \\
\hline & 1 to less than 3 years & 33 & 23.7 & 24.1 & 38.7 \\
\hline & 3 to less than 5 years & 26 & 18.7 & 19.0 & 57.7 \\
\hline & 5 to less than 10 years & 23 & 16.5 & 16.8 & 74.5 \\
\hline & 10 years or more & 33 & 23.7 & 24.1 & 98.5 \\
\hline & All my life & 2 & 1.4 & 1.5 & 100.0 \\
\hline & Total & 137 & 98.6 & 100.0 & \\
\hline Missing & System & 2 & 1.4 & & \\
\hline Total & & 139 & 100.0 & & \\
\hline
\end{tabular}

ZIP What is your home zip code?

\begin{tabular}{|r|r|r|r|r|}
\hline & Frequency & Percent & Valid Percent & \multicolumn{2}{c|}{$\begin{array}{c}\text { Cumulative } \\
\text { Percent }\end{array}$} \\
\hline 99 & 8 & 5.8 & 5.8 & 5.8 \\
97201 & 11 & 7.9 & 7.9 & 13.7 \\
97202 & 13 & 9.4 & 9.4 & 23.0 \\
97203 & 2 & 1.4 & 1.4 & 24.5 \\
97209 & 11 & 7.9 & 7.9 & 32.4 \\
97210 & 10 & 7.2 & 7.2 & 39.6 \\
97211 & 16 & 11.5 & 11.5 & 51.1 \\
97213 & 2 & 1.4 & 1.4 & 52.5 \\
97214 & 40 & 28.8 & 28.8 & 81.3
\end{tabular}




\begin{tabular}{|r|r|r|r|r|}
\hline 97215 & 1 & .7 & .7 & 82.0 \\
97217 & 11 & 7.9 & 7.9 & 89.9 \\
97219 & 1 & .7 & .7 & 90.6 \\
97227 & 8 & 5.8 & 5.8 & 96.4 \\
97232 & 3 & 2.2 & 2.2 & 98.6 \\
97239 & 1 & .7 & .7 & 99.3 \\
97266 & 1 & .7 & .7 & 100.0 \\
Total & 139 & 100.0 & 100.0 & \\
\hline
\end{tabular}

AGE Which of the following age groups are you in?

\begin{tabular}{|c|c|c|c|c|c|}
\hline & & Frequency & Percent & Valid Percent & $\begin{array}{c}\text { Cumulative } \\
\text { Percent }\end{array}$ \\
\hline \multirow{7}{*}{ Valid } & $18-24$ & 10 & 7.2 & 7.3 & 7.3 \\
\hline & $25-34$ & 60 & 43.2 & 43.8 & 51.1 \\
\hline & $35-44$ & 27 & 19.4 & 19.7 & 70.8 \\
\hline & $45-54$ & 17 & 12.2 & 12.4 & 83.2 \\
\hline & $55-64$ & 13 & 9.4 & 9.5 & 92.7 \\
\hline & $65-75$ & 10 & 7.2 & 7.3 & 100.0 \\
\hline & Total & 137 & 98.6 & 100.0 & \\
\hline Missing & System & 2 & 1.4 & & \\
\hline Total & & 139 & 100.0 & & \\
\hline
\end{tabular}

EDUCATION What is the highest level of education you have completed?

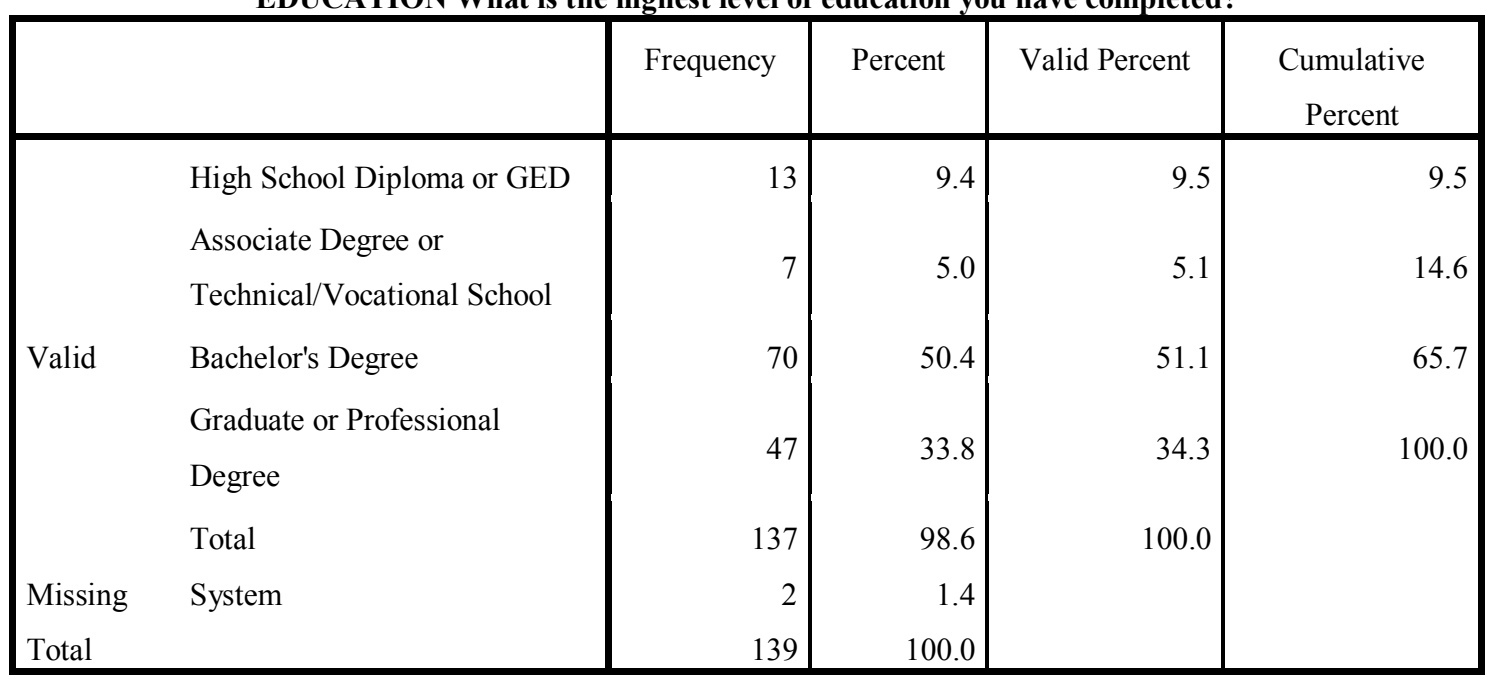


INCOME Finally, which category best describes your yearly total household income before taxes?

\begin{tabular}{|c|c|c|c|c|c|}
\hline & & Frequency & Percent & Valid Percent & $\begin{array}{c}\text { Cumulative } \\
\text { Percent }\end{array}$ \\
\hline \multirow{8}{*}{ Valid } & Less than $\$ 15,000$ & 8 & 5.8 & 6.2 & 6.2 \\
\hline & $\$ 15,000$ to less than $\$ 25,000$ & 16 & 11.5 & 12.4 & 18.6 \\
\hline & $\$ 25,000$ to less than $\$ 35,000$ & 14 & 10.1 & 10.9 & 29.5 \\
\hline & $\$ 35,000$ to less than $\$ 50,000$ & 22 & 15.8 & 17.1 & 46.5 \\
\hline & $\$ 50,000$ to less than $\$ 75,000$ & 28 & 20.1 & 21.7 & 68.2 \\
\hline & $\$ 75,000$ to less than $\$ 100,000$ & 16 & 11.5 & 12.4 & 80.6 \\
\hline & $\$ 100,000$ or more & 25 & 18.0 & 19.4 & 100.0 \\
\hline & Total & 129 & 92.8 & 100.0 & \\
\hline \multirow{3}{*}{ Missing } & -99 & 8 & 5.8 & & \\
\hline & System & 2 & 1.4 & & \\
\hline & Total & 10 & 7.2 & & \\
\hline Total & & 139 & 100.0 & & \\
\hline
\end{tabular}

COMMENTS Do you have any additional comments about this survey?

\begin{tabular}{|lc|r|r|r|r|}
\hline & Frequency & Percent & Valid Percent & $\begin{array}{c}\text { Cumulative } \\
\text { Percent }\end{array}$ \\
\hline & Yes & 64 & 46.0 & 49.6 & 49.6 \\
Valid & No & 65 & 46.8 & 50.4 & 100.0 \\
& Total & 129 & 92.8 & 100.0 & \\
Missing & -99 & 10 & 7.2 & & \\
Total & & 139 & 100.0 & & \\
\hline
\end{tabular}

DRAWING If you would like to be entered into the drawing please enter your contact e-mail address and/or phone number below.

\begin{tabular}{|c|c|c|c|c|c|}
\hline & & Frequency & Percent & Valid Percent & $\begin{array}{c}\text { Cumulative } \\
\text { Percent }\end{array}$ \\
\hline \multirow{4}{*}{ Valid } & Enter e-mail and/or phone & 112 & 80.6 & 84.2 & 84.2 \\
\hline & No thanks & 21 & 15.1 & 15.8 & 100.0 \\
\hline & Total & 133 & 95.7 & 100.0 & \\
\hline & -99 & 4 & 2.9 & & \\
\hline \multirow[t]{2}{*}{ Missing } & System & 2 & 1.4 & & \\
\hline & Total & 6 & 4.3 & & \\
\hline Total & & 139 & 100.0 & & \\
\hline
\end{tabular}




\section{Composite Scores}

Descriptive Statistics: Composite Scores

\begin{tabular}{|l|r|r|r|r|r|}
\hline & $\mathrm{N}$ & Minimum & Maximum & Mean & Std. Deviation \\
\hline Q1 Computed Score & 136 & 10 & 39 & 28.20 & 6.745 \\
Q2 Computed Score & 136 & 8 & 37 & 18.95 & 6.447 \\
Q3 Computed Score & 137 & 10 & 39 & 25.01 & 6.694 \\
Q4 Computed Score & 139 & 10 & 40 & 28.39 & 6.509 \\
Q5 Computed Score & 138 & 10 & 40 & 30.52 & 6.795 \\
Q6 Computed Score & 138 & 10 & 40 & 32.93 & 6.461 \\
Q7 Computed Score & 135 & 16 & 40 & 33.46 & 5.550 \\
Q8 Computed Score & 136 & 10 & 40 & 31.46 & 5.864 \\
Valid N (listwise) & 126 & & & \\
\hline
\end{tabular}

\section{Descriptive Statistics}

\begin{tabular}{|l|r|r|r|r|r|}
\hline \multicolumn{1}{|c|}{ Q1 Tag - Long Live Art in the Streets } \\
\hline $\begin{array}{l}\text { I understand the intended } \\
\text { message }\end{array}$ & 139 & Minimum & Maximum & Mean & Std. Deviation \\
\hline It damaged the surface & 139 & 1 & 5 & 4.38 & .871 \\
\hline $\begin{array}{l}\text { The person who did this } \\
\text { used their imagination }\end{array}$ & 139 & 1 & 5 & 3.38 & 1.218 \\
\hline It is offensive & 139 & 1 & 5 & 3.22 & 1.121 \\
\hline It is gang related & 139 & 1 & 5 & 2.17 & 1.183 \\
\hline It should be considered a \\
crime
\end{tabular}




\begin{tabular}{|l|r|r|r|r|r|}
\hline \multicolumn{1}{|c|}{ Q2 Tag - Fever Pole } & Minimum & Maximum & Mean & Std. Deviation \\
\hline $\begin{array}{l}\text { I understand the intended } \\
\text { message }\end{array}$ & 138 & 1 & 5 & 1.78 & .996 \\
\hline It damaged the surface & 139 & 1 & 5 & 3.70 & 1.177 \\
\hline $\begin{array}{l}\text { The person who did this } \\
\text { used their imagination }\end{array}$ & 139 & 1 & 5 & 2.27 & 1.120 \\
\hline It is offensive & 139 & 1 & 5 & 3.14 & 1.258 \\
\hline It is gang related & 139 & 1 & 5 & 3.08 & 1.029 \\
\hline It should be considered a \\
crime
\end{tabular}

\begin{tabular}{|l|r|r|r|r|r|}
\hline & $\mathrm{N}$ & Minimum & Maximum & Mean & Std. Deviation \\
\hline $\begin{array}{l}\text { I understand the intended } \\
\text { message }\end{array}$ & 137 & 1 & 5 & 2.85 & 1.115 \\
\hline It damaged the surface & 137 & 1 & 5 & 3.20 & 1.277 \\
\hline $\begin{array}{l}\text { The person who did this } \\
\text { used their imagination }\end{array}$ & 137 & 1 & 5 & 2.37 & 1.125 \\
\hline It is offensive & 137 & 1 & 5 & 2.62 & 1.164 \\
\hline It is gang related & 137 & 1 & 5 & 1.89 & .820 \\
\hline It should be considered a \\
crime
\end{tabular}




\section{Q4 Piece - Murg Wildstyle}

\begin{tabular}{|l|r|r|r|r|r|}
\hline & $\mathrm{N}$ & Minimum & Maximum & Mean & Std. Deviation \\
\hline $\begin{array}{l}\text { I understand the intended } \\
\text { message }\end{array}$ & 139 & 1 & 5 & 2.49 & 1.086 \\
\hline It damaged the surface & 139 & 1 & 5 & 2.78 & 1.341 \\
\hline $\begin{array}{l}\text { The person who did this } \\
\text { used their imagination }\end{array}$ & 139 & 1 & 5 & 4.39 & .665 \\
\hline It is offensive & 139 & 1 & 5 & 2.26 & 1.169 \\
\hline It is gang related & 139 & 1 & 5 & 2.40 & .937 \\
\hline It should be considered a \\
crime
\end{tabular}

\section{Q5 Piece - GATS Character}

\begin{tabular}{|c|c|c|c|c|c|}
\hline & $\mathrm{N}$ & Minimum & Maximum & Mean & Std. Deviation \\
\hline $\begin{array}{l}\text { I understand the intended } \\
\text { message }\end{array}$ & 139 & 1 & 5 & 2.88 & 1.117 \\
\hline It damaged the surface & 139 & 1 & 5 & 2.45 & 1.258 \\
\hline $\begin{array}{l}\text { The person who did this } \\
\text { used their imagination }\end{array}$ & 139 & 1 & 5 & 4.46 & .694 \\
\hline It is offensive & 139 & 1 & 5 & 1.92 & 1.064 \\
\hline It is gang related & 139 & 1 & 4 & 1.88 & .860 \\
\hline $\begin{array}{l}\text { It should be considered a } \\
\text { crime }\end{array}$ & 139 & 1 & 5 & 2.53 & 1.309 \\
\hline $\begin{array}{l}\text { It makes the space more } \\
\text { interesting }\end{array}$ & 139 & 1 & 5 & 4.11 & 1.159 \\
\hline It makes the space look dirty & 138 & 1 & 5 & 2.17 & 1.282 \\
\hline Valid N (listwise) & 138 & & & & \\
\hline
\end{tabular}


Q6 Installation - Community Chalk Box

\begin{tabular}{|c|c|c|c|c|c|}
\hline & $\mathrm{N}$ & Minimum & Maximum & Mean & Std. Deviation \\
\hline $\begin{array}{l}\text { I understand the intended } \\
\text { message }\end{array}$ & 139 & 1 & 5 & 3.73 & 1.209 \\
\hline It damaged the surface & 139 & 1 & 5 & 2.12 & 1.180 \\
\hline $\begin{array}{l}\text { The person who did this } \\
\text { used their imagination }\end{array}$ & 139 & 1 & 5 & 4.22 & .852 \\
\hline It is offensive & 139 & 1 & 5 & 1.66 & .864 \\
\hline It is gang related & 139 & 1 & 3 & 1.51 & .695 \\
\hline $\begin{array}{l}\text { It should be considered a } \\
\text { crime }\end{array}$ & 139 & 1 & 5 & 2.04 & 1.194 \\
\hline $\begin{array}{l}\text { It makes the space more } \\
\text { interesting }\end{array}$ & 139 & 1 & 5 & 4.15 & 1.076 \\
\hline It makes the space look dirty & 138 & 1 & 5 & 1.83 & 1.003 \\
\hline Valid N (listwise) & 138 & & & & \\
\hline
\end{tabular}

Q7 Installation - Yarn Free Space

\begin{tabular}{|c|c|c|c|c|c|}
\hline & $\mathrm{N}$ & Minimum & Maximum & Mean & Std. Deviation \\
\hline $\begin{array}{l}\text { I understand the intended } \\
\text { message }\end{array}$ & 138 & 1 & 5 & 3.70 & 1.085 \\
\hline It damaged the surface & 138 & 1 & 5 & 1.62 & .840 \\
\hline $\begin{array}{l}\text { The person who did this } \\
\text { used their imagination }\end{array}$ & 138 & 1 & 5 & 4.20 & .818 \\
\hline It is offensive & 137 & 1 & 5 & 1.59 & .800 \\
\hline It is gang related & 138 & 1 & 5 & 1.53 & .785 \\
\hline $\begin{array}{l}\text { It should be considered a } \\
\text { crime }\end{array}$ & 138 & 1 & 5 & 1.87 & 1.066 \\
\hline $\begin{array}{l}\text { It makes the space more } \\
\text { interesting }\end{array}$ & 138 & 1 & 5 & 4.04 & 1.056 \\
\hline It makes the space look dirty & 136 & 1 & 5 & 1.90 & 1.063 \\
\hline Valid N (listwise) & 135 & & & & \\
\hline
\end{tabular}


Q8 Installation - Guerilla Garden

\begin{tabular}{|c|c|c|c|c|c|}
\hline & $\mathrm{N}$ & Minimum & Maximum & Mean & Std. Deviation \\
\hline $\begin{array}{l}\text { I understand the intended } \\
\text { message }\end{array}$ & 139 & 1 & 5 & 3.46 & 1.211 \\
\hline It damaged the surface & 139 & 1 & 5 & 2.00 & .948 \\
\hline $\begin{array}{l}\text { The person who did this } \\
\text { used their imagination }\end{array}$ & 139 & 1 & 5 & 3.94 & .832 \\
\hline It is offensive & 139 & 1 & 5 & 1.86 & .910 \\
\hline It is gang related & 138 & 1 & 3 & 1.49 & .675 \\
\hline $\begin{array}{l}\text { It should be considered a } \\
\text { crime }\end{array}$ & 138 & 1 & 5 & 1.97 & .996 \\
\hline $\begin{array}{l}\text { It makes the space more } \\
\text { interesting }\end{array}$ & 138 & 1 & 5 & 3.80 & 1.100 \\
\hline $\begin{array}{l}\text { It makes the space look } \\
\text { dirty }\end{array}$ & 139 & 1 & 5 & 2.55 & 1.264 \\
\hline Valid N (listwise) & 136 & & & & \\
\hline
\end{tabular}

\section{T-Test: No Children/Children}

Group Statistics

\begin{tabular}{|c|c|c|c|c|c|}
\hline & [Do you have children?] & $\mathrm{N}$ & Mean & Std. Deviation & Std. Error Mean \\
\hline \multirow{2}{*}{ Q1 Computed Score } & No Children & 102 & 28.40 & 7.084 & .701 \\
\hline & Have Children & 31 & 27.06 & 5.615 & 1.008 \\
\hline \multirow{2}{*}{ Q2 Computed Score } & No Children & 102 & 18.95 & 6.559 & .649 \\
\hline & Have Children & 31 & 18.19 & 5.776 & 1.037 \\
\hline \multirow{2}{*}{ Q3 Computed Score } & No Children & 102 & 25.24 & 6.854 & .679 \\
\hline & Have Children & 32 & 23.75 & 6.196 & 1.095 \\
\hline \multirow{2}{*}{ Q4 Computed Score } & No Children & 104 & 28.77 & 6.740 & .661 \\
\hline & Have Children & 32 & 26.72 & 5.526 & .977 \\
\hline \multirow{2}{*}{ Q5 Computed Score } & No Children & 104 & 30.81 & 7.167 & .703 \\
\hline & Have Children & 31 & 29.00 & 5.279 & .948 \\
\hline \multirow{2}{*}{ Q6 Computed Score } & No Children & 103 & 33.12 & 6.543 & .645 \\
\hline & Have Children & 32 & 31.91 & 6.291 & 1.112 \\
\hline
\end{tabular}




\begin{tabular}{|l|l|r|r|r|r|}
\hline \multirow{2}{*}{ Q7 Computed Score } & No Children & 100 & 33.67 & 5.664 & .566 \\
\cline { 2 - 6 } & Have Children & 32 & 32.44 & 5.162 & .912 \\
\hline \multirow{3}{*}{ Q8 Computed Score } & No Children & 103 & 31.47 & 6.100 & .601 \\
\cline { 2 - 6 } & Have Children & 30 & 31.33 & 5.061 & .924 \\
\hline
\end{tabular}

Independent Samples Test

\begin{tabular}{|c|c|c|c|c|c|}
\hline & & \multicolumn{2}{|c|}{$\begin{array}{l}\text { Levene's Test for Equality of } \\
\text { Variances }\end{array}$} & \multicolumn{2}{|c|}{$\begin{array}{l}\text { t-test for Equality of } \\
\text { Means }\end{array}$} \\
\hline & & $\mathrm{F}$ & Sig. & $\mathrm{t}$ & df \\
\hline \multirow[b]{2}{*}{ Q1 Computed Score } & Equal variances assumed & 2.432 & .121 & .962 & 131 \\
\hline & $\begin{array}{l}\text { Equal variances not } \\
\text { assumed }\end{array}$ & & & 1.089 & 61.752 \\
\hline \multirow[b]{2}{*}{ Q2 Computed Score } & Equal variances assumed & .178 & .673 & .578 & 131 \\
\hline & $\begin{array}{l}\text { Equal variances not } \\
\text { assumed }\end{array}$ & & & .619 & 55.585 \\
\hline \multirow[b]{2}{*}{ Q3 Computed Score } & Equal variances assumed & .219 & .640 & 1.093 & 132 \\
\hline & $\begin{array}{l}\text { Equal variances not } \\
\text { assumed }\end{array}$ & & & 1.153 & 56.801 \\
\hline \multirow[b]{2}{*}{ Q4 Computed Score } & Equal variances assumed & 1.187 & .278 & 1.566 & 134 \\
\hline & $\begin{array}{l}\text { Equal variances not } \\
\text { assumed }\end{array}$ & & & 1.739 & 61.969 \\
\hline \multirow[b]{2}{*}{ Q5 Computed Score } & Equal variances assumed & 4.362 & .039 & 1.302 & 133 \\
\hline & $\begin{array}{l}\text { Equal variances not } \\
\text { assumed }\end{array}$ & & & 1.532 & 66.198 \\
\hline \multirow[b]{2}{*}{ Q6 Computed Score } & Equal variances assumed & .283 & .596 & .922 & 133 \\
\hline & $\begin{array}{l}\text { Equal variances not } \\
\text { assumed }\end{array}$ & & & .942 & 53.503 \\
\hline \multirow[b]{2}{*}{ Q7 Computed Score } & Equal variances assumed & 1.308 & .255 & 1.094 & 130 \\
\hline & $\begin{array}{l}\text { Equal variances not } \\
\text { assumed }\end{array}$ & & & 1.148 & 56.852 \\
\hline
\end{tabular}




\begin{tabular}{|l|l|r|r|r|r|}
\hline \multirow{2}{*}{ Q8 Computed Score } & Equal variances assumed & 2.224 & .138 & .109 & 131 \\
\cline { 2 - 6 } & $\begin{array}{l}\text { Equal variances not } \\
\text { assumed }\end{array}$ & & & .120 & 55.895 \\
\hline
\end{tabular}

Independent Samples Test

\begin{tabular}{|c|c|c|c|c|}
\hline & & \multicolumn{3}{|c|}{ t-test for Equality of Means } \\
\hline & & Sig. (2-tailed) & Mean Difference & $\begin{array}{l}\text { Std. Error } \\
\text { Difference }\end{array}$ \\
\hline \multirow{2}{*}{ Q1 Computed Score } & Equal variances assumed & .338 & 1.337 & 1.390 \\
\hline & Equal variances not assumed & .281 & 1.337 & 1.228 \\
\hline \multirow{2}{*}{ Q2 Computed Score } & Equal variances assumed & .564 & .757 & 1.310 \\
\hline & Equal variances not assumed & .539 & .757 & 1.224 \\
\hline \multirow{2}{*}{ Q3 Computed Score } & Equal variances assumed & .276 & 1.485 & 1.359 \\
\hline & Equal variances not assumed & .254 & 1.485 & 1.288 \\
\hline \multirow{2}{*}{ Q4 Computed Score } & Equal variances assumed & .120 & 2.050 & 1.310 \\
\hline & Equal variances not assumed & .087 & 2.050 & 1.179 \\
\hline \multirow{2}{*}{ Q5 Computed Score } & Equal variances assumed & .195 & 1.808 & 1.389 \\
\hline & Equal variances not assumed & .130 & 1.808 & 1.180 \\
\hline \multirow{2}{*}{ Q6 Computed Score } & Equal variances assumed & .358 & 1.210 & 1.312 \\
\hline & Equal variances not assumed & .351 & 1.210 & 1.285 \\
\hline \multirow{2}{*}{ Q7 Computed Score } & Equal variances assumed & .276 & 1.233 & 1.127 \\
\hline & Equal variances not assumed & .256 & 1.233 & 1.074 \\
\hline \multirow{2}{*}{ Q8 Computed Score } & Equal variances assumed & .914 & .133 & 1.221 \\
\hline & Equal variances not assumed & .905 & .133 & 1.102 \\
\hline
\end{tabular}

Independent Samples Test

\begin{tabular}{|l|l|r|r|}
\hline \multicolumn{2}{|c|}{ Independent Samples Test } \\
\cline { 3 - 4 } & & \multicolumn{2}{c|}{ t-test for Equality of Means } \\
\cline { 2 - 4 } & & Lower & \multicolumn{2}{c|}{ Upper } \\
\cline { 2 - 4 } & Equal variances assumed & -1.412 & 4.087 \\
\cline { 2 - 4 } & Equal variances not assumed & -1.118 & 3.793 \\
\hline \multirow{3}{*}{ Q1 Computed Score } & Equal variances assumed & -1.834 & 3.349 \\
\cline { 2 - 4 } & Equal variances not assumed & -1.695 & 3.210 \\
\hline \multirow{3}{*}{ Q3 Computed Score } & Equal variances assumed & -1.202 & 4.173 \\
\cline { 2 - 4 } & Equal variances not assumed & -1.095 & 4.066 \\
\hline \multirow{2}{*}{ Q4 Computed Score } & Equal variances assumed & -.540 & 4.641 \\
\hline
\end{tabular}




\begin{tabular}{|l|l|r|r|}
\hline & Equal variances not assumed & -.307 & 4.408 \\
\hline \multirow{3}{*}{ Q5 Computed Score } & Equal variances assumed & -.939 & 4.555 \\
\cline { 2 - 4 } & Equal variances not assumed & -.548 & 4.164 \\
\hline \multirow{3}{*}{ Q6 Computed Score } & Equal variances assumed & -1.386 & 3.806 \\
\cline { 2 - 4 } & Equal variances not assumed & -1.367 & 3.788 \\
\hline \multirow{3}{*}{ Q7 Computed Score } & Equal variances assumed & -.997 & 3.462 \\
\cline { 2 - 4 } & Equal variances not assumed & -.918 & 3.383 \\
\hline \multirow{3}{*}{ Q8 Computed Score } & Equal variances assumed & -2.283 & 2.548 \\
\cline { 2 - 4 } & Equal variances not assumed & -2.075 & 2.341 \\
\hline
\end{tabular}

\section{T-Test - Own/Rent}

Group Statistics

\begin{tabular}{|c|c|c|c|c|c|}
\hline & $\begin{array}{l}\text { Do you currently own or rent } \\
\text { your home? }\end{array}$ & $\mathrm{N}$ & Mean & Std. Deviation & Std. Error Mean \\
\hline \multirow{2}{*}{ Q1 Computed Score } & Own & 63 & 26.60 & 6.226 & .784 \\
\hline & Rent & 71 & 29.51 & 6.990 & .830 \\
\hline \multirow{2}{*}{ Q2 Computed Score } & Own & 63 & 16.65 & 5.374 & .677 \\
\hline & Rent & 71 & 20.80 & 6.652 & .789 \\
\hline \multirow{2}{*}{ Q3 Computed Score } & Own & 65 & 22.86 & 5.863 & .727 \\
\hline & Rent & 70 & 26.83 & 6.899 & .825 \\
\hline \multirow{2}{*}{ Q4 Computed Score } & Own & 65 & 26.54 & 5.674 & .704 \\
\hline & Rent & 72 & 29.97 & 6.842 & .806 \\
\hline \multirow{2}{*}{ Q5 Computed Score } & Own & 64 & 28.66 & 5.963 & .745 \\
\hline & Rent & 72 & 32.03 & 7.142 & .842 \\
\hline \multirow[b]{2}{*}{ Q6 Computed Score } & Own & 64 & 31.44 & 5.757 & .720 \\
\hline & Rent & 72 & 34.15 & 6.848 & .807 \\
\hline \multirow{2}{*}{ Q7 Computed Score } & Own & 64 & 33.03 & 5.036 & .630 \\
\hline & Rent & 69 & 33.78 & 6.022 & .725 \\
\hline \multirow[b]{2}{*}{ Q8 Computed Score } & Own & 62 & 30.50 & 5.914 & .751 \\
\hline & Rent & 72 & 32.36 & 5.769 & .680 \\
\hline
\end{tabular}

Independent Samples Test

\begin{tabular}{|c|c|c|c|c|c|}
\hline & & \multicolumn{2}{|c|}{$\begin{array}{c}\text { Levene's Test for Equality of } \\
\text { Variances }\end{array}$} & \multicolumn{2}{|c|}{$\begin{array}{l}\text { t-test for Equality of } \\
\text { Means }\end{array}$} \\
\hline & & $\mathrm{F}$ & Sig. & $\mathrm{t}$ & df \\
\hline Q1 Computed Score & Equal variances assumed & .184 & .669 & -2.526 & 132 \\
\hline
\end{tabular}




\begin{tabular}{|c|c|c|c|c|c|}
\hline & $\begin{array}{l}\text { Equal variances not } \\
\text { assumed }\end{array}$ & & & -2.544 & 131.997 \\
\hline \multirow[b]{2}{*}{ Q2 Computed Score } & Equal variances assumed & 1.542 & .217 & -3.942 & 132 \\
\hline & $\begin{array}{l}\text { Equal variances not } \\
\text { assumed }\end{array}$ & & & -3.992 & 130.893 \\
\hline \multirow[b]{2}{*}{ Q3 Computed Score } & Equal variances assumed & .873 & .352 & -3.587 & 133 \\
\hline & $\begin{array}{l}\text { Equal variances not } \\
\text { assumed }\end{array}$ & & & -3.608 & 131.990 \\
\hline \multirow[b]{2}{*}{ Q4 Computed Score } & Equal variances assumed & 2.579 & .111 & -3.178 & 135 \\
\hline & $\begin{array}{l}\text { Equal variances not } \\
\text { assumed }\end{array}$ & & & -3.208 & 134.064 \\
\hline \multirow[b]{2}{*}{ Q5 Computed Score } & Equal variances assumed & 2.680 & .104 & -2.967 & 134 \\
\hline & $\begin{array}{l}\text { Equal variances not } \\
\text { assumed }\end{array}$ & & & -2.999 & 133.498 \\
\hline \multirow[b]{2}{*}{ Q6 Computed Score } & Equal variances assumed & 2.563 & .112 & -2.486 & 134 \\
\hline & $\begin{array}{l}\text { Equal variances not } \\
\text { assumed }\end{array}$ & & & -2.511 & 133.602 \\
\hline \multirow[b]{2}{*}{ Q7 Computed Score } & Equal variances assumed & 5.094 & .026 & -.777 & 131 \\
\hline & $\begin{array}{l}\text { Equal variances not } \\
\text { assumed } \\
\end{array}$ & & & -.783 & 129.649 \\
\hline \multirow[b]{2}{*}{ Q8 Computed Score } & Equal variances assumed & .001 & .977 & -1.841 & 132 \\
\hline & $\begin{array}{l}\text { Equal variances not } \\
\text { assumed }\end{array}$ & & & -1.837 & 128.051 \\
\hline
\end{tabular}

Independent Samples Test

\begin{tabular}{|c|c|c|c|c|}
\hline & & \multicolumn{3}{|c|}{ t-test for Equality of Means } \\
\hline & & Sig. (2-tailed) & Mean Difference & $\begin{array}{l}\text { Std. Error } \\
\text { Difference }\end{array}$ \\
\hline \multirow{2}{*}{ Q1 Computed Score } & Equal variances assumed & .013 & -2.904 & 1.150 \\
\hline & Equal variances not assumed & .012 & -2.904 & 1.142 \\
\hline \multirow{2}{*}{ Q2 Computed Score } & Equal variances assumed & .000 & -4.152 & 1.053 \\
\hline & Equal variances not assumed & .000 & -4.152 & 1.040 \\
\hline \multirow{2}{*}{ Q3 Computed Score } & Equal variances assumed & .000 & -3.967 & 1.106 \\
\hline & Equal variances not assumed & .000 & -3.967 & 1.099 \\
\hline \multirow{2}{*}{ Q4 Computed Score } & Equal variances assumed & .002 & -3.434 & 1.081 \\
\hline & Equal variances not assumed & .002 & -3.434 & 1.070 \\
\hline Q5 Computed Score & Equal variances assumed & .004 & -3.372 & 1.136 \\
\hline
\end{tabular}




\begin{tabular}{|l|l|r|r|r|}
\hline & Equal variances not assumed & .003 & -3.372 & 1.124 \\
\hline \multirow{3}{*}{ Q6 Computed Score } & Equal variances assumed & .014 & -2.715 & 1.092 \\
\cline { 2 - 5 } & Equal variances not assumed & .013 & -2.715 & 1.081 \\
\hline \multirow{3}{*}{ Q7 Computed Score } & Equal variances assumed & .438 & -.751 & .967 \\
\cline { 2 - 5 } & Equal variances not assumed & .435 & -.751 & .960 \\
\hline \multirow{3}{*}{ Q8 Computed Score } & Equal variances assumed & .068 & -1.861 & 1.011 \\
\cline { 2 - 5 } & Equal variances not assumed & .069 & -1.861 & 1.013 \\
\hline
\end{tabular}

\begin{tabular}{|c|c|c|c|}
\hline & & \multicolumn{2}{|c|}{ t-test for Equality of Means } \\
\hline & & \multicolumn{2}{|c|}{$95 \%$ Confidence Interval of the Difference } \\
\hline & & Lower & Upper \\
\hline \multirow{2}{*}{ Q1 Computed Score } & Equal variances assumed & -5.178 & -.630 \\
\hline & Equal variances not assumed & -5.162 & -.646 \\
\hline \multirow{2}{*}{ Q2 Computed Score } & Equal variances assumed & -6.235 & -2.069 \\
\hline & Equal variances not assumed & -6.209 & -2.095 \\
\hline \multirow{2}{*}{ Q3 Computed Score } & Equal variances assumed & -6.155 & -1.779 \\
\hline & Equal variances not assumed & -6.142 & -1.792 \\
\hline \multirow{2}{*}{ Q4 Computed Score } & Equal variances assumed & -5.571 & -1.297 \\
\hline & Equal variances not assumed & -5.551 & -1.317 \\
\hline \multirow{2}{*}{ Q5 Computed Score } & Equal variances assumed & -5.619 & -1.124 \\
\hline & Equal variances not assumed & -5.595 & -1.148 \\
\hline \multirow{2}{*}{ Q6 Computed Score } & Equal variances assumed & -4.876 & -.555 \\
\hline & Equal variances not assumed & -4.854 & -.577 \\
\hline \multirow{2}{*}{ Q7 Computed Score } & Equal variances assumed & -2.663 & 1.161 \\
\hline & Equal variances not assumed & -2.651 & 1.148 \\
\hline \multirow{2}{*}{ Q8 Computed Score } & Equal variances assumed & -3.861 & .139 \\
\hline & Equal variances not assumed & -3.866 & .143 \\
\hline
\end{tabular}




\section{Frequencies - Years Lived In Neighborhood}

TIME How long have you lived in your current neighborhood?

\begin{tabular}{|c|c|c|c|c|c|}
\hline & & Frequency & Percent & Valid Percent & $\begin{array}{c}\text { Cumulative } \\
\text { Percent }\end{array}$ \\
\hline \multirow{7}{*}{ Valid } & Less than a year & 20 & 14.4 & 14.6 & 14.6 \\
\hline & 1 to less than 3 years & 33 & 23.7 & 24.1 & 38.7 \\
\hline & 3 to less than 5 years & 26 & 18.7 & 19.0 & 57.7 \\
\hline & 5 to less than 10 years & 23 & 16.5 & 16.8 & 74.5 \\
\hline & 10 years or more & 33 & 23.7 & 24.1 & 98.5 \\
\hline & All my life & 2 & 1.4 & 1.5 & 100.0 \\
\hline & Total & 137 & 98.6 & 100.0 & \\
\hline Missing & System & 2 & 1.4 & & \\
\hline \multicolumn{2}{|l|}{ Total } & 139 & 100.0 & & \\
\hline
\end{tabular}

\section{T-Test}

\section{Group Statistics}

\begin{tabular}{|c|c|c|c|c|c|}
\hline & $\begin{array}{l}\text { [How long have they lived } \\
\text { there?] }\end{array}$ & $\mathrm{N}$ & Mean & Std. Deviation & $\begin{array}{l}\text { Std. Error } \\
\text { Mean }\end{array}$ \\
\hline \multirow{2}{*}{ Q1 Computed Score } & $\begin{array}{l}\text { Less Than } 5 \text { Years in } \\
\text { Neighborhood }\end{array}$ & 77 & 29.92 & 6.287 & .716 \\
\hline & $\begin{array}{l}\text { More Than } 5 \text { Years in } \\
\text { Neighborhood }\end{array}$ & 57 & 25.74 & 6.718 & .890 \\
\hline \multirow{2}{*}{ Q2 Computed Score } & $\begin{array}{l}\text { Less Than } 5 \text { Years in } \\
\text { Neighborhood }\end{array}$ & 78 & 20.10 & 6.724 & .761 \\
\hline & $\begin{array}{l}\text { More Than } 5 \text { Years in } \\
\text { Neighborhood }\end{array}$ & 56 & 17.11 & 5.542 & .741 \\
\hline \multirow{2}{*}{ Q3 Computed Score } & $\begin{array}{l}\text { Less Than } 5 \text { Years in } \\
\text { Neighborhood }\end{array}$ & 77 & 26.40 & 6.701 & .764 \\
\hline & $\begin{array}{l}\text { More Than } 5 \text { Years in } \\
\text { Neighborhood }\end{array}$ & 58 & 22.95 & 6.222 & .817 \\
\hline \multirow{2}{*}{ Q4 Computed Score } & $\begin{array}{l}\text { Less Than } 5 \text { Years in } \\
\text { Neighborhood }\end{array}$ & 79 & 30.23 & 5.691 & .640 \\
\hline & $\begin{array}{l}\text { More Than } 5 \text { Years in } \\
\text { Neighborhood }\end{array}$ & 58 & 25.78 & 6.751 & .886 \\
\hline
\end{tabular}




\begin{tabular}{|c|c|c|c|c|c|}
\hline \multirow{2}{*}{ Q5 Computed Score } & $\begin{array}{l}\text { Less Than } 5 \text { Years in } \\
\text { Neighborhood }\end{array}$ & 79 & 32.20 & 6.254 & .704 \\
\hline & $\begin{array}{l}\text { More Than } 5 \text { Years in } \\
\text { Neighborhood } \\
\end{array}$ & 57 & 28.00 & 6.830 & .905 \\
\hline \multirow{2}{*}{ Q6 Computed Score } & $\begin{array}{l}\text { Less Than } 5 \text { Years in } \\
\text { Neighborhood }\end{array}$ & 79 & 34.58 & 5.504 & .619 \\
\hline & $\begin{array}{l}\text { More Than } 5 \text { Years in } \\
\text { Neighborhood }\end{array}$ & 57 & 30.51 & 7.013 & .929 \\
\hline \multirow{2}{*}{ Q7 Computed Score } & $\begin{array}{l}\text { Less Than } 5 \text { Years in } \\
\text { Neighborhood }\end{array}$ & 76 & 34.86 & 4.752 & .545 \\
\hline & $\begin{array}{l}\text { More Than } 5 \text { Years in } \\
\text { Neighborhood } \\
\end{array}$ & 57 & 31.51 & 6.012 & .796 \\
\hline \multirow{2}{*}{ Q8 Computed Score } & $\begin{array}{l}\text { Less Than } 5 \text { Years in } \\
\text { Neighborhood } \\
\end{array}$ & 78 & 32.60 & 5.609 & .635 \\
\hline & $\begin{array}{l}\text { More Than } 5 \text { Years in } \\
\text { Neighborhood }\end{array}$ & 56 & 29.96 & 5.973 & .798 \\
\hline
\end{tabular}

Independent Samples Test

\begin{tabular}{|c|c|c|c|c|c|}
\hline & & \multicolumn{2}{|c|}{$\begin{array}{c}\text { Levene's Test for Equality of } \\
\text { Variances }\end{array}$} & \multicolumn{2}{|c|}{$\begin{array}{c}\text { t-test for Equality of } \\
\text { Means } \\
\end{array}$} \\
\hline & & $\mathrm{F}$ & Sig. & $\mathrm{t}$ & $\mathrm{df}$ \\
\hline \multirow{2}{*}{$\begin{array}{l}\text { Q1 Computed } \\
\text { Score }\end{array}$} & $\begin{array}{l}\text { Equal variances } \\
\text { assumed } \\
\end{array}$ & .258 & .612 & 3.700 & 132 \\
\hline & $\begin{array}{l}\text { Equal variances not } \\
\text { assumed }\end{array}$ & & & 3.664 & 116.170 \\
\hline \multirow{2}{*}{$\begin{array}{l}\text { Q2 Computed } \\
\text { Score }\end{array}$} & $\begin{array}{l}\text { Equal variances } \\
\text { assumed } \\
\end{array}$ & .651 & .421 & 2.733 & 132 \\
\hline & $\begin{array}{l}\text { Equal variances not } \\
\text { assumed }\end{array}$ & & & 2.820 & 129.425 \\
\hline \multirow{2}{*}{$\begin{array}{l}\text { Q3 Computed } \\
\text { Score }\end{array}$} & $\begin{array}{l}\text { Equal variances } \\
\text { assumed }\end{array}$ & .481 & .489 & 3.057 & 133 \\
\hline & $\begin{array}{l}\text { Equal variances not } \\
\text { assumed }\end{array}$ & & & 3.089 & 127.253 \\
\hline \multirow{2}{*}{$\begin{array}{l}\text { Q4 Computed } \\
\text { Score }\end{array}$} & $\begin{array}{l}\text { Equal variances } \\
\text { assumed }\end{array}$ & 1.289 & .258 & 4.179 & 135 \\
\hline & $\begin{array}{l}\text { Equal variances not } \\
\text { assumed }\end{array}$ & & & 4.071 & 110.084 \\
\hline
\end{tabular}




\begin{tabular}{|c|c|c|c|c|c|}
\hline \multirow{2}{*}{$\begin{array}{l}\text { Q5 Computed } \\
\text { Score }\end{array}$} & $\begin{array}{l}\text { Equal variances } \\
\text { assumed }\end{array}$ & .219 & .640 & 3.720 & 134 \\
\hline & $\begin{array}{l}\text { Equal variances not } \\
\text { assumed }\end{array}$ & & & 3.667 & 114.239 \\
\hline \multirow{2}{*}{$\begin{array}{l}\text { Q6 Computed } \\
\text { Score }\end{array}$} & $\begin{array}{l}\text { Equal variances } \\
\text { assumed }\end{array}$ & 1.162 & .283 & 3.793 & 134 \\
\hline & $\begin{array}{l}\text { Equal variances not } \\
\text { assumed }\end{array}$ & & & 3.649 & 102.330 \\
\hline \multirow{2}{*}{$\begin{array}{l}\text { Q7 Computed } \\
\text { Score }\end{array}$} & $\begin{array}{l}\text { Equal variances } \\
\text { assumed }\end{array}$ & .683 & .410 & 3.585 & 131 \\
\hline & $\begin{array}{l}\text { Equal variances not } \\
\text { assumed }\end{array}$ & & & 3.468 & 103.757 \\
\hline \multirow{2}{*}{$\begin{array}{l}\text { Q8 Computed } \\
\text { Score }\end{array}$} & $\begin{array}{l}\text { Equal variances } \\
\text { assumed }\end{array}$ & .192 & .662 & 2.614 & 132 \\
\hline & $\begin{array}{l}\text { Equal variances not } \\
\text { assumed }\end{array}$ & & & 2.587 & 114.047 \\
\hline
\end{tabular}

Independent Samples Test

\begin{tabular}{|c|c|c|c|c|}
\hline & & \multicolumn{3}{|c|}{ t-test for Equality of Means } \\
\hline & & Sig. (2-tailed) & Mean Difference & $\begin{array}{l}\text { Std. Error } \\
\text { Difference }\end{array}$ \\
\hline \multirow[b]{2}{*}{ Q1 Computed Score } & Equal variances assumed & .000 & 4.185 & 1.131 \\
\hline & $\begin{array}{l}\text { Equal variances not } \\
\text { assumed }\end{array}$ & .000 & 4.185 & 1.142 \\
\hline \multirow[b]{2}{*}{ Q2 Computed Score } & Equal variances assumed & .007 & 2.995 & 1.096 \\
\hline & $\begin{array}{l}\text { Equal variances not } \\
\text { assumed }\end{array}$ & .006 & 2.995 & 1.062 \\
\hline \multirow[b]{2}{*}{ Q3 Computed Score } & Equal variances assumed & .003 & 3.454 & 1.130 \\
\hline & $\begin{array}{l}\text { Equal variances not } \\
\text { assumed }\end{array}$ & .002 & 3.454 & 1.118 \\
\hline \multirow[b]{2}{*}{ Q4 Computed Score } & Equal variances assumed & .000 & 4.452 & 1.065 \\
\hline & $\begin{array}{l}\text { Equal variances not } \\
\text { assumed }\end{array}$ & .000 & 4.452 & 1.094 \\
\hline \multirow[b]{2}{*}{ Q5 Computed Score } & Equal variances assumed & .000 & 4.203 & 1.130 \\
\hline & $\begin{array}{l}\text { Equal variances not } \\
\text { assumed }\end{array}$ & .000 & 4.203 & 1.146 \\
\hline
\end{tabular}




\begin{tabular}{|l|l|r|r|r|}
\hline \multirow{2}{*}{ Q6 Computed Score } & Equal variances assumed & .000 & 4.074 & 1.074 \\
\cline { 2 - 5 } & $\begin{array}{l}\text { Equal variances not } \\
\text { assumed }\end{array}$ & .000 & 4.074 & 1.116 \\
\hline \multirow{3}{*}{ Q7 Computed Score } & Equal variances assumed & .000 & 3.346 & .933 \\
\cline { 2 - 5 } & $\begin{array}{l}\text { Equal variances not } \\
\text { assumed }\end{array}$ & .001 & 3.346 & .965 \\
\hline \multirow{3}{*}{ Q8 Computed Score } & Equal variances assumed & .010 & 2.638 & 1.009 \\
\cline { 2 - 5 } & $\begin{array}{l}\text { Equal variances not } \\
\text { assumed }\end{array}$ & .011 & 2.638 & 1.020 \\
\hline
\end{tabular}

\begin{tabular}{|c|c|c|c|}
\hline & & \multicolumn{2}{|c|}{ t-test for Equality of Means } \\
\hline & & \multicolumn{2}{|c|}{$95 \%$ Confidence Interval of the Difference } \\
\hline & & Lower & Upper \\
\hline \multirow{2}{*}{ Q1 Computed Score } & Equal variances assumed & 1.948 & 6.422 \\
\hline & Equal variances not assumed & 1.923 & 6.448 \\
\hline \multirow{2}{*}{ Q2 Computed Score } & Equal variances assumed & .827 & 5.164 \\
\hline & Equal variances not assumed & .894 & 5.097 \\
\hline \multirow{2}{*}{ Q3 Computed Score } & Equal variances assumed & 1.219 & 5.690 \\
\hline & Equal variances not assumed & 1.241 & 5.667 \\
\hline \multirow{2}{*}{ Q4 Computed Score } & Equal variances assumed & 2.345 & 6.559 \\
\hline & Equal variances not assumed & 2.285 & 6.619 \\
\hline \multirow{2}{*}{ Q5 Computed Score } & Equal variances assumed & 1.968 & 6.437 \\
\hline & Equal variances not assumed & 1.932 & 6.473 \\
\hline \multirow{2}{*}{ Q6 Computed Score } & Equal variances assumed & 1.949 & 6.198 \\
\hline & Equal variances not assumed & 1.859 & 6.288 \\
\hline \multirow{2}{*}{ Q7 Computed Score } & Equal variances assumed & 1.500 & 5.193 \\
\hline & Equal variances not assumed & 1.433 & 5.260 \\
\hline \multirow{2}{*}{ Q8 Computed Score } & Equal variances assumed & .641 & 4.635 \\
\hline & Equal variances not assumed & .618 & 4.659 \\
\hline
\end{tabular}

\section{Frequencies: $\mathbf{1}=\mathbf{R}$ is Less than $\mathbf{3 5}$ and $\mathbf{2}=\mathbf{R}$ is Over $\mathbf{3 5}$}

AGE Which of the following age groups are you in?

\begin{tabular}{|r|r|r|r|r|r|}
\hline \multicolumn{2}{|c|}{} & Frequency & Percent & Valid Percent & \multicolumn{2}{c|}{$\begin{array}{c}\text { Cumulative } \\
\text { Percent }\end{array}$} \\
\hline \multirow{3}{*}{ Valid } & $18-24$ & 10 & 7.2 & 7.3 & 7.3 \\
\cline { 2 - 6 } & $25-34$ & 60 & 43.2 & 43.8 & 51.1 \\
\hline
\end{tabular}




\begin{tabular}{|l|l|r|r|r|r|}
\hline & $35-44$ & 27 & 19.4 & 19.7 & 70.8 \\
\cline { 2 - 6 } & $45-54$ & 17 & 12.2 & 12.4 & 83.2 \\
\cline { 2 - 6 } & $55-64$ & 13 & 9.4 & 9.5 & 92.7 \\
\cline { 2 - 6 } & $65-75$ & 10 & 7.2 & 7.3 & 100.0 \\
\cline { 2 - 7 } & Total & 137 & 98.6 & 100.0 & \\
\hline \multirow{2}{*}{ Missing } & System & 2 & 1.4 & & \\
\hline \multirow{2}{*}{ Total } & & 139 & 100.0 & & \\
\hline
\end{tabular}

\section{T-Test}

\begin{tabular}{|c|c|c|c|c|c|}
\hline \multicolumn{6}{|c|}{ Group Statistics } \\
\hline & age123 & $\mathrm{N}$ & Mean & Std. Deviation & Std. Error Mean \\
\hline \multirow{2}{*}{ Q1 Computed Score } & 1 & 95 & 29.09 & 6.782 & .696 \\
\hline & 2 & 39 & 25.82 & 6.249 & 1.001 \\
\hline \multirow{2}{*}{ Q2 Computed Score } & 1 & 95 & 20.09 & 6.430 & .660 \\
\hline & 2 & 39 & 15.82 & 5.311 & .850 \\
\hline \multirow{2}{*}{ Q3 Computed Score } & 1 & 95 & 26.06 & 6.515 & .668 \\
\hline & 2 & 40 & 22.20 & 6.414 & 1.014 \\
\hline \multirow{2}{*}{ Q4 Computed Score } & 1 & 97 & 29.59 & 6.404 & .650 \\
\hline & 2 & 40 & 25.33 & 5.850 & .925 \\
\hline \multirow[b]{2}{*}{ Q5 Computed Score } & 1 & 97 & 31.71 & 6.466 & .657 \\
\hline & 2 & 39 & 27.28 & 6.665 & 1.067 \\
\hline \multirow{2}{*}{ Q6 Computed Score } & 1 & 97 & 34.06 & 5.981 & .607 \\
\hline & 2 & 39 & 29.92 & 6.799 & 1.089 \\
\hline \multirow{2}{*}{ Q7 Computed Score } & 1 & 94 & 33.87 & 5.573 & .575 \\
\hline & 2 & 39 & 32.33 & 5.450 & .873 \\
\hline \multirow[b]{2}{*}{ Q8 Computed Score } & 1 & 95 & 32.42 & 5.277 & .541 \\
\hline & 2 & 39 & 29.26 & 6.723 & 1.077 \\
\hline
\end{tabular}

\begin{tabular}{|c|c|c|c|c|c|}
\hline & & \multicolumn{2}{|c|}{$\begin{array}{c}\text { Levene's Test for Equality of } \\
\text { Variances }\end{array}$} & \multicolumn{2}{|c|}{$\begin{array}{l}\text { t-test for Equality of } \\
\text { Means }\end{array}$} \\
\hline & & $\mathrm{F}$ & Sig. & $\mathrm{t}$ & df \\
\hline \multirow[b]{2}{*}{ Q1 Computed Score } & Equal variances assumed & .172 & .679 & 2.596 & 132 \\
\hline & $\begin{array}{l}\text { Equal variances not } \\
\text { assumed }\end{array}$ & & & 2.686 & 76.420 \\
\hline Q2 Computed Score & Equal variances assumed & .598 & .441 & 3.667 & 132 \\
\hline
\end{tabular}




\begin{tabular}{|c|c|c|c|c|c|}
\hline & $\begin{array}{l}\text { Equal variances not } \\
\text { assumed }\end{array}$ & & & 3.971 & 85.045 \\
\hline \multirow[b]{2}{*}{ Q3 Computed Score } & Equal variances assumed & .039 & .843 & 3.160 & 133 \\
\hline & $\begin{array}{l}\text { Equal variances not } \\
\text { assumed }\end{array}$ & & & 3.181 & 74.417 \\
\hline \multirow[b]{2}{*}{ Q4 Computed Score } & Equal variances assumed & 1.117 & .293 & 3.630 & 135 \\
\hline & $\begin{array}{l}\text { Equal variances not } \\
\text { assumed }\end{array}$ & & & 3.770 & 79.212 \\
\hline \multirow[b]{2}{*}{ Q5 Computed Score } & Equal variances assumed & .018 & .895 & 3.581 & 134 \\
\hline & $\begin{array}{l}\text { Equal variances not } \\
\text { assumed }\end{array}$ & & & 3.535 & 68.332 \\
\hline \multirow[b]{2}{*}{ Q6 Computed Score } & Equal variances assumed & .141 & .708 & 3.507 & 134 \\
\hline & $\begin{array}{l}\text { Equal variances not } \\
\text { assumed }\end{array}$ & & & 3.320 & 62.908 \\
\hline \multirow[b]{2}{*}{ Q7 Computed Score } & Equal variances assumed & .870 & .353 & 1.459 & 131 \\
\hline & $\begin{array}{l}\text { Equal variances not } \\
\text { assumed }\end{array}$ & & & 1.473 & 72.546 \\
\hline \multirow[b]{2}{*}{ Q8 Computed Score } & Equal variances assumed & 2.288 & .133 & 2.904 & 132 \\
\hline & $\begin{array}{l}\text { Equal variances not } \\
\text { assumed }\end{array}$ & & & 2.626 & 58.147 \\
\hline
\end{tabular}

Independent Samples Test

\begin{tabular}{|l|l|r|r|r|}
\hline \multicolumn{2}{|c|}{} & \multicolumn{3}{|c|}{ t-test for Equality of Means } \\
\cline { 3 - 5 } & & Sig. (2-tailed) & Mean Difference & \multicolumn{2}{c|}{$\begin{array}{c}\text { Std. Error } \\
\text { Difference }\end{array}$} \\
\hline \multirow{3}{*}{ Q1 Computed Score } & Equal variances assumed & .011 & 3.274 & 1.261 \\
\cline { 2 - 5 } & Equal variances not assumed & .009 & 3.274 & 1.219 \\
\hline \multirow{3}{*}{ Q2 Computed Score } & Equal variances assumed & .000 & 4.274 & 1.166 \\
\cline { 2 - 5 } & Equal variances not assumed & .000 & 4.274 & 1.076 \\
\hline \multirow{3}{*}{ Q3 Computed Score } & Equal variances assumed & .002 & 3.863 & 1.222 \\
\cline { 2 - 5 } & Equal variances not assumed & .002 & 3.863 & 1.215 \\
\hline \multirow{3}{*}{ Q4 Computed Score } & Equal variances assumed & .000 & 4.263 & 1.174 \\
\cline { 2 - 5 } & Equal variances not assumed & .000 & 4.263 & 1.131 \\
\hline \multirow{2}{*}{ Q5 Computed Score } & Equal variances assumed & .000 & 4.429 & 1.237 \\
\cline { 2 - 5 } & Equal variances not assumed & .001 & 4.429 & 1.253 \\
\hline \multirow{2}{*}{ Q6 Computed Score } & Equal variances assumed & .001 & 4.139 & 1.180 \\
\cline { 2 - 5 } & Equal variances not assumed & .002 & 4.139 & 1.247 \\
\hline
\end{tabular}




\begin{tabular}{|l|l|r|r|r|}
\hline \multirow{3}{*}{ Q7 Computed Score } & Equal variances assumed & .147 & 1.539 & 1.055 \\
\cline { 2 - 5 } & Equal variances not assumed & .145 & 1.539 & 1.045 \\
\hline \multirow{3}{*}{ Q8 Computed Score } & Equal variances assumed & .004 & 3.165 & 1.090 \\
\cline { 2 - 5 } & Equal variances not assumed & .011 & 3.165 & 1.205 \\
\hline
\end{tabular}

Independent Samples Test

\begin{tabular}{|c|c|c|c|}
\hline & & \multicolumn{2}{|c|}{ t-test for Equality of Means } \\
\hline & & \multicolumn{2}{|c|}{$95 \%$ Confidence Interval of the Difference } \\
\hline & & Lower & Upper \\
\hline \multirow{2}{*}{ Q1 Computed Score } & Equal variances assumed & .779 & 5.770 \\
\hline & Equal variances not assumed & .847 & 5.701 \\
\hline \multirow{2}{*}{ Q2 Computed Score } & Equal variances assumed & 1.969 & 6.580 \\
\hline & Equal variances not assumed & 2.134 & 6.414 \\
\hline \multirow{2}{*}{ Q3 Computed Score } & Equal variances assumed & 1.445 & 6.281 \\
\hline & Equal variances not assumed & 1.443 & 6.283 \\
\hline \multirow{2}{*}{ Q4 Computed Score } & Equal variances assumed & 1.940 & 6.585 \\
\hline & Equal variances not assumed & 2.012 & 6.513 \\
\hline \multirow{2}{*}{ Q5 Computed Score } & Equal variances assumed & 1.983 & 6.875 \\
\hline & Equal variances not assumed & 1.929 & 6.929 \\
\hline \multirow{2}{*}{ Q6 Computed Score } & Equal variances assumed & 1.805 & 6.473 \\
\hline & Equal variances not assumed & 1.647 & 6.630 \\
\hline \multirow{2}{*}{ Q7 Computed Score } & Equal variances assumed & -.548 & 3.626 \\
\hline & Equal variances not assumed & -.544 & 3.622 \\
\hline \multirow{2}{*}{ Q8 Computed Score } & Equal variances assumed & 1.009 & 5.320 \\
\hline & Equal variances not assumed & .753 & 5.577 \\
\hline
\end{tabular}

Frequencies: Level of Education

EDUCATION What is the highest level of education you have completed?

\begin{tabular}{|l|l|r|r|r|r|}
\hline \multicolumn{2}{|l|}{} & Frequency & Percent & Valid Percent & $\begin{array}{c}\text { Cumulative } \\
\text { Percent }\end{array}$ \\
\hline \multirow{5}{*}{ Valid } & High School Diploma or GED & 13 & 9.4 & 9.5 & 9.5 \\
\cline { 2 - 6 } & $\begin{array}{l}\text { Associate Degree or } \\
\text { Technical/Vocational School }\end{array}$ & 7 & 5.0 & 5.1 & 14.6 \\
\cline { 2 - 6 } & Bachelor's Degree & 70 & 50.4 & 51.1 & \\
\cline { 2 - 6 } & $\begin{array}{l}\text { Graduate or Professional } \\
\text { Degree }\end{array}$ & 47 & 33.8 & 34.3 & 100.0 \\
\hline
\end{tabular}




\begin{tabular}{|l|l|r|r|r|l|}
\hline & Total & 137 & 98.6 & 100.0 & \\
\hline Missing & System & 2 & 1.4 & & \\
\hline Total & 139 & 100.0 & & \\
\hline
\end{tabular}

Frequencies: Income

INCOME Finally, which category best describes your yearly total household income before taxes?

\begin{tabular}{|c|c|c|c|c|c|}
\hline & & Frequency & Percent & Valid Percent & $\begin{array}{c}\text { Cumulative } \\
\text { Percent }\end{array}$ \\
\hline \multirow{8}{*}{ Valid } & Less than $\$ 15,000$ & 8 & 5.8 & 6.2 & 6.2 \\
\hline & $\$ 15,000$ to less than $\$ 25,000$ & 16 & 11.5 & 12.4 & 18.6 \\
\hline & $\$ 25,000$ to less than $\$ 35,000$ & 14 & 10.1 & 10.9 & 29.5 \\
\hline & $\$ 35,000$ to less than $\$ 50,000$ & 22 & 15.8 & 17.1 & 46.5 \\
\hline & $\$ 50,000$ to less than $\$ 75,000$ & 28 & 20.1 & 21.7 & 68.2 \\
\hline & $\$ 75,000$ to less than $\$ 100,000$ & 16 & 11.5 & 12.4 & 80.6 \\
\hline & $\$ 100,000$ or more & 25 & 18.0 & 19.4 & 100.0 \\
\hline & Total & 129 & 92.8 & 100.0 & \\
\hline \multirow{3}{*}{ Missing } & -99 & 8 & 5.8 & & \\
\hline & System & 2 & 1.4 & & \\
\hline & Total & 10 & 7.2 & & \\
\hline \multicolumn{2}{|l|}{ Total } & 139 & 100.0 & & \\
\hline
\end{tabular}

Frequencies: $1=$ Less than $\$ 50,000$ and $2=$ More than $\$ 50,000$

\begin{tabular}{|l|l|r|r|r|r|}
\hline \multicolumn{2}{|c|}{} & Frequency & Percent & Valid Percent & $\begin{array}{c}\text { Cumulative } \\
\text { Percent }\end{array}$ \\
\hline \multirow{3}{*}{ Valid } & 1.00 & 60 & 43.2 & 46.5 & 46.5 \\
\cline { 2 - 6 } & 2.00 & 69 & 49.6 & 53.5 & 100.0 \\
\cline { 2 - 7 } & Total & 129 & 92.8 & 100.0 & \\
\hline \multirow{2}{*}{ Missing } & System & 10 & 7.2 & & \\
\hline \multirow{2}{*}{ Total } & & 139 & 100.0 & & \\
\hline
\end{tabular}

\section{T-Test}

\begin{tabular}{|l|l|r|r|r|r|}
\hline \multicolumn{1}{|c|}{ Group Statistics } \\
\hline \multirow{3}{*}{ Q1 Computed Score } & 1.00 & $\mathrm{~N}$ & \multicolumn{1}{c|}{ Mean } & Std. Deviation & Std. Error Mean \\
\cline { 2 - 7 } & \multicolumn{1}{|c|}{ IncomeSplit50 } & 60 & 30.57 & 6.176 & .797 \\
\hline \multirow{2}{*}{ Q2 Computed Score } & 1.00 & 68 & 26.24 & 6.741 & .817 \\
\hline
\end{tabular}




\begin{tabular}{|l|l|r|r|r|r|}
\hline & \multicolumn{1}{|c|}{2.00} & 67 & 17.57 & 6.185 & .756 \\
\hline \multirow{4}{*}{ Q3 Computed Score } & 1.00 & 60 & 27.13 & 6.419 & .829 \\
\cline { 2 - 6 } & 2.00 & 67 & 23.51 & 6.510 & .795 \\
\hline \multirow{4}{*}{ Q4 Computed Score } & 1.00 & 60 & 31.08 & 6.328 & .817 \\
\cline { 2 - 6 } & 2.00 & 69 & 26.17 & 6.183 & .744 \\
\hline \multirow{3}{*}{ Q5 Computed Score } & 1.00 & 60 & 32.88 & 6.293 & .812 \\
\cline { 2 - 6 } & 2.00 & 68 & 28.40 & 6.807 & .825 \\
\hline \multirow{4}{*}{ Q6 Computed Score } & 1.00 & 60 & 35.03 & 5.929 & .765 \\
\cline { 2 - 6 } & 2.00 & 68 & 31.16 & 6.605 & .801 \\
\hline \multirow{3}{*}{ Q7 Computed Score } & 1.00 & 59 & 34.69 & 5.481 & .714 \\
\cline { 2 - 6 } & 2.00 & 66 & 32.32 & 5.736 & .706 \\
\hline \multirow{3}{*}{ Q8 Computed Score } & 1.00 & 60 & 33.07 & 5.554 & .717 \\
\cline { 2 - 6 } & 2.00 & 68 & 30.25 & 5.993 & .727 \\
\hline
\end{tabular}

Independent Samples Test

\begin{tabular}{|c|c|c|c|c|c|}
\hline & & \multicolumn{2}{|c|}{$\begin{array}{c}\text { Levene's Test for Equality of } \\
\text { Variances }\end{array}$} & \multicolumn{2}{|c|}{$\begin{array}{l}\text { t-test for Equality of } \\
\text { Means } \\
\end{array}$} \\
\hline & & $\mathrm{F}$ & Sig. & $\mathrm{t}$ & df \\
\hline \multirow[b]{2}{*}{ Q1 Computed Score } & Equal variances assumed & .908 & .343 & 3.772 & 126 \\
\hline & $\begin{array}{l}\text { Equal variances not } \\
\text { assumed }\end{array}$ & & & 3.793 & 125.811 \\
\hline \multirow[b]{2}{*}{ Q2 Computed Score } & Equal variances assumed & .018 & .893 & 2.761 & 125 \\
\hline & $\begin{array}{l}\text { Equal variances not } \\
\text { assumed }\end{array}$ & & & 2.755 & 122.086 \\
\hline \multirow[b]{2}{*}{ Q3 Computed Score } & Equal variances assumed & .035 & .852 & 3.154 & 125 \\
\hline & $\begin{array}{l}\text { Equal variances not } \\
\text { assumed }\end{array}$ & & & 3.157 & 123.828 \\
\hline \multirow[b]{2}{*}{ Q4 Computed Score } & Equal variances assumed & .030 & .862 & 4.449 & 127 \\
\hline & $\begin{array}{l}\text { Equal variances not } \\
\text { assumed }\end{array}$ & & & 4.442 & 123.673 \\
\hline \multirow[b]{2}{*}{ Q5 Computed Score } & Equal variances assumed & .552 & .459 & 3.855 & 126 \\
\hline & $\begin{array}{l}\text { Equal variances not } \\
\text { assumed }\end{array}$ & & & 3.874 & 125.715 \\
\hline \multirow[b]{2}{*}{ Q6 Computed Score } & Equal variances assumed & .433 & .512 & 3.471 & 126 \\
\hline & $\begin{array}{l}\text { Equal variances not } \\
\text { assumed }\end{array}$ & & & 3.494 & 125.959 \\
\hline
\end{tabular}




\begin{tabular}{|c|c|c|c|c|c|}
\hline \multirow[b]{2}{*}{ Q7 Computed Score } & Equal variances assumed & .002 & .966 & 2.362 & 123 \\
\hline & $\begin{array}{l}\text { Equal variances not } \\
\text { assumed }\end{array}$ & & & 2.368 & 122.439 \\
\hline \multirow[b]{2}{*}{ Q8 Computed Score } & Equal variances assumed & .070 & .791 & 2.746 & 126 \\
\hline & $\begin{array}{l}\text { Equal variances not } \\
\text { assumed }\end{array}$ & & & 2.759 & 125.686 \\
\hline
\end{tabular}

\begin{tabular}{|c|c|c|c|c|}
\hline \multicolumn{5}{|c|}{ Independent Samples Test } \\
\hline & & \multicolumn{3}{|c|}{ t-test for Equality of Means } \\
\hline & & Sig. (2-tailed) & Mean Difference & $\begin{array}{l}\text { Std. Error } \\
\text { Difference }\end{array}$ \\
\hline \multirow{2}{*}{ Q1 Computed Score } & Equal variances assumed & .000 & 4.331 & 1.148 \\
\hline & Equal variances not assumed & .000 & 4.331 & 1.142 \\
\hline \multirow{2}{*}{ Q2 Computed Score } & Equal variances assumed & .007 & 3.100 & 1.123 \\
\hline & Equal variances not assumed & .007 & 3.100 & 1.125 \\
\hline \multirow{2}{*}{ Q3 Computed Score } & Equal variances assumed & .002 & 3.626 & 1.149 \\
\hline & Equal variances not assumed & .002 & 3.626 & 1.149 \\
\hline \multirow{2}{*}{ Q4 Computed Score } & Equal variances assumed & .000 & 4.909 & 1.103 \\
\hline & Equal variances not assumed & .000 & 4.909 & 1.105 \\
\hline \multirow{2}{*}{ Q5 Computed Score } & Equal variances assumed & .000 & 4.486 & 1.164 \\
\hline & Equal variances not assumed & .000 & 4.486 & 1.158 \\
\hline \multirow{2}{*}{ Q6 Computed Score } & Equal variances assumed & .001 & 3.872 & 1.115 \\
\hline & Equal variances not assumed & .001 & 3.872 & 1.108 \\
\hline \multirow{2}{*}{ Q7 Computed Score } & Equal variances assumed & .020 & 2.377 & 1.006 \\
\hline & Equal variances not assumed & .019 & 2.377 & 1.004 \\
\hline \multirow{2}{*}{ Q8 Computed Score } & Equal variances assumed & .007 & 2.817 & 1.026 \\
\hline & Equal variances not assumed & .007 & 2.817 & 1.021 \\
\hline \multicolumn{5}{|c|}{ t-test for Equality of Means } \\
\hline \multicolumn{5}{|c|}{ 95\% Confidence Interval of the Difference } \\
\hline & & & Lower & Upper \\
\hline
\end{tabular}




\begin{tabular}{|c|c|c|c|}
\hline \multirow{2}{*}{ Q1 Computed Score } & Equal variances assumed & 2.059 & 6.604 \\
\hline & Equal variances not assumed & 2.072 & 6.591 \\
\hline \multirow{2}{*}{ Q2 Computed Score } & Equal variances assumed & .878 & 5.321 \\
\hline & Equal variances not assumed & .872 & 5.327 \\
\hline \multirow{2}{*}{ Q3 Computed Score } & Equal variances assumed & 1.351 & 5.901 \\
\hline & Equal variances not assumed & 1.353 & 5.899 \\
\hline \multirow{2}{*}{ Q4 Computed Score } & Equal variances assumed & 2.726 & 7.093 \\
\hline & Equal variances not assumed & 2.722 & 7.097 \\
\hline \multirow{2}{*}{ Q5 Computed Score } & Equal variances assumed & 2.183 & 6.790 \\
\hline & Equal variances not assumed & 2.194 & 6.778 \\
\hline \multirow{2}{*}{ Q6 Computed Score } & Equal variances assumed & 1.664 & 6.079 \\
\hline & Equal variances not assumed & 1.679 & 6.064 \\
\hline \multirow{2}{*}{ Q7 Computed Score } & Equal variances assumed & .385 & 4.369 \\
\hline & Equal variances not assumed & .390 & 4.364 \\
\hline \multirow{2}{*}{ Q8 Computed Score } & Equal variances assumed & .787 & 4.847 \\
\hline & Equal variances not assumed & .796 & 4.837 \\
\hline
\end{tabular}

